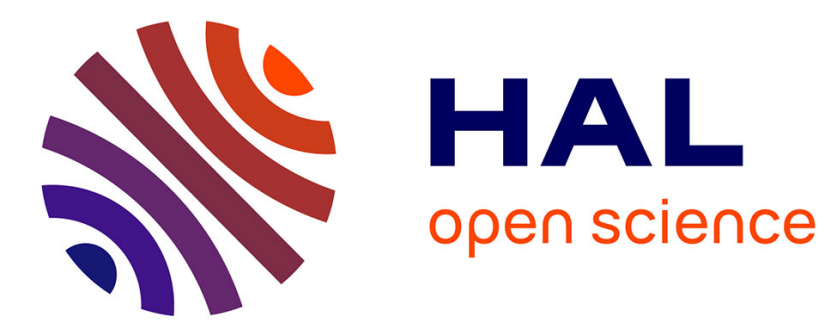

\title{
Hétérodoxies croisées. Catholicismes pluriels entre France et Italie, XVIe-XVIIe siècles
}

\author{
Gigliola Fragnito, Alain Tallon
}

\section{To cite this version:}

Gigliola Fragnito, Alain Tallon (Dir.). Hétérodoxies croisées. Catholicismes pluriels entre France et Italie, XVIe-XVIIe siècles. 2017. hal-02056431

\section{HAL Id: hal-02056431 \\ https://hal.sorbonne-universite.fr/hal-02056431}

Submitted on 4 Mar 2019

HAL is a multi-disciplinary open access archive for the deposit and dissemination of scientific research documents, whether they are published or not. The documents may come from teaching and research institutions in France or abroad, or from public or private research centers.
L'archive ouverte pluridisciplinaire HAL, est destinée au dépôt et à la diffusion de documents scientifiques de niveau recherche, publiés ou non, émanant des établissements d'enseignement et de recherche français ou étrangers, des laboratoires publics ou privés. 


\section{Hétérodoxies croisées}

Catholicismes pluriels entre France et Italie $\mathrm{XVI}^{\mathrm{e}}-\mathrm{XVII}^{\mathrm{e}}$ siècles

Études réunies par Alain Tallon et Gigliola Fragnito 


\section{Hétérodoxies croisées. Catholicismes pluriels entre France et Italie, XVIe-XVIIe siècles}

\section{Gigliola Fragnito and Alain Tallon (dir.)}

Publisher: Publications de l'École française de Rome

Year of publication: 2015

Published on OpenEdition Books: 14 May

Printed version

2015

Pring of publication: 1 January 2016

Serie: Collection de l'École française de

Rome

Electronic ISBN: 9782728311446

ISBN: 9782728311439

\section{Sbooks}

http://books.openedition.org

\section{Electronic reference}

FRAGNITO, Gigliola (ed.) ; TALLON, Alain (ed.). Hétérodoxies croisées. Catholicismes pluriels entre France et Italie, XVIe-XVIIe siècles. New edition [online]. Rome: Publications de l'École française de Rome, 2015 (generated 21 May 2015). Available on the Internet: <http://books.openedition.org/efr/2823>. ISBN: 9782728311446.

This text was automatically generated on 21 May 2015.

(C) Publications de l'École française de Rome, 2015

Terms of use:

http://www.openedition.org/6540 
Issu d'un programme de recherche franco-italien initié en 2008 sous l'égide de l'École française de Rome, de l'Università degli Studi di Parma et de l'Université Paris-Sorbonne, ce volume explore un des paradoxes majeurs du catholicisme moderne: alors qu'il revendique une parfaite unité, argument de choix des controversistes contre le protestantisme, il est en réalité traversé par de profondes divergences doctrinales. Ces divergences ne concernent pas seulement des individus, mais aussi des institutions et des États. Le royaume de France continue ainsi de refuser obstinément la conception romaine du pouvoir pontifical, et avec elle la juridiction doctrinale qui en découle. La papauté de son côté condamne régulièrement les thèses gallicanes. Si les affrontements sont nombreux aux XVI et XVII siècles, ils ne débouchent presque jamais sur une rupture complète entre Rome et l'Église gallicane. Les moyens de régulation, diplomatiques, mais aussi théologiques se révèlent donc efficaces pour maintenir dans l'unité des Églises qui s'accusent volontiers l'une l'autre d'errances doctrinales. Cette situation d'hétérodoxies croisées ouvre à quelques individus une espace de liberté, certes restreint et toujours menacé, mais qui contribue au pluralisme du catholicisme d'Ancien Régine.

\section{GIGLIOLA FRAGNITO}

Gigliola Fragnito est professeur émérite d'histoire moderne à l'Università degli Studi di Parma.

\section{ALAIN TALLON}

Alain Tallon est professeur d'histoire moderne à l'Université Paris-Sorbonne. 


\section{TABLE OF CONTENTS}

Introduction

Alain Tallon and Gigliola Fragnito

\section{Parlement, diplomatie et pouvoirs romains}

Les stratégies d'évitement des crises entre la France et Rome sous Henri IV Bernard Barbiche

Un roi, trois papes

Légats, nonces et ambassadeurs

Le contentieux franco-romain : essai de typologie

Les grands dossiers politiques

Les nominations épiscopales

Des extrémistes virulents : religieux et pasteurs

Le contrôle de la production imprimée

Conclusion

Le parlement de Paris et les actes romains au XVI ${ }^{e}$ siècle : exemples de la pratique judiciaire Sylvie Daubresse

La complainte de novelleté

L'appel comme d'abus

Le Parlement, entre le roi de France et le pape

Conclusion

Il sospetto d'eresia e $i$ " frati diplomatici » tra Cinque e Seicento

Elena Bonora

\section{Organisation du contrôle de l'imprimé}

La censura ecclesiastica nell'Italia della Controriforma : organismi centrali e periferici di controllo

Gigliola Fragnito

Les institutions de censure religieuse en France (XVI ${ }^{e}$-XVII ${ }^{e}$ siècles)

Jean-Louis Quantin

La censure préventive et le système du privilège

La censure a posteriori

L'épiscopat

\section{Controverses}

La loi du magistère. Pouvoir ministériel et formes ecclésiales dans la controverse entre Cajétan et Almain (1511-1512)

Frédéric Gabriel

Les modalités d'attribution et d'exercice de la potestas Orthodoxie, source législative et déliaison du vicariat

L'autorité des docteurs et la doctrine de l'Église 
Le pouvoir du pape sur les royaumes : la controverse imprimée entre catholiques romains et catholiques gallicans à propos des bulles de 1585, 1589 et 1591

Benoît Schmitz

Pouvoir royal et pouvoir pontifical : Pierre de Belloy, Bellarmin et la bulle de 1585

Le pouvoir spirituel et ses effets : la controverse autour des monitoires de 1589 et 1591

Normes canoniques et plenitudo potestatis : du conflit des doctrines à la concorde des pouvoirs

Les thèses gallicanes sur le pouvoir pontifical à l'épreuve du protestantisme

Benoit Schmitz

Réfutation de Luther et défense du pouvoir pontifical

Le silence gallican sur la potestas papee

La réponse gallicane à Luther sur le terrain ecclésiologique

La réponse gallicane à Luther sur le terrain pastoral

L'inflexion de la doctrine gallicane : le rapprochement avec les positions romaines et ses limites

Hors de l'Église, point de salut

Les deux voies des catéchismes : les controverses et l'endoctrinement. France et Italie Michela Catto

Le catéchisme au Concile de Trente

Disputer pour éduquer : les controverses théologiques et les catéchismes

Une nouvelle stratégie: la doctrine simple et élémentaire.

\section{La censure des livres}

Censura romana e libri francesi nella seconda metà del '500. Qualche riflessione su normativa e casi specifici

Giorgio Caravale

«Per la conservatione della religione e dello stato ». Les guerres de religion en France aux yeux des historiens italiens (XVI ${ }^{e}-X V I I^{e}$ siècle)

Elena Valeri

Érudition gallicane et censure romaine au tournant des XVI ${ }^{e}$ et XVII siècles : Papire Masson devant l'Index

Jean-Louis Quantin

Les gallicanismes du De Episcopis urbis

La première censure romaine du De Episcopis urbis

Le long cheminement d'une mise à l'Index

Après la condamnation

"Onde non apparisca che anco tra $i$ cattolici siano diversità d'opinioni in quello che riguarda la fede » : i sermoni di Ignazio di Loyola e le censure della Facoltà di Teologia del 1611 tra Parigi e Roma

Miguel Gotor

Histoire de censures inversées : Nicolas Chichon, Suárez et Saint-Office (1624-1637)

Jean-Pascal Gay

Chichon et le Saint-office : rencontres antijésuites

Nicolas Chichon : pèlerin du Saint-Office et de l'antijésuitisme

Asile et exil romain d'un plaideur importun

Chichon et l'engagement de la monarchie française dans les conflits internes de son ordre

Le cas Chichon, l'Inquisition et la politisation des controverses doctrinales

Conclusions

Paolo Sarpi a colloquio con i gallicani

Corrado Pin 


\section{Venise et la France}

Le mythe politique de la Sérénissime contre les hantises de théocratie. L'hétérodoxie vénitienne face à l'orthodoxie romaine au début de la crise de l'Interdit (1606-1607) Sylvio Hermann De Franceschi

"Si quid e Gallia afferatur, avide lego ». Reti intellettuali, libri e politica tra Venezia e la Francia nella prima metà del Seicento

Antonella Barzazi

Résumés 


\title{
Introduction
}

\author{
Alain Tallon et Gigliola Fragnito
}

1 Le catholicisme d'Ancien Régime a volontiers affirmé son unité face aux Églises issues de la Réforme. Cet argument de controverse est présent dès les débuts de la crise religieuse du XVI ${ }^{e}$ siècle et reste un des thèmes favoris de l'apologétique catholique. Il ne peut cacher cependant la diversité profonde de l'Église catholique au XVI ${ }^{e}$ et au XVII siècles, diversité institutionnelle, ecclésiologique et même dogmatique. Le présent volume rend compte d'un programme de recherche centré sur cette diversité entre France et Italie. Il contribue ainsi à combler un relatif retard des études d'histoire religieuse comparée entre les deux pays pour la période qui nous intéresse, histoire comparée d'autant plus riche que la situation du catholicisme est alors vraiment très différente dans les deux pays, notamment en raison du poids fort inégal que la papauté y représente : essentielle en Italie, elle est une référence beaucoup plus lointaine et surtout beaucoup moins révérée dans la France gallicane. Cette différence fondamentale a eu des conséquences historiographiques évidentes entre des historiens italiens très - trop? - focalisés sur Rome et des historiens français peu - pas assez ? - sensibles au rôle du centre romain, même si de part et d'autres des Alpes des travaux récents tendent à faire évoluer ces traditions intellectuelles. À la suite du colloque de 2005 sur la Réforme en France et en Italie, publié dans la même collection ${ }^{1}$, ce programme de recherche soutenu par l'École française de Rome, l'Università degli studi di Parma et le Centre Roland Mousnier de l'Université Paris-Sorbonne a réuni donc à plusieurs reprises des spécialistes français et italiens autour de ce catholicisme pluriel et le plus souvent conflictuel, qui sait cependant trouver les moyens de régulations internes pour contenir les conflits et éviter toute rupture majeure : les nombreuses crises entre l'Église romaine et la France n'aboutissent jamais à un basculement de l'Église gallicane dans le camp protestant, ou même à une soustraction d'obédience. Et si Rome condamne volontiers des prises de position françaises - qu'elles viennent du roi, du parlement, des évêques, de la faculté de théologie, ou de simples particuliers -, la papauté sait toujours éviter l'escalade qui pourrait mener au schisme.

2 Il y a dans les antagonismes doctrinaux de ce catholicisme pluriel une large part d'héritages des querelles de la période précédente, notamment autour de la question 
ecclésiologique : le conciliarisme français reste bien vivant même s'il ne se traduit plus par la réunion effective d'un concile comme à Pise en 1511. Et il reste vigilant devant les affirmations de l'absolutisme pontifical, renforcé par le courant intransigeant qui le confond avec la lutte contre la nouvelle hérésie. Les héritages se confrontent cependant au cadre nouveau de l'éclatement de la chrétienté, des évolutions propres aussi à la papauté comme à l'Église gallicane. La création de la congrégation du Saint-Office est bien sûr un événement majeur, car si la France ne reconnaît pas sa juridiction, elle doit compter avec sa puissance à Rome. En France, il n'y a aucune révolution institutionnelle similaire, mais le rôle renforcé du Parlement et l'idéologie nouvelle de la souveraineté qui naît dans l'ambiance intellectuelle parlementaire fournit une assisse forte aux prétentions du gallicanisme parlementaire. Le jeu institutionnel complexe qui s'instaure entre des juridictions qui refusent de se reconnaître, mais ne peuvent s'ignorer, ouvre un champ large à la médiation politique : les papes comme les souverains français savent aussi bien mettre en avant les contraintes que leur imposent ces institutions que modérer leurs ardeurs quand elles risquent de mettre en péril le difficile équilibre entre unité affichée et réalité des divergences.

3 Pour autant, la nouvelle situation religieuse crée entre les catholicismes italien et français une différence majeure : alors que toute hétérodoxie est éradiquée en Italie ou en tout cas ne parvient pas à s'ériger en une organisation durable, le royaume connait à partir de la fin des années 1550 une situation de coexistence confessionnelle durable, qui se traduit certes par des conflits d'une violence inouïe, mais aussi par des solutions régulées par l'État qui deviennent durables après 1598. L'active controverse religieuse entre catholiques et protestants ouvre paradoxalement des espaces de liberté théologique difficilement envisageables en Italie et explique que des ouvrages français de controverse catholique comme le catéchisme du Père Auger soient interdits dans la péninsule.

Comme cela émerge des contributions sur l'organisation des appareils et des procédures de censure, sur les interdictions venant de Rome et leur réception ou leur absence de réception en France, sur le poids du Saint-Office sur la diplomatie et la politique pontificale, sur les obstacles à la circulation des écrits publiés en France en défense des privilèges royaux, sur les difficultés de communication à l'intérieur de la République des Lettres, l'historiographie italienne est indiscutablement plus sensible aux effets politiques et culturels de brève ou de longue durée des stratégies mises en œuvre par les organismes romains de répression. Le rôle déterminant de l'Inquisition et de la congrégation de l'Index dans l'orientation de la politique culturelle et religieuse des États italiens et dans le contrôle des esprits et des consciences des fidèles a sans aucun doute focalisé l'attention des historiens italiens, surtout après l'ouverture de l'Archivio della Congregazione per la Dottrina della Fede. Cela ne peut surprendre quand on compare les systèmes de censure en vigueur dans le royaume et dans la péninsule. Le système français se révèle beaucoup plus complexe avec une pluralité d'organismes chargés de veiller sur la production éditoriale à travers la censure et l'instrument du privilège royal, et au cours du XVII ${ }^{e}$ siècle un renforcement du contrôle par le pouvoir royal. Le système en vigueur en Italie est plus simple : la censure d'État s'impose sauf de rares exceptions seulement au XVIII ${ }^{e}$ siècle et les interdictions ecclésiastiques ont une efficacité bien différente au regard des mesures françaises, y compris au travers des nombreuses incohérences qui caractérisent les deux systèmes.

5 L'historiographie française apparaît de fait moins intéressée par les appareils romains de répression qui malgré les aspirations universalistes renforcées de l'Église post-tridentine 
eurent une incidence limitée en France où leurs directives, même dans les moments de plus grande faiblesse de la monarchie française et de plus grand besoin du soutien du Saint-Siège, rencontrèrent de fortes résistances.

6 Dans le panorama historiographique français, l'analyse des écrits de théologie politique et des polémiques doctrinales qui ont opposé la France et le Saint-Siège de manière parfois violente - avec même le risque d'un schisme, toujours évité - a été moins présente jusqu'à des temps récents. Ces polémiques prouvaient des divergences profondes sur des questions cruciales, comme l'autorité du pape, le conciliarisme, les rapports entre pouvoirs spirituel et temporel, la coexistence confessionnelle, la conception de l'histoire, etc. Elles mirent en évidence de manière incisive les divers visages du gallicanisme et la perception rien moins que claire que l'on en avait aussi bien à Rome qu'à Venise ou dans le monde protestant. Ces thèmes qui ont été parcourus avec une plus grande assiduité et beaucoup de pénétration par l'historiographie française éclairent le déplacement marqué des préoccupations romaines entre la fin du XVI et le début du XVII ${ }^{e}$ siècle, des œuvres protestantes aux écrits en défense des libertés gallicanes, des prérogatives de la couronne face au pape, de l'idée de concorde religieuse, d'une vision de l'histoire différente de celle fondée sur l'érudition gallicane, etc. Les priorités de l'Église romaine, ou au moins de l'Inquisition et de l'Index, changent : l'hérésie théologique semble passer au second plan derrière une autre "hérésie » bien plus menaçante, celle qui conteste les pouvoirs du pape, qui défend les « libertés gallicanes » ou qui espère une " concorde » et un dialogue avec les huguenots.

7 Tout aussi éclairants que les confrontations, les moyens de régulation font émerger un rôle nouveau de la politique dans le catholicisme pluriel de notre période, qui vise moins à affirmer l'autonomie ou même la suprématie du pouvoir temporel que sa capacité à surmonter les tensions issues des contradictions théologiques ou des conflits de juridiction. Le transfert sur le plan diplomatique des affrontements ecclésiologiques n'est pas toujours synonyme d'apaisement, loin s'en faut, mais il a été un des rouages essentiels de la survie des équilibres précaires au sein du catholicisme moderne. Ce n'est pas un hasard si Venise, seul État italien en mesure d'affronter directement la papauté, s'est imposée comme un point de passage et de comparaison essentiel pour notre propos. Mais comme dans le cas du royaume de France, l'affrontement direct, pour spectaculaire qu'il soit, est finalement moins révélateur que la gestion quasi quotidienne des tensions provoquées par le pluralisme ecclésiologique.

8 Cette situation complexe a aussi été un moyen pour diverses hétérodoxies de profiter de l'espace de liberté ouvert par cette pluralité, espace réduit en Italie par la centralisation inquisitoriale, plus étendu en France où la multiplicité des instances de régulation doctrinale va de pair avec leur relative inefficacité. Il ne faut cependant pas surestimer cet espace : la querelle janséniste, qui clôt notre période, en montre bien la réalité, mais aussi voit la monarchie française et le Saint-Siège trouver rapidement une position commune.

9 Un des mérites de ces contributions nous semble bien d'avoir permis de confronter non seulement les véhicules principaux et les modalités de circulation des idées entre les deux pays - cercles érudits avec le rôle significatif de Venise avant, pendant et après l'Interdit, correspondances diplomatiques ou de la République des Lettres, œuvres historiographiques italiennes sur les guerres de Religion, écrits hagiographiques, textes juridiques, etc. -, mais aussi les diverses approches historiographiques. Ces regards 
croisés sur des thématiques communes contribuent à notre avis à mieux éclairer les problèmes présents de part et d'autres des Alpes.

\section{NOTES}

1. Ph. Benedict, S. Seidel Menchi et A. Tallon (dir.), La Réforme en France et en Italie: contacts, comparaisons et contrastes, actes du colloque international de Rome, 27-29 octobre 2005, Rome, 2007 (Collection de l'École française de Rome, 384), 671 p.

\section{AUTEURS}

\section{ALAIN TALLON}

Università degli Studi di Parma - fragnit@alice.it

\section{GIGLIOLA FRAGNITO}

Université de Paris IV-Sorbonne - alain.tallon@paris-sorbonne.fr 
Parlement, diplomatie et pouvoirs romains 


\title{
Les stratégies d'évitement des crises entre la France et Rome sous Henri IV
}

\author{
Bernard Barbiche
}

Entre l'absolution de Henri IV par Clément VIII, le 17 septembre 1595, et son assassinat par Ravaillac, le 14 mai 1610, trois papes se sont succédé. Pour bien comprendre l'évolution des relations entre le roi de France et la papauté pendant cette période et les stratégies réciproques d'évitement des crises, il n'est pas inutile d'évoquer les personnalités des pontifes auxquels le premier Bourbon a eu affaire pendant ces quinze années ${ }^{1}$.

\section{Un roi, trois papes}

2 Avec Clément VIII (1592-1605), Henri IV a entretenu des rapports privilégiés². Clément VIII considérait qu'en absolvant ce prince hérétique deux fois relaps, il lui avait donné une nouvelle naissance, et il le considérait quasiment comme son fils spirituel. Aussi fit-il preuve à son égard de la plus grande bienveillance, allant aussi loin qu'il le pouvait dans la voie des concessions, sans porter atteinte à la doctrine de l'Église. Non content de lui avoir accordé son absolution, il accède dans les années suivantes à la plupart des grâces que le nouveau roi Très Chrétien lui demande et s'attache à consolider son trône et sa dynastie: en 1599 il déclare nul son premier mariage avec Marguerite de Valois ; en 1601 il accepte d'être le parrain du dauphin; en 1600 il intervient de façon décisive dans les préparatifs et la célébration de sa nouvelle union avec Marie de Médicis; en 1604 il va même, chose inouïe, jusqu'à accorder la dispense de consanguinité nécessaire à la régularisation du mariage de Catherine de Bourbon, sœur huguenote du roi, avec le très catholique duc de Bar, célébré irrégulièrement en 1599. Henri IV de son côté multiplie les gestes pour manifester sa reconnaissance au pontife qui l'a réintégré dans le giron de l'église romaine : en 1601, il lui demande d'être le parrain du dauphin ; en 1604, il fait don à la basilique du Latran, cathédrale de Rome, et à son chapitre, de l'abbaye Saint-Pierre de Clairac en Agenais, ce qui lui vaut d'être nommé chanoine d'honneur de la basilique; et il distribue largement des pensions à des cardinaux et à 
d'autres membres de la cour pontificale. Le roi et le pape échangeaient une double correspondance: des lettres officielles, préparées en France par le secrétaire d'État chargé des affaires étrangères (Nicolas de Neufville de Villeroy) et à Rome par le cardinalneveu (Pietro Aldobrandini), et des lettres de caractère privé, autographes ou d'apparence autographe (di proprio pugno) ${ }^{3}$.

Le $1^{\mathrm{er}}$ avril 1605, l'élection de Léon XI, ancien légat en France, un Médicis ouvertement francophile, oncle de la reine Marie, fut un triomphe éclatant pour la diplomatie française. Mais ce pontificat dura moins d'un mois, et les espoirs que la France avait mis dans ce pape furent réduits à néant.

Le 16 mai 1605, l'élection de Paul V fut à nouveau présentée comme un succès par la France, une tactique qui relevait probablement de la propagande politique. Certains observateurs en effet s'étonnèrent et virent là une opération de désinformation, car jusqu'alors le cardinal Camillo Borghese n'avait pas été considéré comme particulièrement favorable à la France; il avait d'ailleurs été nonce extraordinaire en Espagne en 1593, et il était pensionné par le roi Catholique. D'où la réaction de l'envoyé du grand-duc de Toscane, par exemple, surpris de la satisfaction manifestée en France à la suite de cette élection ${ }^{4}$. Il reste que Paul V, contrairement aux papes du temps de la Ligue, observa une stricte neutralité dans ses rapports avec les couronnes catholiques et que ses relations avec Henri IV furent empreintes de courtoisie. Mais elles furent moins chaleureuses que sous le pontificat de Clément VIII. En particulier, l'usage de la double correspondance, officielle et privée, fut abandonné.

\section{Légats, nonces et ambassadeurs}

5 Les envoyés pontificaux qui se succédèrent pendant la même période à la cour de France furent de même très différents. Le premier fut un légat a latere, Alexandre de Médicis, cardinal de Florence (futur Léon XI), un prélat très favorable à la France et qui avait beaucoup œuvré à l'absolution du roi. Le choix fait de lui par Clément VIII est d'ailleurs très révélateur de la volonté du pape de tout faire pour plaire au roi réconcilié avec l'Église romaine et favoriser au maximum le rétablissement de relations confiantes entre la cour de France et la cour de Rome. Le cardinal de Florence présida les négociations qui aboutirent à la signature du traité de Vervins entre la France et l'Espagne, le 2 mai 1598. Un autre légat, le cardinal- neveu Aldobrandini, vint en France deux ans plus tard pour interposer la médiation du Saint-Siège entre le roi de France et le duc de Savoie 5 .

6 Au légat Médicis succédèrent quatre nonces ordinaires. Le premier, Gasparo Silingardi, évêque de Modène (1599-1601), était relativement âgé (62 ans). Dernier nonce en France qui ait été directement témoin du concile de Trente (où il avait été commensal d'un des pères conciliaires), il renouait avec la tradition des diplomates de Grégoire XIII, eux aussi évêques résidentiels en Italie, sur qui la papauté comptait pour faire triompher partout l'esprit du concile et, dans le cas de la France, pour faire recevoir celui-ci. Sa correspondance publiée par Bertrand Haan nous fait toucher du doigt le décalage culturel qui existait à cette époque entre Français et Italiens. L'incompréhension du nonce devant la situation religieuse de la France éclate quasiment dans chaque lettre. Il se laisse aller à des lamentations et à des réflexions désabusées sur la ruine de l'autorité du souverain pontife dans le royaume et les infortunes du Saint-Siège. Ces notations qui semblent dénoter un caractère dépressif contrastent avec la relative indulgence dont font preuve de leur côté Clément VIII et le cardinal-neveu Aldobrandini ${ }^{6}$. 
7 Son successeur Innocenzo Del Bufalo, évêque de Camerino (1601-1604), s'il partage en grande partie ses vues, est d'un style tout différent. Beaucoup plus jeune (36 ans), homme d'appareil issu de la curie, créature du cardinal-neveu, dépourvu d'expérience pastorale, il est en quelque sorte le prototype d'une nouvelle espèce de diplomate pontifical dont le modèle s'imposera partout à partir du XVII ${ }^{e}$ siècle. Bien accueilli d'abord par le roi, il perdra sa confiance dès 1602 au moment de la crise internationale provoquée par la conspiration de Biron. Le 9 septembre 1602, Henri IV écrit à son ambassadeur Philippe de Béthune: «Il y a longtemps aussy que je m'aperçois que ledit nonce favorise le party espagnol. " C'est seulement à la fin de la nonciature, en octobre 1604, lorsque la médiation de Del Bufalo permit de mettre fin à la guerre des tarifs, que les préventions du roi à l'égard du nonce se dissipèrent. Il n'empêche que la méfiance persistante du roi à l'encontre du nonce eut des répercussions sur le mode de gestion des litiges pendant la plus grande partie du séjour en France de Del Bufalo7.

8 Avec Maffeo Barberini, archevêque de Nazareth (1604-1607), l'ambiance change du tout au tout. Ce nonce, qui était venu apporter les langes bénits au dauphin à l'automne 1601, était déjà connu à la cour de France où il s'était fait apprécier. L'annonce de sa nomination comme nonce ordinaire, trois ans plus tard, fut donc favorablement accueillie. Pendant son deuxième séjour, il sut nouer des contacts et se faire des relations, au premier rang desquelles le duc de Sully, qui, quoique protestant, entretint avec lui d'excellents rapports qui se prolongèrent jusqu'au pontificat d'Urbain VIII ${ }^{8}$.

9 Le quatrième nonce, Roberto Ubaldini, évêque de Montepulciano (1607-1616), contre toute attente, ne suscita pas le même enthousiasme, bien qu'il fût pensionné par la France, cousin éloigné de Marie de Médicis et ancien maître de chambre du très francophile Léon XI. Henri IV craignit sans doute que ce Florentin ne vînt renforcer l'entourage de son épouse, à une époque où les relations conjugales du couple royal n'étaient pas idylliques. Il fallut bien cependant l'accepter'.

10 Parallèlement, Henri IV, après les deux courtes missions du duc de Luxembourg-Piney en 1597 et de Nicolas Brulart de Sillery en 1599-1600, envoie à Rome trois ambassadeurs ordinaires : Philippe de Béthune (1601-1605), Charles de Neufville d'Alincourt (1605-1608) et François Savary de Brèves (1608-1614). Ces diplomates, dans les audiences régulières que le pape leur accorde, assurent un autre type de liaison entre les deux cours, qui n'est pas toujours en harmonie avec ceux qui s'établissent entre le roi et les nonces. Selon les occurrences et la nature des affaires à traiter, le roi et les papes utiliseront l'une ou l'autre voie pour régler les affaires. Le roi dispose d'autres relais importants à Rome avec les cardinaux français dont certains (Arnaud d'Ossat, Séraphin Olivier-Razali) résident en permanence tandis que d'autres (François de Joyeuse, Jacques Davy du Perron) font des séjours plus ou moins fréquents et plus ou moins longs à la cour pontificale ${ }^{10}$.

11 Tel est le cadre général des relations que Henri IV entretint avec les papes. Ces données permettent de mieux comprendre la stratégie conduite par les deux protagonistes pour faire face aux tensions, litiges et autres crises qui surgirent à cette époque. Il est intéressant de constater que dans ce rapport de force les stratégies du roi et du pape furent changeantes en fonction de la nature des affaires à traiter. Il importe donc d'esquisser une typologie des affaires qui formèrent la trame du contentieux francoromain. L'étude qui suit portera principalement sur la période 1599-1607 correspondant aux trois premières nonciatures (Silingardi, Del Bufalo et Barberini), période fertile en incidents de toute sorte. 


\section{Le contentieux franco-romain : essai de typologie}

12 Les relations entre la France et Rome, dans les années qui suivirent l'absolution de Henri IV, sont marquées par une volonté de réconciliation durable, manifestée par quelques épisodes symboliques déjà mentionnés plus haut, mais dans l'ensemble les sujets de friction, voire d'affrontement, furent nombreux, et les diplomates tant français que pontificaux eurent fort à faire pour éviter des ruptures et maintenir un dialogue entre les deux cours, même si ce dernier ressembla parfois à un dialogue de sourds. On peut distinguer trois types de contentieux.

En premier lieu les trois grands dossiers politico-religieux qui mettaient en jeu les intérêts supérieurs de la chrétienté catholique et auxquels, compte tenu de la situation propre à la France, aucune solution satisfaisante ne pouvait être apportée, à savoir : la réception en France des décrets du concile de Trente (dossier en discussion depuis la clôture du concile), le rappel des jésuites (expulsés en 1595 et rétablis en 1603) et la promulgation de l'édit de Nantes. Dans le règlement des deux premiers dossiers, le roi n'était pas dans la même position vis-à-vis du Saint-Siège. La réception du concile de Trente était l'une des conditions mises par Clément VIII à son absolution (l'équivalent de ce que nous appelons aujourd'hui la « pénitence » ou la «satisfaction » imposée à la suite de l'administration du sacrement de réconciliation). En revanche, le rappel des jésuites relevait d'une simple promesse faite par le roi au pape et plusieurs fois réitérée à ses légats ${ }^{11}$.

Une autre source de conflits potentiels est la mise en œuvre des dispositions fixées par le concordat de Bologne pour la nomination des évêques. Il s'agit là d'une série de cas individuels dans le cadre d'une procédure administrative régulière.

Enfin, à côté de ces questions qui s'inscrivent en permanence dans le jeu normal des relations diplomatiques, surgissent sans cesse, à l'improviste, des problèmes ponctuels qui relèvent de la sphère doctrinale ou pastorale : prédicateurs zélés qui enflamment le peuple du haut de leur chaire, livres suspects que le laxisme de la censure royale laisse paraître et circuler, ministres réformés et magistrats gallicans qui attaquent le pape et l'Église romaine.

16 Les diplomaties française et pontificale sont donc en permanence sur la brèche pour tenter de résoudre, au cas par cas, les litiges soulevés. En fond de tableau, deux grands sujets de différend interfèrent constamment dans les négociations et entretiennent une méfiance réciproque. Le premier, très ancien mais plus que jamais vivace, est la défense des libertés de l'Église gallicane, sur lesquelles veille jalousement, en première ligne, le Parlement de Paris, cible des plaintes continuelles des nonces. Mais plus encore que les résistances gallicanes à la politique de réforme catholique orchestrée par la papauté, c'est la présence inquiétante de l'hérésie en France au sortir des guerres de religion qui préoccupe le Saint-Siège. Après le cardinal de Florence, les nonces dressent des constats alarmistes de cette situation si étrange aux yeux d'évêques italiens. Silingardi ne comprend pas ce pays où les protestants sont présents jusque dans le gouvernement et dans l'entourage proche du souverain. Del Bufalo déplore qu'il soit possible de publier des livres pleins d'hérésies. Tous deux stigmatisent la liberté de conscience qui règne sans entrave. Cet état de choses propre à la France est inconcevable pour les prélats italiens, que le cardinal-neveu a pourtant prévenus dans les instructions qu'il leur a remises avant leur départ en multipliant les conseils pratiques pour parvenir à l'extirpation de l'hérésie. 
17 Aussi bien Henri IV que Clément VIII étaient conscients des difficultés suscitées par ce contexte très particulier. Aucun d'eux ne cherchait l'épreuve de force. Le roi était profondément reconnaissant au pape de l'avoir réintégré dans le giron de l'Église catholique deux ans après l'abjuration de Saint-Denis et d'avoir ainsi permis le ralliement des derniers ligueurs et la pacification intérieure du royaume. Le pape, de son côté, avait conscience qu'il devait tout faire pour maintenir une bonne entente avec le roi Très Chrétien, faute de quoi le risque était grand de voir contesté par les catholiques les plus intransigeants le bien-fondé de l'absolution qu'il lui avait accordée en 1595, en dépit des objections et des mises en garde qu'il avait rencontrées au sein de la curie romaine.

18 De part et d'autre, il fallait donc éviter les crises. Il n'est pas sans intérêt d'analyser, en observant quelques cas concrets, les stratégies qui ont été mises en place à cet effet.

\section{Les grands dossiers politiques}

19 Le concile de Trente. - Henri IV en 1600, à l'issue des négociations insistantes menées par le nonce Silingardi, paraissait résolu (ou plutôt résigné) à recevoir les décrets du concile de Trente. Un projet d'édit fut dressé à cet effet. Mais en prévision de l'opposition inévitable du Parlement de Paris, il contenait une sorte de clause de sauvegarde réservant les droits de la Couronne et les libertés de l'Église gallicane. Avant de l'envoyer au Parlement, Henri IV décida de le soumettre au pape. À l'automne 1601, le nouvel ambassadeur Philippe de Béthune fut chargé de le présenter à Clément VIII. L'affaire échappait dès lors au nonce (Silingardi jusque-là avait mené les négociations avec beaucoup de ténacité et même une certaine efficacité). Mais les réserves mises par le roi de France à l'application du concile, qui ne suffisaient déjà pas à désarmer le Parlement, ne pouvaient non plus être agréées à Rome, où le projet royal fut mis à l'étude. C'est en vain que le nouveau nonce Del Bufalo aborda la question avec le roi dès son arrivée. Henri IV lui répliqua qu'il entendait bien tenir l'engagement pris lors de son absolution, mais que l'affaire se traitait désormais à Rome. Or, jusqu'à la fin de sa nonciature Del Bufalo ne reçut plus la moindre instruction sur ce sujet. On sait que ce dossier ne devait jamais aboutir ${ }^{12}$.

Le rappel des jésuites. - Autre dossier dans lequel Henri IV réussit à faire prévaloir ses vues: le rappel des jésuites bannis du royaume de France le 7 janvier 1595 à la suite de l'attentat de Jean Chastel. Les négociations commencées dès 1596 aboutirent en septembre 1603 avec la promulgation de l'édit de Rouen. Henri IV se trouvait dans une situation difficile: sincèrement désireux de rappeler la Compagnie, il devait tenir compte de l'opposition gallicane et parlementaire. Il posa donc dès le début comme condition au rétablissement des jésuites leur engagement à ne pas s'ingérer dans les affaires d'État et des preuves de loyalisme, exigeant d'eux entre autres un serment annuel de fidélité à sa personne : une exigence qui était difficilement compatible avec le serment spécial d'obéissance que les membres de la Compagnie devaient prêter au pape.

Pour imposer ses conditions, Henri IV s'employa à éviter autant que possible de négocier avec le Saint-Siège et ses représentants. Plutôt que de discuter avec les nonces, il préféra traiter avec des membres de la Compagnie, d'abord en 1598 avec le P. Lorenzo Maggio, proche collaborateur du général Claudio Aquaviva désigné par lui à cet effet, puis à partir du printemps 1603 avec le P. Ignace Armand, provincial de France en exil, réfugié à Pontà-Mousson en Lorraine, et le P. Pierre Coton, nommé à cette occasion prédicateur ordinaire du roi. Par ailleurs, à partir de 1601, Henri IV renonça à traiter de ce dossier avec le nonce Del Bufalo, dont il se méfiait, et en chargea son ambassadeur à Rome 
Philippe de Béthune. Dès lors, l'affaire échappa totalement au nonce en France, qui apprit avec stupeur, en septembre 1603, la promulgation de l'édit, que le Parlement de Paris enregistra non sans réticence le 2 janvier 1604. Quand la nouvelle fut connue à Rome, le pape et le $\mathrm{P}$. Aquaviva venaient de communiquer au nonce leurs réserves sur le projet que leur avait soumis l'ambassadeur Béthune, et ils le chargèrent de protester. Mais les démarches du nonce furent vaines : Henri IV refusa d'apporter au texte les amendements souhaités par le pape et le cardinal-neveu. Tout au plus avait-il accepté, à la demande des P. Armand et Coton, de faire prêter serment par les jésuites une seule fois au moment de leur retour dans le royaume et non pas chaque année comme cela avait été initialement prévu. Une fois de plus, Henri IV avait fait triompher ses vues et placé le pape devant le fait accompli. Clément VIII dut en prendre son parti, trop heureux finalement du résultat, d'autant que le roi combla aussitôt la Compagnie restaurée de ses bienfaits, en lui donnant notamment son château de La Flèche pour y fonder un collège et un noviciat. Dans l'instruction de Barberini en 1604, le pape alla jusqu'à le charger de féliciter le roi de sa décision. L'édit de Rouen ouvrait une ère nouvelle dans l'histoire de la Compagnie de Jésus en France. Il lui donnait une existence légale dans le royaume et créait comme un rameau national de l'ordre. C'était le début d'une sorte de naturalisation de l'ordre dans la monarchie gallicane ${ }^{13}$.

L'édit de Nantes. - L'édit de Nantes, qui accordait un statut légal aux réformés de France, fut signé et scellé en avril 1598, mais, par égard pour le cardinal de Florence, légat a latere, qui se trouvait encore en France à cette époque, Henri IV différa son envoi aux parlements aux fins d'enregistrement. Le roi profita donc d'un intérim de la représentation diplomatique du Saint-Siège en France (assurée de l'automne 1598 au printemps 1599 par un simple chargé d'affaires, Giovanni Bandini) pour faire passer son édit, tandis que Clément VIII, dans l'instruction qu'il remit au nonce Silingardi le 9 février 1599, chargeait celui-ci de s'opposer à cette funeste mesure. Mais quand l'évêque de Modène arriva à Paris, le 30 avril 1599, l'édit était enregistré depuis deux mois. Il fallut toute l'habileté de Nicolas Brulart de Sillery, envoyé à Rome peu après, pour apaiser le pape en lui annonçant notamment le rétablissement du culte catholique en Béarn, conformément à l'article 3 de l'édit. Clément VIII finit par prendre son parti de la situation nouvelle créée dans le royaume de France et il adopta par la suite sur ce point une attitude singulière, consistant à affecter d'ignorer l'existence même de l'édit : ainsi, dans les instructions remises en 1601 et 1604 aux nonces Del Bufalo et Barberini, le cardinal Aldobrandini se contente, dans le passage relatif à l'hérésie, de faire référence à l'édit de Poitiers de 1577, le plus important des édits de pacification qui, avant celui de 1598, avaient jalonné la période des guerres de religion. Henri IV avait donc réussi fort habilement à promulguer son édit sans se brouiller avec le pape. Ce dernier, notons-le, ne s'interdisait d'ailleurs pas d'invoquer l'édit lorsqu'il avait intérêt à en demander l'application (par exemple pour obtenir l'interdiction du culte réformé dans les territoires situés au-delà des monts) ${ }^{14}$. 
Dans les trois grands dossiers qui viennent d'être évoqués, le roi avait donc adopté des stratégies identiques: conscient que les nonces étaient mal préparés à accepter des solutions par trop étrangères à leur univers intellectuel, il avait fait appel à d'autres négociateurs et s'était notamment reposé sur son ambassadeur à Rome, profitant par ailleurs à deux reprises d'un « vide diplomatique ». Cette méthode de contournement lui a réussi dans deux cas. Dans le troisième cas, celui de la réception du concile, il a laissé l'affaire s'enliser, une stratégie qui a d'ailleurs réussi également dans plusieurs dossiers particuliers, comme on le verra plus loin.

\section{Les nominations épiscopales}

Depuis les dispositions prises par Grégoire XIV, qui en 1591 avait chargé les légats et les nonces d'instruire les enquêtes de vie et mœurs des candidats à l'épiscopat (procès de promovendis), le nonce avait un rôle décisif à jouer en matière de nominations épiscopales. Plus encore que l'ambassadeur du roi à Rome, il était en première ligne dans ce genre de dossiers. Compte tenu de la situation du royaume, où la présence de l'hérésie était officiellement reconnue et admise, le choix des hommes destinés à l'épiscopat, dévolu au roi par le concordat, faisait l'objet d'un examen particulièrement vigilant de la part du Saint-Siège. Si la plupart des candidats proposés dans les années qui suivirent l'absolution de Henri IV furent agréés par Clément VIII, quelques-uns attendirent leurs bulles assez longtemps. Ainsi, Renaud de Beaune, évêque de Mende en 1568 puis archevêque de Bourges en 1581, prélat connu pour ses sympathies gallicanes, dut patienter huit ans avant d'obtenir ses bulles pour l'archevêché de Sens où Henri IV l'avait nommé dès 1594. Un autre exemple est celui de Jean Garnier, nommé en 1602 évêque de Montpellier, un diocèse « sensible ». Dans un premier temps, le nonce Del Bufalo avait félicité le roi de son choix. Mais peu après il reçut une mise en garde de Rome car le prélat, dont le comportement était devenu apparemment irréprochable, avait jadis publié des ouvrages qui avaient été brûlés sur ordre de la Sorbonne. Le nonce reprit son enquête et de nouveau donna un avis favorable. Garnier reçut donc l'institution canonique après quelques mois d'attente. Une seule nomination fut refusée par Clément VIII : celle de René Benoist à l'évêché de Troyes.

25 René Benoist (1521-1608) avait commencé sa carrière comme confesseur de la reine Marie Stuart, en France et un temps en Écosse. Nommé en 1568 curé de Saint-Eustache, il fut d'abord ligueur puis se rallia en 1593 à Henri IV et joua un rôle important dans l'abjuration du roi, dont il devint le confesseur, et il fut nommé la même année à l'évêché de Troyes. Le Saint-Siège refusa d'entériner sa nomination, principalement à cause de sa traduction de la Bible, qui empruntait beaucoup à la traduction de Calvin et avait été condamnée par Grégoire XIII en 1575. Benoist s'était soumis à la censure pontificale en 1598 en devenant doyen de la Faculté de théologie. Néanmoins, son repentir parut gravement suspect quand en 1601 il prononça un sermon à Orléans en présence du roi, où il critiquait les indulgences. Peu après son arrivée à Paris, à l'automne 1601, le nonce Del Bufalo le fit comparaitre en présence du nonce extraordinaire Maffeo Barberini, et fit sur lui en janvier 1602 un long rapport dont la conclusion était plutôt favorable. Mais Clément VIII, prudent, jugea bon de consulter le Saint-Office. Le temps passait et Henri IV s'impatientait, déplorant que ce retard pût donner à penser qu'il avait choisi un hérétique comme confesseur. Le pape tint bon, et en janvier 1604 Benoist dut se résoudre à résigner son évêché en faveur d'un des aumôniers du roi, René de Breslay, en échange de bénéfices 
d'un revenu équivalent à celui auquel il renonçait. Pour une fois, Clément VIII avait réussi à imposer sa volonté à Henri IV en matière de nominations épiscopales. On peut noter qu'ici le pape n'a pas suivi son nonce ${ }^{15}$.

Dans l'ensemble, les nominations de Henri IV ont donc été agréées à Rome et, hormis le cas de René Benoist, qui a d'ailleurs été réglé avec une relative discrétion, n'ont pas donné lieu à des crises aiguës. On ne peut en dire autant des nombreuses affaires ponctuelles qui, sans relâche, ont jalonné les nonciatures de Silingardi, de Del Bufalo et de Barberini, affaires qui ont été déclenchées de diverses manières, principalement par la parole et par l'écrit. Sans chercher à dresser un inventaire exhaustif ni à établir des catégories précises, on retiendra quelques cas qui permettront de mettre en lumière divers aspects des stratégies déployées par les pouvoirs, en France et à Rome, pour éviter des ruptures ${ }^{16}$.

\section{Des extrémistes virulents : religieux et pasteurs}

1599: deux prédicateurs bien encombrants. - Au début de l'année 1599, deux capucins, Archange de Lyon et Jean-Baptiste de Paris, attaquèrent en chaire l'édit de Nantes, respectivement à Saint-Germain-l'Auxerrois et à Saint-Étienne-du-Mont, organisant des prières publiques pour qu'il ne fût pas enregistré par le Parlement (la procédure était alors en cours). Jean-Baptiste de Paris était un Brulart, frère de Nicolas Brulart de Sillery, conseiller d'État et président au Parlement, futur garde des sceaux et chancelier, que Henri IV s'apprêtait à envoyer à Rome pour négocier la déclaration de nullité de son mariage avec Marguerite de Valois. Sur ces entrefaites, une femme apparemment possédée, Marthe Brossier, confiée aux soins de deux exorcistes capucins, se déchaîna à son tour dans son délire contre l'édit. Le Parlement intervint et la déclara de prise de corps. Les capucins s'emportèrent contre cette intervention. Le Parlement les cita à comparaître. Le 6 mai, il interdit au P. Archange de Lyon de prêcher pendant six mois, une interdiction dont les deux religieux ne tinrent aucun compte. Finalement, le roi, par l'intermédiaire de son ambassadeur à Rome Sillery et du cardinal de Joyeuse, obtint du général de leur ordre, avec l'accord du pape, leur éloignement temporaire de Paris: le P. Jean-Baptiste fut envoyé à Vérone et le P. Archange à Toulouse. Le nonce Silingardi, qui appréciait le zèle des capucins, pourfendeurs de l'hérésie, fut tenu à l'écart de ces tractations, dont l'issue le surprit. Il se refusa à croire que le pape eût donné son accord à l'exil des deux religieux, jusqu'à ce que le P.Jean-Baptiste lui eut montré son " obédience » (décision de son supérieur qui le transférait dans un autre couvent).

Ce premier cas mérite de retenir l'attention: en l'occurrence, ce ne sont pas des hérétiques ni des hérauts du gallicanisme qui ont déclenché la tempête, mais des religieux dont l'orthodoxie ne pouvait être mise en doute. D'où l'embarras du roi et du pape, dont les intérêts étaient convergents et qui ont œuvré en plein accord pour désamorcer une crise qui prenait des proportions inquiétantes et qui, de surcroît, mettait en cause un proche d'un personnage haut placé. Clément VIII voulait éviter le bannissement de l'ordre tout entier, que Henri IV avait semblé un moment envisager. Les capucins furent invités au calme et à ne plus se mêler des affaires d'État. Il est intéressant de noter que dans ce cas Clément VIII a pris des dispositions qui ont paru surprenantes à son nonce ${ }^{17}$. 
1602-1607 : des huguenots audacieux. - Le 5 février 1602, le pasteur de Nîmes Jérémie Ferrier soutenait une thèse dans laquelle il développait, entre autres, un thème récurrent depuis Luther dans l'idéologie réformée, à savoir que le pape était l'Antéchrist. Le nouveau nonce Innocenzo Del Bufalo, qui avait pu se procurer un exemplaire de la thèse, se plaignit au chancelier, qui saisit aussitôt la chambre de l'édit de Castres, juridiction compétente pour juger les procès civils et criminels mettant en cause des protestants. Del Bufalo aurait voulu que le roi évoquât l'affaire à son Conseil, mais le secrétaire d'État Villeroy donna tous apaisements à l'ambassadeur à Rome Philippe de Béthune et l'assura que la chambre de Castres prendrait les mesures appropriées. De fait, le parlement de Toulouse (dont la chambre de Castres était l'une des composantes) fit peu après brûler publiquement les thèses. Le pape ne s'en montra qu'à moitié satisfait : il pressa le nonce d'obtenir la punition du pasteur lui-même. L'affaire connut d'ailleurs un rebondissement quand le synode de Gap, en octobre 1603, décida d'insérer dans la profession de foi réformée un article désignant le pape comme l'Antéchrist ${ }^{18}$. Cette décision suscita aussitôt le courroux du roi, d'autant plus que la même assemblée avait noué des relations avec les princes protestants d'Allemagne, les Provinces-Unies et l'Angleterre. Henri IV intervint alors directement et interdit purement et simplement l'insertion de l'article sur l'Antéchrist. Les députés s'inclinèrent, suivant en cela le conseil qui leur fut donné par Philippe Duplessis-Mornay, la principale autorité morale du calvinisme à cette époque. Mais l'article sur l'Antéchrist, dont il ne fut pas question au synode de Châtellerault en 1605, fut de nouveau inscrit à l'ordre du jour du synode de La Rochelle en mars 1607. De nouveau, il fallut une intervention de Duplessis-Mornay et du ministre huguenot du roi, Sully (qui représentait alors ce dernier à l'assemblée), pour empêcher l'insertion de l'article. Cependant, la confession de foi avait déjà été imprimée, et même si sa diffusion fut aussitôt interdite et le stock saisi chez l'imprimeur, un exemplaire en était parvenu à Rome. Le cardinal Borghèse, neveu du pape Paul V, chargea le nonce Barberini de se plaindre. Barberini s'exécuta, mais n'obtint du roi et de Villeroy que des regrets assortis du constat de l'impossibilité où ils étaient de faire disparaître tous les exemplaires d'un texte dont la diffusion était commencée. Le nonce fit alors remarquer qu'il en serait allé autrement si le roi avait fait un exemple en punissant sévèrement l'un des responsables de ces désordres. On touche ici du doigt une limite des interventions royales : Henri IV, dans des situations extrêmes, prenait des mesures contre les œuvres mais non contre les auteurs (seuls les imprimeurs étaient éventuellement poursuivis et incarcérés)

Au-delà de l'agitation d'un pasteur et des délibérations des synodes, l'affaire Ferrier met en lumière le rôle de l'imprimé et de sa diffusion, ainsi que la médiocre efficacité de la censure.

\section{Le contrôle de la production imprimée}

31 Le contrôle de la production imprimée était rendu d'autant plus nécessaire aux yeux de Rome que l'organisation de la censure en France laissait beaucoup à désirer. C'était particulièrement le cas sous Henri IV, à une époque où la Faculté de théologie, chargée de la censure des ouvrages religieux, était divisée entre gallicans et "ultramontains». Or, c'est par le livre ou le libelle que se propagent les idées les plus pernicieuses, qui non seulement circulent librement dans le royaume, mais risquent même de pénétrer en Italie, ce que le Saint-Siège redoute par-dessus tout. Les nonces sont donc toujours sur le qui-vive et s'efforcent de faire preuve de la plus grande vigilance, d'autant que ce sont 
eux, en l'occurrence, qui ont toujours l'initiative dans ce genre d'affaire et qui doivent alerter les autorités françaises et romaines. En effet, contrairement aux nominations épiscopales, qui, faisant partie du jeu concordataire, sont préparées et relèvent d'une sorte de routine, les publications d'ouvrages sont par nature imprévisibles et le nonce doit le plus souvent réagir «à chaud» lorsqu'il a connaissance des publications litigieuses, alors que celles-ci, parfois, circulent déjà depuis un certain temps.

Entre 1599 et 1607, un grand nombre de cas de ce genre se sont présentés, qu'il est impossible d'analyser tous dans le cadre de la présente communication. On tentera plutôt, en s'appuyant sur quelques exemples, de dégager des constantes et de proposer une vue d'ensemble des contentieux qui se sont développés pendant cette période, et des solutions qui leur ont été apportées. On commencera par un état des lieux.

Chronologiquement, les affaires qui ont déclenché l'intervention des nonces sont inégalement réparties pendant notre période (1599-1607). Silingardi n'a eu à traiter qu'une seule affaire, mais elle était d'importance : l'Institution de l'Eucharistie de DuplessisMornay en 1599. Del Bufalo en a eu beaucoup plus (outre la thèse de Jérémie Ferrier sur l'Antéchrist en 1602) et surtout cinq coup sur coup de novembre 1603 à février 1604 : la traduction française de la Méditation sur la Révélation du roi d'Angleterre Jacques $\mathrm{I}^{\mathrm{er}}$, le plaidoyer de Louis Servin et l'arrêt du Parlement sur le bréviaire d'Angers, La Fournaise ardente de Palma-Cayet, l'Histoire de Jacques-Auguste de Thou et la Sagesse de Pierre Charron. Quant à Barberini, il eut à intervenir deux fois en 1605 : sur l'Histoire de Pierre Mathieu et la Chronologie septenaire de Palma Cayet) ; et il eut fort à faire en 1606-1607 face à la littérature à laquelle donna lieu l'interdit de Venise. On peut noter ici que la vigilance des nonces a parfois été prise en défaut. Ainsi, Del Bufalo ne parle pas, en 1602, du Catéchisme des jésuites d'Étienne Pasquier ni du Franc et véritable discours d'Antoine Arnauld, deux pamphlets dirigés contre le rappel des jésuites et qui ont été aussitôt inscrits à l'Index (16 et 19 novembre 1602). Rome disposait donc d'autres canaux d'information.

Si l'on considère maintenant la nature des ouvrages incriminés, on constate qu'il est difficile de les répartir en des catégories bien tranchées, tant les thèmes traités s'entremêlent. Ceux qui suscitent prioritairement l'intervention des nonces sont évidemment les traités théologiques dus à des protestants (par exemple l'Institution de l'Eucharistie) et ceux (ce sont parfois les mêmes) qui contiennent des attaques personnelles contre les papes. Sont également dénoncées les publications qui mettent en cause les évêques, les interventions du Parlement dans l'exercice de la juridiction ecclésiastique par le jeu de l'appel comme d'abus, ainsi que les ouvrages de caractère historique qui portent atteinte dans des portraits trop véridiques à l'image officielle et à la réputation de personnages depuis longtemps disparus (De Thou ou Palma Cayet), ou ceux qui semblent préconiser et appeler de leurs vœux l'établissement d'une Église nationale en France.

La revendication identitaire gallicane et l'hérésie sont les deux fléaux que Rome s'attache à combattre prioritairement avec la dernière énergie, tant ils paraissent redoutables aux yeux de la papauté et de ses agents. S'il s'agit en principe de problèmes distincts, les interférences et les amalgames entre les deux idéologies sont vite réalisés: ainsi Del Bufalo assimile sans hésiter l'avocat général du roi au Parlement Louis Servin, un gallican intransigeant, à un huguenot, et il voit des hérésies partout. Le protestantisme et le gallicanisme sont donc réunis dans la démarche accusatrice des nonces. Ceux-ci sont en rapport essentiellement avec deux ministres: Pomponne de Bellièvre, chancelier de 
France de 1599 à 1607, et Nicolas de Neufville de Villeroy, secrétaire d'État. Bellièvre surtout est l'interlocuteur privilégié des diplomates pontificaux, qui trouvent généralement chez lui une oreille bienveillante. C'est un personnage clé en matière de contrôle de la production imprimée depuis qu'en 1566 l'ordonnance de Moulins a prescrit que les privilèges de librairie (autorisations d'imprimer) seraient délivrés par lettres patentes scellées du grand sceau. De plus, étant le chef de la magistrature, il a autorité sur le Parlement.

Il nous faut maintenant essayer, à partir de quatre exemples, d'analyser les stratégies déployées de part et d'autre dans ce contentieux à rebondissements.

1599 : Duplessis-Mornay et le Traité de l'Eucharistie. - À peine arrivé à Paris, au début de mai 1599, Silingardi eut à se plaindre dans la première audience que lui accorda Henri IV de la publication de l'Institution de l'Eucharistie, un traité que Philippe Duplessis-Mornay, figure de proue du calvinisme et conseiller très proche de Henri de Navarre avant son abjuration, avait fait imprimer à La Rochelle l'année précédente et qui circulait librement à Paris ${ }^{19}$. Dans cet ouvrage, le " pape des huguenots » attaquait la doctrine de la Présence réelle, assimilait le pape à l'Antéchrist et l'Église romaine à la grande prostituée de Babylone. Le nonce remontra au roi qu'il était personnellement diffamé, puisque Mornay stigmatisait comme idolâtres tous ceux qui assistaient à la messe. Henri IV répondit qu'il avait ordonné la destruction du livre et exprimé son mécontentement à l'auteur. Ce dernier s'était d'ailleurs excusé en faisant valoir que le livre avait été publié contre sa volonté et que le vrai coupable était l'imprimeur, lequel avait été incarcéré. En outre, le livre, selon lui, n'était qu'une traduction d'un vieux texte latin. Le roi ordonna alors à Pomponne de Bellièvre d'interdire toute attaque contre le pape et l'Église catholique sous peine de mort. Il chargea l'évêque de Paris de veiller à ce que la vente du livre fût interdite à Paris. De fait, des saisies eurent lieu peu après chez plusieurs libraires. Au début d'août 1599, l'interdiction fut enregistrée par le Parlement de Paris, et le livre fut brûlé. Parallèlement, une censure de la Faculté de théologie fut imprimée en latin et en français, dont Silingardi envoya un exemplaire à Rome. On sait que cette affaire fut à l'origine de la célèbre controverse connue sous le nom de "conférence de Fontainebleau ", le 4 mai 1600, dont l'évêque d'Évreux, Jacques Davy du Perron, fut déclaré vainqueur après avoir démontré la fausseté de plusieurs citations figurant dans l'ouvrage.

Henri IV avait en l'occurrence fait preuve de détermination pour donner satisfaction au pape, devant une attaque aussi frontale contre le souverain pontife. Cependant, même s'il n'hésita pas à humilier publiquement son fidèle conseiller et ancien mentor, qui avait succombé dans la conférence de Fontainebleau, il se montra fort modéré dans le châtiment : Duplessis-Mornay ne connut jamais qu'une demi-disgrâce ${ }^{20}$.

1603: le bréviaire d'Angers. - Avec le bréviaire d'Angers, nous quittons le domaine de l'hérésie pour aborder celui des rapports entre la religion et le pouvoir judiciaire, des conflits entre l'épiscopat et le Parlement de Paris. Cette affaire mit aux prises en 1603 le nonce Del Bufalo et l'avocat du roi au Parlement Louis Servin, grand magistrat, fort érudit 
mais aussi gallican extrémiste. Henri IV lui-même le considérait comme un fou (un matto). En le nommant avocat général en 1589, il aurait déclaré (selon L'Estoile) : «Puisque les sages ont mené l'État à sa ruine, les fous doivent le restaurer. »

L'origine du conflit entre le nonce et le magistrat remonte à l'année 1599, quand Charles Miron, évêque d'Angers, sans consulter son métropolitain, l'archevêque de Tours, ni le clergé de son diocèse, avait prescrit aux chanoines de la collégiale de la Trinité d'utiliser le nouveau bréviaire approuvé par le concile de Trente. Ces chanoines, désireux de maintenir les les anciennes traditions, avaient interjeté appel comme d'abus au Parlement. En février 1603, Servin prononça un violent réquisitoire à la suite duquel l'évêque fut condamné Aussitôt Del Bufalo essaya de persuader le chancelier Pomponne de Bellièvre d'interdire la publication de la harangue et de l'arrêt. Dans un premier temps, Bellièvre répliqua que le nonce devait avoir été mal informé. Mais quand la harangue et l'arrêt eurent été publiés quelques mois plus tard ${ }^{21}$, en tête d'un recueil des plaidoyers de l'avocat général, Del Bufalo alerta le cardinal de Gondi, évêque de Paris, et plusieurs autres prélats; il leur demanda de protester auprès du roi contre cet affront fait à l'épiscopat et de s'enquérir de la position de la Faculté de théologie. Celle-ci, dont le doyen était alors René Benoist, confesseur du roi et évêque nommé de Troyes, refusa de se prononcer dans sa séance du $1^{\mathrm{er}}$ décembre. Quant à Servin, il se plaignit à Henri IV de ce que le nonce, simple ambassadeur d'un souverain étranger (c'était le point de vue classique des gallicans), osât traiter avec les évêques. Convoqué devant le Conseil du roi, le cardinal de Gondi prit la défense du nonce et accusa Servin. Le roi reprocha alors à ce dernier d'avoir diffamé Del Bufalo et il essaya de dissuader le nonce de rendre compte de l'incident à Rome. Del Bufalo répliqua qu'il continuerait à protester jusqu'à ce que les autorités désavouent une prise de position jugée par lui "hérétique». Il ne reçut en réponse que de bonnes paroles: Servin retirerait les exemplaires de son livre en circulation et les amenderait à l'avenir; les textes incriminés disparaîtraient d'une prochaine édition. Mais Del Bufalo insistait, harcelait le roi, Bellièvre, Villeroy, sans jamais obtenir d'assurances formelles, d'autant que le Parlement avait interdit à la Faculté de théologie de débattre de ce dossier. À Rome, Clément VIII félicita le nonce de son acharnement, mais décida d'attendre de plus amples informations avant de se plaindre éventuellement à l'ambassadeur.

41 Le chancelier Bellièvre autorisa enfin la Faculté de théologie à se saisir de l'affaire. Le 16 février, une assemblée où ne siégeaient que la moitié des docteurs censura le livre de Servin. Dès le lendemain, le Parlement convoqua le syndic de la Faculté, le bedeau et trois docteurs. Il apparut que le doyen de la Faculté, René Benoist, et au moins trente ou quarante autres docteurs avaient boycotté la séance; que celle-ci aurait dû, en conséquence, être ajournée; que la procédure avait été irrégulière. Le premier président Achille de Harlay demanda que le procès-verbal de la réunion fût transmis au greffe de la cour.

À peine averti de ce nouvel épisode, Del Bufalo se rendit à nouveau chez le chancelier pour se plaindre. Mais déjà le roi était intervenu: pour éviter un affrontement entre la Faculté et le Parlement, il avait évoqué toute l'affaire et annoncé qu'il la traiterait personnellement. Néanmoins, le nonce constatait amèrement que la censure de la Sorbonne rendue le 16 février n'était toujours pas publiée. De plus, quand les Plaidoyers de Servin furent réimprimés, la harangue litigieuse et l'arrêt y demeurèrent inchangés. L'affaire s'enlisa et on n'en parla bientôt plus. 
Plusieurs mois plus tard (juin 1604), Servin déclencha de nouveau une querelle entre le Parlement et l'épiscopat. Del Bufalo, probablement trompé par les critiques de Henri IV à l'égard de Servin, pensa avoir une chance d'obtenir la révocation de l'avocat général. Mais sa démarche indisposa le roi : même s'il appréciait peu le comportement de Servin, il n'admettait pas que le nonce prétendît lui dicter le renvoi d'un officier qu'il avait choisi.

En août 1605, l'assemblée du clergé revint sur la question du bréviaire d'Angers. Une délégation alla demander au roi la révocation de l'arrêt du Parlement et le pria d'interdire à Servin de plaider les causes relatives à l'Église. Cette démarche n'eut aucun succès. Servin fera encore parler de lui lors de l'Interdit de Venise.

Ces démêlés appellent plusieurs remarques. Tout d'abord, il était bien plus difficile de proscrire un ouvrage publié par un officier de haut rang dans l'exercice de ses fonctions que de proscrire un libelle hérétique. D'autre part, l'importance de Servin ne doit pas être exagérée. C'était à coup sûr un agité, mais sa position était forte. Le fait que le pape se soit abstenu de se plaindre à l'ambassadeur de France peut être considéré comme une reconnaissance tacite de cet état de choses. Del Bufalo n'a pas été encouragé à continuer ses protestations contre l'avocat général. Enfin, on peut noter que tout ce que le nonce a demandé aurait de toute façon été exécuté même s'il n'avait rien dit. Ses interventions n'avaient fait qu'aggraver la crise ${ }^{22}$.

1603 : Palma Cayet et La Fournaise ardente. - Né catholique, puis converti au calvinisme, appartenant à l'entourage de Jeanne d'Albret, comme tuteur adjoint de ses enfants, venu à Paris avec Catherine de Bourbon, la sœur protestante du roi, Pierre Victor Palma Cayet était revenu au catholicisme en 1595 et il se lança alors dans la controverse religieuse. Nommé en 1599 professeur royal de langues orientales (il était spécialisé dans l'hébreu), il fut ordonné prêtre en 1600 et reçu docteur en théologie au collège de Navarre.

L'ouvrage de Palma Cayet intitulé La Fournaise ardente parut en 1603. Il prenait place dans une série d'opuscules publiés la même année sur le thème du Purgatoire : par le pasteur réformé Pierre Du Moulin, le docteur André Du Val, professeur royal de théologie à l'université de Paris, et Jacques Suarès de Sainte-Marie, un franciscain portugais. Cayet avait déjà publié plusieurs libelles sur le sujet. Celui-ci fut censuré par l'évêque de Paris, Pierre de Gondi, pour des raisons qui ne sont pas évidentes. Cet ouvrage ne contenait aucune hérésie flagrante. Les nombreuses métaphores tirées de l'alchimie qu'on y trouvait ne justifiaient pas non plus d'éveiller les soupçons des théologiens. Pierre de L'Estoile, qui d'habitude explique pourquoi un livre est condamné, avoue ici ses incertitudes. Les défaillances qui ont justifié la "mise en examen» de l'œuvre étaient donc mineures, et la procédure qui se mit en branle était probablement due avant tout aux rivalités qui depuis 1601 existaient au sein de la Faculté de théologie entre les docteurs gallicans du collège de Navarre (avec à leur tête René Benoist) et les docteurs «ultramontains » menés par André Du Val. Palma Cayet appartenait au premier groupe. Attaqué, interdit de publication, il fit appel à l'archevêque de Sens, Renaud de Beaune, métropolitain de l'évêque de Paris, et qui, comme on l'a dit plus haut, avait des sympathies gallicanes. Del Bufalo tenta en vain de persuader l'archevêque de ne pas donner suite à cette requête : l'official de Sens rétablit Cayet dans son droit de prêcher. Fort de ce premier succès, Cayet, au début de décembre 1603, fit appel comme d'abus au Parlement contre l'évêque de Paris. Del Bufalo insista auprès de Bellièvre et de Villeroy 
pour arrêter la procédure, et il obtint entière satisfaction. C'était l'époque où l'affaire Servin traversait une phase cruciale. Alors que le roi se refusait à prendre des mesures contre son avocat général, il se montra beaucoup plus sévère dans ce nouveau cas qui ne mettait en cause qu'un simple théologien. Le premier président de Harlay reçut instruction de renvoyer le procès à l'évêque de Paris. En mars 1604, Del Bufalo put annoncer à Rome que « ledit sieur Cayet, ayant reconnu ses erreurs, a abjuré et demandé pardon, à la satisfaction des catholiques, qui ont été gravement scandalisés par son livre ». La version donnée par Cayet était toute différente : l'évêque et son vicaire général, écrit-il, ont été obligés de faire la paix avec lui, et il a accepté aux conditions suivantes : que sa réputation fût restaurée, que tous les actes pris contre lui fussent révoqués, que l'interdiction lancée contre son livre fût levée, et qu'il n'aurait aucune modification à apporter à son oeuvre. Cet accord aurait été conclu sur l'avis de quatre magistrats du Parlement nommés par les deux parties.

Les deux camps criaient donc victoire. En l'absence de plus amples informations, il est impossible de trancher entre ces récits contradictoires et de savoir si le nonce a été ou non berné. Les antagonismes reparurent de plus belle deux ans plus tard quand Cayet publia sa Chronologie septenaire. Pour s'en tenir à l'affaire de La Fournaise ardente, deux points doivent être soulignés. Comme l'affaire Servin, l'affaire Cayet mettait en lumière les divisions de la Faculté de théologie. En l'occurrence, il est clair que Del Bufalo suivait l'avis de la faction « ultramontaine » de la Faculté menée par Du Val. Il parle du livre de Cayet comme s'il contenait des hérésies flagrantes, ce qu'il n'aurait peut-être pas fait s'il avait lu l'ouvrage. Cette confiance dans les opinions de Du Val se retrouve dans le cas de Pierre Charron ${ }^{23}$.

1604 : l'Histoire du président De Thou. - En février 1604, le nonce Del Bufalo signalait à Rome deux livres qu'il jugeait pernicieux : La Sagesse de Pierre Charron ${ }^{24}$ et la première édition latine de l'Histoire du président Jacques-Auguste de Thou ${ }^{25}$. Pierre Charron était mort l'année précédente, et De Thou était l'un des magistrats les plus en vue du Parlement. Dans ce genre de circonstance, le nonce était généralement bien reçu par le chancelier Pomponne de Bellièvre, qui écoutait ses doléances et promettait d'intervenir. De fait, le livre de Pierre Charron fut retiré du commerce, une mesure plus théorique qu'efficace car l'ouvrage continua de circuler sous le manteau ${ }^{26}$.

En ce qui concerne l'Histoire du président de Thou, qui nous retiendra seule ici, le nonce se plaignit d'abord au chancelier puis directement au roi. L'affaire prit alors des proportions inattendues car De Thou entendait bien se défendre et se justifier. A cet effet, il envoya son ouvrage à deux des membres les plus en vue du Sacré Collège, les cardinaux Baronius et Bellarmin, et il promit de procéder lui-même aux corrections nécessaires. Del Bufalo vit là aussitôt une manœuvre dilatoire, soupçonnant de Thou de chercher à gagner du temps pour se faire oublier. Mais le nonce était tenace : dans l'audience que le roi lui accorda le 8 mars 1604, il attaqua vigoureusement ce livre «dangereux pour la religion catholique, scandaleux, séditieux, impie et plein de mensonges et d'hérésies ». Le roi lui répliqua que de Thou avait commencé à corriger son œuvre. Le nonce répliqua qu'il était illusoire d'espérer l'améliorer, et que seule sa destruction par le feu pourrait mettre un terme au scandale. Le roi fit alors venir le secrétaire d'État Villeroy, qui confirma que le président de Thou se repentait de ses erreurs et qu'il voulait absolument 
les réparer. Le nonce ne put rien obtenir de plus, si ce n'est que le second tome (pire que le premier d'après lui) ne serait pas imprimé. Le 4 avril, le nonce renouvela ses plaintes, ayant entendu dire qu'une traduction française de l'ouvrage était en préparation. De nouveau le roi fit venir Villeroy et lui ordonna d'empêcher cette édition française. Il semble bien que dans cette occurrence le roi ait réellement tout tenté pour désamorcer une crise qui avait des répercussions internationales et risquait de compromettre sa politique étrangère, d'autant que non seulement le pape, mais aussi les princes de la maison de Lorraine, fort mal traitée dans l'ouvrage, réclamaient le châtiment du président. Le nonce repartit pour Rome à la fin de 1604 sans avoir obtenu satisfaction. De Thou, quant à lui, tentait de sauver son livre en faisant appel aux relations haut placées qu'il avait à Rome. Son ami le cardinal d'Ossat avait établi une longue liste de corrections jugées par lui indispensables, mais il mourut le 14 mai 1604. Ainsi privé d'un puissant appui, de Thou en trouva un autre en la personne du cardinal Séraphin OlivierRazali. Mais celui-ci mourut à son tour le 10 février 1609 et de Thou ne put alors empêcher l'inscription de son œuvre à l'Index, la même année. Dans cette situation, il n'avait plus rien à perdre (d'autant qu'il dut vite renoncer à l'espoir d'accéder à la première présidence du Parlement, charge qu'avait exercée son père Christophe) et il continua donc la publication de son Histoire sans plus se soucier de l'amender ${ }^{27}$.

\section{Conclusion}

51 L'analyse et la comparaison de ces cas très divers permettent de dégager quelques conclusions. En premier lieu, la stratégie du roi est toute différente suivant qu'il s'agit d'affaires politiques ou plus proprement religieuses et doctrinales. Dans les grands dossiers, il évite de traiter avec les nonces et préfère d'autres canaux de négociation, sans hésiter d'ailleurs à devancer les protestations prévisibles du pape et à le placer devant le fait accompli. Dans les affaires individuelles, le roi semble sincèrement désireux de donner satisfaction au pape, surtout quand celui-ci est personnellement visé par les attaques des huguenots et des gallicans. Il veut éviter que des publications intempestives ne viennent contrarier sa politique de réconciliation et d'alliance avec le Saint-Siège. D'où les réponses et les promesses apaisantes prodiguées aux nonces, assorties souvent du constat de l'inefficacité de la législation royale en matière de censure. Un autre moyen de désamorcer les crises est d'annoncer que tel auteur a promis de corriger lui-même ses erreurs (Duplessis-Mornay, Servin, de Thou). En général, le nonce doit constater peu après que l'intéressé n'en a rien fait. Mais la tension initiale est alors retombée.

Quant aux nonces, ils réagissent diversement selon leur tempérament. Silingardi et Del Bufalo, bien que fort différents l'un de l'autre par leur âge, leur formation et leur carrière antérieure, se comportent de la même manière, c'est-à-dire qu'ils se soucient peu d'éviter les crises et font le siège du roi et des ministres pour parvenir à leurs fins. Barberini a une autre stratégie. Certes, il se conforme aux instructions qui lui sont données de Rome comme à ses prédécesseurs, mais sans grande conviction. Il évite autant que possible les affrontements directs et quand il sent des résistances il n'insiste pas, espérant que le temps fera son œuvre et que l'affaire en cause finira par s'enliser. Et il ne se fait guère d'illusions sur l'efficacité de ses interventions. C'est ainsi que le 4 avril 1606, il écrit au cardinal-neveu, sur un ton plus ou moins désabusé, à la suite d'une démarche faite auprès du garde des sceaux Brulart de Sillery à propos d'un libelle dû à un avocat en Parlement, catholique et muni du réglementaire privilège du roi : «À la fin j'ai conclu que 
j'en avais parlé parce que je voulais qu'il [Sillery] fût conscient que j'étais au courant, non parce que j'espérais qu'il y fût porté remède, ayant constaté en d'autres circonstances que mes démarches n'avaient aucun succès. » Barberini a une perception beaucoup plus réaliste que ses prédécesseurs de la situation de la France dans le domaine de la censure. Il voyait juste. Les nonces étaient en effet désarmés devant l'impuissance des autorités françaises à faire appliquer leur propre réglementation. Quand Barberini, en avril 1606, vient se plaindre de ce qu'un libelle sulfureux est paru avec privilège du roi, le garde des sceaux Brulart de Sillery lui fait remarquer que ce privilège a été scellé d'un petit sceau (c'est-à-dire dans la chancellerie d'un parlement) et non pas du grand comme cela était théoriquement obligatoire depuis l'ordonnance de Moulins. Henri IV a d'ailleurs dû, en novembre 1604, rappeler par une nouvelle déclaration les règles fixées par ladite ordonnance. Le cas de Barberini mis à part, il ne faut donc pas trop compter sur les nonces pour apaiser les conflits. C'est plutôt le roi qui, secondé par son chancelier, son secrétaire d'État et son ambassadeur, s'emploie à les désamorcer au mieux. Il arrive que le pape lui-même, de son côté, tempère l'ardeur des nonces et coopère avec le roi pour éteindre un incendie naissant.

Chaque affaire connaît un dénouement spécifique. Plusieurs paramètres entrent en jeu: la position sociale de l'auteur, ses relations personnelles avec le roi ou de hautes personnalités, la nature des "erreurs» contenues dans l'ouvrage incriminé, la coopération éventuelle de l'auteur (suivant qu'il est ou non prêt à corriger son texte).

Le roi est sensible à la qualité et à la dignité des personnes en cause. Que faire quand l'auteur d'une œuvre suspecte est un personnage d'envergure comme Jacques-Auguste de Thou, président au Parlement de Paris, citoyen de la République des Lettres, de surcroît ami de plusieurs cardinaux, époux d'une cousine du cardinal de Joyeuse, et dont le livre a pour seul tort non pas de contester le dogme catholique mais de raconter les turpitudes des papes de la Renaissance? D'une façon plus générale, Henri IV, on l'a vu, accepte de prendre des mesures pour condamner les œuvres, mais, malgré la demande insistante des nonces, se refuse à punir les auteurs eux-mêmes.

Tout se passe donc comme si les deux parties constataient en chœur leur impuissance. Un bon moyen de mesurer l'efficacité réelle du jeu diplomatique en matière de contrôle de la librairie est de se référer aux mises à l'Index. Deux seulement des œuvres qui avaient suscité l'indignation et les récriminations des nonces entre 1599 et 1607 ont été inscrites rapidement à l'Index : La Sagesse de Pierre Charron et la Chronologie septenaire de Palma Cayet (en 1605). L'Histoire de De Thou ne fut inscrite à l'Index qu'en 1609, cinq ans après sa publication; le traité de l'Eucharistie de Duplessis-Mornay en 1613; le Plaidoyer de Louis Servin en 1622. La traduction de la Bible de René Benoist ne fut jamais explicitement condamnée. On peut observer ici le décalage qui existe entre la perception des problèmes sur place par les nonces, qui sont au contact immédiat des hommes et des œuvres, et d'autre part l'appréciation romaine des événements, avec un certain recul et aussi la conviction déprimante qu'une mise à l'Index n'a guère d'effet en France.

En définitive, on peut considérer que globalement les stratégies d'évitement des crises ont assez bien fonctionné, étant entendu que les deux parties étaient conscientes des limites des moyens d'action mis en œuvre de part et d'autre. Le Saint-Siège savait très bien que la marge d'action du roi était limitée par les libertés de l'Église gallicane, la présence dans le royaume d'une forte minorité protestante et l'inefficacité de la législation en matière de censure. En France, on se souciait peu de l'Index. Chacun s'accommodait de cette situation, et la meilleure preuve de ce climat de compréhension 
mutuelle est l'acceptation par Paul $\mathrm{V}$ du choix du cardinal de Joyeuse, sur proposition de Henri IV, comme médiateur dans l'affaire de l'Interdit de Venise.

\section{NOTES}

1. Sur les relations entre Henri IV et le Saint-Siège, voir la synthèse très neuve d'A. Tallon, Henry IV and the Papacy after the League, dans A. Forrestal et E. Nelson (éds..), Politics and Religion in early Bourbon France, New York, 2009, p. 21-41. D'autre part, dans les pages qui suivent, nous nous permettons de renvoyer à quelques-uns de nos articles dont certains ont été réimprimés dans le recueil suivant : B. Barbiche, avec la collaboration de S. de Dainville-Barbiche, Bulla, legatus, nuntius. Études de diplomatique et de diplomatie pontificales (XIII-XVII siècle), Paris, 2007 (Mémoires et documents de l'École des chartes, 85).

2. B. Barbiche, Clément VIII et la France (1592-1605). Principes et réalités dans les instructions générales et les correspondances diplomatiques du Saint-Siège, dans Bulla, legatus, nuntius, p. 347-366. Voir aussi Ibid., p. 465-476 et 509-533.

3. B. Barbiche (éd.), Lettres de Henri IV concernant les relations du Saint-Siège et de la France, 1595-1609, Cité du Vatican, 1968 (Studi e Testi, 250).

4. A. Desjardins (éd.), Négociations diplomatiques de la France avec la Toscane, Paris, 1859-1886, 6 vol. (Collection de documents inédits sur l'histoire de France), t. V (1875), p. 552-553 (lettre du 2 juin 1605).

5. Sur les légats : B. et S. Barbiche, Bulla, legatus, nuntius, op. cit., p. 159-344, 423-446.

6. B. Haan (éd.), Correspondance du nonce en France Gasparo Silingardi, évêque de Modène (1599-1601), Rome, 2002 (Acta nuntiaturae gallicae, 17).

7. B. Barbiche, Correspondance du nonce en France Innocenzo Del Bufalo, évêque de Camerino (1601-1604), Rome-Paris, 1964 (Acta nuntiaturae gallicae, 4) ; Id., " Innocenzo Del Bufalo », dans DBI, t. 36 (Roma, 1988), p. 367-371.

8. P. Blet, Un futur pape, nonce en France auprès d'Henri IV, dans Études, nº 300 (1959), p. 203-220.

9. O. Poncet, Structure et conjoncture de la représentation pontificale en France à l'époque de Paul V (1605-1621). L'enseignement des instructions, dans A. Koller (éd.), Die Aussenbeziehungen der römischen Kurie unter Paul V.Borghese (1605-1621), Tübingen, 2008 (Bibliothek des Deutschen Historischen Instituts in Rom, 115), p. 143-157, aux p. 146-147.

10. B. Barbiche, L'influence française à la cour pontificale sous le règne de Henri IV, dans Bulla, legatus, nuntius, op. cit., p. 512-516.

11. B. Barbiche, Clément VIII et la France, cit., dans Bulla, legatus, nuntius, p. 349-350.

12. V. Martin, Le gallicanisme et la réforme catholique. Essai historique sur l'introduction en France des décrets $d u$ concile de Trente (1563-1615), Paris, 1919; et B. Haan (éd.), Correspondance du nonce Silingardi, cit., p. 153-169. 
13. B Barbiche, Le bannissement et le rappel des jésuites (1594-1603), dans Henri IV et les jésuites. Actes de la journée d'études universitaires organisée le samedi 18 octobre 2003 à La Flèche, La Flèche, 2004, p. 27-37.

14. La bibliographie des travaux consacrés à l'édit de Nantes, notamment à l'occasion du quadricentenaire (1998), est considérable. Voir l'article de synthèse de M. Venard, Un édit bien enregistré: le quatrième centenaire de l'édit de Nantes, dans Revue d'histoire de l'Église de France, t. 87 (2001), p. 27-45.

15. A. Tallon, Henry IV and the Papacy after the League, op. cit., p. 21-41.

16. Les pages qui suivent doivent beaucoup à la thèse d'A. Soman, Book censorship in France (1599-1607), with emphasis upon diplomatic relations between Paris and Rome, Cambridge, Mass., 1967.

17. B. Haan, Correspondance du nonce Silingardi, cit., p. 80-84.

18. J. Poivre, Jérémie Ferrier (1576-1626). Du protestantisme à la raison d'État, Genève, 1990 ( Travaux d'histoire éthico-politique, 50).

19. P. Duplessis-Mornay, De l'institution, usage et doctrine du Saint-Sacrement de l'Eucharistie en l'Église ancienne, La Rochelle, 1598. L'ouvrage est couramment cité sous le titre abrégé Traité de l'Eucharistie.

20. A. Soman, op.cit., p. 37-45; B. Haan, Correspondance du nonce Silingardi, op.cit., p. 101-107 ; et H. Daussy, Les huguenots et le roi. Le combat politique de Philippe DuplessisMornay (1572-1600), Genève, 2002 (Travaux d'Humanisme et Renaissance, 364), p. 582-595.

21. Harangue publiée dans la première édition du recueil des Plaidoyez de Messire Loys Servin, conseiller du roy en son Conseil d'Estat et son advocat general en sa cour de Parlement, Paris, 1603, p. 1-130.

22. A. Soman, op. cit., p. 62-75.

23. A. Soman, op. cit., p. 76-84.

24. P. Charron, De la Sagesse, Bordeaux, 1601.

25. Jacobi Augusti Thuani Historiarum sui temporis pars I, Paris, 1604.

26. A. Soman, op. cit., p. 98-112.

27. A. Soman, De Thou and the Index, Genève, 1972 (Études de philologie et d'histoire, 26).

\section{AUTEUR}

\section{BERNARD BARBICHE}

École des Chartes, Paris - sb.barbiche@free.fr 


\title{
Le parlement de Paris et les actes romains au XVI siècle : exemples de la pratique judiciaire
}

\author{
Sylvie Daubresse
}

1 Depuis la fin du XIII ${ }^{e}$ siècle, la doctrine gallicane s'oppose à la toute puissance pontificale. Le parlement de Paris, dont la compétence et l'autorité juridique sont reconnues, est érigé en gardien des libertés gallicanes. Les crises spectaculaires entre Rome et la cour souveraine, toujours nées de situations conflictuelles particulières, sont bien connues : aux fulminations papales répondaient les lacérations de bulles ${ }^{1}$. Comme le montre l'étude de Bernard Barbiche, les bulles de légation faisaient l'objet d'un contrôle tatillon de la part du Parlement, qui ne se passait pas toujours sans heurt ${ }^{2}$. Certaines bulles portant sur la discipline ecclésiastique, sur les provisions aux bénéfices se sont parfois trouvées, lorsque la politique s'en mêlait et qu'un litige violent opposait entre eux des ecclésiastiques, au cœur d'un bras de fer entre la monarchie française et la papauté. Il est intéressant d'observer quelle a été, dans ces circonstances, l'attitude du parlement de Paris.

2 Toutefois, ces périodes de crispation tendent à cacher les nombreux autres litiges résolus dans le secret du Palais de la Cité. Cette présente étude vise à présenter les différentes voies de recours juridique contre un acte romain devant le parlement de Paris au cours du $\mathrm{XVI}^{\mathrm{e}}$ siècle, à travers quelques exemples de la pratique judiciaire ${ }^{3}$. Elle ne serait pas complète si n'étaient pas abordées les réactions de la cour souveraine à des thèses d'étudiants de la faculté de théologie qui soutenaient trop ostensiblement les positions romaines ${ }^{4}$.

\section{La complainte de novelleté}

3 Au Moyen Âge, la justice laïque est juge de tout ce qui concerne le temporel des églises, des abbayes et des prélats alors que la question spirituelle est du ressort du juge 
ecclésiastique. L'étude de Monique Morgat-Bonnet sur le parlement de Paris transféré à Poitiers (1418-1436) a montré que les hauts magistrats condamnent, mais pas toujours, celui qui exhibe des bulles de collations pontificales ${ }^{5}$. La justice royale est saisie par le moyen de ce que l'on appelle en termes juridiques la complainte en cas de saisine et de novelleté. C'est une action possessoire, qui comme son nom l'indique concerne la possession, et qui est un cas royal. Le Parlement est conduit à trancher quand deux candidats à la possession d'un bénéfice s'affrontent devant lui, chacun prétendant être « en saisine $»^{6}$. Dans beaucoup de procès, le candidat du collateur ordinaire demande l'application des ordonnances royales sur les libertés de l'Église gallicane, à l'encontre des bulles papales brandies par son compétiteur.

4 En règle générale, le Parlement défend au candidat papal d'invoquer des bulles au préjudice des libertés de l'Église gallicane et rappelle à leur observation stricte. Dans la plupart des cas, le candidat du collateur ordinaire est maintenu en saisine du bénéfice, les fruits et revenus qu'aurait pu percevoir son adversaire lui sont restitués. Il arrive aussi que le Parlement prescrive une enquête visant à établir la véracité des faits allégués ; si le résultat de l'enquête s'avère favorable au candidat du pape, le bénéfice lui est attribué. En effet, la cour souveraine applique le droit, comme dans tout autre litige : la procédure d'enquête, en usage depuis saint Louis, et au caractère contradictoire, permet aux adversaires de faire valoir leurs arguments et à la cour de trancher en connaissance de cause. Cette observation peut surprendre tant elle va à l'encontre de l'idée d'une opposition systématique et déterminée du Parlement à tout ce qui venait de Rome.

Pour mieux donner corps à notre propos, citons un exemple de ce type de poursuite, extrait des registres de la cour, qui se situe au début du XVI ${ }^{\mathrm{e}}$ siècle et concerne l'abbaye de Saint-Jean de Thérouanne, près de Saint-Omer, dans le Pas-de-Calais. L'affaire commence en 1518, lorsque l'abbé en place, qui avait décidé de résigner en faveur de Jean Tabart, se heurte au refus de François I ${ }^{\text {er }}$ de le recevoir. Le roi envoie à l'abbé des lettres lui défendant de résigner en faveur de Tabart parce qu'il ne lui est pas "fidelis». François $I^{\mathrm{er}}$ présente donc au pape son candidat, nommé Disque. En réaction, d'ailleurs prévisible, Tabart s'adresse à Charles Quint qui dit intervenir comme comte d'Artois, et obtient des bulles de cour de Rome en 1518. Le roi averti, rédige un placet en faveur de Pierre Disque, qui en attendant les bulles du pape prend possession de son abbaye mais celui-ci, troublé en sa possession, dépose une complainte en matière de novelleté. En effet, malgré les défenses faites par le roi, les religieux de l'abbaye ont reçu Tabart comme abbé. Les parties s'adressent alors à la juridiction la plus proche, celle du prévôt de Montreuil-sur-Mer, dans le ressort duquel se trouve l'abbaye de Saint-Jean. Le prévôt ordonne à Tabart de présenter ses bulles au roi, ce qu'il ne fait pas, il est donc déclaré défaillant. Pour contravention aux ordres du roi, le temporel de l'abbaye est saisi. Après en avoir appelé au parlement de Paris, la cause est plaidée le 19 avril $1520^{7}$. Ainsi deux parties se trouvent face à face, toutes les deux pourvues en cour de Rome, faisant valoir leurs prétentions respectives.

6 L'avocat du roi Lizet, pour le procureur général, partie jointe à Pierre Disque en tant défenseur des droits du roi contre le candidat de Charles Quint, prend le premier la parole ${ }^{8}$. En effet, le procureur général du Parlement porte une attention particulière aux bénéfices ecclésiastiques dont la collation était réservée au roi ${ }^{9}$. Pour lui, l'affaire est de grande et périlleuse conséquence pour l'autorité du roi de France mais aussi pour le bien et la conservation du royaume. Il considère les appelants comme des rebelles et criminels de lèse-majesté. Il veut que tout ce qu'ils ont fait et obtenu en cour de Rome soit cassé. À 
ses yeux, l'affaire est d'autant plus importante qu'il est question «des privileges, prerogatives du roy et de sa couronne qui ne doivent estre traictees ne decidees ailleurs que ceans ».

7 L'avocat du roi fait ensuite référence à Philippe Le Bel qui a fait une "constitution » interdisant d'aller à Rome pour impétrer des bénéfices, constitution qui a été déclarée bonne puisque faite pour la conservation de la « sécurité » du royaume. De tout temps, les rois de France ont joui des droits de nomination «scientibus et approbantis summis pontificibus». Le titre de Tabart n'a pas de valeur car le pape n'a pas entendu « la situation du lieu » (zone limitrophe), sinon il n'aurait jamais accordé sa provision. La provision de Tabart est directement contre les droits et prérogatives du roi, donc elle est frappée de nullité. On n'a jamais pourvu aux églises limitrophes sans le consentement du roi, explique Lizet. Pour conclure sa réquisition, l'avocat du roi, considérant que la collation a été obtenue contre les droits du roi, demande que Tabart soit contraint à faire casser et annuler sa bulle de provision dans les trois mois et que, pour rébellion et désobéissance, les religieux soient condamnés à 1000 livres d'amende chacun. L'avocat Bochard, avocat de Jean Tabart, réplique en alléguant le fait qu'avant le concordat, le pape pouvait admettre la résignation in favorem sans placet. Bochard omet de dire que de nombreuses nominations directes avaient effectivement lieu, mais après accords entre le roi et le pape.

8 La cour souveraine appointe l'affaire au conseil, ce qui signifie un renvoi en délibéré, et non une manière déguisée d'enterrer l'affaire ${ }^{10}$. Malheureusement l'arrêt définitif n'a pas été trouvé, noyé dans la masse des actes du Parlement. La suite du litige est connue grâce à un mémoire rédigé et publié par un abbé de Saint-Jean à la fin du XVII ${ }^{\mathrm{e}}$ siècle $^{11}$. L'abbé Disque, maintenu titulaire de ce monastère, obtient par la suite la mainlevée de tous les biens qui avaient été saisis par son compétiteur. Toutefois, les deux abbés décident de se pourvoir en cour de Rome pour revendiquer leurs droits. Pour les deux religieux, c'était une chance supplémentaire d'obtenir gain de cause.

9 Cette affaire si délicate est mise en délibération dans un consistoire, en présence de Léon $\mathrm{X}$, où il est ordonné qu'il serait expédié des bulles de révocation de la provision délivrée à l'abbé Tabart, comme étant contraire aux droits du roi Très chrétien auquel seul appartient de nommer à cette abbaye. Il est possible qu'informé par la procédure devant le parlement de Paris, le Saint-Siège ait corrigé sa décision. Mais rien n'a entamé la détermination de Tabart. En 1525, celui-ci profitant des mouvements de troupes s'empare des biens et des revenus de l'abbaye. Cette lutte pour un abbatiat montre toute l'âpreté des conflits de pouvoir entre religieux autour des bénéfices ecclésiastiques, très convoités aussi pour leurs revenus ; ceux-ci n'hésitaient pas à porter leur différend devant les juridictions séculières et à utiliser toutes les ressources fournies par le droit pour parvenir à leurs fins ${ }^{12}$.

\section{L'appel comme d'abus}

10 L'appel comme d'abus est une voie de recours à la justice laïque contre une sentence ou un acte de l'autorité ecclésiastique. Cette procédure pouvait être utilisée par les ecclésiastiques comme par les laïques. Il n'a pas été institué par les ordonnances royales, mais à l'initiative du parlement de Paris, au lendemain du Grand Schisme, et apparut comme un moyen de faire respecter la Pragmatique Sanction de Bourges de 1438 sur la collation des bénéfices ${ }^{13}$. Les cas d'applications sont très nombreux ${ }^{14}$. Les ecclésiastiques 
pouvaient l'intenter à l'encontre d'empiétements commis par les officiers royaux. Ils n'hésitaient pas, plutôt que de saisir l'évêque ou le pape, à porter leur recours devant la juridiction séculière.

11 L'appel est relevé par la partie qui s'estime lésée par une décision de la justice ecclésiastique, rendue contre elle. Il est dirigé contre la partie qui a triomphé devant le juge d'Église et non contre le juge lui-même. La procédure débute par des lettres de relief. Celui qui a interjeté oralement appel doit ensuite le relever devant la juridiction compétente : il doit obtenir, à cet effet, des lettres de chancellerie. L'intérêt du roi étant en jeu dès qu'il y a abus, l'appelant a toujours comme partie jointe le procureur général. Le Parlement prononce sur l'appel comme d'abus par ces mots il y a, ou il n'y a abus. La cour souveraine ne tranche donc pas directement la question en litige. En cas d'abus, il y a cassation de la sentence puis renvoi devant le juge ecclésiastique, d'un degré supérieur à celui qui a prononcé le jugement prétendu abusif.

12 Là encore, pour illustrer cette procédure, le mieux est de présenter une affaire déposée devant le parlement de Paris, toujours sous le règne de François $\mathrm{I}^{\mathrm{er}}$. La cause du litige est la suivante : l'évêque de Beauvais a permis aux curés de contraindre le peuple, sous peine d'excommunication, à assister à des processions pour gagner des indulgences, jours fériés et non fériés ; le chapitre de la cathédrale en appelle comme d'abus. La cause est plaidée le $1^{\text {er }}$ février 1524 entre Gilles Seguin, chanoine de l'église de Beauvais d'une part, et Jean Sommereux, vicaire général de l'évêque de Beauvais et l'évêque lui-même, d'autre part ${ }^{15}$.

13 Par la bouche de l'avocat Bochard, intervenant pour le doyen et chapitre de Beauvais qui sont les appelants, on apprend que 70 écus devaient être versés pour obtenir pardons et indulgences (avec remise de peines du purgatoire). Or l'avocat rappelle que le Christ n'a pas communiqué aux apôtres le pouvoir de lier et de délier dans les cieux et au purgatoire ${ }^{16}$. Même si ces indulgences moyennant versement d'argent ont été accordées par le pape de façon limitée et exceptionnelle, elles sont, dans leur principe, abusives ${ }^{17}$. La contrainte, sous peine d'excommunication, les "rebelles » étant ajournés en personne devant l'official, est un abus contre les « saints décrets » (décrets conciliaires). Ils demandent des dommages et intérêts et la restitution de tout ce qui a été pris pour l'employer aux réparations de leur église ${ }^{18}$.

14 Poyet, avocat de l'évêque, déclare qu'il n'a fait que suivre le mandement apostolique confirmé par tous les papes et publié dans l'évêché par lettres patentes du roi, après examen par le Grand Conseil. Pour lui, il n'est pas question de disputer de la puissance du pape. De même, il n'appartient pas aux évêques de connaître de potestate concedentis et validitate des indulgences, leur tâche est uniquement de vérifier si les bulles d'indulgence ne sont pas fausses, avant d'octroyer le placet. Poyet ajoute que l'évêque a agi comme ses prédécesseurs l'ont fait depuis plus de 100 ans, et s'étonne: pourquoi s'en plaindre maintenant ? Il indique ensuite qu'il n'a été pris qu'un seul écu par placet au lieu des 70 soutenus par le chapitre.

15 L'avocat du roi Lizet, pour le procureur général, constate qu'il y a plusieurs abus dont le Parlement doit prendre connaissance et par la suite « reformer », selon ses propres mots, d'autant que le roi est conservateur des saints décrets. Pour Lizet, il y a double abus : le premier va à l'encontre des « décrets anciens et nouveaux » qui défendent de prendre argent contre indulgences et pardons, en second lieu, cette pratique est contraire à une ordonnance du roi Philippe (sans plus de détails), donc les transgresseurs doivent rendre ce qu'ils ont pris pour être reversé sous forme d'aumône. Lizet rappelle également qu'on ne peut appeler de l'octroi d'une bulle mais seulement de son exécution, par respect pour 
le pape. Ces bulles portent une clause qui pose la question de savoir si les indulgences peuvent profiter aux âmes étant au purgatoire. L'avocat du roi se garde d'en parler et déclare que c'est l'affaire des théologiens. En revanche, il condamne l'idée d'une "taxe » pour obtenir des indulgences. Un autre abus figure dans les placets de l'évêque : le peuple peut être "invité " à faire procession les jours fériés et le dimanche, or cela va à l'encontre du bien public car en effet, si le peuple est tenu de « fêter » toutes les fois qu'il plaira à l'évêque, il est alors arraché à ses activités et risque de tomber en mendicité. Et comme ce qui est le plus nécessaire à la chose publique concerne le roi et sa cour de Parlement... Autant dire que la préoccupation du parquet est l'intérêt général, non la théologie ${ }^{19} \cdot \mathrm{L}^{\prime}$ ajournement personnel des réfractaires est inacceptable car les laïques ne sont pas soumis au juge d'Église, sauf dans les cas permis par le droit. Au nom du procureur général, Lizet conclut qu'il a été bien appelé, et requiert que les deniers pris doivent être restitués pour les réparations de l'église et pour un autre usage pieux. Pour finir, il demande que défense soit faite à l'évêque de prendre argent pour le placet des indulgences.

L'avocat Bochard reprend la parole, pour le chapitre. Dans une position qui se rapproche de celle du procureur général, il déclare que « le pape n'a cette puissance taxative de dire que cestuy ou autre captus in purgatorio sera delivré ». Et d'ajouter: "parce que aucuneffois par surprinse ou autrement le pape baille des bulles qui ne sont de raison, les prelats et princes ne sont tenus y obeir et y peuvent et doyvent resister en tel cas ». À la base de cette position se trouve une règle établie par plusieurs ordonnances royales du $\mathrm{XIV}^{\mathrm{e}}$ siècle qui veulent que «toutes lettres surprises, ou obtenuës par importunité au préjudice d'autruy »soient déclarées nulles et subreptices, et qui interdisent au Parlement d'obéir aux lettres qui lui semble être octroyées « sans cause juste et raisonnable ${ }^{20}$. Elle s'inscrit directement dans la pratique judiciaire quotidienne des membres du Parlement.

Après les plaidoyers des avocats, le Parlement rend son arrêt et fait défense à l'évêque de Beauvais de faire de tels placets ; lui et ses officiers sont contraints de donner l'absolution à tous ceux qui ont pu être excommuniés et censurés. Durant cette contestation entre chapitre et évêque fut ainsi abordée la question du pouvoir des papes de vendre des indulgences. C'est, à ce moment précis, un sujet brûlant, quelques années après la publication des thèses de Luther contre ces mêmes indulgences, en octobre $1517^{21}$. Précisons que le débat entre parties adverses se fait toujours à huis clos, et que les allégations des avocats sont des arguments employés uniquement pour emporter la conviction des juges. En raison du secret des délibérations et de la non motivation des arrêts, il n'est pas aisé de repérer l'argument sur lequel les juges se fondent pour rendre leur décision. Dans ce cas précis, il paraît visible que les hauts magistrats parisiens ont été convaincus par les arguments de l'avocat du chapitre de Beauvais qui vont dans le sens des décisions conciliaires.

De la même manière, il peut y avoir appel comme d'abus devant la cour de Parlement d'une monition portant clause d'excommunication, comme c'est le cas de Jean de Hangest, évêque de Noyon, poursuivi pour dettes par l'auditeur de la chambre apostolique de Rome et excommunié par le pape, sous le règne d'Henri II.

19 À Rome, Jean de Hangest avait emprunté de l'argent et pour assurer ses cautions, leur avait vendu certaines terres. Faute de paiement, l'auditeur de la chambre apostolique de Rome avait, en août 1554, décerné contre lui des censures et invoqué le bras séculier. En outre, l'évêque de Noyon avait été excommunié avec aggravation, son effigie traînée dans les rues avec l'image du diable. Il était demandé au roi, au dauphin, au duc d'Orléans, aux 
princes et autres officiers du roi, sous peine d'excommunication, d'exécuter les dites censures, sous la « forme bonifacienne qui commence Unam Sanctam »; cette bulle Unam Sanctam de Boniface VIII, qui ne fut jamais publiée, excommuniait Philippe Le Bel. La saisie du temporel de l'évêque devait également être effectuée. Jean de Hangest appelle comme d'abus des censures et de l'invocation du bras séculier ${ }^{22}$. L'avocat en cour de Rome et deux autres Romains sont les intimés.

Le 20 décembre 1555, les avocats font leur plaidoirie mais les archives du Parlement ne contiennent que l'intervention de l'avocat général ${ }^{23}$. Pour celui-ci, le pape n'a pas été informé de ces faits par ses officiers. Il rappelle qu'en l'Église gallicane, on n'a jamais reçu de pareilles censures et procédures de la cour de Rome. Le contrat en question a été fait à Rome mais l'évêque n'est pas tenu d'y plaider. C'est une chose scandaleuse que de trainer l'effigie d'un évêque dans les rues de Rome. Il s'en prend à la menace d'excommunication lancée à l'égard du roi qui est contraire à ce qui a été décidé en concile universel. Il conclut sur l'avis suivant : il a été mal et abusivement fulminé et se déclare, pour le roi, appelant comme d'abus de la menace d'excommunication contre le souverain. À ceux qui peuvent arguer qu'il y a eu seulement présentation du bref (d'excommunication), il répond que la seule présentation du bref lie le roi. L'évêque peut être excommunié pour dettes mais non contraint par corps. Néanmoins, l'avocat général consent à la vente du patrimoine de l'évêque et à la saisie de son temporel, avec une portion congrue qui lui soit réservée pour subsister. Le Parlement décide, après lecture du bref, de recevoir le procureur général appelant comme d'abus. Quant aux intimés, ils ont l'obligation de révoquer les censures.

21 Le 30 décembre 1555, l'affaire est appointée au conseil, mais les intimés peuvent faire exécuter le contrat fait à Rome pour la vente des biens de l'évêque ${ }^{24}$. Elle rebondit lorsque le 3 mars 1556, l'avocat en cour de Rome présente à la cour des lettres patentes du roi (du 30 janvier) qui ordonnent au premier huissier de prendre au corps l'évêque et de le mener prisonnier à Rome. Les lettres patentes portent aussi l'interdiction faite au Parlement de connaître l'appel comme d'abus. Les gens du roi rappellent alors l'arrêt du 20 décembre : les censures ont été jugées abusives. N'était-il pas scandaleux de mener prisonnier à Rome un sujet du roi, évêque et pair du royaume, s'exclament-ils ? Les membres du parquet seraient-ils plus royalistes que le roi ? Cette position est en tout cas approuvée par le Parlement qui présente des remontrances, le 9 mars 1556, qui rappellent que les sujets du roi ne peuvent être traduits à Rome. Les censures, qui impliquent directement la personne du roi, sa famille, ses sujets, vont à l'encontre des privilèges des rois de France ${ }^{25}$. Pour mieux comprendre l'attitude du roi qui se dissocie de son Parlement, il faut se reporter au contexte diplomatique du moment : à la mi-décembre 1555, a été conclue une alliance anti-espagnole entre Henri II et le Saint-Siège. Le parlement de Paris défend avec constance et fermeté les principes gallicans, hors de toute contingence diplomatique et politique. Mais dans les circonstances d'alors, son devoir était de se faire plus discret afin de ménager la susceptibilité papale. Quant à la poursuite de l'évêque de Noyon par la cour de Rome, avec menaces d'excommunication, elle est surtout un moyen de pression, sans doute excessif, pour obtenir le paiement des dettes de l'évêque et régler une banale affaire de droit privé.

La procédure juridique de l'appel comme d'abus ne manque pas de faire réagir certains nonces comme le nonce Castelli qui en 1582 s'en plaint auprès de Henri III. Il estime que l'appel comme d'abus est un moyen pour les religieux d'échapper à l'autorité de leurs supérieurs comme l'illustre d'ailleurs l'affaire des Cordeliers de Paris. En effet, en mars 
1582, plusieurs Cordeliers refusent l'élection du nouveau supérieur de leur couvent à Paris, et sont excommuniés par le nonce Castelli qui était autorisé par le pape à intervenir. Les religieux font appel au Parlement qui cite Castelli à comparaître, ce qui entre dans le cadre normal de la procédure.

Les lettres de Paul de Foix, ambassadeur de France à Rome, envoyées à Henri III, livrent un éclairage intéressant de cette affaire. L'ambassadeur français envoya au roi un compte-rendu des audiences qu'il eut avec le pape en mars et avril 1582. Il rapporte le mécontentement du pape Grégoire XIII qui estime que c'était un manque de respect à son égard que d'ajourner son nonce à comparaittre devant le Parlement. Impossible pour cette cour de convoquer devant elle des juges délégués par lui. Paul de Foix écrit que le pape méconnaît l'institution que représente le parlement de Paris. Il fallait donc livrer quelques explications au souverain pontife. Il lui rappelle d'abord que les appels comme d'abus sont très enracinés dans le pays, et qu'ils ne sont pas pratiqués comme « choses desirables ny agreables » mais comme une médecine nécessaire pour remédier aux abus qui se commettent contre l'autorité des rois et contre les saints décrets dont les rois de France sont les protecteurs. Paul de Foix précise également que ceux qui appellent témérairement comme d'abus sont condamnés généralement à de lourdes amendes de fol appel. L'ambassadeur pouvait parler du Parlement en toute connaissance de cause puisqu'il en avait été un des membres pendant plusieurs années en tant que conseiller clerc. Condamné à la suite de la mercuriale de 1559, il rentre en grâce sous Charles IX et enchaîne les missions diplomatiques ${ }^{26}$.

Paul de Foix continue ses explications : le pape doit se louer du fait que les rois de France reçoivent dans leur Parlement des ecclésiastiques comme des laïques, ce que ne font pas les autres monarques. La haute cour souveraine ne prend jamais connaissance de choses qui soient purement spirituelles. Paul de Foix précise au pape que la signification du relief d'appel est seulement une formalité et que cette procédure est sans effet, donc qu'il n'y aura pas de comparution pour son nonce ${ }^{27}$.

Le pape le questionne : quels sont les abus trouvés dans son bref ? Paul de Foix répond que le bref prévoit qu'en cas d'appel, la cause sera plaidée à Rome, ce que dénie le pape qui affirme que la cause sera commise sur les lieux conformément au concordat. Autre source de litige : le bref ordonne de contraindre les religieux à obéir par emprisonnement de leurs personnes, or cela ne peut se faire que par le bras séculier et non par personnes ecclésiastiques. Pour Grégoire XIII, on a mal interprété son bref. Par ailleurs, celui-ci contient une dérogation aux statuts de l'Ordre des Cordeliers, lesquels ont été homologués par les rois et le Parlement. Pour le pape, les rois de France ainsi que les autres souverains ne peuvent faire des statuts "en telles matieres". L'ambassadeur réplique que c'est le roi qui est chargé de la protection des religieux, et que pour faire respecter ces statuts, il est besoin du bras séculier, d'où la vérification des statuts ecclésiastiques par les parlements. Une fois ces statuts autorisés et enregistrés, ils sont tenus comme «loix du royaume ». Les papes ont toujours désiré une telle protection. Et de rappeler un point essentiel déjà évoqué dans cette étude : par respect envers le SaintSiège, on n'appelle pas comme d'abus de ses rescrits mais seulement de leur exécution.

Ces explications ne convainquent pas Grégoire XIII puisque, peu de temps après, il rédige un bref qui excommunie tous ceux qui s'opposent à l'exécution de sa bulle. Cette décision provoque la fureur du Parlement qui accuse le nonce d'avoir usurpé la juridiction royale. En réponse, le premier président Christophe de Thou déclare la sentence d'excommunication nulle et contraire aux privilèges de la Couronne, et cite une nouvelle 
fois le nonce à comparaître. Il ordonne que les Cordeliers excommuniés soient absous par l'évêque de Paris. Celui-ci s'y refuse d'abord, puis se soumet.

Là encore, examinons les circonstances précises du conflit. Comme le montre l'étude de Jean-Marie Le Gall, le Parlement a toujours favorisé la réforme des couvents. Mais, dans ce cas précis, il a surtout le souci de ramener l'ordre autour et dans le couvent ${ }^{28}$. Finalement, le roi « évoque» l'affaire à lui, mais de Thou proteste auprès de la reine mère restée seule à Paris, et grâce à elle, le différend prend fin. Pour le nonce Castelli, l'affaire des cordeliers démontre l'impossibilité de réformer la discipline ecclésiastique en France si un roi énergique ne commence par réformer d'abord le Parlement ${ }^{29}$. Ainsi il arrive que pape et nonce fassent preuve d'incompréhension ou qu'ils manifestent une volonté délibérée d'ignorer les procédures de la plus haute cour de justice du royaume de France. Chacun est mu de puissants motifs : d'un côté, le pape et son nonce veulent la réforme des couvents, d'un autre côté, le Parlement défend l'autorité du roi sur son Église. L'appel comme d'abus n'est-il pas finalement une borne que l'autorité du pape ne devait pas dépasser lorsqu'elle intervenait trop ostensiblement dans les affaires de l'Église de France ? De même, la menace d'excommunication brandie par les papes est un moyen spirituel puissant de faire pression sur les monarques. Ainsi, chaque camp dispose-t-il de ses propres "armes " pour signifier à l'autre jusqu'où il peut aller. Utilisées à mauvais escient, elles engendrent d'inévitables réactions négatives.

Mais il ne faut pas s'y tromper, et considérer que le parlement de Paris utilisait inconsidérément cet instrument juridique. L'appel comme d'abus est un moyen procédural dont le Parlement contrôle avec rigueur et minutie l'utilisation. L'étude de Megan Armstrong sur les Franciscains au XVI ${ }^{\mathrm{e}}$ siècle montre que le Parlement chercha à limiter l'appel comme d'abus, souvent suscité par les religieux eux-mêmes ${ }^{30}$. À titre d'exemple également, citons le cas de cette bulle du $1^{\text {er }}$ décembre 1516 , qui en rappelait une autre de 1472 qui défendait sous peine d'excommunication de dire que sainte Catherine de Sienne avait reçu des stigmates et de la peindre avec ces mêmes stigmates; elle réservait au seul pape l'absolution des censures. Les jacobins de Blois se déclarèrent appelants comme d'abus de la publication de la bulle. Le 21 janvier 1517, le Parlement condamna la publication de la bulle à Blois, mais les parties furent contraintes d'obtenir un rescrit du pape pour que l'évêque de Paris juge le procès ${ }^{31}$. Non compétent en matière spirituelle, le Parlement renvoya donc le fond du litige devant une juridiction ecclésiastique.

\section{Le Parlement, entre le roi de France et le pape}

La prétention des papes à excommunier les monarques et à revendiquer le droit de les déposer au nom de leur plenitudo potestatis est insoutenable pour les membres du parlement de Paris $^{32}$. Depuis le XIV siècle, ils ne manquent pas de réagir à chaque fois que des bulles pontificales empiètent sur le pouvoir temporel du souverain français. Leur vigilance est en alerte à chaque arrivée d'une bulle dans le royaume. Ainsi, le 30 janvier 1550, le Parlement vérifie des bulles instituant l'université de Reims, qui ont été octroyées par le pape Paul III à la sollicitation du cardinal de Guise en mars 1547, et les enregistre en apportant une modification sur un passage de cette bulle, dont, explique-t-il, on aurait pu tirer la conséquence que les rois de France étaient sujets aux excommunications ${ }^{33}$.

30 À la fin de l'année 1561, l'étudiant Jean Tanquerel soutient, lors d'une discussion publique, que le pape, détenteur du pouvoir spirituel et temporel, peut priver de leur 
royaume les princes rebelles à ses ordres. Tanquerel est immédiatement interrogé au logis du président de Thou en présence du procureur général et du doyen de la faculté : il reconnut les faits, déclare n'avoir pas voulu offenser la majesté du roi, argue du fait que l'article en question était souvent débattu dans les écoles. Parce que "c'est une proposition de trés grande importance » qui porte préjudice à son État, Charles IX ordonne au Parlement l'arrestation de Tanquerel, le 18 novembre 1561.

31 Le doyen de la faculté de théologie, ainsi que les quatre docteurs les plus anciens, sont convoqués au Parlement, parce qu'ils avaient laissé faire alors qu'ils avaient eu connaissance du contenu de cette thèse. Dans une lettre adressée à Catherine de Médicis, le président de Thou, chargé de mener l'enquête avec le conseiller Charles de Dormans, qualifie cette thèse de "grande faulte». L'avocat du roi Dumesnil définit la charge qui pèse sur l'accusé : son crime est d'avoir mis en dispute un sujet trop hardi, sous les yeux mêmes du prince. Entre-temps Tanquerel s'est enfui.

32 À la demande de la régente Catherine de Médicis qui désire une déclaration publique, la rétractation se fait à la Sorbonne, le 12 décembre 1561, en présence du doyen et des docteurs de la faculté, des bacheliers, du premier président de Thou et du procureur général Bourdin. Ce dernier est chargé de faire la leçon à la faculté de théologie qui avait laissé faire, et leur représente que de « disputer de l'estat de la couronne et du royaume comme de chose vacillante et fluctuante et estant en quelque incertitude » ne peut tendre qu'à la subversion des auditeurs.

Le 12 décembre 1561, en l'absence de Tanquerel, le bedeau de la faculté fait amende honorable et déclare qu'il avait mis « indiscretement et inconsiderement » sa proposition en dispute ; il la renie et supplie le roi de lui pardonner. De même lorsqu'en juillet 1595, à l'instar de Tanquerel, le bachelier Florentin Jacob en juillet 1595 soutient l'idée que le pape a le pouvoir spirituel et temporel (donc détenait en quelque sorte une puissance absolue sur tous les hommes, y compris les rois), sa thèse est condamnée à être lacérée, et la faculté de théologie sermonnée dans ses propres locaux ${ }^{34}$.

Alors que sous Charles IX, les conflits avec la papauté furent quasi inexistants, Grégoire XIII (1572-1585) et son successeur Sixte Quint (1585-1590), poussés par la volonté de faire appliquer les décisions du concile de Trente et d'appuyer le parti des catholiques radicaux en France, eurent des relations difficiles avec la monarchie française et plus encore avec le parlement de Paris.

En septembre 1580, le pape Grégoire XIII exige de tous les prêtres, clercs et confesseurs, qu'ils aient en leur possession la bulle In Coena Domini. Appelée aussi «bulle des vêpres ", datant $\mathrm{du}$ XIII ${ }^{\mathrm{e}}$ siècle, elle excommuniait les hérétiques mais aussi tous ceux qui entraveraient l'exercice de la juridiction ecclésiastique ${ }^{35}$. Le nonce Dandino l'envoie à tous les évêques pour qu'elle soit publiée dans chaque diocèse. L'évêque de Chartres, Nicolas de Thou, frère du premier président, est scandalisé par l'introduction subreptice dans le royaume d'un tel document, et transmet son exemplaire au Parlement. Celui-ci engage alors des poursuites contre le jésuite qui avait fait imprimer la bulle et l'imprimeur de cette dernière.

Cette affaire provoque la colère d'Henri III qui fait examiner la bulle par le Parlement. Malgré l'explication donnée - la bulle était connue depuis longtemps - le 4 octobre 1580, le Parlement rend un arrêt qui la confisque et qui cite en justice tous les évêques qui l'avaient rendue publique. Le 28 septembre 1580, l'imprimeur de la bulle est condamné à verser une amende. 
À cette époque, les relations entre le clergé et la royauté sont tendues à cause des conflits autour de la perception des décimes. Aussi, le roi estime-t-il inopportune la publication de cette bulle, et se retranche derrière son Parlement. Finalement, à la fin de 1581, l'évêque de Rimini, successeur de Dandino, obtient que la minute de l'arrêt soit détruite. Effectivement, ni les registres, ni les minutes du conseil ne gardent trace de ces arrêts. L'action de la papauté s'est heurtée au gallicanisme sans concession du Parlement et à l'autorité jalouse du roi de France sur son Église. À la lumière de ces quelques affaires, il n'est pas surprenant de constater que le roi de France tantôt calme les ardeurs de son Parlement, tantôt s'abrite derrière lui, en fonction des circonstances politiques, voire financières du moment. politiques, fortes et dramatiques de cette fin du $\mathrm{XVI}^{\mathrm{e}}$ siècle. Le début des années 1590 voit le développement de tendances schismatiques, y compris dans une partie de l'épiscopat. Le bruit court que serait élu un patriarche des Gaules qui régirait l'Église de France indépendamment de Rome ${ }^{36}$. Au début du mois d'août 1591, à Tours, le procureur général se déclare appelant comme d'abus de l'octroi et exécution des monitoriales qui confirmaient la bulle de Sixte Quint de 1585 excommuniant Henri de Navarre. Le parlement de Tours, qui a reconnu l'autorité d'Henri IV, déclare les bulles nulles et abusives, séditieuses et damnables, pleines d'impiétés et d'impostures contraires aux saints décrets, et aux libertés de l'Église gallicane. Les copies des bulles sont lacérées et brûlées par l'exécuteur de la haute justice devant la grand'porte du Parlement à Tours. Il est fait défense à tous les prélats de publier les bulles, le pape Grégoire XIV déclaré ennemi de la paix, adhérent à la conjuration d'Espagne et "fauteur des rebelles", et même coupable du parricide du roi Henri III. Ordre est donné de faire le procès du nonce Landriano, entré dans le royaume sans permission du roi et qui se trouve alors à Paris. Quelques jours plus tard, la chambre de justice siégeant à Châlons-en-Champagne rend un arrêt à peu près similaire mais en faisant un distinguo entre le pape et ses légats. En dépit de ces deux arrêts au ton très dur, il semble très improbable que les hauts magistrats aient véritablement souhaité une rupture avec Rome. Là encore, les arrêts du Parlement signifient au pape qu'il est allé trop loin en se mêlant de trop près des affaires de France.

\section{Conclusion}

La défense des «libertés de l'Église gallicane » et de l'autorité du roi de France face au pouvoir pontifical constitua une cause de tensions plus ou moins vives entre Rome et la France, mais on a trop tendance à les exagérer, et à considérer le parlement de Paris comme une machine de guerre contre les actes émanés de la cour de Rome. Avec Rome, les tensions sont parfois fortes mais la confrontation n'est pas toujours au rendez-vous. La doctrine gallicane, à de très rares exceptions, proteste de son attachement à la papauté. Certains hauts magistrats parisiens penchent vers un effort de tous les pouvoirs pour réaliser la réforme de l'Église.

40 Les arrêts du Parlement sont un moyen d'alerter le pape sur les conditions et l'application de ses décisions. Ne visent-ils pas le même but lorsqu'il s'agit de vérifier la législation royale ? Ainsi les actes romains ne bénéficiaient pas d'un traitement particulier de la part d'un parlement de Paris attaché au respect du droit et des ordonnances royales. Comme l'explique Alain Tallon, le gallicanisme parlementaire n'est pas la manifestation de la mauvaise humeur d'avocats et de magistrats procéduriers, soucieux seulement de faire 
barrage aux empiétements du pouvoir pontifical ${ }^{37}$. Son maitre-mot est l'équilibre entre pouvoir spirituel et pouvoir temporel. Il n'est pas question de rupture avec Rome, ce qui aurait totalement rompu cet équilibre. Les membres du Parlement, dont l'intervention vise au strict respect des principes gallicans, s'interposent entre le pape et le roi de France, en dressant une sorte de mur de défense. Il revenait au seul monarque français de décider en dernier ressort sa ligne de conduite. Mais, comme toujours, la part de l'humain est non négligeable. L'autoritarisme obstiné de certains papes s'est inévitablement heurté à la raideur juridique du Parlement, malgré la médiation des ambassadeurs ${ }^{38}$.

\section{NOTES}

1. Il est important de préciser que cette lacération, action spectaculaire s'il en est, n'est pas le sort réservé aux seules bulles pontificales. Le Parlement procédait de la même manière pour les documents reconnus comme faux ou pour des récusations de juges qu'il jugeait irrecevables.

2. Voir l'étude minutieuse de B. Barbiche, Les légats a latere en France et leurs facultés aux XVI et XVII siècles, dans Archivum Historiae Pontificiae, 23, 1985, p. 95-140, reproduit dans idem, Bulla, legatus, nuntius: études de diplomatique et de diplomatie pontificales, XIII-XVII siècle, Paris, 2007, p. 225-280. Au début de l'année 1590, le parlement de Tours défend au cardinal Caetani qui n'a pas présenté ses «facultés » à Henri IV d'entreprendre aucune fonction. Dans sa réquisition, l'avocat général Louis Servin rappelle la séparation des pouvoirs temporel et spirituel. Il n'hésite pas à déclarer que pour être entré dans le royaume de France sans permission du roi, le cardinal aurait pu légitimement être poursuivi et arrêté (S. Daubresse, "De Paris à Tours, le Parlement «du roi » face au Parlement « de la Ligue » (1589-1590), dans Eadem, M. Morgat-Bonnet, I. Storez-Brancourt (éds.), Le Parlement en exil ou Histoire politique et judiciaire des translations du parlement de Paris (XVe-XVIII e siècle), postface de F. Hildesheimer, Paris, 2007, p. 460).

3. Sur le gallicanisme parlementaire, voir la remarquable synthèse de J.Parsons, The Church in the Republic: Gallicanism and Political Ideology in Renaissance France, Washington (D.C.), 2004. L'auteur étudie essentiellement les écrits des juristes et des hauts magistrats. Pour le contexte plus général, voir l'étude novatrice d'Alain Tallon, Conscience nationale et sentiment religieux en France au XVI ${ }^{\mathrm{e}}$ siècle, Paris, 2002.

4. Pour la censure des imprimés, voir le catalogue établi par le père James Farge et alias pour la première moitié du XVI ${ }^{\mathrm{e}}$ siècle (Index des livres interdits, t. I. Index de l'Université de Paris, 1544, 1545, 1547, 1549, 1551, 1556, Sherbrooke, 1985). Cette censure fut marquée par une coopération entre le roi, le Parlement et la faculté de théologie. Après la mort d'Henri II, le droit de censure fut réservé au chancelier de France, laissant à sa seule discrétion le soin de consulter des théologiens censeurs. La censure fut, par la suite, de plus en plus inefficace malgré le rappel à l'ordre de l'édit de Moulins de 1566.

5. M. Morgat-Bonnet, De Paris à Poitiers, dix-huit années d'exil du Parlement au début du XV siècle (1418-1436), dans S. Daubresse, eadem, I. Storez-Brancourt (éds.), Le Parlement en exil ou Histoire politique et judiciaire des translations du parlement de Paris (XV'-XVIII ${ }^{\mathrm{e}}$ siècle)..., 
p. 119-300. L'auteur a étudié cent douze affaires concernant des collations ou élections bénéficiales. Dans soixante-neuf cas, il est fait mention du recours en cour de Rome intenté sur la question pétitoire par le candidat papal.

6. Depuis la fin du XV ${ }^{e}$ siècle, le Parlement se trouve en rivalité avec le Grand Conseil dont la compétence fut toujours imprécise. En effet, il arrivait que le roi attribue au Grand Conseil des causes bénéficiales.

7. Arch. nat., $\mathrm{X}^{1 \mathrm{~A}} 4866$, fol. $22 \mathrm{v}^{\circ}-30 \mathrm{v}^{\circ}$. Tabart et Jean de Saint-Omer, l'abbé qui a résigné en faveur de Tabart, sont les appelants.

8. L'étude scrupuleuse de chaque bref faisait partie des compétences du procureur général du Parlement.

9. Depuis le concordat de Bologne signé avec le pape en 1516, le roi de France possède un droit de collation à presque tous les bénéfices majeurs (10 archevêchés, 82 évêchés, 527 abbayes, ainsi que de nombreux prieurés).

10. Sont délibérées en chambre du conseil les affaires antérieurement plaidées devant la Grand Chambre qui n'ont pu donner lieu à une décision séance tenante, et d'autre part, les affaires sur rapport écrit ou enquête (État méthodique des archives du parlement de Paris par F. Hildesheimer et M. Morgat-Bonnet, Paris, 2011, p. 45-46).

11. Mémoire pour les droits du roi sur l'abbaye de Saint Jean de Thérouanne éclaircis et defendus contre l'injuste prétention de l'Espagne, par Germain, l'abbé de Saint-Jean au Mont, Paris, 1663.

12. Voir également la multiplication des procès entre candidats à l'élection épiscopale, étudiée par Véronique Julerot, pour le règne de Charles VIII ("Y a ung grant desordre»: Élections épiscopales et schismes diocésains en France sous Charles VIII, Paris, 2006).

13. R. Genestal, Les origines de l'appel comme d'abus, Paris, 1950, avant-propos de J. Dauvillier, p. XVII : « En dehors de la France, l'appel comme d'abus ne se retrouve qu'en Savoie et dans les Pays-Bas espagnols, mais dans les autres pays de l'Europe occidentale, existaient des institutions analogues qui visaient au même dessein ".

14. Par exemple, il était possible d'appeler comme d'abus d'un décret de prise de corps décerné par un official.

15. Antoine Lascaris de Tende exerce ses fonctions d'évêque de Beauvais depuis mai 1523. Pour le détail des plaidoiries, voir Arch. nat., $\mathrm{X}^{1 \mathrm{~A}} 4873$, fol. $300 \mathrm{v}^{\circ}-304$.

16. Ibid., fol. 301. La question était disputée dans le monde des juristes. Guy Coquille pensait que tous les apôtres avaient reçu le pouvoir de « lier, délier, remettre ou retenir les péchez» (N. Warembourg, Recherche sur le gallicanisme de Guy Coquille: le pape et le concile, dans Annales de l'École doctorale de Lille II, 1997, n 5, p. 94).

17. Des pardons pour « un fleurin » ont été accordés par le pape Jules II (mort en 1513) et confirmés par Adrien VI (mort en septembre 1523) "à ceux de Saint-Esprit de Dijon ». Saint-Esprit est le nom d'un hôpital à Dijon.

18. Ce litige intervenait dans un contexte déjà extrêmement tendu par des différends antérieurs : un arrêt du Parlement de 1512 avait condamné l'évêque à verser 1000 livres par an à la fabrique, mais l'évêque ne versa pas la totalité des sommes pour les travaux de la cathédrale (bras Nord). L'évêque considérait que le chapitre pouvait assumer seul les travaux (F. Meunier, Les travaux de la cathédrale de Beauvais dans un arrêt du parlement de Paris 1512, dans Bibliothèque de l'École des Chartes, 161, 2003, p. 33-57). 
19. Sur le Parlement défenseur de l'intérêt général, voir les actes du colloque du 8 novembre 2005 sur le thème de L'Histoire de l'intérêt général, publiés dans Histoire et Archives, n¹9, janvier-juin 2006.

20. Voir les ordonnances de décembre 1344 et du 19 mars 1360, citées par S. Daubresse, Le Parlement et l'enregistrement des actes royaux au XVI siècle, dans B. Anagnostou-Canas (éd.), Dire le droit : normes, juges, jurisconsultes, actes du colloque des 4 et 5 novembre 2004, Paris, 2006, p. 257.

21. Luther dénia au pape le pouvoir de remettre des peines spirituelles, sa rupture avec Rome fut consommée en 1520.

22. En octobre 1555, l'évêque déposa une requête auprès du Parlement où il expliquait qu'un de ses créanciers «tenoit propos publiquement que, s'il devoit estre pendu et estranglé, il feroit mettre le bras seculier par luy obtenu à execution... ». Il bénéficia de l'absolution à cautèle qui est une absolution donnée dans le but de prévenir un dommage qui pourrait résulter d'une censure douteuse ou ignorée. Le Parlement ordonna également aux créanciers de ne pas agir au préjudice de l'appel comme d'abus (Arch. nat., U 2282, fol. 247).

23. Arch. nat., $\mathrm{X}^{1 \mathrm{~A}} 4962$, fol. $509 \mathrm{v}^{\circ}-511 \mathrm{v}^{\circ}, 20$ décembre 1555.

24. Le Parlement fait défense à l'appelant, l'évêque de Noyon, d'empêcher la vente de ses terres et exécution du contrat (Ibid., fol. $511 v^{\circ}$ ).

25. Le 11 mars 1556, le plaidoyer non complet du 20 décembre 1555 fut par décision du

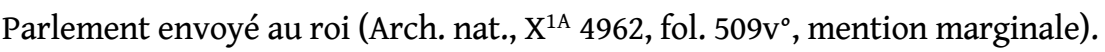

26. Paul de Foix devint conseiller clerc en 1555. Il finit sa vie comme archevêque de Toulouse.

27. Mais Paul de Foix, dans une lettre du 2 mars, ne cache pas son agacement face à ces ajournements qui peuvent paraitre insultants. Il est d'avis «que l'on n'eust donc poind adjourné monsieur le nonce, et possible eust-ce esté mieux fait d'obmettre en l'exploit tel adjournement qui aussi ne sert de rien et est superflu, estime qu'il faut prendre en consideration les affaires d'Etat et les personnes qui les traitent et manient se doivent conduire avec plus de civilité que ne font ordinairement les procedures de justice, que de bien petites formalitez causent quelquesfois de tres grands mescontentemens et mettent les grands princes en mauvais menage» (Lettres de $M^{\text {re }}$ Paul de Foix archevesque de Tolose, et ambassadeur pour le roy Henry III auprès du pape Gregoire XIII, Paris, chez Anthoine de Sommaville, 1636 , p. 389-390).

28. Ce fut l'un des arguments de Paul de Foix comme l'indiquent ses lettres à Henri III. Il explique que le désordre de ce couvent se commet presque devant les yeux du Parlement, et partant « la cour avoit eu particuliere occasion de s'interposer en ce fait et d'entendre à la requeste et semonce (du procureur général et du père spirituel du couvent) pour composer plustost ce different et y mettre les religieux en bonne concorde et union, et obvier aux inconveniens et scandales que les troubles et seditions apportent, mesmement entre personnes ecclesiastiques et monastiques » (Lettres de $M^{\text {re }}$ Paul de Foix archevesque de Tolose, et ambassadeur pour le roy Henry III..., p. 366). Voir la thèse de J.-M. Le Gall, Les moines au temps des Réformes: France (1480-1560), Seyssel, 2001, p.116: le Parlement accueillit beaucoup d'appels des déformés (ceux qui refusent la réforme de leur couvent) mais sa jurisprudence et ses sentences furent favorables aux réformes des couvents.

29. Correspondance du nonce en France, Anselmo Dandino, 1579-1581, éd. Ivan Cloulas, Rome, Paris, 1970, p. 63. 
30. M. Armstrong, Spiritual Reform, Mendicant Autonomy, and State Formation: French Franciscan Disputes before the Parlement of Paris, 1500-1600, dans French Historical Studies, 25, n ○3, 2002, p. 505-530. L'auteur constate que les Franciscains et les autres Mendiants ont utilisé le Parlement pour contrecarrer la réforme et la centralisation voulues par les généraux. Ils voulaient surtout préserver leur autonomie et leur liberté d'élection.

31. Arch. nat., $\mathrm{X}^{1 \mathrm{~A}} 1519$, fol. $41 \mathrm{r}^{\circ}-\mathrm{v}^{\circ}$. Il fut en outre défendu aux parties de susciter des discussions sur le sujet.

32. Pour le célèbre jurisconsulte Guy Coquille, la France est demeurée fidèle au droit commun c'est-à-dire à la législation primitive de l'Église, et a refusé les nouveautés introduites par les papes orgueilleux du XII ${ }^{\mathrm{e}}$ siècle (N. Warembourg, Guy Coquille et le droit français: le droit commun coutumier dans la doctrine juridique $\mathrm{du} \mathrm{XVI} \mathrm{I}^{\mathrm{e}}$ siècle, thèse de droit, Lille II, 2005, p. 74).

33. Arch. nat., $\mathrm{X}^{1 \mathrm{~A}} 1566$, fol. $173 \mathrm{v}^{\circ}$ : « Premierement, en ce que par lesd. bulles est absoult le roy quand à l'effect d'icelles de toutes sentences, excommunimens et censures qu'il pourroit avoir encourues, l'on n'a peu, ne peult et ne pourra on inserer ne conclure le roy avoir esté et estre pour le present et à l'advenir aulcunement ne pour quelque cause que ce soit subject aux excommunimens et censures apostoliques ne prejudicier ne deroger aux droictz privileiges et preeminences du roy et du royaume ».

34. Pour le détail de l'arrêt, voir le procès-verbal de son exécution, dans Trois remonstrances faictes sur la fin des troubles et recueillies depuis peu de temps, Paris, chez Pierre l'Huillier, 1608, p. 93-96.

35. B. Barbiche, Bulla, legatus, nuntius..., p. 202.

36. Pour les détails, voir l'article de M. Penzi, Tours contre Rome au début du règne d'Henri IV , dans Revue de l'histoire des religions, 226, n³, 2009, p. 329-347.

37. A. Tallon, La France et le concile de Trente (1513-1563), Rome, 1997, p. 246.

38. Voir les efforts déployés par Paul de Foix évoqués ci-dessus.

\section{AUTEUR}

\section{SYLVIE DAUBRESSE}

CNRS (UMR 8596) - sylvie.daubresse@paris-sorbonne.fr 


\title{
Il sospetto d'eresia e $i$ « frati diplomatici » tra Cinque e Seicento
}

\author{
Elena Bonora
}

\section{NOTE DELL'AUTORE}

Abbreviazioni $: \mathrm{ACDF}=$ Archivio della Congregazione per la Dottrina della Fede $\mathrm{AG}=$ Archivio Graziani di Vada ; ASV = Archivio di Stato di Venezia ; ASVat. = Archivio Segreto Vaticano $; \mathrm{BAV}=$ Biblioteca Apostolica Vaticana $; \mathrm{BBA}=$ Bologna, Biblioteca dell'Archiginnasio $; \mathrm{BCR}=$ Biblioteca Corsiniana di Roma $;$ Index $=$ Archivio della Congregazione dell'Indice ; SO=Archivio del Sant'Ufficio ;St. St. = Stanza Storica ; DBI = Dizionario biografico degli italiani, Roma, Istituto della Enciclopedia Italiana, 1960-.

1 Nelle pagine che seguono intendo mostrare come princìpi e valori ideologici tratti dalla lotta antiereticale, propugnati dall'Inquisizione e sanciti sul piano giuridico da papi inquisitori siano stati in grado di condizionare i comportamenti della diplomazia pontificia nella seconda metà del Cinquecento, nonché di influire nel lungo periodo sulla strutturazione delle reti politico-diplomatiche dipendenti dalla Santa sede.

Questa proposta di lettura si accompagna del resto alla consapevolezza che l'adozione di una prospettiva interpretativa centrata sull'Inquisizione può render conto solo parzialmente delle dinamiche operanti nella Chiesa cinque-seicentesca. Dinamiche complesse, la cui conoscenza si va approfondendo al volgersi dell'attenzione degli storici verso questioni non più focalizzate solo sulla repressione dell'eresia, e grazie al lavoro di scavo su fonti diverse da quelle inquisitoriali. Penso agli studi basati sulla documentazione di altri grandi dicasteri romani quali le congregazioni del Concilio (cui spettava l'interpretazione dei decreti tridentini ${ }^{1}$ ), dei Vescovi e Regolari, e di Propaganda Fide. $O$ al quadro radicalmente innovativo della Chiesa cinque-seicentesca che emerge dalle recentissime ricerche di Gianni Romeo e di Michele Mancino sul governo dei crimini del clero, un problema mai affrontato sinora in modo sistematico su una mole così vasta $\mathrm{e}$ diversificata di fonti². 
In particolare, la cospicua documentazione della congregazione dei Vescovi e Regolari appare in grado di gettare nuova luce, modificandolo, sul quadro d'insieme della vita religiosa e dell'organizzazione della Chiesa ${ }^{3}$. Questa congregazione cardinalizia creata nel 1573 e preposta al governo delle istituzioni ecclesiastiche con amplissimi poteri giudiziari fu affiancata a partire dal 1622 dalla congregazione di Propaganda Fide cui furono affidati il coordinamento e il governo delle terre di missione, ossia delle aree dove le istituzioni 'ordinarie' della Chiesa erano inesistenti o non ancora sufficientemente delineate ${ }^{4}$.

Dal momento che l'azione evangelizzatrice era svolta in modo preponderante dagli ordini religiosi ${ }^{5}$, Propaganda Fide può considerarsi una sorta di centrale romana addetta al governo dei regolari, cioè di quella componente della Chiesa che la normativa tridentina aveva posto sotto il controllo degli ordinari diocesani, ma che in realtà dopo il concilio recuperò i propri privilegi, autonomie ed esenzioni, trovando nell'attività missionaria ulteriori occasioni e motivi per mantenerli ${ }^{6}$.

5 In rapida sintesi e senza alcuna pretesa di esaurire i molti problemi e spunti di riflessione da esse posti, si può affermare che le recenti ricerche mettono in luce essenzialmente due aspetti.

6 Il primo riguarda la specificità italiana : alla pari del Sant'Ufficio, nonostante la pretesa universalità delle sue competenze, anche la congregazione dei Vescovi e Regolari dovette di fatto circoscrivere l'esercizio dei suoi poteri alla penisola italiana ; ciò avvenne per una serie di ragioni sulle quali non mi posso soffermare nel breve spazio di questo saggio, prima tra tutte i limiti alla giurisdizione papale posti dalle monarchie nazionali europee. Inoltre, se negli studi sugli apparati repressivi centrali e periferici è ormai assodata la disomogeneità tra un'« Italia inquisitoriale » e un'« Italia vescovile », anche le carte della congregazione dei Vescovi e Regolari evidenziano l'esistenza di una geografia differenziata delle istituzioni ecclesiastiche a livello locale, con accentuate difformità tra l'area centro-settentrionale della penisola e il Mezzogiorno. Al di là del lavoro che resta da fare per comprendere e valutare queste diverse articolazioni, l'Italia si precisa quindi rispetto agli altri Stati europei come il «paese del papa " per il peso e l'autorità dei dicasteri romani su istituzioni ecclesiastiche e società civile, e per l'influenza esercitata dalla Santa sede nel plasmare il cattolicesimo che qui si affermò ${ }^{7}$.

7 L'altro risultato verso il quale convergono le recenti ricerche è il carattere per molti aspetti poco 'tridentino' della Chiesa postridentina. Contro il tenace mito del tridentinismo, da almeno un paio di decenni gli studi hanno evidenziato l'ininterrotta centralità delle strutture regolari sia nell'azione pastorale sia nella formazione degli ecclesiastici, nonostante gli obiettivi del concilio fossero quelli di rilanciare il ruolo dei vescovi e del clero secolare con l'istituzione dei seminari e con norme volte a contenere l'invadenza dei religiosi nella cura d'anime ${ }^{8}$. L'apertura degli archivi centrali delle congregazioni del Sant'Ufficio e dell'Indice nel 1998 ha permesso di confermare e ampliare questa prospettiva mettendo in luce, per mezzo di indagini condotte in campi diversi, non solo come le inquisizioni romana e spagnola siano state in grado di condizionare lo svolgimento delle assemblee conciliari, ma anche il sostanziale depotenziamento delle norme e degli orientamenti tridentini attuato in seguito dal Sant'Ufficio e sostenuto da papi inquisitori a scapito della giurisdizione episcopale ${ }^{9}$. Dalle ricerche allargate ad altre congregazioni romane sta emergendo ora come le riforme epocali fissate dal concilio siano state disattese - con tempi e modalità che restano in buona parte da verificare e approfondire - proprio da quei dicasteri centrali che avrebbero dovuto gestirne e controllarne l'applicazione. 
In altre parole, vita religiosa e istituzioni ecclesiastiche locali del Seicento italiano appaiono oggi, alla luce di ricerche condotte da una «angolazione romana $»^{10}$, come realtà ben poco 'disciplinate' rispetto a quanto emergeva in passato da un filone di studi principalmente dedicato al riformismo episcopale e all'applicazione dei decreti conciliari nelle singole diocesi. Le accanite resistenze dei laici e delle autorità civili, ma anche quelle degli ecclesiastici in difesa di privilegi, immunità e abusi del clero, nonché il ripiegare da parte delle autorità centrali romane e degli stessi vescovi su una linea rinunciataria e compromissoria rispetto a quanto stabilito dai rigidi dettati conciliari, restituiscono ora un quadro molto più movimentato e conflittuale della Chiesa postridentina entro il quale, insieme con le divisioni e gli scontri tra le diverse componenti del mondo ecclesiastico, spiccano le contraddizioni interne del modello di cattolicesimo imposto da Roma.

Ho richiamato questi aspetti in primo luogo per chiarire che, analizzando il nesso tra diplomazia pontificia e Sant'Ufficio, non è mia intenzione ridurre sub specie Inquisitionis fenomeni vasti e articolati, trascurando l'influenza e il ruolo rivestito da altri dicasteri romani; in secondo luogo, per marcare la differenza tra cattolicesimi - italiano e francese - entro la quale collocare le osservazioni che seguiranno.

10 C'è infine una terza ragione. Nel corso di questo saggio indicherò nel peso assunto dall'Inquisizione e dall'ideologia inquisitoriale ai vertici della Chiesa altrettanti fattori strutturali in grado di condizionare i comportamenti degli esponenti della diplomazia ufficiale al servizio del papa ${ }^{11}$. Il ruolo rilevante assunto dai regolari nel corso del Seicento nel campo della mediazione diplomatica e delle relazioni internazionali appare in questa prospettiva come l'altra faccia della stessa medaglia: si tratta di un'ulteriore linea di sviluppo del cattolicesimo postridentino che non aveva la sua origine a Trento.

Il sospetto d'eresia Al suo rientro in curia dalla dieta imperiale di Ratisbona nel 1541, il cardinal legato Gasparo Contarini, uno dei più autorevoli diplomatici alla corte papale, fu oggetto di sospetti d'eresia. La sua lettera de iustificatione inviata a Mantova nel maggio dello stesso anno, del resto, figura tra i documenti d'accusa allegati al processo contro il cardinale Giovanni Morone celebrato sotto Paolo IV alla fine degli anni cinquanta. Proprio mentre Morone era detenuto nelle carceri papali, dalla corte imperiale il nunzio apostolico Zaccaria Dolfin trasmetteva un memoriale al cardinal nepote Carlo Carafa nel quale si scagliava contro coloro che definiva i "mediatori della concordia ", accusava il Contarini ormai scomparso di essere stato tra questi, e informava il Carafa di aver trasmesso una compromettente lettera del cardinale e diplomatico veneziano sull'argomento al Sommo inquisitore Michele Ghisleri ${ }^{12}$.

12 Alla luce di questi fatti, alcuni anni fa Massimo Firpo osservava come negli anni quaranta e cinquanta del Cinquecento i dispacci ufficiali degli inviati papali in Germania fossero passati, prima ancora che per le mani degli storici, per quelle del Sant'Ufficio ${ }^{13}$. Vorrei soffermarmi su questa contiguità tra dispacci diplomatici e incartamenti inquisitoriali nei decenni centrali del Cinquecento per leggerla come il riflesso di un processo più vasto che avrebbe portato all'assestamento di concezioni e princìpi ai vertici della Chiesa in grado di influenzare anche la sfera della politica estera e le relazioni con gli altri sovrani.

Nel giro di pochi anni dalla sua istituzione nel luglio del 1542, il Sant'Ufficio si mostrò in grado di condizionare l'elezione papale per mezzo del sospetto d'eresia e degli incartamenti giudiziari fatti circolare dai cardinali inquisitori in conclave ${ }^{14}$. Fu tuttavia 
solo nel 1559 con la bolla Cum ex apostolatus officio - promulgata da Paolo IV nonostante l'opposizione del collegio cardinalizio - che questa prassi ricevette solenne legittimazione dal punto di vista giuridico.

14 La bolla nasceva dalla precisa volontà di Paolo IV di impedire l'ascesa al papato del cardinal Morone, ma era anche densa di implicazioni per il futuro, dal momento che prevedeva la privazione eo ipso, ossia in modo automatico, delle loro dignità e cariche per quanti anche prima di rivestirle si fossero macchiati d'eresia, fossero essi laici o ecclesiastici, ossia vescovi, nunzi, cardinali, e persino pontefici. Nei limiti di questo saggio non posso soffermarmi sulla costituzione di Paolo IV e su aspetti rilevanti quali il suo valore retroattivo, la sua ambiguità nell'indicare a quale autorità spettasse giudicare la « macchia d'eresia », la sua portata destabilizzante per l'autorità papale ${ }^{15}$.

Basti sottolineare come da una parte, la bolla stabilisse contro il diritto canonico una relazione diretta e non graduata tra eresia e rimozione immediata e definitiva da una carica ecclesiastica ; dall'altra, lasciasse nell'indeterminatezza cosa si intendesse per «macchia d'eresia » e quali fossero i modi del suo accertamento. In questa maniera, il provvedimento del papa inquisitore metteva a disposizione del Sant'Ufficio uno spazio grigio extragiudiziale entro il quale, indipendentemente da un processo, il semplice sospetto d'eresia poteva essere utilizzato come strumento di condizionamento e di ricatto, ponendo le massime autorità ecclesiastiche e lo stesso pontefice alla mercé di tale sospetto ${ }^{16}$.

Non stupisce quindi che, a fine Cinquecento, il sospetto d'eresia costituisse l'obiezione più forte che la Santa sede poteva contrapporre alle pressioni delle autorità civili e alle prerogative dei sovrani fissate dai concordati, al fine di bloccare le carriere ecclesiastiche di candidati all'episcopato sgraditi a Roma ${ }^{17}$.

Contro i rappresentanti diplomatici di Pio IV Le conseguenze furono evidenti dopo la morte del Carafa, durante il pontificato del milanese Pio IV. La politica di mediazione di quest'ultimo con l'Impero per mezzo di concessioni religiose alla Germania portò non solo all'isolamento politico di questo papa che non proveniva dai ranghi dell'inquisizione, ma anche alla delegittimazione della sua autorità. Ma non è sulle denunce riguardanti l'eresia di Pio IV formulate apertamente già durante il conclave da cui uscì eletto che vorrei soffermarmi, quanto sul fatto che il sospetto d'eresia fu allora utilizzato dal Sant'Ufficio anche contro quanti erano al suo servizio nella veste di nunzi e di inviati diplomatici ${ }^{18}$.

E' noto, ad esempio, come all'origine del fallimento della candidatura al papato di Morone dopo la morte di Pio IV non ci fosse solo il suo coinvolgimento con gli «spirituali », ma anche il ruolo politico-diplomatico rivestito durante il pontificato di Pio IV, in particolare la missione svolta alla corte di Innsbruck nel 1563 per mezzo della quale Morone era riuscito a ottenere l'assenso dell'imperatore alla conclusione del concilio in cambio della promessa della concessione del calice ai laici e di significative deroghe al celibato ecclesiastico in Germania ${ }^{19}$.

Dell'accusa d'eresia contro i rappresentanti diplomatici di Pio IV si avvalse anche Filippo II di Spagna, strenuo oppositore della politica di concessioni del pontefice verso l'Impero. Occorre precisare come, alla pari dell'Inquisizione romana con la quale in quel periodo si creò una rilevante convergenza sul piano politico e teologico, la corte di Madrid 
considerasse le modificazioni sul piano dei riti e della disciplina del clero perseguite da Pio IV come vere e proprie violazioni sul piano dottrinale, ossia come eresie ${ }^{20}$.

All'epoca il veneziano Zaccaria Dolfin, nunzio apostolico alla corte cesarea, era impegnato in una complessa opera di mediazione con l'imperatore e i suoi consiglieri allargata ad alcuni principi tedeschi ${ }^{21}$. Fautore sotto Pio IV delle concessioni alla Germania che durante la precedente nunziatura negli anni cinquanta aveva invece aspramente criticato, il Dolfin magnificava nei suoi dispacci gli effetti prodotti dalla recente concessione del calice ai laici, offrendo al pontefice le informazioni atte a giustificare di fronte al Sacro collegio l'efficacia della politica conciliatrice e l'opportunità della concessione anche del matrimonio dei preti ${ }^{22}$. In questa situazione d'emergenza, al fine di screditare il Dolfin, i rappresentanti diplomatici di Filippo II raccolsero - e fecero opportunamente circolare in curia - carte compromettenti volte a dimostrare l'eresia del nunzio ${ }^{23}$.

21 Anche gli inviati papali in Francia dovettero scontare il loro coinvolgimento nella politica conciliatrice di Pio IV avversata dalla Spagna e dall'Inquisizione romana. Nel 1563 il cardinale inquisitore Michele Ghislieri istruì i processi contro alcuni vescovi francesi sospetti d'eresia coinvolti nella politica di mediazione della Corona culminata nei colloqui di Poissy. Il nome del cardinale Ippolito d'Este, legato apostolico alla corte del re Cristianissimo, si affaccia ripetutamente nelle deposizioni dei testimoni, in maggioranza teologi, canonisti, uomini di lettere, segretari e predicatori al seguito del cardinale ferrarese $e^{24}$.

22 Se circa due anni prima enorme scandalo aveva suscitato in curia il comportamento del cardinale d'Este che alla corte francese aveva imprudentemente assistito alla predica di un pastore calvinista al seguito della regina di Navarra, le deposizioni raccolte ora nel corso degli interrogatori dischiudevano agli occhi del Ghislieri una realtà in cui la conversazione con gli eretici e la loro frequentazione erano all'ordine del giorno.

23 "Come se fusse stato possibile, ne' tempi passati, quando tutti erano heretici, stare in questo regno senza havere alle volte communicatione con esso loro! » : sono le parole con cui Caterina de' Medici dieci anni dopo avrebbe difeso il suo ambasciatore Paul de Foix, insignito dal re dell'arcivescovato di Tolosa, al quale a Roma ci si rifiutava di accordare l'investitura canonica sulla base del sospetto d'eresia ${ }^{25}$. Per quanto riguarda Ippolito d'Este, lo stesso Pio IV nel '63 era a fatica riuscito a bloccare l'intervento dell'Inquisizione contro di lui ${ }^{26}$. In quello stesso periodo, commentando la nomina del cardinale ferrarese al Sant'Ufficio da parte del pontefice, l'ambasciatore spagnolo osservava con sarcasmo che il posto più appropriato per il porporato sarebbe stato al lato opposto, ossia sul banco degli imputati ${ }^{27}$.

Giovanni Morone, Zaccaria Dolfin, Ippolito d'Este erano uomini di Chiesa dalle fisionomie differenti, ma tutti al servizio della politica europea di Pio IV aspramente contrastata dal Sant'Ufficio. Alla morte di questo papa, con il prevalere ai vertici curiali di criteri di giudizio tratti dalla normativa antiereticale, a mutare non sarebbero stati solo i comportamenti degli uomini, ma anche il loro linguaggio. Se, quindi, nei dispacci dell'ambasciatore veneziano degli anni sessanta del Cinquecento la missione del cardinale d'Este in Francia era encomiata per la " prudentia » e la " destrezza », per la "patientia » e l'« humanità » dimostrate in quell'occasione ${ }^{28}$, di tutt'altro tipo erano le parole scelte un secolo dopo dal gesuita Pietro Sforza Pallavicino che, nell'Istoria del concilio di Trento, elogiava piuttosto la capacità di « dissimulazione» del cardinale ferrarese ${ }^{29}$. 
Nell'arco di tempo trascorso non c'era stata solo un'evoluzione del linguaggio politico legata alla fortuna di concetti seicenteschi e barocchi. C'era anche il fatto che sostantivi quali « patientia » $\mathrm{e}$ « humanità », così spesso utilizzati nei carteggi diplomatici durante il pontificato di Pio IV per connotare la politica di mediazione del papa, si erano caricati di significati negativi, trasformati in allarmanti indicatori di una volontà di dialogo e di compromesso con gli eretici della quale occorreva ora valutare sub specie Inquisitionis circostanze, interlocutori e contenuti ${ }^{30}$.

«Prudenza » e "fedeltà ", e non certo " patientia » e " humanità », erano del resto le virtù che nel 1676 il somasco Stefano Cosmi principalmente attribuiva a Gian Francesco Morosini nella sua biografia dell'ex nunzio e cardinal legato in Francia durante le guerre di religione, per difenderlo da antiche accuse ${ }^{31}$. Tornato a Roma nel 1589 dopo l'assassinio del duca e del cardinale di Guisa da parte del re, il porporato e diplomatico veneziano era stato infatti confinato agli arresti domiciliari in palazzo S. Marco e formalmente accusato dal papa inquisitore Sisto $\mathrm{V}$ di eresia nonché di disobbedienza all'autorità pontificia per il suo atteggiamento conciliante verso gli eretici alla corte di Enrico III $^{32}$.

Il divieto della conversazione con gli eretici sotto Pio V. Il problema storico posto dai tentativi di screditare i rappresentanti diplomatici di Pio IV va al di là dei loro orientamenti religiosi personali, e riguarda piuttosto l'affermarsi ai vertici della Chiesa della massima secondo la quale la conversazione con gli eretici giustificava il sospetto d'eresia. Una volta assunto a criterio di governo e collocato nel cuore del processo di formazione della volontà politica del papato, questo principio avrebbe condizionato i codici di comunicazione, gli schemi mentali e le forme dell'agire della diplomazia pontificia.

All'indomani della morte di Pio IV, sotto il pontificato dell'ex inquisitore Michele Ghislieri, tale principio ricevette consacrazione nella riflessione giuridica, come mostra uno dei responsa di Pietro Belo, procuratore fiscale del Sant'Ufficio, che stabiliva: "Occorre abiurare la familiarità con gli eretici [...] sussiste infatti un grave sospetto d'eresia contro coloro che conversano con un eretico $»^{33}$.

29 Il domenicano Pio V portò nel teatro europeo delle relazioni diplomatiche e della mediazione politica schemi mentali e valori appartenenti alla cultura teologica degli ordini mendicanti, frutto di un impegno secolare nella lotta contro la deviazione dottrinale. Si tratta di una svolta percepita dagli stessi contemporanei come in certa misura estranea alla tradizionale cultura di governo dei papi, quasi fosse una violazione del sistema per mezzo del quale la curia romana aveva sino allora gestito le relazioni politico-diplomatiche con le altre corti ${ }^{34}$.

E' quanto traspare dalle parole dell'ambasciatore veneziano a Roma, che osservava: "Quando si dice a Sua Santità una ragione di Stato, ovvero non la intende, ovvero non la considera più inanzi di quel che consideriria l'interesse di ciascun particolare »; e continuava prospettando ai capi del consiglio dei Dieci per il futuro « cose estraordinarie et non pensate et lontane da ogni ragion di chi governa Stato $»^{35}$.

Sulla base di una percezione analoga, nel 1571 il cardinal Madruzzo in concistoro si spinse sino a obiettare al papa, Sacra Scrittura alla mano, come Dio non avesse proibito agli ebrei di stipulare patti con eretici e infedeli, e che quindi sarebbe stato opportuno inviare rappresentanti diplomatici se non ai calvinisti, almeno ai principi luterani che aderivano 
alla pace di Augusta. In quell'occasione Pio V, furibondo, rispose che non era permesso trattare con i principi eretici, specie con quelli che erano disposti ad accordi sul piano dei riti $^{36}$.

32 La sensazione condivisa di un attacco sferrato dall'interno alla dignità stessa dei rappresentanti diplomatici della Santa sede emerge nella lettera del medesimo anno scambiata tra due segretari di cardinali. Nella missiva, lo scrivente da Roma riferiva come il pontefice avesse proibito al cardinal nepote Michele Bonelli, legato in Francia, non solo d'indossare la berretta rossa che questi gli aveva chiesto di poter portare in deroga al consueto abbigliamento dei cardinali provenienti dal clero regolare, ma negandogli persino la mozzetta, obbligando così il nipote a vestire il solo cappuccio domenicano perchè alla corte dei principi la cosa migliore era non presentarsi « in altro habito che di frate $»^{37}$.

33 Più avanti, sarà lo stesso Bonelli a ottenere da Gregorio XIV una sostanziale modifica dell'abbigliamento dei cardinali provenienti da ordini religiosi, ma sotto Pio V, l'immagine di potenti porporati e legati apostolici obbligati a presentarsi alle corti europee vestiti come frati, dovette urtare la sensibilità di molti ${ }^{38}$.

34 Le difficoltà del cardinal Commendone Il banco di prova per verificare il cambiamento avvenuto con l'elezione di Pio V fu la dieta imperiale di Augusta del 1566. In vista dell'evento, il suo predecessore Pio IV aveva concertato con la corte imperiale una politica di mediazione volta a isolare i principi che avevano aderito al calvinismo, ma non i luterani, designando legato a latere il cardinale veneziano Giovan Francesco Commendone - alla pari di Morone esponente di una generazione di diplomatici d'alto profilo - l'esperienza del quale era maturata nel corso di delicate missioni in Inghilterra, in Fiandra, in Polonia e in Germania ${ }^{39}$.

Alla luce delle trasformazioni che nell'ultimo decennio avevano modificato il quadro europeo, l'incarico si prospettava dei più ardui. Roma doveva ora prendere posizione ufficiale nei confronti della pace di Augusta del 1555, mai riconosciuta da Paolo IV , e, nel contempo, doveva ottenere l'applicazione dei decreti del concilio di Trento appena concluso. Occorreva anche tener conto della richiesta di una parte dei ceti imperiali della conferma del recesso augustano per arginare la diffusione del calvinismo, nonché delle esigenze di Massimiliano II, che ricercava l'appoggio sia del papa sia dei principi tedeschi contro i turchi.

La morte di Pio IV, nello scorcio del 1565, mutò radicalmente le prospettive romane e il significato della missione di Commendone, ponendo il legato in una posizione difficilissima. Alla ricerca di «concordie et misture di religioni $»^{40}$ che aveva caratterizzato l'atteggiamento di Pio IV verso il mondo tedesco, si sostituivano ora categorie estranee alla politica, in base alle quali il nuovo papa proibì agli inviati romani ogni contatto con i principi protestanti, e rifiutò di allacciare relazioni diplomatiche con sovrani la cui ortodossia non fosse certa ${ }^{41}$. «I papi solevano spedire corrieri per interessi di Stati, questo [...] li ispedisce solo per interesse d'inquisitione», osservava un agente fiorentino nel luglio del ' $66^{42}$.

37 In questo contesto, la preoccupazione con la quale a Roma gli amici di Commendone seguivano gli sviluppi della sua missione in Germania appare come il frutto della consapevolezza di un mutato modo di fare politica: "Vostra Signoria Illustrissima 
consideri bene tutti i capi et vada, come è suo solito, col piè di piombo, perché le sue attioni sono troppo osservate », lo avvertiva il suo agente a Roma ${ }^{43}$. Ancora più esplicito il cardinal Sirleto, che raccomandava al porporato veneziano di « non cercare mai di trovar vie di accomodarsi alli heretici »; e gli ricordava le difficoltà incontrate da altri tentativi di mediazione, citando quanto era accaduto anni prima a Ippolito d'Este ${ }^{44}$.

Del resto, in un trattatello inedito sul nunzio ideale redatto nello stesso periodo Giulio Poggiani - un altro uomo di lettere e segretario di cardinali vicino al Commendone raccomandava che i rappresentanti pontifici fossero compositi ad mores, probati ad sanctimoniam, parati ad obedientiam, mansueti ad patientiam [...], rigidi ad censuram, catholici ad fidem [...], in agendo strenui, in loquendo modesti, in adversitate securi [...], ubique in omnibus circumspecti ${ }^{4}$.

39 Alla fine, il legato veneziano non solo uscì indenne, ma accrebbe enormemente il proprio prestigio presso Pio V, che gli avrebbe affidato in seguito altre difficili missioni. Per conseguire quel risultato, però, il prudente Commendone fu costretto a rinunciare alla libertà propria di un diplomatico del suo rango e dotato delle sue prerogative istituzionali. La legazione fu infatti scandita da continue consultazioni con i teologi del suo seguito, i cui voti, messi per iscritto, furono oggetto di fitti scambi epistolari tra Roma e Augusta. Ma tutta la corrispondenza del Commendone in questo periodo è pervasa dall'ansia di tutelarsi da eventuali accuse, di interpretare con esattezza gli ordini provenienti dalla segreteria papale, di non travalicare i limiti delle istruzioni assegnategli, di ridurre i margini di autonomia che quest'ultime gli attribuivano creando, per quanto poteva, momenti collegiali di decisione ${ }^{46}$.

40 Al culmine della crisi, Pio $\mathrm{V}$ ordinò al legato di presentare una protesta ufficiale contro il recesso della dieta. Un gesto politicamente dissennato, come apparve chiaro ai ceti cattolici tedeschi, al nunzio e alla maggior parte degli inviati del papa in Germania ${ }^{47}$. Commendone uscì da questa impasse grazie ai gesuiti. Non solo Nadal, Canisio e Ledesma, teologi ed esperti del mondo tedesco, che ad Augusta si prodigarono nel fornire voti e pareri ${ }^{48}$. Furono il generale Borgia e il Polanco a venire in aiuto del segretario Calligari inviato in gran fretta a Roma da un Commendone sempre più preoccupato e sgomento davanti alla rigidità del pontefice ${ }^{49}$. Essi perorarono la causa presso il cardinal nepote, studiarono le « difficultà della pace del ‘ 55 » e la sua compatibilità con i decreti tridentini, discussero con Pio $\mathrm{V}$ che volle sottoporre la questione all'Inquisizione, procurarono l'appoggio dei cardinali Granvelle e Pacheco per scongiurare «uno scisma tanto pericoloso » tra il papa e l'imperatore, nonché tra Roma e i ceti cattolici tedeschi che domandavano la conferma del trattato di Augusta ${ }^{50}$.

41 Sant'Ufficio e nunzi. ${ }^{51}$ Mi sono soffermata sul caso del cardinal Commendone perché le linee di tendenza e gli orientamenti che lascia intravedere non si esaurirono con il pontificato di Pio V, ma furono in grado di condizionare durevolmente l'evoluzione dell'ideologia religiosa e dei ruoli ecclesiastici, influenzando anche la sfera delle relazioni diplomatiche. Di questa progressiva affermazione dei poteri del Sant'Ufficio romano ai vertici della Chiesa, del resto, il prelato veneziano aveva già colto la portata epocale alcuni anni prima, allorché nel suo Discorso sopra la corte di Roma, a proposito dei cardinali inquisitori aveva osservato : "Parmi ch'ora avvenga quello che avvenne già ai censori della repubblica 
romana, che fatti per un officio particolare crebbero a tanto, che potevano muovere ed alterare tutta la repubblica $»^{52}$.

E difatti, nel corso del Seicento il Sant'Ufficio continuò a esercitare la sua sorveglianza sugli inviati papali presso le corti estere in autonomia dalla segreteria di Stato e dal cardinal nepote, ora trasmettendo ai nunzi norme generali sulla frequentazione degli eretici, ora per mezzo di interventi volti a regolare specifiche situazioni. Se, quindi, al nunzio a Graz nel 1610 i cardinali inquisitori chiarivano come la «conversazione » e i banchetti pubblici con gli eretici fossero consentiti solo in casi eccezionali, quando cioè sussistesse una fondata speranza di conversione ${ }^{53}$, il nunzio a Colonia nel 1622 si sentiva in dovere di chiedere all'Inquisizione un permesso speciale per sé e per il proprio segretario per poter condurre trattative con ministri eretici ${ }^{54}$.

Ma accadeva anche che i nunzi si rivolgessero al Sant'Ufficio per sapere come dovevano comportarsi durante le cerimonie pubbliche allorché le norme per la difesa dell'ortodossia entravano in conflitto con l'ordine delle precedenze presso corti affollate di principi e di ministri protestanti ${ }^{55}$. Analoghe difficoltà a conciliare i comportamenti imposti dalla lotta antiereticale con le esigenze connesse al ruolo di rappresentanza che i legati apostolici dovevano svolgere presso i principi stranieri furono incontrate nel 1604 dal nunzio in Francia Innocenzo Del Bufalo, in grave imbarazzo tra le inflessibili direttive romane e l'impossibilità di sottrarsi al lutto della corte e del re Enrico IV per la scomparsa della sorella Caterina di Borbone la quale, avendo rifiutato la conversione al cattolicesimo, era morta da eretica ${ }^{56}$.

44 I 'frati diplomatici'. La vicenda sopra richiamata del cardinal Commendone e il ruolo svolto dai gesuiti in quel frangente di contro alle difficoltà del legato apostolico conscio della propria vulnerabilità e timoroso di un'accusa per eresia al suo ritorno a Roma, inducono a ulteriori riflessioni.

E' evidente infatti che, di fronte all'affermarsi di criteri tratti dalla lotta antiereticale come il divieto della conversazione con gli eretici, e al diffondersi dell'uso strumentale del sospetto d'eresia per bloccare carriere e delegittimare quanti rivestivano cariche importanti nella Chiesa, alcuni degli elementi costitutivi e delle caratteristiche strutturali del mondo regolare - l'organizzazione gerarchica ; il voto di obbedienza ai superiori ; l'esistenza di forme di giustizia interne ${ }^{57}$; il rigoroso controllo del percorso di studi e la precipua formazione teologica; la fedeltà a un'identità consolidata che tendeva a tradursi in abito mentale e culturale ${ }^{58}$ - diventavano ora un capitale prezioso da spendere entro l'istituzione ecclesiastica. Nell'ultimo scorcio del secolo, questo stato di cose era efficacemente sintetizzato da Antonio Possevino nella Bibliotheca selecta. Qui il gesuita non esitava a enunciare il principio secondo il quale gli ordini religiosi erano maggiormente preservati dall'eresia rispetto al clero secolare ; e, a conferma della propria tesi, adduceva i valori della " coeca obedientia ", del controllo degli studi e della reciproca sorveglianza sul piano dottrinale che caratterizzavano il mondo regolare ${ }^{59}$.

46 "Quando si mandano legati [...], siano catholici e intelligenti», si permetteva del resto di suggerire al cardinal Farnese già nel 1546 Dionigi Zanettini, più noto come il Grechetto, contro l'eventualità di una nuova nomina del cardinal Morone a legato conciliare ${ }^{60}$. Ma se un infimo personaggio quale era il minore osservante vescovo di Milopotamos poteva permettersi di esprimersi con tale libertà a riguardo di uno dei più prestigiosi cardinali $\mathrm{e}$ 
diplomatici della Chiesa romana, ciò accadeva perché egli era frate, teologo e zelante delatore dell'Inquisizione, e nella veste di fustigatore dell'eresia non aveva paura di nessuno ${ }^{61}$.

Nel sottolineare questi aspetti non intendo ridurre i conflitti interni al mondo della diplomazia ecclesiastica a una lotta tra garanti più o meno affidabili dell'ortodossia. Mi pare tuttavia che non si possa fare a meno di leggere il protagonismo dei regolari nella Chiesa postridentina entro il contesto più ampio della lotta per la definizione dei poteri $\mathrm{e}$ per la distribuzione dei ruoli al suo interno ; e di raccordare i compiti che essi si trovarono a svolgere sulla scena diplomatica seicentesca anche a processi di lunga durata avviati dalla crisi religiosa del secolo precedente, nel corso della quale ai vertici curiali erano prevalsi istituzioni, orientamenti e princìpi che traevano la loro origine dalla priorità assegnata alla lotta antiereticale ${ }^{62}$.

Senza dubbio, i fenomeni sin qui considerati possono essere ascritti alla categoria storiografica di « confessionalizzazione » qualora essa venga utilizzata nella sua accezione minimale secondo la quale in Europa, nei decenni a cavallo tra Cinque e Seicento, la teologia influenzò in modo preponderante la politica e le relazioni internazionali ${ }^{63}$. Tuttavia, l'uso di questa categoria onnicomprensiva mi pare rischi di perdere di vista le dinamiche specifiche attraverso le quali i condizionamenti della teologia e dei difensori istituzionali dell'ortodossia si articolarono nel mondo cattolico rispetto a quello riformato, nonché le diverse conseguenze che ne derivarono.

49 A fine Cinquecento i 'frati diplomatici' potevano ancora essere percepiti come un fenomeno inusuale. A suggerirlo è il sarcasmo con il quale nei suoi dispacci da Roma un autentico politico e diplomatico, l'oratore veneziano Leonardo Donà, valutava le missioni entro e fuori d'Italia di Antonio Possevino, constatando quasi con fastidio come il gesuita si vantasse di aver messo pace tra la Polonia e la Moscovia, senza in realtà «devenir a cosa che punto rilevasse $»^{64}$, e sottolineando il carattere velleitario di iniziative che, secondo l'ambasciatore, si limitavano al dono di qualche « Agnus Dei, immagini di Nostra donna, [...] corone d'agata benedette $»^{65}$.

E tuttavia, nonostante lo sprezzo del patrizio veneziano, nel secolo successivo i percorsi che collegano tra loro le corti europee appaiono sempre più spesso solcati da regolari impegnati in missioni diplomatiche di cruciale importanza, ufficiali e non.

51 Nelle Memorie del cardinale Guido Bentivoglio, uno dei più insigni diplomatici alla corte papale nella prima metà del Seicento, si legge come frate Bonaventura da Caltagirone, inviato in Francia per condurre i negoziati sulla restituzione di Saluzzo, dopo essersi posto a capotavola tra i deputati del re Cristianissimo e quelli del duca di Savoia, rifiutasse di sedere allo stesso tavolo con Maximilien de Béthune, marchese di Rosny e futuro duca di Sully, rappresentante del sovrano, perché eretico. Fu accontentato, anche se, come osserva ironicamente il Bentivoglio, il gentiluomo francese si sarebbe in seguito rivelato il più efficace artefice del buon esito del negoziato ${ }^{66}$.

52 La distinzione, se non l'antagonismo, tra rappresentanti ufficiali della diplomazia pontificia quale era il Bentivoglio e i regolari impegnati in missioni politico-diplomatiche emergeva con respiro più largo nelle pagine delle Memorie in cui il porporato, indossati i panni dello storico, polemizzava con le "persone religiose » che scrivevano di «queste materie ». La critica verso coloro che, formati « dall'umil'aura de' claustri e delli esercizi ombratili delle scuole » pretendevano di competere, nella ricostruzione storico-politica degli eventi, con quanti (come lo stesso Bentivoglio) avevano raffinato il loro ingegno nelle « corti » e nel « secolo», postulava infatti l'esistenza di uno scarto incolmabile tra 
gli uni e gli altri, un divario che concerneva le contrapposte « attitudini » maturate lungo percorsi formativi e per mezzo di esperienze del mondo sostanzialmente dissimili ${ }^{67}$.

Era una valutazione che guardava alle differenti appartenenze entro l'universo ecclesiastico ; un punto di vista corporativo sostanzialmente affine all'atteggiamento del nunzio Carlo Carafa che nel 1626, si lamentava con il segretario di Propaganda Fide delle "proposte di frati» che minacciavano di compromettere le sue trattative con la corte imperiale: «Proposte di frati, et altre persone simili che per mostrar di far, e di dire rappresentano molte volte cose di niuna consideratione, anzi qualche volta d'inconvenienti per il stato presente politico di queste parti ${ }^{68}$.

Un panorama più affollato. L'intromissione dei regolari nei negozi di Stato e nella politica è stata solitamente associata sul piano storiografico ai gesuiti per il ruolo rivestito alle corti dei principi nella veste di confessori e consiglieri ${ }^{69}$; per i peculiari rapporti con il papa derivanti dalla fisionomia dell'ordine ; per l'esistenza di una secolare tradizione ferocemente critica verso i maneggi politici della Compagnia ${ }^{70}$. E tuttavia, il panorama che da questo punto di vista ci si presenta nel Seicento è molto più largo, affollato $\mathrm{e}$ diversificato.

Ne fanno parte personaggi noti come il già menzionato generale dei minori osservanti Bonaventura da Caltagirone ${ }^{71}$, il barnabita Tobia Corona ${ }^{72}$, il cappuccino Giacinto Natta da Casale $^{73}$, i suoi confratelli Valeriano Magni ${ }^{74}$, Lorenzo da Brindisi ${ }^{75}$ e Anselmo Marzato da Monopoli ${ }^{76}$, poi insignito della berretta cardinalizia. Tutti religiosi, in buona parte teologi, che trattarono incarichi diplomatici di rilievo usufruendo di estese autonomie rispetto ai nunzi - i quali erano nella maggioranza vescovi ${ }^{77}$ - e spesso in conflitto con loro ; che agivano sulla base di istruzioni papali ad personam o approfittando di canali privilegiati con le congregazioni cardinalizie romane delle quali sovente avevano fatto parte nella veste di consultori e in cui sedevano i loro confratelli ; che trasmettevano le preziose informazioni sulle quali Roma avrebbe basato la sua politica da paesi e da corti in cui si muovevano con maggior libertà rispetto ai nunzi.

Questo quadro d'insieme si è in tempi recenti arricchito grazie al lavoro di scavo nell'archivio della congregazione di Propaganda Fide. Figure come quelle del cappuccino Joseph de Paris (Joseph Leclerc du Tremblay) e del confratello Valeriano Magni, ad esempio, entrambi negli anni venti-trenta del Seicento in stretto rapporto con il potente segretario del dicastero romano Francesco Ingoli, testimoniano dell'esistenza di politiche e di progetti messi a punto tra singoli frati e congregazione cardinalizia che trascendono il governo delle missioni e gli scopi pastorali dell'evangelizzazione, per riverberare i loro riflessi sullo spazio politico europeo e sulle relazioni tra gli Stati.

Se Magni era in grado di condizionare la politica papale per la conquista cattolica della Boemia e di influenzare importanti negoziati tra Roma e la corte imperiale spesso in contrasto con gli orientamenti e le scelte del nunzio ${ }^{78}$, dalla corte di Francia "père Joseph ", per il quale fu coniato il termine di éminence grise, si trovava al centro di una rete informativa e operativa lungo la quale, oltre ai progetti di conversione del mondo islamico e di unione con gli ortodossi, correvano concreti interessi commerciali e disegni egemonici che ben si inscrivevano nella politica internazionale di Richelieu. Nel monopolizzare e gestire questa struttura parallela alla diplomazia ufficiale, il cappuccino francese, che nel capitolo generale del 1625 a Roma era stato nominato prefetto delle 
missioni del suo ordine, operava come alleato e collaboratore di Propaganda Fide nella veste di agente del dicastero romano alla corte di Francia ${ }^{79}$.

Ma i due religiosi qui richiamati sono solo la punta di un fenomeno dalla base larga e ramificata, che coinvolge frati missionari nella veste di informatori, spioni, mediatori non ufficiali. Interlocutori e informatori politici di Propaganda Fide erano anche missionari ed ex missionari meno noti come il francescano Gregorio Bolivar, l'agostiniano Pedro Nieto, i domenicani Diego Collado e Miguel Rangel, il cappuccino Francis Nugent, il francescano osservante Francesco Quaresmio, i quali convogliavano a Roma notizie, pareri e proposte concernenti le sconfinate aree di missione dal Messico alla Virginia, dall'Irlanda e dai confini orientali europei sino all'Oceano Indiano ${ }^{80}$. Non solo dubbi circa la pratica sacramentale dei fedeli o preoccupazioni pastorali ${ }^{81}$, ma informazioni, valutazioni e progetti che riguardavano, oltre alla vita religiosa in queste zone remote, anche le relazioni con potenze come la Spagna, l'Inghilterra, la Francia, l'Impero, con ricadute immediate nello spazio europeo. Un'attività di cui andrebbe indagata la dimensione negoziale alla luce dei compiti assegnati loro da Roma, per affiancarla a quella dei confratelli che facevano la spola tra le corti occidentali ${ }^{82}$.

La congregazione di Propaganda Fide era stata istituita dopo una lunga gestazione nel $1622 \mathrm{da}$ Gregorio $\mathrm{XV}^{83}$. E proprio sotto il breve ma significativo pontificato del Ludovisi si aprirono insperate possibilità di intervento per la Santa sede. La sottomissione della Valtellina, l'offensiva contro gli ugonotti in Francia, la traslazione della dignità elettorale alla Baviera cattolica, la conquista del Palatinato protestante (accompagnato dall'arrivo a Roma della Biblioteca Palatina), la progettata invasione di Ginevra con l'alleanza della Savoia rilanciavano disegni di restaurazione cattolica che parevano ormai dissolti, dischiudendo nuovi orizzonti al ruolo internazionale del papato ${ }^{84}$. In questo contesto, all'infittirsi dell'attività diplomatica e nell'accelerazione impressa alle relazioni internazionali dai conflitti e dalle trattative in corso, le lettere del cardinal nepote (nonché prefetto di Propaganda Fide) si arricchivano di istruzioni e sparsi riferimenti ai padri Tobia, Arnolfo, Giacinto, Giuseppe, e ai tanti 'frati diplomatici', soprattutto cappuccini, sparpagliati per l'Europa, cui Roma aveva affidato negoziati cruciali e segreti ${ }^{85}$

Un'attività diplomatica sotterranea, quella dei regolari, di cui sovrani e autorità civili paiono sempre più consapevoli nel corso del Seicento come dimostra, specie nei problematici anni quaranta, il ricorso a decreti di espulsione dai domini italiani di regolari che non erano sudditi del re Cattolico emanati dalle autorità spagnole non tanto per il timore che i religiosi influenzassero i fedeli con la predicazione o la confessione, ma per l'allarme suscitato dal moltiplicarsi delle attività spionistiche e delle trattative condotte al riparo dei chiostri ${ }^{86}$. Se quindi, nel 1618 il governatore di Milano si adirava con il priore dei carmelitani che, invitato ad abbandonare lo Stato per i suoi noti orientamenti filofrancesi, aveva invece organizzato nella sua cella un vertice segreto tra Philippe de Béthune (diplomatico e fratello del duca di Sully), il residente veneziano e un inviato del duca di Savoia, nel 1642 le autorità milanesi non esitavano a denunciare a chiare lettere come nei conventi e nei monasteri dello Stato vi fossero frati che "non attendono ad altro che a spiare, scrivere, corrispondersi con nemici, sparlare e passar mali offici $»^{87}$. 
Conclusioni L'intensa attività dei regolari nella sfera politico-diplomatica al servizio della Santa sede meriterebbe approfondimenti ben più consistenti delle sparse indicazioni contenute in questo saggio. Occorrerebbe stabilire le scansioni cronologiche del fenomeno ; chiarire il mutare dei referenti romani dei singoli ordini al variare degli equilibri di potere e al riarticolarsi delle relazioni istituzionali in curia ${ }^{88}$; valutare il ruolo di Propaganda Fide e delle reti missionarie oltre che sul piano della cura pastorale e dell'evangelizzazione dei popoli, anche su quello politico. Varrebbe inoltre la pena di raccordare il coinvolgimento dei regolari nella sfera diplomatica a quelle rivalità e contrastanti progettualità tra gli ordini esplose nel Seicento che introdussero alti tassi di conflittualità anche in questo ambito ${ }^{89}$. Occorrerebbe infine verificare la tenuta nel lungo periodo di questa presenza regolare, insieme con la sua evoluzione e trasformazione.

Nella stessa Venezia dove nel 1582 si guardava con sarcasmo all'attività diplomatica del gesuita Possevino ${ }^{90}$, neanche un secolo più tardi i chierici somaschi si dedicavano nella scuola della Salute alla formazione politica del ceto dirigente attraverso esercitazioni su carte e documenti di Stato ${ }^{91}$. Sempre negli anni settanta del Seicento, all'accademia dei nobili detta dei Cosmografi istituita presso la casa professa dei gesuiti, Carlo Maurizio Vota impartiva ai patrizi veneziani lezioni di geografia, cosmografia e storia che «si conformavano con le lettere de gli ambasciatori », tutte materie di studio che il gesuita giudicava indispensabili "in Senato", "nel teatro delle ambasciarie tra le corti degl'esteri », nei «pubblici reggimenti e maneggi $»^{92}$. E di «maneggi» il Vota doveva intendersene, a giudicare dalla sua frenetica attività diplomatica al servizio del papa dispiegata in missioni straordinarie tra la Polonia, la corte imperiale e la Moscovia.

A metà Settecento Voltaire scriveva : «I religiosi, i regolari, i cui capi risiedono a Roma, sono sudditi immediati del papa che popolano tutti gli Stati», e continuava : "Giurare fedeltà ad altri che al proprio sovrano è un crimine di lesa maestà per un laico, ma è un atto di religione nel chiostro ». Era una lettura prettamente politica del ruolo esercitato dai regolari nell'Europa cattolica che, nondimeno, coglieva con chiarezza il carattere strutturale di quella preminenza degli ordini religiosi entro la quale ritengo vada iscritto anche il protagonismo dei 'frati diplomatici'.

Si tratta, come ho cercato di mostrare, di aspetti costitutivi della Chiesa postridentina dei quali, tuttavia, Voltaire indicava sviluppi e articolazioni differenti tra Italia e Francia collocando la svolta nel regno di Luigi XIV :

Un gran cambiamento s'è prodotto per questa via nel nostro costume sotto Luigi XIV, con la persuasione, insinuatasi ormai in tutti i religiosi, d'essere sudditi del re prima che servitori del papa ${ }^{93}$.

\section{NOTE}

1. La congregazione del Concilio raccoglieva anche le relationes ad limina dei vescovi. Le sue carte e quelle della congregazione dei Vescovi e Regolari sono conservate nell'Archivio Segreto Vaticano. Sul suo ruolo più 'teorico' rispetto a quello della congregazione dei Vescovi e Regolari cfr. M. Mancino La giustizia penale ecclesiastica 
nell'Italia del Seicento : linee di tendenza, in Studi storici, 51, n. 4, 2010, p. 1003-1033 (p. 9). Per l'analisi dei suoi interventi in un campo specifico: B. Albani, «In universo christiano orbe » : la Sacra Congregazione del Concilio e l'amministrazione dei sacramenti nel Nuovo Mondo (secoli XVI-XVII), in P. Broggio, Ch. De Castelnau-L'Estoile, G. Pizzorusso (dir.), Administrer les sacrements en Europe et au Nouveau Monde : la Curie romaine et les Dubia circa Sacramenta, Mélanges de l'École française de Rome. Italie et Méditerranée, 121-1, 2009, p. 63-73.

2. G. Romeo, M. Mancino, Clero criminale. Chiesa e onore degli ecclesiastici nell'Italia della Controriforma, Roma-Bari, 2013.

3. Sulla congregazione dei Vescovi e Regolari con ampie analisi e innovative riflessioni sulla Chiesa del Seicento: G. Romeo, Confessione dei peccati e confessori nell'Italia della Controriforma : cosa dire del Seicento? in Studi storici, 51, n. 4, 2010, p. 967-1002 ; M. Mancino, La giustizia penale ecclesiastica...cit., nonché il volume di A. Menniti Ippolito, 1664. Un anno della Chiesa universale. Saggio sull italianità del papato in età moderna, Roma, 2011. Cfr. inoltre G. Romeo, La Congregazione dei Vescovi e Regolari e i visitatori apostolici nell'Italia posttridentina : un primo bilancio, in M. Sangalli (dir.), Per il Cinquecento religioso italiano. Clero cultura e società, II, Roma, 2003, p. 607-661; M. Mancino, Tra autonomia e centralizzazione : la Congregazione dei Vescovi e Regolari e le licenze di confessione nell'Italia del tardo Cinquecento, ivi, p. 615-623.

4. Sull'utilità euristica ma anche la sostanziale astrattezza della distinzione tra uno 'spazio missionario' di competenza di Propaganda Fide e uno " 'spazio tridentino', dove agisce una chiesa 'formata' con una gerarchia episcopale e un sistema di parrocchie » governato dalla congregazione dei Vescovi e Regolari, cfr. G. Pizzorusso, I dubbi sui sacramenti dalle missioni ad infideles. Percorsi nelle burocrazie di curia, in P. Broggio, Ch. De Castelnau-L'Estoile, G. Pizzorusso (dir.), Administrer les sacrements... cit., p. 39-61 (p. 47). Un inquadramento generale su Propaganda Fide in G. Pizzorusso, Agli antipodi di Babele. Propaganda Fide tra immagine cosmopolita e orizzonti romani (XVII-XIX secolo), in Storia d'Italia Einaudi. Annali 16: L. Fiorani e A. Prosperi (dir.), Roma la città del papa. Vita civile e religiosa dal Giubileo di Bonifacio VIII al Giubileo di Papa Wojtyla, Torino, 2000, p. 476-518. Su Propaganda Fide e i regolari: G. Pizzorusso, La Congregazione De Propaganda Fide e gli ordini religiosi : conflittualità nel mondo delle missioni del XVII secolo, in M. C. Giannini (dir.), Religione, conflittualità e cultura. Il clero regolare nell'Europa d'antico regime, in Cheiron, 22, 43-44, 2005, p. 197-240.

5. Il progetto romano (di Francesco Ingoli) di creare un clero missionario secolare alternativo all'impiego dei regolari fallì, ma diede risultati in Francia dove fu istituita la Société des Missions-Etrangères legata alla Corona (ivi, p. 217-218).

6. Per un approccio generale: G. Fragnito, Gli Ordini religiosi tra Riforma e Controriforma, e R. Rusconi, Gli Ordini religiosi maschili dalla Controriforma alle soppressioni settecentesche. Cultura, predicazione, missioni, in M. Rosa (dir.), Clero e società nell'Italia moderna, Roma-Bari, 1992, rispettivamente p.115-205 e 207-274 ; G. Greco, La Chiesa in Italia nell'età moderna, Roma-Bari, 1999, specialmente il cap. IV, p. 93-120 ; F. Rurale, Monaci, frati, chierici. Gli Ordini religiosi in età moderna, Roma, 2008.

7. G. Romeo, Confessione dei peccati... cit., p. 971, 975-978; M. Mancino, La giustizia penale ecclesiastica... cit., p.12-17. L'«italianità del papato in età moderna » è una delle tesi portanti del citato libro di Menniti Ippolito. Sull'immagine dell'Italia del Cinquecento «suburbana» a Roma derivante da ricerche non necessariamente legate alle fonti inquisitoriali aveva richiamato l'attenzione C. Donati, Chiesa italiana e vescovi d'Italia dal 
XVI al XVIII secolo. Tra interpretazioni storiografiche e prospettive di ricerca, in Annali dell'Istituto storico italo-germanico in Trento, 30, 2004, p. 375-389.

8. Cfr. le linee generali tracciate in G. Fragnito, Gli Ordini religiosi tra Riforma e Controriforma ... cit. ; Ead., Vescovi e ordini religiosi in Italia all'indomani del Concilio, ora in Ead., Cinquecento italiano. Religione, cultura e potere dal Rinascimento alla Controriforma, éd. E. Bonora e M. Gotor, Bologna, 2011, p. 34-48.

9. Oltre ai lavori di G. Romeo, si vedano: A. Prosperi, Il concilio di Trento: una introduzione storica, Torino, 2001, p. 143-164 : cap. X, La storia che non passò da Trento ; M. Gotor, I beati del papa. Santità, Inquisizione e obbedienza in età moderna, Firenze, 2002; Id., Santi stravaganti. Agiografia, ordini religiosi e censura ecclesiastica nella prima età moderna, Roma, 2012 ; S. Pastore, Il vangelo e la spada. L'Inquisizione di Castiglia e i suoi critici (1460-1598), Roma, 2003 ; G. Fragnito, Pio V e la censura, in M. Guasco e A. Torre (dir.), Pio V nella società e nella politica del suo tempo, Bologna, 2005, p. 129-158; Ead., Vescovi "censori" : il Tridentino alla prova, ora in Ead., Cinquecento italiano... cit., p. 48-66 ; E. Bonora, Giudicare $i$ vescovi. La definizione dei poteri nella Chiesa postridentina, Roma-Bari, 2007 ; C. Quaranta, Marcello II Cervini (1501-1555). Riforma della Chiesa, concilio, Inquisizione, Bologna, 2010. Si vedano inoltre le linee di ricerca anticipate in G. Fragnito, Istituzioni ecclesiastiche e costruzione dello Stato: riflessioni e spunti, ora in Ead., Cinquecento italiano... cit., p. 17-34. Ma già ricca di indicazioni sullo svuotamento della normativa tridentina dopo il concilio era la monografia di Paolo Prodi sul cardinal Paleotti arcivescovo di Bologna: P. Prodi, Il cardinale Gabriele Paleotti (1522-1597), I-II, Roma, 1959 e 1967.

10. G. Fragnito, Istituzioni ecclesiastiche... cit., p. 19 e 29.

11. Mi sono già soffermata su questi aspetti nel mio "Ubique in omnibus circumspecti ». Diplomazia pontificia e intransigenza religiosa, in R. Sabbatini e P. Volpini (dir.), Sulla diplomazia in età moderna. Politica, economia, religione, Milano, 2011, pp.61-76 di cui il presente saggio sviluppa alcune linee di ricerca.

12. M. Firpo, Inquisizione romana e Controriforma. Studi sul cardinal Giovanni Morone (1509-1580) e il suo processo d'eresia, Brescia, 2005 (ampliamento dell'ed. 1992), p. 466-467. Sulle accuse di eresia messe in circolazione alla corte romana dagli intransigenti contro il legato Contarini cfr. anche: P. Simoncelli, Evangelismo italiano del Cinquecento. Questione religiosa e nicodemismo politico, Roma, 1979, p. 104-117 ; G. Fragnito, Gasparo Contarini. Un magistrato veneziano al servizio della cristianità, Firenze, 1988, p. 57-69.

13. M. Firpo, Inquisizione romana... cit., p. 466-467.

14. Una recente accurata ricostruzione del conclave del 1549 da cui fu eletto Giulio III Del Monte in C. Quaranta, Marcello II Cervini... cit., p. 317 s. Sull'uso dei dossiers inquisitoriali nei conclavi cfr. M. Firpo, Inquisizione romana e Controriforma... cit., p. 259-261; Id., Eresia e Inquisizione in Italia (1542-1572), in Id., "Disputar di cose pertinenti alla fede ». Studi sulla vita religiosa del Cinquecento italiano, Milano, 2003, p. 202-208.

15. Il testo della costituzione di Paolo IV in Bullarium romanum, VI, Augustae Taurinorum, 1860 , p. 551-556. Sull'uso politico della bolla mi permetto di rinviare a E. Bonora, Giudicare $i$ vescovi... cit., e a Conflitti d'autorità tra vescovi, papato e Sant'Ufficio, in P. Arabeyre et B. Basdevant-Gaudemet (dir.), Les clercs et les princes. Doctrines et pratiques de l'autorite ecclésiastique à l'époque moderne, Paris, École nationale des chartes, 2013 (Collection Études et rencontres de l'École des chartes, 41), p. 31-46.

16. Sul sospetto d'eresia contro il papa regnante: E. Bonora, Giudicare $i$ vescovi... cit., p. 238-263. 
17. Cfr. i casi di Filippo Mocenigo e di Paul de Foix esaminati ivi, p. 213 s., e quelli analizzati in G. Fragnito, «Sa Saincteté se resoudra par l'advis des Cardinaux de l'Inquisition, sans lesquels il n'oseroit rien faire ": Clemente VIII, il Sant'Ufficio e Enrico IV di Borbone, in Schifanoia, 38-39, 2010, p. 143-169.

18. Sulla politica europea di Pio IV e sulle resistenze che incontrò mi permetto di rinviare a : E. Bonora, Inquisizione e papato tra Pio IV e Pio V, in M. Guasco e A. Torre (dir.), Pio V nella società... cit., p. 33-67; Ead., Morone e Pio IV, in M. Firpo e O. Niccoli (dir.), Il cardinale Giovanni Morone e l'ultima fase del concilio di Trento, Bologna, 2010, p. 21-52 (sull'accusa d'eresia contro Pio IV in conclave : ivi, p. 25). Su una congiura contro Pio IV maturata in questo contesto e sui suoi possibili mandanti : E. Bonora, Roma 1564. La congiura contro il papa, Roma-Bari, 2011.

19. Il processo inquisitoriale del cardinal Giovanni Morone. Edizione critica, éd. M. Firpo e D. Marcatto, I-VI, Roma, 1981-1995, VI, p. 21-24 ; E. Bonora, Morone e Pio IV... cit. Sulla missione di Morone : G. Constant, La legation du cardinal Morone près l'Empereur et le Concile de Trente, Paris, 1922. Sull'ostilità di Filippo II alla candidatura di Morone al papato nel 1565 cfr. M. Firpo, Inquisizione romana... cit., p. 345 s.

20. Sull'opposizione di Filippo II alle concessioni : E. Bonora, Morone e Pio IV... cit.

21. Sul progetto di Ferdinando I di ripristinare l'unità religiosa ed ecclesiastica attraverso le concessioni, cfr. G. Constant, Concession... cit., I, p. 110 s., 612 s.; K. Repgen, Impero $e$ concilio (1521-1566), in P. Prodi e W. Reinhard (dir.), Il concilio di Trento e il moderno, Bologna, 1996, p. 55-99; H. Louthan, The quest for compromise : peacemakers in Counter-Reformation Vienna, Cambridge, 1997.

22. Nuntiaturberichte aus Deutschland, nebst ergänzenden Aktensücken, II Abteilung. 1560-1572. IV, Nuntius Delfino 1564-1565, éd. S. Steinherz, Wien, 1914. Sul Dolfin (Delfino), nominato poi cardinale da Pio IV grazie alle pressioni dell'imperatore cfr. la voce di G. Benzoni in DBI, 40 , p. 576-588.

23. Si veda la lettera dell'inviato spagnolo Pedro de Avila al re, 21 agosto 1565, in Beiträge zur politischen, kirchlichen und Cultur-Geschichte der sechs letzten Jahrhunderte, éd. J. J. I. von Döllinger, II, Regensburg, 1862, p. 623-624.

24. Cfr. ACDF, SO, St. St., R4-d, fol. 567r-599v, 608r-614v. Per i riferimenti più compromettenti al coinvolgimento del legato, cfr. ivi, fol.565v, 567r, 574r, 575r. Sui processi ai vescovi francesi : E. Bonora, Giudicare i vescovi... cit., p. 165-195.

25. Acta Nuntiaturae Gallicae. Correspondance du Nonce en France Antonio Maria Salviati (1572-1578), 13, t. II, éd. P. Hurtubise e R. Toupin, Rome, 1975, p. 11, il nunzio Salviati al card. Galli, 3 luglio 1574. Sul caso di Paul de Foix cui si fa riferimento qui, cfr. supra, nota 17.

26. Cfr. Die Römische Kurie und das Konzil von Trient unter Pius IV, éd. J. Šusta, I-IV, Wien, 1904-1914, I, p. 297, 303-304, 307-308, 372-374.

27. Cit. da M. C. Giannini, Fra autonomia politica e ortodossia religiosa : il tentativo d'introdurre l'inquisizione «al modo di Spagna » nello stato di Milano (1558-1566), in Società e storia, 91, 2001, p. 103-104.

28. ASV, Senato dispacci Francia, filza 5, 30 aprile 1563.

29. P. Sforza Pallavicino, Istoria del concilio di Trento, I-II, in Roma, 1756-1757, I, p. 240.

30. Nel concistoro del 12 gennaio 1565 Pio IV tentò di convincere i cardinali alla deroga del celibato ecclesiastico in Germania esortandoli a tener conto di valori come la patientia 
nonché dell'opportunità di scelte provvisorie come i remedia ad sanandos haereticos, facendosi quindi sostenitore di una teologia diversa da quella dell'Inquisizione (BCR, Acta Consist.card.Gambarae, 40G13, fol.418r). Per le critiche avanzate da uomini vicini all'Inquisizione contro i pontefici che tradivano la loro missione praticando la pazienza verso gli eretici : E. Bonora, Giudicare i vescovi... cit., p. 243-250, 262-263.

31. S. Cosmi, Memorie della vita di Gio. Francesco Morosini Cardinale della S. R. Chiesa e Vescovo di Brescia, in Venetia, 1676, p. 611.

32. Era questo il terzo dei gravi capi d'accusa presentati al Morosini il 31 ottobre 1589 dal cardinale inquisitore Domenico Pinelli e dal cardinale Girolamo Mattei, membro della congregazione di Francia presieduta dal cardinale inquisitore Giulio Antonio Santoro. Morosini, che era assistito dall'avvocato concistoriale Pompeo Arrigoni, stese allora un sommario difensivo il cui contenuto è riportato estesamente nella biografia del Cosmi sotto il nome di Apologia (ivi, p. 613-641). Sugli attacchi al cardinal legato in Francia Alessandro de' Medici, a sua volta accusato nel 1598 da ambienti curiali di essere « dolce con gl'heretici » cfr. G. Fragnito, « Sa Saincteté »... cit.

33. BAV, Vat. Lat. 5468 , fol. $55 \mathrm{v}$.

34. Mi riallaccio qui ad alcuni suggerimenti di Francesco Benigno a proposito del nepotismo papale : F. Benigno, Ripensare il nepotismo papale nel Seicento, in Storica, 35-36, 2006, p. 93-113.

35. Sugli avvisi di Costantinopoli : «Si vede molto bene che essa non li gusta » (ASV, Capi del consiglio dei Dieci, Lettere degli ambasciatori, Roma, b. 24, 12 gennaio 1566). Cfr. anche i dispacci del 16 e 23 febbraio.

36. Concistoro del 18 giugno 1571 citato da P. Tacchi Venturi, Diario concistoriale di Giulio Antonio Santori cardinale di Santa Severina, in Studi e documenti di storia e diritto, 23, 1902, (estratto Roma 1903), p. 45-47.

37. AG, b. 62 b : G. B. Caro da Roma ad A. M. Graziani, 16 giugno 1571. Il Graziani, futuro nunzio e vescovo, era allora alla corte di Vienna al servizio del cardinal legato Commendone.

38. Si veda G. Catena, Discorso [...] all'illustrissimo cardinale Sfondrato. Della beretta rossa per li cardinali religiosi, in Padova, 1591. Sull'uso della berretta rossa per i cardinali regolari e la sua evoluzione cfr. G. Moroni, Dizionario d'erudizione ecclesiastica, XV, Venezia, 1840, p. 157 s. e G. Fragnito, Buone maniere e professionalità nelle corti romane del Cinque e Seicento, ora in Ead., Cinquecento italiano... cit., p. 106-139 (in particolare p. 118, nota 147).

39. Ricchissima di notizie la biografia del cardinale redatta dal suo ex segretario Antonio Maria Graziani (De vita Joannis Francisci Commedoni, Parisiis, 1669). Cfr. inoltre la voce di D. Caccamo in DBI, 27, p. 606-613.

40. Nuntiaturberichte aus Deutschland... cit. V, Nuntius Biglia 1565-1566, Commendone als Legat auf dem Reichstag zu Augsburg 1566, éd. I. Ph. Dengel, Wien-Leipzig, 1926, p. 88, 91.

41. ASV, Capi del consiglio dei Dieci, Lettere degli ambasciatori, Roma, b. 24, 16 febbraio 1566.

42. Nuntiaturberichte aus Deutschland... cit. V, Nuntius Biglia... cit., p. 158, L. Ceresola al cardinal de' Medici, 19 luglio 1566.

43. Ivi, p. 67, 22 gennaio 1566. «Vostra Signoria Illustrissima è circondato da molti cani et li bisogna molto bene attendere a sé » (ASVat., Segreteria di Stato, Lettere di Principi, 23, fol. 211, 6 febbraio 1566). 
44. « Il cardinal Sirletti ne ha advertito che Nostra Santità è molto scrupoloso nelle cose della fede et che bisogna che Vostra Signoria Illustrissima cerchi di far tutte le sue attioni con molti testimoni, et soprattutto non cercare mai di trovar vie di accomodarsi alli heretici, perché questo dispiace infinitamente a Sua Beatitudine che vole andar in simplicitate, et che non è bene che Vostra Signoria Illustrissima tratti o parli mai con gli heretici da solo a solo né intravenga alle sue prediche come fece Ferrara perché Nostra Santità haveria a malissimo, et qui sono molti osservatori delle sue attioni, et che si tendono molti lacci» (ivi, fol.201, Calligari al card.Commendone, 2 febbraio 1566, pubblicata in A. Caligarii nuntii apost. in Polonia epistolae et acta 1578-1581, in Monumenta Poloniae Vaticana, éd. L. Boratyński, IV, Cracoviae, 1915, p. 200).

45. Il corsivo è mio. AG, b. 46, fasc. 5 , fogli non numerati. La corte cardinalizia del Commendone di cui fecero parte Antonio Maria Graziani, Fulvio Ruggeri, Giovanni Andrea Calligari fu un vero e proprio vivaio di nunzi inviati negli anni successivi in Germania e in Polonia con incarichi che prevedevano progetti di crociata anti-turca, ma che collidevano con la politica estera delle corti asburgica e polacca, specie nei confronti della Moscovia. L'ampiezza delle loro relazioni emerge dal ricchissimo apparato di corredo in : G. Poggiani, Epistolae et orationes olim collectae ab Antonio Maria Gratiano nunc ab Hieronymo Lagomarsinio e Societate Jesu adnotationibus illustratae ac primum editae, Romae, 1756-1762, I-IV.

46. Cfr. Nuntiaturberichte aus Deutschland... cit. V, Nuntius Biglia... cit., e la documentazione pubblicata in K. Repgen, Die römische Kurie und der Westfälische Friede, I-II, Tubingen, 1962-1965, in particolare : I, p. 20-23, Calligari a Commendone, 12 maggio 1566.

47. Come è noto, la dieta confermò il recesso augustano e alla fine Commendone non pronunciò la protesta ma organizzò assemblee separate con i ceti cattolici per la conferma del Tridentino. Sull'importanza di questa dieta per i ceti cattolici tedeschi : O. Christin, La paix de religion. L'autonomisation de la raison politique au XVI siècle, Paris, 1997, p. 53-55.

48. O. Braunsberger, Beati Petri Canisii societatis Jesu epistulae et acta, I-VIII, Friburgi Brisgoviae, 1896-1923, V, p. 253, Nadal, Canisio e Ledesma al generale Borgia, 4 maggio 1566.

49. K. Repgen, Die römische Kurie... cit., I, p. 24-29. Le istruzioni di Commendone a Calligari sono in Nuntiaturberichte aus Deutschland... cit. V, Nuntius Biglia... cit., p. 203-206.

50. K. Repgen, Die römische Kurie... cit., I, p. 25-29. Il cardinal Pacheco era allora membro del Sant'Ufficio.

51. A testimonianza della vivacità della storiografia italiana sul Cinquecento religioso, si veda la lettura radicalmente innovativa delle funzioni dei nunzi nelle recenti ricerche di G. Romeo e M. Mancino sull'attività dei loro tribunali (G. Romeo, M. Mancino, Clero criminale... cit.).

52. G. F. Commendone, Discorso sopra la corte di Roma, éd. C. Mozzarelli, Roma, 1996, p. 113.

53. ACDF, SO, St. St., Q2-n, fol.281. Sul rapporto tra nunzi e Sant'Ufficio nell'area dell'Impero : I. Fosi, Frontiere inquisitoriali nel Sacro Romano Impero, in M. A. Visceglia (dir.), Papato e politica internazionale nella prima età moderna, Roma, 2013, p. 257-274.

54. ACDF, SO, St. St., Q2-n, fol. 175, 19 giugno 1622.

55. Ivi, fol. 288, il Sant'Ufficio al nunzio presso la corte imperiale, 20 novembre 1625. 
56. B. Barbiche Doctrine catholique et diplomatie romaine au début du XVII siècle: le cas de Catherine de Bourbon, duchesse de Bar, in Id., Bulla, legatus, nuntius. Études de diplomatique et de diplomatie pontificales (XIII ${ }^{\mathrm{e}}$-XVII ${ }^{\mathrm{e}}$ siècles), Paris, 2007, p. 465-476.

57. Su questo aspetto poco studiato, ricchi spunti e riflessioni in A. Barzazi, I Servi di Maria dal Cinque al Seicento: tra antiche autonomie e centralizzazione romana, in Studi storici dell'ordine dei Servi di Maria, 61-62, 2011-2012, t. II, p. 453-488.

58. Mi pare si possano applicare al XVI secolo le osservazioni formulate da Paolo Prodi per l'età medievale sulla cultura teologica degli ordini mendicanti rispetto al clero secolare : « Come sul piano religioso gli ordini tendono sempre a richiamarsi al fondatore e alla regola, così trasferendo impropriamente questa tendenza sul piano culturale essi diventano prevalentemente ripetitori e vivono di un pensiero già formulato e completo in sistema » (P. Prodi, Riforma cattolica e Controriforma, in Nuove questioni di storia moderna, I-II, Milano, 1968, I, p. 388). Sul nesso tra appartenenza a un ordine regolare ed elaborazione storiografica : M. Firpo (dir.), "Nunc alia tempora, alii mores». Storici e storia in età postridentina, Torino, 2005, Parte seconda.

59. Coloniae Agrippinae, 1609, p. 236-239 (I edizione 1593).

60. G. Buschbell, Reformation und Inquisition in Italien um die Mitte des XVI.Jahrhunderts, Paderborn, 1910, p. 251.

61. Sul Grechetto organizzatore per mezzo dell'accusa d'eresia di campagne diffamatorie contro uomini di Chiesa, soprattutto vescovi : Il processo inquisitoriale del cardinal Giovanni Morone... cit., I, p. 315-316.

62. Per lo sfondo di lungo periodo sul quale collocare l'attività politica dei «frati diplomatici » si veda il saggio di M. A. Visceglia, The International Policy of the Papacy: Critical Approaches to the Concepts of Universalism and Italianità, Peace and War, in M. A. Visceglia (dir.), Papato e politica internazionale ... , cit., p. 17-62, che oltre a fornire una rassegna critica degli studi sul ruolo del papato nella politica internazionale avanza nuove interpretazioni e periodizzazioni. Ricco di spunti sugli ordini regolari il recente M. C. Giannini (dir.), Papacy, Religious Orders, and International Politics in the Sixteenth and Seventeenth Centuries, Roma, 2013.

63. Viene usata in tale accezione da H. Schilling, La confessionalisation et le système international, in L. Bély (dir.), L'Europe des traités de Westphalie. Esprit de la diplomatie et diplomatie de l'esprit, avec le concours d'I. Richefort, Paris, 2000, p. 411-428. Spunti per una riflessione sulla pluralità dei cattolicesimi (e dei modelli di confessionalizzazione cattolica) nel saggio di A. Molnár, Bosnian Franciscans between Roman Centralisation and Balkan Confessionalisation, in M. C. Giannini (dir.), Papacy, Religious Orders ..., cit., p. 211-229.

64. ASV, Capi del consiglio dei Dieci, Lettere degli ambasciatori, Roma, b. 27, 15 settembre 1582 : «Diversi cardinali che qui hanno trattato seco altre volte sopra il suo viaggio che già fece al re di Svetia, lo tengono per persona che dia molto più larga speranza et promessa delle cose che maneggia di quello che possano correspondere gli effetti ».

65. Ivi, Senato, Archivio proprio, Roma, reg. 25, fol. 259r, primo aprile 1581. Dieci giorni più tardi Possevino teneva davanti alle autorità veneziane un discorso sulla situazione politico-religiosa dalla Transilvania alla Siria perorando il progetto di ricattolicizzazione della Moscovia e la stipulazione di un'alleanza antiturca tra questa e la Polonia (ivi, Consiglio dei Dieci, Esposizioni Roma, reg. 1, fol. 80r-81r, 11 aprile 1581). Sulla politica di Gregorio XIII nell'area nord-orientale dell'Europa e sulla mediazione di Possevino, oltre a L. Karttunen, Antonio Possevino. Un diplomate pontifical au XVI ${ }^{e}$ siècle, Lausanne, 1908, ampi 
riferimenti bibliografici in J. P. Donnelly, Antonio Possevino S. J. as papal mediator between Emperor Rudolf II and king Stephan Báthory, in Archivum Societatis Iesu, 69, fasc. 137, 2000, p. 3-56. Per l'atteggiamento di Venezia, cfr. P. Pierling, La Russie et le Saint-Siège. Études diplomatiques, I-V, Paris, 1896-1912, II, p. 34 s. Sui contrasti tra il gesuita e il nunzio in Polonia Giovanni Andrea Calligari cfr. la voce di G. De Caro, Caligari, Giovanni Andrea, in DBI , 16, p. 711-717.

66. G. Bentivoglio, Memorie e lettere, éd. C. Panigada, Bari, 1934, p. 77. Sul Bentivoglio, oltre alla voce di voce di A. Merola in DBI, 8, p. 634-638, si veda : M. Rosa, Nobiltà e carriera nelle "memorie» di due cardinali della Controriforma: Scipione Gonzaga e Guido Bentivoglio, in M. A. Visceglia (dir.), Signori, patrizi, cavalieri nell'età moderna, Bari, 1992, p. 231-255.

67. G. Bentivoglio, Memorie e lettere... cit., p. 100. La critica di Bentivoglio si sviluppa nel IX capitolo del I libro contro le opere dei gesuiti Giovan Pietro Maffei e Famiano Strada, autori rispettivamente di un'Istoria dell'Indie e delle De bello belgico decades, quest'ultime redatte mentre il Bentivoglio scriveva il suo Della guerra di Fiandra.

68. Lettera del 18 febbraio 1626 a Francesco Ingoli segretario della congregazione di Propaganda Fide citata da A. Catalano, La politica della curia romana in Boemia dalla strategia del nunzio Carlo Carafa a quella del cappuccino Valeriano Magni, in R. Bösel, G. Klingestein e A. Koller (dir.), Kaiserhof Papsthof (16.-18. Jahrhundert), Wien, 2006, p. 110 (p. 105-121).

69. Cfr. F. Rurale (dir.), I religiosi a corte. Teologia, politica e diplomazia in antico regime, Roma, 1998.

70. S. Pavone, Le astuzie dei gesuiti. Le false «Istruzioni segrete» della compagnia di Gesù e la polemica antigesuita nei secoli XVII e XVIII, Roma, 2000. Una lettura sintetica e comparativa in F. Rurale, Monaci, frati, chierici... cit.

71. Generale nel 1593, patriarca di Costantinopoli, grande mediatore in Francia e in Fiandra per la pace di Vervins del 1598 ; incaricato due anni dopo di condurre i negoziati tra Enrico IV e il duca di Savoia sulla restituzione di Saluzzo, fu poi arcivescovo di Messina e di Catania.

72. Al teologo barnabita furono affidati i negoziati in Francia e alla corte di Torino per la crisi valtellinese (cfr. L. von Pastor, Storia dei papi dalla fine del Medioevo, XIII, Roma, 1961, p. 160-161) nonché varie altre missioni sotto Paolo V, Gregorio XV e Urbano VIII (L. M. Ungarelli, Bibliotheca scriptorum e congregatione clerr. regg. s. Paulli, 1836, p. 188-189 ; G. Boffito, Biblioteca barnabitica, I-IV, Firenze, 1933-1937, I, p. 516). Due sue «lettere di negozi » furono pubblicate nella fortunata Idea del Segretario di Bartolomeo Zucchi (Venezia, 1614).

73. Missionario in Germania e poi al seguito del cardinal legato alla corte imperiale, mediatore di pace tra principi italiani, incaricato delle trattative segrete per il conferimento della dignità elettorale alla Baviera, tra il 1621 e il 1622 fece la spola tra la corte cesarea, Parigi e Madrid, dove l'olivares suo malgrado dovette rassegnarsi a trattare con un semplice frate (L. von Pastor, Storia dei papi... cit., XIII, p. 193-199). Nel 1613 inviava da Ratisbona libri da proibire alla congregazione dell'Indice (ACDF, Index, VI/1, fol. 46rv). Su di lui cfr. la voce Giacinto da Casale di A. Koller in DBI, 54, p. 116-118.

74. Sul Magni si vedano gli ampi riferimenti in : A. Catalano, La Boemia e la riconquista delle coscienze. Ernst Adalbert von Harrach e la controriforma in Europa centrale (1620-1667), Roma, 2005.

75. Sull'estesa attività diplomatica di Lorenzo da Brindisi prima presso il duca di Mantova, poi alle corti imperiale, di Baviera e di Spagna per la formazione della Lega 
cattolica, con ampi stralci della sua ricca corrispondenza con nunzi e con il cardinal Borghese: A. M. da Carmignano di Brenta, San Lorenzo da Brindisi dottore della chiesa universale (1559-1619), I-IV, Venezia Mestre, 1960-1963.

76. Teologo del Sant'Ufficio, al seguito in Francia del cardinal legato Pietro Aldobrandini nel 1600, fu nominato cardinale da Clemente VIII. Su di lui : L. Cardella, Memorie storiche de cardinali della Santa romana chiesa, VI, in Roma, 1793, p.111-113 ; A. Iurilli, I cappuccini e il rinnovamento dell'omiletica coram papa. Frate Anselmo Marzato da Monopoli, in A. Musco, G. Musotto, L. Parisoli (dir.), I francescani e la politica, Palermo, 2007, I, p. 577-597. Ma si veda anche, in una fase più tarda, l'importante figura del cappuccino Marco d'Aviano (1631-1699) sul quale mi limito a rinviare alla voce di S. Cavazza in DBI, 69, p. 730-735.

77. Sui rapporti tra episcopato e nunziatura cfr. B. Barbiche, S. de Dainville-Barbiche, $L a$ diplomatie pontificale de la paix de Vervins aux traités de Westphalie (1598-1648), in L. Bély (dir.), L'Europe des traités de Westphalie... cit., p. 561-564.

78. Sul Magni si vedano i già citati lavori di A. Catalano. A lui agli inizi degli anni trenta del Seicento il segretario di Propaganda Francesco Ingoli inidrizzò quel gruppo di lettere conosciute come la Relazione delle Quattro Parti del Mondo (Francesco Ingoli, Relazione delle quattro parti del mondo, éd. F. Tosi, Città del Vaticano, 1999).

79. Cfr. G. Pizzorusso, Reti informative e strategie politiche tra la Francia, Roma e le missioni cattoliche nellimpero ottomano agli inizi del XVII secolo, in G. Motta (dir.), I turchi, il Mediterraneo e l'Europa, Milano, 1998, p. 212-231 (in particolare p. 217-225, 228-231).

80. Sui regolari informatori di Propaganda Fide mi servo qui di: G. Pizzorusso, La Congregazione De Propaganda Fide e gli ordini religiosi... cit., p. 234-236.

81. Tali aspetti sono al centro del volume: P. Broggio, Ch. De Castelnau-L'Estoile, G. Pizzorusso (dir.), Administrer les sacrements en Europe et au Nouveau Monde... cit.

82. Sul ruolo politico dei missionari nel Nuovo Mondo al servizio delle potenze europee cfr. M. Sanfilippo, Missionari, esploratori, spie e strateghi : i gesuiti nel Nord America francese (1604-1763), in F. Rurale (dir.), I religiosi a corte... cit., p. 287-331 ; G. Pizzorusso, Ordini regolari, missionari e politica nelle Antille del XVIII secolo, ivi, p. 249-286. Il recente volume a cura di M. A. Visceglia, Papato e politica internazionale ... , cit., è ricco di spunti utili per una rilettura dell'attività di Propaganda Fide e per una più approfondita ricostruzione delle ricadute politiche di progetti ecclesiastici non riducibili alla prospettiva missionaria dell'evangelizzare e convertire.

83. G. Pizzorusso, Agli antipodi di Babele... cit., p. 483-486.

84. Cfr. L. von Pastor, Storia dei papi... cit., XIII, p. 153-226 ; L. von Ranke, Storia dei papi, Firenze, $1965^{2}$, p. 710-754; A. Koller, Le rôle du Saint-Siège au début de la guerre de Trente ans. Les objectif de la politique allemande de Gregoire XV (1621-1623), in L. Bély (dir.), L'Europe des traités de Westphalie... cit., p. 123-133.

85. Si vedano i molteplici riferimenti nelle lettere scritte da Giovan Battista Agucchi a nome del cardinal nepote Ludovico Ludovisi in BBA, B47 ; BC, ms. 1566 e ms. 1567, nonché nelle istruzioni pontificie di Gregorio XV : K. Jaitner (a cura di), Instructiones Pontificum Romanorum. Die Hauptinstruktionen Gregors XV für die Nuntien und Gesandten an den europäischen Fürstenhöfen (1621-1623), I-II, Tübingen, 1997.

86. M. C. Giannini, Note sul problema del controllo politico degli Ordini religiosi nell'Italia della prima metà del Seicento, in C. J. Hernando Sánchez (dir.), Roma y España. Un crisol de la cultura europea en la Edad Moderna, I-II, I, Madrid, 2007, p. 551-576. 
87. Ivi, p. 565. Sull'utilizzazione da parte delle autorità milanesi di religiosi « naturali » per missioni di rappresentanza alla corte spagnola nel Seicento: G. Signorotto, La "verità » e gli « interessi ». Religiosi milanesi nelle legazioni alla corte di Spagna (sec. XVII), in F. Rurale (dir.), I religiosi a corte... cit., p. 195-227.

88. Soprattutto varrebbe la pena di approfondire il protagonismo dei cappuccini nella prima metà del Seicento quando Francesco Ingoli era segretario di Propaganda Fide. Sull'Ingoli cfr. la voce di G. Pizzorusso in DBI, 62, p. 388-391.

89. Come dimostra lo scontro sulle diverse linee d'attuazione della riforma cattolica in Boemia tra gesuiti e cappuccini analizzato da Catalano (A. Catalano, La politica della curia romana in Boemia... cit.).

90. Cfr. supra.

91. A. Barzazi, Gli affanni dell'erudizione. Studi e organizzazione culturale degli ordini religiosi a Venezia tra Sei e Settecento, Venezia, 2004, p. 108 s. ; Ead., Patriziato e studi a Venezia nella seconda metà del Seicento : alla scuola dei somaschi, in Studi veneziani, n.s. 44, 2002, p. 37-89. Sui somaschi «maestri di politica » alla Salute si veda anche Ead., Formazione del patrizio $e$ ordini religiosi : modelli a confronto, in A. Caracausi e A. Conzato (dir.), Formazione alla politica, politica della formazione a Venezia in età moderna, Roma, 2013, p. 37-58. All'epoca generale della congregazione era Stefano Cosmi, il biografo del nunzio e cardinal legato in Francia Gianfrancesco Morosini (cfr. supra, nota 31).

92. Per le citazioni sull'attività del Vota a Venezia : A. Barzazi, Gli affanni dell'erudizione... cit., p. 109. Per la sua corrispondenza con Carlo Barberini cardinale protettore di Polonia : G. Platania, Le fonti per la storia dell'Europa orientale: la Polonia e la Santa Sede, in M. Sanfilippo e G. Pizzorusso (dir.), Gli archivi della Santa Sede come fonte per la storia moderna, Viterbo, 2001, p. $176 \mathrm{~s}$.

93. Voltaire, Il secolo di Luigi XIV, Torino, 1994, le citazioni alle p. 21-22.

\section{AUTORE}

\section{ELENA BONORA}

Università degli studi di Parma - ele.bonora@libero.it - elena.bonora@unipr.it 
Organisation du contrôle de l'imprimé 


\title{
La censura ecclesiastica nell'Italia della Controriforma : organismi centrali e periferici di controllo ${ }^{1}$
}

\author{
Gigliola Fragnito
}

1 L'apertura dell'Archivio della Congregazione per la Dottrina della Fede nel 1998 ha segnato, è noto, una profonda svolta negli studi sulla censura ecclesiastica in Italia ${ }^{2}$. L'accesso a una ricchissima e inesplorata documentazione ha permesso di illuminare o di approfondire aspetti della politica della Chiesa nei confronti della produzione editoriale e della sua circolazione fino ad allora poco indagati. Uno dei settori in cui le indagini si sono rivelate più proficue è quello relativo al funzionamento della macchina censoria. Grazie all'abbondanza delle fonti è stato possibile delineare le varie fasi dell'organizzazione centrale e periferica del controllo librario e illustrare le ricadute che la complessa costruzione di apparati repressivi ebbe sull'applicazione delle norme censorie. Prima di quella data, infatti, diversamente dall'assetto e dall'attività dell'Inquisizione che potevano essere tracciati nelle loro linee essenziali attraverso la documentazione conservata negli archivi periferici italiani ${ }^{3}$, la possibilità di ricostruire gli apparati censori e il loro funzionamento era preclusa ai ricercatori che dagli archivi locali o esteri potevano ricavare solo notizie frammentarie, inadeguate a fornire, al di là di importanti dati su opere e autori proibiti, un quadro complessivo del sistema di controllo della stampa e della sua circolazione messo in atto da Roma all'indomani della frattura confessionale $^{4}$. Inoltre, diversamente dall'archivio del Sant'Ufficio, le perdite subite da quello dell'Indice sembrano assai più limitate ${ }^{5}$. Queste due circostanze hanno indubbiamente contribuito alla ripresa di studi che dopo i lavori pionieristici degli anni Settanta di Antonio Rotondò, John Tedeschi, Pasquale Lopez, Paul Grendler, Carlo de Frede $^{6}$, avevano attraversato una lunga fase di stallo. Non sono certo mancati importanti e puntuali contributi nell'ultimo trentennio del Novecento, ma essi hanno privilegiato lo studio della diffusione e della soppressione delle opere che veicolavano dottrine teologiche reputate ereticali, lasciando nell'ombra sia altri ambiti della cultura sui quali si 
abbatté la censura, sia i modi e i tempi di predisposizione di apparati centrali e periferici finalizzati alla vigilanza sulla stampa.

2 Ed è su quest'ultimo aspetto che intendo soffermarmi, premettendo che descrivere gli apparati centrali e periferici deputati alla censura ecclesiastica non è, sul piano espositivo, impresa facile ${ }^{7}$. Infatti, le origini e l'evoluzione del sistema centrale e periferico di controllo della circolazione libraria, messo in piedi dalla Chiesa per fare fronte alla penetrazione delle dottrine riformate in Italia, sono intimamente intrecciate con due problemi, pur non identificandosi necessariamente con essi. Il primo, che si colloca a livello centrale, è quello della redazione degli indici universali dei libri proibiti. Il secondo, che tocca il livello locale, è quello della ripartizione delle competenze in materia di controllo librario tra ordinari diocesani e inquisitori. Questi due problemi, strettamente legati alla rivendicazione da parte del Sant'Ufficio dell'esercizio di un ruolo egemone in materia di censura, condizioneranno in maniera determinante la nascita, la crescita e il funzionamento del sistema censorio.

3 Alla vigilia della diffusione delle dottrine protestanti la Chiesa di Roma disponeva soltanto di un sistema di controllo decentralizzato. La bolla di Leone X Inter sollicitudines del 1515 affidava la censura preventiva - ossia il rilascio dell'imprimatur - congiuntamente ai vescovi e agli inquisitori in tutte le diocesi, con l'eccezione di Roma e del suo distretto, che ricadevano sotto la giurisdizione del Maestro del Sacro Palazzo ${ }^{8}$. In assenza di organi censori centrali, fino alla creazione della Congregazione del Sant'Ufficio del 1542 i Maestri, in quanto teologi pontifici, svolsero una funzione rilevante nell'esame e nella condanna di opere reputate eretiche ${ }^{9}$.

Sebbene la bolla istitutiva - la Licet ab initio - non avesse attribuito all'Inquisizione competenze in materia censoria, fin dal 1543 essa aveva incluso nel suo raggio di azione la vigilanza sulla circolazione libraria - strumento, d'altro canto, indispensabile all'estirpazione dell'eresia - e aveva emanato un editto (la cui rilevanza è testimoniata dalla presenza di una sua copia in apertura degli Acta et Decreta della Congregazione dell'Indice) che incaricava propri delegati di ispezionare biblioteche pubbliche e private, botteghe di tipografi e librai, case private, chiese e monasteri e di sequestrare e bruciare $\mathrm{i}$ libri proibiti rinvenuti ${ }^{10}$. Estromettendo i vescovi dal controllo sulla stampa, in violazione delle norme contenute nella bolla del 1515, il Sant'Ufficio aveva, quindi, fin dai suoi esordi, manifestato la volontà di sostituirsi ad essi, aprendo un contenzioso che avrebbe segnato a lungo i rapporti tra ordinari diocesani e inquisitori ${ }^{11}$. Inoltre, a riprova della sua volontà di annettersi la giurisdizione sulla materia libraria, nel 1549 aveva affidato al Maestro del Sacro Palazzo la redazione di un indice dei libri proibiti. Fallito questo primo tentativo, fu la stessa Congregazione - con il forte appoggio dell'allora regnante Paolo IV Carafa - ad assumersi il compito di redigere il primo indice universale dei libri proibiti, che verrà promulgato il 30 dicembre del 1558 con un proprio decreto ${ }^{12}$.

5 La nota severità delle proibizioni, la totale estromissione degli ordinari diocesani dall'esecuzione dell'indice, la gravità delle pene comminate ai rei, che agì da forte deterrente alla consegna dei libri, l'opposizione delle autorità civili costituirono un ostacolo pressoché insormontabile all'applicazione del primo catalogo. Inoltre, la morte di Paolo IV nell'agosto del 1559 e l'ascesa al papato di Pio IV contribuirono al suo affossamento.

6 Determinato a contrastare la posizione di preminenza del cardinale Michele Ghislieri che del primo indice era stato l'artefice, Pio IV sfruttò abilmente le durissime resistenze contro il catalogo per colpire l'esorbitante potere del cardinale. Non contento di averlo 
costretto a pubblicare nel 1561 la Moderatio indicis, che reintegrava i vescovi nelle loro competenze, il papa si rivolse al Concilio, allora riunito a Trento, inizialmente perché rivedesse l'indice del 1558, successivamente perché ne redigesse uno nuovo. Questa decisione, foriera di gravi conflitti ai vertici stessi della Chiesa, avrebbe privato l'Inquisizione fino al 1917 della facoltà di redigere indici.

Il catalogo tridentino, promulgato nel 1564 da Pio IV con la bolla Dominici gregis, presentava rispetto al precedente sia forti elementi di moderazione relativi alle condanne, sia profonde modifiche relative alle modalità di applicazione e introduceva dieci regole generali che disciplinavano la circolazione di alcune categorie di libri. I vescovi, che lo avevano redatto, si attribuirono funzioni rilevanti nell'esecuzione dell'indice e, in generale, nella gestione del controllo sulla stampa, riservandosi la vigilanza su due importanti settori della produzione editoriale - i libri lascivi e osceni (regola VII) e quelli di astrologia giudiziaria, magia e divinazione (regola IX) - e condividendo con gli inquisitori la competenza su alcune delle altre categorie di opere comprese nelle regole generali, tra le quali le traduzioni della Sacra Scrittura e i libri di controversia religiosa nelle lingue vernacolari. Inoltre, rispetto all'indice inquisitoriale, le pene comminate ai trasgressori erano fortemente attenuate. Infatti il decreto anteposto al primo indice estendeva ai detentori di qualsiasi libro proibito le sanzioni della bolla In coena Domini contro chi avesse letto o tenuto scienter libri di eretici ed eresiarchi e stabiliva che i rei potessero essere assolti solo dal pontefice o dai suoi delegati, vale a dire dagli inquisitori. Pio IV, di fronte alle generali proteste, aveva ripristinato lo ius commune, formulando un fondamentale distinguo tra opere di autori eretici o sospetti di eresia e opere proibite, ma non ereticali, e stabilendo una gerarchia della gravità dei reati non prevista nell'indice del 1558. Mentre lettori e detentori delle opere appartenenti alla prima categoria incorrevano ipso iure nella scomunica e contro di loro sarebbe stato lecito procedere giudizialmente per sospetto di eresia e comminare le penesuper hoc ab Apostolica Sede, sacrisque Canonibus constitutas ; lettori e detentori delle opere afferenti alla seconda si sarebbero macchiati di reato-peccato mortale e sarebbero stati severamente puniti Episcoporum arbitrio. La discriminazione tra libro eretico e libro proibito non eretico, oltre a costituire un forte segnale di moderazione, sottometteva alla giurisdizione vescovile ed esclusivamente ad essa la maggior parte dei rei ${ }^{13}$. È indubbio che fu anche questo dispositivo, che gli sottraeva il controllo su gran parte dei reati connessi alla lettura, a indurre il Sant'Ufficio a imboccare la via della progressiva annessione di materie di competenza della giurisdizione ordinaria o condivise con essa : dai libri di astrologia, alle traduzioni della Sacra Scrittura, ai libri di controversia religiosa nelle lingue vernacolari ${ }^{14}$.

8 Con l'elezione di Michele Ghislieri, nel 1566, tornò sulla cattedra di Pietro l'intransigenza di Paolo IV, dal quale era stato creato cardinale e nominato summus inquisitor ${ }^{15}$. Proveniente dall'apparato inquisitoriale, Pio V non tardò a sottoporre a radicale revisione l'operato dei vescovi e a riaffermare la preminenza dell'Inquisizione sul Concilio in materia di definizione dell'ortodossia e della moralità e non esitò a procedere in maniera alquanto surrettizia al ripristino dei divieti del 1558. Solo nel 1571, sul volgere del pontificato, accantonati gli scrupoli nei confronti dello smantellamento della legislazione conciliare $^{16}$, affidò la revisione del catalogo in vigore a una commissione cardinalizia, che l'anno dopo Gregorio XIII trasformò con la bolla Ut pestiferarum opinionum (13 settembre 1572) in Congregazione dell'Indice. 
9 Nasceva un nuovo organo con il compito di rivedere (di fatto inasprire) e aggiornare l'indice tridentino e di correggere le opere sospese donec corrigantur. Sarebbe, però, incauto ritenere che, a seguito della creazione di questo dicastero, tutte le questioni inerenti la censura venissero trattate e decise al suo interno e che i suoi decreti avessero validità giuridica all'esterno. E altrettanto incauto ritenere che la sua istituzione modificasse ipso facto l'organizzazione centrale del sistema di controllo.

10 Composta da un numero variabile di cardinali, affiancati dal Maestro del Sacro Palazzo, da un segretario e dai procuratori degli ordini mendicanti che ne erano tutti membri ex officio, nonché da un numero variabile di consultori, la Congregazione doveva predisporre gli indici dei libri proibiti, stabilendo quali opere o categorie di opere dovessero essere tassativamente vietate e quali sospese in attesa di correzione, nonché procedere all'emendazione dei libri sospesi e alla redazione di un indice espurgatorio. Non diversamente dal Sant'Ufficio, essa cercò nel corso degli anni di ampliare il proprio raggio d'azione, incontrando, però, sempre le resistenze dei cardinali inquisitori. Basti ricordare il fallimento dei tentativi tesi a estendere la propria giurisdizione su autori viventi di cui aveva condannato gli scritti, convocandoli dinanzi a sé e addirittura facendoli ritrattare. Allarmato da iniziative che, se perpetuate, potevano trasformare la Congregazione dell'Indice in un tribunale e farne in pratica un organo concorrenziale, il Sant'Ufficio rivendicò il diritto «de personis cognoscere» e ottenne nel 1599 un vivae vocis oracolo papale che gli riconosceva la giurisdizione sugli autori sospetti o incriminati ${ }^{17}$.

11 È probabile che proprio per evitare questo tipo di sovrapposizioni con l'Inquisizione, la Congregazione dell'Indice non fosse stata autorizzata a dare "pubblicità » ai propri decreti. Questi, infatti, venivano comunicati dal Maestro del Sacro Palazzo, che agiva tanquam commissarius et executor Congregationis, in pratica come una sorta di «braccio » dell'Indice ${ }^{18}$, ed era nel contempo membro ex officio della Congregazione dell'Inquisizione. Infatti, a partire dal 1573, nel suo ufficio cominciarono a essere redatti elenchi di libri proibiti sempre più consistenti, la cui distribuzione venne estesa al di fuori della sua giurisdizione. Intenta per venticinque anni alla laboriosa preparazione del terzo indice universale che verrà promulgato, tra contrasti e conflitti, solo nel 1596, la Congregazione dell'Indice in più occasioni si era vista costretta a intervenire per contenere i crescenti poteri che i Maestri si erano arrogati e controllarne le arbitrarie iniziative. Nel 1583, a seguito delle proteste di un suo membro, il cardinale Gabriele Paleotti, essa riuscì a bloccare la disinvolta redazione e distribuzione fuori Roma di liste di proibizioni non munite della propria preventiva approvazione, e venti anni dopo contestò la validità e l'efficacia degli editti del Maestro fuori dell'Urbe e fuori d'Italia ${ }^{19}$.

12 Non era, però, solo con l'attivismo del Maestro del Sacro Palazzo che doveva fare i conti la nuova Congregazione, ultima arrivata nel campo della censura. Di analoghi interventi era protagonista anche la Congregazione del Sant'Ufficio, le cui competenze in materia di censura non erano state ridefinite dopo l'istituzione del nuovo dicastero. Solo nel 1613, dopo protratte discussioni sulla necessità di razionalizzare un sistema farraginoso di comunicazione delle proibizioni, la Congregazione dell'Indice venne autorizzata da Paolo V a pubblicare e sottoscrivere editti che avrebbero riunito le proprie condanne e quelle pronunciate dall'Inquisizione e dal Maestro del Sacro Palazzo. Nonostante il perdurare di tensioni tra organi centrali, di cui nei primi decenni del Seicento furono protagonisti soprattutto il segretario della Congregazione dell'Indice e il Maestro del Sacro Palazzo ${ }^{20}$, in linea di massima questa nuova sistemazione era destinata a durare fino alla metà del Settecento. Il che non vuole dire che in questo lungo arco di tempo il 
Sant'Ufficio si sia astenuto dall'emanare decreti di condanna. Anzi, proprio per ovviare alla confusione di proibizioni della medesima opera rese note in tempi diversi dalle due Congregazioni, Benedetto XIV con la costituzione Sollicita ac provida (9 luglio 1753) limitò l'intervento del Sant'Ufficio alle sole materie gravioris momenti. Con questo provvedimento egli intese - come scrisse al cardinale Angelo Maria Querini nel dicembre del 1740 - «rimettere la riputazione di quella poco accreditata Congregazione dell'Indice $»^{21}$. Una "riputazione » di cui, peraltro, essa aveva goduto solo negli anni di applicazione del catalogo clementino, ma che si era presto esaurita se già nell'aprile del 1615 il cardinale Paolo Camillo Sfondrati, allora Prefetto, scriveva al Bellarmino di preferire di occuparsi della sua diocesi di Albano, avendogli:

la esperienza [...] mostrato che si fa tanto poco in questa Congregatione dell'Indice per varii rispetti che Vostra Signoria Illustrissima colla molta prudenza sua haverà considerato, che mi pare al fine che né questa né altra Congregatione mi habbia da levare, per quanto si può, dalla residenza ${ }^{22}$.

13 Il declino dell'istituzione era solo in parte il risultato della politica espansionistica dell'Inquisizione sia al centro che in periferia ${ }^{23}$. Il suo prestigio si era appannato anche in conseguenza del fallimento dell'attività espurgatoria che può essere emblematicamente riassunto nel ritiro del primo e unico tomo dell'index expurgatorius apparso nel 1607 ad opera di Giovanni Maria Guanzelli, detto Brisighella dal luogo di nascita ${ }^{24}$.

14 La riforma di papa Lambertini, di cui di recente è stata messa in discussione la moderazione $e^{25}$, giungeva, comunque, troppo tardi. Di fronte all'aggressiva campagna degli Stati regionali della penisola tesa a sottoporre al controllo delle autorità civili la produzione editoriale e ad affidare ai vescovi la vigilanza esclusivamente sui libri religiosi e al conseguente indebolimento o alla soppressione - fuori dello Stato pontificio - dei tribunali inquisitoriali, i provvedimenti di Benedetto XIV si rivelarono del tutto inadeguati ad arrestare il flusso di scritti dei philosophes e a perpetuare la presa della Chiesa su menti e coscienze sempre più lambite dalla secolarizzazione. Le condanne, chiunque le pronunciasse, non trovavano più « bracci secolari » disponibili a eseguirle e il papato dovette sempre più fare ricorso a brevi ed encicliche per mobilitare $\mathrm{i}$ vescovi contro la cultura dei Lumi e la politica giurisdizionalista degli Stati ${ }^{26}$.

Prima di passare a esaminare le strutture censorie periferiche, vorrei riepilogare l'articolazione del sistema censorio romano, che si è venuto faticosamente costruendo nell'arco di circa ottant'anni e che nel secondo decennio del Seicento può dirsi in qualche modo assestato, pur se tensioni e conflitti di competenza continueranno a manifestarsi anche in futuro ${ }^{27}$. Gli organi censori stabili sono tre: la Congregazione dell'Inquisizione che continua a svolgere un ruolo rilevante nella condanna dei libri (anche se rimangono da individuare $\mathrm{i}$ criteri in base ai quali un'opera veniva assegnata all'esame dell'Inquisizione piuttosto che a quello dell'Indice e viceversa), che rilascia permessi di lettura, che controlla l'applicazione dei divieti sul territorio attraverso la sua rete di tribunali ; la Congregazione dell'Indice che, dopo un breve periodo in cui ha cercato di sostituirsi alla Congregazione "rivale » nel coordinamento dell'esecuzione dell'indice in periferia, è costretta a rientrare nei ranghi e a occuparsi esclusivamente di aggiornamento degli indici, di stesura di nuovi indici, di espurgazione di testi sospesi, e di esame di opere che le vengono segnalate o sottoposte in quanto sospette ; infine, il Maestro del Sacro Palazzo che, dopo aver esercitato con un certo arbitrio la funzione di 
commissario ed esecutore della Congregazione dell'Indice e avere ampiamente travalicato i confini della propria giurisdizione, viene richiamato nel 1613 al loro rispetto, salvo ottenere nel 1620 per delega della Congregazione dell'Inquisizione l'estensione delle proprie competenze in materia libraria alle diocesi della Provincia romana, competenze da esercitare insieme con i vescovi ${ }^{28}$.

Appare superfluo osservare che l'esistenza di questa pluralità di organi curiali, dalle sfere d'intervento poco definite, era fonte di permanenti tensioni e di frequenti veri e propri scontri. Questa conflittualità al centro aveva inevitabili ripercussioni sull'organizzazione periferica della censura, oltre a tradursi sul piano della prassi in direttive contraddittorie e confuse che, se talvolta potevano offrire scappatoie ai detentori di libri proibiti, più spesso provocavano danni irrimediabili ${ }^{29}$. Ed è al territorio che occorre ora volgere l'attenzione per cogliere attraverso i problemi sollevati dall'esecuzione dei primi tre indici romani $(1558,1564,1596)$ i riflessi dei mutamenti delle strategie e degli equilibri di potere in seno agli uffici centrali.

$\mathrm{Fu}$ in effetti soprattutto al momento dell'esecuzione degli indici che emerse in tutta la sua concretezza la questione se la gestione della censura sul territorio dovesse essere condivisa da vescovi e inquisitori o di competenza della sola Inquisizione. Vivacemente quanto a lungo astrattamente dibattuta negli uffici romani, essa dovette infatti fare $\mathrm{i}$ conti con l'effettiva disponibilità di strutture, di uomini, di mezzi economici. Ciò fu chiaro fin dall'esecuzione del primo indice del 1558. In quell'occasione la debolezza della rete dei tribunali della fede - che si consoliderà solo nel corso degli anni Ottanta del Cinquecento e solo nell'Italia centro-settentrionale - e la carenza e inadeguatezza di giudici ecclesiastici addestrati alla vigilanza sulla circolazione libraria, rese l'emarginazione degli ordinari diocesani del tutto velleitaria, se già nel febbraio del 1559 il Sant'Ufficio si vide costretto, con la Instructio circa Indicem, a coinvolgerli, quantomeno nelle zone dove non vi erano inquisitori delegati o commissari in missione, e se Paolo IV dovette concedere ampi privilegi ai gesuiti perché collaborassero alla confisca dei libri ${ }^{30}$. Nonostante questi cedimenti, l'esecuzione dell'indice paolino sembra essere stata tutt'altro che capillare e uniforme. D'altro canto, se si considera che ci vollero all'incirca otto anni perché l'opera di sequestro e distruzione dei libri proibiti seguita alla promulgazione dell'indice del 1596 potesse dirsi compiuta, è facile desumere che i nove mesi che intercorsero tra la promulgazione dell'indice (dicembre 1558) e la morte di Paolo IV (agosto 1559) fossero un lasso di tempo troppo breve perché potesse essere portata a termine in maniera estensiva l'opera di rastrellamento degli scritti vietati. L'assenza di precedenti che potessero orientare l'azione degli esecutori, la fragilità dell'assetto inquisitoriale, l'opposizione o al più la scarsa collaborazione delle autorità civili, e soprattutto la severità delle pene previste per i trasgressori costituirono, come accennato, un grave ostacolo. Infatti, pur di consolidare e ampliare il controllo sulle coscienze e sulle menti dei credenti e sottrarlo agli ordinari diocesani, la Congregazione dell'Inquisizione aveva esteso la propria giurisdizione sui lettori di qualsiasi libro proibito - e non solo dei libri eretici comminando la scomunica della bolla In coena Domini anche a chi avesse letto, per fare alcuni esempi, il Morgante del Pulci, i Capricci del bottaio del Gelli, il Decameron di Boccaccio, il Nuovo Testamento in volgare, o una qualsiasi opera di Erasmo.

$18 \mathrm{Fu}$ questa estensione della scomunica a lettori di qualsiasi libro vietato a suscitare, all'indomani della morte del Carafa, forti proteste e a spingere il generale dei gesuiti Diego Laínez e i Legati al Concilio di Trento a chiedere un intervento del nuovo papa, Pio $\mathrm{IV}^{31}$. Onde piegare la riluttanza dei trasgressori a presentarsi al cospetto dei giudici 
per la consegna dei libri e ovviare alla difficoltà di reperire questi ultimi, il pontefice impose al Ghislieri di preparare una Moderatio indicis, che venne pubblicata il 14 giugno 1561. Il documento interveniva sulla scottante questione dell'assoluzione dalla scomunica : agli inquisitori, soli autorizzati ad assolvere nel foro esterno, Pio IV affiancò gli ordinari diocesani con facoltà di delega dei loro poteri e autorizzò gli uni e gli altri ad assolvere in utroque foro coloro che avessero letto o tenuto libri che in forza della Moderatio potevano essere tollerati, purché si dichiarassero disposti a ubbidire in futuro.

di promulgazione dell'indice tridentino, ripristinando lo ius commune, come si è detto, sottometteva alla giurisdizione ordinaria ed esclusivamente a essa la maggior parte dei rei. Se questa normativa, che si prefiggeva di bloccare il tentativo del Sant'Ufficio di sostituirsi completamente all'episcopato nella gestione della censura libraria, abbia trovato concreta attuazione è difficile dire dal momento che anche dell'applicazione dell'indice tridentino si hanno scarsissime notizie e che è difficile verificare l'efficacia dei richiami degli ordinari all'osservanza dei divieti nei decreti sinodali (diocesani e provinciali) o durante le visite pastorali. È, però, ipotizzabile che l'applicazione sia stata tutt'altro che uniforme, considerando quella che appare una totale assenza di coordinamento centrale.

Né sembrano esservi stati nei trentadue anni che separano la promulgazione del secondo indice da quella del terzo (1596) interventi coerenti del centro per dare alla macchina censoria locale un andamento regolare e uniforme. Di fatto affidato allo zelo o all'arbitrio dei singoli inquisitori, il controllo sulla stampa in quel periodo appare episodico, anche se tutt'altro che blando, come testimoniano, tra l'altro, gli stessi inquisitori nel rievocare, al momento dell'esecuzione dell'indice clementino, i precedenti roghi ${ }^{32}$. È, quindi, lecito chiedersi se questi interventi conseguissero risultati estensivi e omogenei e se le condanne di opere pronunciate dopo il 1573, cui si è accennato, spesso formulate con poca chiarezza e in aperto contrasto con l'indice tridentino in vigore ${ }^{33}$, abbiano trovato rigorosa applicazione. La densa presenza tra i libri sequestrati a fine Cinquecento di opere da tempo proibite induce a ipotizzare che in quel periodo le direttive romane abbiano influito in maniera tutt'altro che uniforme sulla prassi censoria quotidiana ${ }^{34}$.

$21 \mathrm{Fu}$, del resto, la palese inadeguatezza del sistema di controllo vigente a spingere la Congregazione dell'Indice a fine secolo a proporne una riorganizzazione e una razionalizzazione. Una proposta che, ove accolta, le avrebbe consentito di uscire dalla posizione sostanzialmente defilata fino ad allora occupata e di sostituirsi al Sant'Ufficio nella direzione dell'esecuzione del primo indice di cui era responsabile. Guidata nell'ultima fase dei travagliatissimi lavori preparatori dell'indice clementino da grandi porporati, pastori di importanti diocesi italiane, che avevano sostituito la prima generazione di « censori » appartenenti prevalentemente agli ordini regolari e orientati sulle posizioni del Sant'Ufficio, la Congregazione dell'Indice intese chiaramente riequilibrare a favore dell'episcopato l'invadente potere dell'Inquisizione. Lo fece anzitutto ripristinando nella sua integrità l'indice tridentino, cui in appendice vennero aggiunte le nuove condanne, e riproponendo la linea di rivalutazione dei poteri e delle prerogative episcopali già perseguita a Trento - in particolare dalla commissione che aveva preparato l'indice -, ma vanificata nel corso degli anni dai papi-inquisitori inclini a trasferire ai giudici della fede e agli ordini regolari settori importanti della pastorale ${ }^{35}$.

Nel 1592 i cardinali avevano, inoltre, ottenuto da Clemente VIII, sul modello della Congregazione del Concilio, la facoltà di dirimere le controversie e di sciogliere i dubbi che fossero sorti durante l'applicazione dell'indice. Questa facoltà, che conferiva loro 
nuovi margini di intervento sul territorio ${ }^{36}$, non fu, peraltro, l'unico strumento che avrebbe permesso loro di pilotare e di coordinare l'attività censoria. Sostenuti da Clemente VIII Aldobrandini, pontefice che non proveniva dalle file della Congregazione del Sant'Ufficio e che era altrettanto desideroso di contenerne l'egemonia, essi cercarono con lucida determinazione di cogliere quell'occasione unica per insediarsi stabilmente nel territorio mediante l'istituzione nelle diocesi di congregazioni dell'indice «locali». Presiedute dagli ordinari, queste diramazioni del dicastero centrale avrebbero dovuto riunirsi con regolarità nel palazzo vescovile per attendere con l'aiuto di consultori laici ed ecclesiastici dalle varie competenze disciplinari all'esecuzione dell'indice: vale a dire, nell'immediato, vagliare le liste dei libri o i libri consegnati, distinguendo tra quelli vietati e quelli sospesi in attesa di espurgazione; mandare al rogo i primi e provvedere, in un secondo tempo, alla correzione dei secondi ; incaricarsi della censura preventiva e della vigilanza sulla penetrazione nei territori sotto la loro giurisdizione di opere sospette o vietate. Nelle aree dove erano presenti tribunali della fede questi nuovi organismi dovevano essere per composizione e per finalità da essi distinti e autonomi e l'inquisitore ne avrebbe fatto parte, ma in una posizione di subordinazione all'ordinario ${ }^{37}$.

Alla base di questo progettato riassetto, che faceva perno sugli ordinari, non vi era, tuttavia, solo una strategia di ridimensionamento del Sant'Ufficio : a suggerirlo vi erano anche ragioni pratiche. I cardinali dell'Indice le esposero a Clemente VIII agli inizi del 1597 in un'interessante documento che elencava le motivazioni a sostegno dell'attribuzione ai vescovi di un ruolo preminente in materia di censura ${ }^{38}$. Al di là del richiamo al Concilio di Trento e al fatto che aveva affidato «Episcopis praesertim munus executionis Indicis » - un richiamo che accompagnerà tutte le fasi di esecuzione del terzo indice universale -, le loro considerazioni si fondavano su presupposti di carattere sia pastorale che pratico. I cardinali ritenevano che ai vescovi competesse il controllo sulla stampa. Ai loro occhi era il vescovo a conoscere optime quae suo gregi sunt necessaria et oportuna ed era quindi dinanzi a lui e presso la sua curia, piuttosto che presso l'inquisitore, che le congregazioni locali dovevano essere convocate, mantenendo anche fuori Roma la distinzione esistente a livello centrale tra Congregazione dell'Indice e Congregazione dell'Inquisizione. Inoltre, i cardinali sottolineavano che gli ordinari erano graves, maturi et eruditi e osservavano con concreto realismo che erano meno soggetti a trasferimenti e più fittamente presenti sul territorio degli inquisitori, i quali rari sunt et longe lateque in diversis Urbibus et dioecesibus suam exercent delegationem apostolicam. A differenza degli inquisitori - osservavano i cardinali - i vescovi disponevano di strutture amministrative adeguate (curiam et ministros et officinas) ${ }^{39}$. Di conseguenza i libri sequestrati non dovevano essere trasferiti dalle singole diocesi al tribunale dell'inquisizione, la cui giurisdizione spesso si estendeva su dodici e più diocesi, né dovevano essere mandati al rogo nel chiostro o sul sagrato della chiesa del convento che ospitava l'inquisitore, ma pubblicamente e alla presenza di un notaio davanti alla cattedrale. Anche i libri espurgabili non dovevano essere depositati presso gli inquisitori, bensì presso il vescovo in luogo sicuro.

24 Al di là dei toni sottilmente polemici nei confronti degli inquisitori, i cardinali toccavano il vero nocciolo della questione: sarebbe stato possibile nell'Italia di fine Cinquecento applicare la normativa censoria in maniera sistematica e rigorosa appoggiandosi unicamente alle strutture inquisitoriali? In altri termini : in che misura le pretese del Sant'Ufficio di monopolizzare la censura rischiavano di pregiudicare un più efficace controllo sulla circolazione del libro? 
Dall'esame dell'articolazione territoriale dei tribunali risulta che la diagnosi dei cardinali rifletteva una oggettiva realtà : a fine secolo l'Inquisizione romana era tutt'altro che uniformemente presente in Italia. Assente dalla Sicilia e dalla Sardegna, sotto la giurisdizione dell'Inquisizione spagnola ${ }^{40}$, nel Regno era presente solo a Napoli con un commissario $^{41}$. Anche nell'area centro-settentrionale la rete dei suoi insediamenti era lungi dall'essere capillare, sebbene negli anni Ottanta si fosse consolidata. I 41 tribunali operanti negli anni di applicazione dell'indice clementino non coprivano uniformemente l'intero territorio ${ }^{42}$. Più fitti nelle zone subalpine dove, per preservare la penisola dalla produzione editoriale d'oltralpe, era stata eretta una barriera che andava dal Piemonte al Friuli, si diradavano al centro fino a ridursi a cinque nello Stato pontificio ${ }^{43}$. Questa dislocazione rispecchiava, però, una strategia relativamente chiara. I tribunali, infatti, erano stati insediati sia in zone dove i rischi di infiltrazioni eterodosse erano più alti, come l'arco alpino, sia in città dove la presenza di università, accademie, tipografie, botteghe di librai, rendeva più vivace l'attività intellettuale e maggiori i pericoli di fermenti culturalmente e religiosamente sospetti. Le aree "scoperte» coincidevano perlopiù con zone culturalmente depresse, dove la maggior minaccia all'ortodossia veniva dalle «superstizioni », verso le quali la Chiesa condusse una tiepida battaglia. Questa situazione comportava che, mentre in alcune zone la giurisdizione inquisitoriale coincideva con quella ordinaria, in altre abbracciava aree vastissime, come del resto rilevavano i cardinali. Per fare solo qualche esempio: Perugia controllava 11 diocesi, Faenza 8, Siena $7^{44}$.

Di fronte a questo assetto inquisitoriale a maglie larghe la scelta di privilegiare le istituzioni diocesane (che nella sola Italia continentale si aggiravano intorno a trecento) ${ }^{45}$, sulla quale insistevano i cardinali, era una scelta quasi obbligata se si volevano garantire un'applicazione uniforme dell'indice, un più capillare controllo della circolazione libraria dopo la sua esecuzione e l'espurgazione delle opere sospese. Fu questa in effetti la strada imboccata dopo la promulgazione del terzo indice romano. Ma fu una strada irta di ostacoli.

Fin dalla prima fase relativa al sequestro dei libri proibiti e sospesi emerse nitidamente l'opposizione dell'Inquisizione a quello che si configurava come un tentativo di esautorazione dei suoi ministri. A questi giunsero immediate istruzioni di farsi consegnare dai vescovi i libri sequestrati, di procedere all'incenerimento di quelli proibiti dinanzi ai loro conventi e di conservare nei loro depositi quelli bisognosi di emendazione ${ }^{46}$. Non solo : veniva vietato ai vescovi di trattenere presso di sé e di leggere libri proibiti, che dovevano consegnare prontamente all'inquisitore, così come era loro vietato di conservare gli originali manoscritti delle opere cui avevano concesso insieme con l'inquisitore l'imprimatur. Col tempo gli inquisitori si arrogarono anche il diritto di pubblicare confusi aggiornamenti dell'indice clementino non soltanto senza la partecipazione dei vescovi, ma anche senza l'approvazione della Congregazione dell'Indice, che nel 1621 fu costretta a vietare tali autonome iniziative ${ }^{47}$. L'esecuzione dell'indice del $1596 \mathrm{fu}$, quindi, all'origine di un'intensa produzione normativa tesa a ribadire e accentuare la subordinazione dell'episcopato all'Inquisizione e a vanificare il progetto dei cardinali dell'Indice di ridimensionare la funzione di quest'ultima nell'ambito della censura ${ }^{48}$.

Se nella prima fase la controffensiva degli inquisitori nell'Italia centro-settentrionale fu in grado di tarpare le ali ai vescovi, nella seconda fase altri fattori contribuirono al difficile decollo e al rapido declino di un sistema di controllo imperniato su di loro. 
Dimostratisi già nella prima fase assai meno incisivi lì dove erano responsabili della tutela della fede, come in gran parte dello Stato pontificio e nel Regno di Napoli ; nella seconda fase, in cui la censura espurgatoria divenne preponderante, i vescovi palesarono la loro inadeguatezza a coordinare la complessa operazione di recupero di un numero incalcolabile di testi sospesi ${ }^{49}$. $\mathrm{Fu}$, infatti, proprio in funzione del decentramento dell'attività espurgatoria che era stato concepito il disegno di creare uffici periferici, destinati a sopravvivere all'esecuzione del terzo indice. Ma intorno alla loro istituzione nacquero problemi non previsti, né forse prevedibili. Tra i maggiori: la carenza specialmente nei piccoli centri - di persone capaci di correggere opere di varie discipline ; la frequente assenza dei vescovi dalla diocesi e l'insufficiente autorevolezza dei vicari che li sostituivano; la mancata comprensione delle confuse direttive romane; la dichiarata superfluità di tali organi in luoghi « di gente idiote et rozze » ${ }^{50}$ o dove c'erano « pochi libri de vecchi et manco comodità d'haverne de nuovi $»^{51}$; la diffusa convinzione che l'uniformità delle correzioni potesse essere garantita solo dagli uffici centrali. Rari, quindi, gli ordinari che, ubbidendo alle reiterate istruzioni romane $e^{52}$, attivarono le congregazioni e queste, comunque, funzionarono pressoché ovunque stentatamente. Spesso sospese per gli allontanamenti temporanei o prolungati degli ordinari al servizio della Santa Sede, per le inadempienze di revisori poco solerti perché non remunerati, per l'ostruzionismo degli inquisitori ${ }^{53}$, le riunioni assunsero andamento irregolare e presto non vennero più convocate.

L'idea di decentrare l'attività espurgatoria e di puntare sull'impegno dei vescovi si rivelò presto fallimentare. L'edificio che i cardinali dell'Indice avevano costruito per affrancare la censura dal Sant'Ufficio e affiancarsi sul territorio ai tribunali inquisitoriali con proprie, autonome strutture deputate al controllo della stampa si andò lentamente sgretolando. L'attività espurgatoria venne ricondotta negli uffici romani e affidata al Maestro del Sacro Palazzo, il quale - come si è detto - nel 1607 produsse le correzioni di cinquantacinque opere pubblicate da cinquanta autori ${ }^{54}$. Lo scarso rigore con cui venne redatto il primo tomo dell'index expurgatorius non soltanto fu causa del suo ritiro, ma anche della mancata prosecuzione dell'opera. Nonostante il progetto di pubblicazione di indici espurgatori, annunciato già nell'indice tridentino, non fosse stato mai ufficialmente abbandonato $0^{55}$, esso si arenò tra la sostanziale diffidenza dei cardinali a fornire uno strumento che avrebbe potuto orientare l'attenzione dei lettori su brani 'perniciosi' e le profonde divergenze e rivalità che opposero consultori e revisori nella loro grande maggioranza appartenenti agli ordini regolari e spesso di diversa formazione teologica ${ }^{56}$.

Esaurita l'azione di coordinamento del sequestro e della distruzione dei libri proibiti - che condusse con esiti di rara efficacia - la Congregazione dell'Indice riesumò sostanzialmente la sua funzione di compilatrice di indici. La corrispondenza con vescovi e inquisitori si diradò già sul finire del primo decennio del Seicento, mentre s'infittì la comunicazione, peraltro mai interrotta, tra Sant'Ufficio e inquisitori locali in materia di censura. La sconfitta del progetto della Congregazione dell'Indice - progetto che aveva trovato nell'applicazione dell'indice clementino il suo banco di prova - sanciva definitivamente l'egemonia del Sant'Ufficio nel campo della censura, ma anche la subalternità del vescovo all'inquisitore, depotenziando ulteriormente l'episcopato e relegandolo, dopo decenni di contrasti, in quella posizione di emarginazione in cui il Sant'Ufficio lo aveva confinato fin dal 1543. Occorrerà attendere la seconda metà del Settecento perché, di fronte alla più risoluta azione delle autorità statali in difesa delle proprie prerogative giurisdizionali e all'indebolimento delle strutture inquisitoriali fuori 
dello Stato della Chiesa, i papi si rassegnassero a fare ricorso all'aiuto dei vescovi per combattere la cultura dei Lumi restituendo loro le competenze che il Concilio di Trento aveva loro conferito ${ }^{57}$.

\section{NOTE}

1. Abbreviazioni : ILI : Index des livres interdits, a cura di J.M. De Bujanda, SherbrookeGenève, 10 voll., 1984-1996 ; ACDF : Archivio della Congregazione per la Dottrina della Fede (ex Sant'Ufficio) ; Index : Archivio della Congregazione dell'Indice (la numerazione romana indica le serie, quella araba i volumi all'interno delle serie) ; SO: Archivio della Congregazione del Sant'Ufficio ; St. St. : Stanza Storica ; ARSI : Archivum Romanum Societatis Iesu ; BAV : Biblioteca Apostolica Vaticana.

2. Cfr. G. Fragnito, Gli studi sulla censura ecclesiastica nella prima età moderna: bilanci e prospettive, in L. Gulia, I. Herklotz, S. Zen (a cura di), Società, cultura e vita religiosa in età moderna. Studi in onore di Romeo De Maio, Sora, 2009, p. 163-176.

3. Si veda in proposito l'importante studio di A. Prosperi, Tribunali della coscienza. Inquisitori, confessori, missionari, Torino, 1996, pubblicato prima di quella data.

4. Cfr. J.A. Tedeschi, Florentine documents for a history of the 'Index of Prohibited Books', in A. Molho e J. A. Tedeschi (a cura di), Renaissance Studies in Honor of Hans Baron, Dekalb, Ill., 1971, p. 577-605 (ora in traduzione italiana in J. Tedeschi, Il giudice e l'eretico. Studi sull'Inquisizione romana, Milano, 1991, p. 161-179) ; A. Rotondò, Nuovi documenti per la storia dell' « Indice dei libri proibiti » (1572-1638), in Rinascimento, 2 ${ }^{\text {a }}$ s., 3, 1963, p. 145-211.

5. A. Cifres, L'archivio storico della Congregazione per la Dottrina della Fede, in L'apertura degli Archivi del Sant'Uffizio Romano, Roma, 1998, p. 73-84.

6. A. Rotondò, Nuovi documenti... cit. ; Id., La censura ecclesiastica e la cultura, in Storia d'Italia, V, I documenti, Torino, 1973, p.1397-1492 ; J.A. Tedeschi, Florentine documents... cit.; P. Lopez, Inquisizione stampa e censura nel Regno di Napoli tra '500 e '600, Napoli, 1974; P.F. Grendler, The Roman Inquisition and the Venetian Press, 1540-1605, Princeton, 1977, e C. de Frede, Ricerche per la storia della stampa e la diffusione delle idee riformate nell'Italia del Cinquecento, Napoli, 1985.

7. Cfr. G. Fragnito, La Bibbia al rogo. La censura ecclesiastica e $i$ volgarizzamenti della Bibbia (1471-1605), Bologna, 1997 ; Ead., Proibito capire. La Chiesa e il volgare nella prima età moderna, Bologna, 2005 ; e V. Frajese, Nascita dell'Indice. La censura ecclesiastica dal Rinascimento alla Controriforma, Brescia, 2006. Sulla censura statale ed ecclesiastica si vedano M. Infelise, I libri proibiti da Gutenberg all'Encyclopédie, Roma-Bari, 1999, e S. Landi, Stampa, censura e opinione pubblica in età moderna, Bologna, 2011, p. 71-98.

8. Per quanto riguarda l'imprimatur rare sono le opere a stampa che prima degli anni Sessanta del Cinquecento registrano l'avvenuta approvazione delle autorità ecclesiastiche. In proposito cfr. U. Rozzo, Gli « Hecatommithi » all'Indice, in La Bibliofilia, 92, 1991, p. 26-31. 
9. Sulle competenze e la giurisdizione del Maestro del Sacro Palazzo cfr. V.M. Fontana, Syllabus Magistrorum Sacri Palatii Apostolici, Romae, 1663 ; Id., Sacrum theatrum dominicanum, Romae, 1666, p. 447-51 ; G.B. De Luca, Theatrum veritatis, et justitiae, XV, Venetiis, 1734, pp. 245-46, 267-68, 278 ; G. Catalano, De magistro Sacri Palatii Apostolici Libri duo. Quorum alter originem, praerogativas, ac munia, alter eorum Seriem continet, qui eo munere ad hanc usque diem donati fuere, Romae, 1751 ; G. Moroni, s.v. Maestro del Sacro Palazzo, in Dizionario di erudizione storico-ecclesiastica, XLI, Venezia, 1846, p.199-219 ; I. Taurisano, Hierarchia ordinis fratrum praedicatorum, Romae, $1916^{2}$, p. 30-63, e G. Fragnito, Un archivio conteso: le «carte » dell'Indice tra Congregazione e Maestro del Sacro Palazzo, in Rivista storica italiana, 119, 2007, p. 1276-1318. I confini del distretto di Roma sono indefiniti, anche se per solito esso viene fatto coincidere con la fascia delle 40 miglia, ma non mancano definizioni diverse, anche più ampie. Si veda G. Pizzorusso, Una regione virtuale : il Lazio da Martino V a Pio VI, in Atlante storico-politico del Lazio, Roma-Bari, 1996, p. 80-81.

10. Cfr. J. Hilgers, Der Index der verbotenen Bücher in seiner neuen Fassung dargelegt und rechtlich-historisch gewüdigt, Freiburg im Breisgau, 1904, p. 483-486. L'editto si conserva in copia in ACDF, Index, I/1, fol. nn.

11. Cfr. G. Fragnito, La censure des livres entre évêques et inquisiteurs, in G. Audisio (a cura di), Inquisition et pouvoir, Atti del Convegno Internazionale, Aix-en-Provence, 24-26 ottobre 2002, Aix-en-Provence, 2004, p. 171-184, e Ead., Vescovi « censori » : il tridentino alla prova, in G.P. Brizzi e G. Olmi (a cura di), Dai cantieri della storia. Liber amicorum per Paolo Prodi, Bologna, 2007, p. 25-35.

12. ILI, VIII, p. 27-39.

13. In proposito cfr. G. Fragnito, Proibito capire... cit., p. 29-42.

14. Nella Observatio, aggiunta dal Sant'Ufficio all'indice del 1596, vennero ribadite, sulla linea della bolla contro l'astrologia Coeli et terrae Creator Deus di Sisto V del 5 gennaio 1586, le competenze anche degli inquisitori su questa categoria di libri (cfr. ILI, IX, p. 930). Per quanto riguarda i volgarizzamenti della Sacra Scrittura e i libri di controversia religiosa cfr. G. Fragnito, Proibito capire... cit., p. 81-117 e 177-190.

15. Sulla politica censoria di Pio V cfr. G. Fragnito, Pio V e la censura, in M. Guasco e A. Torre (a cura di), Pio V nella società e nella politica del suo tempo, Bologna, 2005, p. 129-158.

16. Fin dalle prime sedute della commissione cardinalizia nominata per la revisione dell'indice gli scrupoli vennero superati col pretesto che « non fuit Concilium quod Indicem congessit et instituit, sed tantum quosdam delegit quibus haec provincia demandaretur, a quibus postea fuit compositum » e che di conseguenza modificandolo " nihil contra Concilium fieret " (ACDF, Index, II/1, fol. 19 : riunione del 10 luglio 1571).

17. ACDF, Index, I/1, fol.126r. Riunione del 4 dicembre 1599: «Decretum quod [...] si aliquando libri censurandi Auctor adhuc superstis esset et aliqua poena mulctandus ad Congregationem Sancti Officii, cuius est de personis cognoscere remitteretur». Il vivae vocis oracolo stabiliva: "quod Ill.mi et Rev.mi DD.Cardinales pro tempore deputati super Congregatione Indicis habeant amplam et plenam potestatem et facultatem nedum super libros impressos, et imprimendos, suspendendos, prohibendos et corrigendos, permittendos, concedendos, verum etiam super Auctores librorum, et eosdem imprimentes, et legentes, vel personas quomodocunque et qualitercunque Indicis materiam aut libros concernentes, dummodo in causa haeresis nullatenus se intromittant quod, si quandoque id contigat, ad ufficium Sanctae Romanae et Universalis Inquisitionis personas statim transmittant, cuius est in materia haeresis iudicare " (ACDF, Index, I/1, fol. 128v: l'oracolo papale fu riferito alla Congregazione dell'Indice nella 
riunione del 29 gennaio 1600 dal cardinale Cesare Baronio). In proposito cfr. G. Fragnito, Un archivio conteso... cit., p. 1278-1280.

18. Ivi, p. 1281-1282.

19. Sull'espansione delle competenze del Maestro cfr. G. Fragnito, La censura libraria tra Congregazione dell'Indice, Congregazione dell'Inquisizione e Maestro del Sacro Palazzo (1571-1596), in U. Rozzo (a cura di), La censura libraria nell'Europa del secolo XVI, Udine, 1997, p. 163-175

20. Cfr. G. Fragnito, Un archivio conteso... cit., pp. 1276-1318, e E. Rebellato, La fabbrica dei divieti. Gli Indici dei libri proibiti da Clemente VIII a Benedetto XIV, Milano, 2008, p. 78-82.

21. Lettera citata ivi, p. 201. Sulla Sollicita ac provida, cfr. ivi, pp.198-205, e H. Wolf e B. Schmidt (a cura di), Benedikt XIV. und die Reform des Buchzensurverfahrens. Zur Geschichte und Rezeption von « Sollicita ac provida ", Paderborn, 2010.

22. Aggiungeva : «A Roma al fine vi sono molti cardinali nelle Congregationi et lei, tra gli altri [...] in questa Congregatione dell'Indice può supplire a quanto convenga, ma delli vescovi d'Albano ve n'è un solo, da poco et miserabile » (lettera del 24 aprile 1615, cit. da P. Godman, The Saint as Censor. Robert Bellarmine between Inquisition and Index, Leiden, 2000, p. 174).

23. Cfr. G. Fragnito, L'applicazione dell'indice dei libri proibiti di Clemente VIII, in Archivio Storico Italiano, 159, 2001, p. 131-147, e Ead., "In questo vasto mare de libri prohibiti et sospesi tra tanti scogli di varietà et controversie »: la censura ecclesiastica tra la fine del Cinquecento e $i$ primi del Seicento, in C. Stango (a cura di), Censura ecclesiastica e cultura politica in Italia tra Cinquecento e Seicento, Firenze, 2001, p. 1-35.

24. Ivi, p. 20-35, e G. Fragnito, Un archivio conteso... cit., p.1292-1295.

25. Cfr. P. Delpiano, Il governo della lettura. Chiesa e libri nell'Italia del Settecento, Bologna, 2007, p. 80-92.

26. Ivi, p. 75-92 e 155-212.

27. Di scarso aiuto la ricostruzione frammentaria dei rapporti tra le due Congregazioni nel Seicento di M. Cavarzere, La prassi della censura nell'Italia del Seicento tra repressione e mediazione, Roma, 2011, p. 4-27, nonché il rapido profilo di E. Rebellato, La congregazione dell'Indice da Paolo V a Clemente XII (1607-1740), in Dimensioni e problemi della ricerca storica, 1.2012, p. 21-39.

28. La delega venne conferita l'11 giugno 1620 con un Motu proprio di Paolo V edito in V.M. Fontana, Syllabus Magistrorum... cit., p. 11-14, e in G. Catalano, De magistro Sacri Palatii Apostolici... cit., p. 27-28.

29. Cfr. G. Fragnito, L'applicazione dell'indice... cit., p. 131-147 ; Ead., Proibito capire... cit., p. 191-213.

30. Sulla debolezza delle strutture inquisitoriali ai tempi di Paolo IV e sul coinvolgimento dei gesuiti cfr. G. Romeo, Note sull'Inquisizione romana tra il 1557 e il 1561, in Rivista di storia e letteratura religiosa, 36, 2000, p. 115-141 ; Id., L'Inquisizione nell'Italia moderna, Roma-Bari, 2002, pp. 3-12 ; e Id., Pio V nelle fonti gesuite : le 'Epistolae Generalium Italiae' e le 'Epistolae Italiae', in Pio $V$ nella società... cit., p.111-127. Sul ruolo dei gesuiti nell'applicazione dell'indice del 1558 e di quello del 1564 cfr. anche M. Scaduto, L'epoca di Giacomo Lainez, 1556-1565. L'azione, Roma, 1974, p. 22-35 e 245-56.

31. Lettera scritta a nome del Generale a Pietro Canisio, 25 gennaio 1561: «Domandò Nostro Padre la reducione di quel Indice delli libri prohibiti ad ius comune et il papa si mostrò ben inclinato a farlo, ma disse voleva far Congregacione sopra ciò, nella quale 
intervenessi Nostro Padre » (ARSI, Epp. Gen., Germania, 104, fol. 292r). Il 31 gennaio 1561 si ribadiva: "Sopra l'Indice delli libri prohibiti si comincia a trattare et Nostro Padre [Laínez] pensa procurar di ridurlo al ius commune » (ivi, fol. 296v-297r).

32. Cfr. C. de Frede, Roghi di libri ereticali nell'Italia del Cinquecento, in L. De Rosa (a cura di), Ricerche storiche ed economiche in memoria di Corrado Barbagallo, II, Napoli, 1970, p. 317-328, e G. Fragnito, Proibito capire... cit., p. 191-213.

33. L'inquisitore di Pisa chiedeva lumi al card. Scipione Rebiba il 12 aprile 1572 su «quel che in pratica si determini di quelli libri quali sono prohibiti per l'indice del Santo Officio et non prohibiti per l'indice del Santo Concilio » (ACDF, SO, St. St. HH $2 \mathrm{~d}$ (1), fol. 226r-v).

34. Sotto questo profilo rivestono grande interesse le osservazioni di Antonio Possevino, risalenti agli anni 1593/1595, relative alle biblioteche di cardinali, docenti e conventi «mai forse interiormente vedute» (cfr. C. Carella, Antonio Possevino e la biblioteca «selecta » del Principe cristiano, in E. Canone (a cura di), Bibliothecae selectae da Cusano a Leopardi, Firenze, 1993, p. 510-512). Ma si vedano anche U. Rozzo, Le biblioteche dei cappuccini nell'inchiesta della Congregazione dell'Indice (1597-1603), in V. Criscuolo (a cura di), Girolamo Mautini da Narni e l'ordine dei frati minori cappuccini fra '500 e '600, Roma, 1998, p. 62-64, e molti dei saggi in R.M. Borraccini e R. Rusconi (a cura di), Libri, biblioteche e cultura degli ordini regolari nell'Italia moderna attraverso la documentazione della Congregazione dell'Indice, Città del Vaticano, 2006.

35. Cfr. G. Fragnito, Vescovi e ordini religiosi in Italia all'indomani del Concilio, in C. Mozzarelli e D. Zardin (a cura di), I tempi del Concilio. Religione, cultura e società nell'Europa tridentina, Roma, 1997, p. 13-25.

36. Cfr. la bolla di promulgazione dell'indice Sacrosanctum catholicae fidei (ILI, IX, p. 916), che accoglieva quanto stabilito nella riunione della Congregazione dell's agosto 1592 ed era stato approvato dal papa il 3 novembre 1592 (ACDF, Index, I/1, fol. 48v e 58r. Ma si veda anche ivi, II/20, fol. 6r).

37. Su queste propaggini della Congregazione dell'Indice cfr. G. Fragnito, «In questo vasto mare... » cit., p. 20-35.

38. Nota eorum quae inter Cardinales Congregationis Indicis mature prius discussa iuxta Constitutiones Indicis pro rerum gravitate postmodum consulto S.D. N.ro determinanda sunt, in ACDF, Index, II/16, fol. 25r-26r.

39. Sulle curie vescovili cfr. C. Donati, Curie, tribunali, cancellerie episcopali in Italia durante $i$ secoli dell'età moderna: percorsi di ricerca, in C. Nubola e A. Turchini (a cura di), Fonti ecclesiastiche per la storia sociale e religiosa d'Europa : XVI-XVIII, Bologna, 1999, p. 213-222.

40. Cfr. A. Borromeo, Contributo allo studio dell'Inquisizione e dei suoi rapporti con il potere episcopale nell'Italia spagnola del Cinquecento, in Annuario dell'Istituto storico italiano per l'età moderna e contemporanea, 29-30, 1977-1978, p. 219-276 ; Id., Inquisizione spagnola e libri proibiti in Sicilia ed in Sardegna durante il XVI secolo, ivi, 35-36, 1983-1984, p. 219-271 ; e A. Rundine, Inquisizione spagnola, censura e libri proibiti in Sardegna nel '500 e '600, Sassari, 1995.

41. Cfr. G. Romeo, Per la storia del Sant'Ufficio a Napoli tra '500 e ‘600. Documenti e problemi, in Campania sacra, 7, 1976, p. 5-119 ; Id., Una città, due Inquisizioni : l'anomalia del Sant'Ufficio a Napoli nel tardo '500, in Rivista di storia e letteratura religiosa, 24, 1988, p. 42-67 ; L. Osbat, L'Inquisizione a Napoli : problemi archivistici e problemi storiografici, in L'Inquisizione romana in Italia nell'età moderna. Archivi, problemi di metodo e nuove ricerche, Roma, 1991, p. 263-293 ; 
P. Scaramella, Le lettere della Congregazione del Sant'Ufficio ai tribunali di fede di Napoli 1563-1625, Trieste-Napoli, 2002.

42. Manca una mappa degli insediamenti inquisitoriali, con la data di istituzione e l'estensione (mutevole) delle singole giurisdizioni, ma si veda A. Del Col, Le strutture territoriali e l'attività dell'Inquisizione romana, in A. Borromeo (a cura di), L'Inquisizione, Atti del Simposio internazionale, Città del Vaticano, 29-31 ottobre 1998, Città del Vaticano, 2003, p. 345-380, e J. Tedeschi, New Light on the Organization of the Roman Inquisition, in Annali di Storia moderna e Contemporanea, II, 1996, p. 265-266. La cifra di 41 è stata ricavata dalla corrispondenza relativa all'esecuzione del clementino. La lista è la seguente: Adria, Alessandria, Ancona, Aquileia, Asti, Bergamo, Bologna, Brescia, Capodistria, Casale Monferrato, Ceneda, Cividale, Como, Cremona, Faenza, Ferrara, Firenze, Genova, Mantova, Milano, Modena, Mondovì, Novara, Padova, Parma, Pavia, Perugia, Piacenza, Pisa, Reggio Emilia, Rimini, Saluzzo, Siena, Torino, Tortona, Treviso, Venezia, Vercelli, Verona, Vicenza, Zara. Non è chiaro se i commissari inquisitoriali attivi a Ragusa in Dalmazia e a Curzola durante l'esecuzione dell'indice del 1558 lo fossero ancora a fine Cinquecento. Sui problemi relativi all'insediamento dell'Inquisizione romana negli Stati regionali italiani cfr. A. Prosperi, Tribunali della coscienza... cit., p. 57-116.

43. Ferrara (dopo la devoluzione verranno creati tribunali a Reggio e a Modena), Bologna, Faenza, Ancona, Perugia, ai quali va aggiunto, per quanto riguarda la censura, il tribunale del Maestro del Sacro Palazzo, responsabile per Roma, la Campagna di Roma e il Patrimonio di San Pietro, come risulta dalla « Nota delle persone et paesi per publicare l'Indice per tutto il Christianesimo » stilata dalla Congregazione dell'Indice nel 1596 (ACDF, Index, XVIII/1, fol. 297r).

44. Per Perugia e per Siena ACDF, Index, III/6, fol. 159r e 118r; per Faenza, ACDF, SO, St. St. II 2-f, fol. nn.

45. Per le 270 chiese dell'Italia continentale cfr. D. Hay, La Chiesa nell'Italia rinascimentale, Bari, 1979, p.183-199 ; G. Greco, La Chiesa in Italia nell'età moderna, Roma-Bari, 1999, p. 3-27, includendo Sicilia e Sardegna, calcola all'incirca 300 diocesi, mentre J. Bergin, The Counter-Reformation Church and its Bishops, in Past and Present, 165, 1999, p. 41-42, ne conta 315 circa.

46. Cfr. BAV, Borg. Lat. 538, fol. 261-265.

47. Cfr. E. Rebellato, La fabbrica dei divieti... cit., p. 58-86.

48. Cfr. BAV, Borg. Lat. 538, fol. 262 e 428 ; ACDF, SO, St. St. M 3-g, fol. 179-180, e St. St. 0 2c, fol. 116r.

49. Sulla politica espurgatoria e il suo fallimento G. Fragnito, Aspetti e problemi della censura espurgatoria, in L'Inquisizione e gli storici : un cantiere aperto, Roma, 2000, p. 161-178 e Ead. (ed.), Church Censorship and Culture in Early Modern Italy, Cambridge, 2001.

50. Giovanni Battista del Tufo, vescovo di Acerra, al card. Marcantonio Colonna, Napoli 28 dicembre 1596 (ACDF, Index, III/1, fol. 478r).

51. Il vicario dell'arcivescovo di Manfredonia al card. Simone Tagliavia, Manfredonia 18 ottobre 1596 (ivi, fol. 89r).

52. Per i solleciti di Roma ivi, II/20, fol. 6v : 9 novembre 1596 e 19 aprile 1597. Di nuovo il 16 agosto 1599 con lettera circolare del card. Simone Tagliavia a vescovi e inquisitori (ivi, V/1, fol. 100r-101r). 
53. Ivi, fol 60r-v ; III/2, fol. 54r-v ; III/3, fol. 3r-v ; III/1, fol.451r-v, 435r-v ; III/1, fol. 139r ; ACDF, SO, St. St. 0 2-c, fol. nn. ; BAV, Borg. Lat. 558, f. 435r ; I. Chiesa, Vita di Carlo Bascapè. Barnabita e vescovo di Novara (1550-1615), a cura di S. Pagano, Firenze, 1993, p. 372-374 e 427-428.

54. Indicis librorum expurgandorum in studiosorum gratiam confecti. Tomus primus. In quo quinquaginta auctorum libri prae coeteris desiderati emendantur per Fr.Jo. Mariam Brasichellen. Sacri Palatii Apostolici Magistrum in unum corpus redactus et publicae commoditati aeditus, Romae, Ex Typographia R. Cam. Apost., 1607.

55. Lo stesso Brisighella annunciava nella lettera al " pio ac studioso lectori » il secondo tomo «quem iam prae manibus habemus " (ivi, cc. n.n.). Della necessità della confezione di un indice espurgatorio scriveva ancora nel 1754 il segretario della Congregazione dell'Indice Tommaso Agostino Ricchini a Benedetto XIV (cfr. P.-N. Mayaud, À propos de la révocation par Benoît XIV du décret de l'Index de 1616, in Archivum Historiae Pontificiae, 42, 2004, p. 27-30).

56. In proposito cfr. P. Broggio, La teologia e la politica. Controversie dottrinali, Curia romana e Monarchia spagnola tra Cinque e Seicento, Firenze, 2009, p. 165-167, e M. Cavarzere, La prassi della censura... cit., p. 92-107. La tesi sostenuta da A. Prosperi (L'inquisizione fiorentina al tempo di Galileo, in Novità celesti e crisi del sapere, in supplemento agli Annali dell'Istituto $e$ Museo di Storia della Scienza, 1983, p. 315-325 ; Id., Anime in trappola. Confessione e censura ecclesiastica all'università di Pisa tra '500 e '600, in Belfagor, 54, 1999, p. 257-287 ; Id., La Chiesa e la circolazione della cultura nell'Italia della Controriforma. Effetti involontari della censura, in U. Rozzo (a cura di), La censura libraria... cit., p.53-100 ; e Id., Censurare le favole. Il protoromanzo e l'Europa cattolica, in F. Moretti (a cura di), Il romanzo, I, La cultura del romanzo , Torino, 2001, p. 71-106) e ripresa da M. Cavarzere (La prassi della censura... cit., p. 119-134) e da S. Landi (Stampa, censura... cit., p. 81-82) secondo cui i letterati laici avrebbero collaborato con i censori «ecclesiastici», condividendo con loro la convinzione della necessità di controllare la produzione culturale, andrebbe più attentamente $\mathrm{e}$ compiutamente verificata e documentata.

57. Cfr. P. Delpiano, Il governo della lettura... cit., p.155-212, e Ead., La congregazione dell'Indice nel Settecento (1740-1815), in Dimensioni e problemi della ricerca storica, 1, 2012, p. 41-58.

\section{AUTORE}

\section{GIGLIOLA FRAGNITO}

Università degli Studi di Parma - fragnit@alice.it 


\title{
Les institutions de censure religieuse en France (XVI ${ }^{e}-\mathrm{XVII}^{e}$ siècles)
}

\author{
Jean-Louis Quantin
}

\section{NOTE DE L'AUTEUR}

Abréviations : BNF : Bibliothèque Nationale de France ; ILI : J. M. de Bujanda (éd.), Index des livres interdits, 11 vol., Sherbrooke-Genève, 1984-2002. Pour les ouvrages des XVI ${ }^{\mathrm{e}}$ et XVII ${ }^{e}$ siècles, le nom du libraire n'a été indiqué que lorsqu'il était nécessaire pour comprendre un exemple.

1 Aux XVI ${ }^{\mathrm{e}}$ et $\mathrm{XVII}{ }^{\mathrm{e}}$ siècles, le mot français censure avait le même champ sémantique que censura en latin. Appliqué à des textes - thèses, sermons, traités imprimés ou manuscrits -, il désignait toute espèce de jugement critique, surtout négatif, qu'il émanât d'une autorité institutionnelle ou qu'il fût simplement porté au nom d'une compétence individuelle ${ }^{1}$. Les éditions des Pères de l'Église comportaient des censurae, c'est-à-dire des discussions d'authenticité, et il était courant de parler, en ce sens, de «la censure d'Érasme et des Docteurs de Louvain » sur tel ou tel ouvrage d'Augustin ${ }^{2}$. La censure d'un texte désignait plus particulièrement l'attribution de «notes de censure » à des énoncés denses et discontinus supposés en exprimer la doctrine - des "propositions », toutes constituées dans le cas des thèses, obtenues par un travail d'extrait s'agissant des sermons ou des livres -, et éventuellement, sur la base de ce travail, sa condamnation officielle par une autorité religieuse ${ }^{3}$. Ce que Montaigne, dans son Journal de voyage, appelle «la censure de mon livre », ce sont les observations des théologiens de l'Index, qui lui ont été remises en 1581, pour qu'il puisse lui-même corriger ses Essais ${ }^{4}$. À la fin du $\mathrm{XVII}^{\mathrm{e}}$ siècle, on parlait encore couramment en ce sens de « la censure de Strigonie » - la condamnation de la déclaration du Clergé de France par l'archevêque hongrois d'Esztergom (Strigonium) en 1682 -, ou de « la censure de la Chine » - la condamnation par la Sorbonne, en octobre 1700, de propositions tirées d'ouvrages jésuites sur la religion chinoise. $\mathrm{Au}$ sens littéraire comme au sens technique, censure faisait antithèse avec 
approbation $^{5}$. La troisième Provinciale en joua, en 1656, à un point stratégique dans le dispositif pascalien de « littérarisation » du théologique, en en appelant au public contre les docteurs : «M. Arnauld mériterait l'approbation de la Sorbonne et moi la censure de l'Académie $»^{6}$. Ce à quoi nous pensons aujourd'hui par priorité quand nous parlons de censure, - l'examen préalable des livres, leur prohibition ou leur expurgation, la saisie et la destruction des exemplaires, le contrôle des imprimeurs et des libraires, - tout cela, au $\mathrm{XVI}^{\mathrm{e}}$ et au XVII ${ }^{\mathrm{e}}$ siècle, relevait de la catégorie de la police. Tel est le sens de la plainte adressée à Louis XIII par l'Assemblée du clergé de 1635: vos juges «jugent des livres concernans la doctrine et la Religion, et en font des censures ». À quoi le roi répond le 14 avril 1636: «Les Cours de Parlemens et autres Juges, ne pourront s'entremettre en la censure des Livres, sinon pour la police, et non pour cause de Religion ${ }^{7}$.

2 Le sens actuel de censure et censurer ne paraît pas attesté, ou du moins ne se répandit pas, avant la seconde moitié du XVIII siècle, par métonymie avec le corps des «censeurs royaux $»^{8}$. La «direction de la librairie », aussi bien, développa à partir de 1699, sous les auspices du chancelier de Pontchartrain et de son neveu, l'abbé Jean-Paul Bignon, toute une routine bureaucratique, qu'une abondante documentation conservée permet de suivre avec un détail inaccessible pour la période antérieure ${ }^{9}$. Marque de leur professionalisation, la liste des censeurs royaux, répartis en classes selon les disciplines, parut chaque année dans l'Almanach royal à partir de $1742^{10}$. Ce n'est que pour le XVIII siècle français que l'on peut mener le type d'études - histoire intellectuelle et culturelle de la censure, prosopographie des censeurs -, qu'il est possible d'effectuer pour les congrégations du Saint-Office et de l'Index dès la fin du XVI ${ }^{e}$ siècle. La formalisation des pratiques se fit à Rome beaucoup plus tôt qu'à Paris. L'évolution se reflète dans la langue : c'est la pratique des censeurs qui redéfinit la censure ${ }^{11}$. Les Mémoires secrets sous le nom de Bachaumont signalent ainsi, au début de 1762, une nouvelle " comédie philosophique " de Voltaire, Le Droit du seigneur : "On espère qu'elle triomphera des scrupules de la censure et de la police, et que nous la verrons enfin représenter $»^{12}$. "Censure» et "police» sont ici presque un hendiadys: les Mémoires secrets évoquent peu après «la censure de la police $»^{13}$, sans cesser, du reste, de parler régulièrement, dans le sens traditionnel, des «censures» de la Sorbonne ${ }^{14}$. À la fin de l'Ancien Régime, censure ne s'oppose plus tant à approbation qu'à liberté de la presse $e^{15}$, en une antithèse nouvelle qu'allait définitivement imposer la Révolution française ${ }^{16}$.

3 La plainte de l'Assemblée du clergé de 1635 signale un fait essentiel : la pluralité et la concurrence jamais résolue des institutions de censure religieuse en France. Le conflit de juridiction était un trait structurel de l'Ancien Régime, mais il fut ici particulièrement marqué, ce qui fait de l'histoire de la censure un remarquable observatoire ${ }^{17}$. Partant d'un système essentiellement ternaire, où les rôles étaient partagés entre facultés de théologie, magistrats et pouvoir royal, la tendance, tout au long du XVII e siècle, fut au renforcement de cette dernière instance aux dépens des deux autres, surtout en matière de censure préventive, que le pouvoir royal finit par se réserver complètement. La censure $a$ posteriori, en revanche, resta partagée jusqu'à la Révolution. Il existait en outre un quatrième acteur, dont les prérogatives étaient considérables en droit, même s'il en était largement dépossédé dans les faits: l'épiscopat. Aussi les évêques français ne renoncèrent-ils jamais à reconquérir une place dans le contrôle des livres, notamment au travers de l'institution nouvelle qu'étaient les Assemblées du clergé. 


\section{La censure préventive et le système du privilège}

\section{La mise en place du système}

4 L'université de Paris avait tôt obtenu du roi, dès le XIII siècle, d'avoir autorité sur les métiers du livre, pour contrôler la qualité des textes et le prix des $\operatorname{copies}^{18}$. Son premier règlement pour les «stationnaires » est du 8 décembre $1275^{19}$; les statuts de décembre 1316 leur interdirent de mettre en location un exemplar avant que l'Université l'eût vérifié et eût fixé le prix de location ${ }^{20}$. La juridiction de l'Université passa du manuscrit à l'imprimé. Au milieu du XVII ${ }^{e}$ siècle, dans le dossier qu'elle compila pour prouver son autorité «sur les Escrivains des Livres, et les Imprimeurs qui leur ont succedé ", l'université de Paris inclut de nombreux textes médiévaux, à commencer par le règlement de 1275 et les Statuta de $1316^{21}$. Lorsque se mit en place, à partir des années 1520, un système de censure préalable dont l'objet principal était désormais l'orthodoxie, pour parer à la diffusion de la Réforme par le livre, un rôle essentiel fut logiquement attribué aux facultés de théologie, au premier chef celle de Paris. L'initiative n'en revint pas au pouvoir royal mais à l'alliance forgée entre la Faculté et le parlement de Paris, qui formaient ensemble ce qu'on a appelé « le parti conservateur ", face à un roi, François I ${ }^{\text {er }}$, beaucoup plus louvoyant. On trouve souvent citée une lettre que celui-ci aurait adressée au Parlement, le 18 mars 1521, à la requête de l'Université, pour faire interdire aux imprimeurs la vente des livres, soit en latin soit en langue vulgaire, concernant la foi chrétienne et l'interprétation de l'Écriture, avant qu'ils eussent été contrôlés par la Faculté de théologie ${ }^{22}$. La reprise du dossier par le grand spécialiste de la Faculté au premier $\mathrm{XVI}^{\mathrm{e}}$ siècle, a montré qu'il s'agissait d'un arrêt du Parlement, certes pris au nom $\mathrm{du}$ roi mais où celui-ci, absent de la capitale, ne fut pour rien ${ }^{23}$. Des prescriptions équivalentes figurent dans une longue suite d'arrêts et d'édits. Citons seulement l'édit de Châteaubriant, pris par Henri II en 1551 :

Et ne sera imprimé ne vendu aucuns livres, comments, scholies, annotations, tables, indices, épitomes, et sommaires concernans la saincte escriture et religion chrestienne, faits et composez depuis quarante ans en ça, en latin, grec, hebreu, et autres langues, mesme françoise, que premierement ils n'ayent esté veus et visitez : c'est à sçavoir, ceux qui sont imprimez ès villes de Paris, Lyon et autres villes circonvoisines dudit Paris, où il n'y a faculté en théologie, par la faculté de théologie dudit Paris : et ès villes où il $\mathrm{y}$ a faculté de théologie, par les docteurs et députez d'icelle.

En défendant très-expressément à toutes nos cours de parlement, maistres des requestes et autres gardans les sceaux des chancelleries, juges présidiaux, et autres nos officiers et magistrats quels qu'ils soient, de donner par cy après aucune permission d'imprimer livres, que premierement ceux qui demanderont ladite permission, n'ayent certification desdites facultés de théologie, que lesdits livres ont esté veus et approuvez desdites facultez [...]. Laquelle certification sera enregistrée au commencement desdits livres avec ladite permission ${ }^{24}$.

5 Le système de la censure préalable trouva sa forme définitive en 1566, lorsque y fut intégré le privilège d'imprimerie. Le privilège, apparu en Allemagne et en Italie à la fin du $\mathrm{XV}^{\mathrm{e}}$ siècle et dont le premier exemple français est de 1498, répondait à l'origine à une logique purement économique, de protection contre le piratage, à la demande des intéressés eux-mêmes ${ }^{25}$. Il est frappant de voir, avant comme après 1566, des auteurs ou imprimeurs étrangers, catholiques comme protestants, solliciter et obtenir pour leurs ouvrages des privilèges du roi, en plus de ceux de l'empereur ou des conseils des Pays-Bas 
espagnols ${ }^{26}$. C'était là pour les étrangers le seul moyen d'empêcher que leurs publications ne fussent piratées impunément dans le royaume. Dans un procès devant le parlement de Paris en 1586, à propos du Sénèque de Marc-Antoine Muret, paru à Rome l'année précédente ${ }^{27}$ et dont les libraires parisiens se disputaient la réimpression, l'avocat Simon Marion soutint victorieusement que, dès lors qu'un ouvrage avait été publié à l'étranger sans privilège du roi, il était « rendu purement public, et de libre impression en France, où il ne peut plus estre privilegié $»^{28}$. Mais l'affaire la plus intéressante est celle du Corpus Iuris Canonici, dont l'édition corrigée avait paru à Rome en 1582, avec un privilège de Grégoire XIII valable dix ans, tant dans les États de l'Église qu'au dehors, et frappant d'excommunication latae sententiae les contrevenant ${ }^{29}$. La réimpression officielle française devait être confiée à un libraire lyonnais. En 1583, l'université de Paris s'adressa au Conseil du roi pour que l'ouvrage pût être librement imprimé par ses libraires. Marion, son avocat, représenta que le Droit Canon faisait partie des livres qui n'étaient pas " purs profanes » mais «composez» de corporel et de spirituel : «entant qu'il est corporel, chacun Prince souverain dans le destroict de son domaine temporel y peut mettre police : et entant qu'il est spirituel, l'authorité Apostolique y est universelle, mais gratuitement ». Malgré les protestations du nonce, le Conseil du roi accorda une permission d'imprimer à tous les libraires du royaume ${ }^{30}$. En refusant ainsi de reconnaître un privilège pontifical, le pouvoir royal proclamait que l'imprimerie en France ne dépendait que de lui ${ }^{31}$. Marion appuya sur ce point, dix ans plus tard, quand il remania sa plaidoirie pour la publier :

D'autant que sa doctrine [du Droit Canon] des choses divines est d'authorité pure ecclesiastique, qui estend ses effects universellement par toute la terre: mais si gratuitement que l'Eglise, souz ce pretexte, ne se peult arroger aucun privilege en ce qui concerne l'impression du livre; par ce qu'elle est de droict purement temporel, et du tout soubzmis à la police des Princes seculiers chascun en son destroit, sans que pour ce regard le Pape, non plus que l'un des autres, puisse exceder les fins de sa domination profane et civile ${ }^{32}$.

6 Il n'est pas indifférent de noter que Marion fut nommé en 1597 avocat général au Parlement, et qu'il fut le grand-père maternel d'Antoine Arnauld, qui lut de près ses Plaidoyez ${ }^{33}$.

7 Par l'ordonnance de Moulins de février 1566, pièce maîtresse de l'œuvre législative du chancelier de L'Hospital pour restaurer l'autorité royale, Charles IX fit par surcroît du privilège un instrument de contrôle : "Défendons aussi à toutes personnes que ce soit, d'imprimer ou faire imprimer aucuns livres ou traitez sans nostre congé et permission, et lettres de privilége expédiées sous nostre grand scel $\aleph^{34}$. Cette dernière clause était dirigée contre le parlement de Paris, auquel la monarchie, depuis 1563, tentait d'interdire de délivrer ses propres privilèges et permis d'imprimer ${ }^{35}$.

8 Le contrôle préalable des livres imprimés dans le royaume s'accompagnait de dispositions relatives aux importations où, là encore, les facultés de théologie étaient très impliquées. L'édit de Châteaubriant défendait «à tous libraires, imprimeurs et vendeurs de livres, qu'ils n'ayent à ouvrir aucunes balles de livres, qui leur sont apportez de dehors, sinon en présence de deux bons personnages, qui seront commis par les facultés de théologie, ès villes où il y aura faculté $»^{36}$.

\section{Les failles du système}

9 Il est bien connu que ce système apparemment rigoureux comportait de multiples failles. S'agissant de l'approbation, l'auteur était libre de solliciter les docteurs de son choix - la 
règle définitivement fixée au XVII ${ }^{\mathrm{e}}$ siècle en exigea au moins deux ${ }^{37}$. Ceux-ci, il est vrai, ne pouvaient en principe donner leur approbation sans en avoir obtenu la permission de la Faculté : cette règle fut solennellement renouvelée en 1611, après que la Response apologetique à l'Anticoton, publiée anonymement par les jésuites parisiens, eut trouvé quatre docteurs pour l'approuver ${ }^{38}$. Si la Faculté n'avait pas - ou plus exactement n'avait plus, au XVII siècle -, " accoutumé d'approuver des livres en corps " ${ }^{39}$, tout docteur qui approuvait un livre engageait le corps tout entier. Mais, outre que cette obligation n'était pas toujours respectée, particulièrement pour les docteurs qui ne résidaient pas à Paris ${ }^{40}$, la Faculté ne pouvait guère juger d'un ouvrage dont on ne lui indiquait que le titre: la réforme de la procédure d'approbation que l'ancien syndic Jean Filesac fit adopter en décembre 1623 stipula de manière significative qu'un docteur qui demanderait à approuver un livre devrait désormais, sauf exceptions, préciser le nom et la condition de l'auteur ${ }^{41}$.

10 Arrivait-il souvent que le texte imprimé fût différent de celui qui avait été approuvé, ou que les corrections réclamées par les docteurs ne fussent pas effectuées? La réglementation officielle tenta à plusieurs reprises d'y parer, en ordonnant aux imprimeurs de laisser une copie du manuscrit à l'approbateur (édit de Châteaubriant), puis au procureur du roi au Châtelet (règlement du lieutenant civil de 1610, cassé l'année suivante par le parlement de Paris), et finalement au chancelier ou garde des sceaux (Code Michau de janvier 1629) ${ }^{42}$ : ces cas de fraude proprement dite ne disparurent pourtant jamais, même si l'on ne saurait dire quelle était la proportion entre ceux qui étaient découverts et ceux qui ne l'étaient pas ${ }^{43}$. Il était du moins usuel de ne présenter à l'approbateur que le corps du livre, et de rajouter au dernier moment les préliminaires, qui étaient parfois tout sauf insignifiants : la polémique s'y déployait volontiers et n'y passait pas inaperçue ${ }^{44}$. En 1645, l'université de Paris s'émut d'un nouveau volume de $L a$ Cour sainte du P. Nicolas Caussin, dont la préface revenait sur la récente dispute entre les jésuites et l'Université, et critiquait durement cette dernière; l'ouvrage n'en paraissait pas moins avec l'approbation de deux docteurs de la Faculté de théologie, Jean-Baptiste Blondel et Jean Helies, qui déclaraient n'y avoir « rien trouvé que de grand et d'heroïque [...] : tout y est Saint, tout y est pur ». Sommés de s'expliquer, ceux-ci protestèrent solennellement qu'ils n'avaient jamais vu la préface avant que le livre fût imprimé, et qu'ils la condamnaient comme "injurieuse à l'Université, peu conforme à la vérité et scandaleuse $»^{45}$. On pourrait évidemment soupçonner leur témoignage mais il est vraisemblable qu'ils étaient de bonne foi ${ }^{46}$.

11 Quant aux privilèges, l'ordonnance de Moulins ne parvint pas à imposer le monopole des privilèges royaux, scellés du grand sceau. Les parlements continuèrent, comme par le passé, à octroyer des privilèges « de petit sceau ", valables dans l'étendue de leur ressort, et, à l'échelon encore inférieur, les magistrats des bailliages et des sénéchaussées (le lieutenant général ou le lieutenant civil), du Châtelet à Paris (le lieutenant civil, plus tard le lieutenant de police, au nom du prévôt), à accorder des permissions locales. Cette hiérarchie, qu'on a pu qualifier de "système à deux vitesses ", survécut jusqu'à la fin du $\mathrm{XVII}^{\mathrm{e}}$ siècle ${ }^{47}$. Dans certains cas, la préférence pour la procédure parlementaire put avoir une signification idéologique - Les Libertez de l'Eglise Gallicane de Pierre Pithou virent ainsi le jour avec un privilège du parlement de Paris de septembre $1594^{48}$-, mais les considérations pratiques durent être déterminantes ${ }^{49}$.

12 Il existait, en outre, des privilèges dits généraux, accordés soit à des corps soit à des particuliers pour toutes leurs publications, y compris à venir. Le Clergé de France 
(représenté par ses Assemblées générales et, entre les Assemblées, par ses deux agents) en obtint un en août 1635, pour seize ans, au nom de son imprimeur Antoine Vitré, pour " toutes les Declarations, Lettres patentes, et Arrests concernans le Clergé, Declarations, Lettres Circulaires, Procez Verbaux, et autres actes des Assemblées $»^{50}$. Le caractère trop restrictif de cette énumération apparut au grand jour quelques années plus tard, après que l'Assemblée de 1641 eut décidé de faire réimprimer par Vitré toute l'œuvre ecclésiologique de Petrus Aurelius (pseudonyme de l'abbé de Saint-Cyran). Quand parut l'épais in-folio, en 1642, avec un ancien privilège qui n'en couvrait que le tiers, le chancelier Séguier en fit saisir les exemplaires ${ }^{51}$. Aussi, à l'Assemblée de 1645, l'un des deux promoteurs, Georges d'Aubusson de la Feuillade, futur archevêque d'Embrun, fit-il observer que le privilège accordé à Vitré en 1635 «étoit prêt d'expirer, et que le renouvellement d'icelui ayant à se faire durant la présente Assemblée, il étoit du tout nécessaire de l'obtenir plus ample et d'y faire comprendre en termes exprès, le pouvoir d'imprimer les livres concernant la doctrine Catholique, qui auront été approuvés par les Assemblées-Générales dudit Clergé. Il a été résolu de demander ledit privilege en cette forme $~^{52}$. Selon une logique caractéristique de l'Ancien Régime, cette extension visait à répondre à une situation particulière, plutôt qu'elle ne participait d'une stratégie délibérée $e^{53}$. Le Clergé n'obtint pas la mention explicite qu'il souhaitait mais le nouveau privilège accordé à Vitré lui permit « d'imprimer, vendre et debiter generalement tout ce qui luy sera baillé par les Assemblées generales ou par les Agents generaux du Clergé $»^{54}$ : la traduction des Instructions aux confesseurs de Charles Borromée, munie d'une préface qui était un réquisitoire contre la "morale relâchée », ou le commentaire de François Hallier sur les règlements touchant les réguliers, somme définitive de la doctrine gallicane en la matière, parurent sous ce couvert ${ }^{55}$.

Un cas particulièrement important est celui des ordres religieux, qui avaient leurs propres systèmes internes de censure préalable ${ }^{56}$. Henri III, en 1583, puis Henri IV en 1606, et Louis XIII en 1611, avaient accordé à la Compagnie de Jésus un privilège - c'est le terme employé -, "par lequel il est defendu à tous Imprimeurs ou Libraires, de n'imprimer ou faire imprimer aucun livre de ceux qui sont composez par quelqu'un de nostre dite Compagnie, sans permission des Superieurs d'icelle $»^{57}$. Louis XIV fit encore de même en $1650^{58}$. La Compagnie semble avoir été longtemps seule à jouir de telles dispositions ${ }^{59}$. Quand Pascal, pourtant, fit dire au bon Père des Provinciales, en 1656, que cela était "particulier » à son ordre, l'affirmation n'était plus exacte ${ }^{60}:$ l'Oratoire de France avait obtenu un privilège exactement semblable en juillet $1642^{61}$. Un autre, deux ans après les Provinciales, fut accordé à l'abbé de Cîteaux qui, alors qu'une guerre de pamphlets faisait rage dans l'ordre entre tenants de la commune et de la stricte observance, espérait ainsi réduire au silence ses adversaires - il n'y réussit pas ${ }^{62}$. La monarchie française traduisait sous forme de privilèges d'imprimerie les prescriptions du concile de Trente ${ }^{63}$.

Là encore, les infractions semblent avoir été nombreuses. Passons sur l'impossibilité bien connue, pour un ordre international comme la Compagnie de Jésus, d'assurer un contrôle centralisé de toute la production imprimée. Dans la première moitié du XVII siècle, les jésuites français se plaignirent régulièrement de devoir subir les conséquences des traités sur le pouvoir du pape au temporel, et même le tyrannicide, que leurs confrères italiens ou espagnols continuaient à publier malgré les ordres répétés du général, grâce à la complaisance des réviseurs ou à des pressions politiques: "tellement qu'il arrive quelquefois, écrivait le P.Caussin, que nous n'avons non plus de puissance sur 
l'impression d'un livre, que sur les vents et sur les estoiles ${ }^{64}$. Inversement, certains jésuites français semblent avoir eu recours au généralat pour contourner leurs supérieurs locaux, plus sensibles aux polémiques que certaines publications ne manqueraient pas de susciter ou de relancer ${ }^{65}$. En France même, le général Piccolomini tenta vainement, en 1650, d'empêcher que vît le jour à Lyon le tome II du De gratia de Francisco Suárez toujours inédit car il tombait sous le coup des prohibitions romaines contre toute publication de auxiliis. Une lettre de Louis XIV « au sénéchal de Lyon ou son lieutenant et autres nos justiciers et officiers à qui il appartiendra selon le fait ", rappelant le privilège de Henri IV de 1606 et portant défense de poursuivre l'impression, n'empêcha pas le livre de paraître peu après, avec «consentement » du procureur du roi et "permission »du lieutenant général, sur la base de l'approbation de deux docteurs de Sorbonne, l'un franciscain et l'autre carme ${ }^{66}$. Il est vrai que l'on était en pleine Fronde, et on soupçonnerait en outre volontiers que les jésuites lyonnais, chargés par le général d'empêcher l'édition, ne s'y employèrent que mollement ${ }^{67}$. Dans les années 1680 , à l'Oratoire, qui venait pourtant de subir une reprise en main anti-janséniste, un livre de dévotion ultra-rigoriste dû au P. François de Clugny put paraître anonymement sans permission du général, et connut même trois éditions : mis en cause, l'auteur se défendit en expliquant que son ouvrage avait été imprimé «à son insu et sans sa participation »et ses supérieurs semblent s'être satisfaits de cette banale excuse ${ }^{68}$.

Il ne semble pas, en revanche, que ces privilèges des ordres religieux aient fait une brèche de plus dans le système de censure, au sens où ils auraient exempté auteurs ou imprimeurs de prendre un privilège particulier pour chaque ouvrage. En principe, du moins, la procédure propre à l'ordre et la procédure commune se cumulaient ${ }^{69}$. L'Assemblée du clergé de 1641, il est vrai, dit le contraire à propos de deux jésuites, Étienne Bauny et Louis Cellot, dont elle condamna les ouvrages: «Et pour ce que ces livres s'impriment en vertu de certains privileges généraux, que Sa Majesté accorde à quelques Ordres, la Compagnie a jugé à propos d'en demander au Roi la révocation, attendu les trop pernicieux inconvénients qui en arrivent, et de faire confirmer l'Arrêt de son Conseil, qui porte défenses à tous Imprimeurs d'imprimer aucuns livres sans privilege particulier du grand Sceau $»^{70}$. Mais, si les ouvrages de Bauny comme de Cellot présentent un certain nombre d'irrégularités, le privilège de la Compagnie de Jésus n'y fut pour rien. La Prattique du Droict Canonique de Bauny parut d'abord anonymement en 1633, sans aucune permission de la Compagnie, mais avec l'approbation de deux docteurs de Sorbonne et un privilège particulier accordé au libraire ${ }^{71}$. Ce ne fut qu'un an plus tard, en août 1634, que ce dernier se mit en règle vis-à-vis de la Compagnie, et que le provincial lui accorda une permission conjointe pour La Prattique du Droict Canonique et pour un autre ouvrage de Bauny, la Somme des Pechez ${ }^{72}$. Le livre suivant de Bauny, en revanche, le premier volume de sa grande Theologia moralis, parut en 1640 dûment muni des approbations des docteurs, de la permission du provincial et d'un privilège du roi $^{73}$. L'irrégularité vint ensuite, en 1642 et 1644, quand le libraire utilisa les mêmes permission et privilège, en en retouchant le libellé au fur et à mesure, pour faire paraître un deuxième puis un troisième in-folio, qui n'avaient certainement jamais été examinés, ni par les réviseurs de l'ordre ni par les théologiens de Sorbonne - le procédé était classique ${ }^{74}$. Le De Hierarchia et Hierarchis de Cellot, quant à lui, parut à Rouen en 1641, muni d'une « approbation des docteurs de Paris » (deux Pères augustins du couvent de Rouen), d'une "approbation des docteurs d'Angers" (deux chanoines de saint Augustin), et de la permission du provincial de France: «au vu des approbations des docteurs et de la 
permission du provincial », le lieutenant général du bailliage de Rouen accorda le permis d'imprimer, conformément au « privilège de l'Ordre $»^{75}$.

Les privilèges généraux dont jouissaient des particuliers, en revanche, constituaient une véritable brèche dans le système. En 1569, dans sa requête au roi pour la suppression de la Bible française de René Benoist (qui avait paru trois ans plus tôt, avec un privilège particulier, mais sans approbation $)^{76}$, la faculté de théologie de Paris demanda que fût cassé le privilège général dont jouissait par ailleurs cet auteur extrêmement prolifique et grâce auquel «journellement il fait imprimer plusieurs Livres sans être visitez et approuvés par ladite Faculté $»^{77}$. Un arrêt du Conseil rendu sur cette requête fit défense aux imprimeurs et libraires, "quelques Privileges ou permissions qu'ils puissent avoir " d'imprimer aucun livre concernant la religion sans approbation de « quatre Docteurs en ladite Faculté de Théologie de Paris à ce par elle commis $»^{78}$. L'arrêt ne fut pas exécuté pris au milieu de la troisième guerre de religion, il fut implicitement abrogé, un an plus tard, par l'édit de Saint-Germain-en-Laye ${ }^{79}$. Les livres de Benoist continuèrent longtemps encore, même après que Henri III eut succédé à Charles IX, à paraitre quasiment à jet continu, moyennant un privilège général du 4 décembre 1563 (pour toutes les œuvres de Benoist, " soit de son invention ou traduction »), sans aucune mention de l'approbation des docteurs ${ }^{80}$.

Jusqu'au milieu du XVII ${ }^{e}$ siècle, les privilèges généraux restèrent accordés largement : Antoine Godeau, alors évêque de Grasse et de Vence, en obtint un en 1651 pour une longue liste d'ouvrages, parus ou projetés, « et generalement toutes les CEuvres Morales et Sacrées qu'il a composées, ou qu'il composera cy-apres, tant en Vers qu'en Prose ${ }^{81}$. Certains jésuites en étaient bénéficiaires, à titre personnel, ainsi Fronton du Duc, pour tous les livres "écrits, commentés ou traduits par lui de grec en latin ${ }^{82}$, ou Louis Richeome, lequel avait reçu de Henri IV en 1598, «la permission de choisir tels Imprimeurs que bon luy semblera, pour fidelement imprimer tous et chacuns les livres concernans la foy et Religion Catholique, et autres œuvres par luy faictes et composées, et qu'il pourra cy apres faire et composer ». Richeome en usait encore sous la régence de Marie de Médicis pour publier "avec privilège ", sans autre approbation que celle des réviseurs jésuites de Rome ${ }^{83}$.

Une autre faille concernait les "petits livres » ou «livrets », que pouvaient vendre les colporteurs et pour lesquels la limite était en principe fixée à huit feuilles imprimées (64 pages in-quarto) - mais la règle était tout sauf rigoureuse. Jusqu'en 1618, les livrets paraissent n'avoir été soumis à aucune autorisation préalable; après cette date, la permission des juges locaux fut en principe requise ${ }^{84}$. Cette faille fut systématiquement exploitée au milieu du siècle par le théologien et critique Jean de Launoy, qui publia l'essentiel de son œuvre sous forme de "petits livres », le plus souvent présentés comme des lettres à des amis : «il y dit librement ce qu'il pense, les publie ensuite séparément, les réunit une fois publiées, et forme de leur réunion un volume de taille convenable $»^{85}$; il « ne laisse pas vendre ces petits escrits par les libraires : il en retire tous les exemplaires et en fournit ses amis ${ }^{86}$. Certains paraissent avoir paru, non seulement sans privilège, mais même sans permission ${ }^{87}$. Launoy put ainsi mettre au jour pièce à pièce un redoutable arsenal anti-romain, qu'il revint finalement à un théologien anglican de réunir en un épais in-folio, à Cambridge en $1689^{88}$. 


\section{Centralisation monarchique et resserrement des contrôles}

19 La censure préventive n'assurait ainsi, jusque dans le premier quart du XVII ${ }^{\mathrm{e}}$ siècle, qu'un contrôle très lâche. Le pouvoir royal entreprit alors de s'en réserver le monopole et, ce faisant, d'en fermer une à une toutes les échappatoires. Il commença, en 1623-1624, par l'approbation : l'épisode a été souvent retracé, mais tous les récits dépendent en dernière analyse d'une source unique et nécessairement unilatérale, à savoir les registres de la faculté de théologie de Paris ${ }^{89}$. Par de petites lettres patentes de mars 1623, renouvelées et rendues perpétuelles en août 1624, Louis XIII commit quatre docteurs, André Duval, Pierre Quedarne, Jacques Messier et François de Saint-Père, « pour voir et visiter tous et chacuns les livres concernant la Religion, devotion et bonnes mœurs qui seront imprimés en nostre bonne ville Paris, et donner sur iceux vos avis par escrit et signé de deux de vous, sans lequel avis aucun Livre ne pourra estre imprimé en ladite ville $»^{90}$. Les grandes lettres d'août 1624, qui donnèrent aux mêmes docteurs le titre de "Censeurs et Examinateurs » et prévirent un mécanisme complexe pour leur remplacement, étendirent leur compétence à tout le royaume et, surtout, doublèrent cette mesure d'une réaffirmation $\mathrm{du}$ monopole royal en matière de privilèges, "faisant tres-expresse inhibitions et defenses aux Officiers des Chancelleries d'icelles Cours Souveraines, d'accorder iceux privileges et à tous Imprimeurs d'imprimer aucuns Livres en consequence d'icelles $\aleph^{91}$. On aimerait savoir qui fut à l'origine de cette réforme décisive, dans un contexte de grande instabilité politique: entre les premières et les secondes lettres patentes, les Brûlart, père et fils, qui dominaient le Conseil en 1623, furent disgrâciés ; le père, le chancelier, dut rendre les sceaux, en janvier $1624^{92}$. Une remarque du nouveau chancelier, Étienne d'Aligre, suggère que la réforme pourrait avoir été inspirée par les cardinaux de La Rochefoucauld et de Richelieu ${ }^{93}$. Le rôle décisif fut vraisemblablement tenu par le premier, membre du Conseil pendant toute la période alors que Richelieu n'y entra que le 29 avril 1624 -, alors très écouté de Louis XIII pour les questions ecclésiastiques, pro-romain et philo-jésuite, hostile aux prétentions doctrinales de la Faculté de théologie. Est-il indifférent qu'une douzaine d'années plus tôt, lors de son séjour à Rome, il ait participé avec zèle aux travaux de la congrégation de l'Index, dont il était membre ${ }^{94}$ ? En mars 1623, justement, La Rochefoucauld avait entrepris d'en finir avec le richérisme en obligeant Richer à une rétractation - après une tentative initiale pour intervenir dans l'affaire, Richelieu, proviseur de Sorbonne depuis septembre 1622, eut soin de rester en retrait ${ }^{95}$. Que la réforme de l'approbation ait été dirigée contre l'ancien syndic et ses disciples, le choix d'André Duval, qui tenait le premier rang parmi les quatre censeurs, le marque assez : chef de file des romains à la Faculté de théologie, il était aussi très lié avec La Rochefoucauld ${ }^{96}$. De fait, une des premières victimes du nouveau système fut le traité de théologie morale anti-jésuite du bénédictin anglais John Barnes, Contra aequiuocationem. Duval et Quedarne refusèrent de l'approuver «pour ce principalement qu'il condamne comme méchantes et diaboliques des propositions qui sont communément receues entre les docteurs catholiques et qui ont fondement, voire des exemples insignes en l'Ecriture "; le manuscrit en fut saisi chez l'imprimeur par un commissaire au Châtelet en mai 1624 ; en juin, une sentence du prévôt de Paris en interdit l'impression ${ }^{97}$.

La faculté de théologie de Paris, qui était clairement divisée, réagit avec une certaine hésitation: si elle fit tout de suite opposition aux lettres patentes d'août 1624, elle chercha d'abord à négocier un compromis (acceptant le principe d'un nombre limité de 
censeurs, pourvu que le dispositif restât contrôlé par la Faculté et respectât les formes collégiales) $^{98}$; finalement, la ligne maximaliste l'emporta, et la Faculté décida de ramener tous ses articles d'opposition à un seul «à savoir que tout docteur conserve un droit entier d'approuver les livres $»^{99}$. Les lettres patentes ne furent jamais enregistrées au Parlement; au prima mensis (l'assemblée de la Faculté) de décembre 1626, Duval annonça que ses collègues et lui avaient renoncé à leur commission ${ }^{100}$. Dans l'affaire du Contra aequivocationem, Duval et Quedarne avaient fait une rétractation complète dès août 1624 : si l'on en croit le procès-verbal de la Faculté, ils auraient même été contraints d'avouer qu'ils en avaient jugé sur le rapport d'autrui et sans l'avoir lu ${ }^{101}$. L'ouvrage put paraitre en 1625 , à la fois dans l'original et en traduction française, muni de l'approbation de deux docteurs gallicans et anti-jésuites choisis par l'auteur, lesquels avaient obtenu la permission de la Faculté, selon l'ancien usage, et d'un privilège du roi en bonne et due forme, «apres qu'il nous est apparu du decret et approbation de la Sorbonne $»^{102}$. Cette première offensive du pouvoir royal se terminait donc par un recul et la Faculté restait en possession de ses prérogatives: on comprend le soin qu'elle eut de faire imprimer le dossier.

21 Dès janvier 1629, pourtant, le Code Michau réintroduisait de facto l'approbation restreinte en stipulant, après avoir rappelé l'obligation pour tout livre d'une "permission par lettres de nostre grand sceau » que celles-ci ne pourraient « estre expédiées qu'il n'ait esté présenté une copie du livre manuscrit à nos chancelier ou garde des sceaux, sur laquelle ils commettront telles personnes qu'ils verront estre à faire selon le sujet et matière du livre, pour le voir et examiner, et bailler sur icelui, si faire se doit leur atestation en la forme requise, sur laquelle sera expédié le privilége $»^{103}$. Cette nouvelle procédure fut rigoureusement appliquée dans les années 1630 par le garde des sceaux, puis chancelier, Pierre Séguier. Pour tourner l'opposition de la Faculté (et surtout, derrière elle, du parlement de Paris), il n'y eut plus de nomination officielle de "censeurs", mais quelques docteurs de confiance jouèrent ce rôle en vertu de « commissions particulieres »104. Dans une lettre bien connue à Descartes, le P. Mersenne lui expliquait en 1637: «Jamais on ne fust plus exact qu'a present pour l'examen des livres, car Monsieur le Chancelier a des agents affidés pour juger de ce qui est pour la theologie, d'autres pour la politique, l'Academie de Paris pour les pieces d'eloquence, tant en vers qu'en prose, et des mathematiciens pour le reste $»^{105}$. Tous les docteurs conservèrent le droit de donner des approbations, publiées dans les livres, moyennant permission du corps, mais ce n'était plus là qu'un vestige, voire une fiction: ces approbations ne servaient plus à rien pour l'obtention du privilège à moins d'être «ratifiées par l'un de ces Censeurs Souverains», lesquels agissaient en toute indépendance de leurs collègues ${ }^{106}$. Malgré un relâchement provisoire des contrôles dans les années 1640, au «temps de la bonne régence » chanté plus tard avec nostalgie par Saint-Évremond, quand «la douce erreur ne s'appelait point crime » ${ }^{107}$, puis sous la Fronde - où la Faculté de théologie tenta à nouveau de faire valoir que tous les docteurs avaient « receu ce privilege [d'examiner les Livres qui se publient] comme un appanage qui est attaché à leurs degrez $»^{108}-$, la réforme fut définitive.

Elle fut d'autant plus douloureuse aux gallicans que, dans tout le troisième quart du XVII ${ }^{e}$ siècle en tout cas, les "nouveaux censeurs" incarnaient un courant particulier de la Faculté. C'étaient deux docteurs vigoureusement anti-jansénistes (Claude Morel et Martin Grandin), hostiles a priori à tout ce qui venait de Port-Royal, fût-ce contre le protestantisme, bien disposés au contraire pour l'ecclésiologie romaine et - quoique 
soumis aux évolutions de la politique royale - fort tièdes par eux-mêmes dans la défense des libertés gallicanes ${ }^{109}$. La restriction du droit d'approuver alla de pair avec le rétrécissement de l'orthodoxie. Submergés, d'un côté, par la masse des manuscrits qui leur étaient présentés, soucieux, de l'autre, de ne pas se compromettre, les censeurs d'office semblent avoir été très lents à examiner les livres que leurs auteurs ou leurs sujets rendaient tant soit peu problématiques, et très négligents avec tout le reste ${ }^{110}$. Le sorbonniste Jacques Le Fèvre s'en plaignait amèrement en 1683, à l'époque où l'approbation des livres de théologie appartenait à Edme Pirot :

Il paroît un peu extraordinaire, qu'un Livre de trois semaines de composition, ne puisse être lû en sept ou huit mois par ceux qui sont gagez exprès de Sa Majesté pour l'examen des Livres. Toutefois cela ne doit surprendre, que les personnes qui n'ont point passé par les mains de ces Censeurs des Ouvrages de Théologie qu'on imprime; puisqu'il est certain qu'ils en gardent maintenant des quatre et cinq années, avant qu'on puisse savoir ce qu'ils en pensent. Il est vrai qu'on doit excepter de ce nombre certains Livres de menuës dévotions, et genéralement tous ceux qui vont selon le tran tran du petit monde ${ }^{111}$.

Rendant compte du livre de Le Fèvre dans les Nouvelles de la République des Lettres, Bayle, en une référence classique que s'appropria plus tard l'Encyclopédie, compara les auteurs aux âmes massées sur les bords du Styx et suppliant Charon de les prendre dans sa barque 112 .

24 Pirot semble avoir été un théologien solide, sans distinction particulière. Au jugement de l'abbé Le Gendre, «son principal talent étoit d'être souple, rampant et prêt à tout faire pour plaire aux puissances »- les gouvernements français, depuis le XVII ${ }^{\mathrm{e}}$ siècle et audelà des changements de régimes, manquent rarement de placer leur confiance en des universitaires de ce modèle. L'archevêque de Paris, François II de Harlay, maintint celui-là syndic de la Faculté de théologie pendant treize ans, en violation des statuts, à titre de «sage précaution pour introduire l'ordre dans une compagnie où il n'y en avoit quasi jamais eu $»^{113}$. Les contemporains ne manquèrent pas de relever, en revanche, comment la censure laissait passer ailleurs, surtout dans les livres de piété, des énormités voire des hérésies ${ }^{114}$. Il fallut attendre là encore la toute fin du XVII ${ }^{\mathrm{e}}$ siècle et l'arrivée de Bignon à la direction de la librairie pour que la littérature de dévotion fût soumise à une censure préventive à la fois rigoureuse et cohérente, au nom d'une double lutte contre le quiétisme et contre les dévotions populaires ${ }^{115}$.

Dès les premiers temps, en revanche, il semble qu'il y eut un parti pris de ne pas choisir les censeurs royaux parmi les réguliers, pour éviter que leur jugement ne fût biaisé par des considérations de famille religieuse ${ }^{116}$ et, sans doute aussi, à cause de la méfiance gallicane à leur encontre. En 1668, le parlement de Paris interdit « d'imprimer ou faire imprimer aucuns Livres qui regardent directement ou indirectement les Droicts du Roy, Justice Royalle, libertez de l'Eglise Gallicane, et qui traitent de Theologie Scolastique, positive, Morale, et de Cas de Conscience, sans Privilege du Roy, ou permission des Officiers, et Approbation des Docteurs de Theologie de France, entre lesquels soit du moins un Seculier de la Faculté de Theologie de Paris $»^{117}$. Pontchartrain alla plus loin que le Parlement puisqu'il « s'était fait une loi, comme il le dit dans une de ses dépêches, de ne jamais confier la censure des livres ecclésiastiques à des religieux $»^{118}$.

26 La dépossession de la Faculté porta aussi sur le contrôle des importations de livres et la visite des imprimeries et librairies, qui furent confiés aux intéressés eux-mêmes ${ }^{119}$. Tout au long du XVII siècle, aussi bien, la stratégie du pouvoir fut de favoriser à la fois l'autorégulation de la profession et sa concentration au profit des grands libraires 
parisiens ${ }^{120}$, auxquels il n'hésita pas à déléguer de vastes pouvoirs de police, non seulement à Paris ${ }^{121}$, mais même, sous Louis XIV, pour opérer des descentes en province contre les livres contrefaits ou défendus : connaissant eux-mêmes les ficelles du métier, ces libraires se montrèrent de fait beaucoup plus efficaces que les officiers locaux, du moins tant qu'il y allait de leur propre intérêt ${ }^{122}$.

Le pouvoir royal s'attaqua ensuite aux privilèges généraux. Il y fallut plusieurs hésitations et retours en arrière, tant la logique administrative d'uniformisation des procédures se heurtait au principe du respect des situations acquises, et paraissait même mettre en cause l'honneur des auteurs. Une première révocation eut lieu en juin 1659. Le contexte était celui de ce qu'il est convenu d'appeler «la Fronde ecclésiastique», et plus particulièrement des polémiques sur la morale relâchée, menées en particulier par les curés de Paris, dans le sillage des Provinciales et à la faveur de la vacance de fait du siège archiépiscopal ${ }^{123}$. L'exposé assez embarrassé de l'arrêt est révélateur des difficultés de l'entreprise :

Sa Majesté bien qu'elle soit persuadée de la sincerité et bonne doctrine de ceux ausquels lesdits Privileges ont esté accordez, et qu'ils ne voudroient rien donner au public, qui fust contraire à la vraye doctrine; considerant neantmoins combien il est important d'observer les regles, que l'on a jugées si necessaires pour empécher qu'il ne soit exposé dans le public aucuns traitez, qui pourroient contenir diverses maximes qui ne seroient pas approuvées si elles estoient examinées : a revoqué et revoque tous Privileges generaux qui pourroient avoir esté accordez aux Autheurs, pour les ouvrages qu'ils feront à l'avenir. À fait tres-expresses inhibitions et defenses à tous Libraires et Imprimeurs, d'imprimer en vertu de tels Privileges generaux, aucuns livres, qu'ils n'ayent veu les Privileges particuliers sur chaque ouvrage, à peine d'estre procedé contre eux comme contrevenans aux Ordonnances 124.

De fait, on recommença bientôt à accorder des privilèges généraux. Godeau, qui, en attendant, avait continué à utiliser son privilège révoqué de 1651, en obtint un nouveau en 1665 , conçu exactement dans les mêmes termes que le précédent ${ }^{125}$. L'évêque de Vence en remercia Séguier avec effusion : « Ne craignez donc pas, Monseigneur, que j'abuse du sceau; je le considéreray comme une chose sacrée, puisqu'il porte l'image du roy, et comme une marque de vostre estime et de vostre affection, qui me sont deux choses extrêmement glorieuses $»^{126}$. Pareille faveur était pourtant précaire. Godeau ayant voulu, au printemps 1668, au sommet de la répression anti-janséniste et en pleine polémique sur le Nouveau Testament de Mons, publier sa propre traduction, avec un avant-propos contre la casuistique, Séguier la fit saisir " pour ne vous en avoir point accordé de spécial privilège $»^{127}$. Une nouvelle révocation fut prononcée par arrêt du Conseil en $1673^{128}$ et confirmée, l'année suivante, par une déclaration du roi, où figurait en outre cette clause : "Voulons qu'à l'avenir il ne soit expedié aucunes permissions generales pour faire imprimer toutes sortes de Livres, en faveur de quelque Communauté ou personne particuliere que ce puisse estre ». La seule exception prévue concernait les évêques et les ordres religieux, et seulement " pour l'impression des Missels, Breviaires et autres Livres d'Eglise $»^{129}$. Cela n'empêcha pourtant pas, en 1682, un privilège général d'être délivré à Bossuet pour « faire imprimer par tel Imprimeur qu'il voudra choisir [...] tous les Livres qu'il aura composez, ou qu'il jugera à propos de faire imprimer pour l'utilité publique, et ce pendant vingt années ${ }^{130}$. En 1686 intervint une troisième révocation, qui dut être la bonne puisque ce fut la dernière ${ }^{131}$. Des privilèges généraux furent encore accordés par la suite, mais ce n'était plus qu'à titre exceptionnel - au XVIII ${ }^{e}$ siècle, les Académies royales en avaient, non seulement pour leurs mémoires, mais, de fait sinon de droit, pour tous les 
ouvrages de leurs membres; c'était encore le cas de beaucoup d'évêques, au moins pour leurs instructions pastorales ${ }^{132}$. En outre, en mars 1682, un arrêt du Conseil interdit de publier sans approbation et privilège propres les tomes nouveaux ou continuations des livres, et d'y insérer « aucun Avertissement, Préface, ou Epistre dédicatoire, s'il n'y a eu une Approbation particuliere de celuy qui aura approuvé le corps du Livre, à peine de punition $»^{133}$.

Il restait encore, pour verrouiller l'édifice, à faire respecter l'obligation exclusive du privilège royal. Dès 1604 , le chancelier de Bellièvre tenta d'interdire aux parlements d'accorder des privilèges, mais il se heurta à trop forte opposition ${ }^{134}$. Le principe fut régulièrement réaffirmé par la suite, moyennant des sanctions que leur lourdeur même rendait inapplicables : en 1626, un édit de Louis XIII portait ainsi que les imprimeurs et libraires contrevenants seraient $"$ pendus et estranglez $»^{135}$. La monarchie, surtout hors de Paris, n'imposa efficacement le monopole royal que dans les années $1680^{136}$. Le resserrement même de la procédure d'approbation avait pu inciter jusque là à publier sans privilège. Accusés en 1682 "d'imprimer et debiter toutes sortes de Livres indifferemment : Les uns contenans des Doctrines peu ou point Orthodoxes : D'autres, des Libels diffamatoires ", les imprimeurs et libraires de Lyon se défendirent en représentant «que n'ayant point été nommé des Examinateurs en ladite ville de Lyon, pour revoir des Manuscrits, ils n'ont pas eu le moyen de venir à Paris à cet effet-là ». Le roi ordonna que les lyonnais devraient désormais respecter la procédure réglementaire et que le chancelier désignerait pour l'examen des manuscrits « des Docteurs, ou autres Personnes capables, residens en ladite ville de Lyon ${ }^{137}$. Les infractions paraissaient désormais intolérables. Les parlements de province qui persistaient à délivrer des privilèges se virent sévèrement rappeler par le chancelier qu'« il n'y a que le grand sceau seul d'où puissent émaner les priviléges pour l'impression des livres, si ce n'est quand ce sont des livrets ou feuilles volantes, dont les magistrats des villes permettent l'impression, aprez qu'ils sont approuvez $»^{138}$. Un arrêt de 1701 limita ces livrets à un maximum « de deux feüilles en Caractere, dit Cicero $»^{139}$; encore Pontchartrain jugea-t-il nécessaire, en 1707, de se faire envoyer deux « exemplaires de tous ceux qui s'imprimeront dorénavant » pour pouvoir vérifier «que les juges de Police n'abusent pas de la possession où ils sont d'accorder des permissions d'imprimer [...] ces petits ouvrages $»^{140}$. Le parlement de Paris, qui semble - hormis la parenthèse de la Fronde - avoir perdu ses prérogatives en la matière plus tôt que les parlements de province ${ }^{141}$, avait imaginé un moment de les reconquérir par une voie détournée. Il était arrivé à la fin $\mathrm{du} \mathrm{XVI}^{\mathrm{e}}$ siècle et au début du XVII ${ }^{e}$ siècle, de manière très exceptionnelle, que certains bénéficiaires de privilèges royaux se souciassent de les faire enregistrer au Parlement, pour se prémunir contre toute contestation ${ }^{142}$. Le Parlement tenta de généraliser cette procédure. Enregistrant l'édit de Louis XIII de 1626, il ajouta cette restriction: «à la charge que les Lettres de privilege qui seront apres octroyees seront verifiees en la Cour, et l'Arrest de verification inserees [sic] au commencement ou à la fin desdits Livres ${ }^{143}$. Mais cette clause, qui aurait donné au Parlement le dernier mot en matière de censure préalable, n'eut aucune application. En 1663, sur une plainte des imprimeurs parisiens, un arrêt du Conseil maintint l'usage de faire enregistrer ses privilèges «sur le livre de la Communauté des Libraires de Paris seulement, qui servira pour tous les Libraires du Royaume, et autres impetrans Lettres de Privileges [...]; et sans que lesdits Libraires et autres impetrans soient tenus de faire registrer si bon ne leur semble en aucunes Jurisdictions lesdites Lettres de Privileges d'imprimer ou réimprimer $»^{144}$. 
Les contemporains étaient conscients de l'importance de l'enjeu et que l'imposition effective du monopole du grand sceau venait conclure une longue bataille. "Je sçay ", écrivait sèchement Pontchartrain à Henri François d'Aguesseau, procureur général au Parlement de Paris, à la fin du règne de Louis XIV, « que le parlement a toujours vu avec peine $\mathrm{M}^{\mathrm{rs}}$ les chanceliers connoître directement par eux-mesmes de tout ce qui concerne la librairie, et il leur a mesme toujours envié le droit de faire examiner les livres. C'est pourquoy il n'est pas surprenant qu'il me l'envie, comme à ceux ausquels j'ay eu l'honneur de succéder ${ }^{145}$.

$31 \mathrm{Au}$ début du XVIII ${ }^{\mathrm{e}}$ siècle, la dernière exception à la règle commune concernait les évêques. Ceux-ci, aussi bien, avaient joui jusque là d'une double exemption des formalités de la librairie : d'une part, ils étaient autorisés à publier sans privilège, non seulement leurs propres ouvrages mais aussi ceux qui étaient imprimés par leur ordre pour l'usage de leurs diocèses ; d'autre part, ils pouvaient obtenir un privilège sans avoir à subir au préalable l'examen d'un censeur ${ }^{146}$. Cette seconde dispense revêtait une importance symbolique considérable, alors que les évêques gallicans se représentaient de plus en plus comme docteurs de la foi. Bossuet le prit de haut en 1686, quand des controversistes protestants publièrent que son Exposition de la doctrine de l'église catholique avait été corrigée d'après les critiques de la Sorbonne: "Cette vénérable Compagnie sait trop ce qu'elle doit aux évêques, qui sont naturellement et par leur caractère les vrais docteurs de l'Église, pour croire qu'ils aient besoin de l'approbation de ses docteurs $»^{147}$. Pontchartrain n'en résolut pas moins de réduire les évêques au régime commun. À l'automne 1702, dans un conflit qui avait valeur de test, il s'attaqua à Bossuet lui-même, dont il prétendit faire examiner par un censeur royal les Instructions contre le Nouveau Testament français de Richard Simon, alors même que l'évêque de Meaux avait récemment obtenu, en mars 1701 , un nouveau privilège général pour tous ses ouvrages passés et à venir. Bossuet protesta vigoureusement : « depuis trente à quarante ans que je défends la cause de l'Église contre toutes sortes d'erreurs, cinq chanceliers consécutifs, depuis M. Séguier jusqu'à celui qui remplit aujourd'hui cette grande place, ne m'ont jamais soumis à aucun examen pour obtenir leur privilège $»^{148}$. Si les évêques, expliqua M. de Meaux, demandaient pourtant des privilèges, c'était "pour trois raisons: premièrement, afin que les actes des évêques demeurent toujours éclairés par la puissance publique ; secondement, pour faire foi qu'il n'y a aucune falsification, et que les ouvrages sont véritablement des évêques ; troisièmement, pour empêcher qu'ils ne soient contrefaits et en danger d'être altérés : ce qui regarde aussi la sûreté des libraires et la commodité du débit $\aleph^{149}$. Il s'agissait ainsi de découpler le privilège et la censure, alors que tout l'effort de la monarchie au XVII ${ }^{e}$ siècle avait été de les rendre indissociables. L'affrontement se termina par un compromis assez ambigu pour que l'une et l'autre partie en sortissent avec honneur - Bossuet, "en consideration de son merite personnel ", conservait un traitement de faveur -, mais qui était essentiellement une victoire de la censure royale ${ }^{150}$.

Le livre n'était pas, il est vrai, le seul mode de transmission de la doctrine. Un rôle considérable, surtout au XVI ${ }^{e}$ siècle et dans les deux premiers tiers du XVII siècle, était joué par les thèses. Plusieurs, qui contredisaient les principes de l'ecclésiologie gallicane sur l'autorité du pape au temporel, son infaillibilité, la juridiction des réguliers, devinrent des causes célèbres, surtout à Paris : thèses du dominicain Louis de Combout, que la Faculté de théologie contraignit à se rétracter en 1524 (après qu'il eut nié l'institution divine immédiate des évêques et des curés), thèses de l'augustin Florentin Jacob que le 
parlement de Paris poursuivit en 1595 pour avoir attribué au pape la souveraine puissance spirituelle et temporelle, thèses de Gabriel Drouet de Villeneuve, qui portaient entre autres que le Christ avait doté Pierre et ses successeurs de l'autorité la plus haute sur (et non pas seulement dans) l'Église, et qui donnèrent lieu finalement aux six Articles de 1663 , pour ne donner que quelques exemples.

La seule censure préalable ici était interne à la Faculté de théologie. Toute thèse devait, pour être admise à soutenance, être signée à la fois par le président de l'acte et par le syndic de la Faculté: les nouveaux statuts de 1598-1600 les rendaient responsables au même titre que le candidat en cas de contravention à l'orthodoxie ${ }^{151}$. La fonction de syndic, dont l'origine remonte au XIV ${ }^{\mathrm{e}}$ siècle, avait été recréée en 1520, au moment où la Faculté se trouvait confrontée aux idées de Luther, pour promouvoir l'activité de censure doctrinale de celle-ci. Son premier titulaire, le célèbre Noël Béda, n'avait pas hésité, dans sa détermination à frapper tout ce qu'il tenait pour des déviations de l'orthodoxie, à tenir tête au pouvoir royal ${ }^{152}$. Dans la seconde moitié du XVII siècle, les syndics, on l'a vu, étaient normalement des hommes de confiance de la monarchie, souvent en même temps censeurs des livres. Aussi le pouvoir royal chercha-t-il à renforcer leur autorité par des dispositions exactement parallèles à celles qui étaient adoptées en matière de librairie. En novembre 1682 - après qu'un dominicain italien venu faire sa licence à Paris eut fait imprimer des exemplaires de sa thèse avec une dédicace au pape, "qui possède la souveraineté des deux puissances »-, un arrêt du Conseil déplora que les imprimeurs ajoutassent souvent dans les titres ou les dédicaces des thèses « ce qu'il plaist à ceux qui les doivent soûtenir, d'y faire inserer ", et interdit d'en imprimer dorénavant aucune sans que l'ensemble du texte eût été approuvé par le syndic ${ }^{153}$. Dans l'ensemble, sous Louis XIV, le contrôle semble avoir été d'une efficacité réelle pour éviter les polémiques, au prix de l'aseptisation des disputes académiques et d'un certain désintérêt des étudiants ${ }^{154}$.

Il faut souligner que, sauf sans doute dans les années 1680, exactement comme pour la censure des livres, le pouvoir conféré aux administrateurs universitaires ne favorisa guère la défense des libertés gallicanes. Les statuts de 1598-1600 chargeaient le syndic de faire respecter, non seulement la doctrine orthodoxe, mais aussi « les droits et la dignité du roi et du royaume de France ». Richer y veilla durant son syndicat, de 1608 à $1612^{155}$, mais ses successeurs furent beaucoup moins vigilants. Des thèses d'une romanité militante furent admises à soutenance à plusieurs reprises ${ }^{156}$. Grandin, syndic par intérim en 1674, refusa en revanche de signer la thèse d'un bachelier où figurait cette proposition : «Les Rois et les Princes souverains ont pouvoir de faire des empêchemens annulans les mariages de leurs sujets »; il aurait fallu une intervention du président de la thèse, qui menaça de porter l'affaire devant l'assemblée plénière de la Faculté et déclara même « que si la Faculté de Theologie ne lui faisoit justice, il s'en plaindroit à Messieurs les Gens du Roi ", pour que Grandin acceptât de signer la thèse, et encore sous une forme corrigée ${ }^{157}$.

35 La censure préalable des thèses ne portait pourtant que sur celles qui étaient soutenues dans le cadre des examens universitaires. Les disputes publiques organisées hors de ce cadre, telles celles qui eurent lieu lors du chapitre général des Dominicains en 1611 à Paris, échappaient au contrôle du syndic, qui n'avait d'autre possibilité que de les dénoncer au Parlement, lorsque, comme tout un chacun, il en avait eu connaissance par les affiches ${ }^{158}$. Dans un arrêt fameux de 1624 contre des thèses atomistes dont la soutenance avait été annoncée, hors de tout cadre universitaire, le parlement de Paris fit 
"deffenses a toutes personnes a peine de la vie tenir ny enseigner aucunes maximes contre les autheurs antiens et approuvez. Ny faire aucunes disputes que celles qui seront approuvées par les docteurs de ladicte faculté de theologie » : ces dispositions, plus tard ridiculisées dans l'Arrêt burlesque de Boileau, Racine et Bernier, étaient, une fois encore, de celles que leur dureté même rendait inapplicables ${ }^{159}$. Il faut faire une place à part aux jésuites, persévéramment exclus par l'université de Paris, interdits de collation des grades, et qui, en compensation, échappaient à tout contrôle préalable pour les thèses qu'ils faisaient soutenir, à titre d'exercice et de représentation, dans leur collège de Clermont: l'absence même de débouché professionnel, si l'on ose dire, pour les études théologiques à Clermont, surtout fréquentées, dans la seconde moitié du XVII e siècle, par des jésuites et par quelques étudiants étrangers, pouvait favoriser des thèses extrêmes ${ }^{160}$. Ce fut le cas de la célèbre thèse de 1661, qui soutenait que Jésus-Christ avait laissé à Pierre et à ses successeurs "la même infaillibilité qu'il avait lui-même", et ce "tant dans les questions de droit que dans celles de fait » : selon le P. Rapin, son auteur était « un jésuite flamand, un peu aventurier de son chef ", et la thèse avait été approuvée par le préfet des hautes études du Collège, qui « la laissa passer sans se donner la peine de l'examiner $»^{161}$. La Faculté de théologie, tout comme le Parlement, ne pouvait dans de tels cas agir qu'a posteriori, sur dénonciation.

On peut encore mentionner, pour mémoire, le cas des pièces de théâtre. Jusqu'à la fin du règne de Louis XIV, elles ne furent soumises dans les faits à aucune censure préalable ${ }^{162}$. En août 1594, dans un contexte où l'histoire des Mérovingiens était susceptible de ranimer les souvenirs encore brûlants de la Ligue, le parlement de Paris intervint immédiatement lorsque des affiches annoncèrent la représentation au collège des Capettes (ou de Montaigu) de La tragédie de Chilperic roy de France, second du nom: la représentation fut interdite et défense fut faite "aux principaux et regens des autres colleges de faire reciter publiquement aucunes tragedies ni comedies, sans les avoir préalablement communiquées au procureur general du roy ${ }^{163}$. La question fut réglée de manière drastique, quelques années plus tard, par les nouveaux statuts de l'université de Paris, qui interdirent presque complètement le théâtre scolaire ${ }^{164}$, mais les autres pièces ne furent pas concernées. L'ordonnance du lieutenant civil de 1609 défendant aux comédiens «de representer aucunes Comedies ou Farces, qu'ils ne les ayent communiquées au Procureur du Roy [au Châtelet], et que leur Rôle ou Registre ne soit de Nous signé ${ }^{165}$, n'eut aucune application. Les efforts de contrôle, dans une perspective qui était avant tout de police des mœurs, s'intensifièrent à la fin du règne de Louis XIV. En 1697, « le parti dévot » tenta de faire "établir des commissaires examinateurs de toutes les pièces de théâtre avant qu'elles soient représentées, afin de n'y laisser aucune chose dont les plus scrupuleux puissent murmurer ${ }^{166}$; en 1701 , le roi fit interdire aux comédiens de représenter aucune pièce, sans l'avoir auparavant communiquée au lieutenant de police, « son intention estant qu'ils n'en puissent représenter aucune qui ne soit dans la dernière pureté $»^{167}$. Tout cela resta sans effet. Ce ne fut qu'à partir de 1706 que fut établie une véritable censure préventive, sous la direction du lieutenant de police 168 .

\section{La censure a posteriori}

L'essentiel en matière de censure se jouait $a$ posteriori. C'était dû en partie aux failles de la censure préalable, qui, même dans la seconde moitié du XVII ${ }^{e}$ siècle, était impuissante à 
garantir une orthodoxie univoque - l'Histoire critique du Vieux Testament de Richard Simon, les Réflexions morales de Pasquier Quesnel, les Maximes des saints de Fénelon, tous ouvrages solennellement condamnés par l'Église et l'État, avaient paru avec privilège et approbation -, mais aussi à la persistance des conflits de juridiction. Le pouvoir royal ne tenta jamais d'imposer son monopole à ce niveau.

La censure a posteriori s'exerçait normalement à la suite d'une dénonciation, alors qu'un ouvrage venait de paraître, avec ou sans privilège, ou d'être importé et mis en vente. Les plaintes étaient parfois tout sauf spontanées. En juillet 1644, l'évêque de Gap écrivit aux consuls de Marseille pour leur signaler les « escrits dignes du feu qu'un ministre résidant en mon diocèse a mis au jour en ces quartiers soubz le titre de Marseille sans miracles. [...] Ce sera maintenant à vous, messieurs, de voir si vous en devez avoir quelque ressentiment et faire donner sur les doigts à cest autheur insolent par les magistrats souverains et séculiers [...]. Je ne pense pas que les parlements ny le conseil laisassent la chose impunie si on leur demande justice ${ }^{169}$. Quinze jours plus tard, en tout cas, le parlement de Grenoble ordonna que Marseille sans miracles serait «brûlé en la place de S. André par l'Executeur de la Haute Justice », et décréta de prise de corps l'auteur et l'imprimeur ${ }^{170}$.

Un rôle considérable fut tenu dans cet ordre par le nonce et par les ambassadeurs étrangers à Paris, en particulier celui d'Angleterre. Sans doute fut-ce spécialement vrai au début $\mathrm{du} \mathrm{XVII}^{\mathrm{e}}$ siècle : le phénomène, et la richesse, dès lors, des correspondances diplomatiques comme sources pour l'histoire de la censure dans cette période, ont été relevés pour la première fois par les travaux pionniers d'Alfred Soman ${ }^{171}$. Mais on en trouve des exemples bien antérieurs, ainsi la curieuse affaire de La responce du peuple Anglois à leur Roy Edouard, un pamphlet qui se donnait pour la traduction d'un texte qu'auraient rédigé les habitants du Devon, pendant la Prayer Book rebellion de 1549; il incluait une vive dénonciation de la politique du Protecteur Somerset, et en particulier de sa guerre injuste contre l'Écosse ${ }^{172}$. L'ouvrage parut d'abord avec une permission du lieutenant civil, accordée le 25 octobre 1550 à un certain Jehan Riviere, prêtre, sur une supplique où celui-ci affirmait l'avoir "recouvré et transcript » et obtenu l'approbation de « Monsieur l'inquisiteur de la Foy » [le dominicain Matthieu Ory] «ainsi qu'il appert par certification cy attachée $»^{173}$. Le 5 décembre, pourtant, Robert Masselin, imprimeur de l'ouvrage, obtenait du parlement de Paris un privilège pour le réimprimer « nouvellement reformé sur le vray exemplaire, a la plus part differend des premiers ja imprimez par ordonnance du Prevost de Paris ", avec interdiction à Rivière " et tous autres Imprimeurs, Libraires de ce ressort de plus imprimer ou exposer en vente lesditz livres par cy devant imprimez par ordonnance du Prevost de Paris ou son Lieutenant civil $»^{174}$. Le texte des deux éditions semble en réalité identique mais, alors que Rivière avait dédié la première aux « Recteurs de la maison du Sainct Esprit à Pâris » (l'hôpital du Saint-Esprit-en-Grève), la nouvelle l'était par Masselin à Marie de Guise, reine d'Écosse, qui venait d'arriver en France pour des négociations décisives : la portée de l'ouvrage comme sa signification politique en étaient énormément accrues ${ }^{175}$. Sur les plaintes de l'ambassadeur d'Angleterre, Sir John Mason, Henri II, en février 1551, donna l'ordre au parlement de Paris de supprimer l'ouvrage, « et le lendemain est ordonné que l'un des Huissiers de la Cour saisira tous les exemplaires, avec defenses à tous autres de l'imprimer ny vendre, et seroit publié à son de trompe, que tous ceux qui en avoient en leurs maisons, les rapporteroient au Greffe de la Cour dans le lendemain sur peine d'amende arbitraire ${ }^{176}$. 


\section{La censure répressive : juges de police et parlements}

40 Une fois qu'une plainte avait été reçue, la juridiction responsable pour la censure proprement répressive (la " police ») était normalement, pour Paris, le Châtelet, qui prit de nombreuses sentences pour « supprimer » des livres, en interdire la vente et, dans les cas les plus graves, les faire brûler publiquement, soit place de Grève soit à la Croix du Tiroir (au coin de la rue de l'Arbre Sec) ${ }^{177}$. Le premier magistrat du Châtelet était, on l'a vu, le prévôt ou, pour lui donner son titre exact, le garde de la prévôté de Paris, au nom duquel étaient rendues toutes les sentences. Le rôle effectif semble avoir dès lors été joué par le lieutenant civil ${ }^{178}$.

41 Des condamnations pouvaient aussi être portées directement par les parlements, tant à Paris qu'en province : leurs arrêts comportaient les mêmes dispositions pratiques que les sentences des juges de police, mais la solennité était plus grande puisqu'ils n'étaient pas susceptibles d'appel. Par arrêt du 26 novembre 1610, le parlement de Paris fit ainsi «inhibitions et défenses à toutes personnes, de quelque qualité et condition qu'elles soient, sur peine de crime de leze-Majesté, recevoir, retenir, communiquer, imprimer, faire imprimer, ni exposer en vente» le Tractatus de potestate Summi Pontificis in rebus temporalibus du cardinal Bellarmin. L'arrêt du 26 juin 1614 contre la Defensio fidei de Suárez fit les mêmes interdictions et ordonna en outre «ledit Livre de Suarez être brûlé en la Cour du Palais par l'Executeur de la haute Justice $»^{179}$.

Le Parlement pouvait même ordonner l'expurgation des livres et la correction des exemplaires. On en a au moins un exemple, celui de la Gerusalemme conquistata du Tasse version remaniée du poème, notamment dans un esprit de Contre-Réforme qui faisait droit aux critiques autrefois adressées à la Liberata par les réviseurs romains. La première édition parut à Rome en 1593, "avec privilèges de Notre Seigneur, de la Sérénissime République de Venise, et de tous les autres princes d'Italie "; Lelio Pellegrini, que le Maître du Sacré Palais avait chargé d'examiner l'ouvrage, vantait « le sublime du poème, le rare savoir en tout genre, l'immense abondance des allégories disposées avec art ${ }^{180}$. La Conquistata fut republiée à Paris deux ans plus tard, sans privilège ni permission, par Abel L'Angelier, un libraire qui s'était notamment spécialisé dans la littérature italienne. Or le chant XX, un des chants nouveaux, décrivait la vision de Godefroy de Bouillon, transporté au Ciel en rêve et à qui son père Eustache prophétisait l'histoire des papes jusqu'à Clément VIII, qu'il louait comme seul capable de sauver la France affligée, dont la dynastie avait été frappée d'anathème ${ }^{181}$. Ces strophes ne passèrent pas inaperçues, juste au moment où se négociait à Rome l'absolution de Henri IV. Le $1^{\mathrm{er}}$ septembre 1595 l'absolution fut prononcée par Clément VIII le 17 -, «peu de jours » après que le livre fut sorti des presses, le procureur général au parlement de Paris dénonça à la Cour «des paroles diffamatoires contre le defunct Roy Henry III et contre le Roy regnant, et sur la proposition des fulminations faites à Rome pendant les derniers troubles, et pour persuader qu'il est en la puissance du Pape de donner le Royaume au Roy, et le Roy au Royaume $^{182}$; qui sont termes prejudiciables à l'Estat, desquels il a fait lecture ». Sur ce réquisitoire,

Ladite Cour a ordonné et ordonne, que les dix-neuf vers contenus en la nouvelle edition dudit livre de Tasso, au vingtiesme livre, feuillet 270. depuis celuy qui commence Sisto, jusques au 19. commençant Chiama, iceluy comprins, seront rayez et biffez tant dudit livre, que [des] exemplaires d'iceluy qui se trouveront imprimez en cette ville, lesquels à cette fin seront saisis, pour estre ladite page corrigée et 
remise selon la premiere edition [la Liberata]. A fait et fait inhibitions et defenses à l'Angelier, qui a fait imprimer ledit livre, et tous autres, d'en vendre et debiter aucuns, jusques à ce que ladite correction en ait esté faite [...] : et a enjoint et enjoint à toutes personnes qui ont achetez lesdits livres de ladite nouvelle edition, et qui en ont en leur possession, de les rapporter pour estre reformez; et en cas qu'ils en soient trouvez saisis, sera contre eux procedé ainsi que de raison ${ }^{183}$. condamner les livres imprimés dans leur ressort ni même ceux qui, publiés à Paris, étaient, si l'on peut dire, d'intérêt régional - comme quand le parlement d'Aix supprima le traité de Jean de Launoy contre la légende des Saintes-Maries-de-la-Mer ${ }^{185}$. Une des sentences les plus célèbres du XVII ${ }^{\mathrm{e}}$ siècle fut celle du même parlement d'Aix contre les seize premières Provinciales de Pascal, jugées «diffammatoires, calomnieuses et pernicieuses au Public : et en consequence ordonne [la Cour] qu'elles seront remises entre les mains de l'Executeur de la haute Justice, pour estre par luy brûlées sur le Pilory de la place des Prescheurs de cette ville d'Aix $»^{186}$. Cette condamnation s'inscrivait dans une polémique nationale et ne visait pas tant à empêcher la diffusion de l'ouvrage en Provence - les magistrats firent brûler un almanach à sa place, pour n'en sacrifier aucun exemplaire ${ }^{187}-$, qu'à retentir symboliquement dans tout le royaume, et même au-delà : l'arrêt fut réimprimé à Paris et même inséré dans la Gazette de Renaudot ${ }^{188}$. Elle relève en plein de ce qui a été nommé avec bonheur, pour le XVIII siècle, la «censure à grand spectacle », à laquelle la publicité était essentielle ${ }^{189}$.

\section{La censure répressive : le pouvoir royal}

Le Conseil du roi intervenait également, soit pour condamner des livres en première instance, en vertu de la «justice retenue » du monarque, soit pour suspendre ou casser les arrêts des parlements. Dans le premier cas, la gamme des dispositions, jusqu'à la condamnation au feu, était la même que celle du Châtelet ou des parlements ${ }^{190}$. Il s'agissait notamment de livres ultra-gallicans - ou si l'on préfère, pour reprendre la distinction célèbre de Bossuet, expliquant les libertés de l'Eglise gallicane « de la manière que les entendent les magistrats ", non les évêques -, ou de tendance richériste, que le parlement de Paris n'aurait pas été disposé à condamner ${ }^{191}$. Le cas le plus connu est sans doute celui des deux volumes de Pierre Dupuy, Traitez des droits et libertez de l'Eglise gallicane et Preuves des libertez de l'Eglise gallicane, dont, sur les plaintes du nonce, un arrêt du Conseil du 20 novembre 1638 défendit la vente et la distribution, en se gardant de toucher au fond mais sous le commode prétexte qu'ils avaient été imprimés sans privilège ${ }^{192}$. La mesure, qui eut un écho européen, permettait à Richelieu de dégager officiellement sa responsabilité vis-à-vis de Rome - Rome en fut dupe ou feignit de l'être -, mais elle n'empêcha pas l'ouvrage de continuer à être diffusé, avec la connivence du cardinal ${ }^{193}$.

Parmi les interventions du second type, on peut citer la suspension de l'arrêt du parlement de Paris contre Suárez, que les plaintes de Paul V finirent par arracher au gouvernement de Marie de Médicis, en décembre 1614 - le pape aurait même voulu sa cassation, mais le pouvoir royal se déclara hors d'état d'affronter aussi ouvertement le Parlement ${ }^{194}$. On en arrive parfois à ce qu'on a appelé, pour le XVIII ${ }^{\mathrm{e}}$ siècle, les « censures à tiroir $»^{195}$ : arrêt du Conseil portant cassation d'un arrêt du parlement de Rouen interdisant à l'archevêque de publier sa censure d'un livre... ${ }^{196}$ 

d'imprimeurs, saisies des exemplaires, soit à titre provisoire en attendant un arrêt du Conseil - la «saisie » est alors bien distinguée de la «suppression -, soit pour supprimer définitivement un livre. On a évoqué l'affaire de Petrus Aurelius, réimprimé sur ordre de l'Assemblée du clergé en 1642: «incontinent après la séparation de l'Assemblée, le Sr. Vitré, Imprimeur du Clergé, pour avoir exécuté ses ordres en cette impression, fut arrêté chez lui par le Lieutenant-Criminel, les exemplaires qui étoient en son logis, saisis par autorité du Roi, et transportés avec lui chez M. le Chancelier ». Ils y étaient encore en 1645, quand le chancelier déclara à une délégation de la nouvelle Assemblée du clergé « ne pouvoir rendre les exemplaires, qui avoient été portés en son logis, au nombre de 40 ou environ, à cause qu'ayant été mis en un grenier, ils avoient été mouillés, et s'étoient pourris »; il précisa qu'il avait "eu un ordre exprès du feu Roi de les faire supprimer ». Saisie et suppression sont donc ici synonymes, même si la charge symbolique de la mesure est plus importante que le nombre, finalement restreint, des exemplaires concernés ${ }^{197}$. Dans le cas du Nouveau Testament de Godeau, en 1668, Séguier le fit «saisir par un huissier de la chaisne » - un des quatre huissiers de la Grande Chancellerie : la saisie n'était ici qu'une interdiction provisoire de mise en vente ${ }^{198}$.

Après la création de la charge de lieutenant général de police de Paris, en 1667, ce fut normalement à ce magistrat que le chancelier donnait ses instructions et transmettait les ordres du roi. Le mécanisme de la destruction de l'Histoire critique du Vieux Testament, de la dénonciation à la suppression effective, a pu ainsi être reconstitué précisément. Billaine, un des libraires les plus réputés de Paris, faisait imprimer l'ouvrage avec approbation et privilège : en avril 1678, il ne restait plus que les préliminaires à ajouter. Un érudit lié à Bossuet, Nicolas Toinard, qui fréquentait assidûment les ateliers d'imprimerie, découvrit la table des matières de l'ouvrage et alerta celui qui était alors le précepteur du dauphin. Bossuet se précipita à son tour chez le chancelier Le Tellier, lequel commanda au lieutenant de police La Reynie, le 9 avril, «de faire saisir les exemplaires dudit livre, de faire défenses audit Billaine d'en exposer en vente, et de vouloir m'envoyer deux dits exemplaires pour en faire faire un second examen ». La Reynie transmit cet ordre le lendemain au commissaire de La Mare. Le 13 avril, celui-ci se fit accompagner par la femme de Billaine chez l'imprimeur Antoine Lambin, qui déclara avoir tiré 600 exemplaires, "lesquels sont encore chez lui et entre ses mains, et qu'il nous a représentés » : l'interdiction de vente ayant été signifiée, les livres furent laissés en dépôt chez l'imprimeur, "jusqu'à ce que par justice ait été ordonné ». Le 30 avril, une précaution supplémentaire parut nécessaire: sur ordre du lieutenant de police, le commissaire retourna chez Lambin pour faire « compter et mettre ensemble en quelque endroit par paquets séparés tous les exemplaires » et apposer des scellés sur les paquets. Rebondissement un mois plus tard: la police apprend, sans doute par des indicateurs, que des exemplaires cachés chez des relieurs ont échappé à la saisie. La femme Billaine avoue qu'elle avait tiré, non pas 600, mais 1300 exemplaires, « que si elle n'a pas déclaré d'abord cette quantité c'est qu'elle n'en a pas connu la conséquence, ne croyant pas que ce livre serait supprimé ». Les 700 exemplaires manquants sont rapportés chez l'imprimeur, le 28 mai, et joints aux autres dans des paquets sous scellés. Le 19 juin, un arrêt du Conseil supprime finalement l'Histoire critique ; La Reynie le fait tenir le 23 à La Mare, qui retourne alors une dernière fois chez Lambin : «Et ensuite avons chargé lesdits exemplaires dudit livre dans deux charrettes et conduit en notre hôtel pour être supprimés ». Le 17 juillet, La Reynie ordonne de procéder à la suppression : en cinq trajets successifs, du 18 juillet au 2 août, La Mare fait transporter toute l'édition «en la maison de Jean Dumondel 
marchand papetier à Paris ", où il «fait déchirer les exemplaires et broyer dans l'eau par ledit Dumondel et ses compagnons pour en faire du carton, au moyen de quoi lesdits exemplaires sont devenus bien et dûment supprimés conformément audit arrêt $»^{199}$.

\section{La censure doctrinale : les facultés de théologie} doctrinale - c'est-à-dire, une fois encore, de ce que le XVII ${ }^{e}$ siècle entendait en priorité par censure -, réservée aux instances religieuses. En réalité, la frontière n'était pas rigoureuse. Les sentences et les arrêts donnaient aux livres condamnés et aux "propositions" qu'ils contenaient, des «notes", telles qu'en utilisaient aussi les théologiens. Il s'agissait avant tout de notes plus morales que théologiques, au premier chef "séditieuse ", mais aussi "calomnieuse", «pernicieuse", «scandaleuse ", ou "tendant à subversion des États ${ }^{200}$. La distinction théorique entre hérésie et sédition avait permis au XVI ${ }^{e}$ siècle de confier aux parlements la répression de la Réforme ${ }^{201}$; une fois le protestantisme en général, et le livre protestant en particulier, légalement reconnus par l'édit de Nantes, c'est $a$ fortiori en tant que séditieux et non qu'hérétiques que les juges royaux condamnent certains ouvrages huguenots ${ }^{202}$. Mais d'autres notes, surtout celle de «fausse", paraissent bien toucher à la doctrine même, ainsi quand le Parlement condamna le Tractatus de potestate Summi Pontificis in rebus temporalibus de Bellarmin comme " contenant une fausse et detestable proposition ${ }^{203}$. Plus nettement encore, l'arrêt de 1595 contre Florentin Jacob déclara deux articles de ses thèses "faux, schismatiques, contraires à la parole de Dieu, saincts Decrets, constitutions Canoniques, et loix du Royaume, tendans à rebelion et perturbation du repos public »"204. En 1660, à la suite d'un scandale lors de la soutenance d'une thèse de théologie, le lieutenant criminel au bailliage et présidial de Caen déclara un prêtre de la ville «deuement atteint et convaincu d'avoir avancé plusieurs propositions fausses, seditieuses, et contraires à l'authorité du Roy, et entr'autres Que le Pape pouvoit establir et deposer les Roys ». Se rendant ensuite à l'Université, le procureur du roi « a remontré combien les propositions mises en avant par ledit Fossart sont contraires à l'Ecriture sainte, et à ce que Jesus-Christ et ses Apôtres ont enseigné, et pratiqué pendant qu'ils estoient en ce monde, aux saints Decrets et Constitutions de l'Eglise et des Papes, mémes aux Loix fondamentales de cette Monarchie, laquelle ne dépend que de Dieu seul, et aux droits, libertez, police, privileges de l'Eglise Gallicane " ${ }^{205}$. De même que les notes théologiques «sortent insensiblement du domaine dogmatique - hérésie ou erreur - pour s'engager sur le terrain moral, politique et même littéraire ${ }^{206}$, les magistrats ne peuvent s'empêcher de pénétrer dans l'ordre doctrinal.

Il n'est pas indifférent que les deux exemples d'empiètement patent que l'on a donnés correspondent l'un et l'autre à une intervention des magistrats royaux contre des thèses universitaires, qui avaient échappé aux contrôles préventifs des facultés de théologie. En temps normal, la censure proprement doctrinale appartenait à ces dernières, avec lesquelles les parlements avaient conclu comme un partage des tâches. À la fin du XV siècle déjà, lorsque l'astrologue Simon de Phares, condamné par l'official de Lyon, fit appel au parlement de Paris, ce dernier décida de remettre les livres confisqués à Phares à la Faculté de théologie pour qu'elle les examinât et "condamnât par son autorité doctrinale " ce qu'elle y trouverait de "contraire à la foi orthodoxe et aux bonnes mœurs »: la Faculté condamna les livres et le Parlement prit ensuite un arrêt pour les interdire ${ }^{207}$. Ce précédent fut invoqué avec succès contre la Réforme, au temps où Faculté 
et Parlement étaient les piliers du " parti conservateur ». Ainsi, l'arrêt du parlement du 12 août 1523 ordonnant que tous les livres de Luther, «comme damnez et reprouvez seront bruslez publiquement au Parvis devant l'Eglise de Paris », et interdisant « de ne tenir, alleguer, ne soubstenir les dicts livres et de ne ensuyvir la doctrine du dict Luther ", se réfère expressément, dans ses considérants, à « la détermination sur ce faicte par la Faculté de Theologie de l'Université de Paris $»^{208}$.

51 L'alliance entre Faculté de théologie et parlement de Paris se distendit après $1550^{209}$, mais on la retrouve fréquemment au XVII e siècle. Dans cette période en tout cas, il vaut sans doute mieux parler d'une espèce d'accord de délégation, les deux parties n'étant certes pas à parité : le Parlement contrôlait l'activité doctrinale de la Faculté et lui interdisait le cas échéant de procéder à une censure ${ }^{210}$. Dans l'affaire déjà rencontrée des thèses atomistes de 1624, le Parlement ordonna par arrêt, le 29 août, qu'elles seraient communiquées « aulx docteurs de la faculté de theologie pour cotter ce qui est de vicieulx en icelles ${ }^{211}$; la Faculté ayant proncé sa censure le 2 septembre, le Parlement rendit deux jours plus tard un arrêt, qui ordonnait la lacération des thèses, vu « l'advis de ladicte faculté du deuxiesme septembre contenant la censure des propositions contenues esdictes thezes $»^{212}$. Quelques mois plus tard, le premier président transmit directement au syndic un traité d'alchimie, l'Amphitheatrum Sapientiae Æternae de Heinrich Khunrath, que la Faculté condamna avec des notes extrêmement sévères, jugeant «qu'un livre si contagieux ne peut estre leu, ny exposé en public sans perte de la Foy, de la Religion, et de la pieté $\aleph^{213}$. On retrouve cette association en province. Le parlement d'Aix fit examiner par la faculté de théologie de la ville le traité de Launoy contre la légende des SaintesMaries-de-la-Mer (Disquisitio disquisitionis de Magdalena Massiliensi aduena) : la Faculté le censura, en mars 1644. Deux semaines plus tard, le Parlement s'appuya sur cette censure - durcie du reste par le procureur général sous prétexte de la résumer - pour déclarer l'ouvrage « impie et scandaleux », et ordonner sa suppression ${ }^{214}$.

Dans ce cas, comme dans celui de l'Amphitheatrum de Khunrath, la censure portait contre le livre dans son ensemble. En général, pourtant, les facultés de théologie condamnaient des propositions extraites des livres et, de préférence, sigillatim, c'est-à-dire en affectant à chacune ses propres notes de censure. Ce fut le cas par exemple pour la grande censure de la Faculté de Paris contre Érasme, en 1527, qui condamnait en détail, à travers 112 propositions réparties en trente-deux sections thématiques, toutes les idées et les aspirations de l'humanisme religieux ${ }^{215}$. Sur des questions comme la traduction de l'Écriture en langue vulgaire ou la légitimité de la critique historique et philologique, elle demeura jusqu'à la fin du XVII ${ }^{e}$ siècle une référence majeure des conservateurs - les théologiens et les érudits de Port-Royal s'efforçaient au contraire de la relativiser en la replaçant dans son contexte ${ }^{216}$. Cette méthode de censure était considérée en France comme la seule efficace, par opposition aux censures in globo que l'on pratiquait volontiers à Rome, en condamnant une liste de propositions avec une série de notes prononcées respective: les fidèles étaient alors tenus de croire qu'il n'y avait pas une proposition qui ne méritât au moins une note de censure, et pas une note qui ne s'appliquât au moins à une proposition, mais le rapport exact entre notes et propositions était laissé à l'interprétation des théologiens. Les quatre-vingt-cinq évêques français qui s'adressèrent à Innocent X, en 1651, pour lui demander la condamnation des cinq propositions, lui représentèrent que son prédécesseur Urbain VIII, par la bulle In eminenti, avait condamné l'Augustinus de Jansénius et renouvelé les constitutions de Pie $\mathrm{V}$ et Grégoire XIII contre les propositions de Baïus : «mais, comme aucune note de censure 
précise n'a été attachée en particulier à aucune proposition, un espace a encore été laissé aux chicanes et aux évasions de certains $»^{217}$. La prédilection française pour les censures sigillatim devint même un motif de fierté gallicane ${ }^{218}$. En 1696, pendant l'examen de La mystique Cité de Dieu de Marie d'Agreda à la Sorbonne, Mabillon écrivait ironiquement au procureur de la congrégation de Saint-Maur à Rome :

Tout le gros convient assez que ce livre est plein d'extravagances et d'imaginations creuses que cette bonne fille a voulu faire passer pour de veritables revelations. Mais tous les Docteurs ne conviennent pas des qualifications des députés. En effet il y a une proposition, je crois que c'est la premiere, qui est traitée d'impiété et on a de la peine a y en trouver. Je crois que ces Messieurs seront obligez d'en revenir a la methode Romaine dont ils se sont mocquez autrefois qui est de censurer in globo les propositions reprehensibles avec un respective $e^{219}$.

Mais ce fut surtout au XVIII ${ }^{e}$ siècle, après que Rome eut encore usé voire abusé de cette " commodité dangereuse » dans la bulle Unigenitus ${ }^{220}$, que l'option entre censures sigillatim et in globo devint quasiment une profession de foi. Lorsque la Sorbonne recourut au respective en 1752, pour condamner les propositions extraites de la thèse de l'abbé de Prades, les Nouvelles ecclésiastiques protestèrent que « l'ancienne Sorbonne [...] avoit laissé à la Cour de Rome le fréquent usage d'une métode, qui par sa confusion et son obscurité, ressemble trop aux anciens Oracles du Paganisme ». Et le gazetier janséniste de citer le bon mot d'un magistrat: "Si nous rendions un Arrêt contre cinq ou six Criminels, et que nous les condannassions tous respectivement au bannissement, au fouet, aux Galeres, à être pendus, roués etc : comment le Bourreau s'y prendroit-il pour exécuter le Jugement ${ }^{221}$ ?

Si vives qu'eussent pu être, contre les «théologastres » de Paris, les attaques de ceux qu'ils avaient condamnés, le rôle des facultés de théologie ne fit guère l'objet de contestations institutionnelles en France. Après que celle de Paris eut condamné sa Bible, René Benoist tenta de lui opposer l'autorité de l'évêque de Paris, Pierre de Gondi, qui lui était favorable et «auquel comme l'approbation, aussi la reprobation des Livres appartient de droit». En 1574, Benoist avertit ses confrères "que suivant la détermination des députez du saint et œcumenique Concile de Trente [...], Monseigneur de Paris ne veut et n'entend que ce négoce soit terminé sans que son autorité y intervienne $»^{222}$. La Faculté accusa en retour Benoist de chercher, pour éluder sa condamnation, à «mettre zizanie et trouble entre Monsieur l'Evêque de Paris et icelle Faculté », et porta l'affaire au Saint-Siège ${ }^{223}$. Grégoire XIII, par un bref d'octobre 1575, approuva la censure de la Faculté et loua sa soumission au Saint-Siège et son zèle pour la foi catholique, sans aucune mention de l'évêque de Paris ${ }^{224}$. Dans l'intervalle, une seconde affaire avait mis aux prises Gondi et les docteurs, celle du jésuite Maldonat, professeur au collège de Clermont, que la Faculté avait accusé d'hétérodoxie : l'évêque - pour se venger, si l'on en croit la Faculté, de l'affaire Benoist -, déclara que Maldonat n'avait rien enseigné de contraire à la foi catholique, et menaça les docteurs d'excommunication s'ils le censuraient. La Faculté eut recours au Parlement, auquel elle appella comme d'abus : en août 1575, celui-ci, du moins d'après la Faculté, déclara « la sentence de l'évêque de Paris nulle et sans effet ». Elle écrivit ensuite au pape pour se plaindre que Gondi l'attaquait dans son «droit de porter des censures». Les versions des deux parties sur le déroulement de l'affaire diffèrent fortement mais il paraît clair que la Faculté en sortit confortée dans ses prérogatives ${ }^{225}$.

55 Si les jésuites ne tinrent qu'un rôle annexe dans le conflit entre Gondi et la faculté de Paris, ils menèrent eux-mêmes, en 1645, l'attaque contre la faculté de théologie de Toulouse, après que celle-ci eut censuré le De Scientia media du P. François Annat. Les 
jésuites portèrent l'affaire au Conseil du roi, «demandant la suppression de la Censure avec déffense au dict doyen et autres du corps de la dite Université d'entreprendre à l'advenir de censurer les livres qui seront composés par les religieux de ladite compagnie, approuvés par les docteurs et imprimés par la permission et privilège de Sa Majesté ». Les universités de Bordeaux, Caen, Cahors, Orléans, Paris, et Reims prirent fait et cause pour celle de Toulouse ; l'Assemblée du clergé intervint auprès du chancelier - « d'autant que cette affaire regarde non-seulement les privileges des Universités, dont les Evêques sont les Protecteurs, mais qu'il s'y agit d'une censure doctrinale; de la validité de laquelle le jugement appartient à l'Ordinaire »-, et obtint l'arrêt des procédures ${ }^{226}$.

56 À Rome, en revanche, les censures doctrinales de la faculté de Paris, qui avaient été considérées avec faveur au temps de Benoist, ne paraissaient plus au XVII siècle qu'un empiètement sur les prérogatives pontificales, qui ne devait être encouragé en aucune circonstance $^{227}$. En 1665, la bulle Cum ad Aures d'Alexandre VII condamna comme "présomptueuses, téméraires et scandaleuses» les censures de la Sorbonne contre Vernant et Guimenius : au-delà de leur contenu, c'était le droit même à la censure qui était en cause ${ }^{228}$. Le parlement de Paris - magnifique exemple de censure à tiroir - réagit en supprimant la bulle et en maintenant « la Faculté de Theologie de Paris en son Droit et possession de Censurer tous les Livres qui contiendront des Propositions contraires à l'authorité et discipline de l'Eglise, à la pureté de la Morale Chrestienne, aux Droits de la Couronne et aux Libertez de l'Eglise Gallicane $»^{229}$.

57 La censure universitaire était pourtant affectée d'une ambiguïté jamais résolue: s'agissait-il d'une prérogative des universités ou des seuls docteurs en théologie, à l'exclusion de leurs confrères des autres facultés? Les réponses varièrent selon les circonstances locales et les contextes. En 1527, François ${ }^{\text {er }}$, pour contourner la Faculté de théologie, voulut faire examiner par toute l'université de Paris les Duodecim articuli infidelitatis Bedae - censure anonyme des censures du syndic Béda contre Érasme et Lefèvre d'Étaples. L'Université, après de longues discussions, décida de s'en remettre aux seuls théologiens, "puisque l'affaire concerne le droit divin $»^{230}$. Réciproquement, après que la faculté de théologie de Paris eut adopté, le 4 avril 1626, une censure contre le Tractatus de haeresi du jésuite Santarelli ${ }^{231}$, l'Université tout entière y adhéra. La plupart des universités de France suivirent cet exemple ${ }^{232}$. Celle d'Angers le fit, au mois de juin, sans avoir consulté sa propre faculté de théologie: les docteurs en théologie firent opposition à ce décret, au motif que «nous ne devons pas recevoir la règle de doctrine des professeurs des sciences et arts inférieurs, mais de l'Église et de ses pasteurs »; le décret fut modifié pour faire droit à cette protestation ${ }^{233}$. Quand la faculté de théologie de Toulouse, en revanche, censura le De Scientia media, elle rappela en préambule que «les Universités catholiques du monde chrétien » étaient « spécialement chargées de veiller à ce qu'on ne répande des doctrines hérétiques ", et précisa qu'elle était "assemblée à ce sujet, du consentement de Monsieur le très-sage Recteur et de tous les très-célèbres Docteurs Régens de toutes les autres Facultés de l'Université »"234.

58 En décembre 1626, toujours dans le contexte de la controverse autour du livre de Santarelli et des vifs affrontements entre romains et gallicans, l'université de Paris prit un décret ordonnant la rétractation du dominicain Jean Testefort, qui avait soutenu une thèse au papalisme provocateur, mais dont les romains empêchaient la censure à la Faculté de théologie ${ }^{235}$. Les romains firent alors intervenir leurs soutiens dans l'épiscopat, et ceux-ci obtinrent une déclaration du roi, dix jours plus tard, cassant le décret et interdisant au recteur de l'Université de traiter de questions de foi. Selon l'exposé de la 
déclaration, l'assemblée tenue par le recteur était «composée pour la pluspart de Maistres és Arts et Medecins ». Dès lors :

ledit Decret fait une entreprise la plus pernitieuse et du plus dangereux exemple que l'on puisse imaginer; en ce qu'au scandale de toute l'Eglise, une Compagnie de personnes de Professions differentes à la Theologie qui n'ont aucune doctrine, degré, caractere ny Mission, pour parler, disputer, traitter, terminer et resoudre les points de la Theologie et de l'Escriture, s'ingerent d'y prononcer et de publier et enseigner aux sujets du Roy, qu'en eux est la science de la verité et la puissance de declarer ce qui est conforme et aliené de la véritééc ${ }^{36}$.

Le recteur protesta dans une requête au roi, où il alléguait notamment le rôle tenu par l'Université dans la rétractation imposée en 1430 au dominicain Jean Sarrazin, lequel avait soutenu dans ses thèses que la juridiction épiscopale dérivait du pape, et non immédiatement de Dieu - autre grande référence gallicane ${ }^{237}$. Un arrêt du Conseil du 8 juillet 1631, rendu sur cette requête, maintint finalement l'université de Paris dans ses privilèges.

Malgré les efforts des intéressés, surtout à Paris, pour préserver «le magistère de la Faculté de théologie ", il paraît clair que celui-ci connut au XVII ${ }^{e}$ siècle une espèce d'exténuation, en raison des divisions du corps, du recours croissant à des interventions extérieures, autoritaires voire brutales, pour trancher les affrontements entre docteurs, au mépris de la liberté des débats, et, en dernière analyse, de l'instrumentalisation des censures de la Faculté par le pouvoir royal, qui s'en fit une arme diplomatique dans ses conflits avec Rome ${ }^{238}$. La politisation des débats doctrinaux ne pouvait qu'affaiblir le prestige de la Faculté, que minait aussi, d'un autre côté, leur "littérarisation " ${ }^{239}$. La Sorbonne se trouvait prise entre le pouvoir et le public. Plus subtilement, dans le champ même de la théologie, la nature de son autorité se trouvait réduite et restreinte. Au début $\mathrm{du} \mathrm{XVI}^{\mathrm{e}}$ siècle, le syndic Béda la définissait d'après les conciliaristes du XV siècle. Il s'en expliqua avec une parfaite netteté, en 1522, en réponse à son collègue et ennemi Jacques Merlin, qui avait prétendu exclure de l'examen de son Apologie pour Origène un certain nombre de docteurs «suspects » dont Béda lui-même ${ }^{240}$. Le syndic en appela à Gerson pour maintenir que tout titulaire d'un grade en théologie était " examinateur et juge » à un double titre : il n'était pas seulement juge "doctrinal», en raison de sa compétence technique, mais juge « authentique, en vertu du pouvoir [d'enseignement] qu'il a reçu du Saint-Siège $»^{241}$. Autant dire que la Faculté était une instance doctrinale hiérarchique, investie d'une mission par l'Église universelle. Cette conception fut réfutée au XVII siècle par le jésuite Théophile Raynaud, qui soutint contre Gerson que les docteurs n'avaient en tant que tels aucune autorité doctrinale, mais seulement « une aptitude à être employés par les pasteurs à la discussion des questions douteuses, et à être comme les jurisconsultes des prélats » : et cette aptitude ne dépendait pas du grade mais appartenait " également à tout homme docte, même s'il n'est pas docteur " ${ }^{242}$. Raynaud trouva ici l'approbation du très gallican Adrien Baillet ${ }^{243}$. Ni l'un ni l'autre n'étaient docteurs. Mais on retrouve la même affirmation dans la bouche du chancelier Séguier en 1644, comme argument pour envoyer Arnauld à Rome et y faire juger la doctrine de la Fréquente Communion - et les parlementaires, qui s'élevèrent contre cette atteinte aux libertés de l'Église gallicane, ne le contredirent pas sur ce point ${ }^{244}$. Les docteurs eux-mêmes, non seulement les romains ${ }^{245}$, mais même les gallicans, posaient comme un axiome que la Faculté n'a « qu'un jugement nuëment doctrinal ${ }^{246}$ ». Le docteur n'était plus qu'un expert, à la manière des consulteurs des congrégations romaines. 


\section{L'épiscopat}

\section{Évêques et censure préalable : les principes et la réalité}

61 Ce jeu à trois, entre pouvoir royal, magistrats et docteurs, laissait peu de place aux évêques, tout particulièrement s'agissant de la censure préventive, alors même qu'ils auraient dû, d'après le droit canonique, y tenir le rôle principal. Dès 1487, la constitution Inter multiplices d'Innocent VIII, premier texte pontifical sur le sujet, interdit, sous peine d'excommunication latae sententiae « et d'une amende pécuniaire à la discrétion des ordinaires des lieux ", de rien imprimer ou faire imprimer sans permission, à Rome du Maître du Sacré Palais, ailleurs des ordinaires, à charge pour ceux-ci «d'examiner soigneusement les textes à imprimer ou de les faire examiner par des personnes compétentes et catholiques", "afin qu'on n'imprime rien qui soit contraire à la foi orthodoxe, impie et scandaleux $»^{247}$. Il a été suggéré que cette bulle n'avait " connu qu'une diffusion restreinte », ce qui expliquerait qu'Alexandre VI l'eût reprise telle quelle en 1501, mais en ne l'adressant cette fois qu'à quelques diocèses allemands, où les évêques, concernés au premier chef par l'imprimerie, avaient tôt entrepris d'établir une censure préalable ${ }^{248}$. Elle n'était pourtant pas inconnue en France puisque le prédicateur franciscain Olivier Maillard la cita en chaire, à la fin du XV $\mathrm{X}^{\mathrm{e}}$ siècle, dans une digression contre les libraires, coupables d'imprimer « de misérables livres qui traitent de luxure et de l'art d'aimer », alors que « le pape Innocent ordonne qu'on n'imprime pas de livres s'ils ne sont vus par l'évêque, ou par son vicaire ou député ${ }^{249}$.

62 À la veille de la Réforme, la constitution Super impressione librorum que Léon X promulgua en 1515 au concile de Latran V confia à nouveau aux évêques, conjointement avec les inquisiteurs, la censure préalable ${ }^{250}$. Après des discussions parfois vives à Trente, plusieurs pères auraient voulu réserver toute la censure au Saint-Siège, d'autres partager l'autorité en la matière entre évêques et inquisiteurs, l'un d'entre eux ne craignit pas de déclarer que les évêques étaient en grande majorité incompétents, et que, si on leur laissait cette responsabilité, " il y en aura beaucoup qui consentiront à l'impression de n'importe quel livre pour un morceau de pain ", - le concile interdit en 1546 d'imprimer ou de vendre aucun livre traitant de religion "s'il n'a pas été d'abord examiné et approuvé par l'ordinaire ${ }^{251}$. L'Index du concile, en 1564, reprit les dispositions de Latran $\mathrm{V}$ pour la censure préalable, et confia en outre aux évêques, toujours associés aux inquisiteurs, la surveillance des imprimeries et librairies, qu'ils devaient faire fréquemment visiter par leurs délégués ${ }^{252}$. Entre Latran et Trente, le concile de la province de Sens (dont faisait alors partie le diocèse de Paris) réuni en 1528 par Antoine Duprat - lequel n'était pas seulement cardinal-archevêque de Sens mais aussi chancelier de France -, interdit d'imprimer "les livres sacrés, ou ceux des saints docteurs, qui traitent de la foi et des mœurs ecclésiastiques » sans permission spéciale du métropolitain et de ses suffragants dans leurs diocèses ${ }^{253}$. Tout livre traitant de la foi et des mœurs devrait être muni d'un certificat de l'évêque, attestant qu'il l'avait examiné ou fait examiner et qu'il en permettait la lecture ${ }^{254}$.

63 La législation royale ne fit pourtant à peu près aucune place aux évêques dans la censure. Tout au plus l'édit de Châteaubriant accorda-t-il un rôle aux officiaux pour le contrôle des livres importés et la visite des boutiques, dans les villes où il y avait une officialité et pas de faculté de théologie : double condition qui écartait un bon nombre de diocèses, au 
premier chef celui de Paris. De manière un peu plus significative, à Lyon, qui n'avait ni université ni parlement (la ville était du ressort du parlement de Paris), il était prévu que l'inspection des imprimeries et librairies serait faite par deux ecclésiastiques, l'un député par l'archevêque et l'autre par le chapitre, en compagnie du lieutenant du sénéchal de Lyon $^{255}$. En matière de censure préalable, la seule exception porta sur les almanachs. L'ordonnance d'Orléans de 1561 défendit à tous imprimeurs et libraires « d'imprimer ou exposer en vente aucuns almanachs et prognostications, que premièrement ils n'ayent esté visitez par l'archevêque ou évêque, ou ceux qu'il commettra» (la législation antérieure prévoyait un examen conjoint par un docteur en théologie et un docteur en médecine). Était ainsi fait droit aux remontrances du clergé aux états généraux contre ceux qui « entreprennent sur la connoissance que Dieu s'est réservée » - l'Index du concile de Trente, trois ans plus tard, chargea lui aussi les évêques de lutter contre l'astrologie judiciaire. Les almanachs, depuis quelques années, étaient en outre devenus d'efficaces instruments de la propagande réformée en France. Du point de vue du pouvoir royal, enfin, soucieux de concorde, les prophéties avaient une dangereuse puissance pour enflammer les passions religieuses ${ }^{256}$. La responsabilité conférée aux évêques était donc réelle : reste qu'elle n'en soulignait que mieux, a contrario, le peu de crédit qui leur était accordé s'agissant d'examiner les livres de doctrine. Les ordonnances de Blois de 1579 resserrèrent le contrôle : les almanachs ne pouvaient être publiés «que premierement n'ayent esté vûs et visitez par l'archevêque, évêque, ou ceux qu'ils auront députez expressément à cet effet, approuvez par leurs certificats et signez de leurs mains, et qu'il n'y ait aussi permission de nous ou de nos juges ordinaires ${ }^{257}$. Ces dispositions furentelles appliquées? La déclaration de 1628, de toute manière, qui témoigne d'une « sécularisation » des représentations, ne fait plus mention des évêques ni même d'aucun contrôle préalable : la censure des « prédictions illicites » devint purement répressive ${ }^{258}$.

On rencontre parfois des permissions épiscopales - au début du XVII ${ }^{\mathrm{e}}$ siècle, certains livres publiés à Tournon portent celle du vicaire général de l'évêque de Valence ${ }^{259}$-, sans que l'on puisse dire s'il s'agissait d'un usage local ou d'un choix personnel des auteurs ${ }^{260}$. Un recensement systématique serait souhaitable mais ces cas ne furent certainement pas très nombreux. Les évêques ne se résignèrent pas à cet effacement. Ils réaffirmèrent à plusieurs reprises leur droit, au moins de principe, à contrôler les livres dans leurs diocèses ${ }^{261}$. Les conciles provinciaux réunis en France à la fin du XVI ${ }^{e}$ siècle et au début du $\mathrm{XVII}$ e siècle, dans l'esprit de la réforme pastorale post-tridentine, il est vrai, s'ils mentionnent régulièrement la question des livres interdits, évoquent rarement la censure préalable de l'évêque. Elle figure néanmoins dans le concile de Bourges de 1584 («qu'il ne soit permis aux imprimeurs d'imprimer et de mettre en vente aucun livre traitant de la religion ou de la foi sans permission et approbation de l'évêque ») ${ }^{262}$, et surtout dans celui de Toulouse, tenu par le cardinal François de Joyeuse en 1590. Toulouse avait une situation à part, puisque, à la différence du reste de la France, il y restait un inquisiteur, auquel le concile, faisant fidèlement écho aux règles de l'Index romain, attribua la censure préalable et le contrôle des librairies conjointement avec l'évêque ${ }^{263}$. C'est aussi un des très rares cas où l'on puisse affirmer avec certitude que les prescriptions conciliaires eurent une application: en 1619, avec l'appui du parlement de Toulouse - dans le contexte de la réaction anti-libertine -, le vicaire général et l'inquisiteur firent une grande visite des boutiques des libraires, saisirent et condamnèrent au feu les livres hérétiques ${ }^{264}$. 

le patronage de Charles Borromée, n'allait à rien de moins qu'à placer toute la librairie (et pas seulement le livre religieux) sous contrôle épiscopal. Les imprimeurs devaient prêter serment «qu'ils n'imprimeraient ni ne vendraient jamais aucun livre sans avoir obtenu l'approbation écrite de l'ordinaire »; chaque évêque devait désigner dans son diocèse « un ou deux maîtres en théologie » chargés de procéder à l'examen préalable de tous les livres à imprimer, mais aussi de visiter les boutiques des libraires, y «censurer et noter les livres qui sentent l'hérésie, l'impiété, ou qui sont susceptibles de corrompre le peuple ", recourir au magistrat séculier pour les faire saisir et brûler ${ }^{265}$. Ce concile de Bordeaux, dont les actes furent publiés l'année suivante, eut un grand retentissement mais ne fut jamais officiellement promulgué, faute que Sourdis eût pu le faire approuver à Rome - où la congrégation du concile jugea que certains décrets, surtout sur l'épineuse question des privilèges des réguliers, blessaient les prérogatives pontificales ${ }^{266}$. Dix ans plus tard, en publiant une condamnation sur laquelle on reviendra, François $\mathrm{I}^{\mathrm{er}}$ de Harlay, archevêque de Rouen, tenta d'imposer, au moins au for interne, la censure épiscopale préalable :

De peur aussi que d'oresnavant tels Livres pestilencieux ne troublent nostre Diocese, et ne le deschirent par Schismes et nouvelles Heresies, Nous voulons et ordonnons que tous les Livres qui s'imprimeront cy-apres à Roüen, ou ailleurs en nostre Diocese, traictans de la Religion, ou des choses qui concernent, soit la Doctrine, soit la Discipline Ecclesiastique, et qui n'auront point esté approuvez par le Theologal de nostre Eglise, ou par le P. Jean Morin Prestre et Superieur de la Congregation de l'Oratoire à Roüen, qui est de nostre Conseil, et que nous avons à cét effect constitué Censeur de tels Livres, soient tenus de tous nos Diocesains pour suspects d'Heresie ou de Schisme, et qu'on en évite soigneusement la lecture, comme perilleuse et pleine de fraude et d'imposture.

Aucune peine n'était portée contre les contrevenants, et rien n'était dit des imprimeurs et libraires, vraisemblablement pour éviter un appel comme d'abus au parlement de Rouen, avec lequel l'archevêque était déjà en conflit ${ }^{267}$.

Il ne s'agissait pas là d'initiatives isolées mais bien d'une revendication de tout le corps, que les Assemblées du clergé, pendant plusieurs décennies, portèrent avec persévérance. Celle de 1635 commença par demander une place pour les évêques dans le régime existant : «votre Majesté est suppliée de défendre qu'il ne soit expedié aucuns privileges à imprimer livres, si avec l'attestation des Docteurs, on ne voit aussi la permission de l'Evêque du lieu où se fait l'impression dudit livre $»^{268}$. La réponse de Louis XIII fut une fin de non-recevoir ${ }^{269}$, que vint confirmer brutalement, quelques années plus tard, l'affaire du Petrus Aurelius. Face à un pouvoir affaibli en période de régence, l'Assemblée de 1645 - revanche des évêques après que Richelieu leur eut imposé ses volontés à celle de 1641 -, alla beaucoup plus loin, en proclamant «que les Evêques sont les uniques Juges de la doctrine de l'Eglise, tant de celle qui est prêchée de vive voix, que de celle qui est enseignée dans les Ecrits; que les Conciles de Latran et de Trente ordonnent qu'ils en prendront seuls la connoissance; que c'est les blesser en la chose la plus essentielle à leur autorité, que de réduire l'approbation des livres à quelques Docteurs particuliers choisis par d'autres que par eux, comme cela se voit en ce temps; et que cette introduction est de très-dangereuse conséquence ». Il fut donc décidé de faire "instance très-particuliere à ce qu'il plaise au Roi d'ordonner qu'aucuns livres de doctrine Ecclésiastique ne pourront être imprimés à l'avenir qu'avec l'approbation des Evêques des lieux où ils seront imprimés, ou des Docteurs commis particuliérement par eux; et que les privileges pour l'impression d'iceux, ne pourront être refusés après ladite approbation $»^{270}$. Cette 
délibération ne semble pourtant pas avoir eu de suite. Si l'on en croyait les Considerations publiées par la Faculté de théologie contre les censeurs royaux, en 1650, les évêques auraient considéré «le droict, dont joüissent les Docteurs de la Faculté de Paris pour l'Approbation des livres, et que ce seroit les priver de la possession où ils sont ${ }^{271}$. À supposer que cette considération eût effectivement joué, l'échec définitif de la Faculté à reconquérir ses prérogatives la rendit bientôt sans objet. Aussi l'Assemblée de 1650 pritelle une nouvelle résolution dans le même sens ${ }^{272}$.

68

L'Assemblée de 1655, au lendemain de la Fronde, obtint de Mazarin une déclaration royale en trente et un articles, extraordinairement favorable à la juridiction ecclésiastique : les articles XI et XXIII mettaient aux mains des évêques l'ensemble de la censure des livres, préalable, répressive, et même expurgatoire :

Nos Cours de Parlement, et nos autres Juges, ne pourront s'entremettre de la censure des livres, concernant la doctrine et Religion, laquelle sera faite par les Evesques ; et neantmoins lors que les Evesques, apres leurs censures, imploreront le bras seculier pour le chastiment des coupables, Enjoignons à nosdits Juges de proceder contre iceux, par les voyes de droit, comme aussi en cas de scandale et trouble du repos public ${ }^{273}$.

Defendons à tous Libraires d'imprimer ny vendre aucuns livres qui concernent la Religion, s'ils n'ont été premierement approuvez par l'Evesque Diocesain, ou par son Vicaire general, et par les Docteurs qui seront commis, nonobstant tous privileges par nous accordez aux particuliers, ou Communautez seculieres ou regulieres telles qu'elles soient [...]. Et sur lesdites approbations desdits Ordinaires seront baillez par nous les privileges, et permissions d'imprimer lesdits livres, conformement à nos Ordonnances. Comme aussi défendons ausdits Libraires d'exposer en vente, ny faire une seconde impression des livres, qui ont été une fois censurez, sans qu'il apparoisse de l'approbation et attestation susdites desdits Evesques, que lesdits livres ont été corrigez conformement à la censure ${ }^{274}$.

Pareille déclaration, qui réglementait par ailleurs strictement l'appel comme d'abus, aurait rencontré les plus fortes résistances au Parlement. Aussi n'y fut-elle jamais enregistrée - et il y a tout lieu de penser que Mazarin n'avait jamais envisagé qu'elle pût l'être : il ne s'agissait que de donner au Clergé, pour prix de la contribution financière qu'il votait, une satisfaction à bon compte ${ }^{275}$. Les instances de l'Assemblée de 1665 obtinrent une seconde déclaration, qui répétait très largement la première, mais qui, sur la censure préalable, comportait des retouches de très grande portée. L'approbation « par l'Evesque Diocesain, ou par son Vicaire general, et par les Docteurs qui seront commis " devenait « par l'Evesque Diocesain, ou par son Vicaire general, ou par telles personnes qui seront commises par nous pour l'interest de la police»; les privilèges seraient accordés «sur lesdites approbations », et non plus «sur lesdites approbations desdits Ordinaires » ${ }^{276}$. En tout état de cause, la déclaration de 1666 eut le même sort que celle de 1657 et resta lettre morte ${ }^{277}$.

70 Les revendications épiscopales trouvèrent une de leurs très rares applications concrètes l'année suivante, à la faveur de la lutte anti-janséniste: elles offraient, aussi bien, le moyen le plus aisé de condamner le Nouveau Testament traduit en français par les Messieurs de Port-Royal, que ceux-ci, ne pouvant obtenir un privilège en France, avaient publié à l'adresse de Mons, aux Pays-Bas, avec approbations du censeur de Louvain et de l'évêque de Namur, et permission de l'ordinaire, l'archêque de Cambrai (qui se référait expressément aux règles tridentines) ${ }^{278}$. L'archevêque de Paris, Hardouin de Péréfixe, allégua le concile de Trente et les décrets de « l'Eglise de France [...] dans ses Conciles, soit 
avant, soit apres la celebration de celuy de Trente", pour conclure que la diffusion du Nouveau Testament de Mons dans son diocèse sans sa permission constituait « une contravention manifeste aux Ordonnances et Decrets des Saints Conciles » : il fit défense à tous ses diocésains de le lire et à tous les imprimeurs et libraires, sous peine d'excommunication, de l'imprimer ou de le vendre ${ }^{279}$. Le Conseil du roi n'hésita pas à lui faire écho dans l'exposé de son arrêt de suppression, «le Roy [...] considerant qu'il est dangereux d'exposer au Public des Versions de la Sainte Escriture sans la permission et approbation des Evesques de France $\aleph^{280}$. Antoine Arnauld répliqua que l'ordonnance de Péréfixe était nulle car fondée sur des " erreurs intolérables ", dont la première était que les défenses portées par les conciles de Sens et de Trente obligeaient actuellement dans le diocèse de Paris :

Elles n'ont jamais esté en France dans un usage ordinaire, et on y est toujours demeuré dans la prattique ancienne d'avoir seulement l'approbation de quelques Docteurs, sans qu'on ait obligé aucun de ceux qui ont fait des livres sur les choses de la religion de demander la permission de l'Evesque dans le diocese duquel ils les faisoient imprimer. C'est une verité qui ne peut estre contestée, puisqu'il ne faut qu'avoir des yeux pour trouver dans les Bibliotheques dequoy s'en assurer par dix mille preuves, s'estant bien imprimé autant de livres dans Paris seul depuis les

Conciles de Sens et de Trente sans la permission des Evesques de Paris ${ }^{281}$.

71 Vingt ans plus tard, sous l'archevêque Harlay, successeur de Péréfixe, la sentence de l'officialité de Paris contre la traduction du Bréviaire romain par Nicolas Le Tourneux, un ami de Port-Royal, se fonda à nouveau, entre autres motifs, sur l'absence de permission épiscopale. Le promoteur avait allégué le concile de Sens et, curieusement, celui de Latran au lieu de celui de Trente - s'il s'agissait de parer à l'objection que les décrets disciplinaires du concile de Trente n'étaient pas reçus en France, c'était tomber de Charybde en Scylla ${ }^{282}$. Antoine Arnauld reprit alors pratiquement mot pour mot sa " première nullité et erreur intolerable » de $1667^{283}$.

Il a été bien montré que le conflit de 1702, à propos ou à l'occasion du Nouveau Testament de Richard Simon, avait pour véritable enjeu la prétention du nouvel archevêque de Paris, Louis-Antoine de Noailles, inspiré et poussé par Bossuet, à rendre la permission épiscopale nécessaire pour les traductions bibliques voire pour tous les livres religieux ${ }^{284}$. Conformément à sa théologie de l'épiscopat, Bossuet avait exhorté Noailles à imposer sa censure prélable jusque sur les thèses, du moins sur "toutes les thèses des religieux ", "puisque vous êtes naturellement le juge de la doctrine ${ }^{285}$. Les partisans de la censure épiscopale invoquèrent alors une fois de plus les conciles de Sens et de Trente ${ }^{286}$. Bossuet rappela en outre habilement le précédent du Nouveau Testament de Mons, faisant observer que Séguier, alors chancelier, n'avait rien trouvé à redire à l'ordonnance de Péréfixe et que l'absence de permission de l'ordinaire avait même été mentionnée dans l'arrêt de suppression ${ }^{287}$. Malgré le soutien des dévots ${ }^{288}$, tous les arguments de Bossuet échouèrent devant la résolution de Pontchartrain. L'accommodement qui mit fin à la polémique prévoyait que les évêques ne pourraient plus censurer un livre au seul motif qu'il aurait paru sans leur permission. Ce fut l'échec définitif des prétentions épiscopales.

\section{La censure a posteriori : l'évêque en son diocèse}

Ne restait donc aux évêques que la censure a posteriori. C'était, du reste, un des arguments de Pontchartrain pour leur refuser la censure préalable : «aiant le pouvoir qu'ils ont, Et que Votre Majesté leur laisse, de censurer tous les livres qu'il leur plaira, Ils ont en un 
sens par là, plus que ce qu'ils pretendent, puis qu'ils exercent leurs droits apres le privilege meme, Et qu'il est par consequent inutile, d'avoir un autre droit qui le precede » ${ }^{289}$. Chaque évêque avait le droit, dans les limites de son diocèse, de condamner un livre et d'en interdire au moins la lecture, voire l'impression et le débit ${ }^{290}$, quitte à faire ensuite l'objet d'un appel comme d'abus. En 1634, l'archevêque de Rouen condamna comme « impie, schismatique, portant et frayant le chemin à diverses Heresies, perturbatif de l'Ordre et Iurisdiction Ecclesiastique, destructif de la paix de l'Eglise ", Le Guidon des Prelats et Boucliers des Pasteurs, qu'un curé de son diocèse avait publié à Paris, avec approbation de deux docteurs et privilège du roi ${ }^{291}$. L'ouvrage était issu d'un conflit local «touchant le pretendu droit de Visite des Archidiacres ${ }^{292}$, mais l'auteur, Pierre Morestel, développait à cette occasion une ecclésiologie clairement richériste, exaltant l'institution divine des curés, successeurs des soixante-douze disciples, "la gloire desquels quelques Prelats successeurs des Apostres semblent vouloir obscurcir, esteindre et abolir par le mespris qu'ils font de leurs successeurs les Curez és Synodes Diocesains et Conciles Provinciaux les privant de toute seance, voix deliberative et decisive $»^{293}$. Morestel avait dédié son traité à "Messieurs de la Cour du Parlement de Rouen", qu'il célébrait comme les protecteurs des curés ${ }^{294}$. Aussi le parlement de Rouen, le 2 juin 1634, rendit-il un arrêt interdisant "tant audit Archevesque, son Official, Vicegerant, qu'à sesdits Grands Vicaires et tous autres, de publier, faire publier, imprimer, vendre, ny executer lesdites Ordonnances et Mandement de Censure contre ledit Livre». L'archevêque s'étant immédiatement pourvu en opposition au Conseil du roi, trois mois de bataille juridique s'ensuivirent, les arrêts du Conseil alternant avec ceux du Parlement ${ }^{295}$. Le 5 août, le Parlement prit un arrêt portant «que tres-humbles remonstrances seront faites à sa Majesté, des entreprises faites par ledit Suppliant [l'archevêque], entr'autres d'avoir fait afficher ladite Censure, et cependant que la publication d'icelle demeurera sursise, jusqu'à ce qu'autrement en ait esté ordonné, et que l'Arrest dudit Parlement seroit imprimé, mis et affiché par les carrefours et places publiques de ladite ville $»^{296}$. Un dernier arrêt du Conseil, le $1^{\mathrm{er}}$ septembre, supprima Le Guidon des Prelats, cassa les arrêts du Parlement, lui fit « iteratives inhibitions et defenses, de prendre aucune juridiction ny cognoissance du faict de ladite Censure », permit à l'archevêque de "faire publier ladite Censure par luy faite dudit Livre, et icelle faire afficher en tous les lieux de son Diocese, et de l'Eglise Metropolitaine de Roüen, tels qu'il advisera bon estre ${ }^{297}$. C'était un plein succès pour la juridiction ecclésiastique et le Clergé eut soin d'en conserver la mémoire ${ }^{298}$. Les évêques pouvaient également condamner des thèses et même des pièces de théâtre. Il y en eut au moins un exemple, l'ordonnance de l'archevêque Péréfixe, en 1667, contre Tartuffe, où il fit «très expresses inhibitions et défenses à toutes personnes de notre diocèse de représenter, lire ou entendre réciter la susdite comédie, soit publiquement, soit en particulier, sous quelque nom et quelque prétexte que ce soit, et ce sous peine d'excommunication ${ }^{299}$. La mesure suscita, il est vrai, les réserves de l'érudit et canoniste gallican Étienne Baluze, qui y vit une usurpation sur la juridiction séculière ${ }^{300}$.

Dans la seconde moitié du XVII siècle en tout cas, il est patent que les censures épiscopales n'étaient qu'ostensiblement destinées à leurs diocésains: imprimées ou réimprimées à Paris, elles visaient en réalité le «troisième terme [qui] s'était alors introduit dans les controverses entre théologiens ou entre théologiens et autorités ", à savoir le public ${ }^{301}$. La « censure du public » - expression dont il faudrait faire l'histoire, à partir de celle, plus ancienne, de "censure publique $~^{302}$-, était dès lors assez forte pour faire céder la censure officielle ${ }^{303}$. À intervenir ainsi dans les polémiques, les évêques s'exposaient à y compromettre leur autorité. Quand parut à Paris une ordonnance du 
grand-vicaire de l'archevêque absentéiste d'Embrun, Georges d'Aubusson de la Feuillade, contre le Nouveau Testament de Mons, les amis de Port-Royal en firent la satire. À les en croire, l'ordonnance avait été fabriquée à Paris par les amis de l'archevêque, qui l'avait fait paraitre sous le nom de son grand-vicaire, "parce qu'il estoit ridicule qu'un Archevesque de Cour dressast une Ordonnance pour empescher qu'on ne leust à Ambrun le Nouveau Testament en françois, et qu'il n'y a pas d'apparence qu'elle ait esté publiée dans l'Ambrunois, où le peuple qui parle un adiousias corrompu ne l'auroit pu entendre " - A-Diou-sias, terme par lequel Malherbe désignait avec dédain le sud de la Loire, par opposition au " pays de Dieu vous conduise », est bien révélateur des limites géographiques et sociales $\mathrm{du}$ « public $»^{304}$.

\section{La censure a posteriori : les assemblées}

75 Une censure d'un évêque isolé n'avait pourtant guère de poids. Expliquant au cardinal Barberini, en 1642, que " pour certaines raisons ", il était difficile aux évêques français de se réunir pour condamner le livre du jésuite Michel Rabardeau, qui attaquait les immunités du clergé, et qu'ils ne pourraient donc « en publier une censure que chacun en particulier», l'oratorien Jean Morin ajoutait: «quelle probabilité y aura-t-il que la censure d'un seul évêque puisse prévaloir sur l'autorité d'un livre qui a le témoignage public et l'approbation publique d'une Compagnie très célèbre » - sans parler de l'appui de Richelieu, dont Rabardeau défendait la politique ${ }^{305}$ ? Un moyen de parer à cet isolement était d'organiser une série ou, si l'on veut, une campagne de censures: les rigoristes usèrent efficacement du procédé contre l'Apologie pour les casuistes du P. Pirot, qui fut censurée au total par plus de vingt évêques (certains en se regroupant), entre avril 1658 et mai $1659^{306}$; beaucoup étaient liés de près ou de loin à Port-Royal et ils se firent rédiger leurs censures, en tout ou en partie, par Pascal, Arnauld et Nicole ${ }^{307}$.

Une autre voie consistait à utiliser le cadre des provinces ecclésiastiques. En mars 1612, le cardinal Du Perron, archevêque de Sens - qui était toujours, à cette date, la métropole de Paris -, profita d'une réunion de tous les évêques de sa province pour condamner le $D e$ Ecclesiastica et politica potestate de Richer ${ }^{308}$; l'archevêque d'Aix fit de même en mai, avec trois de ses suffragants ${ }^{309}$. La même procédure, par la volonté de Richelieu, fut suivie par les évêques de la province de Paris - désormais détachée de Sens -, en mars 1640, contre l' Optatus gallus de Charles Hersent ${ }^{310}$. Il faut souligner que, même dans cette période, alors que des conciles provinciaux - on en a vu des exemples -, étaient encore parfois réunis pour prendre des décrets de discipline, les assemblées que l'on vient de citer se gardèrent de prendre le titre de concile et de revendiquer la juridiction qui y était attachée, mais s'intitulèrent seulement "assemblée provinciale " ${ }^{311}$. La différence fut à dessein obscurcie dans certaines publications du temps - et elle semble avoir échappé aux historiens récents ${ }^{312}$-, mais les canonistes du XVII ${ }^{\mathrm{e}}$ siècle en saisissaient parfaitement la signification ${ }^{313}$. La méfiance de la monarchie française vis-à-vis de toutes les structures délibératives, jointe aux prétentions rivales des parlements et de la papauté, fit complètement disparaître les conciles provinciaux après le milieu du siècle. Le grand théologien et canoniste oratorien Louis Thomassin jugeait en 1681 que les obstacles à leur réunion étaient "presque insurmontables " ${ }^{314}$. L'Assemblée du clergé de 1650 tenta vainement de profiter de l'affaiblissement du pouvoir royal pour relancer l'institution. Le seul métropolitain qui s'y risqua, François $\mathrm{I}^{\text {er }}$ de Harlay, se heurta à son vieil adversaire, le parlement de Rouen : 
Sur la requeste présentée par le procureur général du Roy, narrative que par les édicts et ordonnances de sa Majesté, toutes assemblées sont prohibées et défendues dans le royaume, et n'est permis à aucun de ses sujets icelles convoquer, et que l'estat ecclésiastique estant soumis aux mêmes loys du royaume et composant un des estats d'yceluy ne peut former assemblée pour la tenue de ses Conciles sans les ordres exprès de Sa Majesté, ainsi qu'il a esté usé de temps immémorial et à la fin $\mathrm{du}$ dernier siècle, [...] La Cour [...] a fait très expresses inhibitions et défenses audit Archevesque de Rouen, Evesques et autres Ecclésiastiques de ce ressort de s'assembler pour le dict Concile ny assister à yceluy sans lettres et permissions expresses du Roy présentées à la Cour, à peine de saisie de leur temporel et autres au cas appartenant.

Les évêques et chapitres de la province prirent peur et Harlay, malgré le soutien de l'Assemblée du clergé, se retrouva presque tout seul, avec l'évêque d'Évreux. Les deux prélats prirent symboliquement quelques canons dont un contre «les nouveaux augustiniens » (les jansénistes). Ce fut l'ultime tentative en France pour tenir un concile provincial $^{315}$. On ne trouve plus dès lors que des assemblées provinciales, soit les assemblées régulières, chargées d'élire les députés aux Assemblées générales - et qui comprenaient donc à la fois les évêques et les députés du second ordre ecclésiastique ${ }^{316}$-, soit des assemblées exceptionnelles limitées aux évêques. En 1699, après la condamnation à Rome des Maximes des saints de Fénelon, largement sous l'effet des pressions diplomatiques françaises, l'archevêque de Reims Charles-Maurice Le Tellier (fils du chancelier) persuada Louis XIV de faire convoquer les évêques dans chaque province par leurs métropolitains, pour qu'ils pussent recevoir "par forme de jugement ecclésiastique » le bref Cum alias d'Innocent XII. Les tenants de l'ecclésiologie gallicane en triomphèrent, mais ces assemblées, réunies par ordre du roi pour cet unique objet, n'étaient nullement des conciles provinciaux canoniques ${ }^{317}$. Quant à tenir un concile national, c'était évidemment hors de question.

Cette disparition des instances conciliaires fut suppléée par des assemblées sans statut canonique. Elles eurent le plus souvent lieu dans la capitale, puisqu'on y trouvait toujours bon nombre de prélats " pour les affaires de leurs diocèses », selon la formule consacrée. Seize d'entre eux souscrivirent ainsi, en 1640, la censure de leurs confrères de la province de Paris contre l'Optatus gallus ${ }^{318}$ : le résultat était un monstre canonique, mais cette tentative pour donner une espèce de valeur nationale à un ersatz de concile provincial atteste le déficit de collégialité dont souffrait l'Église gallicane. Le vide fut surtout rempli par les Assemblées quinquennales du clergé. Il est bien connu que celles-ci avaient à l'origine une fonction purement financière: voter la contribution du clergé à la monarchie ${ }^{319}$. Leur première intervention dans la censure des livres eut lieu en 1606, à l'occasion d'un conflit entre l'évêque de Senlis, Antoine Rose, et son chapitre, qui avait pris pour avocat l'ardent gallican Jacques Leschassier ${ }^{320}$. L'évêque jugea que Leschassier, dans un de ses écrits pour le chapitre, niait la différence de droit divin, tant d'ordre que de juridiction, entre prêtres et évêques. Il présenta donc une requête au Conseil du roi, "à ce que les escritures de l'exposant [Leschassier] fussent delivrées à la Sorbonne »: le chancelier de Bellièvre et le garde des sceaux Brûlart de Sillery, « apres les avoir leuës et trouvées bonnes ", mirent la requête en délibération au Conseil, qui débouta l'évêque ; le procès fut renvoyé au Grand Conseil ${ }^{321}$. Rose se tourna vers l'Assemblée du clergé, qui siégeait alors et à laquelle il dénonça huit propositions extraites du texte de Leschassier. L'Assemblée, le 22 avril 1606, déclara «les susdictes propositions faulses, erronnées, heretiques, contraires au droict divin, decrets et constitutions canoniques, et ressentans 
impieté $»^{322}$. Leschassier s'inscrivit en faux contre les propositions qui lui étaient attribuées et appela en outre comme d'abus « de ce libelle diffamatoire, que l'Evesque appelle censure $\aleph^{323}$. Au terme de la procédure, un arrêt du Grand Conseil du 22 décembre 1607 déclara que, dans la censure, "il a esté mal, nullement et abusivement jugé et executé", et ordonna que le procès-verbal de l'Assemblée serait "deschargé dudit pretendu jugement, et la minute d'iceluy supprimée; et defenses audit Roze et à tous autres de s'en aider, à peine de faux $»^{324}$. Une ultime tentative de l'évêque de Senlis pour faire casser cet arrêt, en mobilisant l'Assemblée du clergé de 1608, se solda par un échec définitif ${ }^{325}$. Le fond de l'affaire ne nous concerne pas ici, mais Leschassier insista sur l'absence de compétence de l'Assemblée, qui n'était qu' « une Chambre des Comptes", réunie « seulement pour ouyr le compte de Castille » ${ }^{326}$.

Car l'exposant ne veut point croire que la compagnie desdits Procureurs [députés] du Clergé, à laquelle nous n'avons donné aucune jurisdiction, encore moins de droict de ressort sur la jurisdiction de nostre Conseil et de nos Cours Souveraines, ait voulu par une nouvelle entreprise sur nostre jurisdiction Royale, et non encor ouye depuis l'establissement de nostre Couronne, s'attribuer la censure des escrits qui se font en nostre Justice par les Ministres d'icelle, mesme par les Advocats [...] $]^{327}$

De toute manière, souligna Leschassier, beaucoup des évêques députés n'étaient pas qualifiés pour porter un jugement doctrinal à la manière d'une « Université, Eschole, ou faculté $»^{328}$.

La première tentative des assemblées en fait de censure n'était donc guère encourageante. Aussi attendirent-elles vingt ans pour recommencer, à la fin de 1625, contre deux libelles, anonymes mais communément considérés comme d'origine jésuite, Admonitio ad Regem Ludouicum XIII et Mysteria politica, qui attaquaient la politique française dans la guerre de Trente Ans. Cette seconde expérience fut à peine plus concluante. On souhaiterait savoir qui en eut l'initiative, alors que la Sorbonne travaillait au même moment à une censure, qu'elle publia le $1^{\text {er }}$ décembre ${ }^{329}$. Que l'idée soit venue de Richelieu, voilà qui est parfaitement plausible, mais le texte apparemment décisif qu'on a cité à ce propos ne dit en réalité rien de tel ${ }^{330}$. Il faudrait en tout cas des preuves extrêmement fortes - quand bien même la chronologie ne s'y opposerait pas de toute manière -, pour nous faire admettre que ce fut la Faculté de théologie qui sollicita l'Assemblée de porter une censure pour compléter la sienne ${ }^{331}$. L'affaire fit en tout cas éclater les divisions entre évêques et provoqua un conflit majeur avec le parlement de Paris. On en retiendra surtout deux moments. Pour mettre fin aux débats, le cardinal de la Valette, en janvier 1626, fit résoudre de condamner les deux libelles en général sans entrer dans aucun détail, « étant chose mieux séante et convenable à un si grand Corps comme celui de cette Assemblée, d'en user de la sorte, comme il s'est pratiqué dans la Sorbonne sur ce même sujet, laquelle est en possession de censurer ordinairement tous les livres " ${ }^{332}$. L'argument était clairement avancé pour les besoins de la cause mais il montre que les évêques ne remettaient nullement en cause le rôle de la Faculté de théologie. Le Parlement prit alors un arrêt interdisant de publier d'autre censure de l'Assemblée que celle, beaucoup plus explicitement gallicane, qu'avait auparavant composée l'évêque de Chartres. Dans son réquisitoire, l'avocat général Servin précisa qu'il n'entendait pourtant pas approuver «le pouvoir desdits gens du Clergé pour leur Assemblée, en autre chose que pour les affaires pour lesquelles le Roy a permis leur convocation $\Perp^{333}$. 

s'étonnera pas que, dans les deux décennies suivantes, l'activité censoriale des Assemblées, sans disparaitre entièrement, soit restée assez timide ${ }^{334}$. Il fallut la crise janséniste pour les transformer en organe doctrinal de premier plan, tenant de facto le rôle d'un concile national. Leur activité dans cet ordre culmina avec la grande censure de l'Assemblée de 1700 - contre quatre propositions jansénistes, deux propositions « semipélagiennes » et surtout cent vingt et une propositions de " morale relâchée »-, voulue, préparée et conduite par Bossuet. Un évêque ayant eu l'audace de déclarer « qu'il fallait même délibérer si les qualifications se feraient in globo et respective, comme à Rome, ou en détail en les joignant aux propositions particulières [...] M. de Meaux a réfuté le dessein de censurer in globo, comme étant indigne du clergé de France $»^{335}$.

Ceux qui voulaient relever l'autorité des assemblées d'évêques à Paris ou des Assemblées du clergé se plurent à relever - à commencer par Pierre de Marca, au début de la querelle janséniste -, que, à en juger par certains précédents antiques, elles méritaient parfaitement le nom de synodes ou de conciles ${ }^{336}$. Elles se gardèrent pourtant bien de le prendre. « En cela, commenta Thomassin, il y a sujet d'admirer la sagesse de tant de sages Assemblées depuis deux ou trois cents ans, qui ont mieux aimé conserver une autorité mediocre, mais stable, que d'en pretendre une plus haute, mais de peu de durée parmy tant d'adversaires secrets des libertez de l'Eglise $\aleph^{337}$. On en revient toujours à ce fait essentiel de l'histoire du catholicisme français au XVII ${ }^{e}$ siècle, à savoir l'écart entre une auto-représentation nourrie de l'Antiquité chrétienne et la réalité du contrôle étroit exercé par l'État sur la vie de l'Église.

Il faudra une autre étude, que l'on ne peut qu'esquisser ici, pour considérer tous les effets que put avoir la censure. La question va bien au-delà de son efficacité, au sens proprement policier et matériel du terme, et même de sa seule dimension répressive, fûtelle élargie aux phénomènes d'autocensure et à tout ce qui relève de «l'art d'écrire ». La censure ne peut être séparée de son pendant, à savoir l'approbation ${ }^{338}$. Si tout discours d'autorité est en dernière analyse un discours de porte-parole, qui ne "fonctionne » qu'en étant reconnu comme tel ${ }^{339}$, le discours religieux, dans la France des XVI ${ }^{e}$ et XVII ${ }^{e}$ siècles, tirait son efficacité d'un système de délégations institutionnelles, à la fois ecclésiastiques et civiles, que venaient attester l'approbation et le privilège. Le privilège du roi valait comme légitimité symbolique au moins autant que comme facilité matérielle. Le P. Annat l'avait bien compris quand il ironisait sur les circonstances de la publication du Nouveau Testament de Mons :

On sçait bien qu'ils [les jansénistes] y ont [à Paris] des Imprimeurs à gages; ils ne servent neanmoins que pour publier leurs Ouvrages clandestins, et toutes ces petites pieces d'Autheurs inconnus, des Imaginaires, des Visionnaires, des Chamillardes, des Apologies, des Dialogues, et de ces passe-volans qu'ils jettent en foule et par compte neanmoins. Par exemple, le dixiéme Ecrit, la quinziéme Lettre, le huictiéme Memoire, avec leurs Satyres, et leurs Libelles diffamatoires en Poësie et en Prose. [...] Mais l'honneur que meritoit l'Evangile de Port-Royal a empesché qu'on ne l'exposast à cette infamie d'estre rejetté de tout le monde sans le lire, s'il se presentoit comme leurs autres Ouvrages. Il a donc fallu trouver quelque Approbation, quelque Permission de l'imprimer, quelque lieu de l'impression qu'on pust nommer, et quelque homme qui répondist de la fidélité des Ouvriers. Quel moyen de trouver tout cela en France? Quelle honte pour eux d'en aller chercher 
en Holande? Pour obvier à ces difficultez, ils sont allez à Louvain prendre un Approbateur ${ }^{340}$. efforts des port-royalistes pour publier dans les règles leur Perpétuité défendue, où ils s'étaient faits les champions de la foi catholique contre les protestants ${ }^{341}$. Inversement, tant que dura l'édit de Nantes, les pasteurs protestants eurent interdiction de donner des «approbations » aux livres de leur religion ${ }^{342}$ : car approuver un livre était revendiquer une parole d'autorité qui ne pouvait appartenir qu'à l'Église catholique. Il faudra aussi approfondir les rapports entre la censure, au sens institutionnel du terme, et ce que Pierre Bourdieu, dans des pages classiques, a caractérisé comme la censure structurale ou censure de champ ${ }^{343}$. Au XVII ${ }^{e}$ siècle, la stratégie la plus usuelle pour échapper aux instances de censure doctrinale consistait à "tenir le rôle d'un simple historien", rapporter les opinions "plûtôt en qualité d'historien que de Theologien qui décide", «laisser la discussion du droit pour la recherche du fait " $^{344}$. L'érudition ecclésiastique gallicane était en bonne partie de la théologie censurée ou autocensurée. La tendance générale à l'historicisation qui caractérise le catholicisme français du XVII ${ }^{\mathrm{e}}$ siècle en fut puissamment stimulée.

Pour s'en tenir ici à la seule dimension négative, il est acquis que l'efficacité de la répression varia beaucoup selon les périodes. Dans la première moitié $\mathrm{du} \mathrm{XVI}^{\mathrm{e}}$ siècle, la répétition régulière des prohibitions et la diffusion continue et bien attestée de livres condamnés iraient dans le sens d'un impact limité ; il est pourtant très vraisemblable que la censure réduisit l'ampleur du phénomèn ${ }^{345}$. Après 1560 , la succession des guerres et des édits de pacification désorganisa gravement le contrôle des livres, particulièrement en province, où les officiers locaux en venaient à ne plus savoir quelle législation appliquer ${ }^{346}$. Même après la fin des guerres de religion, le régime de la librairie resta marqué pendant deux ou trois décennies par une grande liberté, surtout en comparaison de la plupart des autres États européens - les lamentations répétées que l'on trouve à cet égard dans les correspondances des nonces n'étaient pas sans fondement ${ }^{347}$. Le resserrement des contrôles poursuivi avec persévérance par le pouvoir royal mit en place une mécanique bien huilée mais qui, dès la fin du règne de Louis XIV, tournait à vide - le circuit parallèle du livre se développant au fur et à mesure que se restreignait le marché légal, et la prohibition appelant la fraude, selon une logique qui allait durer jusqu'à la fin de l'Ancien Régime ${ }^{348}$. Les contemporains en eurent conscience. Dans un passage bien connu de son Mémoire sur le Lyonnais pour l'instruction du duc de Bourgogne, en 1698, l'intendant Lambert d'Herbigny expliquait: «les imprimeurs et libraires de Lyon sont dans une espèce de nécessité de contrefaire les livres de Paris et de pratiquer les contraventions qu'on leur reproche, sans lesquelles ils mourroient de faim $»^{349}$. Le bureau de la librairie lui-même fut contraint d'en prendre acte en inaugurant, dès les dernières années du règne de Louis XIV, le système de la permission tacite, pour les livres qu'on ne voulait pas autoriser et qu'on jugeait impossible d'interdire ${ }^{350}$.

Cette évolution n'empêcha pas la censure de demeurer toujours incomplète au XVII siècle, puisqu'elle ne pouvait s'appuyer sur un Index des livres prohibés, à la manière de Rome ou des pays ibériques. L'absence est d'autant plus frappante que le premier de tous les Index des livres interdits fut celui de la faculté de théologie de Paris, publié en 1544 et qui fit l'objet de plusieurs suppléments jusqu'en 1556. Il fut imposé par plusieurs édits royaux, dont celui de Châteaubriant, qui en prévit expressément des rééditions régulièrement augmentées ${ }^{351}$. L'entreprise fut pourtant interrompue après la mort de 
Henri II et ne fut jamais reprise. Les tentatives romaines, dans les premières années du XVII ${ }^{e}$ siècle, pour établir en France une commission de docteurs qui travailleraient à l'expurgation des livres, n'aboutirent pas $^{352}$. Une étude à part devra étudier le rôle que, faute d'un Index national, tint alors l'Index romain: le fameux axiome, In Gallia Index non uiget, ne rend certainement pas compte de la diversité des attitudes ${ }^{353}$. Il n'est pas douteux, en tout cas que la cause fondamentale de la disparition de l'Index gallican fut l'édit de Nantes, qui, fût-ce sous la forme d'une restriction, accordait une reconnaissance légale au livre protestant ${ }^{354}$. Lorsque l'université de Paris, en 1650, obtint confirmation de ses privilèges, et notamment de l'obligation pour les imprimeurs et libraires « de tenir deux catalogues, l'un des livres censurez et reprouvez, et l'autre de tous ceux qu'ils auront en leurs Boutiques ", les libraires objectèrent «la liberté portée par les édicts de pacification ", qui permettaient l'impression et la vente des livres protestants, quoique " censurez et reprouvez $»^{355}$. Preuve en est encore, a contrario, que quand, dans les tout derniers temps de l'édit de Nantes, juste deux mois avant la Révocation, Louis XIV prit un édit ordonnant "que tous les Livres qui ont été faits jusques à cette heure contre la Religion Catholique, par ceux de la Religion Pretendue-Reformée, soient supprimés ", il parut indispensable d'en dresser une liste : le parlement de Paris en chargea l'archevêque François II de Harlay, lequel fit hâtivement compiler par «quelques Docteurs de Sorbonne » un catalogue aphabétique qui était un véritable Index des livres défendus ${ }^{356}$. La Révocation qui intervint presque immédiatement après fit passer la question au second plan, mais ce catalogue servit de guide pour les confiscations ${ }^{357}$.

Cette absence d'Index contribua à donner à la censure en France un caractère épisodique, ad hoc, celui d'une réaction urgente à une parution du moment ${ }^{358}$. On y chercherait en vain, et moins que jamais dans la première moitié du XVII ${ }^{\mathrm{e}}$ siècle, un projet méthodique. Rien n'est plus faux que le portrait qu'on a récemment voulu peindre des «gallicans, acharnés depuis vingt ans [au moment de l'affaire Santarelli, en 1626] à purifier le royaume des plus infimes relents du tridentinisme bellarminien $»^{359}$. Il fut facile à Bellarmin, après la condamnation de son De potestate Summi Pontificis in temporalibus, de faire observer que ses Controverses, qui défendaient la même doctrine, avaient été rééditées à Paris et à Lyon avec privilège du roi ${ }^{360}$ - et le Parlement ne s'en prit jamais à elles. Ce contraste entre tout ce qu'on laissait paraître en France sans aucune opposition, et ce qu'on s'y avisait d'un coup de condamner, fut, dans les années suivantes, un argument constant de la Curie ${ }^{361}$. Face à Rome, l'absence d'un instrument de régulation doctrinale quotidien, permettant de frapper la déviance ordinaire, fit de la censure gallicane une censure de crise, à la fois produit et facteur de tensions exceptionnelles. La théâtralité des condamnations s'inscrivait dans une dynamique de surenchère qui les mettait, si l'on ose dire, au rang des grands moyens. Bossuet le soulignait pour convaincre Noailles de soumettre à examen préalable les thèses des religieux. La condamnation $a$ posteriori de thèses pour l'infaillibilité du pape créerait fatalement un conflit avec Rome : « il faudra donc demeurer exposé à les laisser passer, ou établir un moyen pour les prévenir en les assujettissant à votre examen ${ }^{362}$. Tout au long du XVII ${ }^{e}$ siècle, la monarchie française ne réussit pas à empêcher la diffusion régulière des thèses romaines: elle ne paraît pas même, sauf lors des grandes crises diplomatiques avec la papauté, avoir cherché à le faire. Tout se passa comme si le pouvoir royal, confiant dans le ferme contrôle qu'il exerçait sur l'Église de France, n'avait jamais vraiment cru aux libertés gallicanes, que ce fût dans leur version épiscopale ou parlementaire, et n'avait vu dans les censures à grand spectacle des parlements, des facultés de théologie ou des 
Assemblées du clergé, qu'un instrument, parmi d'autres, d'une diplomatie de la force. Des Valois aux Bourbons, la continuité est frappante à cet égard.

Il ne faut pas, sans doute, surtout avant les dernières décennies du XVII ${ }^{e}$ siècle, exagérer le systématisme de l'Index romain, lui aussi tributaire des dénonciations qui lui parvenaient. Reste que Rome, surtout de loin, donnait l'impression d'une détermination et d'une continuité de dessein qui manquaient fâcheusement à la France. Ce n'était pas pur fantasme si les gallicans jugeaient qu'une des grandes forces des ultramontains était "le soin qu'ils prennent des livres ", interdisant ou expurgeant ceux qui vont contre eux, répandant par tout le monde catholique ceux qui défendent leurs thèses ${ }^{363}$. "Voilà comment ils emportent tout par une perseverance qui ne se lasse jamais; et voilà comment peu à peu les pretensions de la Cour de Rome qui nous ont esté autrefois les plus odieuses, s'établissent dans ce Royaume, et nos anciennes maximes que nos Peres ont eu tant de jalousie de conserver s'alterent et se ruinent ${ }^{364}$. Si, au XVI e siècle, «le royaume de France est le seul en Europe [...] à ne pas avoir pris acte de la victoire de la papauté sur les thèses conciliaristes $»^{365}$, les gallicans du XVII ${ }^{e}$ siècle ne peuvent plus se la dissimuler. Beaucoup plus qu'à la « haine » où l'on a récemment voulu voir le propre des "catholiques antiromains ${ }^{366}$, la passion violente dont le discours gallican est indéniablement susceptible tient à l'écart douloureusement ressenti entre la certitude d'avoir raison - d'avoir, par la supériorité de son érudition et de sa critique, définitivement gagné sa cause au tribunal de l'Antiquité -, et le constat que, en France même, au moyen de ce qu'Arnauld appelait "la Théologie politique ", les prétentions romaines ne cessent de gagner du terrain: angoisse de la vérité altérée, de la pureté primitive corrompue, trahie par les pouvoirs d'Église et d'État, dont le jansénisme fut, en un sens, à l'âge classique, la formulation proprement doctrinale, avant d'en devenir, après l'Unigenitus, la traduction politique.

\section{NOTES}

1. On trouvera une vaste gamme d'emplois du mot dans [A. Baillet], Jugemens des Sçavans sur les principaux ouvrages des Auteurs, I, Paris, 1685, «Des Jugemens sur les livres en general », p. 1-123. Pour un exemple d'usage positif, voir Fénelon, Lettre à l'Académie [1714], dans Euvres, éd. J.Le Brun, 2 vol., Paris, 1983-1997, II, p. 1192 : «Le censeur médiocre ne goûte point le sublime, il n'en est point saisi. Il s'occupe bien plutôt d'un mot déplacé ou d'une expression négligée [...]. Le censeur, qui est grand dans sa censure, se passionne pour ce qui est grand dans l'ouvrage ».

2. E. Aubertin, L'Eucharistie de l'Ancienne Église, Genève, 1633, p.409. Comparer par exemple J. Davy du Perron, Actes de la Conference tenue entre le sieur Evesque d'Evreux et le sieur du Plessis, en presence du Roy à Fontaine-bleau le 4 de May 1600, Évreux, 1601, fol. 232v (sur une fausse citation d'Augustin): «le sieur du Plessis n'aura pas la gloire de ceste censure : Car il n'en est pas le premier observateur ».

3. Toutes procédures décrites et analysées par Br. Neveu, L'erreur et son juge. Remarques sur les censures doctrinales à l'époque moderne, Naples, 1993. Voir A. Furetière, Dictionnaire 
universel, La Haye-Rotterdam, 1690, s.v. Censure («Jugement par lequel on condamne quelque action. [...] On le dit particulierement des ouvrages qui regardent la Religion. Il y a eu une censure de la Sorbone contre un tel livre ») et s.v. Scandaleux ( "Quand on censure une proposition, on la declare scandaleuse, heretique, contraire à la Foy et à la Morale »). L'article Censure de livres ou de propositions de l'Encyclopédie, 28 vol., Paris, 17511772, II, p. 819-820, par l'abbé Yvon, ne prend encore le mot que dans ce sens.

4. Journal de voyage de Michel de Montaigne, éd. Fr. Rigolot, Paris, 1992, p. 131.

5. Voir e.g. P. de Bérulle, Discours de l'état et des grandeurs de Jésus par l'union ineffable de la divinité avec l'humanité [1623], dans Euvres complètes, éd. M. Dupuy et alii, 11 vol. parus, Paris, depuis 1995, VIII, p. 22 (« la conduite de Dieu paraît sur cet écrit en multipliant les approbations par les voies par lesquelles on en veut tirer quelque censure en France»); A. Baillet, Jugemens des Sçavans, I, cit., p. 71 (« il n'y a point d'absurditez si insupportables qui ne trouvent des approbateurs aussi bien que des Censeurs ») et 178.

6. Pascal, Troisième Lettre (février 1656), dans Les Provinciales, Pensées et opuscules divers, éd. G. Ferreyrolles et Ph. Sellier, Paris, 2004, p. 297. Pascal répond ici à la fois à la condamnation d'Arnauld par la Sorbonne et à la «Réponse du provincial aux deux premières lettres", qui lui transmettait les éloges d'un académicien et d'une dame, figures des nouvelles instances de légitimité. Voir le commentaire d'A. Viala, Naissance de l'écrivain. Sociologie de la littérature à l'âge classique, Paris, 1985, p. 174-175, mais aussi, et déjà, Sainte-Beuve, Port-Royal, $3^{e}$ édition, Paris, 1867, III, p. 65-70 et 602-604.

7. Cahier des remontrances du Clergé de France, presenté au Roi Loüis XIII. par l'Assemblée generale, tenuë à Paris ès années 1635 et 1636 avec les reponses faites par Sa Majesté, le 14. Avril 1636, dans Recueil des Actes, Titres et Mémoires concernant les affaires du Clergé de France [... ]. Contenant les Cahiers présentés, et les Remontrances et Harangues faites aux Rois et aux Reines par le Clergé de France, tant aux Etats généraux, qu'aux Assemblées générales et particulieres du Clergé, Paris, 1740, col. 1389 (ce volume sert de supplément à la collection des Mémoires du Clergé en 12 volumes, citée infra, n. 261).

8. Pour une possible exception, voir A. Baillet, Jugemens des Sçavans, t. I, cit., p. 43-44. Mais comparer p. 48.

9. Voir en particulier H.-J. Martin, Livre, pouvoirs et société à Paris au XVII e siècle (1598-1701), 2 vol., Genève, 1969, II, p. 764-768 ; J. Le Brun, Censure préventive et littérature religieuse en France au début du XVIII siècle [1975], repris dans La Jouissance et le trouble. Recherches sur la littérature chrétienne de l'âge classique, Genève, 2004, p. 299-337 ; R. Birn, La Censure royale des livres dans la France des Lumières, Paris, 2007, p. 33-63.

10. Almanach royal, Année MDCCXLII, Paris, 1742, p. 327-329. Voir W. Hanley, A biographical dictionary of French censors 1742-1789, I [seul paru], Ferney-Voltaire, 2005 ; R. Birn, La Censure royale, cit., p. 95-164; B. de Negroni, Lectures interdites. Le travail des censeurs au XVIII siècle, 1723-1774, Paris, 1995.

11. Les dictionnaires de langue (ainsi le Trésor de la langue française, ou A. Rey, dir., Dictionnaire historique de la langue française, nouvelle édition, Paris, 1994) sont d'un très faible secours pour suivre cette évolution sémantique. J'ai procédé à une recherche sur la base Frantext en avril 2012 (783 occurrences de "censure » dans le corpus des textes antérieurs à 1830). Voir par exemple Rousseau, Confessions, l. X, dans Euvres complètes, éd. B. Gagnebin et M. Raymond, I, Paris, 1959, p. 511 et 534, ainsi que les observations de J. Imbert, préface à N. Herrmann-Mascard, La censure des livres à Paris à la fin de l'Ancien Régime (1750-1789), Paris, 1968, p. V-VI ; B. de Negroni, Lectures interdites, cit., p. 18-20. 
12. Mémoires secrets pour servir à l'histoire de la République des Lettres en France, depuis 1762 jusqu'à nos jours, sous la dir. de Chr. Cave et S. Cornand, I, Paris, 2009, p. 10 (7 janvier 1762).

13. Ibid., p. 42 (3 mars 1762).

14. Ibid., p. 96 (7 juillet 1762) et 135 (28 octobre 1762).

15. Le glissement est bien visible dans les chapitres Censeurs royaux [1782], et Censure des livres [1788] de L.-S. Mercier, Tableau de Paris, éd.J.-Cl. Bonnet, 2 vol., Paris, 1994, I, 292-293 et 1254-1258. Voir déjà Rousseau, lettre à Chrétien Guillaume de Lamoignon de Malesherbes, 5 novembre 1760, dans Correspondance complète, éd. R. A. Leigh, VII, GenèveMadison, 1969, p. 298.

16. Voir par exemple M.-J. Chénier, Dénonciation des inquisiteurs de la pensée [1789], éd. Th. Gillybœuf, Paris, 2011 ; R. Estivals, Le dépôt légal sous l'Ancien Régime, de 1537 à 1791, Paris, 1961, p. 96-100.

17. Cet aspect a été bien étudié pour le XVIII ${ }^{\mathrm{e}}$ siècle. Voir R. Birn, La Censure royale, cit., p. 75-94 ; Ph. Lefebvre, Les pouvoirs de la parole. L'Église et Rousseau (1762-1848), Paris, 1992, p. 67-84 ; B. de Negroni, Lectures interdites, cit., en particulier p. 195-251.

18. A. Tuilier, Histoire de l'université de Paris et de la Sorbonne, 2 vol., Paris, 1994, I, p. 143-144 ; J. Vezin, La fabrication du manuscrit, dans H.-J. Martin et R. Chartier dir., Histoire de l'édition française, 4 vol., Paris, 1982-1986, I, p. 35-38.

19. Ordinatio Universitatis Parisiensis de librariis siue stationariis, 8 déc. 1275, dans Chartularium Universitatis Parisiensis, éd. H. Denifle et E. Châtelain, I, Paris, 1889, n 462 , p. 532-534; traduction française annotée dans P. Delalain, Étude sur le libraire parisien $d u$ $\mathrm{XIII}^{\mathrm{e}}$ au XV $\mathrm{V}^{\mathrm{e}}$ siècle, d'après les documents publiés dans le Cartulaire de l'Université de Paris, Paris, 1891, p. 1-6.

20. Statuta Universitatis Parisiensis, de librariis et stationariis, quorum nomina recensentur, 4 déc. 1316, dans Chartularium Universitatis Parisiensis, éd. H. Denifle et E. Châtelain, II, Paris, 1891, n 733, p. 190 ; P. Delalain, Étude, cit., p. 21.

21. Actes concernans le pouvoir et la direction de l'Université de Paris, sur les Escrivains des Livres, et les Imprimeurs qui leur ont succedé: comme aussi sur les Libraires, Relieurs, et Enlumineurs [26 janvier 1652 ; BNF, R. 8181 (18)], p. 1-5.

22. Le texte, daté du 18 mars 1520 (ancien style) est publié dans Ch. Jourdain (éd.), Index chronologicus chartarum pertinentium ad historiam Uniuersitatis Parisiensis, Paris, 1862, p. 326, d'après une copie du XVII ${ }^{e}$ siècle, apparemment défectueuse : ne libros in uulgari aut Latino, fidem Christianam aut interpretationem sacre Scripture concernentes, imprimant [impressores Parisius], quin prius illi per Facultatem theologie aut illius deputatos uisi fuerint. Le Catalogue des actes de François $I^{\mathrm{er}}$, I, Paris, 1887, p. 245, n 1341, se contente de renvoyer à cette édition. Voir par exemple Fr. Higman, Le levain de l'évangile, dans H.-J.Martin et R. Chartier dir., Histoire de l'édition française, cit., I, p. 307-308 ; J. K. Farge, Orthodoxy and Reform in early Reformation France: the Faculty of Theology of Paris, 1500-1543, Leyde, 1985, p. 214 ; A. Labarre, La répression du livre hérétique dans la France du XVI eiècle, dans Revue française d'histoire du livre, 118-121, 2003, p. 337-338 - lequel affirme inexactement qu'il s'agissait de la vente des livres par les libraires.

23. Voir J. K. Farge, Introduction historique, dans ILI, I, p. 54-55 ; id., Early censorship in Paris : a new look at the roles of the Parlement of Paris and of King Francis I, dans Renaissance and Reformation/Renaissance et Réforme, nouvelle série, 13, 1989, p. 175-176 et notes ad loc. ; id., 
Le Parti conservateur au XVI $\mathrm{I}^{\mathrm{e}}$ siècle. Université et Parlement de Paris à l'époque de la Renaissance et de la Réforme, Paris, 1992, p. 33 et 47-48.

24. Édit de Châteaubriant, 27 juin 1551, art. 11 et 12, dans Recueil général des anciennes lois françaises, depuis l'an 420, jusqu'à la Révolution de 1789, éd. Fr.-A. Isambert et alii, 29 vol., Paris, 1821-1833, XIII, p. 194-195 (l'article 10 soumet à la faculté de théologie de Paris, seule nommée ici, les traductions nouvelles de la Bible « et aussi des anciens docteurs de l'Eglise »). Pour les édits précédents, voir J. K. Farge, Orthodoxy and Reform, cit., p. 214-215 ; pour l'ensemble des mesures jusqu'en 1560, A. Labarre, La répression, cit., p. 338-355. Voir aussi É. Maugis, Histoire du Parlement de Paris de l'avènement des rois Valois à la mort d'Henri IV, II, Paris, 1914, Appendice I. L'histoire de la censure des livres et de l'imprimerie par le Parlement au XVI siècle, p. 310-351.

25. E. Armstrong, Before copyright. The French book-privilege system, 1498-1526, Cambridge, 1990. La vieille thèse de droit de H. Falk, Les Privilèges de librairie sous l'Ancien Régime. Étude historique du conflit des droits sur l'œuvre littéraire, Paris, 1906 (reprint Genève, 1970), traite essentiellement du XVIII ${ }^{\mathrm{e}}$ siècle.

26. L'édition de la chronique de Jean Zonaras par le luthérien Hieronymus Wolf, parue à Bâle, en 1557, comporte ainsi un double privilège, de l'empereur pour dix ans, et de Henri II pour six ans à « Jehan Oporin et Henry Pierre marchans, libraires et bourgoys de Basle, l'un des Cantons de nos alliez, confederez et bons comperes les Suisses ». Pour d'autres exemples, voir L. Voet, The Golden compasses. A history and evaluation of the printing and publishing activities of the Officina Plantiniana at Antwerp, 2 vol., Amsterdam, 1969-1972, II, p. 264-265 n. 4, et 268 n. 2 ; la correspondance entre Casaubon et l'érudit luthérien d'Augsbourg David Hoeschel en 1602-1605, dans I. Casaubon, Epistolae, Rotterdam, 1709, $2^{\mathrm{e}}$ pagination, p. 155, 189, 205, 219, 237, 259.

27. L. Annaeus Seneca a M. Antonio Mureto correctus et notis illustratus, Rome, 1585 (sans mention de privilège mais seulement Superiorum permissu). On notera qu'il s'agit d'une édition posthume.

28. Plaidoyer «pour Jacques Dupuys, et Gilles Beys, libraires en l'Université, demandeurs ", reproduit dans L. Annaei Senecae Philosophi scripta quae extant : ex editione Romana uirorum doctorum notis castigata, Paris, D. Duval, 1587, fol. *1v-*2r (le texte publié dans Plaidoyez de M. Simon Marion, Advocat en Parlement, Baron de Druy. Avec les Arrests donnez sur iceux, $3^{\mathrm{e}}$ édition, Paris, 1594, p.9-16, comporte d'assez nombreux remaniements stylistiques, mais le sens est le même). Par un arrêt du 15 mars 1586, le Parlement donna la permission demandée en passant outre à "certaines lettres patentes, en forme de pretendu privilege » obtenues par Nicolas Nivelle le 7 février, pour sa propre réimpression (L. Annaei Senecae Philosophi Stoici Opera quae extant omnia, Paris, N. Nivelle, 1587, avec la mention Cum priuilegio Regis, mais sans que le privilège figure dans le volume). A. Viala, Naissance de l'écrivain, cit., p.97-98, a donné une présentation hautement fantaisiste de l'affaire, où il veut trouver l'«affirmation du droit absolu de propriété littéraire ».

29. Voir le bref de Grégoire XIII du $1^{\text {er }}$ juillet 1580, dans Decretum Gratiani emendatum et notationibus illustratum, una cum glossis, Gregorii XIII Pont. Max. iussu editum, Rome, 1582.

30. Le plaidoyer et l'arrêt sont reproduits dans Corpus Iuris Canonici emendatum et Notis illustratum: Gregorii XIII Pont. Max. iussu editum, Paris, 1587 (Cum Licentia), f. $\alpha 5 \mathrm{v}-\alpha 6 r$. Voir D. Pallier, Recherches sur l'imprimerie à Paris pendant la Ligue (1585-1594), Genève, 1975, p. 12-14. 
31. D. Pallier, Les réponses catholiques, dans H.-J. Martin et R. Chartier, Histoire de l'édition française, cit., I, p. 331.

32. Plaidoyez de M. Simon Marion, op. cit., p. 4-5. La distinction avait été clairement affirmée dès 1532 par complures uiros istius academiae consultés par Josse Bade, afin de pouvoir réimprimer à Paris les commentaires scripturaires de Cajetan : voir la dédicace de Bade reproduite par Ph. Renouard, Bibliographie des impressions et des œeuvres de Josse Badius Ascensius, imprimeur et humaniste 1462-1535, 3 vol., Paris, 1908, III, p. 354-355 ; E. Armstrong, Before copyright, cit., p. 13.

33. Voir A. Arnauld, Difficultés proposées à M. Steyaert, dans CEuvres, 43 vol., Paris-Lausanne, 1775-1783, IX, 94e Difficulté, p. 313.

34. Ordonnance sur la réforme de la justice (Moulins, février 1566), article 78, dans Isambert, Recueil, cit., XIV, p.210. Sur l'œuvre législative de L'Hospital, voir R. Descimon, Présentation, dans M. de L'Hospital, Discours pour la majorité de Charles IX et trois autres discours, Paris, 1993, p. 22-32; S.-H. Kim, Michel de L'Hôpital: The Vision of a Reformist Chancellor during the French Religious Wars, Kirksville, 1997, p.146-170; D. Crouzet, La Sagesse et le malheur. Michel de L'Hospital, chancelier de France, Seyssel, 1998, p. 429-444.

35. Voir É. Maugis, Histoire du Parlement, cit., II, p. 346-348 ; infra, n. 47.

36. Édit de Châteaubriant, art. 15, dans Isambert, Recueil, cit., XIII, p. 195-196. L'article 16, ibid., p. 196, fixe les mêmes règles pour l'inspection des boutiques des libraires. Pour le cas des autres villes, voir infra, n. 255 .

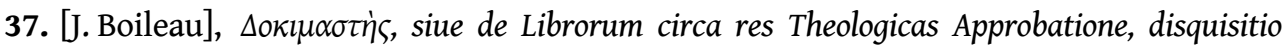
historica, Anvers, 1708, p. 43 (règlement de 1610).

38. Décret de la Faculté sur la Response apologetique à l'Anticoton (1 ${ }^{\mathrm{er}}$ février 1611), dans $\mathrm{Ch}$. Du Plessis d'Argentré, Collectio iudiciorum de nouis erroribus, 3 vol., Paris, 1728-1736, II/2, p. 38-39 (ut moris est).J. Boileau, Dokimastès, cit., p. 35-36, cite un règlement sur ce point de 1559. Sur celui de 1611, voir ibid., p. 43-44; S. H. De Franceschi, La crise théologico-politique du premier âge baroque. Antiromanisme doctrinal, pouvoir pastoral et raison du prince : le Saint-Siège face au prisme français (1607-1627), Rome, 2009, p. 330-331 et 335-336.

39. Bossuet au P.Joseph Shirburne, 6 avril 1686, dans Correspondance de Bossuet, éd. Ch. Urbain et E. Levesque, 15 vol., Paris, 1909-1925, III, p. 215. Je ne connais pas de contre-exemple pour le XVII ${ }^{\mathrm{e}}$ siècle. Pour le $\mathrm{XVI}^{\mathrm{e}}$ siècle, voir en revanche, par exemple, la Censura et approbatio Sacrae Bibliothecae sanctorum probabilium Patrum, per Facultatem sacrae Theologiae Parisiensis, en tête de Sacrae Bibliothecae sanctorum Patrum; seu, scriptorum ecclesiasticorum probabilium, tomi nouem [...], Per Margarinum de la Bigne, ex alma Sorbonae Schola, Theologum Doctorem Paris. Editione secunda, Paris, 1589, I. Nombreux autres exemples dans A. Chevillier, L'Origine de l'Imprimerie de Paris. Dissertation historique et critique, Paris, 1694, p. 389-390, qui regrette, p.391, l'abandon de cette procédure pour les seules approbations individuelles.

40. Isaac Habert approuva sans autorisation de la Faculté l'Antirrheticus II. du P. Sirmond, contre Saint-Cyran, en 1634 (infra, n. 69), et fit approuver de la même manière, dix ans plus tard, sa propre Défense de la foi de l'Eglise et de l'ancienne doctrine de Sorbonne, touchant les principaux points de la Grâce. Voir A. Arnauld, Seconde Apologie pour Monsieur Jansenius Evesque d'Ipre, et pour la doctrine de S. Augustin, expliquée dans son Livre, intitulé, Augustinus [1645], dans Euvres, cit., XVII, p. 6-7; la préface historique et critique, ibid., XVI, p. xv. Pour le cas des docteurs ne résidant pas à Paris, voir note suivante. 
41. Decretum Sacrae Facultatis Theologiae Parisiensis circa Librorum Approbationem $\left[1^{\mathrm{er}}\right.$ décembre 1623], p. 1-2. Dans le cas où l'auteur tenait à rester anonyme, il devait remettre à l'approbateur un écrit avec son nom et sa signature. Les règles étaient néanmoins assouplies pour les docteurs, qui Lutetiae non degunt, quandoquidem et Facultatem ipsam commode consulere nequeunt (Decretum Facultatis circa Librorum Approbationem, cit., p. 3-4). Un exemplaire de ce décret est aux départements des imprimés de la BNF, cote D. 31777 : il doit s'agir d'un de ceux que la Faculté fit imprimer pour les supérieurs des différents collèges, p.7, ut suis, qui Doctores sunt, illud palam faciant, ne quis ipsius ignorantiam praetexat). Les nouvelles règles figurent également dans les extraits des procès-verbaux que la Faculté fit imprimer en 1626 (voir infra, n. 89), Depromptum e tabulis Facultatis circa librorum approbationem, et acta aduersus librorum Censores, p.1; dans J. Boileau, Dokimastès, cit., p. 60-64; dans Ch. Du Plessis d'Argentré, Collectio, cit., II/2, p. 143-144.

42. Voir respectivement édit de Châteaubriant, art. 13, dans Isambert, Recueil, cit., XIII, p. 195 (« à fin que ledit imprimeur ne puisse varier ne changer aucune chose en procédant à l'impression d'iceux [livres]»); Reglement du vingtiéme Novembre 1610. en execution des Edits, Arrests et Ordonnances, pour la Reformation des desordres, abus et malversations des Marchands Libraires, Imprimeurs, Colporteurs, et autres personnes, en l'Impression, vente et exposition de toutes sortes de Livres prohibez et défendus, Libelles diffamatoires et seditieux, au prejudice du repos public [BNF, Ms. Français 22061 (47), et aux imprimés, F-23714 (65)], article XIII, p. 5 ; Code Michau, article 52, dans Isambert, Recueil, cit., XVI, p. 239. La Communauté des libraires ayant interjeté appel au parlement de Paris contre le règlement de 1610, « par Arrest du 15. Fevrier 1611, la Cour mit l'appellation et ce dont a esté appellé au neant [i.e. infirma le règlement]»(L. Bouchel, Recueil des Statuts et Reglemens des Marchands Libraires, Imprimeurs, et Relieurs de la ville de Paris, Paris, 1620, art. 65, p. 55). Les lettres patentes d'août 1624 établissant des censeurs royaux (infra, n. 91) précisaient que ceux-ci conserveraient une copie «signée de l'Auteur et paraphée de lui en tous ses feuillets ». Les nouvelles règles adoptées par la Faculté de théologie en décembre 1623 stipulaient quant à elles que l'approbateur devrait faire signer par l'auteur ou le libraire la liste des corrections à effectuer, et la conserver par devers lui (Decretum Facultatis circa Librorum Approbationem, cit., p. 2-3). Selon une lettre de Richard Simon à Henri Justel, dans Lettres choisies de Mr. Simon, nouvelle édition, II, Rotterdam, 1704, p. 99, l'obligation pour les approbateurs de parapher toutes les pages du manuscrit remonte à François I ${ }^{\mathrm{er}}$, «mais elle a été négligée par les Docteurs qui ont eu toûjours de la peine à s'y soumettre » (le curieux texte cité ensuite par Simon, p. 101-102, se rapporte cependant à Henri II plutôt qu'à François I ${ }^{\mathrm{er}}$ ).

43. Voir e.g. l'affaire de la Bible de René Benoist en 1566 (infra, n. 76) ; Collection des ProcèsVerbaux des Assemblées générales du Clergé de France, depuis l'année 1560 jusqu'à présent, 9 vol., Paris, 1767-1778, III, p. 738 (affaire de 1650) ; un passage d'une lettre de Jean Ballesdens au chancelier Séguier, publié sans date dans R. Kerviler, Le chancelier Pierre Séguier, second protecteur de l'Académie française. Études sur sa vie privée, politique et littéraire et sur le groupe académique de ses familiers et commensaux, $2^{\mathrm{e}}$ édition, Paris, Didier, 1875, p. 675 (d'autres extraits de la même lettre avaient été donnés avec la date $\mathrm{du}$ " $1^{\mathrm{er}}$ dimanche de septembre 1661 [i.e. 4 septembre] » par B. Hauréau, Lettres de Ballesdens au chancelier Séguier, dans Bulletin du Comité historique des monuments écrits de l'histoire de France. Histoire - Sciences Lettres, 1,1849 , p. 87-90) ; l'arrêt du Conseil du 12 septembre 1665 révoquant le privilège de La Concordance des quatre Evangelistes avec des Meditations sur les principaux points de 
l'Evangile, par M. Fedeyer Docteur en Theologie de la Faculté de Thoulouze (exemplaire imprimé, BNF, Ms. Franç. 22071, n 109 ; reproduit d'après cet imprimé par M.-Cl. Dock, Étude sur le droit d'auteur, Paris, 1963, p. 70 et 177-178, sans note ni commentaire: d'après l'arrêt, l'« Auteur qui se cache sous le nom supposé et imaginaire de Fedeyer » est un janséniste, mais il n'apparait pas dans Lexicon pseudonymorum jansenisticorum: répertoire de noms d'emprunt employés au cours de l'histoire du jansénisme et de l'antijansénisme, Louvain, 1989); peut-être l'Histoire critique du Vieux Testament de Richard Simon (lettres du chancelier Le Tellier au lieutenant de police La Reynie, 15 et 28 avril 1678, dans Correspondance de Bossuet, cit., XIII, p. 540-542 ; discussion dans P. Auvray, Richard Simon 1638-1712. Étude biobibliographique avec des textes inédits, Paris, 1974, p. 47-48 n. 6).

44. On sait que les préliminaires étaient imprimés en dernier. Lorsque les dédicaces portent une date, celle-ci est communément postérieure aux approbations. Voir par exemple Jean Chrysostome, Panegyrici Tractatus XVII sanctis Apostolis, Martyribus, et Patriarchis dicti, éd. Fr. Du Duc, Bordeaux, 1601 (l'approbation des docteurs est datée du 8 février 1600 , la dédicace du $1^{\text {er }}$ septembre 1600) ou M. Mersenne, La Vérité des sciences contre les sceptiques ou pyrrhoniens, éd. D. Descotes, Paris, 2003, p. 110 et 114 (approbation du 30 juin 1625, dédicace du $1^{\text {er }}$ août 1625). Pour un exemple de digression polémique, voir l'épître dédicatoire du carme Denys de la Mère de Dieu à l'abbesse de Montmartre, en tête de sa traduction d'Histoire des Sceurs Carmelites Déchaussées, escritte par leur Bienheureuse Mere Fondatrisse Terese de Jesus, Paris, 1616, fol. a6r-a7r : elle n'est pas datée mais elle a toute chance d'avoir été ajoutée après l'approbation des docteurs de la Faculté de théologie (14 août 1615); elle fut en tout cas «censurée à la Sorbonne, et la censure sursise, sur l'assurance que ses amis ont donnée qu'ils supprimeront cette épître » (Bérulle à Claude Bertin, 14 février 1620, dans Euvres complètes, cit., X, p. 183). Voir St.M. Morgain, Pierre de Bérulle et les carmélites de France. La querelle du gouvernement 1583-1629, Paris, 1995, p. 297-298.

45. Autres Actes concernans aussi l'authorité et la jurisdiction de l'Université, touchant la Doctrine et la Discipline, dans Partie des pieces et actes qui concernent l'estat present et ancien de l'Université de Paris, Paris, 1653 [BNF, R. 8180 (21)], paginé à part, p. 15-16. La déclaration de Blondel et Helies est datée du 3 novembre 1645 (eam [praefationem] tanquam Uniuersitati iniuriosam, ueritati parum consonam et scandalosam improbamus et improbauimus); Ch. Du Plessis d'Argentré, Collectio, cit., III/1, p.57. Pour le contexte, voir J. Grès-Gayer, Le jansénisme en Sorbonne, 1643-1656, Paris, 1996, p. 28-31. L'Université parle toujours du "sixiéme Tome de la Cour saincte», mais il s'agit de N. Caussin, La Cour Saincte. Tome V selon l'ordre ancien. Contenant les Vies et Eloges des personnes Illustres qui ont esté adjoustées et inserées dans l'ordre nouveau de la derniere edition, Paris, 1645, « Au Lecteur» (l'approbation des docteurs est datée du 6 février 1645).

46. Les positions d'Helies ne sont pas connues mais Blondel avait au moins des sympathies jansénistes et il fut exclu de la Faculté en 1656 pour n'avoir pas voulu souscrire la censure d'Arnauld (J. Grès-Gayer, Le jansénisme, cit., à l'index, et surtout p. 264 n. 9).

47. Voir l'exposé très clair de J.-D. Mellot, L'Édition rouennaise et ses marchés (vers 1600-vers 1730). Dynamisme provincial et centralisme parisien, Paris, 1998, p. 102-109; id., Le régime des privilèges et permissions d'imprimer à Rouen au XVII siècle, dans Bibliothèque de l'École des Chartes, 142, 1984, p. 137-152. Pour Lyon, voir M. Pallasse, La Sénéchaussée et siège présidial de Lyon pendant les guerres de religion. Essai sur l'évolution de l'administration royale en province au XVI siècle, Lyon, 1943, p.185. Pour les origines de cette pluralité, voir E. Armstrong, 
Before copyright, cit., p. 22-55 ; pour un exemple un peu plus tardif, Burchard de Worms, Decretorum Libri XX, Paris, 1549, Cum Priuilegio Senatum [sic], i.e. avec un privilège du parlement de Paris du 31 décembre 1548. Sur le cas particulier des privilèges pour l'édition des actes royaux, H. Michaud, La Grande Chancellerie et les écritures royales au seizième siècle (1515-1589), Paris, 1967, p. 386-392.

48. Voir ce privilège du 3 septembre 1594 dans [P. Pithou], Les Libertez de l'Eglise Gallicane, Paris, M. Patisson, 1594.

49. Bellièvre accorda en 1603 un privilège à l'Histoire du président de Thou mais celui-ci, pressé par son imprimeur, s'était déjà adressé à la petite chancellerie du parlement de Paris. Voir O. Poncet, Pomponne de Bellièvre (1529-1607). Un homme d'État au temps des guerres de religion, Paris, 1998, p. 248.

50. «Extraict du Privilege du Roy ", 20 août 1635, à la fin de Epistola Archiepiscoporum et Episcoporum Parisiis nunc agentium, ad Archiepiscopos et Episcopos Regni Galliae super animaduersione duorum libellorum [d'E. Knott et J. Floyd], Paris, A. Vitré, 1643. Cet extrait me semble plus digne de foi que celui qu'on trouve, sous la même date, dans Recueil des Edicts, Declarations, Lettres Patentes, et Arrests du Conseil d'Estat et Privé du Roy, obtenus pour les affaires du Clergé de France, durant l'Agence et à la poursuitte des sieurs Abbés de Paimpont, et Prieur de Moustiers, Paris, A. Vitré, 1635: "tous les Edicts, Declarations, Lettes patentes, Arrests, et autres choses generalement quelsconques concernantes les affaires dudit Clergé ». Ce privilège de 1635 prenait la suite de celui qui avait été accordé pour 5 ans à Antoine Estienne, le 4 septembre 1625 (qui avait donc dû être renouvelé une première fois en 1630), dans Relation des Agents Generaux du Clergé de France, a Messeigneurs les Archevesques et Evesques de ce Royaume, sur tout ce qui s'est fait et passé en la derniere Assemblée Generale du Clergé, tenuë à Paris, és années 1625 et 1626, Paris, 1626 : « outre les trois livres des Edicts du Clergé, déja publiés, d'imprimer encor tous les autres Edicts, Lettres Patentes, Arrests, et autres choses concernant les affaires du Clergé de France; qui luy seront par cy-apres baillées par les Agents Generaux dudit Clergé ». Auparavant, les publications du Clergé semblent n'avoir paru qu'avec des privilèges particuliers, quoique sans être soumises à approbation: c'est le cas pour Recueil des Remonstrances, Edicts, Contracts, et autres choses concernant le Clergé de France, 2 vol., Paris, 1606 (privilège à l'imprimeur Jean Richer pour six ans, du 12 mai 1606).

51. Petri Aurelii Theologi Opera, iussu et impensis Cleri Gallicani denuo in lucem edita, 3 t. en 1 vol., Paris, A.Vitré, 1642: seul le t. II, contenant les Vindiciae Censurae Facultatis Theologiae Parisiensis, était muni de l'approbation des docteurs, du 14 mars 1632, et du privilège de l'édition originale, du 23 mars 1632 ; l'Anaereticus contre Sirmond, repris au t. III, avait d'abord paru avec privilège mais celui-ci avait été cassé (infra, n. 141). Sur l'affaire, voir J. Orcibal, Jean Duvergier de Hauranne abbé de Saint-Cyran et son temps (1581-1638) [Les origines du jansénisme, II-III], Louvain-Paris, 1947-1948, p. 368-369 et infra, n. 197.

52. Collection des Procès-Verbaux, cit., III, p. 404-405. Cet extrait est aussi reproduit parmi les testimonia en tête de Petri Aurelii Theologi Opera, iussu et impensis Cleri Gallicani denuo in lucem edita, 3 t. en 1 vol., Paris, A. Vitré, 1646, fol. o4r: à la différence de 1642, cette nouvelle édition a la mention Cum priuilegio Regis sur la page de titre, mais le seul privilège qu'on y trouve reste celui de 1632 aux Vindiciae Censurae Facultatis Theologiae Parisiensis . Sur le rôle des promoteurs, voir Précis par ordre alphabétique, ou table raisonnée des matières contenues dans la nouvelle collection des procès-verbaux des assemblées générales et particulières 
du clergé de France, Paris, 1780, col. 1779-1783 ; L. Serbat, Les Assemblées du clergé de France: origines, organisation, développement, Paris, 1906, p. 248-250.

53. Comparer la manière dont fut plus tard étendu le privilège de l'Académie des Sciences: R. Hahn, The anatomy of a scientific institution: the Paris Academy of sciences, Berkeley-Los Angeles-Londres, 1971, p. 60-65.

54. Privilège du 15 décembre 1651, par exemple dans Procez verbal de l'Assemblée generale du Clergé de France, tenuë à Paris au convent des Augustins és années 1655 et 1656. Messieurs les Abbez de Villars, Chanoine et Capiscot de l'Eglise Cathedrale et Metropolitaine de Vienne: et de Carbon Abbé du Mas d'Azil, et Escolain de Dongat Diocese de Conserans, Secretaires, Paris, A. Vitré, 1655. Ce privilège était accordé " pour le temps et espace de neuf ans »: il fut renouvelé pour dix ans, le 17 février 1661, presque à l'identique ("tous les Edicts, Declarations, Contracts, Arrests, Remonstrances, et generalement toutes les choses qui luy seront baillées par les Assemblées generales, ou par les Agents generaux du Clergé de France ", par exemple dans le commentaire d'Hallier, voir note suivante) puis le 4 décembre 1674, pour vingt ans, au profit de Frédéric Léonard, successeur de Vitré comme imprimeur du Clergé (voir par exemple dans Recueil des Edits et Declarations du Roy, Arrests de son Conseil, et autres Jugemens rendus en faveur du Clergé pendant l'Agence de M. l'Abbé de la Hoguette nommé à l'Evesché de S. Brieu; et de M. l'Abbé de Grammont nommé à l'Evesché de S. Papoul, Paris, 1676).

55. Voir dans Instructions de S. Charles Boromée [sic], Cardinal du tiltre de sainte Praxede, Archevesque de Milan. Aux Confesseurs de sa Ville et de son Diocese. Traduites d'Italien en François [...]. Imprimé par le commandement de l'Assemblée generale du Clergé de France, Paris, A. Vitré, 1657; Ordinationes uniuersi Cleri Gallicani circa Regulares, conditae primum in Comitiis Generalibus ann. M.DC.XXV. renouatae et promulgatae in Comitiis ann.1645. Cum Commentariis Francisci Hallier [...]. Editae in lucem iussu Cleri Gallicani, Paris, A. Vitré, 1665.

56. Sur le cas des jésuites, voir U. Baldini, Uniformitas et soliditas doctrinae. Le censure librorum e opinionum [1985], dans Legem impone subactis. Studi su filosofia e scienza dei gesuiti in Italia 1540-1632, Rome, 1992, p. 75-119; A. Romano, Pratiques d'enseignement et orthodoxie intellectuelle en milieu jésuite (deuxième moitié du XVI siècle), dans S. Elm, É. Rebillard, A. Romano (éd.), Orthodoxie, christianisme, histoire, Rome, 2000, p. 241-260, surtout 258-260 ; E. Olivares, Censura de libros, dans Diccionario histórico de la Compañía de Jesús biográficotemático, 4 vol., Rome-Madrid, 2001, I, p. 731-732.

57. Ces privilèges sont régulièrement rappelés dans les permissions, en français ou en latin, qui figurent en tête des ouvrages jésuites du XVII ${ }^{e}$ siècle, avec des variantes clairement dues à des coquilles. Les dates les plus couramment indiquées (par exemple dans le De Hierarchia de Cellot, infra, n. 75) sont respectivement 10 mai 1583, 20 décembre 1606, 14 février 1611. Dans les Provinciales (infra, n. 60), Pascal donne 10 mai 1583, 20 décembre 1603 et 14 février 1612, selon toute vraisemblance d'après un livre qu'il avait sous les yeux. Je ne sais à quoi correspond l'affirmation, sans référence, de H.J. Martin, Livre, pouvoirs et société, cit., I, p. 459 (transcrite, sans référence précise à H.J. Martin, par S. H. De Franceschi, La crise théologico-politique, cit., p. 530), selon laquelle le parlement de Paris « a reconnu en 1608 à la Compagnie le droit de choisir elle-même ses imprimeurs et d'interdire aux autres de publier quelque ouvrage d'un de ses membres ».

58. Privilège du 23 décembre 1650, rappelé avec les précédents en tête de nombreux ouvrages jésuites (par exemple dans François Pomey, Pantheum mythicum, Lyon, 1659). On trouve cependant aussi la date du 23 décembre 1651 (par exemple dans Pierre-Juste Sautel, Lusus poetici allegorici, Paris, 1665). Si la date de 1650 est la bonne, ce 
renouvellement pourrait être lié à l'affaire de la publication «sauvage » de Suárez à Lyon (infra, n. 66).

59. On n'en trouve en tout cas aucune mention dans l'« Approbation du tres-reverend Pere General des Carmes Déchaussez » (datée de Paris, $1^{\mathrm{er}}$ septembre 1615) à l'Histoire des fondations des Sceurs Carmelites Déchaussées, cit., ni dans le "privilège" accordé par le général des Minimes à Marin Mersenne, le 14 avril 1625, mandandi typis uniuersa opera tua [...], modo tamen a duobus nostri ordinis aut alicuius Facultatis Theologis approbentur (reproduit dans M. Mersenne, La Vérité des sciences, cit., p. 114).

60. Pascal, Neuvième Lettre (juillet 1656), dans Les Provinciales, Pensées et opuscules divers, éd. citée, p.405-406. Louis Cognet, ibid., p. 406 n.1, l'avait déjà relevé, en donnant l'exemple de l'Oratoire (voir note suivante).

61. Voir par exemple la permission du P. François Bourgoing, supérieur général de l'Oratoire, 3 février 1644, dans Les CEuvres de l'Eminentissime et Reverendissime Pierre cardinal de Berulle, Paris, 1644, « suivant le Privilege à nous donné par Lettres patentes du Roy en date du 21. Iuillet 1642. par lesquelles sont faites defenses à tous Imprimeurs, Libraires, et à tous autres, d'imprimer, faire imprimer, ny mettre au jour aucuns des Livres composez par ceux de nostre Congregation, sans nostre expresse Licence par écrit; de laquelle outre les Lettres de permission de sa Majesté, et l'Approbation des Docteurs, soit faite mention au commencement de tous lesdits Livres ». Même référence, avec la même date, dans la permission de Bourgoing du $1^{\mathrm{er}}$ septembre 1661, pour J. Le Jeune, Le Missionnaire de l'Oratoire, ou Sermons pour les Advents, Caresmes, et Festes de l'Année. Premiere partie, « jouxte la Copie imprimée à Tolose », Paris, 1663 ; dans celle du 13 septembre 1651 pour J. Morin, Commentarius historicus de disciplina in administratione sacramenti Poenitentiae tredecim primis seculis in Ecclesia Occidentali, et huc usque in Orientali observata, Paris, 1651, le privilège du roi est daté du 14 juillet 1642 .

62. Lettres patentes du Roy du mois de Decembre 1658. portant defences d'imprimer aucuns livres et ouvrages composez par les Abbez et Religieux de l'Ordre de Cisteaux, sans la permission de l'Abbé, Chef et Superieur General dudit Ordre ou du Chapitre General d'iceluy, verifiées au grand Conseil de sa Majestéle 30. Janvier 1659 [exemplaire imprimé, BNF, Ms. Franç. 22071 (87)], sur la requête de Dom Claude Vaussin, abbé de Cîteaux. Voir L.J. Lekai, The Rise of the Cistercian Strict Observance in seventeenth century France, Washington, D.C., 1968, surtout p. 103 et p. 224 n. 50 .

63. Concile de Trente, session IV, décret 2 (8 avril 1546), dans Les Conciles œecuméniques, 3 vol., Paris, 1994, II/2, p. 1354 [=Concilium Tridentinum. Diariorum, actorum, epistularum, tractatuum noua collectio, éd. St. Ehses, V, Fribourg, 1911, p. 92] : Et si regulares fuerint, ultra examinationem et probationem huiusmodi [par les ordinaires, voir infra, n. 251] licentiam quoque a suis superioribus impetrare teneantur, recognitis per eos libris iuxta formam suarum ordinationum. Le décret porte avant tout sur la Vulgate mais cette clause vaut pour quiuis libri de rebus sacris. La proposition en avait été faite le 17 mars par la commission sur les abus liés à l'Écriture sainte (Concilium Tridentinum, cit., V, p. 30). La discussion, vive sur d'autres points, ne semble pas avoir porté sur celui-ci : voir infra n. 251.

64. N. Caussin, Apologie pour les Religieux de la Compagnie de Jesus, Paris, 1644, p. 108-111. Comparer Fr. Garasse, Récit au vrai des persécutions soulevées contre les Pères de la Compagnie de Jésus dans la ville de Paris l'an 1624, 1625 et 1626 [rédigé en 1636], dans Documents inédits concernant la Compagnie de Jésus, éd. A. Carayon, III, Poitiers, 1864, p. 157-158. Voir aussi les lettres citées par R. de Scorraille, François Suarez, de la Compagnie de Jésus, d'après ses lettres, ses autres écrits inédits et un grand nombre de documents nouveaux, 2 vol., Paris, 
1913, II, p. 217, et P. Blet, Jésuites Gallicans au XVII siècle? A propos de l'ouvrage du P. Guitton sur le P. de La Chaize, dans Archivum Historicum Societatis Iesu, 29, 1960, p. 62-63 ; E. Nelson, The Jesuits and the monarchy. Catholic reform and political authority in France (1590-1615), Aldershot, 2005, en particulier p. 167-170. Pour les décrets du général, voir X. Le Bachelet, La théologie dogmatique dans la Compagnie de Jésus, dans Dictionnaire de Théologie Catholique, VIII/1, Paris, 1924, col.1062; A. Lezza, I decreti sul tirannicidio di Claudio Acquaviva, dans G. Paparelli et S. Martelli (éd.), Letteratura fra centro e periferia. Studi in memoria di Pasquale Alberto De Lisio, Naples, 1987, p. 399-417 (surtout pour les décrets qu'elle publie); S. H. De Franceschi, La crise théologico-politique, cit., p. 254-255, 652-653, 665-666. Pour leur violation, ibid., p. 353-354, 428-432, 435 ; M. Turchetti, Tyrannie et tyrannicide de l'Antiquité à nos jours, Paris, 2001, p. 540.

65. L'exemple classique, si l'on se fie aux Mémoires du P. Rapin, serait celui de l'Apologie pour les casuistes en 1657, mais voir désormais la reconstruction de J.-P. Gay, Morales en conflit. Théologie et polémique au Grand Siècle (1640-1700), Paris, 2011, p. 210-214, d'après les sources romaines. Sur les rapports entre centre romain et jésuites français en matière éditoriale, voir ibid., p. 571-593; pour un cas intéressant de 1666 (une approbation donnée en urgence par le provincial de France et validée rétrospectivement par le général), G. Bottereau, Jacques Nouet, S. J., 1605-1680, dans Archivum Historicum Societatis Jesu, 46, 1977, p. 319 n. 66 ; pour la période antérieure, A. D. Wright, The Divisions of French Catholicism, 1629-1645. 'The Parting of the Ways', Farnham, 2011, p. 122-123 et 165-174.

66. Fr. Suárez, Operis de divina Gratia pars secunda, continens libros III. IV. et V. Nimirum, De Auxiliis Gratiae, in generali ; De Auxilio sufficiente, et de Auxilio efficaci Gratiae Dei. Editio prima, Lyon, 1651 (Cum superiorum permissu) : l'approbation de Michel Micard, O.F.M., et Paul Lombard, prieur des carmes de Lyon, in Alma facultate Parisiensi Theologiae Doctores, datée du 6 décembre 1650, est suivie d'un Consensus du 13 décembre signé « Lorin » (procureur du roi) et d'une Permissio du 12, signée «Sève » (lieutenant général). Voir sur l'affaire R. de Scorraille, Suarez, cit., II, p. 394-398.

67. À en juger par le rôle du P. Théophile Raynaud dans la publication par les mêmes libraires, en 1655, d'un autre inédit de Suárez, De uera intelligentia auxilii efficacis (R. de Scorraille, Suarez, cit., II, p. 398-400).

68. L. Batterel, Mémoires domestiques pour servir à l'histoire de l'Oratoire, 4 vol., Paris, 1902-1904, III, p. 471-472 : encore le général ne paraît-il s'être ému qu'une fois que la seconde édition de l'ouvrage eut provoqué une polémique. Voir [Fr. de Clugny], La devotion des pecheurs par un pecheur. Seconde edition, Lyon, A. Briasson, 1689 (avec privilège $\mathrm{du}$ roi du 5 décembre 1684). Sur les excuses de ce genre, voir A. Baillet, Jugemens des Sçavans, I, cit., p. 13-14.

69. Voir par exemple C. Solii Apollinaris Sidonii Aruernorum episcopi Opera, éd. J. Sirmond, Paris, 1614 (Cum Privilegio Regis: privilège particulier du roi au libraire Sébastien Cramoisy, 7 février 1614 ; permission du provincial à Cramoisy, d'après les privilèges de Henri III, Henri IV et Louis XIII). Dans J. Sirmond, Antirrheticus II. De canone Arausicano, Paris, 1634, ne figurent que le privilège particulier du roi, du 24 janvier 1634 , et l'approbation des docteurs de Sorbonne, sans date (supra, n. 40). Chez les Oratoriens, J. Morin, Commentarius historicus, cit., et J. Le Jeune, Le Missionnaire de l'Oratoire, cit., sont munis d'un privilège particulier en plus de la permission du P. Bourgoing (supra, n. 61). La réforme de Filesac obligeait le docteur qui voulait approuver le livre d'un religieux à se faire remettre au préalable la permission des supérieurs (Decretum Facultatis circa Librorum Approbationem, cit., p. 3-4). 
70. Collection des Procès-Verbaux, cit., III, p. 102.

71. Prattique du Droict Canonique au gouvernement de l'Eglise, correction des Mours, et distribution des Benefices, Paris, M. Soly, 1633 (BNF, E. 6808 : on notera que la page de titre a un blanc au lieu de la marque du libraire, contrairement aux ordonnances), avec approbation des docteurs du 2 mai 1633 et privilège du roi du 3 mai 1633, à Michel Soly ; achevé d'imprimer du 13 août 1633. L'avertissement du libraire, fol. A3r, souligne que l'auteur a tenu à rester anonyme. Certains exemplaires (ainsi BNF, E. 5136) ont été cartonnés pour insérer une nouvelle page de titre, toujours datée de 1633, portant le nom de l'auteur (« Par le R. P. E. Bauny de la Compagnie de Jesus ») et la marque du libraire, et supprimer l'avertissement.

72. Permission du provincial Barthélemy Jacquinot, du 4 août 1634, dans Pratique du Droict Canonique [...]. Par le R. P. E. Bauny de la Compagnie de Jesus. Seconde Edition, Paris, M. Soly, 1635 (l'avertissement du libraire est repris tel quel, moins le paragraphe sur l'anonymat de l'auteur). On la trouve également dans É. Bauny, Somme des Pechez qui se commettent en tous Estats, 5e édition, Paris, M. Soly, 1638 (je n'ai pu voir la $1^{\mathrm{e}}$ édition, de 1635) : on notera que l'approbation, par les mêmes docteurs que pour la Prattique du Droict Canonique, est également du 2 mai, et le privilège du 3 mai, 1633: Soly s'était donc préparé en même temps à faire paraître les deux ouvrages, même si, pour la Somme des Pechez, il attendit finalement la permission de la Compagnie de Jésus.

73. É. Bauny, De Sacramentis ac personis sacris, earum dignitate, obligationibus ac iure [... ]. Theologiae moralis pars prima, Paris, M. Soly, 1640 (achevé d'imprimer du 18 juillet 1640), avec approbations des docteurs, 20 février 1639 et $1^{\text {er }}$ février 1640 , permission du provincial Étienne Binet du 21 février 1639 à Michel Soly (ut librum qui inscribitur Tractatus de Sacramentis etc. a Stephano Bauny nostrae Societatis Theologo, compositum [...] diuendere possit), privilège du roi du 18 mars 1639 à Soly (« un Livre intitulé, Tractatus de Sacramentis, etc. Composé par le R.P. Estienne Bauny, de la Compagnie de Jesus »).

74. É. Bauny, De Censuris Ecclesiasticis [...]. Theologiae moralis pars altera, Paris, M. Soly, 1642 (achevé d'imprimer du 18 juillet 1642), avec permission de Binet du 21 février 1639 (librum qui inscribitur De Censuris Ecclesiasticis, a Stephano Bauny nostrae Societatis Theologo, compositum) et privilège du 18 mars 1639 ("un Livre intitulé, Tractatus de Censuris Ecclesiasticis, Composé par le R.P. Estienne Bauny, de la Compagnie de Jesus») ; id., Theologiae moralis pars tertia. In tres libros digesta, quibus, quae in contractuum ac quasi contractuum materia uidentur ardua ac difficilia enucleantur, Paris, M. Soly, 1645 (achevé d'imprimer du 16 septembre 1644), avec permission de Binet du 21 février 1639 (libros qui inscribuntur De Sacramentis, Censuris Ecclesiasticis, et Contractibus a Stephano Bauny nostrae Societatis Theologo, compositos) et privilège du 18 mars 1639 («un Livre intitulé, Tractatus de Sacramentis, De Censuris Ecclesiasticis, et Contractibus in genere et particulari, Composé par le R.P. Estienne Bauny, de la Compagnie de Jesus »). Aucune approbation des docteurs ne figure dans ces deux volumes.

75. L. Cellot, De Hierarchia et Hierarchis libri IX, Rouen, 1641. Permission du 4 février 1639, signée "Godard» [Artus Godart du Becquet] : Visis Doctorum approbationibus, et facultate Prouincialis, permissum est Ioanni le Boullenger Bibliopolae et Typographi Rothomagensi imprimere et distrahere librum De Hierarchia et Hierarchis auctore P. Ludovico Cellotio, et uetitum ne quis alius idem ausit ad decem proximos annos in Ordinis Priuilegio [i.e. la permission du provincial] memoratos.

76. Sur toute l'affaire, qui se prolongea jusqu'en 1575, voir É. Pasquier, Un curé de Paris pendant les guerres de religion. René Benoist, le pape des Halles (1521-1608), Paris-Angers, 1913 
(reprint Genève, 1970), p. 85-116. Les études plus récentes (voir en particulier Fr. Higman, Les Advertissemens des Bibles de René Benoist $(1566,1568)$ [1998], repris dans id., Lire et découvrir. La circulation des idées au temps de la Réforme, Genève, 1998, p. 563-571, avec bibliographie, n'apportent rien de plus sur ce point. Ch. Du Plessis d'Argentré, Collectio, cit., II/1, p. 398, donne le texte intégral du privilège du roi du 26 décembre 1565, accordé pour huit ans, à compter de l'achevé d'imprimer, aux libraires Sébastien Nivelle, Gabriel Buon et Nicolas Chesneau pour « imprimer, ou faire imprimer, distribuer et exposer en vente la Sainte Bible n'agueres traduite en François, et apostillée par Maistre René Benoist » pourvu « qu'elles [les dites Bibles] soient vûes et approuvées par les Docteurs Regens en ladite Faculté de théologie». La Sainte Bible contenant le Vieil et Nouveau Testament, traduitte en François, selon la version commune [...]. Par M. René Benoist, Angevin, Docteur Regent en la faculté de Theologie à Paris, Paris, 1566 (édition partagée entre quatre libraires : Bibles imprimées du XV $V^{\mathrm{e}}$ au XVIII siècle conservées à Paris, Paris, 2002, $\mathrm{n}^{\circ}$ 401-404), ne donne qu'un extrait de ce privilège, moins justement la clause sur l'approbation des docteurs ; même extrait dans l'édition bilingue, La Sainte Bible contenant le Vieil et Nouveau Testament, latin françois, chacune version correspondante l'une à l'autre, verset à verset [...], Paris, 1568 (édition partagée entre les mêmes libraires: Bibles imprimées, cit., $\mathrm{n}$ -594-596). Il n'y a aucune mention dans l'ouvrage d'une telle approbation: en réalité, Benoist avait fait approuver par certains de ses confrères les cahiers au fur et à mesure qu'ils sortaient de l'imprimerie, sans qu'aucun eût vu l'ouvrage complet, et aurait en outre manqué à faire les corrections demandées (voir les déclarations des docteurs en cause dans Ch. Du Plessis d'Argentré, Collectio, cit., II/1, p. 427 et 431-432; pour la version de Benoist, ibid., p. 437).

77. Ibid., p. 407 (septembre 1569).

78. Arrêt du 17 septembre 1569, ibid., p. 408.

79. L'arrêt avait été pris par le «Conseil privé établi à Paris sous Monseigneur le Duc [d'Alençon] pendant les troubles [la troisième guerre de religion] », sous la présidence du cardinal de Pellevé (ibid., p. 432). Voir H. de la Ferrière, Deux années de mission à saintPétersbourg. Manuscrits, lettres et documents historiques sortis de France en 1789, Paris, 1867, p. 27 ; sur les événements militaires, qui forment l'arrière-plan de cette polémique, voir J. W. Thompson, The wars of religion in France, 1559-1576 : the Huguenots, Catherine de Medici, Philip II, New York, 1909, p. 379-393. Pour l'édit de Saint-Germain-en-Laye, août 1570, j'utilise l'édition électronique des édits de pacification réalisée par les élèves de l'École nationale des Chartes sous la direction de B. Barbiche (http://elec.enc.sorbonne.fr/ editsdepacification). Le livre protestant n'y est pas explicitement mentionné (il l'est pour la première fois par l'édit de Beaulieu, ou Paix de Monsieur, de 1576, art. 5), mais voir l'art. 43 : «nous avons declaré et declarons tous autres edictz, lettres, declarations, modiffications, restrinctions et interpretations, arrestz et registres, tant secretz que autres, deliberations cy devant faictes en noz courtz de parlemens et autres qui par cy aprés pourroient estre faictes au prejudice de nostred. present edict concernant le faict de la religion et des troubles advenuz en cestuy nostre royaulme, estre de nul effect et valeur. Ausquelz et aux derogatoires y contenues avons par icelluy nostred. edict derogé et derogeons, et dès à present comme pour lors les cassons, revocquons et adnullons ». Sur la requête de l'université de Paris, en violation de la paix, Charles IX, le 8 octobre 1570, fit à nouveau « deffenses à tous Libraires, Imprimeurs d'imprimer ou faire imprimer, ni mettre en vente aucuns Livres censurez par la Faculté de Théologie », mais 
rien n'était dit de l'approbation (Ch. Du Plessis d'Argentré, Collectio, cit., II/1, p. 413; J. W. Thompson, The wars of religion, cit., p. 420).

80. Je n'ai pu faire un dépouillement complet mais c'est le cas de R. Benoist, Catecheses ou Instructions touchant les poincts à present controverses en la religion, Paris, Nicolas Chesneau, 1573 ; id., Locorum praecipuorum Sacrae Scripturae, tam ueteris quam noui Testamenti [...] conquisitio, et Catholica expositio, Paris, N. Chesneau, 1576; id., Sermon, sur le cantique 0 salutaris hostia, Paris, N. Chesneau, 1577 ; id., Le Grand Ordinaire, ou Instruction commune des Chrestiens, Paris, G. de la Nouë, 1580 ; id., Ad pios et catholicos Scotos [...] simplex et catholica cohortatio, Paris, N. Chesneau, 1581. Id., Notables Resolutions des presens differens de la Religion , Paris, P. Chevalier, 1608, parut en revanche avec un privilège particulier accordé par Henri IV à l'imprimeur, mais toujours sans aucune trace d'approbation des docteurs.

81. Privilège du 13 septembre 1651, reproduit intégralement dans A. Godeau, Histoire de l'Église, I, Paris, 1653.

82. Voir ce privilège du 12 Juin 1599 dans Sancti Ioannis Chrysostomi Archiepiscopi Constantinopolitani Panegyrici Tractatus XVII sanctis Apostolis, Martyribus, et Patriarchis dicti, éd. Fr. Du Duc, Bordeaux, 1601: ne quis libros a Frontone Ducceo societatis nominis Iesu presbytero conscriptos, commentariis illustratos, uel e Graeco in Latinum conuersos nisi ex ipsius permissu ac uoluntate typis excudat, uel alibi excusos in Galliam importet, aut uenales habeat. Ce privilège est reproduit dans toutes les éditions ultérieures de Du Duc.

83. Voir par exemple L. Richeome, Advis et notes donnees sur quelques plaidoyez de Maistre Louis Servin Advocat du Roy, cy devant publiez en France, au prejudice de la Religion Catholique, de l'honneur du Roy, Tres-Chrestien, et de la paix de son Royaume, Caen, Georges de la Marinière, 1615 : figurent dans l'ouvrage le privilège général du 19 septembre 1598, et l'approbation conjointe des docteurs Jean de Lorini et Charles Vernot, datée de Rome, 3 juillet 1614.

84. Voir H. Carrier, La Presse de la Fronde (1648-1653) : les Mazarinades, 2 vol., Genève, 1991, II, p. 299 (sans référence). Aucun texte légal ne semble affirmer expressément cette règle, mais elle se déduit du règlement de 1618, qui fixa une limite de huit feuilles aux « petits livres » que pouvaient vendre les colporteurs, à condition qu'ils fussent « imprimez par un Libraire ou Maistre Imprimeur de ceste ville de Paris, auquel sera son nom, sa marque et la permission" (Lettres patentes du Roy pour le reglement des Libraires, Imprimeurs et Relieurs de ceste Ville de Paris. Veriffiees en Parlement le neufiesme Juillet mil six cents dix-huict, Paris, 1621, article XXVI, p. 14). La disposition est reprise telle quelle en 1649 (Edit du Roy contenant les nouveaux Status et Reglemens pour le fait de l'Imprimerie, donné en l'an 1649, Paris, 1649, article XXXII, p. 7: "petits Livrets») et encore en 1683 (Conference des statuts accordez par le Roy, à la communauté des imprimeurs et libraires de Paris, en l'Année mil six cens quatre-vingt-trois. Avec les anciennes Ordonnances, Arrests et Reglemens, Paris, 1684, titre VII, art. II, p. 57) et 1686 (Edit du Roy pour le reglement des Imprimeurs et Libraires de Paris ; registré en Parlement le 21. Aoust 1686, Paris, 1687, tit. IX, art. XLVIII, p. 64-65). Le règlement du Châtelet pour les colporteurs, du 6 mars 1634, porte cependant «cinq à six feüilles au plus » (Sentence de Reglement pour les Colporteurs, p. 4 ; un exemplaire imprimé à la BNF, F $\left.23714, n^{\circ} 65\right)$, tandis que, dans un rapport des années 1660, Antoine Vitré parle « de huict, ou dix cayers au plus » (cité par G. Feyel, L'Annonce et la nouvelle. La presse d'information en France sous l'Ancien Régime (1630-1788), Oxford, 2000, p. 242-243 n. 65). H.-J. Martin, Livre, pouvoirs et société, cit., I, p. 460, affirme que, au début du XVII e siècle, «il n'était pas encore nécessaire de solliciter une permission du Châtelet pour imprimer un livret de moins de quarante pages que colporteurs ou merciers se chargeaient de débiter ", mais le Recueil de 
L. Bouchel, auquel l'auteur renvoie de façon fort vague (ibid., n. 47) n'a rien de tel et reproduit seulement le règlement de 1618 (L. Bouchel, Recueil, cit., p. 47). Même avant 1618, il faut au moins faire exception pour les almanachs (infra, n. 256-257). Peut-être trompé par une formulation ambiguë de H.-J. Martin, Livre, pouvoirs et société, cit., II, p. 763-764 (voir encore p. 690), J.-D. Mellot, Le régime des privilèges, cit., p. 144, et encore L'Édition rouennaise, cit., affirme que l'arrêt du 6 octobre 1667 établissait la limite à « deux feuilles en caracteres de cicero ». Mais cette précision n'apparaît qu'en 1701 (voir infra, n. 139). L'arrêt de 1667 fait seulement interdiction de «vendre et debiter aucuns Livres sans Privilege seellé du grand Sceau, ny aucuns Livrets ou Feüilles volantes sans la Permission expresse du principal Magistrat des lieux » (Arrest general du Conseil d'Estat contenant divers Reglemens pour les Imprimeurs et Libraires, et pour l'Impression, vente et debit des Livres [6 octobre 1667; trois impressions différentes dans le recueil BNF, F 23636, n - 415, 416, 417], p. 2, sans aucune définition de ces catégories).

85. J.-B. Thiers, Defensio aduersus Iohannis de Launoy, Constantiensis, Theologi Parisiensis, Appendicem ad Dissertationem de auctoritate negantis argumenti, Paris, 1664, fol. a6v : Breues namque scribit Epistolas, in quibus libere ait quod sentit; eas postea seorsum propalat, propalatas simul iungit, atque ex simul iunctis iustum uolumen constituit. Pour un recueil factice de ce genre, voir infra, n. 87.

86. Sarrau à Rivet, Paris, 31 janvier 1642, dans Correspondance intégrale d'André Rivet et de Claude Sarrau, éd. H. Bots et P. Leroy, 3 vol., Amsterdam, 1978-1982, I, p. 61.

87. Thiers, Defensio, cit., l'affirme expressément, fol. a6v-a7r, et accuse Launoy de tromper le lieutenant civil aussi bien que le chancelier. Certains ouvrages de Launoy, ainsi sa Censura responsionis qua Fr. Norbertus Caillocius sese mendaciis atque erroribus nouis irretiuit, Paris, 1663 (dont on notera qu'elle compte exactement 64 pages -8 cahiers -, avec en plus une épître dédicatoire), ont la mention Cum Permissu sur la page de titre. Ses lettres en revanche (on en trouve toute une série, de 1664, réunie dans le recueil factice coté $8^{\circ} \mathrm{H}$ 19740 à la Bibliothèque de l'Arsenal) ne portent rien de tel.

88. J. de Launoy, Epistolae Omnes, Octo Partibus comprehensae, nunc demum simul editae, éd. W. Saywell, Cambridge, 1689.

89. La Faculté fit elle-même imprimer le dossier de l'affaire à la conclusion de celle-ci, en 1626, Depromptum e tabulis Facultatis circa librorum approbationem, et acta aduersus librorum Censores [BNF, Ms. Franç. 22061 (77 bis)] : le texte n'est pas daté mais la date de 1626 est donnée par A. Chevillier, L'Origine de l'Imprimerie de Paris, cit., p. 396 (dont le témoignage est d'un grand poids puisqu'il était bibliothécaire de la Maison de Sorbonne). Comme Chevillier l'indique lui-même, son récit détaillé de l'affaire, ibid., p. 396-404, est fondé sur cette seule source. Le Depromptum fut ensuite utilisé dans les Considerations sur l'entreprise faite par Maistres Claude Morel et Martin Grandin Docteurs de Sorbone: Et sur la pretention qu'ils ont d'estre commis et establis pour Censeurs et Approbateurs Souverains de tous les livres qui s'impriment, au prejudice des autres Docteurs de la Faculté de Paris, ausquels ce Privilege a tousjours appartenu, datées, à la fin, de 1650 [deux tirages différents, BNF, Ms. Franç. 22061 (77), et aux imprimés, Rp. 12625], qui en sont en partie une traduction (voir p. 4-7, Extraict abregé des Registres de la Faculté de Theologie, contenant le recit de tout ce qui s'est passé durant l'année 1624. et les années suivantes, contre les prétendus Censeurs des Livres) et y renvoient (p. 7) ; les Considerations sont elles-mêmes la source d'A. Baillet, Jugemens des Sçavans, I, cit., p. 35-36. J. Boileau, Dokimastès, cit., p. 70-76, semble avoir utilisé les registres de première main. Ch. Du Plessis d'Argentré, Collectio, cit., II/2, p.145-146, 161-162, 231, donne lui aussi des extraits d'après l'original, qui recoupent parfaitement le Depromptum 
(c'est la source de l'exposé rapide de Ch. Jourdain, Histoire de l'Université de Paris au XVII et au XVIII siècle, Paris, 1862-1866, p.106). Indiquant ses sources avec sa désinvolture ordinaire, H.-J. Martin, Livre, pouvoirs et société, cit., I, p. 441 n. 3 et 4, renvoie à « un recueil factice coté R. 8989 au Département des Imprimés de la Bibliothèque nationale » : mais on ne trouve sous cette cote qu'une plaquette, Extrait du registre des deliberations du bureau de l'Hôpital-Général, du Mercredy sept Janvier 1761, Paris, 1761, contenant un règlement pour les Enfants-Trouvés. Peut-être H.-J. Martin a-t-il voulu désigner en réalité le recueil factice R. 8181, qui contient plusieurs pièces sur les prétentions de l'université de Paris en matière de librairie, mais absolument rien sur l'affaire de 1623-1624.

90. Lettres patentes, scellées du grand sceau de cire jaune, datées de «Paris, le 22. jour de Mars mil six cens vingt trois. Et de nostre regne le quatorziesme ", reproduites dans Depromptum, cit., p. 4-5. Les Considerations sur l'entreprise, cit., p. 4-5, placent ces lettres en mars 1624, mais il s'agit certainement d'une erreur.

91. Lettres patentes d'août 1624 , scellées du grand sceau de cire verte, reproduites dans Depromptum, cit., p.5-9, et dans Ch. Du Plessis d'Argentré, Collectio, cit., II/2, p. 147-149. Pour la différence entre grandes et petites lettres patentes, voir B. Barbiche, Les Institutions de la monarchie française à l'époque moderne, XVI - XVIII siècle, Paris, 1999, p. 168-169.

92. Voir J. Bergin, The Rise of Richelieu, New Haven, 1991, p. 236-259. Pour un récit événementiel détaillé, voir la thèse de B. Zeller, Richelieu et les ministres de Louis XIII de 1621 à 1624: la cour, le gouvernement, la diplomatie d'après les archives d'Italie, Paris, 1880, p. 171-296.

93. Rapport fait par le syndic Besse, le 2 janvier 1625, de son entretien avec le chancelier (la date n'en est pas précisée), dans Depromptum, cit., p. 17 (ou Ch. Du Plessis d'Argentré, Collectio, cit., II/2, p. 161) : responderat Illustrissimus D. Cancellarius se bono animo rectaque mentis intentione huiusmodi litteris consensum praebuisse, ut sic modus aliquis effrenatae tot librorum euulgandorum etiam aliquando in perniciem Religionis et Status libertati tandem adhiberetur, seque saepius de eo cum Illustrissimis Cardinalibus de La Rochefoucauld et de Richelieu, cum amplissimis libellorum Supplicum Magistris, et etiam in priuato Regis Consilio egisse, illudque semper ab omnibus et ubique utile, et necessarium fuisse iudicatum .Cf. A. Chevillier, L'Origine de l'Imprimerie de Paris, cit., p. 397. De janvier 1624 à la mort de Brûlart, en octobre, d'Aligre avait été garde des sceaux et il avait déjà reçu en cette capacité les plaintes de la Faculté (Depromptum, cit., p. 13).

94. Voir J. Bergin, Cardinal de la Rochefoucauld. Leadership and Reform in the French Church, New Haven, 1987, surtout p. 38-66, 126, 130-133 ; sur son opposition aux prétentions de la Faculté, p. 59. La position de Richelieu était encore incertaine : il n'entra au Conseil que le 29 avril 1624 et n'y fut pas dominant avant le 13 août au plus tôt (renvoi de La Vieuville), et peut-être même plus tard encore. Voir la discussion de R. Mousnier, L'homme rouge ou la vie du cardinal de Richelieu (1585-1642), Paris, 1992, p. 221-233 ; R. Mousnier, ibid., p. 406-407, n'en attribue pas moins le choix des quatre censeurs à Richelieu, en suivant R. Pillorget, Richelieu, rénovateur de la Sorbonne, dans R. Mousnier (éd.), Richelieu et la culture. Actes du colloque international en Sorbonne, Paris, 1987, p. 47 : mais celui-ci l'affirme sans preuve et, sans même, semble-t-il, avoir bien compris de quoi il s'agissait. H.-J. Martin, La vie intellectuelle au temps de Richelieu, dans Richelieu et le monde de l'esprit, Sorbonne, novembre 1995, Paris, 1985, p. 191, ignore la chronologie.

95. J. Bergin, La Rochefoucauld, cit., p. 60-61; É. Puyol, Edmond Richer. Étude historique et critique sur la rénovation du gallicanisme au commencement du XVII ${ }^{\mathrm{e}}$ siècle, 2 vol. Paris, 1876, 
II, p. 205-217. La source est E. Richer, Histoire du syndicat d'Edmond Richer par [...] lui-même, Avignon, 1753, p. 342-365 et 394-397 (sur l'attitude de Richelieu, p. 344-348).

96. J. Bergin, La Rochefoucauld, cit., p.59, 87, 132. J. Boileau, Dokimastès, cit., p.69-70, rattache, de manière polémique mais plausible, la réforme de 1623-1624 au conflit entre Duval et les richéristes. Même affirmation, avec des échos textuels de Boileau qui me semblent prouver l'emprunt, dans Encyclopédie, cit., II, s.v. Censeurs de livres, p. 818 (article non signé, parfois attribué pour cette raison à Diderot, mais qui doit plutôt être de l'abbé Yvon, auteur de Censure de livres ou de propositions, qui suit : voir ibid., I, avertissement, p. xlvi, sur les articles consécutifs). Sur la théologie de Duval, on peut voir en dernier lieu S. H. De Franceschi, Gallicanisme, richérisme et reconnaissance de la modernité ecclésiale. La dispute entre le cardinal Bellarmin et le théologien parisien André Duval (1614), dans J.L. Quantin et J.-Cl. Waquet (éd.), Papes, princes et savants dans l'Europe moderne. Mélanges à la mémoire de Bruno Neveu, Genève, 2007, p. 97-121; id., La crise théologico-politique, cit., à l'index (la réforme de l'approbation est passée sous silence dans le bref exposé, ibid., p. 529-531, d'après H.-J. Martin, des efforts de la monarchie pour contrôler la librairie dans les années 1620).

97. Voir L. Ceyssens, Les "sept points" jansénistes [1953-1954], repris dans Jansenistica minora , II, Malines, 1954, n XIX, p. 5-21; Y. Chaussy, New evidence on the English Benedictines (1581 ?-1661), dans Downside Review, 88, 1970, p. 36-49, et surtout id., Libraires et imprimeurs parisiens en 1624, dans Bulletin de la société de l'histoire de Paris et de l'île-de-France, 98, 1971, p. 93-113. Ces deux auteurs publient d'importants documents mais, ni l'un ni l'autre n'ayant fait le lien avec la réforme du système d'approbation, ils n'ont pas compris la nature du rôle de Du Val et Quedarne (Chaussy a imaginé gratuitement qu'ils étaient intervenus à la demande du nonce Bernardino Spada).

98. Voir Moyens d'opposition et remonstrances tres-humble [sic] des Doyen, Syndic, et Docteurs en la Faculté de Theologie en l'Université de Paris. Sur les Lettres en forme d'Edict de Creation de quatre Examinateurs et Censeurs des livres nouveaux qui dorenavant s'imprimeront en ce Royaume, et Articles que la Faculté de Theologie de Paris presente à Monseigneur le Chancelier de France, pour estre inserez dans les Lettres des Censeurs et Examinateurs des livres, dans Depromptum, cit., p. 9-13 et 14-15.

99. Depromptum, cit., p. 17 (procès-verbal du 2 janvier 1625) : articulosque ad unicum restringendos quo scilicet singulis ius approbandorum librorum remaneat integrum. Même texte dans Ch. Du Plessis d'Argentré, Collectio, cit., II/2, p. 162.

100. Depromptum, cit., p. 19 ; Ch. Du Plessis d'Argentré, Collectio, cit., II/2, p. 231.

101. Ch. Du Plessis d'Argentré, Collectio iudiciorum, cit., II/2, p. 146: cumque se non perlegisse, sed ex aliarum sententia loquutos fuisse confessi fuissent et aliquas dumtaxat ex Scotorum nonnullorum actis potius mirandis quam imitandis protulissent. Scotorum est évidemment une coquille pour Sanctorum : il s'agit des exemples d'équivoques que l'on pensait trouver chez les patriarches de l'Ancien Testament.

102. Voir l'approbation d'Élie du Fresne de Mincé et Urbain Garnier, daté du 13 juillet 1624, dans J.Barnes, Dissertatio contra aequiuocationes, Paris, 1625 : exceptionnellement, cette approbation est accompagnée d'un extrait du procès-verbal de la Faculté du $1^{\text {er }}$ août 1624, qui la déclare valide. Ces deux docteurs étaient des proches de Richer, voir E. Richer, Histoire du syndicat, cit., p. 345 et 417-418; ce fut du Fresne de Mincé qui dénonça à la Faculté la thèse de Testefort en 1626 (infra, n. 156). L'extrait du privilège du roi du 4 février 1625 figure dans l'exemplaire BNF, D. 25014 ; le feuillet correspondant 
manque en revanche dans l'exemplaire D. 13481 (2). Mêmes approbation et même privilège dans la traduction, Traicté et dispute contre les équivoques, Paris, 1625.

103. Code Michau, article 52, dans Isambert, Recueil, cit., XVI, p. 238-239.

104. Considerations sur l'entreprise, cit., p. 3 et 8.

105. Mersenne à Descartes, 15 février 1637, Correspondance du P. Marin Mersenne, éd. C. de Waard, VI, Paris, 1960, p. 188.

106. Considerations sur l'entreprise, cit., p. 9 et 16-17; l'approbation des docteurs, dans [A. de Bourzeis], Contre l'adversaire du concile de Trente et de Sainct Augustin Dialogue premier, s.l., 1650, fol.c1v; [A. Arnauld], Apologie pour les Saincts Peres de l'Eglise, Defenseurs de la Grace de Jesus-Christ. Contre les erreurs qui leur sont imposées, Paris, 1651, f. ii2r. En 1685, la Replique a Monsieur Arnauld de J. Le Fèvre parut sans privilège, faute d'avoir pu obtenir l'approbation du censeur royal Pirot (infra, n. 111), mais avec l'approbation conjointe de pas moins de dix docteurs en théologie.

107. Saint-Évremond, Cuures choisies, éd. A.-Ch. Gidel, Paris, [1867], p. 112.

108. Considerations sur l'entreprise, cit., p. 2.

109. Voir "Raisons d'opposition contre les Censeurs prétendus", ibid., p. 23 ; J.L. Quantin, De la Contre-Réforme comme monopole : les anti-jansénistes et la Perpétuité de la foi, dans Chroniques de Port-Royal, 47, 1998, p. 121 et 132-133; et surtout un très intéressant Factum pour les Superieurs et Boursiers Théologiens des Collèges de l'Université de Paris, contre les Docteurs Professeurs en Théologie des Colléges de Navarre et de Sorbonne, s.l.n.d. (5 janvier 1677), p. 15-33 : il avait été rédigé par Jean de Launoy et fut repris dans ses Opera omnia, 10 vol., Genève, 1731-1732, IV/2, p. 105-121. Launoy avait lui-même été brièvement censeur dans les années 1640, mais dut quitter cette charge pour ses vues hétérodoxes, en particulier son hostilité aux réguliers (voir Remarques sur les considerations que Monsieur de Launoy Docteur en Theologie a été obligé de publier pour se justifier contre le rapport que Monsieur Pereyret Docteur en Theologie a fait de l'examen de l'Histoire des Hospitaliers du Saint Esprit, ibid., IV/1, p. 249-250, et Launoiana seu Collectio eorum omnium, quae ad Launoium ipsiusque Scripta pertinent. Pars prima, Commentarium de Launoii vita complectens, IV/2, p. 343-345). Au début du XVIII ${ }^{e}$ siècle, en revanche, au temps de Bignon, les censeurs défendaient fermement "nos libertés » (J. Le Brun, Censure préventive, cit., p. 322-323; R. Birn, La Censure royale, cit., p. 53).

110. Un cas extrême étant à la fin du XVII ${ }^{e}$ siècle celui de Pierre Courcier, dont "quoiqu'il ait été censeur de livres plus de trente ans, on disoit qu'il n'en avoit pas lu une douzaine entièrement » (L. Le Gendre, Mémoires, éd. Roux, Paris, 1863, p. 59).

111. Replique a Monsieur Arnauld pour la défence du livre des Motifs invincibles, contre son livre du Renversement de la Morale, et celui du Calvinisme convaincu de nouveau. Par Mr. Le Fèvre, Docteur en Théologie de la Faculté de Paris, Lille, 1685, fol. ${ }^{* *} 4 \mathrm{v}$ (ouvrage publié sans privilège, d'après une copie prétendument diffusée à l'insu de l'auteur : voir «Avis de l'Imprimeur ", au verso de la page de titre).

112. Nouvelles de la Republique des Lettres. Mois de Fevrier 1685, Amsterdam, 1685, p. 147-148, citant Virgile, Énéide, chant VI, v.313-316; Encyclopédie, cit., s.v.Censeurs de livres, p. 819. L'emprunt avait déjà été noté par F. Brunetière, La direction de la librairie sous $M$. de Malesherbes [1882], dans Nouvelles études critiques, Paris, 1882, p. 177. Au XVIII ${ }^{\mathrm{e}}$ siècle, en réalité, les censeurs royaux rendaient généralement leur rapport dans la semaine (B. de Negroni, Lectures interdites, cit., p. 284 n. 3). 
113. L. Le Gendre, Mémoires, cit., p. 52, corrigé par J. Grès-Gayer, Le gallicanisme de Sorbonne. Chroniques de la Faculté de théologie de Paris (1657-1688), Paris, 2002, p. 243 n. 301. Jugement confirmé par J. Le Brun, Censure préventive, cit., p. 307-308. Sur Pirot censeur, on trouvera de très riches références dans Correspondance de Bossuet, cit., à l'index général. Voir aussi, sur l'approbation qu'il donna aux Maximes des saints de Fénelon, Ch. Urbain, L'affaire du quiétisme. I. Témoignage de l'abbé Pirot, dans Revue d'histoire littéraire de la France, 3, 1896, p. 409-434, en particulier p.420-422 ; le commentaire de J. Orcibal dans Correspondance de Fénelon, 18 vol. parus, Paris, puis Genève-Paris, depuis 1972, V, p. 137-139.

114. Nombreux exemples dans [J. Boileau], Dokimastès, cit., p. 104-126. Voir encore la formule «purement nestorienne" que les approbateurs laissèrent passer dans la traduction de Jean Chrysostome par Nicolas Fontaine, d'une manière que Pierre Thomas du Fossé jugeait « inconcevable [...] à moins qu'ils ne l'ayent pas luë » (J.-L. Quantin, Le catholicisme classique et les Pères de l'Église. Un retour aux sources (1669-1713), Paris, 1999, p. 407-408).

115. J. Le Brun, Censure préventive, cit. ; R. Birn, La Censure royale, cit., p. 51-53.

116. Comparer l'exclusion des jésuites lors de la création de l'Académie des Sciences (R. Hahn, Anatomy of a scientific institution, cit., p. 15-16). Les statuts de 1699, préparés par Bignon, portent expressément que nul ne pourra être académicien "s'il est régulier, attaché à quelque ordre de religion, si ce n'est pour remplir quelque place d'académicien honoraire " (L'Institut de France. Lois, statuts et règlements concernant les anciennes académies et l'institut de 1635 à 1889, éd. L. Aucoc, Paris, 1889, p. LXXXVI, art. XII)

117. Arrest de la Cour de Parlement. Portant suppression du Livre intitulé, La Politique secrette des Jansenistes, et l'Estat present de la Sorbonne [par É. Dechamps, S. J.] : Avec deffences à tous Imprimeurs et Marchands Libraires d'imprimer, vendre et debiter aucuns Livres qui traitent de Theologie et des cas de Conscience, sans Privilege du Roy, et Approbation des Docteurs en Theologie de France, dont il y ait du moins un Docteur Seculier de la Faculté de Paris, Paris, 1668 [BNF, F-21030 (4) et F-23670 (268)].

118. G. B. Depping, introduction à Correspondance administrative sous le règne de Louis XIV, entre le cabinet du Roi, les secrétaires d'État, le chancelier de France, II, Paris, 1851, p. XXII (sans référence) : je n'ai rien retrouvé de tel dans le corpus du volume et suppose que la source est une des dépêches qui ne sont pas incluses dans l'édition.

119. Voir les très intéressants factums échangés par l'université de Paris et la Communauté des libraires et imprimeurs, à l'occasion du règlement de 1649 (supra, n. 84) dans le recueil factice BNF, R. 8181 (18-23). L'Université fit les mêmes protestations contre le règlement de 1686: voir Memoire pour l'Université de Paris. Contre certains pretendus Reglemens de l'année 1686. touchant les Imprimeurs, Libraires et Relieurs, s.l.n.d. [imprimé, BNF, Ms. Franç. 21734, fol. 203r-211v; Addition aux griefs que l'Université de Paris a cy-devant mis entre les mains de Monsieur de Harlay Conseiller d'Estat, en execution de l'Arrest du Conseil d'Estat du mois de Juin dernier 1689. Contre certains Imprimez, intitulez du nom de Reglemens pour les Libraires, Relieurs et Imprimeurs, faits en l'année 1686 [2 exemplaires imprimés BNF, Ms. Franç. 22061 (125 et 126)].

120. H.-J. Martin, Livre, pouvoirs et société, cit., est tout à fait convaincant sur ce point (voir en partic. I, p. 50-57, 451-455 ; II, p. 570-580, 678-698).

121. Voir par exemple en 1640 la saisie par les «Syndic et Adjoints de la Librairie et Imprimerie » de la Metaphysica de Campanella, que les dominicains de la rue Saint-Honoré 
avaient entrepris de faire vendre par un chandelier, ce « qui tend à introduire la liberté du commerce de Livres deffendus »: Sentence rendue par Monsieur le Lieutenant Civil, portant defenses à toutes personnes, s'ils ne sont du corps de la Librairie, de faire aucun traffic de Livres, ny d'imprimer aucunes Affiches ou l'addresse pour la vente, soit ailleurs qu'en la maison d'un Libraire, Imprimeur, ou Relieur (9 juin 1640) [BNF, F. 23714 (81)] ; M.-P. Lerner, Tommaso Campanella en France au XVII siècle, Naples, 1995, p. 104-106. Voir aussi A. Sauvy, Livres saisis à Paris entre 1678 et 1701, La Haye, 1972, p. 8.

122. Voir J. Roubert, La situation de l'imprimerie lyonnaise à la fin du XVII siècle, dans Cinq études lyonnaises, Genève, 1966, p. 77-111.

123. Voir en général R. M. Golden, The Godly Rebellion. Parisian Curés and the religious Fronde, 1652-1662, Chapel Hill, 1981. Un autre arrêt du même jour supprimait le Septiéme écrit des curez de Paris (dont l'auteur était vraisemblablement Antoine Arnauld) comme « imprimé contre les formes portées par les Ordonnances, sans nom d'Autheur ny d'Imprimeur, et permission par Lettres patentes »: Arrest du Conseil d'Etat contre le Libelle intitulé: Journal de ce qui s'est passé tant à Paris que dans les Provinces, sur le sujet de la Morale de l'Apologie des Casuistes. Du 7. Juin 1659, Paris, 1659 (BNF, F. 23635 (272) ; le texte est aussi reproduit dans la deuxième édition de Fr. Annat, Recueil de plusieurs faussetez et impostures contenues dans l'Imprimé qui a pour titre, Septiesme écrit des curez, ou Journal de ce qui s'est passé, etc., Paris, 1659 [BNF, D. 6196], p. 19-20).

124. Arrest du Conseil d'Estat portant revocation des Privileges generaux, qui pourroient avoir esté accordez aux Autheurs, pour les ouvrages qu'ils feront à l'avenir. Du 7 Juin 1659, imprimé, BNF, Ms. Franç. 22071 (91) ; autre exemplaire aux imprimés, F-23635 (271).

125. Voir ce privilège du 8 août 1665 (pour « toutes les œuvres morales et sacrées qu'il a composées, ou qu'il composera cy-apres, tant en Vers qu'en Prose ») dans Version expliquée du Nouveau Testament de Nostre Seigneur Jesus-Christ, Paris, 1668 [= t. I ; le t. II a un titre propre, Version expliquée des Epistres de l'Apostre S. Paul]. Le privilège qui figure (en extrait) dans A. Godeau Eloges des Evesques, qui dans tous les siecles de l'Eglise ont fleury en Doctrine et en Sainteté, Paris, 1665 (achevé d'imprimer du 9 juillet 1665) est encore celui du 13 septembre 1651 .

126. Lettre de Godeau à Séguier, publiée sans date dans Lettres de M. Godeau, Evesque de Vence; sur divers sujets, Paris, 1713, p. 421-422; avec la date du 16 oct.1665, d'après l'original (BNF, Ms. Franç. 17406, fol. 311r-312r), par R. Kerviler, Le chancelier Séguier, cit., p. 686. A. Cognet, Antoine Godeau, évêque de Grasse et de Vence, un des premiers membres de l'Académie française (1605-1672), Paris, 1900, p. 425, la cite d'après les Lettres de 1713.

127. Chapelain à Godeau, 22 mai 1668, dans J. Chapelain, Lettres, éd. Ph. Tamizey de Larroque, II, Paris, 1883, p. 572-573. L'achevé d'imprimer de l'ouvrage (supra, n. 125) est du 5 mai 1668. Sur le contexte, voir Ph. Dieudonné, La Paix clémentine. Défaite et victoire du premier jansénisme français sous le pontificat de Clément IX (1667-1669), Louvain, 2003, p. 96-104 et 136-139.

128. Arrest du Conseil d'Etat qui revoque tous les Privileges generaux surpris pour plusieurs livres, 18 février 1673, copie manuscrite, BNF, Ms. Franç. 22071 (136).

129. Declaration portant revocation des permissions generales d'imprimer, donnée au camp devant Dôle le 4 juin 1674, imprimé, BNF, Ms. Franç. 22071 (138).

130. Extrait du privilège du 12 août 1682, dans Traité de la Communion sous les Deux Especes. Par Messire Jacques Benigne Bossuet Evesque de Meaux, Conseiller du Roy en ses Conseils, 
cy-devant Précepteur de Monseigneur le Dauphin, Premier Aumosnier de Madame la Dauphine, Paris, 1682 (soulignement dans l'original).

131. Arrêt du Conseil du 13 mai 1686. Exemplaires imprimés BNF, Ms. Franç. 22071 (161 et 162) ; au département des imprimés, F-20979 (1) et F-23640 (57).

132. L'Histoire de Louis XI de Charles Duclos parut en 1745 en vertu d'un « Privilège en Commandement pour l'Impression des Ouvrages de l'Académie des Inscriptions et BellesLettres » accordé par Louis XV le 15 février 1735, un précédent privilège de Louis XIV de décembre 1701 ayant expiré : sur les objections du Parlement, voir B. de Negroni, Lectures interdites, cit., p. 168-170. Pour l'Académie des Sciences, voir R. Hahn, Anatomy of a scientific institution, cit., p. 60-65 ; pour les évêques, B. de Negroni, Lectures interdites, cit., p. 121 et 169 .

133. Arrêt du Conseil du 28 mars 1682 [un exemplaire imprimé, BNF, Ms. Franç. 22071 (152)], le roi ayant été informé « que les Libraires entreprennent journellement d'inserer dans les Livres dont l'impression leur est permise, des Préfaces, Avertissemens ou Epistres dedicatoires, dans lesquels les Auteurs glissent des choses qu'ils n'ont ozé mettre dans les corps des Livres, connoissant bien que les Examinateurs n'auroient pû les approuver ». Interdiction renouvelée par l'arrêt du 7 septembre 1701 : Lettres patentes et Arrest du Conseil d'Estat du Roy, portant Reglement pour la Librairie. Données à Fontainebleau le 2. octobre 1701. Registrées en Parlement le 7. Janvier 1702, Paris, 1702 [BNF, F. 23616 (896) ; le n - 895 est le texte publié après enregistrement par le parlement de Metz, dès le 14 novembre 1701], article VII, p.6. Pour un exemple de lutte contre l'abus des " continuations », voir A. Sauvy, Livres saisis, cit., $\mathrm{n}^{\circ} 1081$, p. 346-347.

134. O. Poncet, Pomponne de Bellièvre, cit., p. 249, d'après la thèse inédite d'A. Soman (voir infra, n. 171). Une déclaration de 1612 interdit aux petites chancelleries de délivrer des privilèges, mais le Parlement n'accepta de l'enregistrer que pour la minorité du roi (B. Barbiche, Le régime de l'édition, dans H.-J. Martin et R. Chartier dir., Histoire de l'édition française, cit., I, p. 372).

135. Edict du Roy, portant defenses d'imprimer aucuns livres sans permission du grand Sceau, et d'attacher et semer aucuns Placards et libelles diffamatoires sur les peines y contenuës. Verifié en Parlement le 19. Janvier 1626, Paris, 1626 [un exemplaire dans BNF, Ms. Franç. 22071 (61)], p. 6. Le texte est également reproduit dans P. Guenois, La nouvelle et derniere Conference des ordonnances et edicts royaux, édition de nouveau augmentée [...] par J. Thaumas, 2 vol., Paris, 1627, I, 1. X, tit. XIV. Des Imprimeurs, et Libraires jurez, p. 853.

136. Voir J.-D. Mellot, L'Édition rouennaise, cit., p. 305-307.

137. Arrêt du Conseil du 27 février 1682 [exemplaire imprimé, BNF, Franç. 22071 (150)]. Il figure également dans un dossier de textes contre les livres contrefaits, probablement imprimé par la communauté des libraires de Paris (ibid., $n^{\circ} 108$ et $n^{\circ} 149$ ).

138. Le chancelier Le Tellier aux procureurs généraux du Parlement de Provence, 11 novembre 1683, dans Correspondance administrative, éd. G. B. Depping, cit., II, Paris, 1851, p. 243. Voir déjà Le Tellier au premier président du Parlement de Rouen, 4 oct. 1678, ibid., p. 210.

139. Lettres patentes et Arrest du Conseil d'Estat du Roy, portant Reglement, cit., article II, p. 4 .

140. Circulaire aux intendants du 29 oct. 1707, dans R. Estivals, Le dépôt légal, cit., p. 90-91.

141. L'Anaereticus de Petrus Aurelius (Saint-Cyran) contre Sirmond parut avec un privilège "obtenu par surprise en la petite Chancellerie du Parlement de Paris", le 2 juillet 1633, mais ce fut un des motifs de la suppression du livre par arrêt du Conseil du 
$1^{\text {er }}$ décembre suivant (un exemplaire imprimé dans BNF, Ms. Franç. 22071, $n^{\circ} 67$; J. Orcibal, Jean Duvergier de Hauranne abbé de Saint-Cyran, cit., p. 365). Pour la période de la Fronde, surtout parlementaire, en 1649, voir H. Carrier, La Presse de la Fronde, cit., II, p. 301-302.

142. Voir e.g. Psalmi Davidis, éd. G. Genebrard, Paris, 1587. Ce fut le cas - ce n'est certainement pas un hasard - de [J. Gillot (éd.)], Traictez des droits et libertez de l'Eglise Gallicane, Paris, O. de Varennes, 1609, « Avec privilege du Roy ». Le privilège ne figure pas dans le volume mais on y trouve un arrêt du Parlement du 13 mars 1609: "Veu par la Cour les lettres obtenuës par Pierre Chevalier Libraire Imprimeur de l'université de Paris, de permission d'imprimer, faire imprimer, vendre et debiter les Traictez des Privileges droits et libertez de l'Eglise Gallicane, pendant six ans [...], Requeste par luy presentee, afin d'entherinement desdites lettres [...], Ladite Cour entherinant lesdites lettres ordonne que l'impetrant ioüira du contenu en icelles, selon leur forme et teneur ». Certains des textes du recueil avaient en outre déjà paru séparément avec des privilèges, lesquels sont reproduits : c'est en particulier le cas des Libertez de l'Eglise Gallicane de Pithou (supra, n. 48). L'arrêt est reproduit dans l'édition augmentée du recueil, Paris, P. Chevalier, 1612 ; on y trouve en outre un privilège du roi du 22 février 1606 à Jacques Leschassier, pour " un petit discours intitulé De la liberté ancienne et canonique de l'Eglise Gallicane », qui est un des trois traités ajoutés.

143. Edict du Roy, portant defenses d'imprimer sans permission du grand Sceau, cit., p. 8. Le Parlement profita de la Fronde pour renouveler l'obligation d'enregistrer les permissions " au greffe de la Cour », par arrêt du 25 janvier 1649 (H. Carrier, La Presse de la Fronde, cit., II, p. 313-314).

144. Arrêt du Conseil du 25 octobre 1663 [exemplaire imprimé dans BNF, Ms. Franç. 22071 (101)].

145. Le chancelier de Pontchartrain au procureur général du Parlement de Paris, 11 sept. 1711, dans Correspondance administrative, éd. G. B. Depping, cit., II, p. 480.

146. Ces deux possibilités d'échapper à la procédure normale sont bien marquées dans une lettre de Henri de Laval de Boisdauphin, évêque de La Rochelle, à sa mère, Mme de Sablé, 13 février 1668, à propos de La Perpetuité de la foy de l'Eglise catholique touchant l'Eucharistie, deffendue d'Arnauld et Nicole, que le censeur Grandin refusait d'approuver : «si ces messieurs nous vouloist confier leur livre [à lui et aux deux évêques voisins de Saintes et de Luçon], nous l'examinerions et en cas qu'il ni eust rien à redire comme j'en suis persuadé par advense, nous l'approuverions dans nos diocèses ou nous en demanderions conjointement le privilège à $\mathrm{M}$. le Chanselier » (lettre publiée par E. Jovy, Un fils de Mme de Sablé. M. de Laval, évêque de La Rochelle et Phelippes de La Brosse, Paris, 1916, p. 124).

147. Bossuet au P. Joseph Shirburne, 6 avril 1686, dans Correspondance, cit., III, p. 215.

148. Bossuet, Mémoires au sujet de l'impression des ouvrages de doctrine composés par les évêques, mémoire pour le chancelier, 6 octobre 1702, ibid., XIV, p. 163. Même affirmation dans le premier mémoire au roi, p. 165.

149. IV mémoire au roi, ibid., p. 178.

150. Voir J. D. Woodbridge, Censure royale et censure épiscopale : le conflit de 1702, dans Dixhuitième siècle, 8, 1976, p. 333-355, et encore infra. H.J. Martin, Livre, pouvoirs et société, cit., II, p. 691, confond la question avec celle des privilèges généraux, alors que, selon Pontchartrain, elles sont tout à fait différentes (J. D. Woodbridge, Censure royale, cit., 
p. 352 n. 1). Bossuet, Instructions sur la version du Nouveau Testament imprimée a Trevoux en l'année M. DCC. II [1 $1^{\mathrm{e}}$ partie], Paris, 1702, et Seconde Instruction sur les passages particuliers de la version du Nouveau Testament, imprimée à Trévoux en l'année M.DCC.II. Avec une Dissertation Préliminaire sur la doctrine et la critique de Grotius, Paris, 1703 (achevés d'imprimer respectivement du 20 décembre 1702 et du 4 août 1703) parurent avec le privilège général accordé à l'évêque le 26 février 1701 (reproduit intégralement dans le premier volume, en extrait dans le second), sans aucune mention d'approbation des docteurs. Entre 1686 ( supra, n. 131) et 1701, Bossuet semble avoir pris pour ses ouvrages des privilèges particuliers. L'exemple de l'Histoire des variations allégué sur ce point par F. Brunetière, La direction de la librairie, cit., p. 175, puis par N. Herrmann-Mascard, La censure des livres, cit., p. 20, n'est pourtant pas entièrement clair. L'imprimeur Sébastien Mabre-Cramoisy avait obtenu le 16 janvier 1687, un privilège pour des ouvrages de Bossuet pour l'instruction des nouveaux convertis, à savoir " un Catéchisme pour son Diocese; un autre Catéchisme des Festes, à l'usage du mesme Diocese, etc. » (privilège reproduit intégralement dans Catéchisme $d u$ diocèse de Meaux, Paris, 1687). Ce même privilège servit ensuite à l'Histoire des variations des Eglises protestantes, Paris, 1688 (où il n'est donné qu'en extrait et reformulé pour «quelques ouvrages composez par Monseigneur Jacques Benigne Bossuet Evesque de Meaux, sçavoir L'Histoire des variations des Eglises protestantes, etc. »).

151. Statuta Facultatis Sacrae Theologiae, art. XXIII, dans Ch. Jourdain, Histoire, cit., Pièces justificatives, p. 14: Nihil a doctrina Christiana alienum, nihil contra patrum orthodoxorum decreta, nihil contra regis regnique Gallici iura et dignitatem disputetur, aut proponatur: si secus fecerint, et syndicus et praeses et respondens extra ordinem puniantur. Il existait des mécanismes analogues dans les universités de province. Voir par exemple, pour Caen, les explications du doyen de la Faculté de théologie, dans [Ch. Dufour], La Condamnation d'un Prestre de l'Hermitage par l'Université et par le Presidial de la Ville de Caën. Pour avoir soustenu dans l'un de ses actes de Theologie, cette Doctrine fausse, impie et seditieuse. Que le Pape a pouvoir sur le temporel des Roys, et qu'il a droict de les establir, et de les deposer, s.l., 1661 , p. 5-6.

152. Pour la fonction de syndic, voir J. K. Farge, Orthodoxy and Reform, cit., p. 41-42 et 127 ; pour le rôle de Béda (que l'on s'efforce désormais de comprendre selon son propre point de vue, au lieu de s'en tenir aux caricatures de ses ennemis), voir ibid., passim, et id., Biographical Register of Paris doctors of theology 1500-1536, Toronto, 1980, s.v., p. 31-36 ; M. Crane, Competing Visions of Christian Reform: Noël Béda and Erasmus, dans Erasmus of Rotterdam Society Yearbook, 25, 2005, p. 39-57 ; J. K. Farge, Noël Beda and the defense of the tradition, dans E. Rummel (éd.), Biblical humanism and scholasticism in the age of Erasmus, Leyde, 2008, p. 144-164.

153. Arrêt du Conseil du 14 novembre 1682. Exemplaire imprimé BNF, Ms. Franç. 22071 (153). Sur l'affaire qui donna certainement occasion à cet arrêt, voir J. Grès-Gayer, Le gallicanisme de Sorbonne, cit., p. 273-281.

154. Selon une hypothèse plausible de J. Grès-Gayer, La réforme des études en Sorbonne (1673-1715), dans Revue d'Histoire de l'Église de France, 88, 2002, p. 375 et 385-386.

155. A. Magnaudet-Barthe, Edmond Richer et la réforme de l'Université de Paris (1594-1610), dans Positions des thèses de l'École nationale des Chartes, 1983, p. 146. Pour les statuts, voir supra, n. 151.

156. Par exemple, en novembre 1626, la majeure ordinaire (une des thèses de licence) du dominicain Jean Testefort, qui rangeait les décrétales des papes dans l'Écriture sainte : sacram Scripturam esse, quae partim Bibliis sacris, partim Epistolis Decretalibus summmorum 
Pontificum quatenus explicant sacram Scripturam, partim sacris Conciliis continetur (la clause, quatenus explicant sacram Scripturam, avait été imposée par le syndic à titre d'atténuation). Voir les extraits des procès-verbaux de la Faculté imprimés dans Seconde Partie contenant ce qui s'est passé en la Faculté de Theologie de Paris, et dans l'Université en corps, touchant le livre de Sanctarel, ensemble les Arrests rendus de part et d'autre à cette occasion en l'année 1626. et depuis jusqu'en l'année 1648. [...], s.l.n.d., p. 24-25 [BNF, R. 8180 (27)] et Ch. Du Plessis d'Argentré, Collectio, cit., II/2, p. 230-231 (S. H. De Franceschi, La crise théologicopolitique, cit., p. 682, traduit : "que les Décrétales font partie de la Tradition»); E. Richer, Histoire du syndicat, cit., p. 403-404 ; Fr. Garasse, Récit au vrai, cit., p. 145.

157. J. de Launoy, Factum pour les Superieurs et Boursiers Théologiens des Collèges de l'Université de Paris, cit., p. 21-22: l'affaire aurait eu lieu «il y a deux ans» (en 1674), "Monsieur Grandin faisant par interim l'office de Syndic pendant la maladie et quelque tems apres la mort de son intime ami le feu Syndic " (Denis Guyart). Sur cet intérim de Grandin, voir J. Grès-Gayer, Le gallicanisme de Sorbonne, cit., p. 237 (qui l'a oublié en reconstruisant la succession des syndics, p. 385-386). Le bachelier concerné était «Varret » (Noël Varet), reçu licencié en 1676; J. Grès-Gayer, ibid., tout en ignorant cet épisode, le classe parmi les "gallicans intégraux " (voir à l'index).

158. Voir St.-M. Morgain, La soutenance des doctrines romaines lors du chapitre général des Jacobins de mai 1611 à Paris, dans Mémoire dominicaine, 6, printemps 1995, p. 209-236.

159. Arrêt du Parlement du 4 septembre 1624 dans D. Kahn, La condamnation des thèses d'Antoine de Villon et Étienne de Clave contre Aristote, Paracelse et les "cabalistes" (1624), dans Revue d'histoire des sciences, 55, 2002, p. 171. Voir id., Alchimie et paracelsisme en France à la fin de la Renaissance (1567-1625), Genève, 2007, p. 500-567; S. Murr (éd.), La Requeste des Maistres ès arts et l'Arrêt burlesque, Bernier porte-plume des meilleurs esprits de son temps, dans Corpus, revue de philosophie, 20/21, 1992 [Bernier et les Gassendistes], p. 231-239.

160. L'affirmation de J. Grès-Gayer, Le gallicanisme de Sorbonne, cit.,, p. 71, à propos de la thèse du P. Coret en 1661 (voir note suivante) selon laquelle le collège de Clermont faisait soutenir des thèses aux "candidats aux grades académiques délivrés par lui », paraitt fantaisiste, surtout à cette date. La dernière tentative des jésuites pour obtenir la collation des grades remonte à 1643 : voir A. Douarche, L'Université de Paris et les Jésuites

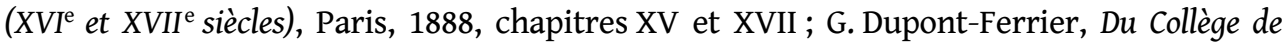
Clermont au lycée Louis-le-Grand (1563-1920), 3 vol., Paris 1921-1925, I, p. 26-28. Sur le déclin corrélatif de leurs classes de théologie, voir M.-M. Compère et $\mathrm{D}$. Julia, Les collèges français, $16^{\mathrm{e}}-18^{\mathrm{e}}$ siècles, Répertoire, III, Paris, 2002, p. 379-380; sur les thèses soutenues au collège de Clermont, voir G. Dupont-Ferrier, Du Collège de Clermont au lycée Louis-le-Grand, cit., I, p. 246-247, et III, Appendice I, p. 273-285 (liste chronologique). Voir aussi infra, n. 285.

161. R. Rapin, Mémoires sur l'Église et la société, la Cour, la ville et le jansénisme, 1644-1669, éd. L. Aubineau, Paris, 1865, III, p. 139-140. Texte de la thèse par exemple dans [A. Arnauld ou P. Nicole], La nouvelle Heresie des Jesuites soutenuë publiquement à Paris dans le College de Clermont par des Theses imprimées du 12. Decembre 1661. denoncée à tous les Evesques de France, s.l.n.d. (texte daté du $1^{\mathrm{er}}$ janvier 1662), p.1-2. Voir la préface historique et critique à A. Arnauld, CEuvres, cit., XXI, p. LIV-LXV.

162. Tout le dossier est commodément rassemblé, malheureusement en anglais seulement et avec quelques erreurs de traduction, dans les chapitres Documents of control, des quatre parties chronologiques de French theatre in the neo-classical era, éd. W. D. Howarth, Cambridge, 1997. 
163. Arrest au sujet des pieces de theatre des colleges, 23 août 1594, dans M. Félibien et G.A. Lobineau, Histoire de la ville de Paris, 5 vol., Paris, 1725, V, p. 25 (cf. ibid., II, p. 728-729). Voir A. Soman, The Theatre, diplomacy and censorship in the reign of Henri IV, dans Bibliothèque d'humanisme et Renaissance, 35, 1973, p. 273-288.

164. Statuts de 1598-1600, Statuta Facultatis Artium, art. XXXV, dans Ch. Jourdain, Histoire, cit., Pièces justificatives, p. 5.

165. Ordonnance de police du 12 novembre 1609, dans N. de La Mare, Traité de la Police, $2^{\mathrm{e}}$ édition, 4 vol., Paris, 1722-1738, I, Livre III, Titre III, p. 472.

166. Gazette d'Amsterdam de 1697, citée dans Saint-Simon, Mémoires, éd. A. de Boislisle, IV, Paris, 1884, p. 125-126 n. 7.

167. Jérôme Phélypeaux de Pontchartrain, secrétaire d'État de la Maison du Roi (fils du chancelier), à d'Argenson, lieutenant de police, 31 mars 1701, dans Correspondance administrative, éd. G. B. Depping, cit., II, p. 739.

168. Voir J. Dunkley, Theatrical censorship and Nicolas Boindin's Le Bal d'Auteuil (1702), dans Studies on Voltaire and the Eighteenth Century, 329, 1985, p. 185-196, qui corrige les exposés classiques de V. Hallays-Dabot, Histoire de la censure théâtrale en France, Paris, 1862, chapitre II ; E. Despois, Le Théâtre français sous Louis XIV, 4e édition, Paris, 1894, p. 163-167.

169. Lettre d'Artus de Lionne, évêque de Gap, aux consuls de Marseille, 13 juillet 1644, publiée par B. Montagnes, Mentalités religieuses, dans le catalogue Marseille au XVII ${ }^{e}$ siècle. Archives communales, Marseille, février-mars 1980, Marseille, 1980, p. 74.

170. Arrêt du 28 juillet 1644, dans J. Filleau, Decisions catholiques, Poitiers, 1668, p. 254-255.

171. Sa thèse, Book Censorship in France (1599-1607), with Emphasis upon Diplomatic Relations between Paris and Rome, Ph.D. dissertation, Harvard, 1967, reste malheureusement inédite et je n'ai pu la consulter (O. Poncet, Pomponne de Bellièvre, cit., p. 242-251, l'a utilisée pour la section qu'il consacre aux « problèmes de librairie »), mais voir A. Soman, Deux grandes sources d'archives encore inexploitées pour l'étude de la censure au XVI siècle en France, dans Bulletin philologique et historique (jusqu'à 1610) du Comité des travaux historiques et scientifiques, 1974, p. 81-89, surtout 86-88; id., Press, pulpit, and censorship in France before Richelieu, dans Proceedings of the American Philosophical Society, 120, 1976, p. 439-463. S. H. De Franceschi, La crise théologico-politique, cit., a depuis lors suivi pas à pas les correspondances diplomatiques pour sa chronique des controverses sur le pouvoir du pape au temporel.

172. Voir F. Rose-Troup, The Western Rebellion of 1549 : an account of the insurrections in Devonshire and Cornwall against religious innovations in the reign of Edward VI, Londres, 1913, p. 211-231, surtout 214-217; l'Appendice H, p. 441-445, est à ma connaissance la seule discussion de La Responce du peuple, qui n'est pas mentionnée dans les études plus récentes (voir en particulier J. Youings, The South-Western Rebellion of 1549, dans Southern History, 1, 1979, p. 99-122, qui rectifie la chronologie des Articles des rebelles, p. 103-104). F. RoseTroup, p. 445-470, reproduit ensuite intégralement l'ouvrage d'après l'exemplaire de la British Library, G.11906.

173. Permission signée « Des Essars » (le lieutenant civil, Antoine des Essarts), reproduite ibid., p. 469-470. Sur Ory, voir J. K. Farge, Biographical Register, cit., p.353-356 (avec références et bibliographie). Il venait d'obtenir de Henri II, par édit du 22 juin 1550, confirmation des pouvoirs qui lui avaient été accordés par une ordonnance de François I ${ }^{\text {er }}$ de 1536 (Isambert, Recueil, cit., XIII, p. 173). Je ne connais pas d'autres cas où il aurait approuvé des livres. Sur son rôle dans les questions de censure, voir J. K. Farge, Early censorship of printed books in Paris : New perspectives and insights, dans J. M. de Bujanda (éd.), 
Le Contrôle des idées à la Renaissance. Actes du colloque de la FISIER tenu à Montréal en septembre 1995, Genève, 1996, p. 87.

174. Voir ce privilège dans La responce du peuple Anglois à leur Roy Edouard, sur certains articles qui en son nom leurs [sic] ont esté envoyez touchant la religion Chrestienne. Nouvellement imprimé sur le vray exemplaire, qui est pour la plus part differend des premiers. Avecques privilege , Paris, R. Massellin, 1550 (Bodleian Library, Vet. E1 f. 324), au verso de la page de titre.

175. Ibid., fol. a2r-a2v. Voir R. K. Marshall, Mary of Guise, London, 1977, p. 177-198 (résumé par l'auteur dans son article de l'Oxford Dictionary of National Biography, XXXVII, p. 74-75) et surtout désormais P. E. Ritchie, Mary of Guise in Scotland, 1548-1560. A Political Career, East Linton, 2002, p. 61-90.

176. Arrest du Vendredy 13. Fevrier 1550 [ancien style], résumé dans J. Corbin, Suite des Droicts de Patronage, honorifiques, et autres Recueils d'Arrests et Plaidoyez. Extraicts des anciens Registres Olim, et autres Modernes de la Cour de Parlement à Paris, sur diverses et notables matieres, Paris, 1622, c. 281, De la Peine des livres imprimez qui vont contre la Religion ou l'honneur du Prince, p.640-641 (seul exemple du chapitre), et, d'après Corbin, dans P.J. Brillon, Dictionnaire des Arrests, 3 vol., Paris, 1711, II, s.v. Livres défendus, p.622 ; É. Maugis, Histoire du Parlement, cit., II, p. 336-337. Pour la correspondance sur le sujet entre Mason et le privy council, voir F. Rose-Troup, The Western Rebellion, cit., p. 442-443.

177. Voir par exemple Sentence du Prevost de Paris, contre un livre intitulé, Apologia Adolphi Schulckenii, etc. Avec l'Extraict d'iceluy, [Paris,] 1613 (sentence du 10 juin 1613, «que ledict Livre sera bruslé, par l'executeur de la haulte justice, en la place publique de Greve») ; Sententia Praetoris Praefecturae Parisiensis, aduersus famosum libellum inscriptum, in Iac. Aug. Thuani Historiarum libros Notationes, auctore Io. Baptista Gallo, Paris, 1614 (sentence du 7 juin 1614 ordonnant que cet ouvrage, imprimé à Ingolstadt et rapporté par quelques libraires postremis Francofurtensibus nundinis, serait supprimé ; l'auteur était en réalité le jésuite français Jean Machault : voir S. H. De Franceschi, La crise théologico-politique, cit., p. 474-475); Sentence de Monsieur le Prevost de Paris, ou son Lieutenant Civil, portant suppression du libelle diffamatoire intitulé, Advis et notes donnez sur quelques plaidoyez de M. Louis Servin Advocat du Roy, publiés en France au prejudice de la Religion Catholique, de l'honneur du Roy Tres-Chrestien, et de la paix de son Royaume, par Louys Richeome [... ]. Du 27 Janvier 1616, Paris, 1616. On notera que le livre de Richeome avait été publié en vertu de son privilège général (supra, n. 83). Pour la condamnation au feu, voir par exemple Fr. Annat, La conduitte de l'Église et du Roy, justifiée dans la condamnation de l'Heresie des Jansenistes, Paris, 1664, préface, fol. e2v : « toute leur artillerie ne peut que noircir du papier, qui ne laisse pas pour cela de bien brusler, quand la Justice du Roy y fait mettre le feu à la Croix du Tiroir et à la Greve ». J'ignore sur quel critère on choisissait un lieu plutôt que l'autre.

178. Le chef du Châtelet était le roi lui-même (B.Barbiche, Les Institutions, cit., p. 351-352). À la fin de l'Ancien Régime, Louis-Sébastien Mercier, dans un texte célèbre, qualifia le prévôt de «juge qui ne rend point la justice ; c'est un fantôme ; il n'y a que son nom qui domine ses trois lieutenants » (Tableau de Paris, cit., II, s.v. Hôtel du Lieutenant civil, p. 1058-1059; cf. déjà I, s.v. Châtelet, p. 1301). M. Chassaigne, La Lieutenance générale de police de Paris, Paris, 1906 (repr. Genève, 1975), p. 16, applique sans hésitation ce texte au XVII ${ }^{e}$ siècle. Y. Chaussy, Libraires et imprimeurs parisiens en 1624, cit., p. 97 n. 7, a néanmoins suggéré que, au début du XVII ${ }^{\mathrm{e}}$ siècle, le prévôt Louis Séguier, membre de la Compagnie du Saint-Sacrement (R. de Voyer, comte d'Argenson, Annales de la Compagnie du St- 
Sacrement, éd. H. Beauchet-Filleau, Marseille, 1900, p. 169), se serait fait l'auxiliaire du nonce contre les livres qui déplaisaient à Rome.

179. Les textes de ces arrêts, qui font partie des grandes références gallicanes, figurent dans de nombreux recueils. Voir en particulier L. Bouchel, La Bibliotheque ou Thresor $d u$ droit françois, 3 vol., Paris, 1629, II, s.v. Libelles diffamatoires, p. 585-587 ; [P. Dupuy (éd.)], Preuves des Libertez de l'Eglise Gallicane, s.l., 1639, p. 61 et 65-66; Ch. Du Plessis d'Argentré, Collectio iudiciorum, cit., II/2, p. 34-35 et 90-91. Ils sont tous deux énumérés parmi ceux que le Parlement, dans le contexte des débats sur l'article du Tiers aux états généraux, ordonna d'observer selon leur forme et teneur (Arrest de la Cour de Parlement du 2. Janvier 1615. Touchant la Souveraineté du Roy au temporel, et contre la pernicieuse Doctrine d'attenter aux personnes sacrées des Roys. En suite duquel sont les Arrests donnés sur le mesme subject, Paris, 1615, p. 5 ; l'arrêt contre Súarez est reproduit à la suite, p. 27-28).

180. Approbation du 20 octobre 1592, dans Di Gerusalemme conquistata Del Sig. Torquato Tasso Libri XXIIII, Rome, 1593 : ob sublimitatem carminis, reconditam omnis generis eruditionem, atque ingentem allegoriarum, concinne appositarum, siluam, typis dandum censeo, et eruditis viris attentius lectitandum.

181. Ibid., p. 233 ; Di Gerusalemme conquistata. Del Sig. Torquato Tasso. Libri XXIIII, Paris, Abel L'Angelier, M.D.LCXV. [sic pour 1595], seconde foliotation, fol. 270r [=T. Tasso, Gerusalemme conquistata, 20.75-77, éd. L. Bonfigli, 2 vol., Bari, 1934, II, p. 229-230]. Voir J. Balsamo et M. Simonin, Abel L'Angelier \& Françoise de Louvain (1574-1620). Suivi du catalogue des ouvrages publiés par Abel L'Angelier (1574-1610) et la veuve L'Angelier (1610-1620), Genève, 2002, Catalogue n² 263, p. 271-272 ; S. Evans, Bibliography of the "Gerusalemme Conquistata ", dans Notes and Queries, $7^{\mathrm{e}}$ série, 6, $\mathrm{n}^{\circ} 139,25$ août 1888, p. 141-143. Sur la signification de ce chant XX, voir Cl.Gigante, "Vincer pariemi piú sé stessa antica» : La Gerusalemme conquistata nel mondo poetico di Torquato Tasso, Naples, 1996, p. 115-145.

182. Di Gerusalemme conquistata, Rome, 1593, cit., p. 233 ; Di Gerusalemme conquistata, Paris, 1595, cit., seconde foliotation, fol. 270r : « ei solo il Rè può dare al Regno, / E 'l Regno al Rè » [20.77.2-3, éd. L. Bonfigli, II, p. 230]. Voir le commentaire de F. Birago, Dichiarationi, et Avertimenti Poetici, Istorici, Politici, Cavallereschi, \& Morali [...] nella Gerusalemme Conquistata del Signor Torquato Tasso, Milan, 1616, p. 519-520.

183. Arrêt du 1er septembre 1595 dans P. Dupuy (éd.), Preuves des Libertez, cit., p. 59-60. L'arrêt est également reproduit, d'après cette édition, dans J.Balsamo et M. Simonin, Abel L'Angelier, cit., Documents, $n^{\circ}$ CCV, p. 458-459.

184. J. Balsamo et M. Simonin, Abel L'Angelier, cit., p. 271; S. Evans, Bibliography of the «Gerusalemme Conquistata », cit., p. 143.

185. Voir infra, n. 214.

186. Arrêt du 9 février 1657, reproduit par exemple dans CEuvres de Blaise Pascal, éd. L. Brunschvicg, P. Boutroux et F. Gazier, VI, Paris, 1914, p. 377-378 (il y est parlé de dix-sept lettres, à savoir les seize premières Provinciales et la Lettre au P. Annat du P. Fronteau).

187. Les anecdotes de ce genre sont classiques : comparer, par exemple, ce qui se passa lorsque les livres sociniens furent condamnés au feu aux Provinces Unies en 1599 (H. J. McLachlan, Socinianism in seventeenth-century England, Oxford, 1951, p. 21 n. 2).

188. Voir G. Hermant, Mémoires sur l'histoire ecclésiastique du XVII siècle (1630-1663), éd. A. Gazier, 6 vol., Paris, 1905-1910, III, p. 292-297, qui, comme il était prévisible, attribue toute l'affaire aux intrigues des jésuites. Un exemplaire imprimé de l'arrêt figure 
dans le dossier de la condamnation des Provinciales au Saint-Office (J.-L. Quantin, «Si mes Lettres sont condamnées à Rome... ». Les Provinciales devant le Saint-Office, dans XVII ${ }^{\mathrm{e}}$ siècle, $\mathrm{n}$ - 265 , oct. 2014, p. 602).

189. B. de Negroni, Lectures interdites, cit., p. 62 et $2^{\mathrm{e}}$ partie, Les censures à grand spectacle, p. 75-231.

190. Voir par exemple Arrest du Conseil d'Estat portant que le Libelle diffamatoire intitulé, Lettre de l'Autheur des Regles tres-importantes, au Sieur de Marca, Archevesque de Tholose: Contenant diverses Propositions scandaleuses et injurieuses tant à l'authorité du S. Siege, que à l'honneur et reputation dudit Sieur Archevesque. Sera bruslé par l'Executeur de la haute Justice. Executé le Mercredy 21. May 1659, Paris, 1659 : arrêt du 5 mai 1659, ordonnant que l'ouvrage serait remis au lieutenant civil « pour, à la diligence du Substitut du Procureur General, estre fait brusler à la Croix du Tiroir par les mains de l'Executeur de la haute Justice ». Il y aurait ici une différence avec le XVIII ${ }^{e}$ siècle où, selon B. de Negroni, Lectures interdites, cit., p. 95, les arrêts du Conseil «se contentent d'ordonner que le texte soit supprimé, comme si l'intervention directe du roi rendait inutile la médiation du bûcher » (mais voir aussi p. 128) : ce point serait à vérifier. L'arrêt du 7 juin 1659 contre le Septiéme écrit des curez de Paris (supra, n. 123) porte seulement que l'ouvrage "demeurera supprimé ».

191. C'est le cas de [G. Drappier], Lettre de l'Autheur des regles tres-importantes, etc. A Monseigneur de Marca, s.l., 1658 (voir note précédente). Pour la formule de Bossuet, voir sa lettre au cardinal d'Estrées, décembre 1681, dans Correspondance de Bossuet, cit., II, p. 277.

192. Voir G. Demante, Histoire de la publication des livres de Pierre Du Puy sur les Libertés de l'Église gallicane, dans Bibliothèque de l'École des Chartes, 5, 1843-1844, p. 585-606, surtout p. 589-590. Les volumes n'avaient pas de privilège propre, mais le premier, Traitez des Droits et Libertez de l'Eglise gallicane, reproduisait tous les privilèges qui figuraient dans l'édition de 1612 (supra, n. 142); certaines des additions, au premier chef les arrêts du Parlement, avaient aussi été publiées avec privilège. L'affirmation de J. Orcibal, Jean Duvergier de Hauranne abbé de Saint-Cyran, cit., p. 130, selon laquelle les traités reproduits par Dupuy avaient obtenu précédemment des privilèges, « la plupart, il est vrai, pendant la Ligue ", est inexacte.

193. Sur «ce double jeu », voir J. Orcibal, ibid., Appendice IV, Le patriarcat de Richelieu devant l'opinion, p. 127-132. Pour les réactions romaines, voir la correspondance entre le nonce en France et la secrétairerie d'État, publiée par H. Laemmer, Meletematum Romanorum mantissa, Ratisbonne, 1875, p. 467-469 ; P. Blet, Richelieu et l'Église, Versailles, 2007, p. 267-269; pour l'écho en Angleterre, An Historical Account of all Material Transactions relating to the University of Oxford, from Arch-bishop Laud's being elected Chancellor to his Resignation of that Office. Written by Himself, dans W. Laud, Remains, éd. H. Wharton, II, Londres, 1700, p. «178» [sic pour 168].

194. L'épisode est des plus connus : voir V. Siri, Memorie recondite dall'anno 1601 sino al 1640, 8 vol., Paris, 1677-1679, p. 256-258, 269-272, 298-303, résumant les correspondances diplomatiques françaises; L. F. H. Bouchitté (éd.), Négociations, lettres et pièces relatives à la conférence de Loudun, Paris, 1862, p. XXIII-XXXIV n. 1 (qui publie l'acte envoyé à Rome pour attester la suspension); F.-T. Perrens, L'Église et l'État en France sous le règne de Henri IV et la régence de Marie de Médicis, 2 vol., Paris, 1872, I, p. 231-235; R. de Scorraille, Suarez, cit., II, p. 209-212 ; J. M. Hayden, France and the estates general of 1614, Cambridge, 1974, p.133; en dernier lieu S.H. De Franceschi, La crise théologico-politique, cit., p. 485-486, 491, 493-499. 
195. B. de Negroni, Lectures interdites, cit., notamment p. 154-155 et 271.

196. Voir infra, n. 295.

197. Collection des Procès-Verbaux, cit., III, p. 407-410. Il restait des exemplaires du livre en grand papier «entre les mains de Vitré » (p. 408). Mais «si un livre qui la défendoit si puissamment [l'institution de la Prélature dans l'Eglise], demeuroit saisi par autorité de Justice, sa doctrine, toute orthodoxe et approuvée universellement de tous les Prélats et Docteurs, sembleroit être condamnée, et perdroit beaucoup de son autorité » (p. 410).

198. Chapelain à Godeau, 22 mai 1668, dans J. Chapelain, Lettres, cit., II, p. 573 : «nous esperons que cette saisie n'en empeschera pas le débit ». Sur les huissiers de la Grande Chancellerie, voir G. Tessier, L'audience du sceau, dans Bibliothèque de l'École des Chartes, 109, 1951, p. 76.

199. Voir F. Preyat, Le Petit Concile de Bossuet et la christianisation des mours et des pratiques littéraires sous Louis XIV, Berlin, 2007, p. 247-250; la correspondance de Le Tellier et La Reynie en avril 1678 dans Correspondance de Bossuet, cit., XIII, p. 538-542; P. Auvray, Richard Simon, cit., p. 46-47; et surtout P. Auvray et Fr. Monfort, Richard Simon d'après des documents inédits ou peu connus, dans Oratoriana, n.s., 1, mai 1960, p. 59-65, qui publient les procès-verbaux du commissaire de La Mare.

200. La sentence du prévôt de Paris contre In Thuani Historias Notationes du P. Machault ( supra, n. 177) supprime l'ouvrage quia perniciosus est et multa continet seditiosa aduersus tranquillitatem publicam, pacificatoria edicta, ac denique plenus est imposturarum et calumniarum aduersus magistratus Regios. L'arrêt du parlement contre la Defensio fidei de Suárez (supra, n. 179) «déclare les propositions et maximes contenuës audit livre, scandaleuses et séditieuses, tendantes à subversion des Estats, et à induire les subjets des Rois et Princes souverains, et autres, d'attenter à leurs personnes sacrées : et les propos faisans mention des Rois Clovis, et Philippes le Bel, faux et calomnieux ». Sur la gamme des notes théologiques, voir Br. Neveu, L'erreur et son juge, cit., surtout p. 294-306 et 326 (noter en particulier la note euersiua regnorum).

201. N. M. Sutherland, Was there an Inquisition in Reformation France?, repris in ead., Princes, politics and religion 1547-1589, Londres, 1984, p. 13-29.

202. Dans son arrêt contre Marseille sans miracles (supra, n. 169), le parlement de Grenoble déclara ainsi « les propositions contenuës audit Livre scandaleuses et seditieuses, pleines d'impostures et de calomnies contre le S. Siege et contre les Evesques et les Prelats de l'Eglise » (J. Filleau, Decisions catholiques, cit., p. 255).

203. Voir supra, n. 179. Sur la notion délicate de falsitas, qui peut être ou non une note théologique, voir Br. Neveu, L'erreur et son juge, cit., p. 344-346.

204. Arrêt du 19 juillet 1595 [un exemplaire imprimé, BNF, F. 47084 (7)], reproduit par exemple dans Traitez des Droits et Libertez de l'Eglise gallicane, s.l., 1639, p. 448.

205. Ch. Dufour, La Condamnation d'un Prestre, cit., p. 10-12.

206. Br. Neveu, L'erreur et son juge, cit., p. 295-296.

207. Censure de la Faculté du 19 février 1494, et arrêt du Parlement du 26 mars. Voir Ch. Du Plessis d'Argentré, Collectio iudiciorum, cit., I/2, p. 324-331 (p. 324 : si quid aut Fidei orthodoxae, aut morum honestati aduersum in eis [libris] deprehenderemus, illud notaremus, doctrinalique auctoritate damnaremus); Le Recueil des plus célèbres astrologues de Simon de Phares, éd. J.-P. Boudet, 2 vol., Paris, 1997-1999, II, 104-120 et Appendice III, p. 331-347. 
208. Ch. Du Plessis d'Argentré, Collectio iudiciorum, cit., I/2, p. 406-407. Voir J. K. Farge, Orthodoxy and Reform, cit., p. 165-169 et 214 (pour la référence au précédent de Phares, voir p. 168-169).

209. Voir en particulier l'affaire de la censure du Commentaire de l'édit des petites dates de Charles Du Moulin (É. Maugis, Histoire du Parlement, cit., II, p. 345-346, et surtout J.L. Thireau, Charles Du Moulin, 1500-1566. Étude sur les sources, la méthode, les idées politiques et économiques d'un juriste de la Renaissance, Genève, 1980, p. 35-38). En 1574, dans l'affaire de la Bible de René Benoist (infra, n. 223), la Faculté écrivait au cardinal de Pellevé : «Vous sçavez qu'en cecy ni choses semblables, n'avons eu il y a long tems le Parlement, ne autre Justice en iceux, pour propice » (Ch. Du Plessis d'Argentré, Collectio iudiciorum, cit., II/1, p. 432).

210. Voir en particulier l'arrêt du $1^{\text {er }}$ février 1612 enjoignant à la Faculté de surseoir à toute délibération sur le De Ecclesiastica et politica potestate de Richer (E. Richer, Histoire du syndicat, cit., p. 70-76). La formule d'E. Armstrong, Robert Estienne, royal printer : an historical study of the elder Stephanus, $2^{\mathrm{e}}$ édition, Abingdon, 1986, p. 198, sur l'alliance entre Parlement et Faculté ( a system which gave the Faculty the power to determine policy and the Parlement [the power] to execute it»), reprise par J. K. Farge, Introduction historique, dans ILI, I, p. 76, ne s'applique certainement pas au XVII siècle.

211. Texte découvert et publié par D. Kahn, La condamnation des thèses, cit., p. 151 n. 22.

212. Édition critique de la censure et de l'arrêt, ibid., p. 160-171. Voir aussi supra, n. 159.

213. Voir D. Kahn, Alchimie et paracelsisme, cit., p. 568-593. La censure de la Faculté, dans la traduction de Marin Mersenne, est donnée p. 570-571. Il s'agit d'un cas fort rare de censure d'un livre déjà ancien, publié à Hambourg en 1595, puis, dans une seconde édition augmentée, à Hanau en 1609.

214. Censure de la Faculté du 3 mars et arrêt du Parlement du 17 mars 1644, dans J. de Launoy, Opera omnia, cit., IV/2, Launoiana, Pars Tertia, p. XVII-XVIII. Résumant la censure dans son réquisitoire, le procureur général rajouta la note de "tendant à l'hérésie », que les théologiens n'avaient pas employée.

215. Determinatio Facultatis super quamplurimis assertionibus Desiderii Erasmi Roterodami, 16 décembre 1527, dans Ch. Du Plessis d'Argentré, Collectio iudiciorum, cit., II/1, p. 53-77. Pour la complexe histoire de cette censure, très éclairante pour les rapports entre la Faculté, le Parlement et le roi, voir J.K. Farge, Orthodoxy and Reform, cit., p. 186-196; E. Rummel, Erasmus and his Catholic critics, 2 vol., Nieuwkoop, 1989, II, p. 46-55.

216. Voir en particulier la section De Traductione sanctarum Scripturarum in linguam uulgarem (Ch. Du Plessis d'Argentré, Collectio, cit., II/1, p.60-62), et sa reprise, en traduction française, dans Recueil des declarations de la Faculté de theologie sur les Versions Françoises de l'Ecriture et de l'Office de l'Eglise, fait en 1661 le quatriéme Janvier, et presenté par Elle à l'Assemblée du Clergé de France. Avec la Sentence renduë en l'Officialité de Paris, le dixiéme Avril 1688, et l'Ordonnance de Monseigneur l'Archevesque du troisiéme May de la mesme année, Paris, 1688, p. 5-8, avec la réponse d'[A. Arnauld], Defense des versions de l'Ecriture Sainte, des Offices de l'Eglise, et des Ouvrages des Peres. Et en particulier de la nouvelle traduction du Breviaire contre la Sentence de l'official de Paris, du 10. Avril 1688. Avec l'Avocat du Public contre la Requeste du Promoteur du III. May, Cologne, 1688, p. 53-69 (pour le contexte de cette controverse, voir infra, n. 282). Pour l'utilisation de cette même censure de 1527 (De Dionysio Areopagita, p. 72) dans les discussions sur l'authenticité du corpus pseudodionysien, voir J.-L. Quantin, La menace des faits: érudition moderne et condamnations 
romaines, dans Ph.Levillain (éd.), "Rome, l'unique objet de mon ressentiment». Regards critiques sur la papauté, Rome, 2011, p. 141.

217. Texte par exemple dans Ch. Du Plessis d'Argentré, Collectio, cit., III/2, p. 260 : sed quia nulli sigillatim propositioni certa censura nota inusta fuit, locus etiamnum aliquis quorumdam cauillis et effugio relictus est. Rappelons que la bulle Ex omnibus afflictionibus de Pie V avait condamné 76 propositions de Baïus comme haereticas, erroneas, suspectas, temerarias, scandalosas, et in pias aures offensionem immittentes, respectiue (sans parler de l'ambiguïté supplémentaire du comma pianum, que n'évoque pas la lettre des évêques).

218. Voir infra, n. 335, la réponse de Bossuet en 1700.

219. Mabillon à Dom Claude Estiennot, 7 août 1696, dans Ph. Schmitz, Lettres de Mabillon au procureur de la congrégation de Saint-Maur à Rome, dans Revue Mabillon, 22, 1932, p. 223. En réalité, la censure finalement adoptée, le $1^{\mathrm{er}}$ octobre 1696, condamnait bien les propositions sigillatim, en distinguant pour la première deux sens, l'un dans lequel elle était falsa, temeraria, scandalosa, et impia, l'autre dans lequel elle n'était que falsa, temeraria, et scandalosa (Ch. Du Plessis d'Argentré, Collectio, cit., III/1, p. 150-156). Sur les débats, voir J. Grès-Gayer, D'un jansénisme à l'autre. Chroniques de Sorbonne 1696-1713, Paris, 2007, surtout p. 93-101.

220. Voir Br. Neveu, L'erreur et son juge, op.cit., p. 349-350 et 352-355 («la commodité dangereuse de ce respective ", p. 355).

221. Nouvelles ecclésiastiques, 1752, p. 42. Voir aussi ibid., p. 37-38, et pour l'opposition des parlementaires aux censures in globo, B. de Negroni, Lectures interdites, cit., p. 223.

222. Requête de Benoist du 16 septembre 1574, dans Ch. Du Plessis d'Argentré, Collectio, cit., II/1, p. 428. Voir aussi Juste et necessaire complainte pour M. René Benoist, ibid., p. 438-439.

223. Réponse de la Faculté, ibid., p. 429 ; Conclusio sacrae Facultatis (20 septembre 1574), ibid., p. 431 ; lettre de la Faculté au cardinal de Pellevé, ibid., p. 432.

224. Bref du 3 octobre 1575, ibid., p. 442.

225. La controverse porta d'abord sur l'Immaculée Conception puis sur la durée des peines du purgatoire. Voir le dossier, ibid., p. 443-448 (p. 444 : Episcopi Parisiensis sententia nulla et irrita declarata est; p. 447 : de nostro in censuras agendas iure). Voir les études, partisanes mais bien informées, de J. M. Prat, Maldonat et l'Université de Paris au XVI siècle, Paris, 1856, p. 350-410, et surtout J. I. Tellechea Idígoras, La Inmaculada Concepción en la controversia del P. Maldonado, S.I.con la Sorbona, Vitoria, 1958 (pour les versions contradictoires de la Faculté et de l'évêque sur l'arrêt du parlement, voir p. 117-118, et appendice, p. 335 et 365). On peut consulter aussi P. Schmitt, La Réforme catholique. Le combat de Maldonat (1534-1583), Paris, 1985, p. 421-473 (de seconde main).

226. L. Vié, Un incident à l'Université de Toulouse en 1645 à propos de la censure du livre De Scientia media, dans Bulletin de la Société archéologique du Midi de la France, nouvelle série, 40-41, nov. 1910-juillet 1912, p. 313-319; id., Quelques précisions au sujet de l'affaire (déjà exposée) du livre De Scientia media, 1645-46, ibid., p. 389-393; H. Bégouen, À propos de la censure du livre De Scientia media, ibid., 42-43, nov. 1912-juillet 1914, p. 73-76 ; A. Auguste, Les origines du jansénisme dans le diocèse de Toulouse (notes et documents), Paris-Toulouse, 1922, p. 33-43 ; Collection des Procès-Verbaux, cit., III, p. 412.

227. Voir une lettre révélatrice de Guidi di Bagno, nonce à Bruxelles, au cardinal Spada, 7 janvier 1627, citée par L. Ceyssens, Les "sept points" jansénistes, cit., p. 15-16 (bref résumé dans Correspondance du nonce Guidi di Bagno, cit., II, p. 810). 
228. Voir J. Grès-Gayer, Le Gallicanisme de Sorbonne cit., p. 182-187.

229. Arrest de la Cour du Parlement, sur la Bulle de nostre S. Pere le Pape contre les Censures de la Faculté de Theologie, 29 juillet 1665, dans [J. Boileau], Recoüil de diverses pieces concernant les censures de la Faculté de Theologie de Paris. Sur la Hierarchie de l'Eglise et sur la Morale Chrestienne, Munster, 1666, p. 191-192.

230. N. Béda, Apologia aduersus clandestinos Lutheranos, dans Ch. Du Plessis d'Argentré, Collectio, cit., III/2, p.5-6 (cum ius concernat diuinum). Voir E. Rummel, Erasmus, cit., p. 43-44 ; J. K. Farge, Le Parti conservateur, cit., p. 90 n. 101 ; M. Crane, A Scholastic Strikes Back: Noël Béda's Apologia ... adversus clandestinos Lutheranos (1529), dans Opuscula. Short texts of the Middle Ages and Renaissance, 1/3, 2011, p. 3-4 (http://opuscula.synergiesprairies.ca/ ojs/index.php/opuscula/article/view/18).

231. Ch. Du Plessis d'Argentré, Collectio, cit., II/2, p. 211-214.

232. Ibid., p. 218-220.

233. L. de Lens, La faculté de théologie de l'université d'Angers, dans Revue historique, littéraire et archéologique de l'Anjou, sept. 1879, p. 159-160 (la citation, donnée entre guillemets sans référence, semble être la traduction par l'auteur des procès-verbaux de la Faculté).

234. Censure du $1^{\mathrm{er}}$ mai 1645. Édition bilingue dans [J.-A. Gazaignes], Annales de la société des soi-disans Jésuites, 5 vol., Paris, 1764-1771, III, p. 985-986; texte latin seulement dans Collection des Procès-Verbaux, cit., III, Pièces justificatives, p. 40.

235. Voir supra, n. 156. Le décret de l'Université, du 3 décembre 1626, est imprimé dans Actes tirez des Archives et Registres de l'Université de Paris, pour justifier sa Jurisdiction exercée par ses Deputez, s.l.n.d. [BNF, R. 8180 (11)], p. 15-18, et dans Seconde Partie [...] touchant le livre de Sanctarel, cit., p. 26-28; il est aussi dans Ch. Du Plessis d'Argentré, Collectio, cit., II/2, p. 235-237.

236. Declaration du Roy sur le Decret du Recteur de l'Université de Paris touchant une These de F. Jean Testefort Dominicain, soustenüe le 26. de Novembre 1626, 13 décembre 1626, dans Seconde Partie [...] touchant le livre de Sanctarel, cit., p. 28-30, et dans Ch. Du Plessis d'Argentré, Collectio, cit., II/2, p. 233-235. L'exposé de la déclaration mentionne la plainte «par un grand nombre de Prélats de nostre Royaume, estans de present assemblez en nostre bonne Ville de Paris, et autres » : il faut très vraisemblablement mettre au premier rang de ceux-ci le cardinal de La Rochefoucauld, grand soutien des duvallistes de la Faculté de théologie (supra, n. 96).

237. Seconde Partie contenant ce qui s'est passé en la Faculté de Theologie de Paris, et dans l'Université en corps, touchant le livre de Sanctarel, cit., p. 46-53; Ch. Du Plessis d'Argentré, Collectio, cit., II/2, p. 244-250. Pour la condamnation de Sarrazin, voir ibid., I/2, p. 227-229 (il s'agit en fait d'un décret de la Faculté de théologie, mais rendu praesertim cum Dominus Rector et multi de Uniuersitate talem reparationem requisiissent in praesentia dictae Facultatis).

238. C'est là le principal enseignement des travaux déjà cités de Jacques Grès-Gayer.

239. Voir supra, n. 6.

240. N. Béda, Documentum quo docetur nullum Theologum debere arceri ab examine doctrinarum Fidei, nisi fuit suspectus in Fide, dans Ch. Du Plessis d'Argentré, Collectio, cit., I/2, p. 410-412. L'intérêt de ce texte pour comprendre l'attitude de Béda a été relevé par J. K. Farge, Noël Beda, cit., p. 151-152 et 163. Il n'est pas daté mais il doit dater de décembre 1522 (voir Registre des procès-verbaux de la Faculté de théologie de Paris, éd. A. Clerval, I. De 1505 à 1523, Paris, 1917, p. 332) ; la Faculté l'adopta (ibid., p. 344-345). Sur la controverse, 
voir A. Godin, Origénisme et antiorigénisme à la Faculté de Théologie de Paris au XVI siècle, dans Mélanges de la Bibliothèque de la Sorbonne, 4, 1983, p. 6-29; J. K. Farge, Introduction historique, dans ILI, I, p. 54-55; id., Early censorship in Paris: a new look at the roles of the Parlement of Paris and of King Francis I, dans Renaissance and Reformation/Renaissance et Réforme, nouvelle série, 13, 1989, p. 175-176 et notes ad loc. Les plaidoiries sur l'affaire au parlement de Paris sont publiées dans id., Le Parti conservateur, cit., p. 79-94.

241. N. Béda, Documentum, cit., p. 410 : quilibet Licentiatus et Magister in sacra Facultate Theologiae est idoneus Examinator et Iudex, partim authenticus, propter potestatem ab Apostolica Sede ei concessam, partim doctrinalis, propter peritiam, quam habere praesumitur omnium doctrinarum ad Christianam Religionem pertinentium. Comme deduit le Docteur de Jarsonno en sa premiere partie, consideratione quarta libelli de examinatione doctrinarum. Voir J. Gerson, De examinatione doctrinarum (mai 1423), dans CEuvres complètes, éd. P. Glorieux, IX, Tournai, 1973, p. 462. Pour les origines de cette conception, initialement favorisée par la papauté elle-même, voir P. McKeon, Concilium generale and studium generale: the transformation of doctrinal regulation in the Middle Ages, dans Church History, 35, 1966, p. 24-34.

242. Th. Raynaud, Erotemata de bonis ac malis libris, deque iusta aut iniusta, eorumdem confixione, Lyon, 1653, Partitio III, Erotema II, p. 272-273 : habent, inquam, ueri Doctores idoneitatem, et aptitudinem, ut a Pastoribus assumantur ad discussionem punctorum ambiguorum, sintque Praesulum quasi consulti [...] et aeque cuiuis uiro docto competit, tametsi non Doctori.

243. A. Baillet, Jugemens des Sçavans, I, cit., p. 35.

244. O. Talon, Mémoires, éd. J.-J. et A. Champollion-Figeac [Nouvelle collection des Mémoires pour servir à l'histoire de France, éd. Michaud et Poujoulat, $3^{\mathrm{e}}$ série, VI], Paris, 1839) p. 103 : le chancelier dit «que le jugement de la Sorbonne ne pouvoit être qu'un avis doctrinal ». Le premier président répondit " qu'il y a dans le royaume des prélats capables de décider des différents de cette qualité par assemblées provinciales et conciles nationaux, si la matière y étoit disposée; que la Faculté de théologie de Paris prend connoissance de la doctrine, et peut être consultée». Voir aussi l'intervention du président de Mesmes, ibid., p. 105.

245. Voir La Nunziatura di Francia del cardinale Guido Bentivoglio. Lettere a Scipione Borghese, éd. L. de Steffani, 4 vol., Florence, 1863-1870, II, 17 janvier 1618, p. 168.

246. Les Avis de M. Jean Rousse, Docteur de la Societé de Sorbonne, Curé de S. Roch de Paris, sur la seconde Lettre de M. Arnauld, aussi Docteur de Sorbonne, du 10 juillet 1655. aux Parroissiens de sainct Roch, $2^{\mathrm{e}}$ éd., Paris, 1656, p. 28 (repris dans A. Arnauld, Cuvres, cit., XX, appendice, p. 509).

247. Constitution Inter multiplices, 17 novembre 1487: Omnibus et singulis dicte artis impressoribus [...], sub excommunicationis late sententie pena ipso facto incurrenda et mulcta pecuniaria per locorum ordinarios pro eorum arbitrio exigenda auctoritate apostolica praesentium tenore districte praecipiendo inhibemus ne de cetero libros, tractatus aut scripturas qualesumque imprimere aut imprimi facere praesumant, nisi consultis prius super hoc, in dicta curia magistro sacri palatii seu in eius absentia ipsius uicesgerenti, et extra eam locorum ordinariis et eorum speciali expressa impetrata licentia gratis concedenda, quorum conscientia oneramus ut antequam huiusmodi licentiam concedant imprimenda diligenter examinant siue a peritis et catholicis examinari faciant et procurent ac diligenter aduertant ne quid imprimatur quod orthodoxe fidei contrarium, impium et scandalosum existat. Voir C.-J. Pinto de Oliveira, Le premier document pontifical sur la presse. La constitution Inter multiplices d'Innocent VIII, dans Revue des Sciences 
philosophiques et théologiques, 50, 1966, p. 628-643, avec édition bilingue du texte (pour le passage cité, voir p. 639-641).

248. Ibid., p. 634.

249. Diuini eloquii preconis celeberrimi fratris Oliuerii Maillardi, ordinis Minorum professoris, Sermones de Aduentu, declamati Parisius in ecclesia sancti Iohannis in Grauia et Lugduni nouiter impressi, Lyon, 1498 [Bibliothèque Nationale, Catalogue des Incunables, n M-29 (1)], Sermo xxix, fol. LIIIIr, sur le devoir de faire l'aumône: Exemplum habetur euidens quod non est scriptum in libro des quenoilles gallice. Estis hic, impressores librorum. Innocentius papa precepit ne imprimerentur libri : nisi uiderentur ab episcopo uel eius uicario uel commissario. $O$ pauperes librarii non sufficit uobis quod sitis damnati solum: sed imprimitis uiles libros de luxuria de arte amandi et datis materiam male faciendi. uos uaditis ad omnes diabolos. Le passage est bien connu. Il a déjà été cité, en particulier, par A. Péricaud, Bibliographie lyonnaise du XVe siècle, Lyon, 1851, p.16, et (avec une coquille qui le rend inintelligible) par A. Renaudet, Préréforme et humanisme à Paris pendant les premières guerres d'Italie (1494-1517), $2^{\mathrm{e}}$ édition, Paris, 1953, p. 208. A. Péricaud, qui en donne une traduction, comprend uiles libros dans le sens de « livres à bas prix » : le sens moral me paraît préférable.

250. Constitution du 4 mai 1515, Concile de Latran V, sess. $\mathrm{X}$, dans Les Conciles œecuméniques, cit., II/1, p. 1292.

251. Concile de Trente, session IV, décret 2 (8 avril 1546), dans Les Conciles cecuméniques, cit., II/2, p. 1354 [= Concilium Tridentinum, cit., V, p. 92] : quosuis libros de rebus sacris [...], nisi primum examinati probatique fuerint ab ordinario, sub poena anathematis et pecuniae in canone concilii nouissimi Lateranensis apposita. La commission sur les abus liés à l'Écriture sainte avait présenté un projet complexe, lu par un des très rares pères français, Antoine Filhol, archevêque d'Aix, pour une censure aut a Sanctissimo D.N. siue deputatis per Suam Sanctitatem, aut a metropolitano cum suffraganeis ad minus duobus [...], aut saltem ab ordinario suo iuxta canonem concilii ultimi Lateranensis (Concilium Tridentinum, cit., V, p. 30). Pour les débats, voir ibid., I, 1901, p. 36-48 et 514-534 (intervention de Dionisio Zanettini, dit il Grechetto, évêque de Milopotamos et Chironissa en Crète, p. 43 : Quamobrem actum de re erit, si hec auctoritas episcopis relinquatur, quoniam multi erunt ex illis, qui consentient impressioni cuiuslibet libri per una fogazza); H. Jedin, Geschichte des Konzils von Trient. II. Die erste Trienter Tagungsperiode 1545/47, Fribourg en Br., 1957, p. 56-57, 69-70 et 77. Filhol était avant tout soucieux de lutter contre les traductions de la Bible en langue vulgaire (A. Tallon, La France et le concile de Trente (1518-1563), Rome, 1997, p. 726-727).

252. ILI, VIII, p. 152-153 et 818-821 (regula X).

253. Decreta Prouincialis Concilii Senonensis, Paris, 1529, Decreta morum, c. XXIII, fol. 32v : prohibemus: ne deinceps per prouinciam nostram imprimantur libri sacri aut sanctorum doctorum, qui uel de fide aut moribus ecclesiasticis habeant tractatum, sine nostra suffraganeorumque nostrorum per suas dioceses speciali authoritate et permissione.

254. Ibid., c. XXIV, fol. 33r. Le concile ordonnait même, ibid., à tous ceux qui possédaient des livres fidem aut mores concernentes, a uiginti annis citra in uulgari seu latino sermone aeditos, de les apporter immédiatement à leur diocésain pour qu'il les examinât: disposition évidemment inapplicable! Sur le retentissement de ce concile, voir A. Tallon, La France et le concile, cit., p. 450-451.

255. Édit de Châteaubriant, art.15, dans Isambert, Recueil, cit., XIII, p. 195-196: l'ouverture des «balles de livres» devait se faire en présence de "l'official et juge présidial, s'il y a siéges d'officialité et présidial : et aux autres villes ausquelles ne seront 
lesdits sièges, en la présence du juge, et de nostre procureur audit siège » (i.e. de baillage ou de sénéchaussée, éventuellement de prévôté); mêmes dispositions pour la visite des " officines et boutiques des imprimeurs, libraires et vendeurs de livres", art. 16, p. 196 : pour Lyon, art. 17, ibid. Voir le commentaire de G. Dupineau ( $† 1644)$ dans $\mathrm{Cl}$. Pocquet de Livonnière, Coustumes du Pays et Duché d'Anjou [...]; avec le commentaire de $M^{\mathrm{e}}$ Gabriel Dupineau, Conseiller du Roy au Presidial d'Angers, 2 vol., Paris, 1725, II, col. 936-937 : « Si bien que par cet Edit l'Approbation des livres, et la connoissance sur les Imprimeurs n'est point attribuée aux Evêques, sauf la visitation des Imprimeurs de Lyon, qui appartient à l'Archevêque et au Chapitre par l'art. 17. dudit Edit. Voire même que Monsieur d'Angers ne le peut aucunement prétendre en la ville, puisqu'en icelle il y a Faculté de Theologie, ni aux autres villes du Diocese, parce qu'en icelles il n'y a Siege d'Officialité ».

256. Ordonnance générale rendue sur les plaintes, doléances et remonstrances des états assemblés à Orléans, janvier 1560 [ancien style], dans Isambert, Recueil, cit., XIV, p. 71; pour les remontrances du clergé, voir Recueil [...]. Contenant les Cahiers, cit., art. XVI, col. 929-930. Comparer ILI, VIII, p. 152 et 818 (regula IX) ; l'Index de Paul IV (publié le 30 décembre 1558) interdisait déjà tous les livres d'astrologie judiciaire, ibid., p. 291-292 et 775. Pour les dispositions antérieures, voir É. Maugis, Histoire du Parlement, cit., II, p. 326-330. Pour les almanachs réformés, E. Droz, Le calendrier genevois, agent de la propagande et Le calendrier lyonnais, dans Chemins de l'hérésie. Textes et documents, 4 vol., Genève, 1970-1976, II, p. 433-456 et III, p. 1-29. Sur L'Hospital, auteur de l'ordonnance d'Orléans, et le contrôle de l'« imaginaire eschatologique », D. Crouzet, La Sagesse et le malheur, cit., p. 434-435 ; sur les enjeux des almanachs de pronotiscations, voir aussi id., Les guerriers de Dieu : la violence au temps des troubles de religion (vers 1525-vers 1610), Seyssel, 1990, I, p. 101-162 (sur l'ordonnance d'Orléans, p. 143).

257. Ordonnance rendue sur les plaintes et doléances des états-généraux assemblés à Blois en novembre 1576, relativement à la police générale du royaume, mai 1579, dans Isambert, Recueil, cit., XIV, p. 390-391. Des sanctions étaient en outre portées contre "tous devins et faiseurs de prognostications et almanachs, excédans les termes de l'astrologie licite ».

258. Déclaration qui défend d'insérer dans les almanachs des prédictions illicites, 20 janvier 1628, dans Isambert, Recueil, cit., XVI, p. 215-216. Voir H. Drévillon, Lire et écrire l'avenir: l'astrologie dans la France du grand Siècle (1610-1715), Seyssel, 1996, p. 65-66 et 94-105.

259. Le cas le plus intéressant est celui des Advis et notes sur quelques plaidoyez de Louis Servin de Richeome, publiés à Caen en 1615, condamnés par le Châtelet l'année suivante ( supra, n. 85 et 177), réédités sans changement à Tournon, par Claude Michel, «imprimeur de l'Université » (le collège jésuite), en 1617, avec permission de Benoît Varnier, « Prestre Docteur ez Droicts, Vicaire general au Diocese de Valence», du 19 février 1617; le privilège est toujours le privilège général accordé à Richeome par Henri IV. Voir aussi É. Binet, S.J., Consolation et resiouissance pour les malades et personnes affligees, Tournon, Claude Michel, 1620 (avec permission de Varnier du 10 février 1620, d'après H. Vaschalde, Établissement de l'imprimerie dans le Vivarais, dans Revue du Dauphiné et du Vivarais, 1, 1877, p. 311); Cl. Picquet, Prouinciae D. Bonauenturae seu Burg. Ord. FF. Minorum Reg. Obser. ac coenobiorum eiusdem initium, progressus et descriptio, $2^{e}$ éd., Tournon, Claude Michel, 1621 : la permission du provincial des Franciscains observants, du 24 avril 1621, est donnée au vu de l'approbation des théologiens de l'ordre du 19 mars 1610 (pour la première édition), habita insuper ratione, concessionis emittendi in lucem eumdem librum per R. D. Benedictum Varnier I.U.D. et Vicarium Generalem R. in Christo patris, et D. Petri Andreae Deleberon Episcopi Valentinensis et Dyensis. Datae Valentiae anno praefato mens. Martii 22. Pour d'autres 
exemples, voir M. Chomarat, Répertoire bibliographique des livres imprimés en France au XVII siècle, VIII. Rhône Alpes, Baden-Baden, 1983, Tournon n ${ }^{\circ} 57$ et 120. M. Chomarat donne malheureusement cette information de manière très aléatoire (il l'omet dans le cas de Binet, $n^{\circ} 111$, et de Picquet, $n^{\circ} 58$ ) et, quand il la donne, sans toujours distinguer entre approbations des docteurs et permission de l'ordinaire (ainsi pour Richeome, $n^{\circ} 94$ ) : aucune conclusion ne peut donc être tirée du dépouillement de son répertoire.

260. On connaît au moins un cas, célèbre parce qu'il concerne Montaigne, de privilège général conditionné à l'approbation épiscopale. Le privilège du roi du 9 mai 1579 accordé au bordelais Simon Millanges, lui permettait « d'imprimer tous livres nouveaux : pourveu qu'ils soient approuvés par Monseigneur l'Archevesque de Bourdeaux, ou son Vicaire, et un ou deux Docteurs en theologie » (extrait reproduit en tête de M. de Montaigne, Essais, Bordeaux, S. Millanges, 1580).

261. L'essentiel du dossier est reproduit dans les différentes éditions des Mémoires du Clergé, ce qui confirme qu'il s'agit là d'une revendication permanente de l'ordre : voir par exemple Recueil des Actes, Titres et Mémoires concernant les affaires du Clergé de France, 12 vol., Paris, 1716-1750, I. De la Foi Catholique et de la Doctrine de l'Eglise, titre 4, De l'impression et approbation des livres qui concernent la Religion.

262. Decreta Concilii prouincialis Bituricensis, De abusu Scripturarum tollendo. Titulus quartus, canon 1, dans Concilia nouissima Galliae a tempore concilii Tridentini celebrata, éd. L. Odespunc de La Meschinière, Paris, 1646, p. 398 : Typographis uero nullos de religione aut fide libros, sine Episcopi licentia et probatione excudere et uenales habere liceat.

263. Concilium prouinciale Tholosanum, pars 4a, c. 10-11, ibid., p. 549.

264. M. Desbarreaux-Bernard, L'Inquisition des livres à Toulouse au XVII siècle, Nîmes, 1997 [reprint d'un tiré à part des Mémoires de l'Académie des Sciences, Inscriptions et Belles-Lettres de Toulouse, $7^{\mathrm{e}}$ s., 6, 1874, p. 330-381]. L'arrêt du parlement pour la visite des boutiques des libraires est du 26 octobre 1619 (p. 9-10). Vanini avait été brûlé le 9 février. Sur le contexte, voir R. A. Schneider, Public Life in Toulouse, 1463-1789: From municipal Republic to cosmopolitan City, Ithaca, NY, 1989, p.135-163. Dans les années 1590, Joyeuse et l'inquisiteur pratiquaient des brûlements de livres chaque année (A. Soman, Press, pulpit, and censorship, cit., p. 454 n. 68). Dans la seconde moitié du siècle, en revanche, l'inquisiteur semble avoir été réduit à l'impuissance, en partie à cause de l'opposition des jésuites (A. Auguste, Les origines du jansénisme, cit., p. 105-109).

265. Decreta Concilii prouincialis Burdigalensis, De professione fidei, c. IV (nunquam se ullos libros impressuros uel uendituros, quin eius approbatione Ordinarii in scriptis obtenta id sibi licere comprobetur) et XII (quosque libros impressos, haeresim, impietatem ac causas temerandae plebis redolentes, censere et notare), dans Concilia nouissima Galliae, cit., p. 632-634. On comparera les Ordini da osservarsi da librari, stampatori, ed altri, secondo le regole, et Indice di libri prohibiti, intimati, e dati a loro per commissione di mons. Illustr. et Rever. Cardinal Borromeo Arcivescovo, e del Rev. Padre Inquisitore, dans Acta Ecclesiae Mediolanensis ab eius initiis usque ad nostram aetatem, éd. A. Ratti, II, Milan, 1890, col.1107-1111 (sur la censure préalable par l'archevêque, art. 29-31), qui ne se limitent pas non plus aux livres religieux mais concernent en bloc « libri, o scritti di qualonche altra sorte » (col. 1110).

266. Sur le concile de Bordeaux et sa réception, voir A. Degert, Saint Charles Borromée et le clergé français, dans Bulletin de Littérature ecclésiastique, 4, 1912, p.151-153 et surtout B. Peyrous, La Réforme catholique à Bordeaux (1600-1719). Le renouveau d'un diocèse, 2 vol., Bordeaux, 1995, I, p. 291-305, qui passe cependant sous silence la question de l'imprimerie 
(et n'a rien sur les approbations et privilèges dans son chapitre sur le livre religieux, II, p. 817-824).

267. Censure des Livres intitulés, le Thresor des Prieres; et le Guidon des Prelats et Boucliers des Pasteurs. Par le seigneur Archevesque de Roüen, dans Recueil des Edicts [...] à la poursuitte des sieurs Abbés de Paimpont, et Prieur de Moustiers, cit., p. 480-482. Voir infra, n. 291.

268. Recueil [...]. Contenant les Cahiers, cit., col. 1399. Les évêques ajoutaient: «et que conformément à l'Ordonnance de Château-briant aucuns livres d'impression étrangère ne soient vendus et distribuez qu'ils n'aïent été visitez et examinez par l'Evêque, ses grands Vicaires ou Officiaux ». Sur ce que prescrivait en réalité l'édit de Châteaubriant, voir supra , n. 255.

269. Réponse faite par le roi le 14 avril 1636, ibid.: « Défenses à tous Libraires d'imprimer aucuns livres sans permission de sa Majesté, laquelle ne sera accordée pour les livres qui concernent la Religion, qu'ils n'aient été approuvés par les Docteurs de la Faculté de Paris, et pour les livres étrangers, défenses à tous Libraires d'en vendre qu'ils n'aïent été visitez suivant l'Edit de Château-briant. "

270. Collection des Procès-Verbaux, cit., III, p.407. On en rapprochera les plaintes des évêques dans l'affaire de Petrus Aurelius, supra, n. 197.

271. Considerations sur l'entreprise, cit., p. 18.

272. Collection des Procès-Verbaux, cit., III, p. 737.

273. Declaration du Roy, sur le cahier presenté à sa Majesté par l'Assemblée generale du Clergé de France; tenuë à Paris és années 1655. 1656. et 1657. Donnée au mois de Fevrier, 1657, Paris, 1657, article XI, p. 8-9.

274. Ibid., article XXIII, p. 16-17. Une dernière clause portait : « Ne pourront pareillement les Juges des lieux empescher la publication des livres de pieté et devotion, et autres qui seront imprimez par ordre et approbation desdits Evesques, pour l'instruction de leurs Diocesains ». Le Clergé eut soin de faire imprimer la déclaration par Antoine Vitré : un exemplaire à la BNF, F-47009 (16).

275. P. Blet, Le Clergé de France et la Monarchie. Etude sur les Assemblées Générales du Clergé de 1615 à 1666, Rome, 1959, II, p. 291, ne fait que mentionner très rapidement cette déclaration (ou bien celle de 1666 : il ne donne pas de date), mais voir ce qu'il dit, p. 405, de la manière dont le Clergé obtint les déclarations de 1656 et 1666 contre les protestants.

276. Declaration du Roy, sur le cahier presenté à sa Majesté par l'Assemblée generale du Clergé de France, tenuë à Paris és années 1665 et 1666. Donnée au mois de Mars, 1666.Paris, 1666, p.13-14. La clause «Ne pourront pareillement les Juges des lieux empescher la publication des livres de pieté et devotion, et autres qui seront imprimez par ordre et approbation desdits Evesques, pour l'instruction de leurs Diocesains » était par ailleurs supprimée. L'article XI de 1657, devenu article XIV, était en revanche repris tel quel (p. 8). Comme en 1657, l'impression fut faite par les soins du Clergé: on trouve deux tirages différents à la BNF, F. 47010 (5) et (6).

277. Voir Recueil des Actes [...]. I. De la Foi Catholique et de la Doctrine de l'Eglise, cit., col. 841 : «Ces deux declarations du mois de Fevrier 1657. et du mois de Mars 1666. n'ont été registrées en aucune Cour ».

278. Le Nouveau Testament de Nostre Seigneur Jesus Christ, Traduit en François selon l'edition Vulgate, avec les differences du Grec, Mons, Gaspard Migeot, 1667. La permission de Gaspar Nemius, archevêque de Cambrai, est datée du 12 octobre 1665 : Cum a sacrosancto Concilio 
Tridentino decretum sit ne cui Typographo liceat imprimere quosuis libros de rebus sacris, nisi primum ab Ordinario examinati, probatique fuerint; hinc est quod Nouum Testamentum [...] Gaspari Migeot imprimendi et euulgandi licentiam damus et impertimur. L'ouvrage avait en fait été imprimé par Daniel Elzevier à Amsterdam (Bibles imprimées, cit., $\mathrm{n}^{\circ}$ 4107). Sur les vaines tentatives des port-royalistes pour obtenir un privilège du chancelier Séguier, voir la préface historique et critique à A. Arnauld, Euvres, cit., VI, p. IV-V; et les curieuses accusations de Fr. Annat, Remarques sur la conduite qu'on tenu les Jansenistes en l'impression et publication du Nouveau Testament imprimé à Mons, Paris, 1668, p. 3.

279. Ordonnance de Monseigneur l'Illustrissime et Reverendissime Hardoüin de Perefixe Archevesque de Paris, Portant defense de lire, vendre et debiter une Traduction du Nouveau Testament, imprimée à Mons, 1667, Paris, 1667 (18 novembre 1667), p. 5-6. Sont cités les conciles de Sens et de Bourges, ainsi que le concile provincial de Narbonne en 1609, qui avait interdit la lecture (mais non la publication ou la vente) des traductions françaises de la Bible, nisi ab Episcopo, aut eius Vicario generali, expressa in scriptis obtenta licentia (Concilia nouissima Galliae, cit., p. 577). Le concile de Bordeaux est en revanche passé sous silence: est-ce parce que ses prescriptions étaient manifestement impraticables ou, plus vraisemblablement, à cause de son défaut de promulgation?

280. Arrest du Conseil d'Estat contre la Traduction du Nouveau Testament, imprimée à Mons. Du 22. Novembre 1667, Paris, 1667, p. 2.

281. [A. Arnauld], Abus et nullitez de l'ordonnance subreptice de Monseigneur l'Archevesque de Paris, par laquelle il a defendu de lire et de debiter la Traduction du Nouveau Testament imprimée à Mons, s.l.n.d. [1667], p. 3.

282. Sentence rendue en l'officialité de Paris, portant condamnation de la Traduction du Breviaire Romain en langue Françoise, Paris, 1688, p. 4-5 (10 avril 1688). D'où les plaintes du très gallican archevêque de Reims, Charles Maurice Le Tellier, au théologal de Paris, qui lui avait envoyé la sentence : « les décisions de ce Concile [de Latran], à l'exception de ce qui regarde le Concordat, ne devant être d'aucune considération en France" (lettre du 21 avril 1688, publiée dans la préface historique et critique à A. Arnauld, Euvres, cit., VIII, p. VII-VIII). Le Recueil des Actes [...].t. I. De la Foi Catholique et de la Doctrine de l'Eglise, cit., col. 817-818, ouvre son titre De l'impression et approbation des livres qui concernent la Religion sur le décret tridentin, mais en notant en marge qu'il n'est pas reçu en France. Face aux critiques dont faisait l'objet la sentence de l'officialité, Harlay jugea nécessaire de la confirmer le 3 mai par une Ordonnance de Monseigneur l'Archevesque de Paris, sur la Traduction du Breviaire Romain en langue Françoise, Paris, 1688. Ce fut dans ce contexte que fut publié le Recueil des declarations de la Faculté de theologie (supra, n. 216).

283. [A. Arnauld], Defense des versions, cit., p. 19-24, reprenant Abus et nullitez, cit., p. 2-5.

284. J. D. Woodbridge, Censure royale et censure épiscopale, cit.

285. Bossuet à Noailles, 15 août 1697, Correspondance, VIII, p. 324-327, à l'occasion d'une série de thèses récemment soutenues au collège de Clermont (hors donc du contrôle de la faculté de théologie de Paris), où se trouvait « en termes formels l'infaillibilité du Pape d'une manière aussi odieuse que dans la censure de Strigonie », et qui défendaient en outre l'attritionisme et la doctrine de Fénelon sur le pur amour.

286. Ordonnance de son Eminence Monseigneur le Cardinal de Noailles, Archevêque de Paris; portant condamnation de la Traduction du Nouveau Testament imprimée à Trevoux, 15 septembre 1702, reproduite à la fin de R. Simon, Lettres choisies [...]. Nouvelle édition, revuë, corrigée et augmentée [...] par M. Bruzen la Martiniere, II, Amsterdam, 1730, p. 335 
(outre Sens et Trente, Noailles cite les conciles de Bourges et de Narbonne); une lettre d'Antoine Dorsanne à Gaston de Noailles, 2 septembre 1702, citée par J. D. Woodbridge, Censure royale et censure épiscopale, cit., p. 341.

287. Bossuet, $3^{\mathrm{e}}$ mémoire au roi, novembre 1702 , dans Correspondance, cit., XIV, p. 172-174. L'arrêt du Conseil contre le Nouveau Testament de Mons est également cité par Noailles, Ordonnance, cit., p. 336.

288. Voir la lettre du duc de Beauvillier à Noailles, 19 sept. 1702, dans Correspondance de Bossuet, cit., XIII, p. 537-538.

289. Mémoire secret de Pontchartrain à Louis XIV, 17 novembre 1702, publié par J. D. Woodbridge, Censure royale, cit., p. 345.

290. L'interdiction d'imprimer et de vendre pouvait être tenue pour un empiètement sur la juridiction des juges royaux : voir e.g. F.-T. Perrens, L'Église et l'État, cit., II, p. 144.

291. Fr. de Harlay, Censure des Livres, cit., p. 477-480 ; P. Morestel, Le Guidon des Prelats et Boucliers des Pasteurs, Paris, 1634. Sur l'autre ouvrage condamné en même temps (l'association était clairement polémique), le Thresor des Prieres, «composé par quelque Heretique de la secte de Calvin, afin d'insinuer et de faire couler frauduleusement le Huguenotisme, sous pretexte de Prieres et d'Oraisons, dans les Ames tendres et simples des Catholiques ", voir la mise au point de M. Carbonnier-Burkard, Calvin dans des recueils de prières "nicodémites", dans Bulletin de la Société de l'Histoire du Protestantisme Français, 155/1, janvier-mars 2009 [Jean Calvin et la France], p. 141-151.

292. P. Morestel, Guidon des Prelats, cit., fol. a7r. Pour les étapes antérieures du conflit, voir Replique pour les Curez du Dioceze de Rouen. A la Responce de Maistre Adrian Behotte Chanoine et Archidiacre en l'Eglise de Roüen. Touchant le pretendu droict de visite des Archidiacres. Par André Chrestian Advocat au Parlement de Roüen. Fait imprimer par les Curez de l'Archevesché, Rouen, 1628. A. Tougard, Un curé du diocèse de Rouen sous Louis XIII, dans Revue catholique de Normandie, 23, 1913-1914, p. 133-146 et 225-244, a peu d'intérêt (comme l'auteur en convient lui-même, p. 238, «le titre de cette modeste étude ne vaut rien. Il devait faire espérer une bonne biographie ecclésiastique, tandis que les lecteurs y ont à peine trouvé quelques mots sur le docteur Pierre Morestel, avec l'analyse plus ou moins complète de son Guidon»).

293. P. Morestel, Guidon des Prelats, cit., fol. c5r-v.

294. Ibid., fol. a4v.

295. Arrest du Conseil Privé du Roy, portant cassation d'un Arrest du Parlement de Roüen, rendu contre la Censure d'un Livre intitulé, le Guidon des Prelats et Boucliers des Pasteurs, que ledit Conseil a supprimé, avec deffenses audit Parlement d'en prendre plus aucune cognoissance $\left(1^{\mathrm{er}}\right.$ sept. 1634), dans Recueil des Edicts [...] à la poursuitte des sieurs Abbés de Paimpont, et Prieur de Moustiers, cit., p. 483-508. L'exposé rappelle et résume toute la procédure antérieure (pour l'arrêt du Parlement du 2 juin, voir p. 498-499).

296. Ibid., p. 500-501.

297. Ibid., p. 503-506.

298. Outre l'édition de l'arrêt dans le Recueil publié par les Agents du Clergé en 1635, il fut inclus dans les Mémoires du Clergé: voir par exemple Recueil des Actes [...]. t. I. De la Foi Catholique et de la Doctrine de l'Eglise, cit., col. 747-753. Il figure aussi dans Le Mercure de Gaillon, ou Recueil de Pieces curieuses, tant Hierarchiques que Politiques, Gaillon, 1644, n 17, paginé à part, sous le titre Arrest celebre du Conseil d'Estat, par lequel il est declaré que ceux qui 
detruisent la Hierarchie, sapent les fondemens de la Monarchie (ce recueil, que Harlay fit imprimer sur une presse établie dans son château archiépiscopal, a été reproduit en facsimilé, avec introduction par N. Periaux, Rouen, 1876).

299. Ordonnance du 11 août 1667, par ex. dans G. Mongrédien, Recueil des textes et des documents du XVII siècle relatifs à Molière, 2 vol., Paris, 1965, I, p. 292-293. Le placard est reproduit dans Fr. Rey et J.Lacouture, Molière et le roi.L'affaire Tartuffe, Paris, 2007, illustration $\mathrm{n}^{\circ} 27$.

300. Consultation canonique de Baluze, publiée par F.Chambon, Document inédit sur Tartuffe. Contribution à l'histoire de la pièce, dans Revue d'Histoire littéraire de la France, 3, 1896, p. 124-126 (citation p. 126) : «Car la Comédie est un divertissement public, permis par les princes dans tous les Estats de la Chrestienté, et qui se donne dans des lieux destinés pour cela, et esloignés des églises et des lieux sacrez, et dans des temps qui ne sont pas ordinairement destinés pour la célébration des devoirs chrestiens. Ainsy l'Eglise ne peut pas se mesler d'empescher cette sorte de divertissemens, encore moins le peutelle par l'employ des peines canoniques et des excommunications ».

301. La formule est de J. Le Brun, La condamnation de l'Explication des maximes des saints et la publication du Télémaque au jour le jour, dans Fr.-X. Cuche et J. Le Brun éd., Fénelon. Mystique et Politique (1699-1999). Actes du colloque international de Strasbourg, Paris, 2004, p. 129. La plupart des censures épiscopales contre l'Apologie pour les casuistes (infra, n. 307), imprimées à Bourges, Châlons, Sens, Toulouse etc., furent ainsi immédiatement réimprimées à Paris.

302. Les premières occurrences données par la base Frantext sont de l'abbé Prévost, au milieu du XVIII ${ }^{\mathrm{e}}$ siècle, mais l'expression apparaît à la fois dans le Dictionnaire de Furetière, s.v. Censure (« signifie aussi, la correction ou reprimende que fait un superieur, ou le public. [...] tous les Auteurs sont exposez à la censure du public ») et dans celui de l'Académie française, en 1694, s.v. Travail («exposer son travail à la censure du public»). Pour "censure publique», la première attestation fournie est d'Antoine Godeau, non encore évêque, en 1633 ( «Si j'eusse esté plus soigneux de ma reputation que du profit de mon prochain, je n'eusse pas exposé ces ouvrages à la censure publique »). [A. Baillet], La vie de Monsieur Des-Cartes, 2 vol., Paris, 1691, I, p. 266, parle de «la malignité du Public qui censure souvent ce qu'il devroit approuver ». L'étude littéraire d'H. Merlin, Public et littérature en France au XVII siècle, Paris, 1994, est de peu de secours dans notre perspective.

303. D'après la préface historique et critique à A. Arnauld, Euvres, cit., VIII, p. IX-X, ç'aurait été le cas pour le Bréviaire de Le Tourneux. On a vu (supra, n. 216) qu'Arnauld se fit dans cette affaire "l'Avocat du Public ».

304. [M. Girard], Dialogues entre deux Parroissiens de S. Hilaire du Mont, sur les Ordonnances, contre la Traduction du Nouveau Testament Imprimée à Mons. Dialogue second sur l'Ordonnance de Monseigneur l'Archevesque d'Ambrun, s.l.n.d. [1667], p. 5-6 (voir encore p. 12). Voir aussi la préface historique et critique à A. Arnauld, Euvres, cit., VII, p. III. Sur A-Diou-sias, voir G. Tallemant des Réaux, Historiettes, éd. L. J. N. Monmerqué et P. Paris, $3^{\mathrm{e}}$ édition, I, Paris, 1862, p. 189-190.

305. Morin à Francesco Barberini, 15 mai 1642, dans Antiquitates Ecclesiae Orientalis, Clarissimorum Virorum Card. Barberini, L. Allatii, Luc. Holstenii, Joh. Morini [...] Dissertationibus Epistolicis enucleatae, Londres, 1682, 2de pagination, p. 309-310: cum enim nunc Episcopi Parisiis non conueniant, et eos conuenire certis de causis sit difficile, illius libri censuram edere non 
possunt nisi singuli, at qui probabile fiet Episcopi unius Censuram libri istius authoritati praeualituram qui a celeberrima Societate testimonium habet publicum et publicam approbationem? Le sommaire de la lettre, p. 308, affirme que Morin parle du livre de Cellot, mais il s'agit sans doute possible de M. Rabardeau, Optatus Gallus de cauendo schismate etc. benigna manu sectus, Paris, 1641, publié en toute régularité, avec privilège particulier du roi, permission du provincial de France, approbations de deux théologiens jésuites et de deux docteurs de Sorbonne.

306. Voir la liste dans la préface historique et critique à A. Arnauld, Euvres, cit., XXX, p. XXV-XXVI. Ces censures furent souvent recueillies à l'époque dans des recueils factices (e.g. BNF, Ms. Franç. 15504, ou Bibliothèque de la Société de Port-Royal, Paris, recueil Le Paige 380).

307. G. Lanson, Après les «Provinciales». Examen de quelques écrits attribués à Pascal, dans Revue d'Histoire littéraire de la France, 8, 1901, p. 13-34; J. Mesnard, La collaboration des écrivains de Port-Royal aux censures des évêques contre l'Apologie pour les casuistes (1658-1659) , dans Chroniques de Port-Royal, 32, 1983, p. 3-20.

308. Censure du 9 mars 1612 dans Concilia nouissima Galliae, cit., p. 623. Voir E. Richer, Histoire du syndicat, cit., p. 100 et 368, d'après le témoignage de Jean de Vieuxpont, évêque de Meaux: "les prélats de la province de Sens s'étant assemblés chez le cardinal du Perron pour élire un syndic du clergé de la province de Sens ", c'est-à-dire un député à l'Assemblée du clergé de 1612 (qui s'ouvrit en mai : Collection des Procès-Verbaux, cit., II, p.29). Dans son relief d'appel, Richer, p.120, parle par confusion, ou peut-être par synecdoque, d'« une prétendue congrégation provinciale des évêques suffragans de l'archevêché de Sens, députés et envoyés en notre ville de Paris par le clergé de leurs diocèses [...] pour entendre les comptes de Castille en l'assemblée générale » (la formule trahit clairement l'influence de Leschassier, infra, n. 326).

309. Censure du 24 mai 1612 dans Concilia nouissima Galliae, cit., p.624. Des cinq suffragants d'Aix, il manquait l'évêque de Gap et celui d'Apt, lequel siégeait alors comme député à l'Assemblée du clergé (Collection des Procès-Verbaux, cit., II, p. 29).

310. Concilia nouissima Galliae, cit., p. 729-730. La procédure avait été envisagée mais n'avait pu aboutir un an plus tôt, très probablement du fait de l'opposition de Richelieu, pour censurer les volumes de Dupuy sur les Libertez de l'Eglise gallicane (J. Bergin, La Rochefoucauld, cit., p. 77-78).

311. In nostra Congregatione prouinciali : Concilia nouissima Galliae, cit., p. 623, 624, 730. Dans les trois cas, le compilateur Odespunc met en titre Concilium (Senonense, Aquense, Prouinciae Parisiensis, respectivement). Dans le cas de Richer, la censure de Du Perron ne fut officiellement publiée en 1612 qu'en traduction française (voir F.-T. Perrens, L'Église et l'État, cit., II, p. 144-145), sous le titre de Censure faicte par les Evesques de la province de Sens d'un Livre intitulé, De ecclesiastica et politica potestate (la souscription porte "en nostre Congregation provinciale »). Voir aussi les plaintes d'E. Richer, Histoire du syndicat, cit., p. 104, contre la « mauvaise foi » de « ceux qui voulant concilier une plus grande envie à Richer, ont écrit et publié que son livre avoit été condamné en un synode » voire en « un Concile provincial».

312. Selon P. Blet, Le Clergé de France, cit., I, p.17, Du Perron «réunit son concile provincial »; S. H. De Franceschi, La crise théologico-politique, cit., p. 412 et 417, appelle «synode provincial» les réunions des évêques des provinces de Sens et d'Aix contre Richer. 
313. Voir le commentaire de L. Thomassin, Ancienne et nouvelle Discipline de l'Eglise touchant les Benefices et les Beneficiers, III, Paris, 1681, Partie IV, 1. II, c. 78, p. 351.

314. Ibid.

315. J. Loth, Un chapitre inédit de la vie de M. de Harlay. Concile provincial de 1651, dans Revue de la Normandie, 5, 1865, p. 268-280, et 351-365 (arrêt du Parlement du 7 janvier 1651, p. 354-356) ; A. Feron, Un concile normand inédit, dans Revue catholique de Normandie, 22, 1912-1913, p. 110-114; id., Contribution à l'histoire du jansénisme en Normandie. L'attitude du clergé dans le diocèse de Rouen sous l'épiscopat des deux archevêques de Harlay (1630-1671), Rouen, 1913, p. 31-32.

316. Gondrin, archevêque de Sens, fit ainsi confirmer par son assemblée provinciale, réunie pour élire ses députés à l'Assemblée du clergé de 1660, la censure qu'il avait prise en 1658, dans son synode diocésain, contre l'Apologie pour les casuistes: Ordonnance de l'Assemblée provinciale de Sens, contenant la condemnation du livre intitulé, Apologie pour les casuistes contre les calomnies des Jansenistes. Et le renouvellement et Approbation des Censures qui ont esté faites de ce Livre, par Monseign. l'Archevesque de Sens, et Monseign. l'Evesque de Nevers, s.l.n.d. (11 mai 1660) : on notera que les députés du second ordre souscrivent avec les évêques. Pour la censure initiale de Gondrin, voir Censure d'un livre intitulé Apologie pour les casuistes, etc. Imprimé à Paris, mil six cens cinquante-sept. Faite par Monseigneur l'Illustrissime et Reverendissime Archevesque de Sens, Primat des Gaules et de Germanie, et publiée en son Synode tenu à Sens le 4 septembre 1658, Sens, 1658. L'ordonnance de l'évêque de Nevers, du 8 novembre 1658, est attribuée à Pascal.

317. Les procès-verbaux de ces assemblées provinciales sont rassemblés dans Recueil des Actes [...].t. I. De la Foi Catholique et de la Doctrine de l'Eglise, cit., col. 419-557. Sur cette procédure et ses enjeux ecclésiologiques, voir A.-G. Martimort, Le Gallicanisme de Bossuet, Paris, 1953, p. 682-685. Bossuet avait proposé pour sa part soit une réunion des évêques présents à Paris, soit une assemblée extraordinaire du Clergé de France.

318. Concilia nouissima Galliae, cit., p. 730 : Nos infrascripti, Archiepiscopi et Episcopi pro rebus Ecclesiae Parisiis agentes superiori censurae ab Illustrissimis et Reuerendissimis Archiepiscopo et Episcopis Parisiensis Prouinciae confectae, uisae et examinatae subscripsimus.

319. L. Serbat, Les Assemblées, cit.; P. Blet, Le Clergé de France, cit., t. I, p.135-264; M. Peronnet, Naissance d'une institution : les assemblées du clergé, dans Pouvoir et institutions en Europe au XVI siècle. Vingt-septième colloque international d'études humanistes, Paris, 1987, pp. 249-261 ; F. Gerbaux et Fr. Hildesheimer, Agence générale du Clergé. Répertoire de la soussérie $G^{8}$, Paris, 2001.

320. L'ensemble des écrits et factums de Leschassier, d'abord publiés à part, sont commodément rassemblés dans Cuvres de Maistre Jacques Leschassier, Parisien, Advocat en Parlement, Paris, 1652, Procedures contre un escrit fait à l'occasion du Livre de l'ancienne et Canonique liberté de l'Eglise Gallicane. Qui servent de Memoires et Instructions pour la liberté de l'Eglise Gallicane, p.317-400. Une bonne vue d'ensemble de l'affaire est donnée par Th. Amalou, Jacques Leschassier, Senlis et les libertés de l'Église gallicane (1607), dans Revue de l'histoire des religions, 226, 2009, p. 445-466.

321. Relief d'appel comme d'abus de Leschassier, 17 octobre 1607, dans Euvres, cit., p. 317-318. Voir aussi Examen dudit Escrit [la censure du Clergé], ibid., p. 369 ; Requeste presentée au Roy, depuis l'Arrest, ibid., p. 380-381. Le Grand Conseil était un tribunal concurrent du Parlement, surtout chargé de "juger les affaires pour lesquelles les parlements auraient manifestement manqué de l'impartialité nécessaire» (M. Marion, 
Dictionnaire des institutions de la France aux XVII ${ }^{\mathrm{e}}$ et $\mathrm{XVIII}{ }^{\mathrm{e}}$ siècles, Paris, 1923, s.v, p. 265-266). Pour plus de précisions, voir C. Trani, Les magistrats du Grand Conseil au XVI siècle (1547-1610), dans Paris et Île-de-France. Mémoires publiés par la Fédération des Sociétés historiques et archéologiques de Paris et de lîle-de-France, 42, 1991, surtout p. 64-68. Le chancelier en était le " premier président né ».

322. Texte dans A. Fontanon, Les Édicts et ordonnances des Rois de France traittans de la police sacrée et discipline ecclesiastique, ensemble de ce qui en depend, éd. G. Michel [= Les Édicts et ordonnances des rois de France, depuis Louys VI, dit le Gros, jusques à présent, IV], Paris, 1611, p. 1287, et dans Leschassier, CEuvres, p. 337-338. La censure ayant été supprimée, elle ne figure pas dans le procès-verbal conservé : voir Collection des Procès-Verbaux, cit., I, p. 763, avec la longue note, p. 763-764.

323. Relief d'appel comme d'abus de Leschassier, dans Euvres, cit., p. 320.

324. Arrest du Grand Conseil pour la suppression dudit écrit, ibid., p. 379. A. Viala, Naissance de l'écrivain, cit., p. 87-89, qui ne semble pas avoir compris la procédure (à l'en croire, c'est Leschassier qui rédigea une Requête contre l'évêque, « qu'il voulait présenter aux docteurs en théologie de la Sorbonne. Mais il la soumit d'abord au Conseil du roi » afin « d'obtenir la double approbation des autorités politiques et de la faculté de théologie »), voit dans cette décision la première reconnaissance judiciaire $\mathrm{du}$ « droit au respect des textes ».

325. Collection des Procès-Verbaux, cit., t. I, p. 804 ; J. Leschassier, Requeste presentée au Roy, depuis l'Arrest, dans Euvres, cit., p. 386.

326. Relief d'appel comme d'abus, ibid., p. 320 ; Examen dudit Escrit, ibid., p. 338-339. Voir encore ibid., p. 354 et 373-374; Discours sur ledit relief d'appel, ibid., p. 331 (« ce fabricateur a abusé du nom des Députez du Clergé lors trop occupez à leurs comptes»). François de Castille était receveur général du Clergé de France.

327. Relief d'appel comme d'abus, ibid., p. 320-321.

328. Requeste presentée au Roy, depuis l'Arrest, ibid., p. 382-383.

329. Textes dans Ch. Du Plessis d'Argentré, Collectio, cit., II/2, p. 190-198. La censure de la Faculté ne porta finalement que sur l'Admonitio, mais, dans son assemblée extraordinaire du 26 novembre, il avait été décidé d'examiner les deux libelles. Leur première mention à l'Assemblée du clergé est du 7 novembre; l'évêque de Chartres y fit un discours sur ce sujet le 29 ; il fut chargé de préparer une censure le 2 décembre (P. Blet, Le Clergé de France , cit., I, p. 337-338, que l'on peut suivre pour l'événementiel). Pour les différents auteurs auxquels les libelles ont été attribués, voir S. H. De Franceschi, La crise théologico-politique, cit., p. 606-607.

330. Selon P. Blet, Le Clergé de France, cit., I, p. 337 (répété dans id., Richelieu et l'Église, cit., p. 38), «la forme de ces pamphlets et les considérations théologiques auxquelles ils faisaient appel rendaient désirable le concours de l'autorité religieuse: "La voix et l'approbation du Clergé, écrira Richelieu, ne servira [sic] pas peu, spécialement en ce temps qu'on a voulu calomnier le Roi et ses ministres d'avoir peu de zèle au bien de la Religion" »). Mais la citation, tirée de l'Advis sur les affaires présentes qu'a le Roy en février 1626 (désormais publié dans Les Papiers de Richelieu. Section politique intérieure. Correspondance et papiers d'État, éd. P. Grillon, I, Paris, 1975, p. 296), porte en réalité, non sur la censure, qui est évoquée ensuite, mais sur la contribution financière de l'Assemblée : «Cela fait qu'il est beaucoup meilleur de tirer quatorze cent mil livres avec la satisfaction du clergé que quinze cent mil livres de leur mescontentement. La voix et l'approbation du clergé ne feroient pas peu, spécialement en ce temps qu'on a voulu 
calomnier le Roy et ses ministres d'avoir peu de zelle au bien de la religion. Quant au point des censures [...]».

331. S. H. De Franceschi, La crise théologico-politique, cit., p. 623 : «Quand la Sorbonne les a priés de se saisir eux aussi de l'Admonitio et des Mysteria politica, les prélats gallicans ont saisi avec empressement l'occasion qui leur était présentée de se venger du désaveu récemment essuyé » [i.e. d'avoir dû suspendre leur déclaration sur les réguliers à cause des pressions du nonce]. Aucune justification de ces affirmations n'est offerte.

332. Collection des Procès-Verbaux, cit., II, p. 516.

333. Arrêt du 21 janvier 1626, dans Ch. Du Plessis d'Argentré, Collectio, cit., II/2, p. 199-200.

334. L'Assemblée de 1641, qui condamna en général les livres de Bauny et Cellot, décida d'envoyer une lettre circulaire à tous les évêques de France, «contenant la présente résolution [...], avec les extraits faits par la Sorbonne des endroits les plus pernicieux desdits livres, et la censure de la Congrégation de l'Indice, laquelle sera réimprimée à cette fin; et le tout étant dressé, sera présenté à Mgr. le Cardinal Duc [Richelieu], à ce qu'il lui plaise lui donner son approbation et protection » (Collection des Procès-Verbaux, cit., III, p. 102).

335. Fr. Ledieu, Les dernières années de Bossuet. Journal, éd. Ch. Urbain et E. Levesque, 2 vol., Bruges-Paris, 1928-1929, I, p. 102 (séance du 26 août 1700).

336. Le canoniste janséniste [Gabriel-Nicolas Maultrot], Mémoire sur la nature et l'autorité des Assemblées du Clergé de France, s.l.n.d. [1777], p. 191-196, s'indigne que J.-G. Le Franc de Pompignan, Défense des Actes du Clergé de France, concernant la religion, publiée [sic] en l'Assemblée de 1765. Par M. l'Evêque du Puy, Louvain, 1769, p. 93, ose comparer l'Assemblée du clergé de 1765 au second concile d'Orange. Mais le rapprochement était déjà fait dans Relation des deliberations du Clergé de France, sur la Constitution, et sur le Bref de N.S.P. le Pape Innocent X. Par laquelle [sic] sont declarées et définies cinq Propositions en matiere de Foy, Paris, 1656 (rédigée par Marca), p. 7.

337. L. Thomassin, Ancienne et nouvelle Discipline de l'Eglise, cit., III, p. 351.

338. On trouvera des remarques intéressantes sur ce point dans N. Schapira, Quand le privilège de librairie publie l'auteur, dans Chr. Jouhaud et A. Viala, De la publication entre Renaissance et Lumières, Paris, 2002, p.121-137 (repris et développé dans id., Un professionnel des lettres au XVII siècle. Valentin Conrart: une histoire sociale, Seyssel, 2003, p. 98-151) et Cl.Lévy-Lelouch, Quand le privilège de librairie publie le roi, ibid., p.139-159. Mais ces études ne s'affranchissent pas du modèle de sociologie littéraire d'A. Viala, qui, en ramenant tout à des logiques de carrière individuelle, néglige le fonctionnement et les enjeux spécifiques du champ religieux (A.Viala, Naissance de l'écrivain, cit., p. 179, présente ainsi la controverse antijanséniste des jésuites comme une forme de clientélisme).

339. Voir P. Bourdieu, Ce que parler veut dire. L'économie des échanges linguistiques, Paris, 1982, en particulier p. 105-119.

340. Fr. Annat, Remarques sur la conduite, cit., p. 16.

341. J. Claude, Réponse au livre du Pere Noüet Jesuite. Sur le sujet du Saint Sacrement de l'Eucharistie, Amsterdam, 1668, fol. a2v : «Je ne say ce qui peut avoir porté ces Messieurs à vouloir poursuivre avec un si grand attachement des permissions autentiques pour l'impression de cet ouvrage, puis qu'ils s'en passent bien pour celle de tant d'autres, qu'ils 
mettent tous les jours en lumiere sans en demander ny d'Approbation, ny de Privilege ». Voir supra, n. 146 ; J.-L. Quantin, De la Contre-Réforme comme monopole, cit.

342. Voir Arrest du Conseil Privé du Roy, contre Aubertin, et les autres Ministres de Charenton (14 juillet 1633), dans Recueil des Edicts [...] à la poursuitte des sieurs Abbés de Paimpont, et Prieur de Moustiers, cit., p. 431-436 (et dans Recueil des Actes [...]. t. I. De la Foi Catholique et de la Doctrine de l'Eglise, cit., col. 1398-1400), avec les explications de Lettre de Monsieur Aubertin a un sien amy, s.l., 1633, p. 21-23; Arrest de la Cour de Parlement. Portant deffences aux Ministres de la Religion pretenduë Reformée de donner des Approbations aux Livres qu'ils auront permission de faire imprimer, mais seulement de simples Attestations; Et de prendre d'autre qualité que celle de Ministre de la Religion pretenduë Reformée, Paris, 1671.

343. P. Bourdieu, La censure, dans Questions de sociologie, Paris, 1984, p. 138-142; id., Ce que parler veut dire, cit., surtout p.76-79, 167-171, 204-205. Cette problématique a été appliquée de manière convaincante au XVIII ${ }^{\mathrm{e}}$ siècle par R. Birn, La Censure royale, cit.

344. Pour citer seulement, entre bien des exemples possibles, Vita Johannis Morini, dans J. Morin, Commentarius historicus, cit., p. 76-77 (Historici tantum partes agere) ; R. Simon, Lettres choisies, cit., II, p. 91; P. de Marca, De Concordia Sacerdotii et Imperii, Paris, 1641, fol. e2r (Relicta discussione Iuris, tutior est plane Facti inquisitio).

345. Voir la discussion de J. K. Farge, Early censorship in Paris, cit., p. 178-179; id., Early censorship of printed books in Paris, cit., p. 89-91.

346. O. Poncet, Pomponne de Bellièvre, cit., p. 244. Voir aussi É. Maugis, Histoire du Parlement, cit., II, p. 348-349 ; A. Labarre, La répression, cit., p. 359 ; S. Soleil, Le Siège royal de la sénéchaussée et du présidial d'Angers (1551-1790), Rennes, 1997, p. 76.

347. H.-J. Martin, Livre, pouvoirs et société, cit., I, p. 451 ; A. Soman, Deux grandes sources, cit., p. 83 n. 6 ; id., Press, pulpit, and censorship, cit., p. 457 ; B. Barbiche, Le régime de l'édition, cit., I, p. 372.

348. Voir J.-D. Mellot, L'Édition rouennaise, cit., p. 301-405.

349. J.-P. Gutton (dir.), L'Intendance de Lyonnais, Beaujolais, Forez en 1698 et en 1762 : édition critique du mémoire rédigé par Lambert d'Herbigny et des observations et compléments de La Michodière, Paris, 1992, p. 192. Le texte est cité par exemple par J. Roubert, La situation de l'imprimerie lyonnaise, cit., p. 98).

350. La découverte que la permission tacite ne date pas de la Régence mais fut introduite par Bignon dès 1709 est un des grands apports de J.-D. Mellot, L'Édition rouennaise, cit., p. 596-599.

351. Édit de Châteaubriant, art. 7, dans Isambert, Recueil, cit., XIII, p. 193-194. Voir J. K. Farge, Introduction historique, dans ILI, I, p. 64-76.

352. Voir Correspondance du nonce en France Innocenzo del Bufalo évêque de Camerino (1601-1604), éd. B. Barbiche, Rome-Paris, 1964, p. 83-87 ; G. Fragnito, Diplomazia pontificia e censura ecclesiastica durante il regno di Enrico IV, dans Rinascimento, $2^{\mathrm{e}}$ série, 42, 2002, p. 151-159.

353. On trouvera d'intéressantes références, surtout aux conciles provinciaux du tournant des XVI ${ }^{e}$ et XVII ${ }^{e}$ siècles (recueillies dans un esprit que l'on comprend assez), dans D. Bouix, Tractatus De curia Romana, Paris, 1880, p. 492-495 ; H. Montrousier, L'Index est-il reçu en France?, dans Revue des Sciences ecclésiastiques, 13, janvier-juin 1866, p. 369-371. 
354. Édit de Nantes, art. 21, dans Isambert, Recueil, cit., XV, p. 177-178: « Ne pourront les livres concernant ladite religion prétendue réformée estre imprimez et vendus publiquement qu'ès villes et lieux où l'exercice public de ladite religion est permis ». Voir [P. Loride Desgallesnières], Sommaire des procés, differens et contestations qui arrivent ordinairement dans l'execution des Edicts de Pacification. Contenant les moyens de ceux de la Religion pret. Reformée, Paris, 1661, p. 57. Dans les faits, l'impression et la vente des livres protestants (sous l'adresse de Charenton et de Quevilly, respectivement) se faisaient librement à Paris et à Rouen : voir les plaintes du Clergé en 1675, dans Collection des ProcèsVerbaux, cit., V, Pièces jointes, p. 138-139.

355. Moyens d'opposition fournis par les soy-disans Syndic et Adjoints des Libraires, opposans à la verification des Lettres patentes obtenuës par l'Université, pour la confirmation de ses Privileges [BNF, R. 8181 (21)] p. 2-3 (signifié le 26 mars 1652).

356. Édit du roi d'août 1685, dans Collection des Procès-Verbaux, cit., V, Pièces jointes, p. 300 ; Arrests du Parlement et Ordonnances de Monseigneur l'Archevesque de Paris, portant la deffense et suppression des Livres Hérétiques. Avec l'Edit du Roy portant deffenses de faire aucun Exercice public de la R.P.R. dans son Royaume. Registré en Parlement en la Chambre des Vacations le 22. Octobre 1685, Paris, 1685 : le catalogue est p. 9-81. Sur sa préparation, voir [R. Simon], Bibliotheque critique, ou recüeil de diverses pieces critiques, dont la plûpart ne sont point imprimées, ou ne se trouvent que très-difficilement, publiées par Mr. de Sainjore, t. IV, Amsterdam, 1710, p. 174-183.

357. L'édit de révocation ne mentionne pas les livres. Les mesures adoptées semblent avoir varié localement. Voir O. Douen, La Révocation de l'édit de Nantes à Paris, d'après des documents inédits, 3 vol., Paris, 1894, II, p. 132-139; A. Th. van Deursen, Professions et métiers interdits. Un aspect de l'histoire de la révocation de l'Édit de Nantes, Groningue, 1960, p. 92 ; D. Julia, Postface. Entre sacré et savoir : l'Oratoire au XVIII siècle, dans J. Ehrard (éd.), Le Collège de Riom et l'enseignement oratorien en France au XVIII' siècle, Paris-Oxford, 1993, p. 288-289.

358. Les spécialistes ont bien relevé ce caractère, mais en l'attribuant avant tout au manque de personnel: A. Soman, Deux grandes sources, cit., p. 89 ; id., Press, pulpit, and censorship, cit., p. 457 ; H. Carrier, La Presse de la Fronde, cit., II, p. 312.

359. S. H. De Franceschi, La crise théologico-politique, cit., p. 641. Voir encore p. 139 (« des esprits que démangeait le désir d'en découdre définitivement avec la papauté »); p. 279 ( « censurer systématiquement l'ecclésiologie posttridentine promue par les théologiens romains »); p. 290 (" éradiquer l'influence du zélantisme catholique »).

360. Lettre de Bellarmin à Marie de Médicis, 20 déc. 1610, publiée par S. Mastellone, $L a$ reggenza di Maria de' Medici, Messine-Florence, 1962, p. 227.

361. Voir les correspondances diplomatiques citées par S. H. De Franceschi, La crise théologico-politique, cit., p. 331 et 666-667.

362. Bossuet à Noailles, 15 août 1697, Correspondance, VIII, p. 326-327.

363. Les pernicieuses Consequences de la nouvelle Heresie des Jesuites contre le Roy et contre l'Estat. Par un Advocat en Parlement, $2^{e}$ édition, s.l., 1664, p. 33.

364. Ibid., p. 27. Sur ce texte, dont le fond, mais sans doute pas la rédaction, est d'Arnauld, voir les préfaces historiques et critiques à A. Arnauld, Euvres, cit., X, p. XL-XLI, et XXI, p. LXI- LXIII.

365. A. Tallon, La France et le concile, cit., p. 423. 
366. S. H. De Franceschi, La crise théologico-politique, cit., p. 858. L'auteur parle, dans le même registre, des "épidermiques réactions des catholiques antiromains", des «morbides tentations du Parlement», de "la dénonciation haineuse d'un absolutisme ecclésial», des "coupables pulsions du Tiers», de «calomnieuse tendance», de « redoutable perfidie» (ibid., p. 350, 431, 445, 512, 737, 859). Cette réduction systématique à l'émotionnel (voir encore p. 541 et supra, n. 331), articulée avec une définition exclusivement négative du gallicanisme comme "antitridentin et antiromain » (p. 23), permet de l'interpréter tout entier en termes d'«outrances" (p. 370) et d'«excès " (p. 558). Son échec aurait dès lors été fatal, à la fois du fait de son abandon par un pouvoir royal «lassé par les excès du gallicanisme» (p.638), et, intrinsèquement, parce que "l'antiromanisme catholique est une sensibilité confessionnelle singulièrement poreuse et vulnérable qui essaie de tenir l'impossible milieu entre hérésie et orthodoxie, soit une pensée ecclésiologique de la limite et qui se méfie de ses propres excès» (p.557; voir encore p. 695 : «impraticable ecclésiologie de la limite »). On retrouve là très exactement la thèse de l'apologétique catholique et de l'historiographie confessionnelle du premier XX siècle: comparer par ex. M. Dubruel, Gallicanisme, dans A. d'Alès (dir.), Dictionnaire apologétique de la Foi catholique, $4^{\mathrm{e}}$ édition, Paris, 1911, II, col. 201; Fr. Gaquère, Pierre de Marca (1594-1662). Sa vie, ses cuvres, son gallicanisme, Paris, 1932, p. 102. Une étude qui reste à mener, en particulier sur la généalogie du concept d' " antiromanisme ", trouverait sans doute les racines d'une telle représentation autour de 1820 : voir F. de La Mennais, Sur un ouvrage intitulé Du Pape, par M. le comte de Maistre, dans Euvres complètes, 10 vol., Paris, 1836-1837, VIII, p. 133 : « en ce qui concerne le pouvoir du souverain pontife le système gallican se réduit à croire le moins possible sans être hérétique, afin d'obéir le moins possible sans être rebelle» (c'est l'auteur qui souligne).

\section{AUTEUR}

\section{JEAN-LOUIS QUANTIN}

École pratique des Hautes Études - jean-louis.quantin@ephe.sorbonne.fr 
Controverses 


\title{
La loi du magistère. Pouvoir ministériel et formes ecclésiales dans la controverse entre Cajétan et Almain (1511-1512)
}

\author{
Frédéric Gabriel
}

1 Assurément, la controverse entre Cajétan et Almain est exemplaire. Très peu d'années avant la rupture luthérienne, et avec l'un de ses acteurs essentiels ${ }^{1}$, elle rappelle si bien la force de deux positions antagonistes qu'elle en devient un point de référence pour les autres controverses ${ }^{2}$ et pour les collections partisanes récoltant les textes qui ont fait date : en 1606, Edmond Richer intègre par exemple le De auctoritate Ecclesiae seu sacrorum Conciliorum d'Almain dans son édition des Opera de Gerson ${ }^{3}$, agencement repris par Louis Ellies du Pin au tout début du XviII ${ }^{\mathrm{e}}$ siècle quand il édite à son tour les œuvres du chancelier.

2 Même si elle ne représente peut-être pas un écart extrême au sein de la doctrine chrétienne, puisque les deux auteurs prétendent défendre chacun une via media, cette controverse est un bon exemple d'accusations croisées, dans un climat général tendu ${ }^{4}$. Elle s'inscrit dans le cadre diplomatique des guerres d'Italie, après le retournement de l'alliance de Cambrai par Jules II, qui s'allie avec Venise contre la France. Louis XII invoque alors le serment fait par le pape, lors de son élection, d'assembler régulièrement un concile. Giovanni Francesco Poggio, un partisan du pouvoir pontifical, avait déjà imploré Jules II en ce sens. Après le refus romain, et alors que parmi les douze nouveaux cardinaux récemment nommés, aucun n'est français ${ }^{5}$, l'assemblée de Tours envisage en 1510 la soustraction d'obédience, et en avril 1511, l'assemblée de Lyon réaffirme les décrets conciliaristes de Bâle ${ }^{6}$. Tous les prétextes sont réunis par Louis XII, et en mai 1511, la convocation du concile de Pise met directement en cause l'autorité de Jules II, lequel riposte en juillet avec la bulle Sacrosanctae Romanae Ecclesiae, qui convoque le concile de Latran pour le mois d'avril 1512. C'est alors qu'entre en scène Cajétan, procureur de son ordre auprès de la Cour romaine depuis 1501 et maître général des Frères prêcheurs depuis $1508^{7}$. Il rédige son Auctoritas Pape et Concilii sive Ecclesia comparata; achevé en octobre, le texte est publié à Rome au mois de novembre $1511^{8}$, au moment même de 
l'ouverture du concile de Pise, dont il ne manque pas de saper la légitimité ${ }^{9}$ À côté de ses fonctions officielles, Cajétan enseigne depuis longtemps la théologie, et outre ses consultations romaines, il a déjà achevé le premier volume de son commentaire à la Somme de Thomas d'Aquin, paru à Rome en 1507, le second volume paraissant en décembre 1511.

En janvier 1512, les membres du concile de Pise, transféré à Milan, soumettent l'écrit du dominicain à la faculté de théologie de l'université de Paris. Après une certaine hésitation, le 24 avril 1512, il est décidé d'examiner l'ouvrage ${ }^{10}$, et la réfutation en est confiée à un membre du collège de Navarre qui vient tout juste d'obtenir, en mars, le grade de docteur en théologie ${ }^{11}$. En mai, Jacques Almain termine sa réponse qui paraît à Paris en novembre ${ }^{12}$. Les attendus de la controverse réservent bien sûr peu de surprise : Cajétan écrit pour Jules II et défend une monarchie pontificale pétrinienne quand Almain, par ordre de la faculté de théologie - qui répond elle-même à la demande pressante du concile de Pise appuyée par une lettre de Louis XII en février 1512 - rappelle la structure conciliariste de l'Église. Pourtant, le fait même que Jules II et Louis XII engagent une controverse doctrinale prouve bien le poids de cet exercice dans les forces mises en présence, même si les positions sont connues avant le début des hostilités. C'est un premier indice de la nature de ces controverses qui défendent des traditions. Les noms d'auteurs sont avant tout des porte-parole, ils s'inscrivent dans des familles de pensée et de pouvoir. Cette modalité des controverses pèse lourd sur leurs règles et leur déroulement. C'est pourquoi, après m'être penché sur le sujet affiché de la controverse, les modalités d'attribution et d'exercice de la potestas et leur système de référence, j'en viendrai à l'inscription proprement scolastique du débat, pour préciser le contexte de cet échange.

\section{Les modalités d'attribution et d'exercice de la potestas}

4 Comparatio : le titre de Cajétan entre en résonance avec la notion d'hétérodoxie croisée. Il témoigne de l'objectif et de la méthode utilisée, qui renvoient l'un et l'autre à une question de fondation. D'emblée, en choisissant son sujet, Cajétan pose aussi les termes d'un axiome que rien ne peut ébranler, le pape dispose d'un pouvoir suprême : certa est ista propositio, Papa habet supremam potestatem in ecclesia Dei : fundaturque super institutione Iesu Christi. Matth. 16 [18-19] \& Ioan. ult. ${ }^{13}$. Comment détailler les implications de cette institution qui décide du lieu du pouvoir? Cette fondation dépend de l'immédiateté de la donation de la potestas dont témoigne Pierre, que le Christ, rex regum et dominus dominantium a établi, seul, sur son seul siège. Pour Cajétan, le simple fait de citer Tibi dabo claves devrait suffire à clore toute discussion. Cette hiérarchie implique nécessairement une primauté, d'institution évangélique ${ }^{14}$, et un regimen, (in unitate consistit), regimen qui est qualifié d'optimal dans le Contra Gentes (Iv, c. 76) de Thomas d'Aquin ${ }^{15}$. La primauté et son regimen découlent, pour Cajétan, de la mission pastorale confiée à Pierre par le Christ: factus est Petrus pastor universalis ${ }^{16}$. Trois mots sont élevés à la hauteur d'un principe martelé tout au long de son livre : Pasce oves meas (Jean 21.17) ${ }^{17}$. Un seul troupeau pour un seul pasteur, la communauté et son gouvernement sont confiés à Pierre, et un terme exprime en même temps cette relation de supériorité et le dépôt du Christ : Petrus non ecclesia, sed Iesu Christi vicarius esset ${ }^{18}$. Michele Maccarrone a montré combien cette expression correspondait à une version «forte »du vicariat ${ }^{19}$. L'expression du regimen, par cette relation du Christ à Pierre et de Pierre à la communauté, impose d'elle-même la 
comparaison du pouvoir entre les apôtres. Deux autorités abondent dans le sens de la hiérarchie constatée par Cajétan. La première, citée d'après le Décret (d. 19, c. 7), est la lettre 78 du pape Léon: Ita Dominus huius muneris sacramentum ad omnium Apostolorum officium pertinere voluit, ut in beatissimo Petro Apostolorum omnium summo principaliter collocaret, ut ab ipso quasi à quodam capite dona sua, velut in corpus omne diffunderet ${ }^{20}$. Corrélat de cette fonction diffusive, la place capitale et unifiante de Pierre est développée par la seconde autorité, que Cajétan emprunte au parti d'Eugène IV, auquel il crédite la réunion des Grecs et des Arméniens à l'Église latine :

Diffinimus sanctam apostolicam sedem et Romanum pontificem in universum orbem tenere primatum, et ipsum Romanum pontificem successorem esse beati Petri principis Apostolorum, et verum Christi vicarium, totiusque ecclesiae caput, et omnium Christianorum patrem ac doctorem existere, et ipsi in beato Petro pascendi, regendi et gubernandi universalem ecclesiam, à Domino nostro Iesu Christo plenam potestatem traditem esse. ${ }^{21}$

5 Pour Cajétan, les titres accumulés ne laissent subsister aucun doute sur l'évidence du rôle de Pierre - et de ses successeurs - par rapport et au sein de l'Église. À l'autorité du diffinimus du concile œcuménique de Florence ${ }^{22}$, répond la distinction radicale de Cajétan : Ex quibus patet propositionem dictam non solum esse veram, sed contrariam esse erroneam ${ }^{23}$. En même temps qu'il précise sa position (pour Eugène IV et contre le concile de Bâle ${ }^{24}$ ), il puise dans cette définition conciliaire l'outil de discernement de l'hétérodoxie. En une phrase, tout est dit de l'ampleur du pouvoir institué dans la personne de Pierre. Sa supériorité sur les apôtres - des $\operatorname{socios}^{25}$ - n'est que l'expression initiale d'une supériorité sur l'ensemble de l'Église et surtout, d'un modèle juridique qui détermine la propriété de la potestas et sa transmission. Si les apôtres sont égaux quant au pouvoir d'ordre et de juridiction, le principe unum ovile et unus pastor implique une supériorité pétrinienne qui ne se cantonne pas à l'autorité pastorale ${ }^{26}$. La nature même du regimen institué par le Christ donne à Pierre un pouvoir ordinaire dont dérivent les autres ${ }^{27}$. Pierre reçoit per viam ordinariam ce que les autres reçoivent ex gratia ${ }^{28}$. Alors que les apôtres possèdent une potentia executive [...] Autoritas vero data soli Petrum quum factus est Papa, dicent Christo, Pasce oves meas, est potentia praeceptiva. Cette différence de nature s'accompagne d'une différence de temporalité, car si le pouvoir de Pierre est donné usque ad consummationem seculi $^{29}$, les titulaires des évêchés institués par les autres apôtres ne peuvent se réclamer du même type de succession: Paul, Jean ou Jacques n'ont pas institué une généalogie comme celle de Pierre. De la différence hiérarchique nécessaire et de la propriété pétrinienne de la potestas découle une distinction essentielle: Petrus enim ex propria sui pontificatus officii autoritate gubernabat, alii vero Apostoli ex privilegio domini delegantis eis gubernationis officium..$^{30}$ Vicaire général ${ }^{31}$, Pierre tient lieu de Christ (Loco mei praepositus est, et caput fratrum tuorum), et sa potestas iurisdictionis s'applique aux apôtres. Malgré les termes de la préface de la messe romaine, les apôtres ne sont pas appelés vicaires absolutè, sed vicarij operis. Ce sont bien des pasteurs délégués, dont l'exécution ne remet jamais en cause le principe ${ }^{32}$ : Petrus solus caput et pastor est Apostolorum, et quod ei subditi fuerunt Apostoli ${ }^{33}$.

6 Dès lors, la comparaison de Pierre aux apôtres débouche sur un modèle de transmission du pouvoir dont le vicaire du dominus iuris est l'unique vecteur : In Petro enim, et à Petro inchoat omnis ecclesiae potestas, et derivatur in totam ecclesiam via ordinaria ${ }^{34}$. Plus loin, Cajétan ajoute : Et quia officium Petri est officium capitis, quod habet influere in corpus reliquum, avant d'utiliser le même extrait du pape Léon chez Gratien, qui affirme : à Petro in corpus omnes potestas derivaretur ${ }^{35}$. La primauté du pape s'impose aux Églises particulières ${ }^{36}$; et de 
même pour les conciles, l'autorité vient de la tête : un concile acéphale n'aurait aucun poids, il remettrait en cause l'intégrité du corps ${ }^{37}$ et serait en proie à l'errance ${ }^{38}$. D'autant que placer le concile au-dessus du pape pervertirait le regimen ecclesiae. Derrière la construction théorique se profile la question pratique de la tenue du concile de Pise. Cajétan le rappelle inlassablement: le Christ n'a pas donné la plenitudo potestatis à la communauté ecclésiale, mais à un seul ${ }^{39}$. Ce n'est qu'au dixième chapitre qu'apparaît le véritable adversaire théorique: Gerson, dont Cajétan fustige la nova imaginatio ${ }^{40}$. Le chancelier de l'université de Paris situe le pouvoir dans l'Église universelle. La papauté est dans l'Église qui modère et régule son pouvoir, notamment par le biais de sa représentation conciliaire, supérieure au pape par son extension, sa direction infaillible et sa puissance coactive, la tête de l'Église restant le Christ.

7 C'est exactement dans cette ligne que se situe la réponse de Jacques Almain. Elle se fonde sur le tout contre la partie, sur la communauté parfaite qui œuvre pour sa conservation et en laquelle réside la Potestas coërcitiva immediatè à Christo instituta ${ }^{41}$. Avant de conclure in Ecclesia est Potestas legislativa ${ }^{42}$, Almain détaille justement les attributions de la communauté et de l'instance qui la représente, le concile général ${ }^{43}$ : par exemple le pouvoir de lier et délier, d'excommunier, de déposer ${ }^{44}$. Pour confirmer la nature de ce ius divinum, avant de citer le fameux canon Sicut Sancti Evangelii de Grégoire compilé dans la quinzième distinction de Gratien, canon qui compare les quatre premiers conciles aux quatre évangiles ${ }^{45}$, Almain se réfère au concile des apôtres à Jérusalem (Actes 15, 22-28), au sein duquel Pierre n'impose rien ${ }^{46}$. De même, glosant le canon Decrevit de la quatrevingt-huitième distinction, il constate : ubi dicitur Decrevit sancta Synodus, et non dicitur: decrevit Summus Pontifex; ad denotandum quod authoritas definitiva apud Synodum residet ${ }^{47}$. Se référant à l'histoire des premiers conciles, Almain rétorque à Cajétan que Gerson ne développe pas une nouvelle fiction mais témoigne d'une antique véritét ${ }^{48}$.

Il ne s'agit bien sûr pas de dénier au pape tout pouvoir, mais de mettre en évidence, à partir de l'Église primitive ${ }^{49}$, un rapport de proportion et de supériorité qui aboutit à cette thèse : Ecclesia, sive Concilium Generale est in hac Potestate Summo Pontifice superior ${ }^{50}$, ou plus loin : Concilium Generale, in singulis et omnibus est supra Summum Pontificem ${ }^{51}$. Quel rôle pour ce dernier? Le pouvoir des clefs est donné à l'Église, et dans cette scène, Pierre n'est que la figurae Ecclesiae ${ }^{52}$. Almain en prend pour preuve le canon Quodcumque de la cause 24 du Décret qui reprend un extrait du commentaire d'Augustin sur Jean, où l'on peut lire : Petrus quando claves accepti Ecclesiam sanctam significavit (D. c. 24, q. 1, c. 6). Dans le nom même de Pierre est signifiée l'Église, et le pape exerce le pouvoir et la juridiction que détient la communauté ${ }^{53}$. Parce que son office est celui de la tête, les clefs ont été données à tout le corps; et c'est à l'Église qu'est conféré en premier un pouvoir plénier ${ }^{54}$ qu'elle communique par la suite à Pierre, ut vice Ecclesiae eam exercet ${ }^{55}$. S'il y a bien une tête, elle est ministérielle, le pape n'est pas Dominus Ecclesiae, sed minister, dictum est enim Petro à Christo: Tu es Petrus, et super hanc Petram aedificabo Ecclesiam meam ${ }^{56}$. C'est une version toute différente du vicariat que celle défendue par Cajétan, Almain insistant - à la suite de Jean de Paris - sur la simple fonction d'administration de la charge pastorale visà-vis du Corps du Christ (et de non de Pierre) qu'est l'Église ${ }^{57}$, le Christ n'ayant pas donné à son vicaire tous les pouvoirs qu'il possédait ${ }^{58}$ : Summum Pontificem esse Vicarium Ecclesiae Universalis et ministrum, quamvis dicatur etiam Vicarius et minister Dei ${ }^{59}$. Quand on parle de sa supériorité, c'est en le comparant non pas à l'Église universelle, mais à un patriarche, à un primat, à un archevêque ou à un évêque. Le docteur parisien insiste aussi sur une distinction qui peut se retrouver dans le Tu es Petrus, le Christ prononçant Pasce oves 
meas, non tuas ${ }^{60}$. Mais que l'on parle de l'Église ou du pape, il s'agit bien de la même plenitudo potestatis, à ceci près que dans le cas du pape, elle est conférée ou retirée par l'Église, et in ordine ad singula, non consequenter ad omnia ${ }^{61}$.

Plus encore que sur le moment fondateur de l'instauration du pouvoir ecclésial plénier et de ses modalités, la controverse ne porterait-elle pas surtout sur le critère de l'ultime recours? Que se passe-t-il face à une éventuelle défaillance de l'instance pontificale ? Comment penser la déliaison du vicariat ? Comment, en regard, sauvegarder la décision finale en matière de foi?

\section{Orthodoxie, source législative et déliaison du vicariat}

10 À côté de la conservation et du bien de la communauté, chez Almain, la compréhension conciliariste de l'Église est en partie motivée par un impératif dogmatique : Non habebit ibi Deum Patrem, qui noluit hîc habere Ecclesiam matrem ${ }^{62}$. Cette phrase, tirée du De symbolo d'Ambroise indique la sujétion du pontife, mais elle renvoie aussi au rôle supérieur de l'Église pour établir des lois, contrôler et limiter la délégation de pouvoir, et donc servir de recours en cas de litige lorsqu'un pape est contesté ${ }^{63}$. Par défaut, c'est toujours vers le supérieur que le pouvoir reflue, autrement dit vers l'Église qui, regulariter, le tient immédiatement du Christ ${ }^{64}$. Par cette proximité, l'Église partage une qualité qui lui est attachée: indeviabilis. Avec ce vocabulaire se fait plus sensible encore une autorité qui apparaît à des moments clefs du texte et qui renforce, si besoin était, l'incompatibilité théorique avec l'adversaire romain: Guillaume d'Occam (1285 ?-1347) et ses Octo quaestiones de potestate papae sur lequelles Almain a rédigé une Expositio ${ }^{65}$. Au moment où Almain étudie et écrit, les œuvres d'Occam sont très diffusées et ses Octo quaestiones ont notamment fait l'objet d'une édition lyonnaise en $1495^{66}$. Si le franciscain anglais opte pour la succession a priori neutre du pro et du contra sans avouer sa position, le docteur parisien, dans son Expositio, prend clairement parti. Toutes les grandes thèses de son écrit contre Cajétan s'y trouvent, et l'on peut lire : Papa est deviabilis, et Concilium Generale ritè congregatum est indeviabile $e^{67}$. Au Nam Papa potest diviare, imo potest haereticari, Almain oppose le concile dirigé par le Saint-Esprit ${ }^{68}$. De cette différence radicale découle notamment la légitimité législatrice de l'Église universelle et de ses conciles ${ }^{69}$.

11 Plus significatif encore, déjà présent chez Gerson, ce couple deviabilis-indeviabilis figure dans un texte d'Almain qui précède de quelques mois son De auctoritate Ecclesiae. Dans cette Quaestio resumptiva, soutenue dans le cadre de son doctorat, il affirme, avant de citer les Actes (15.28) sur l'aide du Saint-Esprit :

Potestas est major perfectione et extensione in Ecclesia, quàm in Summo Pontifice : quod sit major perfectione, probatur sic: Est in Ecclesia indeviabiliter, ita quod errare non potest in his quae sunt Fidei et bonorum morum, nec errare potest in sententiando [...] sed in Summo Pontifice est deviabiliter ${ }^{70}$.

Il s'ensuit qu'il n'est pas nécessaire de croire ce que dit et détermine le pape en matière de foi, et Almain de citer les Octo quaestiones d'Occam qui font la liste de propos pontificaux entachés d'hérésies, avant d'ajouter: multa in Decretalibus contineri quae haeresim sapiunt. C'est dans les mêmes termes et avec les mêmes références - comme celle d'Innocent III donnant les lois deutéronomiques comme étant applicables à la lettre - que le traité contre Cajétan affirme que la décision finale en matière de foi n'appartient pas au pape $^{71}$ - un pape qui doit croire en l'Église et non en lui-même, le Rogavi pro te ne s'adressant pas à l'individu mais à l'institution qu'il représente ${ }^{72}$. Si d'ailleurs le pape était 
le point de référence en matière de foi, comment alors juger un pape hérétique ? ${ }^{73}$ Contrairement à ce que suppose Cajétan, ce dernier n'accepterait pas de se soumettre au simple pouvoir ministériel de l'Église, surtout si ce pouvoir découle de lui ${ }^{74}$. En conséquence, même une Église locale peut faire part de la nécessité d'assembler un concile pour sauvegarder l'Église contre le pape, et si la cause est légitime, les légats ainsi réunis possèderont l'autorité de toute l'Église ${ }^{75}$.

Avant d'insister à nouveau sur la formulation de l'assistance du Saint-Esprit au concile des apôtres dans les Actes (15.28), où Almain lit Visum est Spiritui sancto et nobis, et non pas Visum est Petro et nobis, la conclusion s'impose d'elle-même : Concilium Universale in his quae Fide sunt errare non potest, et sic ad ipsum ultima Fidei decisio spectat ${ }^{76}$. De même que la recherche de la légitimité veut déterminer le critère de la décision souveraine en matière de foi, la capacité normative est fondée sur cette inerrance doctrinale. Almain évoque à nouveau le socle de la formule de foi, en ajoutant les quatre notes de l'Église, pour témoigner de l'aspect élémentaire et essentiel de ce dispositif institutionnel qui concerne la foi de chacun ${ }^{77}$. Il s'agit ni plus ni moins de la nature de l'Église, à laquelle le Christ a confié son héritage ${ }^{78}$, une nature qu'Almain, citant le Dialogus d'Occam et la position identique de Gerson, qualifie de spécifiquement spirituelle ${ }^{79}$. Son Expositio sur Occam s'ouvrait sur la distinction des deux pouvoirs, l'ecclésiastique étant qualifié avec le même terme, qui, bien plus qu'une simple nécessité dialectique, touche au cœur de la foi chrétienne ${ }^{80}$. Dès le deuxième chapitre contre Cajétan, une place de choix est réservée au Christ Legislator qui a incarné une Loi de grâce et de liberté, et instauré une potestas qui conserve la Loi évangélique ${ }^{81}$. C'est une conception radicalement différente de l'imperium dominateur défendu par Cajétan qu'Almain perçoit dans la doctrine chrétienne, utilisant encore les mots du Dialogus d'Occam (III, 1, 1, cap. 5) : Lex Christiana, ex institutione divine, est Lex maximae libertatis ${ }^{82}$. L'épître de Jacques l'avait assuré : Lex Evangelicae dicitur: Lex perfectae libertatis, Jacob 1.25 $5^{83}$. Mais si le pape a un pouvoir suprême, alors la liberté ne peut être présente nullo modo ${ }^{84}$.

14 Dès lors, quelle est la nature de la contrainte? Un leitmotiv traverse le traité contre Cajétan : la correction fraternelle, qui apparaît dès la mise en scène du duo Occam-Gerson au sujet de la nature du pouvoir ecclésiastique ${ }^{85}$. Elle est alors conçue comme une preuve apportée par l'autorité du Christ à la thèse exposée. La référence à Matthieu 18.17 permet surtout de souligner l'institution divine du recours à l'Église (et au concile) et de leur potestas cognoscendi et ligandi avec le syntagme Dic Ecclesiae, sur lequel Almain reprend le commentaire de Gerson ${ }^{86}$. De même, dans l'Expositio, Almain en conclut: Ex prima institutione Christi, authoritas Jurisdictionis est Ecclesiae communicata, et per consequens Concilio Generali Ecclesiam Universalem repraesentati ${ }^{87}$.

On imagine fort bien, dans le cas du pape hérétique, les avantages de cette forme dialogique et souple d'exercice du pouvoir ecclésiastique qui permet, avant l'exclusion, d'élargir la sphère de consultation et d'expertise. Par cet exemple, Almain rapporte cette pratique à l'essence même de la signification dogmatique du pouvoir chrétien, et de délier ainsi le vicariat. En a-t-on pour autant fini avec le sujet traité ? Comment situer le porteparole et l'autorité dont il peut se prévaloir vis-à-vis de la matière concernée ? Autrement dit, malgré le poids des déterminations en présence, diplomatiques par exemple, quelle est la part du scripteur dans la revendication présentée ? Outre les deux premiers plans abordés, sur l'institution et la distribution de la potestas, puis sur son rapport à l'orthodoxie comme socle législatif, je fais l'hypothèse d'un troisième plan qui sous-tend l'ensemble de la controverse et qui découle de son cadre scolastique. 


\section{L'autorité des docteurs et la doctrine de l'Église} qui concerne le cadre dans lequel est discuté le problème posé à la papauté par la convocation du concile de Pise : il s'agit de théologie et non de droit canon. D'ailleurs, l'autorité du pape immediatè est à Deo, et revelata in Sacra Scriptura: il est question de l'Écriture quae vera theologia est, et le problème doit donc être posé sur le terrain de la théologie. Pour un thomiste, cette précision fait immanquablement penser à la synonymie entre sacra Scriptura et sacra doctrina, et aux deux manières d'enseigner l'Écriture, que Thomas distingue en commentant les Sentences: «l'une est celle qui revient aux prélats dans la prédication, en raison de leur office de prélat: ex officio praelationis, qui praedicat docet; l'autre revient aux professeurs de théologie, en raison de leur office d'enseignement : ex officio magisterii, magistri theologiae docent. ${ }^{88}$ confrontation de doctrines, ce qui est appuyé par un deuxième indice. Cajétan s'en prend nommément à cet emblème de l'université de Paris, Gerson, et à sa pestiferam perniciosissimamque doctrinam ${ }^{89}$. En regard, quand le concile de Pise transféré à Milan, écrit à l'université de Paris, le 10 janvier 1512, il lui demande d'examiner rapidement et de discuter le livre de Cajétan ad nos celeriter determinationem vestram doctrinam. Ce document, publié dans l'Ecclesiae Gallicanae in schismate status de Pithou et repris dans les Preuves des libertez de l'Église gallicane de Pierre Dupuy, identifie précisément les cibles du dominicain, qui a écrit contra Concilium Constantiense, et Basileense, ac nostrum, et contra Ioannem Gersonem optimum Ecclesiae defensorem ${ }^{90}$. Il prouve aussi la compétence attribuée aux docteurs auxquels on s'adresse pour se munir d'une caution doctrinale.

Une accusation d'hétérodoxie est par définition l'expression d'un pouvoir, la controverse qui en découle prenant pour objet celui-ci, comme bien souvent. Elle s'empare d'un objet sur lequel elle n'a pas de pouvoir matériel direct, mais sur lequel les porte-parole comptent bien faire valoir leur propre forme de pouvoir. Déclarer que le sujet en question est avant tout théologique est déjà une manière de le rapporter à une discipline instituée, et à son institution compétente. Si le théologien ne peut juger le pape, il est toutefois en son pouvoir de discuter de la forme générale de l'autorité, et de proposer, avec la force que lui donnent les mots mêmes de l'Écriture, sa vision du ius divinum. Avec Augustin, le Décret de Gratien rappelait : Divinum ius in Scripturis habemus (D. 8, c. 1) ${ }^{91}$. Quel droit, et de quel magistère? Qui décide de telle ou telle doctrine? Ce sujet touche aussi bien la nature de l'Église que la fonction de l'homme qui en fait la théorie, le docteur en théologie.

Parmi d'autres, Elsa Marmursztejn a fait l'histoire de l'élaboration de l'autorité propre des maîtres en théologie au XIII ${ }^{e}$ siècle, et l'université apparait comme le lieu d'une légitimité normative portant notamment sur les «fondements supra-juridiques du droit divin ou naturel $»^{92}$. C'est dans cette tradition que se situe Almain, tradition qu'il défend avec le nom de Gerson et l'autorité d'Occam, dont il rappelle fréquemment la qualité de Doctor. Dans l'épître dédicatoire de son De auctoritate Ecclesiae, adressée à Tristan de Salazar, archevêque de Sens et membre du concile de Pise, il évoque les demerentes doctrinas de Cajétan, et remarque plus loin l'ancrage particulier du sujet en question: Tanta est inter Doctores controversia de plenitude hujus Potestatis, juste avant de faire référence au Dialogus d'Occam ${ }^{93}$. Mais c'est bien le consensus d'une École (omnibus [...] doctoribus), qu'il oppose à Cajétan, soulignant la force de leurs autorités additionnées et 
appuyées sur une longue tradition ${ }^{94}$. S'opposant au Magistrum Thomam [de Vio], il ne voit pas dans les décrets de Constance et de Bâle une fiction novatrice, sed antiquam Doctorum sententiam ${ }^{95}$. Cette autorité doctrinale du docteur est revendiquée par Almain au sujet des questions de Fide. Si la décision authoritative et judiciali appartient au concile, la détermination de la doctrine est d'abord le fait des hommes compétents, autrement dit des docteurs ${ }^{96}$. Prenant la parole, Almain affirme: Dico quod docti viri judicabunt doctrinaliter ${ }^{97}$.

Cet ancrage doctrinal et scolastique est d'autant plus prégnant et significatif que le jeune docteur puise à pleines mains dans sa Quaestio resumptiva pour écrire son De auctoritate Ecclesiae. Après la licentia docendi, la resumpta participe autant de la validation du doctorat que de la reconnaissance de l'enseignement du nouveau maître ${ }^{98}$. Les arguments d'Almain sont donc issus d'un travail universitaire validé publiquement et solennellement par la faculté de théologie, et intégré à sa tradition ${ }^{99}$. Mais cette correspondance entre les deux textes n'est pas anodine puisqu'il cite déjà, dans sa Quaestio, l'opuscule de Cajétan identifié comme adversaire du courant dont il se prévaut (Occam, Jean de Paris, Gerson ${ }^{100}$ ); et de même, il fait référence positivement, dans le cadre de la correction fraternelle, au concile de Pise ${ }^{101}$. À Paris, "capitale du Studium »"102, Almain s'inscrit dans les pas d'un magistère doctrinal déjà clairement reconnu. Dans l'Expositio, sous le titre Resolutio Scholae Parisiensis et Ecclesiae Gallicanae est, in omnibus Actibus Jurisdictionis, Papam subesse Concilio, il constate : dicunt communiter omnes Doctores Parisienses, quod Potestas Papae, est sub Potestate Conciliii ${ }^{103}$.

21 Avant Gerson, Pierre d'Ailly fait partie des grands bustes fondateurs de l'autorité des docteurs gallicans, et il est connu pour avoir considérablement renforcé le statut du théologien ${ }^{104}$. Même si le docteur n'occupe pas un statut évangélique reconnu comme celui de l'épiscopat, la licentia docendi fait entrer son titulaire dans la fonction plus générale de diffusion du message confié aux apôtres et aux disciples. Participant ainsi du pastorat, la parole du docteur a une portée ecclésiologique. Son autorité doctrinale devient un socle indispensable à l'autorité judiciaire du prélat. Dans un Tractatus rédigé contre le dominicain Jean de Monzon en 1388, et intégré par Duplessis d'Argentré à sa Collectio judiciorum de novis erroribus, Pierre d'Ailly reprend la distinction classique du dictum de Gratien concernant la determinatio fidei : uno modo, scholasticè et doctrinaliter; alio modo, auctoritativè et judicialiter ${ }^{105}$. Donnant toute son importance au premier mode, il précise ses implications dans l'action du docteur : pertinet sacram Scripturam docere, et ex ea haereticas assertiones et in fide erroneas reprobare ac veritates Catholicas approbare. Pour lui, cette doctrinalis potestas vel auctoritas Doctorum Theologorum les rattache directement à l'autorité apostolique ${ }^{106}$. Il en veut pour preuve le chapitre Cum ex injuncto du De haereticis des décrétales de Grégoire IX. Après avoir cité l'épître aux Éphésiens (4.11): Alios dedit Apostolos, alios Prophetas, alios autem Doctores ${ }^{107}$, le texte d'Innocent III comporte une phrase répétée trois fois par Pierre d'Ailly dans la même page : doctoris ordo est quasi praecipuus in Ecclesia $^{108}$. Fort de ces paroles qui font directement participer les docteurs au ministère et à l'édification du corps du Christ, Pierre d'Ailly donne de solides arguments aux docteurs pour faire entendre leur voix au sein de l'Église toujours assistée par l'Esprit saint, veritatis Doctor, \& infallibilis director comme le qualifie Almain ${ }^{109}$. Mais c'est bien une Ecclesia magistra que prétend incarner le siège romain dans la bulle Sacrosanctae Romanae Ecclesiae publiée par Jules II contre le concile de Pise ${ }^{110}$.

Pour autant, la décision magistérielle d'une parole universitaire égale-t-elle toute autre autorité ? Solidement ancré dans cette tradition parisienne et magistérielle, Almain n'en 
présente pas moins sa réponse à Cajétan comme un travail de Sisyphe ${ }^{111}$. Son adversaire commençait ainsi son traité : Ego Praedicatorum ordinis (Romanae Ecclesiae veritatisque studiosissimi) generalis Magister ${ }^{112}$. À la compétence du docteur en théologie, lestée de l'autorité du doctor communis ${ }^{13}$, il ajoute celle du général de son ordre et celle, implicite, de porte-parole du pape, un pape à la compétence plénière. Quelle loi, pour quel magistère ? La réponse de Cajétan est simple : tota ecclesia non potest autoritativè mutare legem factam à Papa ${ }^{114}$. Expliquant que les pouvoirs d'ordre et de juridiction dérivent de ceux de Pierre, il ajoutait : Et hoc intendunt omnes sacri autores, cum dependentia omnium à Petro doctrinam tradunt ${ }^{115}$ Par principe, les docteurs qui soutiennent la supériorité du concile sont dans l'erreur ${ }^{116}$, puisque rien ne peut s'y faire contre le pape qui reste le pasteur de l'ensemble de l'Église : solus est pater, pastor, doctor, rector et gubernator omnium ${ }^{117}$. Cajétan se réfère à la définition du 6 juillet 1439 , prononcée au concile de Florence sous l'autorité d'Eugène IV, dans laquelle sont énumérés ces titres et où se trouve détaillée sa plenam potestatem pascendi, regendi, gubernandi universalem ecclesiam ${ }^{118}$. Or, dès le deuxième chapitre, commentant le Pasce oves meas - avant de citer les derniers mots de Matthieu, Docete omnes gentes - Cajétan glosait: pascere tripliciter sit, doctrina, vita, et correction $^{119}$. Le gouvernement confié à Pierre comprend une pleine compétence doctrinale. Cajétan insiste : c'est par ignorance que l'on préfère se référer aux docteurs en matière de foi, en négligeant de considérer l'assistance divine attachée à l'office pontifical ${ }^{120}$. En effet, il veut montrer avec Jean 16.13, que le pape est assisté par le Saint-Esprit: Spiritussanctus docebit vos omnem veritatem ${ }^{121}$.

Dans ces deux positions, réunies dos à dos par l'unique Église, la rencontre parait d'autant plus difficile qu'elle a une incidence directe sur la manière dont le locuteur considère son rapport à la vérité, ou à l'expression de celle-ci par le dépôt de la foi. Comment transmettre ce que l'on a reçu, et à quelles conditions? Le contexte scolastique paraît d'autant moins contingent que le docteur en théologie se pense comme un porte-parole de ce dépôt. Comment concilier un magistère du pastorat pétrinien et un magistère des docteurs, une loi scolastique soumise à la doctrine biblique, qui pense différemment ce nomen collectivum qu'est l'Église ? Comment pourrait-on éviter la situation d'hétérodoxies croisées, dès lors que les critères mêmes de la loi du magistère sont en question? Le phénomène d'hétérodoxies croisées serait-il l'une des pierres de touche de la recherche d'un référent orthodoxe?

\section{NOTES}

1. Thomas de Vio Caietanus, De divina institutione pontificatus Romani pontificis (1521), herausgegeben von F. Lauchert, Münster, 1925; G. Hennig, Cajetan und Luther. Ein historischer Beitrag zur Begegnung von Thomismus und Reformation, Stuttgart, 1966 ; J. Wicks, Cajetan und die Anfänge der Reformation, Münster, 1983.

2. Voir J.-R. Armogathe, L'ecclésiologie de Cajétan et la théorie moderne de l'État, dans Rationalisme analogique et humanisme théologique. La culture de Thomas de Vio 'Il Gaetano', Naples, 1993, p.171-182, ici p.171: "C'est de l'aval que j'en suis venu à étudier 
l'ecclésiologie de Cajétan, et à partir de modèles politiques : il apparaît en effet au XVII siècle comme le théoricien classique du pouvoir pontifical». Cette controverse constitue aussi le centre du volume Conciliarism and Papalism édité par James H. Burns et Thomas Izbicki, Cambridge, 1997.

3. I. Gersonii, Opera; Multo quam antehac auctoria \& castigatiora; Inque partes quatuor distributa. Huic editioni, accessit vita Gersonii, ex eius operibus fideliter collecta; cum Indice rerum \& Verborum, \& aliquot Opusculus Petri de Alliaco Cardinalis; Iacobi Almaini, \& Ioannis Maioris Doctorum Parisiensium ; super Ecclesiae et Concilii auctoritate, pro Gersonij, \& placitorum scholae Parisiensis propugnatione, Paris, 1606. En 1611, Melchior Goldast fait figurer Almain dans sa fameuse collection: Monarchia S. Romani Imperii, sive Tractatus de iurisdictione imperiali seu Regia, \& Pontificia seu Sacerdotali..., Hanovre, 1611.

4. Sur la via media: Cajétan, De Comparatione auctoritatis Papae \& concilij, dans: Opuscula omnia Thomae de Vio Caietani..., I, Lyon, Apud haeredes Iacobi Iuntae, 1562, p. 21.

5. F. J. Baumgartner, Louis XII's Gallican Crisis of 1510-1513, dans A. E. Bakos (éd.), Politics, Ideology and the Law in Early Modern Europe. Essays in honor of J. H. M. Salmon, Rochester (NY), 1994, p. 55-72, ici p. 60.

6. O. de La Brosse, Le Pape et le concile. La comparaison de leurs pouvoirs à la veille de la Réforme , Paris, 1965, p. 55.

7. M.-H. Laurent, Cajétan (Thomas de Vio), dans A. Baudrillart et alii (éd.), Dictionnaire d'histoire et de géographie ecclésiastique, XI, Paris, 1949, col. 248-252.

8. Auctoritas Pape et Concilii sive Ecclesie comparata, Rome, impraessus per Marcellum Silber, 1511.

9. Des attaques croisées ont également lieu entre Italiens, opposant Filippo Decio et Zaccaria Ferreri (pour le concile de Pise) à Angelo Fondi (pour Jules II). Voir O. de la Brosse, op. cit., et N. Hochner, Louis XII. Les dérèglements de l'image royale (1498-1515), Seyssel, 2006, p. 158-159.

10. A. Clerval (éd.), Registre des procès-verbaux de la faculté de théologie de Paris, I, Paris, 1917, p.111: fuit sacra theologie Facultas apud Sanctum Maturinum ad audiendum relationem deputatorum magistrorum nostrorum qui fuerant deputati super codice fratris Thome de Vio ; qua relatione facta fuit conclusum, quod distribuerentur articuli sive propositiones malesonantes omnibus magistris nostris exepensis Facultatis. Sur les autres hésitations au sujet de Cajétan, voir le 15 janvier 1513 (p. 122-123), le 15 mars 1513 (p. 127). Je remercie Thierry Amalou de m'avoir signalé cet ouvrage.

11. J. K. Farge, Biographical Register of Paris Doctor of Theology, 1500-1536, Toronto, 1980, p. 15.

12. Libellus de auctoritate ecclesie seu sacrorum conciliorum eam representantium editus a magistro Jacobo Almain Senonensis diocesis doctore theologo contra Thomam de Vio qui his diebus suis scriptis nisus est omnem ecclesie Christi sponte potestatem enervare. Auctoritas ecclesie seu conciliorum ad auctoritatem pape comparata, Paris, Jehan Granion, 1512. À une époque où l'imprimerie - assez récente - n'est pas aussi prolifique en pamphlets que la fin du siècle, remarquons l'accès rapide à l'imprimé et ce choix précis de publicité dans cette controverse. L'ouvrage est d'ailleurs réédité à Paris en 1518 et 1520 dans les Opuscula, et en 1526 dans les Moralia d'Almain. James K. Farge remarque que « Almain's Moralia was a standard text in the Faculty of Arts for years after his premature death in 1515 (BN ms. lat. 12846, f. 162r) » (Bibliographical Register, p. 16). 
13. Cajétan, De Comparatione auctoritatis Papae \& concilij, dans : Opuscula omnia Thomae de Vio Caietani..., I, Lyon, Apud haeredes Iacobi Iuntae, 1562, p.5 (désormais abrégé en «Cajétan »).

14. Cajétan, p. 6. Il allègue la distinction 21 c. 3 du Décret: Quamvis universae per orbem Catholicae Ecclesiae unus thalamus Christi sint, sancta tamen Romana, Catholica, \& Apostolica Ecclesia nullis synodicis constitutis, caeteris ecclesiae praelata est, sed Evangelica voce Domini, \& Salvatoris nostri primatum obtinuit.

15. Cajétan, p. 5-6.

16. Cajétan, p. 5.

17. Cajétan, p. 8.

18. Cajétan, p. 6.

19. M. Maccarrone, Vicarius Christi. Storia del titolo papale, Rome, 1952, notamment p. 276 sur Cajétan.

20. Cajétan, p. 5.

21. Cajétan, p. 6.

22. Il s'agit de la sixième session, le 6 juillet 1439: G. Alberigo et alii (éd.) Conciliorum Oecumenicorum Decreta, Bâle, 1962, p. 504.

23. Cajétan, p. 6.

24. De même, voir Cajétan, p. 11.

25. Cajétan, p.6. Sur le pouvoir de Pierre comparé à celui des apôtres, voir le deuxième chapitre.

26. Cajétan, p. 7, et cf.: Quomodo autem verificari possunt haec duo simul, quod scilicet omnes Apostoli fuerunt pares in autoritate gubernandi ecclesiam, atque a Iesu Christo eam immediatè habuerunt, \& quod Petrus solus fuit institutus pastor universalis ecclesiae, \& maior autoritate super alios Apostolos. Cajétan, renvoyant à la glose sur ovile, cite: id est in catholicam ecclesiam (p. 10).

27. Cajétan, p. 7: nam in institutione ecclesiastici regiminis ordinario iure perpetuo servandi monarchicum, id est, unius principatum instituit, et posuit Petrum caput unum totius corporis ecclesiae : à quo in omnes potestas iurisdictionis et ordinis ordinarie derivaretur.

28. Cajétan emploie aussi l'expression gratuita praeventione (p. 8).

29. Cajétan, p. 7 : Petri vero potestas usque ad consummationem seculi perseverat : quia data est sibi in persona propria non solum pro seipso, sed omnibus successoribus suis : quod sancti doctores exprimunt sub aliis verbis, dicendo, quod data est Petro in persona Ecclesia. Cf. p. 12, à propos du pouvoir conféré : [...] non soli personae Petri, sed officio suo perpetuo.

30. Cajétan, p. 7.

31. Cajétan, p. 7 : Petrus factus est vicarius generalis Iesu Christi, alij vero facti velut legati seu delegati ejus.

32. Cajétan, p. 8 : vicarios operis tui, id est missos, ut vice tuae ad executionem operis tuis. Petrus autem creatus est pastor ovium Christi absolutè et universaliter, dicente Christo ipsi soli, Pasce oves meas. Unde (ut unico verbo dicatur) plus datum est per haec verbo Petro, quam per quaecunque alia simul congregata caeteris: qui autoritas regiminis universalis simpliciter hic clauditur.

33. Cajétan, p. 8. De même : Erant enim pares in potestate executiva regiminis ecclésiae; Erat Papa excedens in autoritate regminis. 
34. Cajétan, p. 7. L'expression de dominus iuris pour désigner le Christ se trouve à la page 8. Sur le rapport à l'Église, voir p. 10: Amplius, Papa habet supremam potestatem in ecclesia Dei : ergo Papa non subest ecclesiae.

35. Cajétan, p. 12.

36. Cajétan, p. 12 : primatus Papae est super ecclesias particulares.

37. Cajétan, p. 10-11.

38. Cajétan, p. 13.

39. Cajétan, p. 10 : non communitati ecclesiae, sed uni soli in illa Christus plenitudinem potestatis ecclesiasticae dedit. Cajétan répète les paroles Pasce oves meas: in hoc instituens regimen ecclesiae monarchicum (p.10). Voir aussi p.13: potestas Papae est tota potestas ecclesiae universalis, \& aliae potestates sunt participationes ipsius in partem solicitudinis datae. Iam enim dictum est quod non plus potest Papa et ecclesia quam Papa solus.

40. Cajétan, p. 14.

41. J. Almain, Tractatus de auctoritate Ecclesiae et conciliorum generalium: Adversus Thomam de Vio, dans : J. Gersonii, Opera omnia... Operâ et studio M. Lud. Ellies du Pin, II, Anvers, 1706, col. 980. Désormais abrégé en « Almain ».

42. Almain, col. 989.

43. Almain, col.987: [...] capiendo Ecclesiam pro collectione omnium fidelium; sive pro collectione omnium Praelatorum, majorum et minorum, qui succedunt Apostolis et Discipulis; sive pro Concilio Generali Ecclesiam repraesentante.

44. Almain, col. 987-989.

45. Almain, col. 987, Gratien, D. 15 c. 2. Cf. Almain, col. 1002 : Summus Pontifex potest errare, sententiendio in materia Fidei. Si enim errare non potuisset, frustra fuissent convocata quatuor Concilia Generalia principalia, contra quatuor Haeresiarchas, puta Nicaenum, Constantinopolitanum, Ephesinum, et Chalcedonense.

46. Cf. Almain, col.987: Non dicitur enim, quia dum Petri aut Summi Pontificis consensu constituta sunt, nec dicitur quos Summos Pontifex ligat, sed quos Patres ligant, et col. 992 : illa Congregatio Apostolorum erat Petro major.

47. Almain, col. 988. S'appuyant sur la lettre 72 d'Ambroise, il donne également l'exemple de la réponse du pape Damase au concile de Capoue qui fait appel à lui : il renvoie le jugement de cette cause au concile qui a une meilleure connaissance que lui du cas, et une plus grande autorité pour le juger.

48. Almain, col. 990.

49. Voir Almain, col. 989, titre du chapitre VII.

50. Almain, col. 989.

51. Almain, col. 1011.

52. Almain, col.990: contulit Dominus claves Petro Summo Pontifici, ut signo et figurae Ecclesiae. Ergo per ampliùs, et magis contulit Ecclesiae.

53. Almain, col. 991 : ergo in Petri nomine figurata est Ecclesia. Etiam ad istum sensum, Petrus et quodlibet ejus Successor, utitur clavibus vice Ecclesiae Universalis quam significat, sicut Rex quilibet, vice Communitatis exercet Jurisdictionis actus, ita quod Summus Pontifex excommunicat, confert Beneficia, similiter et Indulgentias, et sic de aliis actibus Ecclesiasticae Potestatis, authoritate totius Ecclesiae. 
54. Voir aussi Almain, Quaestio resumptiva, Agitata in Vesperiis... de Dominio naturali, civili, \& ecclesiastici, dans : J. Gersonii, Opera omnia..., col. 972: Christus prius corpori suo mystico Ecclesiasticam Potestatem contulit.

55. Almain, col. 991. Sur la priorité temporelle, voir p. 993 : Ecclesiastica Potestas, est priùs tempore in Ecclesia, quàm fuerit in aliquo Summo Pontifice.

56. Almain, col. 995. Cf. col. 996 : est ergo minister inferior, et non Superior dominae. Respectu tamen Ecclesiarum particularium, Papa est Caput ministeriale; quia ratione ministerii Petro commissi, habet super eas superioritatem.

57. Almain, col. 996.

58. Almain, col. 1010 : Christus non instituit Summum Pontificem suum Generalem Vicarium in omnimoda Potestate quam habebat, secundum humanitatem : non habebat Potestatem instituendi Sacramenta, similiter instituendi Summum Pontificem, similiter faciendi Articulum novum super infideles, et super totam Ecclesiam categorematicè, et nullam istarum habet Summus Pontifex.

59. Almain, col. 1010.

60. Almain, col. 996 : Ecclesia distincta contra Papam est ovile et oves Christi ; nam dictum est Petro, Pasce oves meas, non tuas. Et illi ovili data est à Christo Potestas unumquodque membrum arcendi ad Legem Ecclesiasticam, quae quia regulariter exerceri non potest per totum, communicavit eam uni supposito, vice totius, relinquens Ecclesiae exemplum, quonam pacto ipse facere deberet in posterum, et ille dici potest Pastor totius residui, modo supradicto.

61. Almain, col. 997.

62. Almain, col. 991 : Papa est Universalis Ecclesiae filius, ergo ei subjectus, et antecedens patet ex Ambrosio, in Libro de Symbolo, Non habebit ibi Deum Patrem, qui noluit hîc habere Ecclesiam matrem. Cavendum est ergo Summo Pontifici, ne Ecclesiae deneget obedientiam. Sur cette qualification de l'Église, voir K. Delahaye, Ecclesia Mater chez les Pères des trois premiers siècles, Paris, 1964.

63. Almain, col. 989.

64. Almain, col. 999. Sur l'Église comme juridiction supérieure, voir aussi col. 992.

65. Sa première publication est posthume, dans le recueil: Aurea Clarissimi et acutissimi doctoris theologi magistri Jacobi Almain, Senonensis, Opuscula..., Paris, venundantur a Claudio Chevallon, 1518, f. 1-47 (foliotation propre). En 1526, le même éditeur publie indépendamment cette Expositio circa decisiones quaestionum M. Guillermi Ockam, super potestate Summi Pontificis. Sur Almain et Occam, voir: Perroniana sive excerpta ex ore Cardinalis Perronii, Genève, 1669, p. 7 ; P. Bayle, Dictionnaire historique et critique, $5^{\mathrm{e}}$ éd., 1, Amsterdam-Leyde-La Haye-Utrecht, 1740, p. 165 (article « Almain »).

66. Magistri Guilhelmi de Ockam, Super potestate summi pontificis octo questionum decisiones, [Lyon, Jean Trechsel, 1595]. Sur le contexte de rédaction de cet ouvrage, voir H. S. Offler, The Origin of Ockham's Octo Quaestiones, dans The English Historical Review, 82, $\mathrm{n}^{\circ} 323$, avril 1967, p. 323-332. Cet ouvrage date des années 1340-1342.

67. Almain, Expositio circa decisiones Magistri Guillielmi Occam, Super Potestate Summi Pontificis , dans : J. Gersonii, Opera omnia..., col. 1071.

68. Almain, Expositio, col. 1071: Concilium ritè congregatum non possit errare, patet: semper enim dirigitur specialiter à Spiritu sancto [...]. Visum est Spiritui sancto et nobis [Act. 15.28]. Praeponitur Spiritus sanctus quasi regens Concilium, et gubernans; ergo signum est quod Spiritus sanctus semper regit, et gubernat Concilium; ergo ratione indeviabilitatis nituntur ostendere quod Concilium sit supra Papam, quantùm ad istud, quod est de ratione superioris 
Potestatis, certis Legibus posse arctare inferiorem. Voir aussi le titre de paragraphe, col. 1072 : Potestas Concilii intensivé, extensivé, et indeviabiliter, major est Potestate Papae. Ces thèses sont citées et identifiées comme typiquement gallicanes dans le Mémoire dans lequel on examine ces deux Questions. 1. Si l'Appel de la Constitution Unigenitus..., dans Mandement et instruction de Monseigneur l'Evesque de Boulogne, au sujet de l'appel qu'il a interjetté, Paris, 1717, p. 20. Sur le pape deviabilis, voir aussi la Censura Sacrae Facultatis Theologiae Parisiensis, in Librum cui titulus est: La Défense de l'authorité de N. S. P. le Pape... par Jacques de Vernant..., Paris, 1665, p. 102 ; et la Dix-neuvième lettre touchant l'inquisition, qu'on veut établir en France, à l'occasion de la nouvelle Bulle du Pape Alexandre VII, qui a couru sous le titre de Lettre d'un Avocat au Parlement, à un de ses Amis, du 1 Juin 1657, dans [B. Pascal], Les Provinciales..., Cologne, 1685, p. 468, qui reprend l'adjectif de Gerson. Cf. Fr. Leytam, Impenetrabilis Pontificae dignitatis clypeus. In quo Vera Doctrina de Potestate Summi Pontificis Romani indubitati supra omnia Concilia etiam generalia, \& legitimè congregata; \& legitimè congregata; \& de ejusdem infallibilitate in rebus ad fidem..., Rome, 1695, p. 279.

69. Almain, Expositio, col. 1071.

70. Almain, Quaestio resumptiva, Agitata in Vesperiis... de Dominio naturali, civili, \& ecclesiastici, dans J. Gersonii, Opera omnia..., col. 972.

71. Almain, col. 1002 : quod determinatis per Summos Pontificos non est necessarium credendum . Sur les errances pontificales, Almain cite Jean XXII et Nicolas III, et certains décrets pontificaux qui sont allés à l'encontre de l'Évangile (col. 1001).

72. Almain, col. 1002-1003.

73. Almain, col. 1001-1002.

74. Almain, col. 1007 et 1011.

75. Almain, col. 1011.

76. Almain, col. 1003 : Concilium Universale in his quae Fide sunt errare non potest, et sic ad ipsum ultima Fidei decisio spectat. Quod non possit in his quae Fidei sunt errare, patet; qui specialiter dirigitur à Spiritu sancto, qui, juxta promissum Christi, omnem veritatem docet. Unde et in conclusione Concilii Apostolorum, Actuum 15.28 dixerunt Apostoli, Visum est Spiritui sancto et nobis, praeponentes Spiritum Sanctum tanquam Praesidentem, et specialem directorem Concilii : et non dixerunt Visum est Petro et nobis. Almain précise plus loin (col. 1005) : Cum ex supradictis constet Ecclesiam et Concilium esse in Jurisdictione majorem Summo Pontifice simpliciter, et in Potestate applicativa Papatus ad certam personam, et in Potestate definitiva eorum quae sunt Fidei.

77. Almain, col. 1003 : Ista conclusio iterum patet ex alio: nam fatetur quilibet Christianus se credere in unam Sanctam Ecclesiam Catholicam, et sic ad eam eorum quae sunt Fidei ultima decisio spectabit.

78. Almain, col. 1003.

79. Almain, col. 985.

80. Almain, Expositio, col.1013. Dans l'ouvrage contre Cajétan, ses références sont aussi Jean de Paris et Pierre d'Ailly (col. 980)

81. Almain, col. 979.

82. Almain, Expositio, col. 1029. En regard, sur l'administration du siège romain de Pierre comme libertas, voir G. Manfredi, De Cardinalibus Sanctae Rom. Eccles. Liber, in quo omnia quae ad hanc materiam pertinent, coposissimè tractantur..., Bologne, 1564, p. 24.

83. Almain, Expositio, col. 1039. 
84. Almain, Expositio, col.1029. Cf. col. 1039: Similiter Potestas Ecclesiastica, de ratione sua, nullum facit dominantem, et est egregium verbum Occam, et bona similiter de servo.

85. Almain, col. 985.

86. Almain, col. 987-988, 992 ; Quaestio resumptiva, col. 971.

87. Almain, Expositio, col. 1068.

88. A. Oliva, "Doctrina et sacra doctrina chez Thomas d'Aquin», dans Ph. Büttgen et alii (éd.), Vera Doctrina. Zur Begriffsgeschichte der Lehre von Augustinus bis Descartes, Wiesbanden, 2009, p. 35-61, ici p. 77 ; sur l'échange, par les copistes, entre sacra Scriptura et sacra doctrina, voir p. 57. Voir aussi A. Oliva, Les débuts de l'enseignement de Thomas d'Aquin et sa conception de la sacra doctrina..., Paris, 2006, p. 281: «L'étude des implications de la transmission, de l'enseignement, de cette sacra doctrina nous permettra de confirmer cette unité substantielle de la sacra Scriptura, de la sacra doctrina et de ce qu'aujourd'hui nous appelons la théologie. »

89. Cajétan, p. 15.

90. [P. Pithou], Ecclesiae Gallicanae in schismate status.Ex actis publicis, Paris, 1594, p. 159-160; [P. Dupuy], Preuves des Libertez de l'Église gallicane..., I, Paris, 1651, p. 485. Yves Congar note le poids inédit des docteurs au concile de Bâle : lors de la $34^{\mathrm{e}}$ séance, en 1439 , il y a 300 docteurs pour 13 prêtres et 7 évêques. Y. Congar, Bref historique des formes $d u$ 'magistère' et de ses relations avec les docteurs, dans Id., Papauté et Église. Regards historiques, Paris, 2002, chap. XII, p. 305.

91. Voir Y. Congar, Jus divinum, dans Id., Papauté et Église, chap. III.

92. E. Marmursztejn, L'Autorité des maîtres. Scolastique, normes et société au XIII siècle, Paris, 2007, p. 268. Pour le XII ${ }^{\mathrm{e}}$., voir C. Giraud, Per verba magistri : Anselme de Laon et son école au XII siècle, Turnhout, 2010.

93. Almain, col. 981.

94. Almain, col. 982, voir aussi col. 978, 987.

95. Almain, col. 989.

96. Almain, col. 1001.

97. Almain, Expositio, col. 1065.

98. H. Rashdall, The Universities of Europe in the Middle Ages, I, Oxford, 1987, p. 486. Sur le contexte d'Almain, voir R. G. Villoslada, La Universidad de Paris durante los estudios de Francisco de Vitoria O. P. (1507-1522), Rome, 1938, cap. VII. Sur la licentia, voir Jacques Verger, Les ambiguités de la licentia docendi : entre tutelle ecclésiastique et liberté universitaire, dans Revue d'histoire des facultés de droit et de la culture juridique, 29-30, 2009-2010, p. 17-28. Sur la resumpta, je remercie Monica Brinzei de me signaler : P. Glorieux, L'enseignement au Moyen Âge. Techniques et méthodes en usage à la faculté de théologie de Paris au XIII siècle, dans Archives d'histoire doctrinale et littéraire du Moyen Âge, 35, 1968, p. 65-186; et B. C. Bazán, Les questions disputées, principalement dans les facultés de théologie, dans: Les questions disputées et les questions quodlibétiques dans les Facultés de théologie, de droit et de médecine, Turnhout, 1985, p. 15-149.

99. Voir S. Menache, La naissance d'une nouvelle source d'autorité: l'université de Paris, dans Revue historique, 268/2, oct.-déc. 1982, p. 305-327 ; A. E. Bernstein, Magisterium and Licence: Corporate Autonomy Against Papal Authority in the Late Medieval University of Paris, dans Viator , 9, 1978, p. 291-307. 
100. Almain, Quaestio resumptiva, col. 967, et 966 pour ses autorités.

101. Almain, Quaestio resumptiva, col. 975.

102. Y. Congar, L'Église de saint Augustin à l'époque moderne, Paris, 1997, p. 243.

103. Almain, Expositio, col. 1070.

104. D. Taber, Pierre d'Ailly and the Teaching Authority of the Theologian, dans Church History, 59/2, juin 1990, p. 163-174, ici p. 164. Sur Gerson, voir Z. Kaluza, La doctrine selon Jean Gerson, dans Vera Doctrina, op. cit., p. 115-140.

105. Pierre d'Ailly, Tractatus ex parte Universitatis Studii Parisiensis pro causa Fidei, contra quemdam Fratrem Johannem de Montesono Ordinis Praed. Editus à Petro de Alliaco Episcopo et Cardinali Cameracensi circa annum 1388, dans C. D. d'Argentré, Collectio judiciorum de novis erroribus..., I, Paris, 1728, partie II, p. 75-129, ici p. 77. Le manuscrit autographe se trouve à la BnF, ms. lat. 3122, f. $7 \mathrm{r}^{\circ}-48 \mathrm{r}^{\circ}$. Sa conclusio tertia est intitulée: Ad Doctores Theologos pertinet determinatione doctrinali, et scholasticâ, circa ea quae sunt fidei, doctrinaliter fidei. Voir Tractatus, p. 77.

106. Pierre d'Ailly, Tractatus, p. 77 : Quod autem haec doctrinalis potestas vel auctoritas Doctorum Theologorum magna sit et merito venerabilis in Ecclesia Dei ; manifestum est auctoritate Apostoli, qui inter Dei dona officium Episcoporum, qui succedunt loco Apostolorum et Officiis Doctorum, connumerat: Alios, inquit, dedit Apostolos, alios Prophetas, alios autem Doctore, $\& c . .$. ad Eph. $4^{\circ}$. Ex qua auctoritate concluditur, Extra. De haereticis : Cum ex injuncto : \& in cap. Sicut: quod Doctoris ordo est quasi praecipuis in Ecclesia.

107. Pierre d'Ailly, Tractatus, p. 77.

108. Décrétales de Grégoire IX, lib. V, tit. VII, cap. XII (texte de 1199). De même chez Occam, Dialogus, part. I, lib. 4, cap. 28. Pour d'Ailly, cette place éminente au sein de l'Église lui permet d'exercer sur ses supérieurs une caritativa correctio (Tractatus, p. 80). Pierre d'Ailly est sensible à Occam dès sa thèse de vespéries: V. Martin, Les origines $d u$ Gallicanisme, 2, Paris, 1939, p. 53.

109. Almain, Quaestio resumptiva, col. 972.

110. Bullarum privilegiorum ac diplomatum Romanorum Pontificum amplissima collectio... Opera et studio Caroli Cocquelines, III, pars tertia, Rome, 1743, p. 325 : Sacrosanctae Romanae Ecclesiae Martyrum sanguine consecratae, magistrae Fidei, veritatis alumnae, omnium erronum expertis, unicae, \& immaculatae, divina institutione, Sanctorum auctoritatibus, Conciliorum Canonumque omnium testimonio, Ecclesiarum cunctarum Primatum tenentis, fidelium Matris, regimini superna dispositione praesidentis, circa Religionis Christianae puritatem, ipsiusque unitatem, pacem, \& tranquillitatem, quae in conjunctione membrorum ad unum caput Christum videlicet, cujus vices in terris gerimus, principaliter tendit, divisionem ovilis nostri ex alto commissi, in illoque schisma, per quod Ecclesia scindi. Sur le concile de Pise, voir aussi p. 348-349. Dans la bulle du 26 octobre 1431, Eugène emploie aussi cette expression d' Ecclesiae mater ac magistra.

111. Almain, col. 976.

112. Cajétan, p. 4.

113. Voir A. A. Robiglio, La sopravvivenza e la gloria. Appunti sulla formazione della prima scuola tomista, Bologna, 2008.

114. Cajétan, p. 17 (faussement numérotée 18).

115. Cajétan, p. 7. 
116. Cajétan, p. 19.

117. Cajétan, p. 11. De même p. 14 : Papa habet potestatem super Universali Ecclesia \& concilio, ut caput, pastor, rector et director illius.

118. Cajétan, p. 11.

119. Cajétan, p. 6. Dans la même page: Maiores autem ministri in ecclesia sunt Apostoli : ad quorum officium tri pertinent. Quorum primum est autoritas gubernandi fidelem populum, quae propriè pertinet ad officium apostolatus: secundo facultas docendi: tertio potestas miracula faciendi ad confirmationem doctrinae.

120. Cajétan, p.13: Et non advertere ad hanc distinctionem de fide personali vel in iudicio autoritativè, est causa quare à multis ignoranter et materia fidei ecclesiae, imo doctores Pape praeferantur : considerant enim ipsum non officium cum assistentia divina ad fidem in officio, etsi non in persona.

121. Cajétan, p. 13.

\section{AUTEUR}

\section{FRÉDÉRIC GABRIEL}

CNRS, UMR 5037 - frederic.gabriel@gmail.com 


\title{
Le pouvoir du pape sur les royaumes : la controverse imprimée entre catholiques romains et catholiques gallicans à propos des bulles de 1585, 1589 et 1591
}

\author{
Benoît Schmitz
}

1 La mort de François d'Anjou le 10 juin 1584 ouvrit dans le royaume de France une crise sans précédent de la légitimité politique. Le décès du frère d'Henri III faisait en effet du protestant Henri de Bourbon, roi de Navarre, l'héritier présomptif de la Couronne. Pendant une décennie, l'attitude à adopter à son égard déchira les catholiques français : les règles traditionnelles de dévolution devaient-elles être observées malgré le calvinisme du prétendant? Fallait-il au contraire s'en affranchir pour préserver le principe plus essentiel de l'orthodoxie du roi «Très-Chrestien » et de sa fidélité à l'Église romaine ? À trois reprises, la papauté intervint de la manière la plus solennelle dans ce débat. Le 21 septembre 1585, Sixte V publia une bulle qui excommuniait Henri de Bourbon et Henri de Condé, et les privait de l'exercice de toute autorité : le Béarnais se trouvait ainsi non seulement déchu de son trône de Navarre mais aussi de ses droits à la succession au royaume de France. Dans un monitoire du 5 mai 1589, le même pape menaçait Henri III d'excommunication et de déposition s'il ne venait à résipiscence après l'exécution à Blois du duc et du cardinal de Guise. Le $1^{\mathrm{er}}$ mars 1591, enfin, Grégoire XIV fulminait deux bulles monitoriales par lesquelles il rappelait les censures et peines frappant Henri de Bourbon désormais reconnue comme Henri IV par une large partie du royaume - et enjoignait au clergé et aux laïcs français de cesser de le soutenir sous peine d'être à leur tour excommuniés.

2 En moins de six ans, ce fut donc par trois fois que la papauté se prononça sur les affaires de France en se posant comme le souverain juge de la légitimité politique. Ces bulles réveillèrent et exacerbèrent la controverse traditionnelle sur les prérogatives respectives du roi de France et du pape. Catholiques gallicans et catholiques romains jetèrent à nouveau une lumière crue sur leur désaccord doctrinal quant au pouvoir du souverain 
pontife sur les royaumes. Sans doute a-t-on, avec cette crise, un cas exemplaire, illustrant parfaitement la formule retenue par Gigliola Fragnito et Alain Tallon pour caractériser les hétérodoxies croisées entre France et Italie : « vérité en-deçà des Alpes, erreur au-delà ». Mais il faut immédiatement nuancer et prendre la mesure de la complexité de la situation.

À chaque fois, la sentence romaine ne fut pas un coup de tonnerre dans un ciel serein. Le pape avait en face de lui un royaume profondément divisé, qui réclamait, ou à l'inverse redoutait, son intervention. Il était loin d'être le seul à prétendre dire la légitimité : on ne l'attendait pas pour prononcer la déchéance des princes accusés d'hérésie. Dans son manifeste de Péronne, publié sous le nom du cardinal Charles de Bourbon, la Ligue n'avait-elle pas proclamé dès le 31 mars 1585 que «les subjets [n'étaient] tenus de recognoistre ny souffrir la domination d'un prince qui s'est separé tant de fois de la religion catholique $»^{1}$ ? De même, la Faculté de théologie de Paris précéda le pape en déliant les Français de leur serment de fidélité à Henri III le 7 janvier $1589^{2}$. De surcroît, l'essentiel de la controverse, à l'exception notable de celle qui suivit la bulle de 1585, se déroula en France. À dire vrai, les Alpes étaient moins qu'à aucune autre époque une véritable frontière doctrinale, qui nous permettrait d'opposer commodément deux blocs homogènes. De part et d'autre des monts, les catholiques étaient divisés sur la manière de sortir des guerres de religion.

Dans cette montée aux extrêmes, c'était l'unité même de l'Église qui se trouvait menacée. Je me concentrerai ici sur la controverse imprimée consacrée au pouvoir pontifical par les catholiques intransigeants et les catholiques politiques. Ce fut précisément à la fin des années 1580 et au début des années 1590 que la guerre des imprimés atteignit son point culminant en France: elle opposa surtout les catholiques entre eux au sujet de l'obéissance à accorder ou à refuser à Henri III, puis à Henri IV ${ }^{3}$. L'ampleur de la controverse ne correspondit pas seulement à un prurit polémique. À la recherche d'une solution qui mît fin aux guerres civiles, les meilleurs esprits firent assaut d'érudition théologique, juridique et historique pour retrouver les principes par lesquels l'ordre et l'autorité seraient rétablis. À côté des angoisses eschatologiques et des imaginaires paniques qui travaillaient l'inconscient des Français ${ }^{4}$, il faut, me semble-t-il, remettre en lumière la démarche doctrinale par laquelle des consciences inquiètes trouvaient une voie de salut. La querelle théologico-politique fut, dans les années qui séparèrent la mort de François d'Anjou de l'absolution d'Henri IV par Clément VIII, tout autre chose qu'un exercice académique ; reprenant le fil d'un conflit qu'on savait n'être qu'endormi par des concordes durables mais fragiles, il ne s'agissait de rien moins que de proposer à des contemporains désorientés le fondement d'un ordre qui permettrait de renouer avec le meilleur - très largement idéalisé - de l'histoire du royaume et de l'Église.

\section{Pouvoir royal et pouvoir pontifical : Pierre de Belloy, Bellarmin et la bulle de 1585}

5 La controverse imprimée sur la succession au trône de France et sur la puissance du pape débuta quelques semaines avant la publication par Sixte $\mathrm{V}$ de la bulle contre Henri de Navarre et Henri de Condé. Pierre de Belloy, juriste gallican proche des «politiques » et des milieux navarristes, fit paraître en 1585, alors que la sentence n'avait pas encore été prononcée, une Apologie catholique, qui fut traduite en latin l'année suivante ${ }^{5}$. Sans révéler son nom, l'auteur ne se disait pas seulement bon catholique romain, mais aussi bon 
Français : comme tel, il devait rappeler - contre les écrits des ligueurs - les obligations naturelles que ses compatriotes avaient à l'égard de leurs princes légitimes ${ }^{6}$. Le livre était, pour l'essentiel, une réponse minutieuse aux divers arguments qu'employaient les ennemis du Béarnais. De loin la plus longue, la seconde partie était principalement consacrée à la réfutation de l'objection religieuse : le roi de Navarre était hérétique et les hérétiques étaient privés de tout droit de succession. Le problème était pour une part une question de fait ${ }^{7}$ : selon l'auteur, Henri de Bourbon ne pouvait être qualifié d'hérétique car la condamnation du protestantisme au concile de Trente n'était pas valable. Le plus important, à ses yeux, n'en était pas moins le point de droit ${ }^{8}$.

6 C'était en effet sur ce terrain-là que Pierre de Belloy pouvait formuler le principe cardinal de son argumentation contre ceux qui mesuraient l'autorité royale à l'aune de sa fidélité religieuse : les rois tenaient leur royaume immédiatement de Dieu. Les lois civiles et les canons qui prévoyaient de priver les hérétiques du droit de succession ne s'appliquaient dès lors qu'aux particuliers'. Nul n'avait sur terre le pouvoir de dispenser de l'obéissance due à l'autorité temporelle : le devoir de soumission au souverain, même mauvais, était intangible ${ }^{10}$. Le lien unissant le peuple et le roi était indissoluble, comme le lien de mariage ${ }^{11}$.

7 C'était en fonction de cette théorie du droit divin des rois qu'était longuement examinée la prétention de la papauté à déposer les princes et à délier les sujets de leur serment de fidélité $^{12}$. Pour Pierre de Belloy, il n'existait que deux sortes de juridiction, auxquelles l'Église n'avait nulle part : la terrestre était confiée aux rois et s'exerçait sur tout homme, la céleste n'appartenait qu'à Dieu et ne rétribuait chacun que dans l'éternité ${ }^{13}$. Le pouvoir ecclésiastique était ainsi vidé de sa substance. Le pape ne détenait nulle parcelle de la juridiction divine. Cela se vérifiait dans le cas des hérétiques : leur peine en ce monde ne relevait que du prince temporel ${ }^{14}$.

8 L'auteur soulignait fortement ce qui différenciait la prêtrise de la royauté en refusant à celle-là tout pouvoir de contrainte : « ... les prestres qui sont gardiens \& pedagogues de la loy de Dieu, ne sont pas establis pour juges, ains comme doux medecins de l'ame... ${ }^{15}$. L'office des clefs était à ses yeux purement déclaratoire :

C'est veritablement au prestre, \& à l'evesque de sçavoir, \& declarer quant \& quant par les Escritures sainctes, \& jugement de l'Eglise universelle, qui est celuy qui a failli contre la volonté de Dieu, \& qui estant chrestien, s'est desuni, ou desvoyé du giron de l'Eglise. Ce sont les vrayes clefs du ciel, que Dieu luy a mises en main, \& les deux glaives qu'il porte, par lesquels le prestre monstre \& designe ceux, qui sont soluti vel ligati ab Ecclesia : en quoy seulement consiste le pouvoir qu'il a de deslier ou lier au ciel ${ }^{16} \ldots$

9 Si une telle conception limitait étroitement les prérogatives de l'Église, elle n'empêchait pas une réaffirmation de son rôle éminent quant au salut des âmes. La charge des prêtres était d'enseigner les fidèles et de les admonester afin de les conduire à la vie éternelle ${ }^{17}$. En ce sens, leur autorité était grande : «Or n'est pas ce pouvoir [de lier et délier au ciel] si petit, qu'il doive estre mesprisé par les Chrestiens fideles... ${ }^{18}$.

10 L'objectif de Pierre de Belloy n'était pas en effet de minimiser le rôle salvifique de l'Église, mais de l'établir sur un plan complètement séparé des affaires temporelles : sa juridiction ne concernait que le Royaume des cieux et ne touchait en rien les royaumes de la terre ${ }^{19}$. Cette disjonction impliquait que l'excommunication des princes ne pouvait entraîner, de soi ou par l'effet d'une disposition particulière, leur déposition ${ }^{20}$. Dans ces conditions, le 
roi pouvait résister par les armes au pape quand celui-ci outrepassait les pouvoirs de sa charge ${ }^{21}$.

11 Le juriste gallican ruinait toute velléité ecclésiastique d'échapper à l'autorité temporelle en condamnant ceux qui soutenaient

que le pape, \& les evesques, ou autres ecclesiastiques, [devaient] establir un royaume terrien à part, non suject aux empereurs, \& rois du monde, ains tel qu'il

[pût] commander à ceux-cy, \& les suppediter quand bon luy [semblerait] ${ }^{22}$.

12 C'était dire clairement que l'Église était dans l'État; c'était aussi tirer toutes les conséquences de ce principe en attaquant les immunités ecclésiastiques et l'État temporel du pape, c'est-à-dire ce qui donnait une assise au pouvoir des prêtres, à « une monarchie autre, \& plus puissante que la royale $»^{23}$.

13 L'ouvrage de Pierre de Belloy ne passa pas inaperçu à Rome. Sous un pseudonyme, Robert Bellarmin publia en 1587 une réfutation en latin, qui fut très vite traduite en français ${ }^{24}$. Avec la publication de la bulle contre Henri de Bourbon et Henri de Condé, l'Apologie catholique avait pris un sens beaucoup plus subversif, qui conduisait Bellarmin à estimer qu'elle s'opposait « couvertement » à la sentence pontificale ${ }^{25}$. Vu de Rome, il n'était pas nécessaire d'entrer dans le dédale des questions abordées par Pierre de Belloy. Deux points seulement importaient: le crime d'hérésie commis par Henri de Navarre et la privation prononcée par Sixte $\mathrm{V}^{26}$.

14 Après avoir établi dans la préface et les deux premières parties de la Responce l'hérésie de Pierre de Belloy, d'Henri de Navarre et des protestants, Bellarmin se concentrait dans la troisième section de l'ouvrage sur le problème du pouvoir du pape sur les royaumes. La première étape de la démonstration consistait à anéantir le principe du droit divin des rois. Les canons avaient pu prévoir la déposition des souverains hérétiques sans déroger à la loi divine parce que les royaumes n'étaient pas établis immédiatement par Dieu mais "par l'humain consentement \& jugement ${ }^{27}$. La portée de cette affirmation était soigneusement limitée : la médiation de l'élection n'ouvrait pas la voie à la souveraineté du peuple mais à l'exercice par l'Église de sa juridiction. L'obéissance restait due aux princes tant que l'autorité spirituelle ne les avait pas réduits au rang de simples particuliers ${ }^{28}$.

15 La juridiction ecclésiastique était fondée sur la parole du Christ à Pierre: "Pais mes brebis » (Jn. 21, 15-17). Ce pouvoir pastoral s'exerçait sur tous les fidèles: le Sauveur n'avait pas prévu d'en exempter les Français. Bellarmin en soulignait la dimension coercitive : « ... comme le pasteur sur les brebis, c'est à sçavoir de les contraindre d'aller aux bons pasturages, \& non seulement les retenir par sa voix des choses nuisibles : mais aussi pour son pouvoir, les battre du baston $»^{29}$. Il prenait ainsi le contre-pied de Pierre de Belloy qui limitait le pouvoir pontifical tant en extension qu'en nature. Mais l'opposition des deux auteurs se situait plus fondamentalement encore au niveau des relations entre la puissance politique et la puissance ecclésiastique. À l'inverse du juriste gallican, le théologien romain considérait qu'à partir du moment où les rois étaient membres de l'Église, les deux puissances ne pouvaient être séparées, mais seulement distinguées : elles étaient unies comme le corps et l'âme, c'est-à-dire que l'âme - la puissance spirituelle commandait au corps - la puissance temporelle - pour parvenir à sa fin, le salut ${ }^{30}$.

16 Bellarmin avait le souci de démontrer, contre l'opinion de son adversaire, que la thèse qu'il soutenait ne lésait aucunement les droits du prince. Il utilisait à cette fin la théorie $\mathrm{du}$ pouvoir indirect: le roi administrait directement les affaires temporelles, le pape directement les affaires spirituelles ; mais comme les premières étaient subordonnées aux 
secondes de même que le corps à l'âme, il appartenait au pontife d'exercer "par consequent » (consequenter) sa juridiction sur les royaumes terrestres quand le salut des hommes était en cause ${ }^{31}$. Le souverain temporel ne recevait nul préjudice de ce qui découlait simplement de l'unité de l'Église, comme l'assurait Bellarmin dans une vigoureuse défense de la bulle Unam sanctam ${ }^{32}$. De même, le souverain spirituel ne trahissait pas sa charge en exerçant son pouvoir sur le temporel: les clefs du Royaume des cieux impliquaient celles des royaumes de la terre lorsque le salut des âmes était en cause $^{33}$.

17 Restait toutefois à comprendre l'exhortation de saint Paul : omnis anima potestatibus sublimioribus subdita sit $(\mathrm{Rm} .13,1)$. Cela signifiait nécessairement que les ecclésiastiques devaient être soumis aux rois pour ce qui touchait au temporel et les rois aux ecclésiastiques pour ce qui concernait le spirituel. Bellarmin reprenait ici la théorie du pape Gélase $\mathrm{I}^{\mathrm{er}}$. Mais comment concilier concrètement la théorie gélasienne et la théorie du pouvoir indirect ? Comment des évêques soumis temporellement au roi pouvaient-ils exercer indirectement une juridiction terrestre en vertu de leur pouvoir spirituel sans encourir le reproche de s'affranchir de l'autorité de leur souverain légitime? Seule une juridiction spirituelle dotée d'une assise temporelle permanente et indépendante permettait de résoudre la contradiction. Dès lors, la double identité du pape était pour Bellarmin la raison de sa suprématie sur les rois : prince souverain de l'Église, il leur commandait en matière spirituelle ; prince souverain de l'État ecclésiastique, il échappait à leur pouvoir tempore ${ }^{34}$. C'était là aussi s'opposer diamétralement à Pierre de Belloy qui refusait que l'Église établît « un royaume terrien à part » ${ }^{35}$ : le Français avait bien compris que c'était la condition sans laquelle l'Église ne pouvait exercer le pouvoir sur les royaumes auquel elle prétendait.

18 La controverse se prolongea puisque l'Examen pacifique de la doctrine des Huguenots, qui parut durant le mois d'octobre 1589, avait pour ambition de répondre aux « objections de la response faicte à l'Apologie catholique $»^{36}$. De son côté, Pierre de Belloy avait fait paraitre après la publication de la bulle contre Henri de Navarre les Moyens d'abus ${ }^{37}$, toujours de manière anonyme. L'ouvrage stigmatisait désormais directement les débords du pape Sixte $\mathrm{V}$ et montrait que la sentence était entachée de nullité. Il reprenait les arguments déjà développés dans l'Apologie catholique, mais en insistant davantage sur l'ambition dévorante des papes qui les avait conduits à usurper, d'une part, l'autorité ecclésiastique en se prétendant évêque universe ${ }^{38}$ et, d'autre part, le pouvoir des princes temporels: «... les papes, despuis long temps, ne sont plus pasteurs en l'Eglise chrestienne, comme ils doyvent, ains roys \& monarques du monde, contre leur institution \& devoir $»^{39}$.

La charge était rude, mais elle se distinguait nettement de la polémique protestante, qui assimilait l'institution pontificale à l'Antéchrist ${ }^{40}$. Pierre de Belloy se plaçait dans un cadre pluriséculaire où la lutte contre les abus des papes était destinée à les rappeler aux devoirs de leur charge, et non à condamner le principe de celle-ci : "Ce n'est depuis Luther, ou ses semblables seulement, qu'on a tasché par raisons, \& par l'exemple des plus anciens evesques de Rome, nourris en toute sainteté, à ramener leurs successeurs, au chemin de l'humilité, de la pieté, \& de la droiture de leurs devanciers... $»^{41}$. Cela conduisait le juriste gallican à exhorter le pape dans la plus pure tradition du discours sur la papauté spirituelle: le pontife devait se consacrer au salut des âmes et non à la conservation ou à l'accroissement de ses possessions ${ }^{42}$. Pierre de Belloy offrait même une porte de sortie au pape en rejetant la responsabilité de la bulle sur la Ligue: le pontife 
pouvait se rétracter sans perdre la face puisqu'il avait été trompé43. Les Moyens d'abus ne rejoignaient le discours protestant que sur le plan politique, dans l'appel lancé à l'ensemble des princes européens: ils devaient s'opposer aux entreprises de la papauté s'ils ne voulaient pas être mis en proie les uns après les autres ${ }^{44}$.

\section{Le pouvoir spirituel et ses effets : la controverse autour des monitoires de 1589 et 1591}

Ce fut entre 1589 et 1594 que la controverse sur le pouvoir du pape sur les royaumes fut portée à son comble. Cela tint d'abord au fait que les bulles romaines de 1589 et 1591 ne s'en prenaient plus seulement à un droit de succession, mais au règne de deux rois. L'assassinat d'Henri III ne fit qu'exacerber une polémique qui avait désormais des implications politiques immédiates et dans laquelle se jouait, pour chacun des partis en présence, le salut de la France. Rome ne participa pas directement à la guerre des imprimés que se livrèrent les ligueurs et les " politiques ». Chacune des bulles réaffirmait, par elle-même, la prétention de la papauté à juger de la légitimité politique. Elles furent largement diffusées dans le royaume grâce au relais que représentait la Ligue, et l'on en profita d'ailleurs pour répandre celle de 1585 dont la publication avait été jusque-là interdite. Mais si Rome resta en retrait de la controverse doctrinale, la question du pouvoir pontifical fut bien alors l'une des lignes de fracture entre des catholicismes français engagés dans une lutte à outrance. Dans ce conflit, les "politiques " purent bénéficier du renfort apporté par un certain nombre d'auteurs protestants : les écrits de Toussaint Berchet et de Denys Godefroy contre les monitoires de 1591 s'en tenaient à des arguments gallicans, sans emprunter à la controverse réformée sa virulente identification du pape à l'Antéchrist ${ }^{45}$. Les catholiques évitaient, quant à eux, de se servir de l'arsenal polémique des huguenots ${ }^{46}$. Cette convergence avait bien sûr un objectif stratégique, mais elle reflétait aussi la conviction, partagée par un certain nombre de catholiques et de protestants français, que, dans le cadre de l'Église gallicane, la fracture confessionnelle était encore évitable.

L'un des principaux reproches adressés à la papauté était qu'elle tentait d'usurper des prérogatives qui n'appartenaient qu'aux souverains temporels. Pour Toussaint Berchet, c'était en cela que les bulles de Grégoire XIV étaient dangereuses : «Il est question de veoir en ce royaume une authorité souveraine, qui nous commande, autre que celle du roy... ${ }^{47}$. Devant le péril, les Français ne devaient retenir qu'une seule règle : « ... le salut de l'Estat est la loy souveraine $»^{48}$. La prêtrise et la royauté étaient des puissances que le Christ avait séparées et qui ne pouvaient donc être confondues ${ }^{49}$. À la seconde revenait le droit de faire respecter ce partage en réglementant l'usage d'une autorité spirituelle qui, par «l'empire des esprits » qu'elle détenait, menaçait l'équilibre divinement institué ${ }^{50}$.

Dans ces conditions, la séparation revendiquée présupposait une conception particulièrement restrictive du spirituel. On invitait en fait le pape à considérer que son pouvoir était d'autant plus grand qu'il était éthéré. « Sainct-Pere, imitez plus naïfvement le fouldre, \& comme il blesse sans offenser la robe, ny les habits, faites tousjours passer le vostre, sans s'arrester aux biens temporels : il est trop divin pour s'aheurter à des choses terrestres ", proclamait François de Clary ${ }^{51}$. Les peines spirituelles n'avaient donc aucune conséquence sur le lien de fidélité politique, qui était d'un autre ordre ${ }^{52}$. 
Aux yeux des "politiques ", l'Église était donc dans l'État et non l'inverse ${ }^{53}$. La royauté était le principe d'ordre qui devait permettre de rétablir l'harmonie qui avait existé entre la puissance spirituelle et la puissance temporelle dans l'Antiquité chrétienne, avant que les déportements des papes n'en ruinassent les fondement ${ }^{54}$. Car, conformément à la mentalité gallicane, c'était l'époque des débuts de l'église qui devait servir de règle et de modèle ${ }^{55}$.

Les catholiques zélés refusaient, quant à eux, de séparer la puissance spirituelle et la puissance politique. Comme le Christ, le pape pouvait les détenir l'une et l'autre ${ }^{56}$. Contre ceux qui suivaient la doctrine énoncée par Pierre de Belloy, un traité anonyme de 1589 montrait que seuls saint Pierre et ses successeurs avaient reçu immédiatement de Dieu un pouvoir universel, qui s'appliquait aux rois puisque ceux-ci faisaient partie des fidèles et ne détenaient pas leur royaume immédiatement de Dieu ${ }^{57}$. La mission que l'Église avait reçue du Christ d'œuvrer au salut des âmes justifiait cette suprématie.

5 Le discours sur le pouvoir du pape au temporel ne se résumait pas en effet à une froide argumentation théologico-juridique. Les catholiques romains avaient à cœur de montrer que cette puissance du pape correspondait à sa mission pastorale : « ... il n'y a point plus grand acte de charité que de pacifier une Republique, comme faict \& peut faire le pape reconciliant le prince avec le peuple, ou le deposant de son authorité quand il en abuse, ou quand il est d'autre religion que le peuple, comme est le Biarnois " ${ }^{58}$. Répondant aux arrêts des parlements en exil de Châlons et de Tours, qui condamnaient les bulles de Grégoire XIV ${ }^{59}$, l'Italien Matteo Zampini, qui avait fait partie de l'entourage de Catherine de Médicis et était devenu ligueur, exposait que le pape s'exprimait et agissait comme le bon pasteur soucieux du salut de ses brebis, comme un père avec ses enfants ${ }^{60}$.

C'était donc au pouvoir ecclésiastique de régler le pouvoir temporel, de lui fixer des bornes, et non l'inverse. Les catholiques zélés agitaient la menace d'un roi qui pourrait faire tout ce qu'il voulait, sans être soumis au contrôle du pape ou des évêques ${ }^{61}$. Ils montraient que les parlements étaient sortis de leur rôle en censurant l'Église, sur laquelle ils ne pouvaient avoir aucun pouvoir, puisqu'elle était, contrairement à eux, une institution surnaturelle ${ }^{62}$. Cela revenait à dire que l'État était dans l'Église.

Certains catholiques romains plaçaient dans le pouvoir pontifical les mêmes espoirs que les catholiques gallicans mettaient dans le pouvoir royal. Y obéir permettrait de rétablir l'ordre et de chasser les maux accablant la chrétienté. L'un des Seize, Matthieu de Launoy, exaltait ainsi la puissance de lier et de délier, qui était, dans le châtiment comme dans le pardon, pleinement efficace ${ }^{63}$.

8 C'était précisément sur les effets du pouvoir des clefs que portait un autre aspect de la controverse. Les "politiques» expliquaient qu'il n'y avait pas lieu de craindre les censures des papes. Pour Claude Fauchet, le pontife n'avait plus aucun pouvoir à partir du moment où il ne se comportait pas en digne chef de l'Église mais en "gendarme partial » ${ }^{64}$. François de Clary n'hésitait pas à défier le pape : «Car vostre fouldre, comme il n'est que contrefaict, peu genereux \& au contraire du naturel, flechit quand on luy resiste, \& n'offense que quand on luy cede $»^{65}$. Toussaint Berchet remarquait que "telles excommunications, ont esté de tout temps tonnerres qui ne faisoient que du bruit, sans pouvoir offenser personne : \& que nos predecesseurs ne s'en sont jamais donné de peine, mais les ont rejettées, \& s'en sont mocquez $\|^{66}$. Elles ne valaient rien car elles étaient utilisées contre la volonté de Dieu. L'argumentation ne se contentait plus ici de critiquer les pasteurs indignes de leur charge, mais reprenait la conception protestante du ministère des clefs ${ }^{67}$ : 
... nos peres sçavoient aussi que Dieu accomplit ses promesses, quand on fait sa volonté, \& que l'on y procede selon qu'il ordonne. Car c'est proprement sa parole, qui lie, de laquelle les hommes ne sont que ministres seulement. Que si on en use autrement, il n'y a plus de promesse de Dieu : \& par ainsi les excommunications ne sont plus que paroles des hommes, \& menaces, qui s'en vont au vent. Car Dieu n'est pas executeur des fautes que l'on y fait, \& des passions bien souvent, que l'on y apporte 68. fidélité au pape contre le roi - était soit une voie de salut, soit une voie de perdition.

\section{Normes canoniques et plenitudo potestatis : du conflit des doctrines à la concorde des pouvoirs}

Les fidèles devaient craindre le jugement de Dieu et non les sentences pontificales. Aux «bulles d'un homme menteur » s'opposaient les « lettres monitoires du Dieu vivant » qui prescrivaient d'obéir aux princes temporels ${ }^{69}$.

Les catholiques favorables au pape rappelaient, au contraire, combien étaient redoutables des censures spirituelles que Dieu ratifiait et qui compromettaient donc le salut de ceux qu'elles frappaient. Jean Le Bloy mettait solennellement en garde ceux qui persistaient à suivre les princes excommuniés au lieu de rompre avec eux ${ }^{70}$. Les bulles pontificales ne s'arrêtaient pas aux Alpes :

Que si vous venez à me rechanter le ramage de nos françoys huguenotizéz, qui disent \& faussement leur proverbe heretique excommunicationes papales non transeunt montes, comme si la puissance d'un pape estoit bornée seulement en Italie, mon sauveur \& le vostre, vous desment appertement, quand il dit, qucecumque ligaveris super terram, tout ce que tu lieras sur la terre, dit-il [Mt. 16, 19], à S. Pierre il ne dit pas seulement en Italie (aussy n'y estoit pour lors, estant en Cesarée) mais il dit sur toute la terre cum signo universali qucecunque: or est-il que le royaume de France est sur la terre \& non en utopie: la puissance du pape s'estend donc sur ce royaume aussi bien qu'en Italie ${ }^{71}$.

La mort d'Henri III était un signe éclatant que Dieu exécutait les sentences pontificales : ce roi qui méprisait les liens et les clefs de l'Église avait été châtié le $1^{\mathrm{er}}$ août, «le jour de sainct Pierre aux liens $»^{72}$. Un autre pamphlet ligueur de 1589 mettait aussi en garde les catholiques qui sous-estimaient les effets de l'excommunication ${ }^{73}$. Matthieu de Launoy consacrait également une partie de son texte à décrire les malheurs qui s'abattaient sur les excommuniés ${ }^{74}$. Sans s'inscrire directement dans la controverse, même s'il fut profondément influencé par les débats français, Giovanni Botero a lui aussi pris position au début des années 1590 sur ce sujet. Dans sa relation sur le pontife romain, il rappelait, en prenant l'exemple d'Henri III, que le châtiment divin s'abattait en général dès cette terre sur ceux que le pape avait condamnés ${ }^{75}$.

Un fossé profond séparait donc les catholiques gallicans et les catholiques romains. Au prisme de doctrines diamétralement opposées, la fidélité au roi contre le pape - ou la rupture qui au début des années 1590 semblait difficilement évitable n'a-t-elle pas eu lieu? Comment est-t-on passé, en quelques années, d'un pluralisme doctrinal de controverse à un pluralisme doctrinal de concorde? Mon propos n'est pas ici d'aborder l'ensemble des problèmes posés par l'absolution d'Henri IV par Clément VIII ${ }^{76}$, mais plutôt de discerner, à travers la controverse entre catholiques gallicans et catholiques romains sur le pouvoir du pape au temporel, ce qui l'a rendue possible. 

Chaque parti s'enfermait dans une vision du monde exclusive, qui n'était pas de nature à rallier la cohorte, de plus en plus nombreuse, de ceux qui souhaitaient - par-delà l'apparente incompatibilité des doctrines gallicane et romaine - rester fidèles à la fois au pape et au roi. Comme l'écrit Alain Tallon, « la majorité des catholiques français [...] sont en réalité d'accord sur le fait que l'Église gallicane est à la fois dans et au-dessus de l'État $\gg^{77}$. Mais cette majorité demeurait silencieuse ou, du moins, ne participait pas à la guerre des imprimés. Pour reconstituer les sentiments qui l'animaient, le discours des «politiques" est très éclairant. La plupart disaient écrire pour affranchir leurs compatriotes des scrupules qui les attachaient encore au pontife romain. « [L'auteur] veut seulement oster cest erreur de l'ame des chrestiens singulierement des François, de croire que cest homme soit si grand, \& si espouvantable qu'il se fait, qu'il ait pouvoir ou puissance, autre que de docteur, \& de pasteur ecclesiastique, en son evesché seulement, non ailleurs : sans aucune juridiction ni authorité mondaine... », écrivait Pierre de Belloy au début de ses Moyens d'abus ${ }^{78}$. François de Clary ne donnait pas d'autre objectif à ses Philippiques de $1592^{79}$. Il avouait que les armes spirituelles devaient être prises au sérieux : si la peur de la peine de mort faisait la force du magistrat, combien plus la terreur de la damnation faisait-elle celle du pape ${ }^{80}$ !

François de Clary plaçait ses espoirs dans les cours souveraines du royaume: "Qui se deffiera qu'elles ne puissent casser les abus de ces superstitieux liens? Qu'elles ne puissent delivrer les plus froids, \& plus foibles subjects du roy du vain scrupule qui pourroit assaillir leurs consciences? $»^{81}$ C'était là aussi reconnaître l'effet que produisaient les censures pontificales. Toussaint Berchet ambitionnait également de délivrer les âmes des inquiétudes infondées qui les empêchaient de désobéir à Rome ${ }^{82}$. À en juger par les efforts déployés pour les convaincre, les consciences tourmentées et les esprits indécis devaient être nombreux durant ces années cruciales. Sans se ranger à toutes les thèses romaines - peu, par exemple, étaient prêts à considérer qu'une excommunication et une privation fulminées par le Saint-Siège suffisaient à réduire un roi au rang de simple particulier -, les Français n'étaient pas disposés à franchir le pas qui séparait un conflit avec la papauté du schisme, dont ils ne savaient que trop où il avait conduit l'Allemagne et l'Angleterre ${ }^{83}$.

36 La guerre des imprimés ne devait qu'ajouter au désarroi de ceux qui espéraient une solution de concorde. Elle clarifiait moins les choses qu'elle ne les obscurcissait à force d'interprétations opposées des mêmes textes et des mêmes faits. Elle finissait aussi par éroder la majesté des pouvoirs en compétition et par rendre impossible leur nécessaire dialogue. Une perception aiguë des risques que cette controverse faisait courir à l'autorité pontificale explique peut-être le relatif silence de Rome et des théologiens italiens. Certains avaient pourtant plaidé pour répondre aux imprimés dirigés contre les bulles. Le nonce auprès de l'empereur, Filippo Sega, avait recommandé en 1586 au Saint-Siège d'entrer en lice en faisant paraître des réponses à l'Apologie catholique et au Brutum fulmen ${ }^{84}$. Les nombreux mensonges de l'auteur de l'Apologie, à commencer par celui de se prétendre catholique, expliquait Sega, risquaient d'être " authentifiés par notre silence " ${ }^{85}$. Le Saint-Siège s'abstint pourtant de participer systématiquement à la controverse.

La réserve romaine disparaissait certes quand l'orthodoxie catholique ou la Péninsule étaient directement menacées. Il est significatif de ce point de vue que Bellarmin ait réfuté l'Apologie catholique et qu'il n'ait repris la plume que pour réfuter l'Aviso piacevole dato alla bella Italia, un ensemble hétéroclite de textes antiromains destiné au public 
italien - ou du moins aux exilés italiens en terres protestantes - à l'occasion de la sentence de Sixte $\mathrm{V}^{86}$.

La Responsio du théologien jésuite était dirigée contre un texte jugé particulièrement dangereux parce que son auteur se présentait comme catholique, tout en minimisant les différends doctrinaux entre le catholicisme et le protestantisme. Le but de Bellarmin était de démasquer ce "pseudo-catholique " (pseudocatholicus) ${ }^{87}$ et de tracer une ligne de démarcation claire entre l'orthodoxie catholique et l'hérésie. Quant à la réfutation de l' Aviso piacevole, elle s'imposa probablement parce que le livre mettait en cause l'alliance entre l'Italie et l'Église romaine nouée dans le cadre de la Contre-Réforme.

Dans ces deux cas, le recours à la controverse imprimée semble s'être finalement imposé parce qu'il fallait contredire la prétention à détacher le catholicisme romain français ou italien de la suprématie pontificale. Encore cette participation à la polémique fut-elle entourée de précautions qui révèlent la circonspection des autorités romaines, si tant est qu'elles eussent encouragé et approuvé ces publications. La Responsio de Bellarmin parut sous pseudonyme et sans adresse, ce qui permit de n'engager dans la bataille ni l'autorité du titulaire de la chaire de controverse du Collège romain, ni celle de la papauté. C'était une manière de combattre les arguments invoqués par Pierre de Belloy sans donner l'impression que le juge suprême consentait à débattre de son bon droit et de ses raisons avec les hérétiques. L'absence de caractère officiel limitait aussi les conséquences de l'instrumentalisation de l'ouvrage par les ligueurs qui le firent traduire. Sixte Quint était soucieux de marquer la différence entre son pouvoir de déposition et la rébellion de la Ligue contre l'autorité légitime. Quant à la réfutation de l'Aviso piacevole, elle semble avoir été écrite dans un tout autre contexte ${ }^{88}$ et n'avoir été publiée qu'au début du XVII ${ }^{\mathrm{e}}$ siècle en appendice d'une réédition des Controverses.

En règle générale, la papauté se garda de répondre aux ouvrages dirigés contre ses excommunications et ses dépositions, en particulier quand ils venaient du monde protestant ou quand ils lui étaient destinés. Personne ne contredit le Brutum fulmen au nom du Saint-Siège. Les pontifes s'en tinrent aux bulles qu'ils édictaient : la rhétorique permettait d'instituer dans ce cadre « une inégalité de l'échange entre le vicaire du Christ et ses interlocuteurs » car «le verbe pontifical tombait de haut et venait de loin $»^{89}$. Le Saint-Siège n'avait rien à gagner en revanche à entrer dans des polémiques où il risquait d'avoir à justifier ce qui lui semblait aller de soi et de se lier les mains dans l'avenir en en disant trop. En gardant la complète maîtrise de son propre discours, il sauvegardait parfaitement les principes tout en se ménageant la possibilité d'en venir, plus tard, à un compromis pragmatique ${ }^{90}$.

41 Pour bien saisir ce qui a rendu possible le dénouement - ou, tout du moins, l'apaisement de cette crise, il faut aussi prendre toute la mesure de l'écart qui existait entre les positions de la papauté et celles de la Ligue radicale, et de ce qui, au contraire, pouvait rapprocher Rome de certains "politiques » modérés. Les ouvrages ligueurs anticipaient en effet très largement les sentences pontificales d'excommunication et de déposition en se fondant sur les canons de l'Église. Ce décalage fut particulièrement sensible en 1589 pour le cas d'Henri III. L'auteur anonyme du pamphlet De L'excommunication, \& censures ecclesiastiques considérait qu'il n'y avait pas besoin de déclaration contre le roi et que tout sujet, par le fait même du double crime de Blois, pouvait se considérer comme délié de son serment de fidélitée ${ }^{11}$. Il se fondait notamment sur un décret du concile de Lyon I qui prévoyait la déchéance pour le prince qui, en ayant ordonné un assassinat, avait mis une âme en danger ${ }^{92}$. Il expliquait aussi qu'Henri III était excommunié et déposé de iure pour 
n'avoir pas appliqué, au terme du délai d'un an fixé par le concile de Latran IV, la bulle promulguée en 1585 contre Henri de Navarre ${ }^{93}$. Une perspective similaire façonnait certaines interprétations ligueuses $\mathrm{du}$ monitoire de 1589. Cette menace d'excommunication remettait-elle en cause le fait que le roi de France était déjà excommunié et déposé ? Exploitant une réelle ambiguïté de la bulle - sans doute voulue -, le rédacteur de l'Advertissement aux catholiques expliquait que la déclaration du pape ne faisait que rendre plus solennelle et plus notoire la sentence prévue par les canons ${ }^{94}$. La Ligue entendait bien refermer la porte que Sixte V laissait encore ouverte à Henri III.

Cette tension entre l'application presque mécanique des canons et la plenitudo potestatis du pape semble ne pas avoir échappé à certains " politiques " modérés. En 1589, Gilbert Genebrard avait publié un texte où il cherchait à démontrer que les ecclésiastiques qui avaient communiqué dans les choses spirituelles avec Henri III après le massacre de Blois et avant la publication de la bulle du pape étaient frappés de l'excommunication majeure, puisqu'ils s'étaient joints à un excommunié notoire ${ }^{95}$. Ces clercs, dont un certain nombre d'évêques, devaient donc, selon lui, aller quérir à Rome leur absolution. Deux réfutations de ce texte furent rédigées par des proches des "politiques", avec des arguments semblables ${ }^{96}$ : l'excommunication majeure n'était encourue qu'une fois Henri III excommunié nominatim par le pape car la notoriété n'était pas équivalente à cette sentence expresse $\mathrm{e}^{97}$; l'excommunication de iure avait une valeur inférieure au jugement prononcé par le pontife ${ }^{98}$. La tentative de ramener les sentences du juge à des excommunications par le droit (les premières n'étant dotées que d'un plus grand degré d'évidence et de certitude) était enfin dénoncée comme une dénaturation du pouvoir des clefs: l'usage de celles-ci risquait en effet de ne plus apparaitre que comme un acte purement déclaratoire et non comme un acte de juridiction ${ }^{99}$. Dans un combat à fronts renversés était donc dénoncée la tentation ligueuse de se passer de la médiation du pape pour lier et délier les hommes.

43 Ce conflit entre les normes imposées par les textes et la plenitudo potestatis du pape parvint à son paroxysme au milieu des années 1590 lorsque l'Inquisition, l'Espagne et les ligueurs les plus intransigeants s'opposèrent à la réconciliation d'Henri IV avec l'Église romaine ${ }^{100}$. Dans l'Apologie pour Jehan Chastel, Jean Boucher n'hésitait pas à contester au pape la capacité de réhabiliter Henri de Navarre pour lui donner, après son absolution, la faculté d'user du droit de succession au trône de France dont il avait été privé par la bulle de 1585 : selon lui, cela excédait le pouvoir des clefs et c'était de surcroît contraire aux canons de l'Église ${ }^{101}$.

Catholiques zélés et "politiques" radicaux se rejoignaient en ce qu'ils érigeaient quelques textes et quelques principes en règles absolues et intangibles. Le devoir de soumission inconditionnelle au souverain temporel obéissait à la même logique que l'impératif de combattre en toutes circonstances les hérétiques. La papauté a manifestement beaucoup hésité sur l'attitude à suivre dans ces années de crise. Les bulles de Sixte $\mathrm{V}$ suivaient les normes juridiques en vigueur, mais elles exaltaient en même temps le pouvoir plénier du souverain pontife et tentaient - plutôt maladroitement d'offrir à Henri III une marge de manœuvre que la Ligue ne lui laissait pas. Après la brève parenthèse du pontificat de Grégoire XIV, Clément VIII parvint à s'émanciper des canons pour imposer la réconciliation d'Henri IV. Ce changement de politique réussit parce qu'au même moment des gallicans modérés comprenaient qu'il était temps d'en venir à une concorde. Dans deux traités de 1594, Antoine Hotman et Pierre Pithou abandonnèrent la polémique et manifestèrent la volonté de renouer le dialogue avec Rome: bien compris, 
les libertés de l'Église gallicane et le pouvoir suprême du pape n'étaient pas incompatibles ${ }^{102}$. À la fin de son texte, Pithou expliquait combien il importait de préserver l'union entre la France et le Saint-Siège :

Au surplus, tous ceus qui jugent droictement des choses, peuvent assez recognoistre de quelle importance a esté, \& est encores autant \& plus que jamais, la bonne \& entiere intelligence d'entre nostre Sainct-Pere le pape, \& le roy de France, lequel pour tres-justes causes \& tres-grands merites, a emporté sur tous autres le tiltre de Tres-Chrestien, \& premier fils \& protecteur de l'Eglise. Et pour ce doivent-ils en general \& en particulier estre d'autant plus soigneus d'entretenir les liens de ceste concorde par les mesmes moyens qui l'ont faict durer jusqu'à cy, supportant plustost les imperfections qui y pourroient estre, que s'efforçans de roidir outre mesure les cordes d'un nœud si franc \& volontaire : de peur que par trop serrer \& estreindre, elles ne se relaschent, ou (qui pis seroit, ce que Dieu ne vueille permettre) rompent tout à fait, au danger \& dommage certain de toute la chrestienté, \& particulierement du Sainct-Siege, duquel un de ses plus sages prelats a tres-prudemment recogneu \& tesmoigné par escrit que la conservation des droits \& prerogatives de la couronne de France estoit l'affermissement ${ }^{103}$.

De part et d'autre des Alpes, on se fiait désormais moins à des principes et à des textes, qu'au dialogue et à la concorde de deux pouvoirs souverains qui, incarnés par le roi et le pape, pouvaient, comme lois vivantes, lier et délier les hommes selon ce que commandait la raison d'État ou le salut des âmes. Peut-être y a-t-il là l'une des voies de passage au sein du catholicisme d'un pluralisme doctrinal de controverse à un pluralisme doctrinal de concorde.

\section{NOTES}

1. Declaration des causes qui ont meu Monseigneur le Cardinal de Bourbon, et les Princes, Pairs, Prelats, Seigneurs, Villes, \& communautez Catholiques de ce Royaume de France, de s'opposer à ceux qui veulent subvertir la Religion, \&l'Estat, [s.l.], [s.n.], 1585, p. 4.

2. Advis et resolution de la Faculté de Théologie de Paris, [s.l.], [s.n.], 1589, p. 7-8.

3. A. Pettegree, La réforme en France, 1520-1570. Les leçons à tirer de la culture de l'imprimé, dans Ph. Benedict, S. Seidel Menchi et A. Tallon (éd.), La réforme en France et en Italie. Contacts, comparaisons et contrastes, Rome, 2007 (Collection de l'École française de Rome, 384), p. 51-52.

4. Voir D. Crouzet, Les guerriers de Dieu : la violence au temps des troubles de religion, vers 1525vers 1610, Seyssel, 2005 (1990) ; Id., Dieu en ses royaumes : une histoire des guerres de religion, Seyssel, 2008.

5. [P. de Belloy], Apologie catholique contre les libelles, declarations, advis, et consultations faictes, escrites, \& publiées par les Liguez... Par E. D. L. I. C., [s. l.], [s. n.], [La Rochelle], [Pierre Haultin], 1585 , in- $8^{\circ}, 328$-[8] p. (cette édition porte, à la fin de la dernière page, la mention : "Achevé d'imprimer le 12. de Juillet. 1585 »); [Id.], Apologia catholica ad famosos et seditiosos libellos conjuratorum..., [s. 1.], [s. n.], 1584 (en réalité 1586), in-8º [24]-303 p. L'étude complète des trois éditions françaises de 1585, de l'édition française de 1586, des 
deux traductions latines, indépendantes l'une de l'autre, de 1586 et de l'édition anglaise a été faite par Francis Higman: The Examen pacifique de la doctrine des huguenots, Jacques Davy Du Perron and Henry IV (1994), dans Id., Lire et découvrir. La circulation des idées au temps de la Réforme, Genève, 1998 (Travaux d'Humanisme et Renaissance, 326), p. 583-602, ici p. 583-584 et p. 598-600. L'une des éditions latines porte sur la page de titre la date de 1584 : elle doit être datée en réalité de 1586. Voir ibid., p. 599.

6. [P. de Belloy], Apologie catholique... cit., p. 10-13.

7. Ibid., p. 190-223.

8. Ibid., p. 76-190.

9. Ibid., p. 76 et p. [167], paginé par erreur 716 .

10. Ibid., p. 80-81 et p. 172-180.

11. Ibid., p. 178. Sur l'usage politique de la métaphore du mariage, voir R. Descimon, Les fonctions de la métaphore du mariage politique du roi et de la république en France, $\mathrm{XV}^{\mathrm{e}-\mathrm{XVIII}}{ }^{\mathrm{e}}$ siècles, dans Annales. Économies, Sociétés, Civilisations, 47 (1992/6), p. 1127-1147.

12. [P. de Belloy], Apologie catholique... cit., p. 140-190.

13. Ibid., p. 151, p. 154-155.

14. Ibid., p. 155-157.

15. Ibid., p. 148.

16. Ibid., p. 157.

17. Ibid., p. 159.

18. Ibid., p. 157.

19. Ibid., p. 180-181.

20. Ibid., p. 166-182. Pierre de Belloy considérait par ailleurs que l'excommunication des princes ne relevait pas d'un évêque seul, ou même du pape, mais de l'Église, c'est-à-dire vraisemblablement du concile. Ibid., p. 162.

21. Ibid., p. 182-190.

22. Ibid., p. 154.

23. Ibid., p. 165.

24. La première édition de la version latine date de 1587. J'utilise ici des éditions de 1588 : [Robert Bellarmin], Responsio ad procipua capita Apologice, quae falso catholica inscribitur..., Auctore Francisco Romulo, Iuxta exemplar Romæ editum, 1588, 150 p. ; [Id.], Responce aux principaux articles \& chapitres de l'Apologie du Belloy, faulsement \& à faux tiltre inscrite Apologie Catholique..., traduit nouvellement du Latin sur la copie imprimee à Rome, par M. M., [s.l.], [s.n.], 1588, 144 p. La traduction française doit être comparée avec la version latine car celle-là n'est pas toujours fiable et tend à accentuer la virulence du propos: vraisemblablement faite dans la précipitation par les milieux ligueurs, elle visait un public plus large que l'original latin. Sur l'attribution de ce texte à Bellarmin, voir X. M. Le Bachelet (s. j.), Bellarmin avant son cardinalat. 1542-1598. Correspondance et documents , Paris, 1911, appendice I, Memoria Roberti Bellarmini, p. 437 : Bellarmin mentionne cet ouvrage parmi ceux dont il est l'auteur. Un exemplaire manuscrit de cet ouvrage est conservé à Rome à la bibliothèque Vallicelliana (Ms. M. 1). L'étude des différentes éditions de la Responsio a été faite par Francis Higman: The Examen pacifique... cit., p. 585 et p. 600-601. Sur la controverse entre Bellarmin et Pierre de Belloy, voir V. Frajese, Una teoria della censura: Bellarmino e il potere indiretto dei papi, dans Studi storici, 25, 1984/1, 
p. 139-152, ici p. 146-147 ; G. M. Barbuto, Il « principe » di Bellarmino, dans R. De Maio et alii (éd.), Bellarmino e la controriforma, Sora, 1990, p. 124-189, ici p. 161 et s. ; F. Higman, The Examen pacifique... cit.; R. Descendre, Géopolitique et théologie. Suprématie pontificale et équilibre des puissances chez Botero, dans Pensiero politico, 33, 2000/1, p. 3-37, ici p. 10-15; S. H. De Franceschi, L'orthodoxie catholique posttridentine face aux Politiques. Recherches d'histoire des idées politiques et religieuses, à paraître dans La période des guerres de Religion. Historiographie, méthodologie, histoire des idées politiques, actes des journées d'études organisées à Paris les 7 et 8 avril 2006 par F. Gabriel, I. Bouvignies et M. Penzi (je remercie l'auteur de m'avoir aimablement communiqué son texte avant sa parution).

25. [R. Bellarmin], Responce... cit., p. 4.

26. Ibid., p. 4-5.

27. Ibid., p. 56.

28. Ibid., p. 61-62.

29. Ibid., p. 72.

30. Ibid., p. 80-84.

31. Ibid., p. 90-91. [Id.], Responsio... cit., p. 94. En utilisant consequenter comme antonyme de directe, Bellarmin reprenait ici la formulation utilisée par Torquemada au siècle précédent : Romanus pontifex [...] habet potestatem in temporalibus ex consequenti... (Juan de Torquemada, Summa de Ecclesia..., Venetiis, apud M. Tramezinum, 1561, livre II, chp. 114, fol. 265v). Il n'employait pas en revanche explicitement dans ce texte la distinction directe / indirecte dont il avait fait usage dans le premier volume des Controverses, paru un an auparavant, pour énoncer sa solution quant au pouvoir du pape au temporel (R. Bellarmin, Disputationes [...] de controversiis christianae fidei, adversus huius temporis hareticos..., I, Ingolstadii, Ex officina typographica D. Sartorii, 1586, Tertia controversia generalis. De summo pontifice, Liber V, col. 1082-1111).

32. [R. Bellarmin], Responce... cit., p. 93-94.

33. Ibid., p. 108.

34. Ibid., p. 109.

35. [P. de Belloy], Apologie catholique... cit., p. 154.

36. F. Higman, The Examen pacifique... cit.

37. [P. de Belloy], Moyens d'abus, entreprises et nullitéz du rescrit et bulle du pape Sixte $V^{\mathrm{e}}$..., [s.l.], [s.n.], Imprimé Nouvellement, 1586, VIII-30-451 p.

38. Ibid., p. [I]-[II].

39. Ibid., p. 429-430.

40. Voir notamment: De postremis motibus Gallice varia utriusque partis scripta scitu dignissima, quorum catalogus tertia pagina exponitur. Omnia fere ex gallico in latinum sermonem, ad usum eruditorum et historice studiosorum, fideliter conversa. Addita est præfatio, qua scriptorum ratio, historia et analysis declaratur, Francfort, Apud Joannem Wechelum, 1586, in-8 ${ }^{\circ}$, [16]-387 p.; [F. Hotman], Brutum fulmen Papæe Sixti V. adversus Henricum Serenissimum Regem Navarre, et illustrissimum Henricum Borbonium, Principem Condoeum. Una cum protestatione multiplicis nullitatis, [s. l.], [s. n.], [s. d.], in-8 ${ }^{\circ}, 234-[22]$ p.

41. [P. de Belloy], Moyens d'abus... cit., p. [II].

42. Ibid., p. 433-434. Sur ce discours, voir A. Prosperi, Un papato « spirituale» : programmi e speranze nell'età del Concilio di Trento, dans G. De Rosa, G. Cracco (éd.), Il papato e l'Europa, 
Soveria Mannelli, 2001, p. 239-254 ; B. Schmitz, Un office spirituel. Le pape et les devoirs de sa charge dans les projets de réforme autour du concile de Latran V, dans MEFRIM, 121-1, 2009, p. 219-259.

43. [P. de Belloy], Moyens d'abus... cit., p. 431 et p. 441.

44. Ibid., p. 446-447.

45. [T. Berchet], Conseil chrestien sur les monitoires et menaces d'excommunication et interdiction du pape Sfondrato, dict Grégoire XIIII..., [s.l.], [s.n.], 1591, 171 p. Cet ouvrage attribué à Toussaint Berchet a été ensuite traduit en latin par celui-ci: [Id.], Pium Consilium super papae Sfondrati, dicti Gregorii XIIII, monitorialibus [...] bullis et excommunicationis atque interdicti..., Francfort, M. Lechlerus, 1591, 276 p. [D. Godefroy], Maintenue \& defense des princes souverains et eglises chrestiennes, Contre les attentats, usurpations, \& excommunications des papes de Rome, [s.l.], [s.n.], 1592, [20]-357 p.

46. Claude Fauchet, Traicté des Libertéz de l'Eglise Gallicane..., dans J. Gillot (éd.), Traictéz des droicts et libertéz de l'Eglise gallicane, Paris, P. Chevalier, 1609, p. 196-197.

47. [T. Berchet], Conseil chrestien... cit., p. 5.

48. Ibid., p. 89.

49. [François de Clary], Les Lauriers du roy, Contre les foudres pratiquéz par l'Espagnol, Tours, J. Mettayer, 1590, p. 80-81.

50. [Id.], Philippiques, contre les bulles et autres pratiques de la faction d'Espagne..., Tours, J. Mettayer, 1592, fol. 60v-61r.

51. [Id.], Les Lauriers du roy... cit., p. 61. Voir aussi ibid., p. 78.

52. [T. Berchet], Conseil chrestien... cit., p. 129-137.

53. [Fr. de Clary], Les Lauriers du roy... cit., p. 167.

54. Ibid., p. 81.

55. [D. Godefroy], Maintenue \& defense des princes souverains... cit., p. 136-137.

56. L'Aveuglement et grande inconsideration des politiques, dicts Maheutres, lesquels veulent introduire Henry de Bourbon [...] à la Couronne de France... Par Fr. I. P. D. en théologie, Paris, R. Thierry, 1592, p. 58-59.

57. De L'excommunication, \& censures Ecclesiastiques, encourues par Henry de Valois..., Paris, G. Bichon, 1589, p. 79-82.

58. L'Aveuglement et grande inconsideration... cit., p. 55.

59. Sur l'action du Parlement de Tours, voir M. Penzi, Tours contre Rome au début du règne d'Henri IV, dans La culture gallicane. Références et modèles (droit, ecclésiologie, histoire), numéro de la Revue de l'histoire des religions, 226, 2009/3, p. 329-347.

60. M. Zampini, Ad calumnias et imposturas, a pseudo-parlamentis Cathalaunensi, \& Turonensi, ac Carnotensi Conventiculo, [...] impiè confictas in Gregorium XIIII..., I. C., Paris, R. Thierry, 1591, p. 2-3, p. 20-21, p. 80-86.

61. De L'excommunication... cit., p. 87.

62. M. Zampini, Ad calumnias et imposturas... cit., p. 13.

63. M. de Launoy, Remonstrance. Contenant une instruction Chrestienne de quatre poincts à la Noblesse de France..., Paris, N. Nivelle et R. Thierry, 1590, p. 61-62.

64. Cl. Fauchet, Traicté des Libertéz de l'Eglise Gallicane... cit., p. 196.

65. [Fr. de Clary], Les Lauriers du roy... cit., p. 90-91. 
66. [T. Berchet], Conseil chrestien... cit., p. 70-71.

67. Cf. Jean Calvin, Institution de la religion chrétienne (1560), dans Id., Opera quae supersunt omnia, IV, éd. G. Baum, É. Cunitz, É. Reuss, Brunswick, 1866, livre IV, chp. XI, col. 801.

68. [T. Berchet], Conseil chrestien... cit., p. 71. Je souligne.

69. Ibid., p. 170.

70. [J. Le Bloy], L'effroiable esclat de l'anatheme, et les merveilleux effets d'iceluy..., Paris,

D. Cotinet, 1589, p. [2] et p. 1-18.

71. Ibid., p. 12-13.

72. Effects espouventables de l'excommunication de Henry de Valois, \& de Henry de Navarre..., Paris, N. Nivelle et R. Thierry, 1589, p. 9.

73. Advertissement aux catholiques sur la bulle de nostre Sainct-Pere touchant l'excommunication de Henry de Valois. Avec plusieurs exemples des punitions estranges \& merveilleux jugements de Dieu sur les excommuniéz, Paris, G. Chaudiere, 1589, p. 17.

74. M. de Launoy, Remonstrance... cit., p. 109-120.

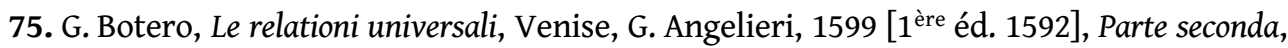
libro IV, p. 150-151. Sur Botero, voir R. Descendre, L'état du monde. Giovanni Botero entre raison d'État et géopolitique, Genève, 2009.

76. Je renvoie pour cette étude d'ensemble à ma thèse: B. Schmitz, Le pouvoir des clefs au $X V I^{e}$ siècle. La suprématie pontificale et son exercice face aux contestations religieuses et politiques , thèse de doctorat, Université de Paris-Sorbonne, 2013, t. II, chp. IX, « Le pouvoir de pardonner : des monitoires de Grégoire XIV à l'absolution d'Henri IV par Clément VIII », p. 1051-1293.

77. A. Tallon, Conscience nationale et sentiment religieux en France au XVI siècle, Paris, 2002, p. 11.

78. [P. de Belloy], Moyens d'abus... cit., p. [VI]-[VII].

79. [F. de Clary], Philippiques... cit., fol. [1r]-[1v].

80. Ibid., fol. 62r-62v.

81. Ibid., fol. 72r.

82. [T. Berchet], Conseil chrestien... cit., p. 4-5, p. 101-102.

83. Sur le lien que le gallicanisme maintenait avec Rome, voir A.Tallon, Conscience nationale et sentiment religieux... cit.

84. Lettre de Filippo Sega au cardinal Azzolini, Prague, 29 avril 1586, dans Nuntiaturberichte aus Deutschland nebst ergänzenden Aktenstücken, 1585 (1584)-1590, Zweite Abteilung, Die Nuntiatur am Kaiserhofe, Erste Hälfte, Germanico Malaspina und Filippo Sega. (Giovanni Andrea Caligari in Graz), éd. R. Reichenberger, Paderborn, 1905 (Quellen und Forschungen aus dem Gebiete der Geschichte, X), n 111, p. 228 ; Lettre de Filippo Sega au cardinal Azzolini, Prague, 10 juin 1586, dans ibid., n 119, p. 251-252.

85. Lettre de Filippo Sega au cardinal Azzolini, Prague, 29 avril 1586, dans ibid,, $n^{\circ} 111$, p. 228.

86. Aviso piacevole dato alla bella Italia da un nobile giovane francese sopra la mentita data dal [... ] re di Navarra a papa Sisto V, Monaco, G. Swartz, [Londres, J. Wolfe], 1586, [1]-62-[1] fol. ; R. Bellarmin, Appendix ad libros de summo pontifice. Quce continet responsionem ad librum quendam anonymum. Cujus titulus est: Aviso piacevole dato alla bella Italia, dans Id., Disputationes Roberti Bellarmini Politiani, S. R. E. cardinalis, De controversiis christiance fidei, 
Adversus hujus temporis hereticos. Quatuor tomis comprehense. Editio plurimis locis aucta et emendata, ex correctorio libello ab auctore vulgato Romce Ann. 1613, Paris, Ex officinis TriAdelphorum Bibliopolarum, 1613, t. I, col. 1013-1046. La controverse demeura de toute façon limitée dans ce cas: la diffusion de l'Aviso fut très faible en Italie et l'écrit de Bellarmin ne semble pas avoir donné lieu à une publication immédiate, indépendante des Controverses. Sur l'Aviso piacevole, voir J. Balsamo, Dante, l'Aviso piacevole et Henri de Navarre, dans Italique, 1, 1998, p. 79-94.

87. [R. Bellarmin], Responsio... cit., p. 4.

88. Elle cite Clément VIII comme le pape régnant : R. Bellarmin, Appendix... cit., col. 1016.

89. P. Gilli, J. Théry (éd.), Le gouvernement pontifical et l'Italie des villes au temps de la théocratie (fin XII - -mi-XIV s.), Montpellier, 2010, « Avant-propos », p. 19.

90. Une stratégie analogue fut suivie au début de la crise de l'interdit vénitien: comme Filippo De Vivo l'a bien montré, les autorités vénitiennes et romaines n'en vinrent à la "guerre des écritures » que parce qu'elles n'étaient pas parvenues à imposer le silence. F. De Vivo, Information and Communication in Venice. Rethingking Early Modern Politics, Oxford-New York, 2007, chp. 5 et 6.

91. De L'excommunication... cit., p. 39-40, p. 59-63, p. 75-76 et p. 77-79.

92. Les conciles œcuméniques, II/1, Les Décrets. Nicée I à Latran V, éd. G. Alberigo et alii, Paris, 1994, p. 611 et 613.

93. De L'excommunication... cit., p. 39-40. L'auteur du pamphlet négligeait le fait que le canon ne prévoyait pas des sentences ipso facto: l'excommunication devait être prononcée par l'ordinaire et la déposition par le pape.

94. Advertissement aux catholiques sur la bulle... cit., p. 31-32.

95. G. Genebrard, De clericis, praesertim episcopis, qui participarunt in divinis scienter \& sponte cum Henrico Valesio post cardinalicidium. T.P. assertio, Paris, A. Gorbinus, 1589, [2]-46 p.; [Id.], Excommunication des ecclesiastiques [...] qui ont assisté au divin service, sciemment \& volontairement avec Henry de Vallois, apres le massacre du cardinal de Guyse. Traduit du Latin d'un Docteur, par I. M., Paris, G. Gourbin, 1589, [2]-60 p.

96. [Charles Faye], Ad tractatum de clericis, prosertim episcopis, qui participarunt in divinis scienter \& sponte cum Henrico Valesio post Cardinalicidium, [s.l.], [s.n.], 1589, 112 p.; [René Benoist, Jean Lomedé et Jean Prévost], Ad assertionem, seu famosum libellum, contra clericos, praesertim episcopos, qui participaverunt in divinis scienter \& spontè, cum Henrico Valesio rege, post cardinalicidium, responsio, [s.l.], [s.n.], 1590, [16]-133-[1] p.

97. [Ch. Faye], Ad tractatum de clericis... cit., p. 21-33.

98. Ibid., p. 33-41.

99. Ibid., p. 42-43.

100. Sur le vif débat qui précéda l'absolution d'Henri IV et opposa les tenants de l'application rigoureuse des canons et les défenseurs du pouvoir de dispense du pape, voir B. Schmitz, Le pouvoir des clefs... cit., t. II, chp. IX, p. 1257-1293.

101. [J. Boucher], Apologie pour Jehan Chastel, parisien, exécuté à mort, et pour les pères et escholliers, de la Société de Jésus, bannis du Royaume de France. Contre l'arrest de Parlement, donné contre eux à Paris, le 29 décembre 1594. Divisée en cinq parties. Par François de Vérone Constantin, [s. 1.], [s. n.], 1595, chp. VIII, p. 54-64. 
102. A. Hotman, Traicté des droicts ecclesiastiques, privileges \& Libertéz de l'Eglise Gallicane, dans J. Gillot (éd.), Traictéz des droicts et libertéz... cit., livre premier, p. 271-363 ; P. Pithou, Les Libertéz de l'Eglise Gallicane, dans ibid., p. 251-270.

103. Ibid., p. 268-269.

\section{AUTEUR}

\section{BENOÎT SCHMITZ}

École normale supérieure / Centre Roland Mousnier (UMR 8596) / Institut de Recherches pour l'Étude des Religions - benoit.schmitz@yahoo.fr 


\title{
Les thèses gallicanes sur le pouvoir pontifical à l'épreuve du protestantisme
}

\author{
Benoît Schmitz
}

1 Dans son commentaire de l'Évangile selon saint Matthieu de 1518, le théologien écossais John Major (ou Mair), professeur à la Faculté de théologie de Paris, consacra deux digressions à la question du pouvoir pontifical ${ }^{1}$. S'il prolongeait la querelle qui avait opposé Cajetan et Almain à l'occasion du concile de Pise en répondant directement à certains arguments du dominicain ${ }^{2}$, son propos dépassait la polémique liée à ce schisme désormais refermé en offrant une défense de la position constante de l'Université de Paris et de la France depuis le début du XV siècle : l'Église universelle et le concile général qui la représentait étaient supérieurs au souverain pontife. La tradition théologique gallicane était présentée comme le meilleur antidote aux erreurs répandues par les curialistes, les thomistes, les canonistes et les Italiens ${ }^{3}$. Sans doute Major simplifiait-il abusivement les clivages - après tout certains canonistes italiens, comme Filippo Decio ou Girolamo Bottigella, avaient soutenu de leur autorité le synode pisan ${ }^{4}$; mais sa position témoignait d'une conviction largement partagée, à savoir qu'il n'y avait pas d'accord, de part et d'autre des Alpes, quant aux pouvoirs respectifs du pape et du concile et quant à la manière de concevoir la hiérarchie ecclésiastique. Le magistère parisien était ainsi posé en gardien d'une ecclésiologie et d'une théologie du pouvoir conciliaristes, beaucoup plus vigoureuses au début du XVI e siècle qu'on ne l'a parfois $\mathrm{cru}^{5}$. Contre les thèses romaines, les docteurs parisiens affirmaient la supériorité du concile sur le pontife car la suprématie de celui-ci ne s'entendait que par rapport à chaque membre de l'Église et non par rapport à l'ensemble de la communauté ou par rapport à l'assemblée qui la représentait. Du conflit ouvert par le concile de Pise à l'émoi provoqué à Paris par le concordat de Bologne, la crise ecclésiologique de la seconde décennie du siècle fut un moment privilégié pour l'expression des hétérodoxies croisées. Tout le problème est de savoir ce qu'il en advint avec la division confessionnelle.

2 On sait les espoirs placés par Luther dans la Faculté de théologie de Paris durant les premières années de la Réforme. Engagé dans un conflit avec le Saint-Siège, il avait quelques motifs de compter sur un soutien des gallicans. À mesure qu'il découvrait que 
seule une nouvelle conception de l'Église pouvait donner cohérence et sens à sa critique des doctrines et des pratiques romaines, il tendait à se placer sur un terrain qui n'avait rien de vierge, qui était saturé des débats et des controverses ecclésiologiques des années 1510. Il attendait, sinon une alliance, qui n'était guère dans sa manière de faire, du moins un appui contre le pape et, surtout, la reconnaissance de l'orthodoxie de ses thèses et de l'hétérodoxie de celles des « romanistes ». Il entrait toutefois dans ces espérances quelque chose d'illusoire : Luther forgeait une ecclésiologie complètement étrangère à la tradition gallicane. Son appel au concile à la fin de l'année 1518 après sa rencontre avec le légat pontifical Cajetan ne fit pas longtemps écho à celui qu'avaient lancé le Parlement et l'Université de Paris au printemps précédent : dès la controverse de Leipzig, durant l'été 1519, Luther s'employa à relativiser l'autorité des conciles.

3 La révolte luthérienne ne s'inséra donc pas dans ce jeu d'hétérodoxies croisées mais devint ce tiers terme contre lequel devaient se cristalliser des orthodoxies rivales. Pour les gallicans, il s'agissait de ne pas laisser à Rome le beau rôle dans la condamnation de l'hérésie : il fallait donc se prononcer en réfutant et en condamnant, mais sans pour autant se rallier aux thèses romaines à l'occasion d'une dissidence dont on pouvait raisonnablement penser que l'Église universelle aurait tôt fait de la digérer pour revenir au sempiternel conflit qui opposait la curie et l'Église gallicane.

\section{Réfutation de Luther et défense du pouvoir pontifical}

$4 \quad$ S'il est un thème qui émerge dans les premières réponses à Luther, c'est bien celui de la primauté pontificale, même s'il n'est pas exclusif d'autres sujets ${ }^{6}$. En s'en tenant aux ouvrages qui y font directement référence dans leurs titres, on peut notamment citer le Super apostolica sede (1520) du franciscain de Leipzig, Augustin von Alveldt, le In presumptuosas Martini Luther conclusiones de potestate pape dialogus (1518) du Maître du Sacré Palais Silvrestro Mazzolini, dit Prierias, la Revocatio Martini Lutherii augustiniani ad sanctam sedem (1520) d'Isidoro Isolani, le De Primatu Petri adversus Ludderum (1521) de Jean Eck, le De Authoritate summi pontificis et his quae ad illam pertinent, adversus impia Martini Lutherii dogmata (1521) de Cristoforo Marcello, le De divina institutione pontificatus totius Ecclesice in persona Petri apostoli (1521) de Cajetan, le Libellus de potestate Summi Pontificis (1523) de Tommaso Illirico, le De Petro et Roma adversus velenum Lutheranum (1525) de Jean Cochlaeus ou encore l'Apologia de convenientia institutorum Romance Ecclesice cum evangelica libertate adversus Lutherum de hoc pessime sentientem (1525) du Maître général des Dominicains, Francesco Silvestri. Comme l'a observé Adriano Prosperi, il n'y a pas eu de solution de continuité entre la lutte contre le conciliarisme et la polémique contre la Réforme protestante ${ }^{7}$. De fait, les contradicteurs de Luther étaient pénétrés d'une ecclésiologie héritée des grands conflits entre le pape et le concile et dont l'objet propre était de déterminer la supériorité de l'un ou de l'autre : certains, notamment dans l'ordre dominicain, étaient même des vétérans du combat mené, dans les années 1510, pour la papauté contre le concile gallican de Pise-Milan ${ }^{8}$.

5 Le choix de réfuter Luther en défendant l'institution pontificale est assurément révélateur de la réception de ses thèses et contribua en retour à orienter celles-ci : de l'aveu même du Réformateur, les ripostes l'aidèrent à prendre conscience de la rupture définitive avec la papauté qu'impliquait la théologie qu'il élaborait dans la conjoncture de son conflit avec Rome9. Le cas du cardinal Cajetan est emblématique : s'il avait écrit, lors de sa rencontre avec Luther à Augsbourg à l'automne 1518, des opuscules sur les 
indulgences, le Purgatoire ou la satisfaction, qui ne furent publiés qu'en $1523^{10}$, le premier ouvrage imprimé qu'il consacra à la réfutation de Luther fut le De divina institutione pontificatus, achevé le 17 février 1521, un mois et demi seulement après la condamnation définitive de Luther par le Saint-Siège ${ }^{11}$. Tout se passa comme si le dominicain avait jugé que la meilleure manière d'en finir avec l'hérésie luthérienne était de réaffirmer l'institution divine du pouvoir pontifical. À la lecture, le traité parait avoir prolongé davantage la controverse avec le conciliarisme que celle avec Luther. Aucune place n'était faite aux intuitions centrales de la théologie élaborée à Wittenberg. L'assimilation de la papauté à l'Antéchrist n'était pas non plus réfutée. Le cadre d'ensemble restait celui de la dispute entre le conciliarisme et le papalisme : apparemment, Luther ne faisait aux yeux de Cajetan que renouveler de vieilles hérésies et ne se distinguait pas fondamentalement des théologiens gallicans. Son livre n'était pourtant pas une simple redite des arguments utilisés dans les traités dirigés contre le concile de Pise et Jacques Almain ${ }^{12}$. Avec encore plus de netteté qu'en 1511 et 1512, il prenait comme critère de la vérité chrétienne l'interprétation par l'Église de l'Écriture sainte:

[...] les Chrétiens qui sont véritablement catholiques font preuve de sagesse en comprenant l'Écriture Sainte selon le sens que lui donnent les saints docteurs, et selon l'interprétation qu'en font les saints conciles, forts de l'autorité apostolique. Et si l'on rejette cette méthode lorsqu'on cherche à connaître la vérité chrétienne, on n'est pas chrétien ; celui qui s'en affranchit apparait comme un infidèle ${ }^{13}$.

6 La méthode devenait elle-même objet de foi et permettait d'établir avec certitude qu'il fallait tenir comme une vérité de fide credenda que le successeur de Pierre était, par l'institution du Christ, pasteur de toute l'Église. Cela revenait bien entendu à prendre position sur un point crucial de la controverse avec Luther puisque celui-ci défendait, de son côté, le Sola Scriptura.

7 Dans le corps de l'ouvrage, Cajetan ne se contentait pas, de surcroît, de réaffirmer les fondements de la suprématie du pape sur l'Église et le concile. Il s'efforçait de déterminer l'essence et le contenu du pouvoir pontifical : la métaphore des clefs lui permettait de montrer que la potestas spiritualis du vicaire du Christ consistait à ouvrir et fermer le Royaume des cieux et ne se limitait pas aux actes du pouvoir d'ordre et de juridiction ; et c'était à partir de cette essence qu'il distinguait dans la plenitudo potestatis quatre sortes de pouvoirs : le pouvoir de juger au for interne du sacrement de pénitence comme au for externe; le pouvoir de gouverner l'Église universelle; le pouvoir portant sur le Purgatoire ; le pouvoir de commander aux princes chrétiens en vue du Royaume des cieux ${ }^{14}$. En liant étroitement le pouvoir pontifical et l'économie du salut, Cajetan formulait une réfutation directe des positions de Luther.

Dans l'un des opuscules d'Augsbourg, le cardinal avait écrit à propos de l'une des thèses par lesquelles Luther remettait en cause les moyens traditionnels du salut: Hoc enim est novam ecclesiam construere ${ }^{15}$. Il avait ainsi compris dès 1518 que la doctrine luthérienne du salut était indissociable d'une nouvelle ecclésiologie. Répondre à Luther par un opuscule sur le pouvoir pontifical n'avait donc rien d'incongru. Beaucoup d'autres théologiens poursuivirent d'ailleurs dans cette voie, en accordant toutefois, dans leur apologie de l'autorité du pape, une plus grande attention aux principaux thèmes luthériens. Francesco Silvestri montra ainsi que les institutions de l'Église romaine ne contrevenaient en rien à la liberté évangélique ${ }^{16}$. Si les théologiens italiens et allemands donnaient une telle importance à la défense de la papauté, c'était parce que celle-ci était, à leurs yeux, la clef de voûte de leur ecclésiologie et de leur doctrine du salut, ce en quoi ils s'accordaient pleinement avec Luther. Ailleurs en Europe, on fit aussi bloc derrière le souverain pontife, 
comme en témoigne l'exemple d'Henri VIII : en 1521, Thomas More tenta de modérer le papalisme qu'il entendait exprimer dans son Assertio septem sacramentorum adversus Martinum Lutherum ${ }^{17}$.

\section{Le silence gallican sur la potestas papæ}

9 Le silence gallican n'en fut que plus éloquent. Si la Réforme ouvrit une nouvelle carrière au traité de potestate papce en Italie, en Allemagne et en Espagne, il n'y eut rien de similaire en France. Entre les premières et les dernières décennies du XVI siècle, l'éclipse des ouvrages gallicans sur le pouvoir pontifical fut bien réelle. Cette abstention était ambiguë car elle pouvait signifier soit que l'Église gallicane refusait d'abandonner ses maximes pour se rallier à la lutte contre l'ennemi commun, soit, au contraire, qu'elle s'en tenait à une prudente réserve pour ne pas donner d'armes aux protestants contre le Saint-Siège. James K. Farge a prouvé que si les théologiens parisiens mirent de 1518 aux années 1560 une sourdine à leurs doctrines, ils ne renoncèrent pas à leur indépendance : dans leurs censures, ils défendirent l'autorité pontificale lorsqu'elle était attaquée, mais n'épousèrent pas pour autant les thèses romaines et n'hésitèrent pas à s'y opposer au besoin ${ }^{18}$. La Réforme protestante n'était de toute façon pas le principal frein à l'expression du conciliarisme : la philosophie politique qui le sous-tendait battait trop en brèche l'absolutisme royal - allié à l'absolutisme pontifical depuis le concordat de Bologne - pour ne pas inviter à la prudence. Toute attaque directe contre le pape au nom des droits de la communauté risquait de passer pour ce qu'elle était parfois : une prise de position en faveur d'une monarchie modérée ${ }^{19}$.

10 Cette évolution correspondit-elle à une décadence de l'ecclésiologie gallicane ? Je crois qu'il faut ici distinguer entre le conciliarisme proprement dit, qui fut effectivement frappé d'atonie, et la théologie de l'Église développée par les gallicans en réaction à la Réforme protestante. Car ceux-ci n'ont pas déserté le terrain ecclésiologique dans leur combat contre l'hérésie : avec la même acuité que les théologiens italiens ou allemands, ils ont pris la mesure du défi qui était lancé à l'Église. Et s'il y eut peu d'ouvrages de l'ampleur de ceux des décennies précédentes, ce fut d'abord parce que ces théologiens donnèrent la priorité aux besoins pastoraux en s'efforçant de confirmer les fidèles dans la foi traditionnelle.

11 La determinatio du 15 avril 1521 par laquelle la Faculté de théologie de Paris condamna la doctrine luthérienne fournit un point de départ révélateur ${ }^{20}$. Comme l'écrit Philippe Büttgen, « les théologiens parisiens ont [...] réussi un tour de force : condamner Luther en 1521 , sans mentionner sa critique de l'autorité pontificale $»^{21}$. Contrairement à la bulle Exsurge Domine du 15 juin 1520, qui, parmi les articles censurés, en comptait six consacrés directement à la question du pouvoir pontifical ${ }^{22}$, la sentence parisienne ne mentionnait parmi les propositions condamnées aucune thèse portant atteinte à la potestas papce. Cette absence était d'autant plus remarquable que la Faculté avait été saisie, à l'origine, pour se prononcer sur la dispute de Leipzig, dont l'objet était précisément l'autorité du pape. Le choix de censurer dans la première partie de la "décision" des propositions tirées exclusivement du Prélude sur la captivité babylonienne de l'église permettait de « détourner l'attention de la question des limites de l'autorité pontificale vers celle, beaucoup moins épineuse, des sacrements de l'Église ${ }^{23}$. Mais cela revenait surtout à occulter une dimension majeure de ce texte où Luther avait renié tout ce qu'il avait reconnu auparavant à la papauté pour l'assimiler désormais à l'Antéchrist : c'était d'elle qu'il 
fallait affranchir l'Église pour retrouver la véritable économie sacramentelle voulue par le Christ $^{24}$. Le biais était d'autant plus sensible qu'une section de la condamnation était consacrée à la défense de l'autorité des conciles généraux ${ }^{25}$.

12 Jérôme Aléandre, qui, dix ans plus tôt, au moment du concile de Pise, avait été un témoin privilégié du conciliarisme gallican, ne s'y trompait pas: le seul défaut de la censure parisienne était de ne faire aucune mention de la primauté du pontife, article qu'il estimait pourtant plus facile à prouver par l'Écriture sainte que bien des autres choses tenues pour absolument certaines dans l'Église. Il ne croyait pas aux raisons avancées par les docteurs pour expliquer leur attitude: s'ils n'en disaient mot, ce n'était pas pour éviter qu'on les jugeât à la solde de la papauté et que leur sentence fût par conséquent écartée comme suspecte, mais à cause de l'antique conception de l'école parisienne super pontifice et concilio. Aléandre se promettait de convaincre les théologiens parisiens d'embrasser la position des autres écoles et d'inclure une défense de la primauté pontificale dans un nouveau texte: un avantage décisif serait ainsi pris dans la lutte contre Luther car les docteurs parisiens avaient une grande influence en Allemagne ${ }^{26}$.

\section{La réponse gallicane à Luther sur le terrain ecclésiologique}

Le silence observé par la determinatio sur l'autorité pontificale n'aboutissait pas pourtant à une désertion du terrain ecclésiologique ou à une simple réaffirmation de l'autorité doctrinale des assemblées représentant l'Église universelle. La condamnation parisienne manifestait une grande lucidité quant aux implications ecclésiologiques des thèses luthériennes. Elle élevait ainsi une vigoureuse protestation en faveur de la conception traditionnelle: l'Église était organisée hiérarchiquement afin d'exercer le pouvoir d'essence divine dont le Christ l'avait dotée. La négation du sacrement de l'ordre était notée d'hérésie. La proposition qui attribuait un pouvoir identique à tous les chrétiens quant aux sacrements était condamnée comme hérétique et comme «destructrice de l'ordre hiérarchique ", de même que celle qui soutenait que les clefs de l'Église étaient communes à tous et que celle qui affirmait le sacerdoce universel ${ }^{27}$. La thèse selon laquelle le pécheur pouvait être absous par n'importe quel fidèle était également censurée $^{28}$. La Faculté rejetait aussi tout ce qui contribuait à restreindre le pouvoir ecclésiastique divinement institué. Elle qualifiait ainsi d'hérétique la proposition selon laquelle toute l'efficace des sacrements dépendait de la foi ${ }^{29}$. Elle dénonçait aussi la doctrine qui opposait les constitutions de l'Église à la liberté évangélique et qui qualifiait de tyrannique l'autorité spirituelle quand elle s'appliquait au chrétien sans son consentement $^{30}$. Elle dénonçait aussi fermement, mais sans leur infliger la note d'hérésie, deux propositions selon lesquelles il n'était pas au pouvoir des hommes de remettre, en vertu des clefs, les peines dues à la justice divine ${ }^{31}$. La section sur les châtiments qu'il fallait infliger aux hérétiques rappelait implicitement que l'église détenait un pouvoir coercitif $^{32}$. Enfin, les docteurs défendaient la liberté ecclésiastique contre les empiètements des princes ${ }^{33}$. À bien des égards, la réponse parisienne à Luther rejoignait donc la défense du pouvoir de l'Église telle qu'elle avait été entreprise par les théologiens italiens et allemands : elle soutenait en particulier l'efficace surnaturelle du pouvoir des clefs. Son originalité était de partir de l'ensemble de la hiérarchie et non du seul pontife. Deux des affirmations condamnées mentionnaient le pape: à chaque fois, la Faculté répondait en se plaçant sur le terrain de l'obéissance due aux prélats et sur celui de 
l'autorité de l'Église ${ }^{34}$. Les gallicans parvenaient ainsi à contribuer à la lutte commune contre ce qui portait atteinte à la potestas spiritualis sans renoncer à leur méfiance à l'égard de la théologie papaliste.

Cette perspective fut développée par Josse Clichtove dans l'un des meilleurs traités composés en France contre Luther, l'Antilutherus de $1524^{35}$. Comme l'a noté Jean-Pierre Massaut, Clichtove y concevait l'Église essentiellement comme un pouvoir ${ }^{36}$. Le théologien considérait la Réforme luthérienne comme une attaque contre l'ecclesiae statum ${ }^{37}$. Le premier livre était consacré à condamner la licence effrénée que les luthériens appelaient faussement liberté évangélique en montrant que l'Église et ses chefs avaient le pouvoir d'établir des peines qui obligeaient en conscience. Le deuxième livre réfutait la doctrine du Réformateur sur la messe en rappelant qu'il y avait des ordres et des grades différents dans l'Église, que tous n'étaient pas prêtres et que l'Eucharistie était un vrai sacrifice. Le troisième livre défendait la valeur des vœux religieux. La théologie de Luther était donc réfutée à partir d'une apologie de l'ordre et des pouvoirs constituant l'Église. La faculté d'édicter des lois ecclésiastiques était notamment déduite du pouvoir de lier et délier : conformément à la perspective gallicane, Clichtove ne distinguait pas ici les prérogatives du pape de celles des autres évêques, mais exposait le bien-fondé d'un pouvoir de gouvernement qu'il attribuait, sans plus de précisions, "aux suprêmes pasteurs de l'Église ${ }^{38}$. La prudence était de mise : le théologien s'efforçait de contourner les points de désaccord entre Rome et Paris, pour mieux soutenir leur conception commune du pouvoir spirituel. Clichtove ne répugnait d'ailleurs pas à affirmer parfois, en termes généraux, la place éminente du pape : au chapitre III du second livre, il montrait à partir des Évangiles que Pierre avait été institué principal recteur de l'Église, que les Apôtres avaient reçu, quant à eux, le gouvernement de celle-ci sur des territoires bien déterminés et, enfin, que soixante-douze disciples avaient été aussi établis par le Christ ; à Pierre succédaient les souverains pontifes, aux Apôtres les évêques, aux disciples les prêtres ; ce n'était donc pas, concluait Clichtove, par invention humaine, comme le disait Luther, mais par constitution divine que l'Église était partagée en plusieurs parties ordonnées hiérarchiquement ${ }^{39}$. Quand il s'agissait de défendre le principe de la hiérarchie ecclésiastique, il n'hésitait donc pas à se rapprocher des positions romaines.

Les décrets du concile provincial de Sens de 1528 étaient de la même veine ${ }^{40}$. Le premier décret affirmait l'unité et l'infaillibilité de l'Église, le second expliquait qu'elle n'était pas invisible, le troisième traitait de l'autorité des conciles, le quatrième et le cinquième du rapport entre l'autorité de l'Église et l'autorité des Écritures, le sixième des constitutions humaines, que détaillaient les articles suivants consacrés aux jeûnes, au célibat des prêtres et aux vœux. Le dixième décret portait sur les sept sacrements, le onzième sur le sacrifice de la messe, le douzième sur la satisfaction, le Purgatoire et la commémoration des fidèles défunts, le treizième sur la vénération des saints et le quatorzième sur celle des images. La question du libre arbitre et celle du rapport entre la foi et les œuvres n'étaient traitées que dans les quinzième et seizième décrets. L'ordre des articles et les thèmes abordés étaient significatifs : le luthéranisme était essentiellement perçu comme une hérésie de nature ecclésiologique. Le concile de Sens y répondait par conséquent en privilégiant une défense de l'autorité ecclésiastique ${ }^{41}$. Celle-ci ne se confondait pas avec l'autorité pontificale, à laquelle aucun décret n'était directement consacré, mais elle l'incluait explicitement. Dans le décret sur les conciles, il était ainsi précisé que si le Christ était au milieu de deux ou trois fidèles rassemblés en son nom $(M t .18,20)$, il était à plus forte raison présent lorsque le souverain pontife et les principaux prélats se 
réunissaient ${ }^{42}$. De plus, le dix-septième décret dressait une liste d'erreurs qui avaient déjà été condamnées mais qui ressurgissaient. Parmi celles-ci, on trouvait une proposition assimilée aux thèses de Jean Hus, telles qu'elles avaient été proscrites lors de la quinzième session du concile de Constance : Primatus summi pontificis : non est a Christo ${ }^{43}$. La place faite au pape était encore plus grande dans le commentaire des décrets composé par Josse Clichtove : l'un des arguments pour établir la visibilité de l'Église partait du pouvoir pastoral de Pierre et des pasteurs que celui-ci avait institués ${ }^{44}$.

\section{La réponse gallicane à Luther sur le terrain pastoral}

La réponse gallicane à l'ecclésiologie protestante fut aussi développée dans les expositions du Credo, du Pater Noster et des Dix Commandements, souvent rédigées en français parce qu'elles étaient destinées aux laïcs. Guillaume Petit, évêque de Troyes et confesseur de François $\mathrm{I}^{\mathrm{er}}$, publia ainsi en 1526 Le viat de salut ${ }^{45}$. Il insistait tout particulièrement sur le magistère de l'Église, c'est-à-dire sur celui des clercs, auxquels les laïcs devaient s'en rapporter :

Parquoy s'il te vient quelque doubte ou tentation de la foy, ou en lisant ce livre, ou escoutant la lecture d'iceluy, ne puisse entendre le contenu, remetz le tout a Dieu et a l'Eglise, disant Credo in deum. Credo sanctam ecclesiam. Et plus n'en enquiers. Car nous sommes en ce monde pour croire seullement ce que Dieu a dit, qui est escript aux sainctz prophetes, apostres et evangelistes. Et ce que l'Eglise veult que nous croyons. En paradis c'est le lieu de voir, entendre et posseder ce que par deça nous croyons \& esperons ${ }^{46}$.

Les simples n'avaient de toute façon pour seule obligation que de connaître le Symbole des Apôtres :

Vray est que les autres considerations subtiles qu'on peult faire sur les articles de la foy \& sont escriptes aux docteurs. Le simple peuple n'est pas tenu les croire explicitement, mais seulement les superieurs a qui appartient de leur office rendre raison a ceulx qui la demanderoyent quant au regard de la foy ${ }^{47}$.

Petit utilisait le concept de "foi implicite»: les fidèles "ne peuvent pas bien en particulier avoir la foy de tout ce qui est en l'Escripture car ilz ne l'entendent pas. Mais ilz ont implicitement en la foy de l'Eglise disans: Credo sanctam ecclesiam, Je croy ce que $l^{\prime}$ Eglise croyt $»^{48}$. Le théologien esquivait donc le problème du modèle ecclésiologique, sur lequel il n'y avait pas de consensus parmi les catholiques, et prescrivait seulement l'obéissance à l'autorité ecclésiastique, sans préciser qui en était le titulaire en dernier ressort.

\section{L'inflexion de la doctrine gallicane : le rapprochement avec les positions romaines et ses limites}

Face à l'extension de la Réforme en France, ce choix du silence sur les questions disputées au sein du catholicisme fut assez vite dépassé. Un certain nombre d'évolutions eurent alors lieu dans le sens d'un rapprochement avec les positions romaines. Francis Higman a montré comment les évangéliques français avaient adapté des textes de Luther traduits et repris par Guillaume Farel dans Le Pater noster et le Credo en françoys de $1524^{49}$. Dans le Livre de vraye et parfaicte oraison, qui fut imprimé par Simon Du Bois pour Chrétien Wechel en 1529 et qui fut très largement diffusé dans les années suivantes, le passage que le texte 
d'origine consacrait à la concession des clefs fut modifié: une phrase était d'abord remaniée afin qu'il ne fût pas dit que les clefs étaient données à la communauté ; puis la proposition selon laquelle les Apôtres «représentoient la multitude des chrestiens » lorsqu'ils avaient reçu les clefs était omise; mieux encore, était supprimée l'idée que Pierre avait reçu cette concession comme signe et figure de l'unité de l'Église, une interprétation pourtant très classique dans les milieux gallicans, qui ne se faisaient pas faute de citer à ce sujet un texte de saint Augustin repris dans le Décret de Gratien ${ }^{50}$. Cet émondage est bien le signe qu'une révision de certaines positions gallicanes paraissait indispensable dans le nouveau contexte créé par la Réforme. La même prudence inspira John Major lorsqu'il reprit son commentaire sur saint Matthieu à l'occasion de la publication en 1529 de ses In Quatuor Evangelia expositiones : l'orientation conciliariste du propos initial fut soigneusement atténuée au profit d'une défense ferme de l'autorité du pape $^{51}$.

D'autres textes manifestent également cette pénétration des doctrines papalistes dans la théologie gallicane, jusqu'à produire parfois un mixte de papalisme et de gallicanisme. Le Dyalogue instructoire publié en 1538 par le dominicain et docteur de la Faculté de théologie de Paris Pierre Doré, en réponse au catéchisme de Gaspard Megander, pasteur à Berne, indiquait ainsi que Jésus-Christ était la pierre du fondement ${ }^{52}$. C'était là une formule gallicane traditionnelle, qui permettait de dire que Simon-Pierre n'était pas cette pierre sur laquelle était fondée l'Église. Mais l'auteur affirmait en même temps que le Christ avait fait de Pierre son successeur, position qui allait au-delà de ce que la théologie romaine la plus intransigeante attribuait au pape en le désignant comme le vicaire du Christ. Pierre Doré expliquait aussi que seule l'Église romaine était préservée des hérésies qui avaient gâté toutes les autres Églises particulières ${ }^{53}$. Le théologien précisait ensuite que le pontife était infaillible dans l'exercice de ses fonctions de pape : "s'il faict ce que est en luy d'assembler l'Eglise ou sacré consille, ne peult errer en determination de la foy \& disposition des bonnes meurs ${ }^{54}$. Au lieu de poser la papauté et le concile en rivaux, l'ecclésiologie de Doré privilégiait donc une concorde entre les deux institutions. Quant à l'absolution conférée dans le sacrement de pénitence, elle devait être donnée par

ceulx qui ont les clefz de l'Eglise en la vertu et puissance de Dieu : est assavoir ceulx qui ayantz l'ordre de prebstrise, ont science de celuy qui est digne ou indigne d'estre absous, et avec ce ont la puissance ou reguliere comme supérieurs en leurs subjectz, ou commise a iceulx par le pape, evesques ou curéz $z^{55}$.

La hiérarchie ecclésiastique au sommet de laquelle trônait le pape jouait donc un rôle essentiel dans l'accomplissement de l'œuvre de rédemption.

Un autre ouvrage de Guillaume Petit, l'Hortus fidei, publié de manière posthume en 1537 et destiné aux simples prêtres qui n'avaient pas le temps de se plonger dans les volumes des docteurs mais avaient besoin d'en connaître le contenu pour instruire les fidèles, témoigne également de cette inflexion doctrinale, qui n'était nullement un reniement des doctrines gallicanes, mais qui consistait plutôt en une tentative de les rapprocher des positions romaines ${ }^{56}$. Réfléchissant à la note d'apostolicité du symbole de NicéeConstantinople, Petit la concevait comme une note de firmitas: la solidité de l'Église reposait en premier lieu sur le Christ, mais aussi, en second lieu, sur les Apôtres et leur doctrine. Il ajoutait immédiatement que c'était pour signifier cette firmitas de l'Église que saint Pierre était dit vertex. Il rappelait que l'Église ne pouvait être détruite en citant les promesses faites par le Christ au prince des Apôtres et en concluait que seule l'Église de Pierre demeurait ferme dans la foi et était pure de toute erreur ${ }^{57}$. Plus encore que Doré, il 
insistait sur l'autorité doctrinale du pape qui avait le pouvoir de prononcer des sentences en matière de foi car il était le seul à pouvoir assembler les conciles et confirmer leurs décrets $^{58}$. Il liait enfin l'exercice du pouvoir de remettre les péchés à la hiérarchie ecclésiastique, dont le pape occupait le sommet ${ }^{59}$.

La Faculté de théologie elle-même contribua à cette évolution dans ses décisions doctrinales. Les articles de foi de 1543 réaffirmaient un pouvoir spirituel qui, dans la plupart des articles, était attribué à l'Église, sans plus de précision ${ }^{60}$. Le vingt-deuxième article précisait que les décisions infaillibles de l'Église universelle étaient prises par les conciles $^{61}$. Le vingt-troisième article abordait directement la question du pape, ce que les docteurs n'avaient pas fait en 1521 :

Et n'est moins certain, que de droit divin il y a un pape, qui est chef souverain en l'Eglise militante de Jesu-Christ, auquel tous Chrestiens doibvent obeir. Qui aussi a puissance conferer les indulgences ${ }^{62}$.

Sans abdiquer leurs positions conciliaristes, les théologiens rappelaient donc la suprématie du pape dans le gouvernement de l'Église et reconnaissaient, à travers la faculté d'octroyer des indulgences, son rôle quant au salut des âmes.

Les plus gallicans n'allaient bien évidemment pas jusque-là. En 1566, dans son Du Symbole des Apostres, \& des douze articles de la foy, Jean Du Tillet, évêque de Meaux, ne mentionnait pas le pape et se bornait à dire que les clefs de l'Église avaient été confiées aux Apôtres et à leurs successeurs ${ }^{63}$. Il y avait de toute façon des limites au-delà desquelles les gallicans les plus conciliants ne s'aventuraient pas. Dans les catéchismes et les manuels français, la définition de l'Église comme congregatio fidelium n'incluait pas la soumission au pontife romain, à la différence des catéchismes composés par Canisius, Lindanus ou, plus tard, Bellarmin $^{64}$.

\section{Hors de l'Église, point de salut}

Tout dans le discours des gallicans disait l'attachement à l'économie traditionnelle du salut, qui ne se concevait que dans la fidélité à l'Église de leurs pères. Ils rejetaient la doctrine de Luther car sa critique de la papauté impliquait un renversement de la conception du salut qui faisait coopérer harmonieusement la grâce divine et l'œuvre humaine, la toute-puissance de Dieu et le pouvoir de l'Église. Contre les protestants, ils défendaient l'ecclésiologie qui correspondait à leur conception du rôle de la hiérarchie ecclésiastique dans l'accomplissement de l'œuvre de rédemption. Ces théologiens le répétaient : hors de l'Église, point de salut. Il ne fallait donc s'en séparer à aucun prix. Dans son Epistre envoyée à un quidam fauteur des nouveaux Evangeliques, Gentien Hervet le disait très nettement :

Car ainsi comme la chose est certaine, que sans la foy operante par charité, nul est sauvé, aussi hors de l'Eglise nul ne l'est, ainsi comme au deluge nul ne l'estoit, qui ne fust en l'arche de Noé. [...] Car hors de l'Eglise on ne peut estre en charité, ne un martyr mesme ne pourroit estre sauvé. Il nous fault donq bien regarder que nous soyons en l'Eglise : car autrement quoy que nous facions, nous ne pouvons avoir salut $t^{65}$.

Et il ajoutait à la fin de son opuscule : «Car puis que hors de l'Eglise catholique il n'y a nul salut, ne pensez pas que vous puissiez estre sauvé en une Eglise qui est nouvellement forgée, \& laquelle Jesus-Christ ne recognoist pas pour son espouse ${ }^{66}$. 
défenseurs de la papauté savaient parfaitement jouer sur la hantise du schisme qui conduirait à l'hérésie ${ }^{67}$. En 1544, l'Alexipharmacon du dominicain et Inquisiteur général du royaume Mathieu Ory faisait du schisme une troisième espèce d'hérésie: la première était contre la raison naturelle, la seconde contre l'Écriture sainte, la troisième contre l'Église ${ }^{68}$. Dans son De la puissance et authorité du pape de 1565 , le bénédictin dijonnais Léger Bontemps montrait, en s'appuyant sur saint Cyprien qui associait étroitement hérésie et schisme, subversion doctrinale et désobéissance ${ }^{69}$, que la controverse sur le pouvoir pontifical était un point crucial du débat avec les protestants :

Ceste preditte secte \& ligue baille plusieurs faux enseignementz contraires à la foy chrestienne, lesquelz je ne veux à present tous refuter, de peur d'estre par trop prolixe, ains tant seullement (pour ceste heure) je veux dresser la pointe de ma plume, contre celuy point qui est l'un des principaux, si nous voulons croyre à Monsieur sainct Cyprian, sçavoir est, l'erreur suyvant lequel ces novateurs \& perturbateurs du repoz public, enseignent \& dogmatizent, que les Chrestiens ne sont tenus d'obeir au souverain Evesque, \& Lieutenant general de Jesu-Christ, qui est nostre Saint-Pere le Pape : ce que jamais en nul aage, \& en nul siecle du passé n'a esté approuvé par les arrestz \& sentences de noz ancestres ${ }^{70}$.

Certains discours allaient encore plus loin en liant le bonheur des hommes à la soumission au souverain pontife, à l'instar d'Artus Désiré dans Les Combatz du fidelle papiste de $1550^{71}$. La radicalisation du propos annonçait des temps plus âpres, aux positions plus tranchées. Mais des années 1520 aux années 1560, les écrits les plus papalistes restèrent plutôt marginaux en France et n'étaient pas de nature à ébranler sérieusement les gallicans.

30 Car ce qui frappe dans ce demi-siècle, c'est plutôt la tranquille assurance avec laquelle les théologiens français tracèrent leur propre voie. Le protestantisme ne provoqua pas une crise de conscience de la pensée gallicane. Ce fut certes une épreuve, mais le gallicanisme sut s'adapter à la nouvelle situation créée par la division confessionnelle. Il n'est pas toujours évident de reconstituer la doctrine exacte de la Faculté de théologie de Paris quant au pouvoir du pape car les formulations condamnées ou approuvées pouvaient varier. Ce qui est certain en tout cas, c'est que les gallicans n'éprouvaient pas le besoin de se placer sous l'enseigne du pape pour combattre l'ecclésiologie protestante.

31 La leur était trop liée à l'idée d'un pouvoir spirituel œuvrant en faveur du salut des âmes pour ne pas leur faire rejeter d'emblée les idées des "novateurs». Sans se rallier à l'apologie de l'autorité pontificale des théologiens italiens et allemands, l'Église gallicane a développé une défense de la potestas Ecclesioe, qui offrait à la monarchie française une alliance avec la puissance ecclésiale contre la subversion et qui faisait une place à la papauté dans la mesure où les gallicans partageaient avec Rome une même conception du pouvoir ecclésiastique et ne différaient d'elle que sur l'identité du détenteur du pouvoir suprême. Le conciliarisme et le papalisme étaient deux options possibles dans le cadre d'une ecclésiologie commune, qui formait entre eux un lien doctrinal d'autant plus solide que l'hérésie l'attaquait à la racine. La Réforme protestante les obligea à sortir du face-àface dangereux dans lequel ils tendaient à s'enfermer au début du XVI ${ }^{e}$ siècle et à mettre en avant la fonction salvifique de l'Église. Dès lors, c'étaient moins des hétérodoxies croisées que des orthodoxies croisées qui se trouvaient aux prises, chacune défendant, dans la condamnation du protestantisme, à la fois la cause commune et le modèle qui lui était propre. 


\section{dire qu'on ne pouvait être gallican sans l'être un peu, mais aussi que si l'obédience était}

une lettre de 1534, Jean Du Bellay écrivait : «Je ne suys pas trop papiste... » ${ }^{72}$. C'était acquise, elle était susceptible de degrés.

\section{NOTES}

1. Le premier excursus, Disputatio de Authoritate Concilii, supra Pontificem Maximum, et le second, Disputatio de Potestate Papce in rebus temporalibus, s'inséraient respectivement dans le commentaire du chapitre XVIII et dans celui du chapitre XVI de l'Évangile selon saint Matthieu. Ils furent publiés dans J. Major, Joannis Majoris [...] in Mattheu[m] ad literam expositio..., [Paris], apud J. Granjon, 1518, et furent réédités dans J. Gerson, Opera omnia, II, éd. M. L. Ellies du Pin, Antwerpiae, 1706, col. 1131-1145 et col. 1145-1164. Sur John Major et son conciliarisme, voir F. Oakley, Almain and Major: Conciliar Theory on the Eve of the Reformation (1965), dans Id., Natural Law, Conciliarism and Consent in the Late Middle Ages. Studies in Ecclesiastical and Intellectual History, Londres, 1984 (Variorum Reprints. Collected Studies Series, 189), $\mathrm{n}^{\circ} \mathrm{X}$, p.673-690; A.Ganoczy, Jean Major, exégète gallican, dans Recherches de Science Religieuse, 56, 1968/3, p. 457-495 ; J. K. Farge, Biographical Register of Paris Doctors of Theology, 1500-1536, Toronto, 1980, n 329, p. 304-311; J. K. Cameron, The Conciliarism of John Mair: A Note on A Disputation on the Authority of a Council, dans D. Wood (éd.), The Church and sovereignty, c.590-1918: essays in honour of Michael Wilks, Oxford, 1991, p. 429-435.

2. J. Major, Disputatio de Authoritate Concilii..., dans J. Gerson, Opera... cit., col. 1137 et s.

3. Ibid., col. 1132 ; col. 1144 ; Id., Disputatio de Potestate Papce in rebus temporalibus, dans ibid., col. 1150 .

4. Sur le débat entre canonistes et théologiens au moment du concile de Pise, voir B. Schmitz, Le pouvoir ecclésiastique : question canonique ou théologique? Filippo Decio, Cajetan et le concile de Pise-Milan, dans Les clercs et les princes. Doctrines et pratiques de l'autorité ecclésiastique à l'époque moderne, éd. P. Arabeyre et B. Basdevant-Gaudemet, Paris, 2013 (Études et rencontres de l'École des Chartes, 41), p. 271-284.

5. Voir l'analyse de Francis Oakley, contre celle de Remigius Bäumer: R. Bäumer, Nachwirkungen des konziliaren Gedankens in der Theologie und Kanonistik des frühen 16. Jahrhunderts, Münster (Westphalie), 1971 (Reformationsgeschichtliche Studien und Texte); F. Oakley, Conciliarism in the Sixteenth Century: Jacques Almain Again (1977), dans Id., Natural Law, Conciliarism and Consent... cit., $\mathrm{n}^{\circ} \mathrm{XII}, \mathrm{p} .130-132$.

6. Pour une analyse de cette production, je me permets de renvoyer à: B. Schmitz, Le pouvoir des clefs au XVI ${ }^{\mathrm{e}}$ siècle. La suprématie pontificale et son exercice face aux contestations religieuses et politiques, thèse de doctorat, Université de Paris-Sorbonne, 2013, t. I, chp. II, «Le tournant de la Réforme luthérienne : pouvoir des clefs et salut », p. 155-251.

7. A. Prosperi, Un papato "spirituale»: programmi e speranze nell'età del Concilio di Trento, dans G. De Rosa, G. Cracco (éd.), Il papato e l'Europa, Soveria Mannelli, 2001, p. 243. 
8. Voir U. Horst, o. p., Zwischen Konziliarismus und Reformation. Studien zur Ekklesiologie im Dominikanerorden, Rome, 1985.

9. Voir par exemple Martin Luther, Prélude sur la captivité babylonienne de l'Église (Juin 1520), dans Id., Cuvres, I, éd. M. Lienhard et M. Arnold, Paris, 1999 (Bibliothèque de la Pléiade), p. 712. Pour une lecture conjoncturelle des énoncés luthériens, voir Ph. Büttgen, Hérétique dans l'Église des Pères. Martin Luther, 1519-1521, dans L'argument hérésiologique, l'Église ancienne et les Réformes, XVI ${ }^{\mathrm{e}}-\mathrm{XVII} \mathrm{e}^{\mathrm{e}}$ siècles, sous la direction d'I. Backus, Ph. Büttgen et B. Pouderon, Paris, 2012 (Théologie historique, 121), p. 45-68.

10. Ch. Morerod, o. p., Cajetan et Luther en 1518. Édition, traduction et commentaire des opuscules d'Augsbourg de Cajetan, Fribourg (Suisse), 1994, $2 \mathrm{t}$.

11. Cajetan (Thomas de Vio), De divina institutione pontificatus Romani pontificis, éd. F. Lauchert, Münster (Westphalie), 1925, trad. fr. J.-M. Gleize, Le successeur de Pierre. L'institution divine du souverain pontificat de l'évêque de Rome, [Versailles], 2004.

12. Id., Scripta theologica, vol. 1, De comparatione auctoritatis papee et concilii cum Apologia eiusdem tractatus, éd. V. M. I. Pollet, o. p., Rome, 1936.

13. Cajetan, Le successeur de Pierre... cit., chp. 14, p. 159-160.

14. Ibid., chp. 5, p. 62-63; chp. 7, p. 84-86.

15. Cajetan, Questio decima. De fide ad fructuosam absolutionem sacramentalem necessaria, dans Ch. Morerod, o. p., Cajetan et Luther... cit., I, p. 336-337. Pour un commentaire de cette phrase, voir ibid., II, p. 471-476.

16. Fr. Silvestri, ... Apologia de convenientia institutorum Romance Ecclesice cum evangelica libertate, adversus Lutherum de hoc pessime sentientem, Venetiis, B. de Vianis de Lexona, 1525.

17. J. M. Headley, Thomas More and Luther's Revolt (1969), dans Id., Church, Empire and World. The Quest for Universal Order, 1520-1640, Aldershot (GB)-Brookfield (É-U), 1997, n I, p. $147-148$.

18. J. K. Farge, Orthodoxy and Reform in Early Reformation France. The Faculty of Theology of Paris, 1500-1543, Leyde, 1985 (Studies in Medieval and Reformation Thought, 32), p. 228-236.

19. A. Tallon, La France et le concile de Trente, 1518-1563, Rome, 1997 (Bibliothèque des Écoles françaises d'Athènes et de Rome, 295), p. 423-453.

20. Le texte de cette determinatio est donnée dans C. E. Du Boulay, Historia universitatis parisiensis..., VI, Ab anno 1500 ad an. 1600, Parisiis, P. de Bresche et J. de Laize de Bresche, 1673, p. 116-127.

21. Ph. Büttgen, Luther et la philosophie. Études d'histoire, Paris, 2011, p. 163. Sur l'histoire de cette condamnation, voir ibid., p. 157-163.

22. Bullarum diplomatum et privilegiorum sanctorum romanorum pontificum..., $V, A b$ Eugenio IV (an. 1431) ad Leonem X (an. 1521), Turin, 1860, p. 748-757. Les articles condamnés touchant le pouvoir pontifical portent les numéros 13, 17 et 25 à 28 . Ibid., p. 750-751.

23. Ph. Büttgen, Luther et la philosophie... cit., p. 162.

24. M. Luther, Prélude sur la captivité babylonienne... cit., p. 712, p. 768-771.

25. C. E. Du Boulay, Historia universitatis... cit., p. 125.

26. Lettre de Jérôme Aléandre à Jules de Médicis, 29 avril 1521, dans Monumenta reformationis lutherance ex tabulariis secretioribus S. Sedis, 1521-1525, éd. P. Balan, RatisbonneNew York-Cincinnati, 1884, p. 201. 
27. C. E. Du Boulay, Historia universitatis... cit., p. $119, \mathrm{n}^{\text {os }} 2,3,4$ et 5 de la section De sacramentis.

28. Ibid., p. $120, \mathrm{n}^{\circ} 19$ de la section De sacramentis.

29. Ibid., p. $120, \mathrm{n}^{\circ} 16$ de la section De sacramentis.

30. Ibid., p. 120, proposition unique de la section De constitutionibus Ecclesice.

31. Ibid., p. 122-123, $\mathrm{n}^{\text {os }} 5$ et 7 de la section De satisfactione.

32. Ibid., p. 125, proposition unique de la section De pæena hereticorum.

33. Ibid., p. 126, proposition unique de la section De immunitate ecclesiasticorum.

34. Ibid., p. 120, proposition unique de la section De constitutionibus Ecclesice; ibid., p. 122-123, $n^{\circ} 7$ de la section De satisfactione.

35. J. Clichtove, Antilutherus Judoci Clichtovei..., Paris, Ex officina S. Colinæi, 1524, 181[9] fol.

36. J.-P. Massaut, Thèmes ecclésiologiques dans les controverses antiluthériennes de Josse Clichtove: ordre, pouvoir, hiérarchie, dans B. Chevalier et R. Sauzet (éd.), Les Réformes. Enracinement socioculturel, Paris, 1985, p. 327-355.

37. J. Clichtove, Antilutherus... cit., fol. 2 r.

38. Ibid., fol. $45 \mathrm{v}$.

39. Ibid., fol. 59v-60r.

40. Decreta provincialis concilii senonensis..., Paris, Ex officina S. Colinæi, 1529.

41. Le premier décret rappelait qu'hors de l'Église, il n'y avait point de salut. Ibid., fol. 10r. Le troisième décret insistait sur la nécessité du pouvoir ecclésiastique. Ibid., fol. 11r. Le sixième décret prescrivait l'obéissance aux prélats et à ce qui avait été ordonné par les conciles et les souverains pontifes. Ibid., fol. 12r.

42. Ibid., fol. 11r.

43. Ibid., fol.20r. Cf. Les conciles cecuméniques, II/1, Les Décrets. Nicée I à Latran V, éd. G. Alberigo et alii, Paris, 1994, p. 884-889.

44. J. Clichtove, Compendium veritatum ad fidem pertinentium, contra erroneas Lutheranorum assertiones, ex dictis \& actis in concilio provinciali Senonensi..., Paris, Ex officina S. Colinæi, 1529 , fol. $5 \mathrm{v}$.

45. [G. Petit], Le viat de salut tres necessaire \& utile a tous chrestiens pour parvenir a la gloire eternelle, Troyes, J. Lecoq, [1526], 47 fol. Sur G. Petit, voir J. K. Farge, Biographical Register... cit., $n^{\circ} 386$, p. 367-373 ; F. Higman, Premières réponses catholiques aux écrits de la Réforme en France, 1525-c. 1540 (1988), dans Id., Lire et découvrir. La circulation des idées au temps de la Réforme, Genève, 1998 (Travaux d'Humanisme et Renaissance, 326), p. 500-503, p. 513-514 ; G. Bédouelle, Guillaume Petit, humaniste, théologien et politique, dans Les Dominicains en France devant la Réforme, 1520-1563, numéro de Mémoire dominicaine. Histoire - Documents - Vie dominicaine, 12, 1998/1, p. 63-73.

46. [G. Petit], Le viat de salut... cit., fol. B7v-B8r.

47. Ibid., fol. C4r.

48. Ibid., fol. C2r.

49. G. Farel, Le Pater noster et le Credo en françoys, éd. F. Higman, Genève, 1982 (Textes littéraires français). 
50. Ibid., p. 61. Cf. J. Almain, Tractatus de auctoritate Ecclesiae seu sacrorum Conciliorum eam reprcesentatium..., dans J. Gerson, Opera... cit., col. 990-991 ; J. Major, Disputatio de Authoritate Concilii... cit., col.1133-1134 ; Augustin (saint), Euvres de saint Augustin, 73 B, Homélies sur l'Évangile de saint Jean, XLIV-LIV, éd. M.-Fr. Berrouard, Paris, 1989, cinquantième homélie, p. 280-283; Grat., C. 24, q. 1, c. 6.

51. A. Ganoczy, Jean Major... cit.

52. P. Doré, Dyalogue instructoire des chrestiens..., Paris, J. Real pour V.Certenas, 1538, fol. F3r. Sur ce texte, voir F. Higman, Premières réponses catholiques... cit., p. 509-514, et Id., La réfutation par Pierre Doré du catéchisme de Megander, dans P.Colin, E.Germain, J. Joncheray et M. Venard (dir.), Aux origines du catéchisme en France, Paris, 1989, p. 55-66: F. Higman montre qu'il s'agit moins d'un catéchisme que d'un manuel de théologie. Sur Doré, voir J. K. Farge, Biographical Register... cit., n 151, p. 137-142, et J. Langlois, o. p., Pierre Doré, écrivain spirituel et théologien des laïcs, dans Les Dominicains en France... cit., p. 39-47.

53. P. Doré, Dyalogue instructoire... cit., fol. F3v.

54. Ibid.

55. Ibid., fol. G8v.

56. G. Petit, Hortus fidei..., [Paris], Vaenit apud Galeotum a Prato, [apud L. Cyaneum], [sumptibus Galeoti a Prato], 1537, [12]-97-[1] fol.

57. Ibid., fol. 86r-87v.

58. Ibid., fol. 81r-v.

59. In ecclesia sit plena potestas dimittendi peccata, sed gradatim, scilicet a papa in alios preelatos. Ibid., fol. 89r.

60. Les Articles de la Faculté de theologie de Paris, touchant \& concernant nostre Foy \& religion Chrestienne..., Paris, J. André, 1551, [8] fol.

61. Ibid., fol. [5v]-[6r].

62. Ibid., fol. [6r].

63. J. Du Tillet, ... du Symbole des Apostres, \& des douze articles de la foy, Paris, Chez la veufve G. Morel imprimeur du Roy, 1566, fol. D2v.

64. Comparer, d'une part, [G. Petit], Le viat de salut... cit., fol. B6r-B6v; J.Clichtove, Compendium veritatum... cit., fol. 5v ; G. Petit, Hortus fidei... cit., fol. 87v ; P. Doré, Dyalogue instructoire... cit., fol. F1r ; J. Du Tillet, ... du Symbole... cit., fol. D1r-D1v; Gentien Hervet, Epistre envoyée à un quidam fauteur des nouveaux Evangeliques..., Paris, G. de Nyverd, [s. d.], [1 ère éd., 1562], fol.5r ; Émond Auger, s.j., Catechismus..., Madriti, apud P. Madrigal

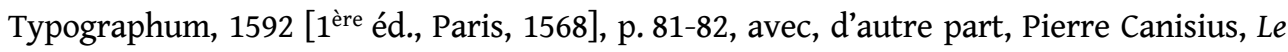
grand catéchisme de Canisius ou Précis de la doctrine chrétienne... (1554), II, trad. A. C. Peltier [d'après l'édition de Cologne de 1586, qui est une réimpression de l'édition de Cologne de 1569, procurée par le P. Pierre Busée], Paris, 1873, p. 23; Wilhelm Damasi Lindanus, Catechisme ou sommaire de la foy, \& devoir du vray Chrestien..., trad. G. Hervet, Paris, N. Chesneau, 1561, fol. 10r ; Robert Bellarmin (saint), Dichiaratione piu copiosa della dottrina christiana..., Rome, L. Zannetti, 1600, p. 59.

65. G. Hervet, Epistre envoyée à un quidam... cit., fol. 5r.

66. Ibid., fol. 32v. 
67. Sur l'articulation entre les notions de schisme et d'hérésie, et sur la hantise du schisme à l'époque moderne, voir A. Girard et B. Schmitz, Réflexions sur le schisme moderne: cadres doctrinaux, enjeux historiographiques et perspectives de recherche, dans De l'Église aux Églises: réflexions sur le schisme aux Temps modernes, sous la direction d'A. Girard et de B. Schmitz, MEFRIM [En ligne], 126-2, 2014 mis en ligne le 22 octobre 2014, consulté le 2 janvier 2015, URL : http://mefrim.revues.org/2018

68. M. Ory, ... Ad haeresum redivivas affectiones Alexipharmacon, Paris, B. Prevost pour J. André, 1544, fol. 2v-4r. Sur M. Ory, voir H. Bernard-Maitre, s. j., L'Inquisiteur dominicain Mathieu Ory et son Alexipharmacon contre les hérétiques (1544), dans Revue des sciences religieuses, 30, 1956/3, p. 241-260 ; J. K. Farge, Biographical Register... cit., n 372, p. 353-356.

69. Sur cette association, qui n'empêchait pas Cyprien de faire parfois la différence entre les deux notions, voir Cyprien de Carthage, L'unité de l'Église (De Ecclesiae catholicae unitate), éd. P. Mattei et alii, Paris, 2006 (Sources chrétiennes, 500), en particulier app. 2, n. 4, p. 268-269, et The Letters of St. Cyprian of Carthage. IV. Letters 67-82, éd. G. W. Clarke, New York/Mahwah (N.J.), 1989 (Ancient Christian Writers, 47), Lettre 69, p. 32 et s., et n. 4, p. 178-179.

70. L. Bontemps, De la puissance et authorite du pape..., Paris, N. Chesneau, 1565, fol. 2v-3r.

71. A. Désiré, Les Combatz du fidelle papiste..., Rouen, R. et J. Du Gort frères, 1550, fol. A4rA4v.

72. Lettre de Jean Du Bellay à Louis de Perreau, Rome, 22 février [1534], dans Correspondance du cardinal Jean Du Bellay, I, 1529-1535, éd. R. Scheurer, Paris, 1969 (Société de $l^{\prime}$ Histoire de France, 475), n 173, p. 356.

\section{AUTEUR}

\section{BENOÎT SCHMITZ}

École normale supérieure / Centre Roland Mousnier (UMR 8596) / Institut de Recherches pour l'Étude des Religions - benoit.schmitz@yahoo.fr 


\title{
Les deux voies des catéchismes : les controverses et l'endoctrinement. France et Italie
}

\author{
Michela Catto
}

1 Le catéchisme est la systématisation du savoir religieux élémentaire, la summa de tout ce que le fidèle doit savoir et pratiquer, l'exposition des doctrines chrétiennes fondamentales. Au cours du temps, le mot a pris un sens plus large qui a accentué péjorativement les caractères d'un contenu idéologique enseigné sans prétendre à aucune explication, d'un code à mémoriser, comme une table de multiplication, "comme un perroquet», pour reprendre une critique de Ludovico Antonio Muratori qui, dans le climat de dévotion bien réglée du XVIII ${ }^{\mathrm{e}}$ siècle italien, se plaignait de la diffusion d'une pratique religieuse sans $"$ entendement $»^{1}$.

2 Le catéchisme en tant qu'expression d'une pratique "dé-intellectualisée $»^{2}$, dénuée de moments de réflexion et de compréhension vraies, fut un produit de l'Église posttridentine. Il fut influencé par les nombreuses décisions prises ou mises en place à la fin du Concile de Trente, qui ne sont pas toujours claires et simples à interpréter sous le signe d'une continuité temporelle : de l'interdiction de lire la Bible en langue vulgaire à l'accentuation du rôle de médiateur et d'intermédiaire du clergé, de la tentative d'attribuer à la paroisse une fonction-charnière dans le réaménagement territorial de l'Église aux livres mis à l'Index, pour ne citer qu'un autre aspect. Catéchisme, Index et réforme des textes liturgiques, c'est-à-dire instruction des fidèles, barrage contre les hérésies et codification de la tradition, étaient trois problèmes que le Concile n'avait pas résolus et que lors de sa dissolution il avait remis au Pape; « dans l'expérience collective de l'époque post-tridentine, l'œuvre du Concile s'identifia surtout avec ces trois points qu'il n'avait pas affrontés, mais qui furent réalisés en son nom $»^{3}$.

3 Avant et après la promulgation du Catéchisme romain (1566), l'exigence d'une éducation religieuse et de contraster la doctrine des milieux protestants fut souvent satisfaite par un pullulement de catéchismes de controverse. Écrits en polémique ouverte contre les catéchismes luthériens ou calvinistes, ils insistaient sur les autres doctrines chrétiennes, 
en discutaient implicitement ou explicitement les thèses et les oppositions à la doctrine catholique, dans un esprit polémique, en s'appuyant souvent sur la Bible avec des récits de l'histoire sainte et de longues citations des Écritures. Progressivement ce type de catéchisme perdit du terrain. Comme j'essaierai de montrer, les autorités romaines jugèrent inadéquats les catéchismes de controverse - de ceux d'Edmond Auger à ceux de Pierre Canisius pour les territoires de l'Empire - car ils faisaient connaître les doctrines des hérétiques, ne serait-ce que pour les réfuter, et le récit biblique qui avait été interdit en langue vulgaire, bien que de façon assez incohérente du point de vue chronologique, avec des changements d'avis. Dans les années qui suivirent la publication du Catéchisme romain officiel, en langue vulgaire et en latin, destiné à la formation théologique du clergé, apparut un autre modèle : le catéchisme de Robert Bellarmin (1597) que la papauté essaya de promouvoir en imposant sa traduction dans toutes les langues et son usage dans les écoles relevant de l'Archiconfrérie de la Doctrine chrétienne, mais auquel en Italie et en France fut réservé un succès différent.

\section{Le catéchisme au Concile de Trente}

4 L'impératif de donner à la chrétienté un nouveau catéchisme qui organise la matière religieuse et améliore la connaissance de la doctrine chrétienne de la part des pasteurs et de leurs ouailles, resta en marge des débats du Concile. La question se posa tôt, elle affleura de temps en temps parmi d'autres problèmes, comme par hasard, sans arriver à une conclusion. Le Concile se termina en demandant au pape la rédaction d'un nouveau catéchisme ayant un caractère officiel. Mais au cours des discussions, de leurs enchaînements et des événements historiques qui les accompagnèrent, certains traits de ce catéchisme furent esquissés: son urgence en tant qu'instrument de préparation des chrétiens, la nécessité de construire une "structure" pour la catéchisation, comme les écoles de doctrine chrétienne instituées par les évêques dans leurs diocèses, et la valeur politique aussi d'un petit livre d'instruction religieuse élémentaire par lequel imposer des modèles de morale et de comportement.

Dès la première session du Concile, le 6 avril 1546, la discussion porta sur une methodus doctrinae christianae, un thème présent entre les lignes du débat plus complexe sur les " abusibus et remediis» des Saintes Écritures qui avait été ouvert la veille ${ }^{4}$. Le 20 avril Benedetto de Nobili résumait ainsi la délibération : "prima, che si faccia uno methodo delli luoghi principali della scriptura sacra per introductione di quella a tucti che si vorranno exercitar in quella; 2 uno chathechismo per li pucti per allevarli in le cose che spectano alla salute nostra e buoni costumi $»^{5}$. La discussion sur le catéchisme fut donc animée et soutenue par celle sur la Bible, sur la connaissance des Écritures de la part du clergé séculier et des ordres religieux. La préparation des prédicateurs et des hommes d'Église était conçue comme le premier point de l'instruction de la chrétienté, d'un clergé préparé et d'ouailles bien instruites. Le lien parait clair étant donnée la nature complémentaire des deux livres : l'un pour la parole de Dieu, l'autre pour un ensemble de règles et de savoirs tirés des Écritures et de la tradition de l'Église. Plus inattendu semble le résultat final, la décision plus de trente ans après le Concile de confier au catéchisme de Robert Bellarmin la tâche d'éduquer les catholiques, y compris les ecclésiastiques.

6 Un débat en opposition à la sola scriptura, et donc au protestantisme, vit les préliminaires d'un catéchisme, d'une réorganisation des livres officiels que l'Église prévoyait non seulement pour les textes liturgiques mais aussi pour la doctrine chrétienne. À la 
conclusion du Concile, le lien entre Évangiles et catéchisme serait renforcé suite aux décisions sur la langue de la Bible ${ }^{6}$ et au souci urgent d'endiguer la diffusion du protestantisme ${ }^{7}$. Il s'agissait d'une part d'élaborer un catéchisme à partir de la tradition biblique et des Pères de l'Église et de l'autre de créer les conditions qui autorisent et obligent les évêques à instituer des écoles de doctrine chrétienne dans tout leur diocèse, d'exercer un contrôle sur les prêtres, de vérifier la moralité des fidèles et des ministres du culte et plus en général d'appliquer les directives issues des débats doctrinaux.

Dans ce vaste projet de réforme, un nouveau catéchisme officiel était donc une nécessité. Il en fallait deux, un en latin et l'autre en langue vulgaire, pour satisfaire les exigences de chaque lecteur potentiel, et chacun d'eux devait être comme le "lait», capable d'instruire le chrétien. L'important n'était pas de résumer l'instruction dans un petit livre tout simple, mais de coordonner l'éducation religieuse avec un programme d'action pédagogique et pastorale.

8 Sans vouloir parcourir la longue histoire de la rédaction du Catéchisme romain $(1566)^{8}$, il faut souligner que l'idée du Concile d'un catéchisme pour les enfants ne fut réalisée ni par le Concile ni par le pape. Les catéchismes pour l'éducation des enfants, et des adultes non érudits, restèrent liés pour quelques décennies encore à une production libre et spontanée, aux exigences pratiques de l'éducation ou de la prédication, à des feuillets volants, à des doctrines de quelques pages, ou plus sophistiquées, qui répondaient aux idées protestantes ${ }^{9}$, presque des ouvrages de circonstance selon les besoins de leurs auteurs et du contexte où ils se trouvaient. Ce fut le cas au moins jusqu'en 1597 quand le jésuite Robert Bellarmin fut chargé de rédiger la doctrine chrétienne, ensuite approuvée et dotée de privilège par Clément VIII, qui marqua un tournant de la politique posttridentine concernant la catéchèse.

9 L'idée d'un nouveau catéchisme, exprimée lors d'un débat sur les Évangiles, reprit vigueur entre 1547 et 1548 lors d'une discussion sur les abus de la pénitence où «si concluse di farsi un catechismo, come tante volte s'è ragionato, nel qual si potranno includere la maggior parte di queste monitioni et provisioni delli abusi de sacramenti $»^{10}$. Le débat sur le catéchisme reflétait donc celui sur la Bible et s'élargissait aux devoirs et aux obligations des croyants, à la sphère des coutumes, en soulignant l'importance des sacrements - mis en discussion par les protestants - et des signes visibles de l'appartenance à l'Église et à son corps mystique. La reprise de la discussion pendant la période bolonaise, sans la présence d'évêques allemands ni espagnols, ${ }^{11}$ suggère que dans le contexte général du débat conciliaire la question du catéchisme était marginale.

10 La diffusion du savoir religieux et donc de normes religieuses et morales avait forcément une valence politique puisque savoir et normes étaient enseignés et imposés à des croyants-sujets. Les États ne pouvaient rester totalement étrangers à la question, d'autant plus qu'à l'époque du "disciplinamento", ils voulaient dicter les normes gouvernant leurs sujets et éviter que les pouvoirs religieux aient l'exclusivité des consciences et des corps. La production d'un catéchisme reprit son élan lors des débats du Concile, dans les années soixante, peu après que Ferdinand $\mathrm{I}^{\mathrm{er}}$ avait demandé un catéchisme à l'université de Vienne et aux jésuites. Sa requête fut immédiatement satisfaite et le jésuite Pierre Canisius écrivit, sur ordre d'Ignace de Loyola, un catéchisme pour les territoires impériaux. Quand s'ouvrit la dernière période du Concile, l'empereur demanda à l'assemblée de faire pour l'Église universelle un ouvrage destiné avant tout aux curés et aux prédicateurs des régions encore catholiques, pour qu'ils puissent l'utiliser pour instruire le peuple contre les ennemis de la religion catholique ${ }^{12}$.Uncatéchisme était 
d'autant plus nécessaire après l'Index de Paul IV en 1557, en partie exonéré en $1562,{ }^{13}$ qui avait condamné en manière générale les œuvres des hérétiques, des auteurs catholiques traduits par les hérétiques, tous les livres sans nom d'imprimeur, lieu ou date d'impression, même s'ils ne contenaient rien sur la foi ou la religion, ainsi que les livres imprimés par des typographes produisant également des textes hérétiques ${ }^{14}$. La généralisation de l'interdiction s'appliquait aussi aux catéchismes ${ }^{15}$. Bien que l'empereur incitât le Concile à produire un catéchisme universel, il n'avait pas l'intention de laisser circuler dans son royaume un texte entièrement dû à l'autorité ecclésiastique et échappant à son contrôle.

11 À partir de là, la question devenait également politique. Ferdinand $\mathrm{I}^{\mathrm{er}}$ proposa que le corpus des doctrines élaboré à Trente soit promulgué sur ses terres par « Sa Majesté et par les princes de l'Empire", c'est-à-dire par l'autorité politique, et imposé à tous les pasteurs, catholiques ou non. En outre, les princes devaient être autorisés à y apporter des changements et à en faire des synthèses, par exemple un sommaire simple et précis à l'usage des enfants. Les catéchismes sans imprimatur impérial étaient exclus. Le 3 janvier 1563 le roi de France fit parvenir par ses légats un mémoire où il faisait sienne la requête impériale d'un "bref sommaire de la doctrine chrétienne ", « en opposition directe aux erreurs actuelles $»^{16}$.

12 Selon Paolo Sarpi, les propositions de l'empereur avait suscité un "grand dégoût de la Cour romaine », parce que le catéchisme impérial n'avait pas été envoyé « au pontife pour être approuvé avec son autorité », qu'il n'était pas « sorti sous le nom des évêques de la région »; et surtout parce qu'il était intolérable que « le prince séculier se charge de faire composer et d'autoriser des livres en matière de religion, tout particulièrement ayant le nom de catéchisme», ce qui "ne démontrait rien d'autre que le fait qu'il revenait à l'autorité séculière de délibérer quelle religion le peuple devait avoir et laquelle répudier $»^{17}$.

13 Étant donné aussi ces exigences politiques, en mars 1563 une nouvelle commission du Concile fut préposée à l'examen de la question. Par le canon Ut fidelis, le septième des Decreta de reformatione, le Concile œcuménique donnait l'ordre formel de rédiger et de promouvoir le catéchisme ${ }^{18}$. Sans entrer ici dans les détails, je rappelle seulement que par la bulle solennelle Benedictus Deus du 26 avril 1564, Pie IV assuma la tâche que le Concile lui avait confiée. Il nomma dans ce but une commission pour le catéchisme qui coïncidait parfaitement avec celle de l'Index ${ }^{19}$.

14 Les travaux de l'Index se conclurent en mars et la commission fut libre de se dédier au catéchisme. Les mêmes hommes qui avaient rédigé l'Index, qui interdisait pour mieux contrôler, s'occupèrent de l'instrument de pédagogie et d'enseignement et annoncèrent d'avoir terminé leurs travaux à la fin de l'année. En septembre 1566 le Catechismus ad parochos était imprimé sur ordre de Pie V sous le titre de Catechismus ex decreto concilii Tridentini; un titre, écrit Hubert Jedin, qui «souligne qu'il ne prétend pas passer pour l'œuvre du Concile $»^{20}$ mais qui exprime le lien doctrinal avec ce dernier. Il est traduit en italien l'année même par le dominicain Alessio Figliucci et paraît en français à Bordeaux en 1567.

Le but du catéchisme était clair dès sa préface : «tum certe hoc tempore maiori studio et pietate elaborandum est, ut sana et incorrupta doctrina, tamquam pabulo vitae, fideles nutriantur et confirmentur [...]. Quae in re illorum impietas, omnibus Satanae artibus instructa, tam longe progressa est ». Et le ton était apocalyptique car «nulla tam remota regio, aut tam munitus locus, nullus Christianae reipublicae angulus inveniri potest, quo haec pestis occulte irrepere non 
tentarit » et les moyens pour véhiculer la peste comprenaient les «ingentia volumina », et surtout les infinis "libellos $»^{21}$. L'idée de formuler et d'imposer une uniformité de la religion dans le monde catholique était l'expression des ambitions universelles de l'Église du Concile. Elle allait devoir bientôt affronter les résistances des églises nationales et les particularismes locaux.

\section{Disputer pour éduquer : les controverses théologiques et les catéchismes}

16 Le premier catéchisme "catholique tridentin en français » ${ }^{22}$, comme le définissent les historiens-théologiens, parut à Lyon en 1563 sous le titre Catéchisme et sommaire de la doctrine chrétienne avec un formulaire de diverses prières catholiques et plusieurs advertissements pour toutes manières de gens, puis en forme réduite en 1568 et traduit en latin la même année, suivant à l'envers le parcours linguistique du Catéchisme romain. Son auteur Edmond (ou Emond) Auger ${ }^{23}$ était un personnage fascinant dont il manque encore une biographie moderne. Jésuite, proche du cardinal de Lorraine et de Henri III, longtemps prédicateur surtout dans le sud de la France, il était - selon la rumeur - un des grands partisans de la guerre de religion ${ }^{24}$. L'adjectif “tridentin" qui caractérise l'ouvrage n'est pas seulement lié à l'époque de sa parution: c'est le premier catéchisme catholique de l'âge moderne qui utilise la structure dialogique des questions et réponses, déjà utilisée par Luther, quoiqu'en forme élémentaire, dans son Petit catéchisme (1529) et par Jean Calvin (1541). En outre c'est le premier catéchisme ayant pour but de rétorquer au niveau pratique et théorique, à la doctrine protestante : écrit en langue vulgaire ${ }^{25}$, lu directement par les fidèles chez eux, sans aucune intermédiation ecclésiastique. Il aura un grand succès avec plus de vingt éditions françaises entre 1563 et 1582, et dans la même période des traductions en espagnol, italien, allemand et $\operatorname{grec}^{26}$.

17 Écrit au début des guerres de religion (1562-1598), le catéchisme d'Auger était formellement adressé aux enfants mais destiné à un public plus ample, comme le suggèrent ses «advertissements pour toutes manières de gens » : ecclésiastiques, nobles, juristes, lettrés, marchands, artisans, époux, jeunes et domestiques. Il paraissait peu après l'approbation de la Faculté de Paris du 29 janvier 1563, vue la nécessité de contraster la prédication calviniste. Le catéchisme est entièrement écrit à partir du Formulaire d'instruire les enfants en la chrétienté publié par Calvin (1541). Le jésuite Auger écrit dans les premières pages qu'il s'agit d'instruire "contre les erreurs de ce temps" pour que "les cervelles soient à tout le moins quelque peu mieux armées de quelques solides réponses contre les objections qu'on fait aux catholiques où est cette diversité de religion, que par le passé». Et pour que tout bon chrétien puisse répliquer aux observations des hérétiques, il ajoutait une «table des points plus contentieux et nécessaires qui sous brièveté sont ici traités comme s'ensuit ».

18 D'emblée Auger exprime la nature essentiellement de controverse de son catéchisme, sa fonction d'instruire pour pouvoir réagir à la prédication calviniste et repousser chaque point de sa pensée doctrinale. L'opposition est dans le contenu et dans la forme. Auger semble avoir sous les yeux le Formulaire de Calvin, il utilise la même structure (la foi, c'està-dire les mystères; la loi, c.à.d. le décalogue; la prière et les sacrements) dans un dialogue idéal qui en conditionne et déséquilibre la structure, comme dans les abondantes explications sur l'Église en relation avec les différentes parties du Symbole. 

qui n'est pas une narration de la foi chrétienne, mais un dialogue avec la doctrine calviniste ou l'antidote à Calvin. Dans le Décalogue, Auger évoque les critiques du culte des saints et des images; il corrige la doctrine de la concupiscence; il ajoute un bref commentaire de l'Ave Marie; il consacre aux sept sacrements plus des deux tiers de son ouvrage, une place qui n'est pas seulement déterminée par le moindre nombre de sacrements commentés par Calvin, il faut aussi répondre longuement aux doctrines calvinistes du baptême et de l'eucharistie. À l'eucharistie Auger consacre en effet huit de ses vingt-et-une leçons. Les neuf questions que pose Calvin pour définir l'église deviennent dix-neuf chez Auger, avec de longues réponses, un vocabulaire théologique riche de références aux Saintes Écritures - comme celui de Pierre Canisius que nous verrons ensuite - et un style plus polémique que dans le reste de l'ouvrage. Dans son catéchisme en somme, Auger menait ses combats théologiques en faveur des bonnes œuvres et en opposition à la certitude de la foi. Pour un dialogue, les articles sont trop longs et trop pleins de subtilités théologiques pour être appris par cœur; pour un catéchisme «neutre » la place consacrée aux différentes matières varie trop. Et le ton est celui de la lutte aux hérétiques qu'il s'agirait de convaincre « doucement $~^{27}$. du 15 juillet 1563 à Laínez ${ }^{28}$, venaient du territoire où il prêchait, " nel fondo del luogo dove è più guasta la Francia et più maltrattata e del quale bisogna havere più cura che di qualsivoglia altro "; où, dit-il dans une autre lettre, sévit la prédication de l'hérétique Pierre Viret et «aultres ministres de Sathan avec plus grande animosité et ostentation que en nul aultre lieu $»^{29}$. Auger parle de la nécessité d'« approuver un catéchisme unique pour la province au lieu de multiplier tant de livres superflus [...], faire composer des cantiques spirituels dans chaque langue pour se débarrasser des psaumes de [Clément] Marot $\aleph^{30}$. Il faudra aussi faire en français ces confessions de foi « et altre orationi brevi, acciochè perdano il credito questi libricciuoli venenosi etc. ». Il faut combattre l'hérésie en utilisant les mêmes instruments que les hérétiques, en faisant connaître et en rendant accessible la vérité romaine.

21 À l'époque où Auger écrit ces mots, la première édition de son catéchisme avait déjà paru et elle est souvent évoquée dans la correspondance du général Diego Laínez. Par exemple, le commissaire Oliviero Manareo écrit le 20 juillet 1564 à Laínez pour l'informer et se plaindre du fait qu'Auger a fait imprimer une deuxième édition - généreusement augmentée - bien qu'il ait « avisato che non gli aggiongesse altro di quello era stato visto da PP. Nostri » et sans les corrections suggérées aux « 4 luoghi che mi parevano molto duri, et altri che saria stato meglio, a mio giudicio, metterli altrimenti». Nous ne connaissons pas les objections du Père Manareo mais l'allusion aux passages «très durs " laisse supposer que la controverse trop vigoureuse faisait problème; de plus l'ouvrage ne plaisait guère à certains catholiques français. Dans son célèbre discours à la Sorbonne contre la Compagnie de Jésus ${ }^{31}$ Étienne Pasquier évoque le catéchisme d'Auger, et sa lecture publique, en l'accusant de désobéissance et d'irrégularités; ce catéchisme semble perçu comme une rupture avec la tradition religieuse française.

22 Dans une lettre du 18 juin 1564, le Père Auger se dit convaincu que « quantunque si facia el cathachismo per ordine del concilio, non per questo sarano condennati gli altri $»^{32}$. Prévision en partie erronée. Une nouvelle politique s'esquissait pour combler le vide partiel laissé par le Concile avec un catéchisme élémentaire dans les langues nationales, mais identique pour toute la chrétienté, une politique qui allait s'abattre sur le 
catéchisme de Pierre Canisius ${ }^{33}$. Écrit en 1555, en plein Concile de Trente, et révisé en 1566, malgré son succès dans les pays allemands (jusqu'à la parution du Deharbe, vers la moitié du XIXe siècle) $)^{34}$, il fut considéré inadéquat par la politique romaine posttridentine, peut-être à cause de la place qu'y prenait la dispute avec les autres doctrines. À ce sujet, il est intéressant de citer quelques exemples des idées protestantes ou hétérodoxes contenues dans les Summae de Canisius, bien que dans les notes et en latin et donc bien plus discrètement que dans le catéchisme d'Auger. « Perché dobbiamo venerare i Sagramenti, ed averli in somma stima, e onore? ? est la question rhétorique que pose le jésuite. Longue explication en note: «Rationes quatuor afferuntur: praeterea duo credenda proponuntur. Quod sacramenta Novae Legis non sint mera signa, ac sigilla, aut gratiae per fidem praehabitae, ut Lutheri; aut praedestinationis divinae, ut Calvini Sectatores dicunt [...] ». Pour quelle raison doit-on fuir le péché ? Encore en note le jésuite rappelle que «Igitur Deus non vult peccata, ut Calvini Sectatores docent, sed ea tantum permittit: Non Deus volens iniquitatem tu es $»^{35}$. Les noms de Luther et de Calvin reviennent souvent, tout comme les références bibliques - en latin - dont 150 seulement pour expliquer la messe. L'esprit fortement apologétique de Canisius déséquilibre certains articles, comme celui des commandements de l'Église dont le ton est plus celui de la polémique que de l'enseignement. Dans l'ensemble et compte tenu des différences, les catéchismes d'Auger et de Canisius ne sont pas faits pour être mémorisés.

Par leur références aux autres doctrines chrétiennes, les catéchismes d'Auger ou de Canisius semblaient plus aptes à satisfaire le besoin d'endiguer l'avancée du crédo protestant que ceux d'une Église qui se voulait unique dépositaire de la foi ; ils semblent des textes de réfutation doctrinale plus que des livres rapportant les vérités indiscutables de l'Église de Rome. Leurs citations bibliques en langue vulgaire semblaient trop évidentes à une Église qui à l'époque disciplinait fermement les traductions de la Bible. En 1566 et 1567, furent publiées les « dernières éditions des traductions intégrales italiennes de la Bible et du Nouveau Testament parues dans la Péninsule jusqu'à la moitié du XVIII ${ }^{e}$ siècle $\aleph^{36}$. Auger et Canisius s'occupaient trop des autres doctrines aux yeux d'une Église qui à l'époque discutait âprement sur l'application de la Règle IV de l'Index tridentin, concernant la concession de licences pour la lecture des œuvres de controverse en langue vulgaire, et dont les positions, sous la poussée de l'Inquisition, devenaient de plus en plus rigides $^{37}$.

Les écrits contraires à la théologie post-tridentine romaine étaient considérés dangereux car ils risquaient de diffuser l'hérésie et, pis encore, de permettre de comparer entre elles des opinions contraires et d'encourager ainsi une réflexion critique personnelle sur d'autres idées religieuses.

\section{Une nouvelle stratégie: la doctrine simple et élémentaire.}

En 1597 Clément VIII demanda à Robert Bellarmin, alors recteur du Collège romain (1594-1599), d'écrire un livre sur sa méthode d'enseignement du catéchisme ${ }^{38}$. L'intervention du pape suivait de près la publication de l'Index ${ }^{39}$ et donc l'interdiction définitive de lire la Bible en langue vulgaire, interdiction qui contribua à former et à " forger certains des "caractères originaires" des Italiens, évidents encore aujourd'hui dans notre mentalité collective $»^{40}$. Le premier fruit de la décision du pape fut la Dottrina cristiana breve perché si possa imparare a mente, publiée à Rome en 1597 ; le deuxième la 
Dichiarazione più copiosa della dottrina cristiana parue un an plus tard. Respectivement de 48 pages et 96 questions et de 276 pages et 273 questions, les Doctrines se développent de la même façon: le maître dialogue avec son disciple mais dans la version copieuse ce dernier pose les questions et dans la Doctrine brève la situation est inversée ${ }^{41}$.

Les doctrines de Bellarmin reçurent l'approbation de Clément VIII avec la Pastoralis Romani du 15 juillet 1598, qui en recommandait la plus vaste diffusion possible, les imposait comme unique texte des écoles de doctrine chrétienne dans les États de l'Église et en concédait le monopole à l'Archiconfrérie de la doctrine chrétienne de Rome, un monopole renouvelé jusqu'au XIX siècle. Pour l'enseignement, le pape exhortait " patriarchi, arcivescovi, vescovi, loro vicari e tutti i parroci in ogni parte del mondo " à adopter le catéchisme écrit par son ordre, et justifiait son intervention "considerando che i catechismi in uso, scritti da persone diverse e secondo metodi differenti » causent « grandi difficoltà e confusioni per l'insegnamento $\$^{42}$. L'ordre d'adopter l'œuvre de Bellarmin était encore suivi, comme une règle non écrite, par l'Inquisition lors de son recensement, en $1743^{43}$, des catéchismes présents dans la Péninsule italienne. Pendant le « recensement» inquisitorial, qui exigeait d'envoyer à l'Inquisition un exemplaire du catéchisme utilisé dans chaque paroisse, les cardinaux avait décidé que "nel caso si fosse trovata [...] qualch'una [doctrine] diversa dalla già composta dal fu Cardinal Bellarmino ", ils l'auraient examinée, corrigée ou interdite en utilisant comme modèle de référence le catéchisme de Robert Bellarmin. La concession de privilèges et de monopoles facilita un succès témoigné par 56 versions en langues étrangères et plus de 500 éditions. Le catéchisme de Robert Bellarmin était encore un modèle d'éducation religieuse, quoique profondément critiqué par les évêques français et allemands ${ }^{44}$, pendant le Concile Vatican I (1868).

27 Tout doué qu'il fut pour la controverse, le cardinal Bellarmin ${ }^{45}$ élimina de son catéchisme tout ce qu'il jugeait trop difficile pour les «simples" car il tenait à faciliter sa mémorisation, son apprentissage en langue vulgaire par l'entremise du maitre-curé des écoles de doctrine chrétienne. Deux siècles plus tard l'évêque janséniste de Prato et Pistoia Scipione de' Ricci trouve que les ouvrages de Bellarmin contiennent «falsità ed inesattezza ", regrette l'absence de " molte essenziali verità », les considère une source de « indebolimento della sana morale » à cause de la "puerilità » de certains de leurs enseignements, défauts qui « non possono tollerarsi a danno delle anime innocenti, che non debbono bere il veleno in quello studio che dovrebbe dar loro la vita, né debbon rimaner prive delle cognizioni più necessarie $»^{46}$.

Un ouvrage à la fois clair, simple et accessible à tous qui sache résoudre les doutes sans jamais créer d'incertitudes, exige bien des corrections et le sacrifice de tout ce qui peut paraitre superflu. Sur le manuscrit autographe de la Dichiaratione della dottrina christiana de Bellarmin, les mots, les adjectifs, les précisions qui pourraient engendrer d'autres questions sont barrés par le cardinal lui-même. Pour expliquer la Trinité, par exemple, Bellarmin prend l'exemple de trois personnes imaginaires, Pierre, Paul et Jean qui sur terre n'ont qu'une seule âme et qu'un seul corps, et il efface « un istesso volere, et sapere, un'istessa carne e un medesimo sangue » qui pouvait susciter des malentendus et surtout d'autres questions ${ }^{47}$ sur un concept déjà très difficile dont on comprendra « quel poco che si potrà ».

29 Du point de vue pédagogique, le cardinal se rapproche le plus possible des destinataires de ses doctrines, avec une forme de catéchisme plus simple, plus pratique et populaire qui reflète bien le projet religieux et culturel du temps : interdire les vulgarisations bibliques 
et faire du catéchisme le seul instrument de formation religieuse pour d'amples couches de la population. Comparé aux catéchismes précédents écrits à l'époque du Concile ou peu après, l'ouvrage de Bellarmin est construit sur des cas pratiques, des exemples tirés de la vie réelle, et insiste sur les aspects d'exercice de la foi, et non sur les questions théologiques, c'est une sorte de vadémécum contenant l'essentiel pour vivre chrétiennement. Alors que le Catéchisme romain parlait de foi, d'adoration avec piété, de sainteté de Dieu et de servir Dieu de tout cœur, Bellarmin parle de baptême, de foi et d'obéissance au souverain pontife, et il insiste sur les actes extérieurs, visibles et publics de la foi, professés explicitement par obéissance au pape et pratiqués en observant les sacrements et les commandements. Alors que les catéchismes de controverse élaborés pour les régions où le catholicisme était en contact avec l'hérésie, réfutaient les autres confessions sur un ton polémique, Bellarmin utilise un style simple et mesuré et ne parle que de la doctrine chrétienne vécue au quotidien.

Par exemple, pour expliquer le Créateur il recourt à l'image du maçon: "Siccome un muratore non può fare una casa di niente; ma di sassi, calcina, e legnami; né la può guastare con ridurla in niente ; ma con ridurla in sassi, polvere, legna, e simili cose. Sicché solo Dio, si dice, è Creatore, perché egli solo non ha bisogno di materia alcuna per far niente $»^{48}$. Pour faire comprendre le deuxième article de la foi et l'éternité du Verbe, à un miroir : comme "quando uno si mira in uno specchio, subito produce un'immagine di se stesso tanto simile, che non può trovar differenza veruna poiché non solamente è simile nelle fattezze ma ancora nel movimento, perciocché se l'uomo si muove, anco l'immagine si muove. E questa immagine tanto simile non si fa con fatica, né con tempo, né con istromento, ma in un subito, e con uno sguardo solo. Ora così avete da pensare, che Dio mirando se stesso con l'occhio dell'intelletto nello specchio della sua Divinità, produsse un'immagine similissima a se stesso $~_{49}$. Pour l'Incarnation, à l'habillement : " quando un uomo si mette una veste e due altri l'ajutano a vestirsi, allora tre sono, che concorrono a vestire, e pur un solo resta vestito : così tutte tre le persone divine sono concorse a fare l'incarnazione del figliuolo, ma il solo figliuolo si è incarnato, e si è fatto uomo ${ }^{50}$. Bellarmin affronte avec la même simplicité les thèmes des sacrements. L'eucharistie qui prenait tant de place dans les catéchismes de controverse est racontée sans références à l'Évangile ou à la théologie, mais d'un point de vue pratique. Qu'est-ce que l'hostie avant sa consécration? Quand le prêtre la rompt, rompt-il le corps du Christ? Dans quelle partie le corps du Christ est-il présent? Le Christ est-il vivant ou mort? Dans sa doctrine brève, le cardinal arrive à une simplicité extrême : combien de temps faut-il garder l'hostie dans la bouche? Que faire si elle colle au palais? ${ }^{51}$ Les rares références aux Écritures sont toujours en marge du texte et en latin, et se limitent le plus souvent à citer une source.

31 La rapidité des traductions du catéchisme de Bellarmin, ses nombreuses éditions, tout comme le monopole conféré aux écoles de doctrine chrétienne adhérant à l'Archiconfrérie de la doctrine chrétienne sont l'expression de la politique post-tridentine d'imposer un modèle simple et pratique d'éducation religieuse élémentaire, dénué de controverses et même de contenus bibliques. Au-delà des Alpes, il n'arriva pas à remplacer les catéchismes de controverse qui, surtout dans les régions de frontière, continuèrent à être produits pendant toute l'ère moderne ${ }^{52}$, parfois pour contraster les autres confessions religieuses, parfois dans la tradition catholique française des évêques hostiles à l'introduction d'un catéchisme pontifical. En Italie où l'épiscopat n'avait pas une forte tradition précédente de textes pour la catéchèse, les évêques étaient prêts à l'adopter pour l'enseignement dans leur diocèse ${ }^{53}$. 
La Doctrine de Bellarmin semblait interpréter parfaitement les décisions prises par l'Inquisition et la Congrégation de l'Index des livres, et l'interdiction de la lecture des Écritures et de la théologie de controverse en langue vulgaire: le chrétien était tenu à l'écart d'une connaissance directe des écritures et accompagné dans la pratique d'une religion ritualisée. Si le Catéchisme romain était un livre de théologie d'une Église qui aspirait encore à l'universalité, l'œuvre de Robert Bellarmin était l'expression d'un catholicisme refermé sur lui-même qui avait remplacé les contenus théologiques et intérieurs par des actes extérieurs ${ }^{54}$. C'était le fruit d'une nouvelle phase d'endoctrinement, désormais dépourvu de sens critique, plus focalisé sur la participation à la vie sacramentaire, aux cérémonies et aux rites que sur les savoirs théologiques. Un modèle pour un monde où il n'y avait qu'une religion et le pouvoir de la Congrégation de l'Inquisition limitait celui des évêques ${ }^{55}$. Ailleurs, dans les régions de frontière et de contact avec les autres confessions, où le sentiment d'identité nationale était plus fort, il fallait fournir les instruments de la controverse, la possibilité pour le croyant de confronter son adversaire. Dans le Discorso sopra il modo da tenersi nell'esame de' Vescovi que Giovanni Battista de Luca écrit en 1680 et adresse à Innocent XI, la situation italienne est claire. De Luca critique les épreuves prévues pour les candidats-évêques des diocèses d'Italie, et considère inutile et superflu l'examen de théologie scolastique. Selon lui, la théologie est utile dans un diocèse ayant «la mistura, overo una molta confinanza d'eretici, ò scismatici overo infedeli, sì che il principale istituto del vescovo all'uso della Chiesa primitiva consista nel predicare, e disputare sopra le cose appartenenti alla fede » ${ }^{56}$. Ce n'est pas le cas des évêques italiens qui « non hanno da disputare con infedeli, overo con eretici, e scismatici, né hanno da predicare a i medesimi per convertirli alla fede", sur leurs territoires il n'y avait « niuna mistura, overo infezzione, ò sospetto sia d'eresia, ò di scisma, overo di giudaismo ».

\section{NOTE}

1. L.A. Muratori, Della regolata devozione dei cristiani. Introduction de P. Stella, Torino, 1990, p. 50; mais voir aussi p. 77-78.

2. A. Biondi, Aspetti della cultura cattolica post-tridentina. Religione e controllo sociale, dans C. Vivanti (éd.), Storia d'Italia. Annali IV, Intellettuali e potere, Torino, 1981, p. 253-303, 277-286.

3. A. Prosperi, Il Concilio di Trento : una introduzione storica, Torino, 2001, p. 99.

4. S. Ehses, Concilii Tridentini Actorum, Friburgi-Brigoviae, 1911, p. 72-73. Le thème fut repris lors de la congrégation générale du 13 avril 1546 : ibid., p. 106.

5. G. Buschbell, Concilii Tridentini Epistularum, I, Friburgi Brisgoviae, 1916, p. 864.

6. Sur les traductions en vulgaire de la Bible G. Fragnito, La Bibbia al rogo. La censura ecclesiastica e i volgarizzamenti della Scrittura (1471-1605), Bologna, 1997 et Ead., Proibito capire. La Chiesa e il volgare nella prima età moderna, Bologna, 2005 ; et pour la France l'essai dans B.E. Schwarzbach (éd.), La Bible imprimée dans l'Europe moderne, Paris, 1999, et 
particulièrement A. Labarre, La censure de la Bible en France au XVI siècle, p. 400-406. Voir aussi E. Droz, Bibles françaises après le Concile de Trente (1546), dans Journal of the Warburg and Courtauld Institutes, 28, 1965, p. 209-222. Voir aussi G. Fragnito, Per una geografia delle traduzioni bibliche nell'Europa cattolica (sedicesimo e diciassettesimo secolo), dans J.-L. Quantin et J.-C. Waquet (éd.), Papes, princes et savants dans l'Europe moderne. Mélanges à la mémoire de Bruno Neveu, Genève, 2007, p. 51-77.

7. De la très vaste bibliographie sur la catéchèse dans le monde protestant, je rappelle la synthèse de J.F. Gilmont, Riforma protestante e lettura, dans G. Cavallo et R. Chartier (éd.), Storia della lettura nel mondo occidentale, Roma-Bari, 1995, p. 243-275.

8. Ici je renvoie à P. Rodriguez, R. Lanzetti, El Catecismo Romano : fuentes e história del texto $y$ de la redacción. Bases críticas para el studio teológico del Catecismo del Concilio de Trento (1566), Pamplona, 1982 ; et M. Catto, Un panopticon catechistico. L'arciconfraternita della dottrina cristiana a Roma in età moderna, Roma, 2003, p. 21-59.

9. Pour une histoire des catéchismes voir P. Braido, Lineamenti di storia della catechesi e dei catechismi. Dal "tempo delle riforme" all'età degli imperialismi (1450-1870), Torino, 1991 et G. Biancardi, Per una storia del catechismo in epoca moderna: temi e indicazioni bibliografiche, dans C. Mozzarelli (éd.), Chiesa romana e cultura europea in Antico Regime, Roma, 1998, p. 163-223.

10. G. Buschbell, op. cit., p. 303.

11. H. Jedin, Il significato del periodo bolognese per le decisioni dogmatiche e l'opera di riforma del Concilio di Trento, dans Problemi di vita religiosa in Italia nel Cinquecento. Atti del convegno di storia della Chiesa in Italia (Bologna, 2-6 sett. 1958), Padova, 1960, p. 1-16, p. 8.

12. Ferdinand I ${ }^{\mathrm{er}}$, écrivant au Concile le 20 octobre 1561, soulignait la nécessité d'un catéchisme pour les «dottori, parrochi, predicatori, maestri e rettori di scuole, che stavano nei luoghi dove ancora esisteva la religione cattolica ", pour qu'ils "potessero ricorrere e giovarsene nell'istruire il popolo e la gioventù sia dal pulpito e nelle prediche, sia nelle scuola, contro gli avversarii della religione cattolica » : P. Paschini, Il Catechismo Romano del Concilio di Trento. Sue origini e sua prima diffusione, Roma, 1923, p. 8, [aussi dans Cinquecento romano e Riforma cattolica, Roma, 1958, p. 33-89].

13. G. Fragnito, La Bibbia al rogo... cit., p. 75-95.

14. Index des livres interdits. VIII. Index de Rome 1557, 1559, 1564. Les premiers index romains et l'index du Concile de Trente, par J.M. De Bujanda, Genève, 1990, p. 38.

15. Sur la nécessité de produire un nouveau catéchisme après la publication de l'Index voir S. Steinherz, Briefe des Prager Erzbischofs Anton Brus von Müglitz 1562-1563, Prag, 1907, p. 59-60, lettre du 5 mai 1562.

16. Voir P. Paschini, op. cit., p. 11. Voir aussi la lettre de Claudio Jaio dans MHSI, Epistolae PP. Paschasii Broëti, Claudii Jaji, Joannis Codurii et Simonis Rodericii, Roma, 1971, p. 372-376, 373. La proposition prévoyait « di divider le materie, dando a una ventina di vescovi con la presidentia de doi legati theologi a considerar bene le cose che spettassero a i dogmi; quello che concernesse la reformatione ad altri venti con un altro legato; et il terzo de il catechismo e di riformar messali e breviarii a un numero pari pur con il terzo legato, li quali havessero ogni giorno separatamente a congregarsi sopra le dette materie, e con obligo che una camera havesse a conferir con l'altra le risolutioni che havessero preso, e che come poi tra loro si fossero accomodate le materie, si proponessero un giorno da $\mathrm{i}$ ss.ri legati in congregatione alla carica di haver a risponder i padri per verbum placet vel non placet, eccettuati però i tre più degni di queste tre classi, che potriano estendersi in 
quello che tornasse lor bene» : H. Jedin, Krisis und Wendepunkt des Trienter Konzils (1562/63), Würzburg, 1941, Sommario delli avvertimenti dati dal S.r Cardinal di Lorena intorno alle petitioni che l'ambasciatori di Francia hanno date a i SS.ri legati, p. 167-168.

17. P. Sarpi, Istoria del Concilio Tridentino, éd. G. Gambarin, II, Roma-Bari, 1935, p. 194.

18. G. Alberigo, G.A. Dossetti, P.P.Jannou, C. Leonardi, P. Prodi, (éd.), Conciliorum Oecumenicorum Decreta, Bologna, 1973³ , sessio XXIV, canon VII de reformatione, p. $764:$ «[...] si opus sit et commode fieri poterit, servari studeant, iuxta formam a sancta synodo in catechesi singulis sacramentis praescribendam, quam episcopi in vulgarem linguam fideliter verti atque a pa rochis omnibus populo exponi curabunt ».

19. J.M. De Bujanda, Index des livres interdits. VIII. Index de Rome 1557, 1559, 1564, p. 97.

20. H. Jedin, Storia del Concilio di Trento, Brescia, 1981, IV, t. II, p. 343.

21. Catechismus ex decreto Concilii Tridentini ad Parochos, éd. E. Benedetti, Roma, 1944, p. 4-6.

22. La définition est de M. Pernot, L'univers spirituel du Père Emond Auger, s.j., confesseur du roi Henri III, dans Revue d'histoire de l'Église de France, 75, 194, 1989, p. 103-114, 103.

23. J.P. Donnelly, Auger Emond, dans Ch.E. O'Neill, J.M. Domínguez (éd.), Diccionario histórico de la Compañía de Jesús, I, Roma-Madrid, 2001, p. 268-69. D’autres écrits d'Auger font penser qu'il voulait écrire un grand ouvrage en suivant l'index d'un catéchisme : De la vraye, reale et corporelle présence de Jésus Christ au Saint Sacrement de l'Autel, 1565; Des sacraments de l'Église catholique et vrai usage d'iceaux, 1567 ; Des sacrements, savoir du Baptême et de la Confirmation, de l'Eucharistie et du sacrifice de la Messe, 1567 ; Discours du sacrement de Marriage, 1572 ; Du Sacrement de Pénitence, 1574.

24. A. Lynn Martin, The Jesuit Emond Auger and the Saint Bartholomew's Massacre at Bordeaux: the Final Word, dans J. Friedman (éd.), Regnum, Religio et Ratio. Essays Presented to Robert M. Kingdon, Kirksville, 1987, p. 117-124 et Id., The Jesuit Mystique, dans Sixteenth Century Journal, 4, 1, 1973, p. 31-40. Sur le rôle d'Auger et de son Pédagogue d'armes (Paris, chez Sebastien Nivelle, 1568) dans le développement de l'idéologie belliqueuse de la Contreréforme voir G. Civale, Guerrieri di Cristo. Inquisitori, gesuiti e soldati alla battaglia di Lepanto, Milano, 2009, p. 35-38.

25. «J'ai suivi la façon de parler et d'enseigner en notre langage qui m'a semblé le plus commode pour le temps que nul n'ignore être rude et fâcheux »: pour la citation voir J.C. Dhôtel, Les origines du catéchisme moderne. D'après les premiers manuels imprimés en France , Paris, 1967, p. 55.

26. J.C. Dhôtel, op. cit., p. 61 et F. J. Brand, Die Katechismen des Edmundus Augerius S.J. in historischer, dogmatischmoralischer und katechetischer Bearbeitung, Freiburg im Breisgau, 1917.

27. Pour une description détaillée voir J.C. Dhôtel, op. cit., p. 56-59.

28. Lainii Monumenta, Epistolae et acta, VII, Matriti, 1916, p. 190-195, p. 194.

29. Lainii Monumenta, Epistolae et acta, VIII, Matriti, 1917, lettre des Lugdunenses cives du 15 mars 1563, p. 571-572.

30. Lainii Monumenta, Epistolae et acta, VII, p. 194.

31. É. Pasquier, Les Recherches de la France, Paris, Iamet Mettayer et Pierre L'huillier, 1596, p. 178 : Ils « font publier un Cathechisme sous le nom de Maistre Emond Auger, frère de la société du nom de Iesu, et non seulement le font publier, mais le lisent publiquement dans leur maison. Non contents de ceste première irrégularité et désobéissance ». Auger est également nommé dans le célèbre Catéchisme des Iesuites ou Examen de leur doctrine de 
Pasquier (Villefranche, Guillaume Grenier, 1602, p. 23 e p. 237) où il est indiqué comme appartenant au groupe de prédicateurs qui sévit en France si bien que «nous n'avons pas autres Prédicateurs pour soutenir notre ancienne Église qu'eux", expression d'une altération des valeurs traditionnelles de l'Église de France, et dénoncé pour son ingérence dans les affaires d'État ( Aimond Auger Jésuite par belles hypocrisies gagna l'oreille du Roy »). L'accusation, qui envahit tout le Catéchisme, est liée aux impostures qui selon Pasquier sont à la base de la Compagnie de Jésus et de son rôle dans la chrétienté : celle de sa fondation, de son insertion dans l'Église, de ses institutions. Selon lui, la Compagnie a enfreint irrémédiablement les traditions, les lois et les idéaux les plus anciens et plus respectés de l'Église et en particulier de la tradition catholique française. La voie indiquée est celle de la discipline des premiers siècles de l'histoire de l'Église: la défense du gallicanisme et de l'indépendance du roi temporel, le respect des traditions. Sur ces thèmes, voir l'ample préface de Claude Sutto dans E. Pasquier, Le Catéchisme des Jésuites, Sherbrooke, 1982, p. 11-121.

32. Lainii Monumenta, Epistolae et acta, VIII, p. 612.

33. Pierre Canisius imprima à Vienne une Summa doctrinae christianae per questiones tradita et in usum christianae pueritiae nunc primum edita. Divisée en 211 questions, elle prit vite le nom de Catechismus maior pour la distinguer des deux autres productions de Canisius : la Summa pour les enfants de 1556 divisée en 59 questions, dite aussi Catechismus minimus, et Parvus Catechismus Catholicorum imprimé en 1559 à Cologne, divisé en 122 questions et dit aussi Catechismus minor ou medius. En conclusion du Concile et après la publication de ses actes, le jésuite préparera une réédition de la Summa qui sortira sous le titre de Summa doctrinae christianae per quaestiones luculenter conscripta, nunc demun recognita et locupletata (1566) adressée aux enseignants, curés et prédicateurs : C. Wackenheim, Breve storia della catechesi. Tradizione e novità, Bologna, 1985, en part. p. 44 e s.

34. Ce qui est pleinement attesté par le succès éditorial de l'ouvrage pour lequel voir F. Streicher, S. Petrii Canisii Doctoris Ecclesiae Catechismi Latini et Germanici, RomaeMonachii, 1933-1936, et par sa réception pour laquelle voir par exemple G. Bedouelle, L'influence des catéchismes de Canisius en France, dans P. Colin, E. Germain, J. Joncheray, M. Venard (éd.), Aux origines du catéchisme en France, Paris, 1989, p. 67-86.

35. P. Canisio, Catechismo il minore, Trento, Giambattista Monauni, 1767, p. 184, 266, et 236.

36. Voir G. Fragnito, La Bibbia al rogo... cit., p. 106 ; et du même auteur Pio V e la censura, dans M. Guasco-A. Torre (éd.), Pio V nella società e nella politica del suo tempo, Bologna, 2005, p. 129-150.

37. Sur les contrastes et les difficultés d'application de la censure entre l'Index tridentin de 1564 et la promulgation de celui de Clément VIII voir G. Fragnito, La Bibbia al rogo... cit., p. 173-198.

38. En réalité Bellarmin dit d'avoir obéi à un ordre pontifical dans une lettre à son frère Thomas (ARSI, Opp. NN 244/II, Lettere originali del S. Card. Bellarmino 1577-1603, f. 43v) et d'avoir accepté une invitation du cardinal Tarugi dans son Autobiografia (Brescia, 1999, p. 63).

39. G. Fragnito, La Bibbia al rogo... cit., p. 227-273.

40. Ibid., p. 20.

41. M. Catto, Un panopticon catechistico... cit., p. 61-91.

42. Institutum Societatis Iesu, Florentiae, 1893, I, p. 128-129 
43. Sur le recensement inquisitorial M. Catto, La "guerra dei catechismi» nel Settecento : il caso di Roberto Bellarmino, dans Annali dell'Istituto storico italo-germanico in Trento, 18, 2002, p. 95-131.

44. J.C. Dhôtel, op. cit., p. 101.

45. Sur les controverses de Bellarmin: F. Motta, Bellarmino. Una teologia politica della Controriforma, Brescia, 2005.

46. Lettera XXX, dans P. Stella (éd.), Atti e decreti del concilio diocesano di Pistoia dell'anno 1786, Firenze, 1986, I, p. 90.

47. ARSI, Opp. NN 232, Dottrina Christiana del ven. Card. Roberto Bellarmino della Compagnia di Gesù. Autografo, c. 3r.

48. R. Bellarmino, Dichiarazione della dottrina cristiana, Bergamo, 1806, p. 13.

49. Ibid., p. 16.

50. Ibid., p. 20.

51. R. Bellarmino, Dottrina breve, dans Roberti Bellarmini Opera omnia, Neapoli, 1872, p. 152.

52. J.C. Dhôtel, op. cit., p. 203-226.

53. P. Stella, I catechismi in Italia e in Francia nell'età moderna. Proliferazione tra analfabetismo e incredulità, dans Salesianum, 49, 1987, p. 303-322 ; J.-R. Armogathe, Les nouvelles exigences de l'âge classique, dans J.-R. Armogathe-Y.-M. Hilaire (éd.), Histoire générale de christianisme de XVII siècle à nos jours, Paris, 2010, p. 427-437.

54. E. Germain, Langages de la foi à travers l'histoire. Approche d'une étude des mentalités, Paris, 1972, p. 51.

55. Sur les rapports entre les évêques italiens et l'Inquisition voir E. Bonora, Giudicare $i$ vescovi. La definizione dei poteri nella Chiesa postridentina, Roma-Bari, 2007.

56. G. Fragnito, Vescovi «censori » : il tridentino alla prova, dans G.P. Brizzi-G. Olmi (éd.), Dai cantieri della storia. Liber amicorum per Paolo Prodi, Bologna, 2007, p. 25-35, p. 34.

\section{AUTORE}

MICHELA CATTO

CARE-CHR, EHESS-CNRS, Paris - michelacatto@gmail.com 


\section{La censure des livres}




\title{
Censura romana e libri francesi nella seconda metà del '500. Qualche riflessione su normativa e casi specifici
}

\author{
Giorgio Caravale
}

1 I primi editti contro i libri luterani e le prime liste di libri proibiti furono stilate sulla base della bolla Exsurge Domine con la quale nel 1520 Leone X condannò Martin Lutero, dichiarando contestualmente eretico e degno di scomunica chiunque detenesse i suoi libri 1. A partire da quella bolla la proibizione dei libri stampati fuori d'Italia si andò ad aggiungere all'unica forma di censura fino a quel momento in vigore nei territori di dominio pontificio: ovvero la censura preventiva. La disciplina dell'imprimatur introdotta da Innocenzo VIII nel novembre 1487 (con la bolla Inter multiplices), ovvero l'esame e l'approvazione del manoscritto preventivi alla stampa era stata codificata dalla bolla Inter sollicitudines del 4 maggio 1515 con la quale la decima sessione del V Concilio lateranense aveva introdotto l'obbligo di sottoporre i libri destinati alla stampa all'esame preventivo del Maestro del Sacro Palazzo o del vicario papale nella città di Roma, e dei vescovi e degli inquisitori fuori dei confini dell'Urbe.

2 In esecuzione dei compiti ricevuti con la bolla Licet ab initio del 21 luglio 1542, la neonata Congregazione del Sant'Uffizio emanò nel 1543 un editto di proibizione di libri erronei, scandalosi e sediziosi, attribuendosi competenza sopra ogni genere di libri². Iniziò una fase di esclusivo potere del Sant'Uffizio sulla censura libraria che avrebbe trovato nell'indice inquisitoriale del 1557 e poi 1558, l'unico indice stilato interamente dall'Inquisizione, il suo degno coronamento.

Fin tanto che l'Inquisizione fu l'unica istituzione a occuparsi della proibizione dei libri la procedura di condanna fu dunque piuttosto lineare. La Congregazione del Sant'Uffizio (spesso di concerto con i singoli inquisitori locali) emanava gli editti o i decreti di proibizione i quali, tra il 1557 e il 1559, furono vagliati e raccolti all'interno del primo indice ufficiale romano ${ }^{3}$. 
4 L'indice tridentino, stilato da un'apposita commissione vescovile nominata nell'ultima fase del Concilio tridentino con l'incarico di rivedere il precedente indice paolino, introdusse per la prima volta in modo ufficiale lo strumento dell'espurgazione, ovvero la possibilità, riservata ai libri di autori cattolici o ai libri di autori eretici di argomento non religioso, di emendare il contenuto dell'opera prima di rimetterla in circolazione in una nuova veste editoriale. Questo principio - che, si badi, non coincideva necessariamente con la distinzione tra prima e seconda classe dell'indice - si reggeva dal punto di vista della legislazione penale su un doppio canale normativo che, introdotto già negli anni precedenti e definitivamente razionalizzato in questa sede, distingueva nettamente tra libri eretici, la cui lettura e il cui possesso implicava la scomunica e il processo di inquisizione, e libri espurgabili, facilmente individuabili questi attraverso la formula donec corrigatur che accompagnava nell'indice il relativo titolo, il cui possesso o la cui lettura implicavano il peccato mortale e le penitenze imposte dal vescovo.

La Congregazione del Sant'Uffizio godeva sempre dell'esclusiva competenza in materia di censura che si era conquistata all'indomani della bolla istitutiva ${ }^{4}$, ma l'indice formalmente in vigore, stilato da una commissione di vescovi, spesso in palese disaccordo con il contenuto dell'indice inquisitoriale paolino del 1559, attribuiva ora ai vescovi stessi una competenza specifica sui libri espurgabili.

6 Il quadro si venne ulteriormente complicando con l'istituzione della Congregazione dell'Indice. Essa venne istituita nel concistoro del 5 marzo 1571 con lo scopo di rivedere l'indice tridentino del 1564, secondo un progetto di Pio V che sin dall'inizio del suo pontificato aspirava a tornare al rigore dell'indice romano del 1559. L'istituzione venne ratificata poco dopo dallo stesso Pio V con la costituzione In apostolicae del 4 aprile 1571. Alla morte di quest'ultimo, il suo successore Gregorio XIII ne esplicitò e fissò i compiti con la bolla Ut pestiferarum opinionum del 13 settembre 1572 : chiarire i dubbi sorti in merito all'indice tridentino e alle dieci regole che ne facevano da premessa; espurgare i libri sospesi donec corrigentur; inserire nell'indice in preparazione le opere recentemente proibite, eliminando invece quelle considerate non più pericolose; controllare la circolazione libraria ${ }^{5}$. Il punto è che la bolla istitutiva non solo si guardava bene dall'attribuire alla Congregazione dell'Indice una potestà esclusiva in materia di censura, ma non si pronunciava neppure sulla provvisorietà o meno della neonata istituzione, non determinava in altre parole se il compito della Congregazione si sarebbe esaurito con la revisione dell'indice tridentino e l'espurgazione delle opere sospese oppure se essa fosse destinata a diventare un ufficio stabile della Curia romana.

7 A ciò va aggiunto che il Maestro del Sacro Palazzo, teologo personale del papa, membro di diritto delle due Congregazioni del Sant'Uffizio e Indice, continuava a esercitare i suoi tradizionali compiti : la città di Roma, la Campagna e il Patrimonio di San Pietro erano sottoposti alla sua giurisdizione dal punto di vista del controllo della circolazione libraria, dell'emanazione di nuovi divieti e del rilascio degli imprimatur 6 . Inoltre, a queste competenze se n'era aggiunta un'altra non meno impegnativa. Con un Motu proprio del 19 novembre 1571 Pio V aveva accentrato a Roma l'attività espurgatoria e la supervisione della pubblicazione presso la Stamperia Vaticana delle opere corrette, affidandone la responsabilità proprio al Maestro del Sacro Palazzo ${ }^{7}$. Così, quando pochi mesi dopo il 13 settembre 1572, Gregorio XIII emanò la citata bolla Ut pestiferarum opinionum attribuendo alla Congregazione dell'Indice anche il compito dell'espurgazione delle opere sospese si andò verso un'inevitabile sovrapposizione di competenze. A complicare ulteriormente il quadro normativo si aggiungeva infine il fatto che l'Indice, a differenza 
dell'Inquisizione, non era stata autorizzata a dare pubblicità alle proprie decisioni attraverso editti o decreti a stampa - solo nel 1613 ottenne l'autorizzazione a pubblicare editti e decreti, nei quali avrebbe potuto raccogliere, oltre alle proprie proibizioni anche quelle emanate dall'Inquisizione e dallo stesso Maestro : doveva perciò per il momento affidarle alla diffusione che ne poteva fare il Maestro o chi ne faceva le veci, il socius o compagno ${ }^{8}$. Per molti anni, dunque, il Maestro diffuse editti e liste di proibizione anche al di fuori dell'Urbe, a volte senza sottoporli alla preventiva approvazione dell'Indice.

Difficile dire se e in che misura la sovrapposizione di competenze con il Maestro del Sacro Palazzo in materia di espurgazione di libri abbia intralciato o rallentato l'azione della Congregazione dell'Indice, che ancora nel 1585 non era riuscita a stilare né un nuovo indice dei libri proibiti né l'auspicato indice espurgatorio che avrebbe dovuto raccogliere $i$ testi delle emendazioni dei libri sospesi (e che per tanti anni ancora si fece attendere). Di sicuro i Maestri del Sacro Palazzo che si succedettero in quel decennio non si fecero scrupoli di esercitare ampiamente le competenze attribuite loro. In particolare, dopo il temuto domenicano Paolo Costabili, già inquisitore generale dei domini estensi, in carica dal 1573 al 1580, noto per un atteggiamento intransigente e centralizzatore che portò alla condanna di ampi settori della letteratura italiana e dei volgarizzamenti biblici ${ }^{9}$, il suo successore Sisto Fabri, in carica nel triennio 1580-1583, prese a occuparsi espressamente di libri di autori cattolici (e più in generale di libri che non trattavano espressamente di religione) e della loro emendazione o espurgazione, in nome dei poteri attribuitigli da Pio V nel novembre 1571 e secondo quelle regole generali dell'indice tridentino che permettevano la pubblicazione in forma emendata dei libri di argomento 'buono' (bonum), che presentassero qualche elemento di empietà, superstizione o eresia (regola VIII) ${ }^{10}$.

Il caso delle censure agli Essais di Michel de Montaigne offre un significativo esempio di questo modo di procedere. Come noto dai resoconti riportati nel suo Journal de voyage, al momento della sua entrata nello Stato della Chiesa, nel novembre 1580, Montaigne era stato sottoposto al sequestro della sua biblioteca dalla quale i doganieri fecero in tempo a sottrarre alcuni volumi sospetti, compresa una copia dei suoi Essais freschi di stampa, appena approvati dalla curia di Bordeaux, come prescritto dal privilegio reale concesso al libro. In ottemperanza delle proprie prerogative era stato il Fabri a sovraintendere alla perquisizione di quei volumi che avrebbero potuto costituire una minaccia all'integrità del territorio ricadente sotto la sua giurisdizione. Trascorsi quattro mesi nella città del papa, la sera del 20 marzo 1581 Montaigne fu ricevuto dal Maestro del Sacro Palazzo per discutere nel merito dei propri scritti. L'incontro si ripetè poche settimane dopo, il 15 aprile, sempre alla presenza di Giovan Battista Lanci, 'socio' di Fabri ma anche segretario della Congregazione dell'Indice, carica per la quale era stato recentemente nominato (il 17 novembre 1580). Nonostante l'informalità dell'incontro e il tono colloquiale della conversazione, quella presentata al Montaigne fu a tutti gli effetti una censura della sua opera principale. Il Fabri infatti si era premurato di sottoporre gli Essais all'attenzione di un esperto di sua fiducia e di provate competenze linguistiche, e questi gli aveva prontamente fornito un dettagliato elenco di osservazioni censorie. Il fatto che le censure siano state presentate oralmente al loro interlocutore deve essere considerato, come hanno recentemente sottolineato Armogathe e Carraud, un gesto di riguardo nei confronti di un autore cattolico universalmente stimato in ambienti curiali - non va dimenticato che Montaigne era un abituale frequentatore dell'abitazione romana del cardinal de Pellevé, membro autorevole della Congregazione dell'Indice ${ }^{-11}$, ma ciò non deve distogliere l'attenzione dal fatto che di vera espurgazione (o censura) si trattò ${ }^{12}$, 
L'intervento del Maestro del Sacro Palazzo si risolse in un'ammonizione a modificare il contenuto di alcune affermazioni, a espungere le espressioni più violente, a temperarne delle altre e il francese sembrò raccogliere pienamente il senso di quell'operazione. Montaigne si sarebbe preoccupato di recepire immediatamente le osservazioni censorie presentando alle stampe un'edizione emendata (già nel 1582), riuscendo così a centrare il suo obiettivo: nessuno degli indici stilati nel decennio successivo avrebbe contemplato l'opera incriminata.

10 Un secondo intervento censorio gli Essais lo avrebbero subìto venti anni dopo, nel gennaio 1600 , allorquando la Congregazione dell'Indice si accorse tardivamente di una traduzione italiana che il giurista Girolamo Naselli aveva fatto stampare a Ferrara nel 1590, intitolata I discorsi politici et militari del cavalliere Montagne tradotti dal sig.r Girolamo Naselli ${ }^{13}$. La Congregazione si rivolse allora all'inquisitore di Ferrara, Giovanni Battista Scarella, il quale nel giro di un mese fece recapitare la sua censura ai cardinali dell'Indice. Anche in questo caso l'intervento non ebbe alcuna conseguenza. Né gli editti del 1603 e 1605 né il successivo indice del 1666 contemplarono la traduzione del Naselli ${ }^{14}$. Si sarebbe dovuto attendere gli anni settanta del ' 600 per vedere gli Essais infine posti all'indice. In un clima culturale e religioso sensibilmente mutato, l'opera di Montaigne sarebbe stata nuovamente sottoposta a censura nel 1675 da parte della Congregazione dell'Indice. La lettura che ne diede in quell'occasione uno dei suoi più fidati consultori, Antonio Gillio dell'ordine dei minori, spostò nettamente l'attenzione censoria dalle istanze filoluterane che il Fabri aveva pensato di ravvisare in alcuni passaggi del testo verso gli aspetti più libertini dell'opera del Montaigne. L'anno dopo (1676) gli Essais finirono all'indice ${ }^{15}$.

11 Come insegna il caso del giurista francese Charles Du Moulin, tuttavia, e in misura forse meno eclatante anche il caso di Jean Bodin che esamineremo di seguito, neppure la presenza del proprio nome all'interno della prima classe dell'indice equivaleva ad una condanna definitiva delle proprie opere. L'opposizione della Chiesa alla circolazione dei suoi scritti trovava la sua ragione fondamentale nelle posizioni gallicane del giurista, nel suo strenuo giurisdizionalismo, nella netta difesa del primato della legislazione civile in materia di commerci e di usura a tutto discapito della giurisdizione ecclesiastica ${ }^{16}$. In questa sede, però, interessa soffermarci piuttosto sulle norme che hanno presieduto alla condanna delle sue opere e sulla contorta vicenda della loro proibizione.

12 Pochi anni dopo la prima edizione parigina, nel 1550 il suo Tractatus commerciorum et usurarum aveva fatto la sua comparsa a Venezia all'interno degli ultimi due volumi dei Tractatus pubblicati dalla "Società della corona ", la più ampia raccolta di trattati giuridici mai edita fino a quel momento. Cinque anni dopo, sempre a Venezia, avevano visto la luce i commentari di Filippo Decio al De regulis iuris del Digesto giustinianeo con tanto di additiones firmate dal giurista francese. A quanto pare, queste due furono le uniche edizioni italiane a contemplare il nome del Du Moulin sul frontespizio. Nel 1557, infatti, il primo indice inquisitoriale (non promulgato, ma ripreso subito in quello del 1558) inserì il suo nome tra gli autori della prima classe, ovvero tra quegli autori di cui risultavano proibiti gli opera omnia. L'Instructio circa indicem (febbraio 1559), redatta per risolvere alcuni dubbi legati all'interpretazione normativa dell'Indice paolino, e la Moderatio indicis del 1561 non alleggerirono la sostanza della proibizione : non solo i suoi trattati erano condannati omnino ma i testi di diritto canonico da lui curati potevano essere permessi solo dopo aver eliminato le annotazioni da lui apposte. Lo stesso genere di proibizione venne ripetuta pochi anni dopo nell'indice tridentino all'interno del quale, 
nonostante l'attenuazione di altre precedenti condanne, per il Du Moulin fu confermata la collocazione nella prima classe.

Come ha sapientemente ricostruito Rodolfo Savelli, il problema era tutt'altro che risolto. La diffusione dei testi del giurista francese tra studiosi, docenti universitari, professionisti del diritto era tale che persino un vescovo nel 1559 dovette ammettere che le sue opere erano apprezzate « da quasi tutti i legisti per essere molto utili e non parlare d'heresia né d'altra materia scandalosa ». Tipografi e stampatori reagirono alle dure proibizioni da par loro: attratti dalle ghiotte possibilità di guadagno, del tutto intenzionati dunque a non gettare al vento l'occasione della forte domanda di mercato, presero a stampare molte delle stampe lionesi curate dal giurista parigino, mantenendo gran parte dell'apparato di additiones da lui approntate, con l'unico accorgimento di levare il suo nome dal frontespizio. Il caso più noto è quello del giurista marchigiano Gaspare Cavallini il quale, tra il 1574 e il 1576, fece stampare a Venezia tre trattati di Du Moulin, tra cui lo scritto sulle usure, sostituendo il nome del francese con il proprio ${ }^{17}$.

Probabilmente per fronteggiare questa nuova emergenza (un altro caso clamoroso era stato quello della stampa nel 1566 del Decretum Gratiani e degli altri textus canonici che riprese fedelmente la seconda edizione lionese curata dal Du Moulin nel 1559) Pio V diede avvio a un'operazione di espurgazione dei testi canonici che rappresentò di fatto la prima concreta applicazione dello strumento dell'espurgazione riconosciuto e sancito ufficialmente a Trento. Siamo nel 1568, la Congregazione dell'Indice è di là dall'essere istituita e responsabile di questa operazione venne nominato il Maestro del Sacro Palazzo Tomás Manrique. Fu l'inizio di una lunga fase in cui quest'ultimo e le due Congregazioni (Indice e Inquisizione) si mossero congiuntamente nella direzione di una sostanziale negazione dei divieti contenuti nei precedenti indici, promuovendo e avallando le più disparate iniziative di espurgazione degli scritti del francese, nonché dei testi canonici da lui curati, al fine di rimetterli a disposizione della comunità dei giuristi e professionisti del diritto che ne richiedevano insistentemente l'utilizzo ${ }^{18}$. Dalla documentazione disponibile si ricava la conferma di quella sostanziale comunanza di vedute che caratterizzò i rapporti tra Indice e Inquisizione, fino al pontificato di Sisto $\mathrm{V}$, ovvero fino alla riorganizzazione dell'Indice da parte di quest'ultimo nel 1587. A partire da quella data i rapporti tra le due Congregazioni si incrinarono pesantemente e si aprì una lunga fase di contrasti. ${ }^{19}$ Il caso di Du Moulin non fa eccezione al quadro generale così lucidamente tracciato da Gigliola Fragnito, se non per il fatto che - in virtù della perfetta coerenza delle proibizioni riguardanti Du Moulin contenute nell'indice (inquisitoriale) paolino e nell'indice tridentino - la Congregazione dell'Inquisizione si trovò di fatto schierata su inedite posizioni di difesa della normativa tridentina.

Nonostante la nettezza della condanna romana, dunque, periodicamente in questi anni si ripeterono tentativi di ripulitura di questa o di quell'opera (anche da parte di consultori che collaboravano con Sirleto alla preparazione del nuovo indice) e al contempo si rinnovarono divieti che avrebbero dovuto essere ormai noti a tutti.

16 Neppure i tre indici degli anni novanta risolsero la situazione. La soluzione adottata dall'indice sistino fu quella di ribadire la condanna completa di Du Moulin. E tale rimase la condanna nell'indice sisto-clementino del 1593. L'indice del 1596 complicò, se vogliamo, ulteriormente il quadro con una formulazione alquanto ambigua che rifletteva la confusione normativa che aveva fino a quel momento contraddistinto il caso : sotto la lettera C, tra gli autori di prima classe, era collocato Carolus Molinaeus (come negli indici del 1559 e 1564), mentre nell'appendice alla lettera $G$, dove erano ricordati i trattati editi 
da Gaspar Caballinus (il giurista che aveva ripubblicato i testi del francese sostituendo il suo nome con il proprio), era aggiunta la clausola dell'espurgabilità ${ }^{20}$.

Che cosa avvenne in sede di applicazione del clementino? Se legittimamente, secondo le disposizioni dell'indice, si provvide a espurgare i trattati editi da Cavallini, il progetto della Congregazione dell'Indice di espurgare gli altri scritti del Du Moulin, i commentari prima di tutto, continuava a rimanere in piedi. Per porre un freno a tali velleità, il 5 ottobre 1596 il Sant'Uffizio decise di preparare un nuovo decreto di proibizione di tutte le opere del giurista francese e già la settimana successiva l'ordine di sequestro fu spedito a Milano e Napoli. Bisognò però aspettare ancora due anni prima di vedere la Congregazione dell'Indice capitolare di fronte alla volontà inquisitoriale. Due anni in cui i cardinali dell'Indice, impegnati a lavorare all'indice espurgatorio, continuarono dritti per la loro strada, come confermato tra l'altro dalla lettera inviata a Cherubino da Verona per informarlo di aver approvato « la censura del Molineo, la qual hora si rivede, e subito si

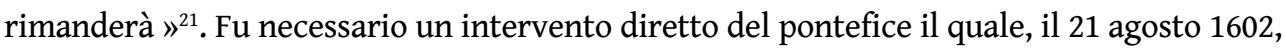
accogliendo le istanze dell'Inquisizione, si decise a pubblicare una bolla contenente il divieto totale delle sue opere, allegando un'espurgazione alle additiones apposte da Du Moulin ai testi dei giuristi italiani e al corpus canonistico: le opere con le sue additiones - stabiliva la bolla mettendo la parola fine a questa tortuosa vicenda - potevano essere possedute solo se espurgate in base a quella 'censura' contestualmente edita ${ }^{22}$. Si tornava così di fatto, dopo quasi cinquanta anni di traversie, alla situazione prevista dalle rigide disposizioni dell'indice inquisitoriale del 1559.

Il feroce contrasto che divise la Congregazione dell'Indice e quella dell'Inquisizione e il difficile, a volte ambiguo, ruolo di mediazione svolto dal pontefice nell'ultimo decennio del Cinquecento emergono in modo evidente anche dalla vicenda censoria di un altro grande autore francese messo all'indice, Jean Bodin. Le opere di Bodin avevano attirato l'attenzione di Roma sin dal 1587 e le critiche alla République, come ha efficacemente dimostrato Enzo Baldini, ebbero un ruolo non marginale nell'avvio del dibattito intorno alla ragion di Stato. Ma non tutti erano d'accordo sull'opportunità di condannarle. $O$ comunque non tutti guardavano al suo autore con gli stessi occhi ${ }^{23}$. La République era inserita nell'Indice del 1590 con la clausola donec corrigatur, ma successivamente era stata oggetto di un intervento della Congregazione dell'Inquisizione ${ }^{24}$. Durante i mesi di preparazione del nuovo indice, il cosiddetto sisto-clementino, nella riunione del Sant'Ufficio del 4 febbraio 1593 il pontefice Clemente VIII aveva assecondato gli umori dei cardinali inquisitori decidendo di inserire Bodin nell'elenco degli autori eretici, gli autori dei quali proibire omnino gli opera omnia: all'indomani di quella riunione il cardinal Santoro poteva così annunciare agli inquisitori di Torino e Bergamo, non senza un moto di soddisfazione, che Bodin «tenuto per herretico, come anco si vede ne suoi libri de Republica, [...] è stato posto nell'Indice che hora si dà fuora ». Così invece non avvenne. La Congregazione dell'Indice tradì infatti la sostanza di quella decisione: nell'indice approvato dal pontefice nel maggio del 1593 a distanza di poche settimane da quella riunione del Sant'Uffizio, il cosidetto indice sisto-clementino, la République figurava insieme alla Démonomanie e alla Methodus ad facilem historiarum cognitionem tra le opere sospese donec expurgantur (in attesa di essere emendate), confermando così le indicazioni dell'indice sistino del $1590^{25}$.

19 L'atto unilaterale della Congregazione dell'Indice ricevette di lì a poco una sostanziale legittimazione da parte del pontefice. Nelle Oppositiones contra indicem del febbraio 1594 l'Aldobrandini espresse infatti una posizione radicalmente diversa da quella assunta nella 
citata riunione inquisitoriale del febbraio 1593, arrivando addirittura a criticare la presunta severità della Congregazione dell'Indice. Esprimendo forti riserve rispetto all'inserimento nell'indice di opere di autori cattolici viventi, chiedeva, con esplicito riferimento al Bodin, che i loro scritti fossero sospesi, come effettivamente avvenuto nell'indice sisto-clementino dell'anno precedente, ma con la clausola che gli stessi autori provvedessero a emendare $\mathrm{i}$ propri testi. Dietro questa radicale svolta stava naturalmente, come sottolineato da Gigliola Fragnito, la politica di progressivo riavvicinamento alla Francia adottata all'indomani dell'abiura di Enrico IV (25 luglio 1593) che avrebbe condotto all'assoluzione e alla riconciliazione con il re di Francia nel settembre $1595^{26}$.

20 La reazione del Sant'Uffizio, per ragioni specularmente opposte, ovvero per l'ostilità che molti dei suoi membri nutrivano nei confronti della nuova politica filofrancese del pontefice, fu di segno radicalmente contrario. In una riunione nella quale spiccava l'assenza del pontefice, l'8 marzo 1595, i cardinali inquisitori pronunciarono una nuova formale condanna della République, che il cardinal Santoro si affrettò a diramare con lettera circolare a tutti gli inquisitori periferici, a testimonianza della chiara volontà del Sant'Uffizio di farne una norma generale ${ }^{27}$. La Démonomanie, per conto suo, era stata intanto omnino proibita dall'Inquisizione coram Sanctissimo il primo settembre $1594^{28}$. L'ultima parola sembrò così spettare, almeno in un primo momento, a una Congregazione dell'Indice composta prevalentemente di sostenitori della causa francese come Agostino Valier e Francesco Toledo. Nell'Indice clementino del 1596 infatti la République e la Methodus furono sospese solo fino all'avvenuta emendazione da parte dell'autore, proprio come indicato da Clemente VIII nelle sue Oppositiones ${ }^{29}$.

21 Intanto, come noto, il cardinal Santoro e la Congregazione del Sant'Uffizio da lui presieduta si fecero promotori di una clamorosa operazione. A indice clementino già promulgato e inviato a nunzi, vescovi e inquisitori, ne imposero la sospensione. Non mi soffermo su vicende già ampiamente ricostruite nel dettaglio ${ }^{30}$, se non per ricordare che in tre delle cinque stesure della Observatio - il documento che formalizzava le modifiche che Santoro volle imporre alla Congregazione dell'Indice e al pontefice - si leggeva una clausola che, entrando nel vivo della questione delle proibizioni, mirava di fatto a sottomettere il giudizio del pontefice a quello del Sant'Uffizio: «i libri proibiti o che verranno proibiti in futuro dalla santa, romana e universale inquisizione devono essere considerati proibiti in tutta la Chiesa secondo la forma e il modo in cui la Congregazione li avrà proibiti, nonostante qualsiasi cosa in contrario ». Si trattava, come è stato sottolineato, di una clausola che mirava a consacrare il Sant'Uffizio come « unica istituzione abilitata a definire e tutelare la dottrina e la moralità dei cattolici $\aleph^{31}$. Non era un semplice attacco alle prerogative della Congregazione dell'Indice. Non una mera richiesta di integrare all'interno dell'Indice autori e titoli precedentemente condannati dall'Inquisizione, bensì un vero e proprio attacco all'autorità dottrinale e morale del pontefice: la formula infatti non prevedeva neppure che le condanne inquisitoriali dovessero essere pronunciate in presenza del pontefice (coram Sanctissimo nelle riunioni della feria quinta $)^{32}$.

La partita tra Sant'Uffizio, Indice e pontefice, soprattutto direi in questo caso la partita tra il cardinal Santoro e Clemente VIII si giocò dunque su questioni di potere estremamente delicate. E se il pontefice, cogliendo la gravità dell'attacco sferratogli dall'Inquisizione, riuscì a far depennare quella clausola, dovette però cedere alle pressioni del Santa Severina sulle altre tre questioni sul tappeto, ovvero il Talmud, le traduzioni 
bibliche e le opere di Jean Bodin. Il Sant'Uffizio riuscì infatti a ristabilire con la versione finale dell'observatio l'irrevocabilità della condanna totale (omnino) della République di Bodin, vanificando di fatto la sospensione voluta dalla Congregazione dell'Indice di concerto con il pontefice, esprimendo così tramite quel documento tutta la propria avversione alla politica filofrancese di riconciliazione dell'eretico relapso Enrico IV ormai condotta in porto da Clemente VIII.

La Congregazione dell'Indice ribatté come poté alla prova di forza dell'Inquisizione. In un memoriale datato primo maggio indirizzato a Clemente VIII, essa rispose all'observatio inquisitoriale (ormai vicinissima alla sua formale approvazione e pubblicazione) con l'unica arma che le rimaneva in mano, il sarcasmo : la Congregazione si rammaricava di non aver proceduto alla proibizione totale della Répubblique, lo avrebbe sicuramente fatto, scrivevano i suoi membri, se soltanto non si fosse persa memoria del decreto papale del 1592, ovvero di quel decreto che il Santoro aveva utilizzato per gettare discredito sul loro operato, ma che alla prova dei fatti era risultato essere una mera invenzione dell'inquisitore ${ }^{33}$.

Nemmeno quest'ultimo intervento di forza del Sant'Uffizio riuscì a porre la parola fine alla questione - che meriterà dunque nuove ricerche d'archivio - se è vero che ancora nel 1617 Urbano VIII sentì l'esigenza di condannare l'autore francese con un 'decreto speciale', concedendo la République in lettura solamente a chi si sarebbe occupato di redigerne una confutazione scritta ${ }^{34}$.

Sostenere che neppure i protagonisti di quelle battaglie avessero un'idea chiara delle procedure di condanna dei libri sarebbe un modo sicuramente troppo semplicistico di rappresentare il problema ma certo non sarebbe un'affermazione troppo lontana dal vero. Concludendo queste brevi note che per certi versi sembrano complicare piuttosto che chiarire la comprensione delle procedure di condanna della censura ecclesiastica cinquecentesca, è lecito sostenere che, al di là di ogni tentativo di sistematizzare dati e procedure normative per lo più riluttanti a qualsiasi schematizzazione, rimane la constatazione che ogni volume racconta una storia a sé, che ciascuna opera va seguita nelle diverse fasi della sua vicenda censoria, che per comprendere la storia complessiva della censura cinquecentesca lo storico deve avere la pazienza di soffermarsi su ogni singola vicenda, su ogni sua sfumatura, sugli scontri che si addensarono intorno alla proibizione delle singole opere e sugli esiti mai scontati di quegli scontri, nella piena consapevolezza che gli unici veri sconfitti di queste battaglie furono i lettori italiani e, più in generale, la cultura italiana, cui l'accesso a grandi capolavori della cultura europea quali le opere dei tre autori francesi qui citati fu reso sicuramente più difficile. 


\section{NOTE}

1. V. Frajese, Nascita dell'Indice. La censura ecclesiastica dal Rinascimento alla Controriforma, Brescia, 2006, p. 52.

2. Ivi, p. 225

3. J. M. De Bujanda, Index de Rome, 1557, 1559, 1564, vol. VIII della serie Index des livres interdits, 11 voll., a cura di J.M. De Bujanda, Sherbrooke-Genève, 1984-2002.

4. Era un sistema che si reggeva, dal punto di vista della legislazione penale, su quella speciale competenza inquisitoriale sui libri proibiti sancita dalla bolla Cum moderatio cordis nostri, pubblicata il 29 aprile 1550 con il consenso di Giulio III. Essa infatti concedeva agli inquisitori il diritto esclusivo di leggere e tenere in custodia i libri proibiti e assimilava di fatto la detenzione dei libri eretici all'eresia (lo faceva in particolare sottoponendo i trasgressori del tempo di grazia alle pene stabilite per gli eretici). Con la bolla In Coena Domini del 1557 Paolo IV aveva poi proseguito per questa strada, comminando la scomunica di riserva papale a lettori e possessori di libri eretici. L'Instructio che il cardinal Michele Ghislieri, capo dell'Inquisizione, fece seguire alla pubblicazione dell'Indice paolino, introdusse per la prima volta la distinzione tra libri eretici, del tutto proibiti e dunque da mandare al rogo, e libri di umanità o di autori cattolici curati da eretici, espurgabili e dunque da restituire ai legittimi proprietari dopo l'avvenuta espurgazione. Il principio introdotto nell'Instructio fu in certo modo perfezionato da un decreto del 1561 che codificò il principio di espurgabilità dei testi non eretici (proibiti per motivi marginali, quali difetti morali, lievi errori dottrinali, curatela di eretici), attribuendo a vescovi e inquisitori, o a confessori da essi delegati, il potere di assolverli in foro interno ed esterno (V. Frajese, Censura libraria, in A. Prosperi (dir.), con la collaborazione di V. Lavenia e J. Tedeschi, Dizionario storico dell'Inquisizione, 4 voll., Pisa, 2010, I, p. 325).

5. G. Fragnito, La Bibbia al rogo. Censura ecclesiastica e volgarizzamenti della Scrittura (1471-1605), Bologna, 1997, p. 115.

6. Sul Maestro del sacro palazzo vedi da ultimo G. Fragnito, Un archivio conteso: le "carte" dell'Indice tra Congregazione e Maestro del Sacro Palazzo, in Rivista storica italiana, 119, 2007, p. 1276-1318, e la voce di A. Borromeo in Dizionario storico dell'Inquisizione... cit., II, p. 956-958.

7. Ivi.

8. G. Fragnito, Proibito capire. Chiesa e lingua volgare nella prima età moderna, Bologna, 2005, ad indicem.

9. Ivi, p. 87-90.

10. Su Fabri, cfr. G. Fragnito, La Bibbia al rogo... cit., ad indicem.

11. Ivi, p. 132 nota 52.

12. J.-R. Armogathe, V. Carraud, Les Essais de Montaigne dans les archives du Saint-Office, in Papes, princes et savants dans l'Europe moderne. Mélanges à la mémoire de Bruno Neveu, réunis par J.-L. Quantin et J.-C. Waquet, Genève, 2007, p. 79-96. Sulla censura romana delle opere di Montaigne si veda anche M. Smith, Montaigne and the Roman Censors, Genève, 1981; P. Godman, The Saint as Censor. Robert Bellarmine between Inquisition and Index, Leiden- 
Boston-Köln, 2000, p. 44-47 e 339-342 ; sull'intera vicenda vedi ora S. Ricci, Inquisitori, censori, filosofi sullo scenario della Controriforma, Roma, 2008, p. 99-220.

13. J.-R. Armogathe, V. Carraud, Les Essais... cit., p. 88-91.

14. J. M. De Bujanda, Index... cit., vol. XI.

15. Ivi, p. 91-94.

16. R. Savelli, The Censoring of Law Books, in G. Fragnito (ed.), Church, Censorship and Culture in Early Modern Italy, Cambridge, 2001, p. 233-253.

17. R. Savelli, Da Venezia a Napoli : diffusione e censura delle opere di Du Moulin nel Cinquecento italiano, in C. Stango (dir.), Censura ecclesiastica e cultura politica in Italia tra Cinque e Seicento, Firenze, 2001, p. 101-154, in partic. p. 119 ; vedi ora dello stesso autore Censori e giuristi : storie di libri, di idee e di costumi (secoli XVI-XVII), Milano, 2011.

18. Ivi.

19. G. Fragnito, Proibito capire... cit., p. 44 et sqq. ; vedi della stessa anche La Bibbia al rogo... cit., passim.

20. R. Savelli, Da Venezia a Napoli... cit., p. 143.

21. Ivi, p. 149.

22. Ivi, p. 151.

23. La Methodus ad facilem historiarum cognitionem era stata inserita nell'Indice di Parma del 1580 e nell'indice sistino erano state già contemplate, con la clausola donec corrigantur, le traduzioni in volgare italiano della Démonomanie e della République. A. E. Baldini, Jean Bodin e l'Indice dei libri proibiti, in C. Stango (dir.), Censura ecclesiastica... cit., p. 79-100. Sulla vicenda della censura alla Démonomanie cfr. M. Valente, Bodin in Italia. La Démonomanie des sorciers e le vicende della sua traduzione, con un saggio introduttivo di D. Quaglioni, Firenze, 1999.

24. Secondo quanto riportato da una successiva testimonianza del cardinal Santoro si trattava di una condanna omnino pronunciata sotto Gregorio XIV della quale non è stata sinora trovata traccia ; per il documento di Santoro cfr. G. Fragnito, Proibito capire... cit., p. 52; e A. E. Baldini, Albergati critico di Bodin: dall" "Antibodino» ai «Discorsi politici», in Jean Bodin a 400 anni dalla morte : bilancio storiografico e prospettive di ricerca, Atti del convegno internazionale, Torino, 6-7 dicembre 1996, a cura di A. E. Baldini, Il Pensiero Politico, XXX ; 1997 , n. 2, fasc. spec., p. 287-309, in partic. p. 294. Secondo diverse altre testimonianze, tra cui una dello stesso Santoro, si trattava invece di una condanna emanata dall'Inquisizione il 15 ottobre 1592; in realtà nei verbali della riunione della Congregazione dell'Inquisizione del 15 ottobre 1592 è registrato solo l'ordine di trasmissione a tutti gli inquisitori di un 'decreto di proibizione' della République e non risulta dunque che il decreto stesso sia stato emanato in quell'occasione (cfr. G. Fragnito, Proibito capire... cit., p. 67 nota 101).

25. A. E. Baldini, Jean Bodin... cit.

26. G. Fragnito, Proibito capire... cit., p. 57-58.

27. Ivi, p. 69.

28. Ivi, p. 70.

29. Ivi, p. 71. Per quanto riguarda la Démonomanie, essa fu sì proibita omnino in ottemperanza alla proibizione inquisitoriale del 1594 ; di fatto, però, la Congregazione dell'Indice, anche dopo la pubblicazione definitiva dell'indice, lasciò aperta la possibilità 
di far circolare un'edizione espurgata addirittura fino al febbraio 1606, data in cui fu definitivamente respinta la richiesta di risarcimento presentata dall'editore veneziano Nicolò Manassi, curatore della traduzione italiana dell'opera.

30. Ivi, p. 48-72.

31. Ivi, p. 61.

32. Ivi.

33. Santoro aveva sostenuto che la République di Bodin era stata erroneamente sospesa dalla congregazione dell'Indice nonostante fosse stata omnino condannata già da Clemente VIII il 15 ottobre 1592: i verbali della riunione del Sant'Uffizio smentiscono questa versione dei fatti, dal momento che testimoniano che l'Aldobrandini non fu presente a quella riunione (ivi, p. 67).

34. ACDF (Città del Vaticano, Archivio della Congregazione per la dottrina della fede), St. St. Q 2-n, fol. 485 ; A. E. Baldini, Jean Bodin... cit., p. 89.

\section{AUTORE}

\section{GIORGIO CARAVALE}

Università degli Studi Roma Tre - gcaravale@gmail.com 


\title{
"Per la conservatione della religione e dello stato ". Les guerres de religion en France aux yeux des historiens italiens $\left(\mathrm{XVI}^{e}\right.$-XVII ${ }^{e}$ siècle)
}

\author{
Elena Valeri
}

\section{NOTE DE L'AUTEUR}

Abréviations : ASV : Archivio Segreto Vaticano ; BAV : Biblioteca Apostolica Vaticana ;

BA : Biblioteca Angelica, Roma.

«Mi duole sommamente che sì come io ricevo molto piacere per le lettere de Vostra Signoria, così non possi renderle se non arido contraccambio, essendo noi qui in una quiete, anzi ozio tanto profondo, che non somministra materia alcuna da scrivere $»^{1}$. Par ces mots, un observateur de l'histoire italienne de l'envergure de Paolo Sarpi représentait la péninsule en 1609. Un demi-siècle s'était alors écoulé depuis la paix de Cateau Cambrésis et l'Italie, qui avait été dans le passé l'objet privilégié de tant d'entreprises historiographiques, semblait ne plus offrir de sujets aux historiens. Le combat opposant la France et l'Espagne qui avait affecté le territoire de la péninsule au cours de la première moitié du XVI e siècle s'était déplacé désormais à l'intérieur de ces mêmes puissances, bien que sous des formes différentes : la révolte pour l'indépendance aux Pays-Bas d'un côté et les guerres de religion en France de l'autre. Cependant, le calme de la péninsule, auquel Sarpi faisait allusion avec sarcasme, n'était pas sans liens avec ce qui se produisait en France. D'un côté, il était dû à l'engagement guerrier déployé par les pays en lutte, mais, d'un autre, il était fortement menacé par les éventuels contrecoups et les extensions du conflit $^{2}$. Un homme de lettres et ecclésiastique beaucoup moins connu que Sarpi, Omero Tortora de Pesaro, s'apprêtant à écrire dans les premières années du XVII ${ }^{e}$ son histoire des guerres civiles de France, après avoir lui aussi évoqué la «lunga quiete che goduta 
habbiamo ", s'empressait de rappeler que ce qui s'était produit en France: «se ben si riguarda [...], potrà più ragionevolmente chiamarsi causa comune di tutto il cristianesimo che particolare di quel Regno $\aleph^{3}$. L'intérêt diffus suscité en Italie par l'histoire contemporaine des principaux pays européens doit donc être aussi envisagé comme un effet de cette conscience, au-delà de l'élargissement de perspectives et de sensibilité.

2 Malgré, en effet, la pénurie d'événements politico-militaires entre le XVI ${ }^{\mathrm{e}}$ et le XVII ${ }^{\mathrm{e}}$ siècle, on enregistra dans la péninsule un remarquable essor de la production historiographique. Alors que certaines des grandes fresques composées par les historiens humanistes et conçues dans la phase trouble des « guerres d'Italie » étaient mises au ban ou soumises à la censure ${ }^{4}$, on assistait d'un côté à un regain de vigueur des histoires municipales, et d'un autre côté, à la diffusion de formes plus divulgatrices telles que le sommaire et la chronologie universelle ${ }^{5}$. En même temps s'affirmait une historiographie où l'attention aux événements extérieurs, qu'il s'agisse des guerres de France ou des guerres turques, loin de ne présenter qu'un caractère d'agrément, faisait ressortir les dynamiques politiques, religieuses et culturelles qui s'étaient mises en branle dans les différents états de la péninsule à la suite de ces événements ${ }^{6}$. Le conflit intérieur qui affligea la France pendant environ quarante ans après la mort prématurée du roi Henri II en 1559 constitua un sujet d'attention particulière pour cette historiographie ${ }^{7}$, tant parce qu'on avait conscience que le sort de la monarchie française était étroitement lié à la seule possibilité d'endiguer la puissance espagnole en Europe, et par conséquent en Italie ${ }^{8}$ , que parce que de nombreux hommes de lettres, dans la foulée de l'émigration intellectuelle des premières années du XVI ${ }^{e}$ siècle causée par les invasions étrangères en Italie, s'étaient rendus en France à la recherche de la protection économique ou de la promotion sociale devenues de plus en plus incertaines dans la péninsule, et y avaient acquis une connaissance directe des événements et des dynamiques politiques de France9

Pour essayer de voir plus clair dans les différentes positions qui s'expriment dans le cadre d'une production caractérisée dans sa majeure partie par l'opposition entre panégyristes d'un côté et polémistes à outrance de l'autre, nous ne nous attarderons que sur certains textes et moments particuliers de la longue histoire des guerres de religion françaises. Nous concentrerons l'analyse en particulier sur un certain nombre d'événements qui se sont vérifiés en 1593, une année décisive pour la solution du combat entre, d'une part, les partisans d'une pacification autour d'un roi français et, d'autre part, ceux en faveur d'une solution centrée sur la conservation et l'unité de la religion catholique dans le règne; entre les partisans de la «ragione ordinaria di stato» et les défenseurs de la «ragione di stato ecclesiastica $»^{10}$. Parmi ces derniers, le légat pontifical et cardinal de Plaisance Filippo Sega ${ }^{11}$, qui s'était déjà distingué par son zèle et son intransigeance dans les années où il avait été nonce en Espagne de 1577 à $1581^{12}$. Envoyé à Paris dès 1589 en soutien de la mission du cardinal Enrico Caetani, il allait par la suite assumer un rôle central dans le combat qui s'était engagé pour l'élection du nouveau roi de France ${ }^{13}$. L'an 1593, en effet, inauguré par l'ouverture solennelle des États généraux à Paris le 26 janvier, convoqués pour la première fois dans l'histoire de France non pas par le roi mais par le chef de la Ligue Charles de Lorraine, duc de Mayenne, fut ponctué par les rencontres de préparation aux entretiens de Suresnes entre les délégués catholiques du parti ligueur et ceux du parti royaliste, et marqué par la trêve militaire qui s'ensuivit. Il eut son point d'orgue, à la fin juillet, dans la conversion d'Henri IV au catholicisme à laquelle fit suite, le 8 août, la dernière séance des États généraux ${ }^{14}$. Ce fut une circonstance décisive pour l'issue finale des guerres civiles qui déchiraient la France depuis plus de trente ans. De nombreux 
observateurs politiques en suivirent attentivement les péripéties, ainsi que le démontrent les très nombreuses dépêches diplomatiques échangées entre Paris et les capitales européennes les plus importantes. Rome en particulier fut directement impliquée en raison de l'action frénétique in loco du cardinal Sega ainsi que du laborieux débat en Curie à propos de la réconciliation avec l'« hérétique ", ainsi qu'on avait pris l'habitude de nommer Henri de Navarre dans les appartements du Vatican ${ }^{15}$.

Dans les Registres Journaux du mémorialiste français Pierre de l'Estoile, rédigés dans le feu des événements, ce qui y est consacré à l'année 1593 s'ouvre par le compte rendu de deux imposantes cérémonies religieuses qui impliquèrent la population parisienne et contribuèrent ostensiblement à placer l'assemblée des États généraux, inaugurée quelques jours plus tard, «sotto la particolare protettione della Sede Apostolica », comme le légat lui-même l'assurait dans l'un de ses rapports informatifs plus ou moins quotidiens au cardinal neveu Pietro Aldobrandini ${ }^{16}$. Le 6 janvier, dans la cathédrale de Notre-Dame, en présence du clergé parisien et des princes de la Ligue, Filippo Sega avait reçu le chapeau de cardinal (arrivé à Paris le 24 octobre) et la croix de la légation des mains du cardinal de Pellevé ${ }^{17}$, en compagnie duquel il avait défilé dans les rues de la ville dans une atmosphère de grande fête religieuse ${ }^{18}$. Dans ces mêmes rues, le 17 janvier, s'était déroulée une procession générale guidée par le nouveau cardinal « pour prier Dieu pour les Etats ${ }^{19}$ ainsi que par le duc de Mayenne, et qui été composaée de religieux armés « en moult [très] belle ordonnance Catholigue, Apostoligue et Romaine ", comme l'on ironisait dans un célèbre pamphlet anonyme rédigé par un groupe de politiques parisiens et publié à Tours au début de 1594 sous le titre de Satyre Ménippée de la vertu du catholicon d'Espagne et de la tenue des Estatz de Paris ${ }^{20}$. Dans ce même libelle, grotesque parodie des États généraux de 1593, le duc de Mayenne prononçait une oraison surréelle sous l'effet d'une drogue vendue par un charlatan espagnol, une sorte de quintessence "CatholiqueJesuite-Espagnole » connue sous le nom de "Catholicon simple de Rome»" ${ }^{21}$. Le chef de la Ligue était représenté, dans ce pamphlet politique, comme un simple exécutant des dispositions du parti hispano-romain. Mais, même dans certains ouvrages historiques imprimés en France au cours des premières décennies du XVII ${ }^{\mathrm{e}}$ siècle, lorsque les exigences de la lutte politique étaient devenues moins pressantes, la conduite politique de Mayenne était considerée comme inspirée par les préceptes du légat apostolique et de l'ambassadeur ibérique, le duc de Feria. Dans l'Histoire Universelle d'Agrippa d'Aubigné, imprimée entre 1616 et 1620, le duc de Mayenne ne semble pas disposer d'autonomie dans la gestion des événements cruciaux ayant ponctué le déroulement des États généraux de $1593^{22}$. C'est plutôt l'idée d'une action impétueuse et à la fois concordée avec le légat apostolique et les ministres espagnols qui y est divulguée. Même les Historiae sui temporis de Jacques-Auguste de Thou, publiées pour la première fois en latin à Paris en 1604, représentaient Mayenne comme étant «honteusement» au service des Espagnol. L'auteur, toutefois n'hésitait pas à rappeler la grande expérience du lieutenant et son intime conviction que les Espagnols ne lui étaient pas favorables ${ }^{23}$. L'ample déploiement de la Ligue, guidée par le duc de Mayenne, bénie par le cardinal de Plaisance et soutenue par les doublons espagnols, apparait nettement moins solide si l'on parcourt les pages de certains historiens italiens qui se consacrèrent au cours des premières décennies du XVII ${ }^{e}$ siècle à l'histoire des guerres de religion ${ }^{24}$.

5 En 1630 furent ainsi imprimés à Venise les 15 livres de l'Historia delle guerre civili di Francia de Enrico Caterino Davila, descendant d'une noble famille chypriote qui s'était réfugié, après la conquête turque de l'île, à Paris puis à Venise en 1599, où il avait parfait la 
rédaction de l'ouvrage ${ }^{25}$. En plus de provenir d'un territoire, celui de la Sérénissime, traditionnellement plus ouvert à la dimension européenne que d'autres états de la péninsule ${ }^{26}$, Davila avait vécu une expérience vicennale singulière en France, d'abord comme page de la reine Catherine de Médicis, puis comme soldat à la suite d'Henri de Navarre dans la dernière phase de la crise de la couronne française, de l'assassinat d'Henri III à l'édit de Nantes, événement qu'il plaçait en conclusion de son Historia. La narration concernant l'année 1593 s'ouvre, dans l'oeuvre de Davila, par une claire référence de l'auteur à l'« universale dispositione degli animi dell'un partito e dell'altro più inclinata allo stabilimento degli affari che al maneggio e all'esecutione dell'armi $»^{27}$. La « prima novità » - affirmait l'historien - remontait en réalité au mois de décembre de l'année précédente et consistait en la déclaration du duc de Mayenne, publiée seulement le 5 janvier, dans laquelle le chef de la ligue annonçait non seulement son intention de réunir les états de son parti - comme le spécifiait Davila - mais exortait aussi les catholiques qui soutenaient le roi «ad unirsi a un medesimo fine con lui e prendere espediente alla salute e pacificazione del Regno [...] per la conservatione della religione e dello stato ${ }^{28}$. Dans cette déclaration, ${ }^{29}$, le duc de Mayenne, bien qu'il ait défendu ses propres raisons ainsi que la cause de son parti, ne s'était pas engagé à élire un nouveau souverain, «ma tenendo le cose in bilancia si lasciò aperta la strada a poter prendere con l'opportunità qualsivoglia deliberatione, che consigliasse il tempo, e che permettesse la qualità degli affari [...] altrimente era risoluto $o$ di rimettersi in piena autorità di luogotenente generale del Regno, e seguitare la guerra, se potesse per mezzo degli Stati ridurre le cose a segno, che con poche dependenze forestiere potesse sostenere l'impresa, o vero se questo non gli riuscisse, di poter conseguire più tosto condurre gli stati ad accordarsi col re mediante la conversione sua, che tollerare che il Regno pervenisse in alcuna altra persona, fermo sempre nel suo proposito di non permettere né la unione delle corone [de France et d'Espagne], né la divisione del Regno $»^{30}$. Davila focalisait ainsi l'attention sur la question cruciale de l'élection du roi, qui par une hétérogenèse des fins avait fait converger dans une apparente harmonie toutes les différentes composantes du parti contraire à Henri de Navarre vers la convocation des États généraux : les Espagnols pour obtenir, en opposition à la loi salique du Règne ${ }^{31}$, que l'infante Isabelle, fille de Philippe II et d'élisabeth de Valois, puisse prétendre au trône de France ; le cardinal légat pour conjurer que la couronne du roi christianissime n'allât à un hérétique; le duc de Mayenne, enfin, pour jouer sa dernière carte en vue d'une toujours plus improbable succession assurée par lui-même et par sa descendance. Davila reproduisait également un écrit, en réponse à la déclaration de Mayenne, publié par le légat apostolique où il était précisé que ni lui ni les ministres espagnols n'avaient été «ben sodisfatti della dichiaratione così ambigua, nella quale pareva che s'aspirasse più all'accomodamento con i Cattolici del contrario partito, che all'elettione di nuovo Re $»^{32}$. Après avoir fulminé contre l'hérésie, qui « è sempre l'istessa, sempre pernitiosa, maledetta, esecrabile ${ }^{33}$, le légat avait donc bien précisé que « il voler sostenere, che li privilegij e libertà della Chiesa Gallicana s'estendono fin là, di permettere, che si riconosca per Re un heretico relapso et escluso dal corpo della Chiesa universale, è un sogno da frenetico che non procede d'altronde, che dalla contagione heretica $»^{34}$. Pour conjurer tout danger, à l'occasion de la deuxième réunion des États, le légat, en accord avec l'ambassadeur espagnol, avait également demandé aux députés - en vain - le serment solennel de ne jamais reconnaître Henri de Navarre comme roi, même au cas où il se serait converti et aurait démontré vivre catholiquement. L'Historia de Davila s'attache à souligner la stratégie du duc de Mayenne qui joue sa partie «ben sicuro che senza l'assenso e la volontà sua [les 
Espagnols] non harebbono ottenuto cosa alcuna ». " Del tutto alieno dal contentarli ${ }^{35} \mathrm{il}$ aurait été au contraire, plus enclin «a praticare non solo i Senatori del medesimo parlamento [de Paris] ma anco quelli i quali per inclinare a favore del Re erano chiamati politici, per potersi al bisogno valere anco dell'opera loro $»^{36}$. Selon ce récit, le duc de Mayenne «procedeva con tanta arte e tanta dissimulatione per la pratica grande che haveva del negotio e delle persone, che i ministri spagnoli e il legato non si accorgevano di molte cose, se non dopo che erano stabilite e guadagnava più animi con l'arte ch'essi non erano sufficienti a guadagnare con l'oro o con le promesse $»^{37}$. Toutefois, la correspondance entre Filippo Sega et le cardinal neveu Pietro Aldobrandini révèle la conscience d'un raidissement du duc de Mayenne, bien que le légat fût toujours très soucieux d'en faire retomber la faute sur l'outrecuidance espagnole et de se démarquer, sur le papier du moins, par rapport aux prises de position ibériques, étant données les indications précises provenant de Rome toujours plus orientées vers une différenciation de la stratégie du pape vis-à-vis de celle du roi catholique.

6 L'ecclésiastique Omero Tortora, auteur à Venise en 1619 d'une Historia di Francia en 22 livres sur les évènements survenus de 1560 à 1601, et dédiée au souverain pontife Paul V, traita aussi de la progressive opposition entre Mayenne et les représentants espagnols à Paris. Cherchant à nuancer le plus possible le rôle joué par le légat en faveur de l'accession de l'infante Isabelle au trône de France, Tortora négligeait de préciser un grand nombre d'éléments, comme par exemple le serment demandé par le cardinal de Plaisance aux députés parisiens, afin qu'ils s'engagent à ne reconnaître en aucun cas Henri de Navarre. Un épisode embarassant pour les hiérarchies ecclésiastiques, auxquelles Tortora s'adressait prioritairement, du moment qu'Henri avait régné avec la bénédiction du pape et que son héritier légitime siégeait sur le trône de France à la date de publication de l'Historia di Francia.

7 Le vicissitudes que dut subir dans de telles circonstances un agent de Mayenne à Rome, Girolamo Frachetta, illustrent à quel point la position de Mayenne était éloignée de celle de Sega et, tout bien considéré, plus proche des dispositions qui parvenaient de Rome au légat mais qui n'étaient pas, pour autant, appliquées. ${ }^{38}$ Frachetta, qui est l'auteur des Commentari delle cose successe nel Regno di Francia, est favorable à la Ligue catholique et au strict ralliement de celle-ci à Madrid. Il se montre aussi partisan d'une thèse assez répandue dans la péninsule au cours des décennies où les luttes de religion ensanglantaient de nombreux pays européens. Dans ses Commentari, il s'inquiète de " quanto fosse perniciosa in uno Stato la diversità della fede, quai mali apportino le civili discordie che da quelle hanno origine, et come non è Regno così florido, né così concorde, che in breve tempo non possa perdere il suo vigore et dividersi in molte parti $»^{39}$. Frachetta déploit une intense activité d'informateur dans les mois où se tenaient à Paris les États généraux - globalement une centaine de rapports et discours, dont beaucoup anonymes - activité récompensée par sa nomination à responsable des services postaux français à Rome, en septembre 1593. Considérant l'aversion de Mayenne envers desseins espagnols ruineuse pour la cause de la Ligue, il se décide alors à remettre sa correspondance avec le duc français à l'ambassadeur espagnol à Rome, qui la trasmet promptement à $\mathrm{Madrid}^{40}$. Un an après ces événements, Frachetta, mandaté peut-être à l'origine par Mayenne lui-même, acheva ses Commentari qui vont de 1585, année de la reconstitution de la Ligue, jusqu'à l'entrée d'Henri IV dans Paris en 1594 (dans certaines rédactions jusqu'à 1598). Même si les nombreuses copies manuscrites en attestent une certaine faveur auprès des contemporains, les Commentari restèrent inédits. Les rapports 
de Frachetta avec la Curie, en effet, s'étaient soudainement détériorés et, en 1604, un mandat d'arrêt à son encontre avait été délivré par le souverain pontife Clément VIII luimême ; l'obligeant à chercher refuge dans le domaine espagnol du règne de Naples.

Après l'accession au trône d'Henri IV, Mayenne n'eut pas à subir la foudre de la vindicte royale qui pourtant avait sévi contre de nombreux représentants du parti de la Ligue. Mayenne dut renoncer au gouvernement de la Bourgogne, mais reçut en échange celui de l'île de France, à l'exception de Paris, en plus d'indemnités financières considérables. Il fut, de surcroît, déclaré innocent d'éventuelles implications dans l'assassinat du roi Henri III. Enfin, en 1599, le roi accorda les rentes de certaines terres dans le duché d'Aiguillon à son fils aîné, déclarant dans le préambule du document de concession vouloir récompenser les services du vieux sujet rebelle ${ }^{41}$.

9 Si l'on se place dans la perspective italienne, l'axe Rome-Madrid s'avère moins aligné qu'il n'apparaît en France. Il est intéressant de s'attarder sur le discours prononcé par le légat à l'ouverture des États généraux dans sa version parodique de la Satyre Ménipée. Cette oraison imaginaire, en effet, avait été composée par Jacques Gillot, conseiller du Parlement de Paris et chanoine de la Sainte-Chapelle, dans la demeure duquel avait été conçue l'idée du pamphlet avec d'autres représentants du parti politique comme, par exemple, le parlementaire Pierre Pithou. Gillot avait axé le discours du légat, qui était lui aussi étant sous l'effet de la drogue du catholicon, dans un élan de franchise cynique, sur trois motifs principaux : Rome ne souhaitait pas la paix en France parce que cela aurait pu mettre en danger la paix en Italie ; le pape ne se préoccupait de la France qu'en ce qu'il en tirait de l'argent et, enfin, Rome estimait pouvoir dispenser de n'importe quelle loi pour des fins politiques. C'était là une stratégie qui se conjuguait parfaitement dans l'esprit de Gillot avec celle de l'Espagne visant à faire de la France, de la Flandre, du Portugal aussi bien que de l'Italie autant de provinces de l'empire : un dessein d'hégémonie politique sous couvert d'aspiration à l'universalisme catholique. Cette accusation, reprise dans le catholicon d'Espagne, était devenue un thème récurrent dans les pamphlets politiques surtout au lendemain de l'assassinat d'Henri III. Dans les années qui suivirent, elle s'était répandue au-delà des frontières françaises pour s'installer dans la polémique politique et religieuse du début du XVII ${ }^{e}$ siècle, ainsi que le montre l'utilisation qu'en faisait l'un des protagonistes de ce débat, le frère servite Paolo Sarpi. Dans la correspondance que ce dernier entretint avec les réformés de France et avec les principaux représentants du gallicanisme - au nombre desquels figure justement Jacques Gillot - il n'est pas rare de rencontrer des allusions à la drogue du diacatholicon qui, répandue par les Espagnols et les jésuites, «massime quando è indorata, è di gran virtù » et peut aveugler même les plus perspicaces, selon ce qu'écrivait Paolo Sarpi dans une lettre de 1608 au réformé Francesco Castrino $^{42}$. Pour combattre l'action conjointe du diacatholicon espagnol et du totatus romain ${ }^{43}$, ce même Paolo Sarpi avait souhaité, dans les années suivant immédiatement l'Interdit, une initiative politico-militaire, guidée par le roi de France Henri IV, contre la suprématie des Habsbourg d'Espagne et de l'Empire étroitement rattachée à l'Église de Rome. Qu'au moment des États généraux de la Ligue, le cardinal de Plaisance ait pu être considéré par les partisans d'Henri de Navarre comme un garant de cette stratégie était évident; que ce légat agit dans cette direction en dépit des indications provenant de Rome apparaît tout aussi clair depuis l'Italie.

10 Alors que Tortora négligeait complètement cet aspect de l'événement, au point qu'à un moment donné de sa narration le légat apostolique disparaît littéralement, sans prendre congé, de la scène des États généraux, Davila n'hésitait pas à souligner les écarts entre les 
actions de Sega et les indications provenant de Rome, où par ailleurs - précisait l'historien - le pape avait été aussi informé par l'ambassadeur vénitien Paolo Paruta de tels soupçons qui pointaient sur le fait que le légat se préoccupait davantage de la satisfaction des Espagnols que du salut de l'État et de la religion. Quand Mayenne et d'autres députés des États avaient refusé de prêter le serment demandé par le légat, qui les aurait engagés à ne jamais reconnaître " per superiore il Re di Navarra, ancor ch'egli si convertisse, e montrasse di vivere cattolicamente", Davila rappelait que Mayenne, mettant en évidence l'initiative du cardinal « come a cosa molto diversa dalle pratiche e dall'intentione sua ", avait affirmé ne pas vouloir offenser, par une décision « aliena dalla potestà secolare, e tutta propria della giuridizione ecclesiastica», la majesté et la juridiction du Siège apostolique et du pape, « la quale ragione chiuse la bocca al legato $»^{44}$. Les bons offices de l'ambassadeur Paruta étaient au centre de la reconstitution de ces circonstances produites par un autre historien vénitien, Alessandro Campiglia de Vicence, auteur d'une histoire Delle turbolenze della Francia in vita del re Henrico il grande, publiée à Venise en 1617 avec une dédicace au roi Louis XIII ${ }^{45}$. Il est intéressant de noter que les motifs invoqués, selon Campiglia, par le prudentissime Paruta afin que le pape prête l'oreille aux propositions que faisaient les Français et qu'il consente à la reconciliation du roi avec le Siège apostolique, étaient l' "interesse della libertà d'Italia e della Christianità $»^{46}$. Campiglia, qui dans l'une de ses lettres n'avait pas hésité à se déclarer « servitore sviscerato » de la monarchie française et dont l'œuvre sera suspendue en 1621, soutenait également que le pape Clément VIII ne s'était pas montré favorable au roi de Navarre «non solo per conoscere meglio e discoprire co'l tempo i fini degl'altri principi, ma per farlo maggiormente geloso di sua salute, e cupido della Religione Cattolica e per accelerare la sua conversione $»^{47}$.

11 La même conclusion se trouve dans une Expositio ad Summum Pontificem de misera conditione regni Franciae, rédigée très probablement à la veille des États généraux et anonyme, mais certainement expression dans la Curie d'un parti anti-espagnol ${ }^{48}$. L'auteur se proposait de bien informer le souverain pontife de l'état où se trouvait le royaume de France, doutant que le pape ne soit trompé par de «non vere o corrotte relazioni o circunvenuta da alcuni che sotto zelo di pietà christiana cercano per aventura solamente il proprio interesse; et quasi astuti crocodilli, non piangono ad altro effetto che per devorare, non sia mai stato rappresentato a S. Santità il vero methodo da curar questa malattia $»^{49}$. L'auteur continuait ensuite en expliquant que la guerre engagée par la Ligue contre Henri III et, conséquemment, son homicide avaient aplani la route d'Henri de Navarre; que, par ailleurs, le roi d'Espagne fomentait avec son or les dissensions civiles et la haine contre celui-ci dans le seul but de faire disparaitre en France la dignité royale et de la soumettre et, enfin, qu'un accord au sein de la maison de Guise sur le nouveau roi à élire, et donc sur le fait que «riducendosi Navarra a vivere da Cattolico, questa sarebbe la vera medicina della Religione et del Regno di Francia », mais également «per tutti coloro che amano la pubblica quiete » était impraticable ${ }^{50}$.

12 Clément VIII, comme on le sait, avait pris soin de ne pas adopter une attitude de fermeture totale sur la question de la succession au trône de France, d'autant plus qu'entre temps la position politique et militaire d'Henri se consolidait progressivement ${ }^{51}$. Le pape Aldobrandini, fils d'un juriste florentin exilé en France à cause de ses positions anti-Médicis ${ }^{52}$ et dévot à Filippo Neri ${ }^{53}$, avait montré dès le début de son pontificat qu'il n'adhérait pas passivement à la stratégie politique de Philippe II et qu'il souhaitait pour le moins maintenir une position d'équilibre entre les deux principales puissances 
catholiques. Cette attitude avait déjà, dans le passé, rendu le cardinal Ippolito Aldobrandini suspect aux yeux des Espagnols eux-mêmes. Ceux-ci s'étaient opposés à sa candidature, proposée par Sixte $\mathrm{V}$, en tant que légat en France au lendemain de l'assassinat d'Henri III ${ }^{54}$. Les courriers envoyés de Rome à Paris au cours des premiers mois de 1593 multipliaient les avertissements au légat à «non vestirsi mai delle passioni et interessi d'altri ", à veiller et à avoir «l'occhio in tutte le parti » et à parler "sempre genericamente che si desidera un Re Cattolico, securo, atto a tranquillare il Regno $»^{55}$. Des signaux sans équivoque arrivaient surtout au sujet des requêtes de plus en plus pressantes des Espagnols, que Sega signalait régulièrement ${ }^{56}$. En particulier, il convient de rappeler le refus de Clément VIII d'accéder à la demande du duc de Feria de déclarer "l'incapacità alla Corona di Francia dei Borbonesi, et altri Cattolici tanto ecclesiastici, quanto secolari, che seguiranno Navarra, che fanno professione di Cattolici ${ }^{57}$. Cependant, le cardinal de Plaisance, dans son intervention aux États généraux à la fin du mois de juin, avait offert son soutien apertis verbis à la résolution de la délégation espagnole, expliquant que l'accession de l'Infante Isabelle au trône de France et le maintien de la religion catholique dans le royaume n'allaient pas l'une sans l'autre ${ }^{58}$. La décision des États généraux produisit, à ce moment-là, une accélération des événements, bien que dans un sens opposé à celui espéré par ses promoteurs. Elle eut pour double conséquence d'accentuer l'affrontement entre l'assemblée des États et le Parlement de Paris, qui déclara nulle toute mesure contraire à la loi salique ${ }^{59}$, et de rendre impérative la conversion au catholicisme d'Henri de Bourbon, qui sera célébrée environ un mois plus tard dans la cathédrale de Saint-Denis.

13 Alors que les États généraux étaient désormais sur le point de s'achever, Filippo Sega écrivait à Pietro Aldobrandini, dans un courrier du 26 juillet, que «l'assemblea non era libera ma sottoposta alla volontà d'altri et all'insolenze di questi Politici delli Magistrati » ${ }^{60}$. De surcroît, la trêve proclamée par le duc de Mayenne avec Henri de Bourbon persistait, malgré la dénonciation par Sega des violations continuelles de la part de ce dernier. À Rome aussi, au fil des jours, la préoccupation que les États généraux puissent donner naissance à « qualche mostro " grossissait ${ }^{61}$, et le nombre de recommandations au légat de « cavare da questa convocatione, se non si può tutto il bene necessario, almeno il manco male, il che N.ro S.re rimette alla prudenza sua e le raccomanda questa santa causa con la maggior caldezza che sia possibile $[. .$.$] » augmentait { }^{62}$. Le 8 août se tint la dernière séance des États généraux de la Ligue, au cours de laquelle fut proclamée la réception des décrets du Concile de Trente en présence du légat pontifical, qui conclut les travaux par une bénédiction solennelle ${ }^{63}$. Mais dès le 11 août Sega se plaignait des «false voci » qui commençaient à se répandre sur son compte: il aurait trompé le souverain pontife, il n'aurait pas «rappresentato il vero" des affaires françaises et, de surcroît, certaines lettres de sa main adressées au roi d'Espagne auraient été interceptées «dalle quali si comprende ch'io sia molto più spagnuolo che ecclesiastico et che havendo creduto per questa via di acquistare il pontificato, ho perduto finalmente in cotesta corte in grosso ${ }^{64}$. Malgré les propos rassurants provenant de Rome ${ }^{65}$, la position du légat pontifical à Paris était désormais définitivement compromise. Dans une lettre du 9 juin, Henri de Navarre recommandait à son délégué en mission à Rome de se faire le porte-parole auprès du souverain pontife de sa décision de se convertir, le priant de bien vouloir remettre, le cas échéant, ses dispositions «à quelques prélats» et non pas au cardinal de Plaisance, puisqu' « il faudroit remonstrer que ses deportemens sont tellement formez au desir des Espagnolz, que ce seroit autant que de me remettre à eux-mesmes. D'en envoyer un aultre non partial, c'est ce que j'avois desiré et dont vous auriés charge de le requerir $\aleph^{66}$. 

nissuno impedimento $"{ }^{67}$ - le légat quitta spontanément la ville, refusant de négocier avec les partisans de l'« hérétique », et se retira dans la neutre Montargis en attente des instructions du pape. La légation de Filippo Sega en France s'était achevée. Au cours des mois qui suivirent, la politique pontificale envers les affaires de France connut une nouvelle phase ${ }^{68}$. Avec l'entrée d'Henri à Paris un très long chapitre de l'histoire de France prenait fin. En commentant cet épisode, Girolamo Frachetta, soutien convaincu de la Ligue, affirmait que Henri de Bourbon devenait le nouveau et légitime roi de France et « così - affirmait-il - da qui avanti lo chiameremo, et non più di Navarra "69.

Si l'on excepte les pourtant nombreux écrits anonymes rédigés au moment même où se produisaient les évènements qui gisent encore dans de nombreuses bibliothèque italiennes, ce n'est qu'à partir de la deuxième décennie du XVII ${ }^{e}$ siècle, une fois surmontée la crainte d'être impliqués dans la guerre ou d'être broyés par les factions en lutte, que les historiens de la péninsule commencèrent à commenter ces événements.

Au-delà de la pure apologie ou la polémique stérile, il est intéressant de noter que la quasi-totalité de ces écrits s'accorde sur le principe de l'unité religieuse comme garantie et fondement de la solidité de l'État et de l'harmonie sociale. Sur ce point, les historiens et les essayistes politiques ont maintenu dans l'ensemble une position séparée par rapport au débat qui s'était développé en France, où l'expérience des guerres de religion déboucha sur un certain consensus en faveur de la cohabitation entre confessions différentes, condition nécessaire pour mettre en route le long et laborieux processus qui conduisit en France de la religion d'État à la laïcité d'État.

\section{NOTES}

1. P. Sarpi, Lettere ai protestanti, 2 voll., éd. M.D. Busnelli, Bari, 1931, I, p. 89-90, lettre à Jerôme Groslot de l'Isle (Venise, 18 août 1609).

2. Sur l'attention portée par les historiens de la péninsule à la révolte des Pays-Bas voir A. Clerici, Ragion di Stato e politica internazionale. Guido Bentivoglio e altri interpreti italiani della Tregua dei Dodici anni (1609), dans Dimensioni e problemi della ricerca storica, 2/2009, p. 187-223 ; S. Moretti, La trattatistica italiana e la guerra : il conflitto tra la Spagna e le Fiandre (1566-1609), dans Annali dell'Istituto storico italo-germanico in Trento, 20, 1994, p. 129-164; S. Mastellone, Il modello politico olandese e la storiografia italiana nella prima metà del Seicento, introduzione a G.Bentivoglio, Relatione delle Province Unite, ristampa anastatica dell'edizione di Bruxelles, 1632, éd. S. Mastellone et E. Haitsma Mulier, Firenze, 1983, p. 5-31.

3. O. Tortora, Historia di Francia, apresso Giovan Battista Ciotti, Venezia 1619, p. 1-2. Sur Omero Tortora (1550-1624) voir G. Spini, Enrico Caterino Davila e la 'Storia delle guerre civili in Francia', in Id., Barocco e Puritani. Studi sulla storia del Seicento in Italia, Spagna e New England, Firenze, 1991, p. 89-117: 97-98, déjà in P. Vaccari, P.F. Palumbo (dir.), Studi di storia 
medievale e moderna in onore di Ettore Rota, Roma, 1958, p. 173-204 ; E. Cicogna, Delle iscrizioni veneziane, 6 voll., Venezia, 1824-53, V, p. 539.

4. Pour ne citer que le cas de la Storia d'Italia de Francesco Guicciardini voir J.M. De Bujanda, Index des livres interdits, IX, Genève, 1994, ad indicem, et P. Guicciardini, La censura nella Storia guicciardiniana. Loci duo e Paralipomena, dans La Biliofilia, LV, 1953, p. 134-156 e LVI, 1954, p. 31-46. Sur la censure romaine des ouvrages historiques écrites en France à cheval sur le XVI ${ }^{\mathrm{e}}$ et le XVII ${ }^{\mathrm{e}}$ siècle voir E. Bonora, La «censura inavvertita ». Censura romana e opere di storia tra l'Italia e la Francia nel primo Seicento, dans Rivista Storia Italiana, 125, 2013, 1, p. 41-75. Plus généralement, sur la question de la censure, aussi bien ecclésiastique que civile, des ouvrages historiques voir les considérations, relatives à Florence sous les Médicis, de C. Callard, Le Prince et la République. Histoire, pouvoir et société dans la Florence des Médicis au XVII siècle, Paris, 2007, p. 47-89.

5. E. Cochrane, Historians and Historiography in the Italian Renaissance, Chicago and London, 1981, p. 215-382 (IV, The revival of municipal history; V, From municipal history to world history) ; G. Benzoni, La storiografia e l'erudizione storico-antiquaria. Gli storici municipali, dans Storia della cultura veneta, IV, Il Seicento, Vicenza, 1984, t. 2, p. 67-93.

6. B. Croce, Storia dell'età barocca in Italia, Bari, 19675, p. 99-138; G. Galasso, Aspetti della storiografia italiana tra Rinascimento e età barocca, in Id., Dalla "libertà d'Italia » alle "preponderanze straniere », Napoli, 1997, p. 374-396:380-381.

7. S. Moretti en délinée un tableau soigné, Da una "allegrezza » all'altra, dalla pace di Cateau Cambrésis alla notte di San Bartolomeo. Le guerre civili in Francia nella trattatistica italiana, dans Annali dell'Istituto storico italo-germanico in Trento , 21, 1995, p. 229-66.

8. Alessandro Campiglia, auteur d'un ouvrage intitulé Delle turbolenze della Francia in vita del re Henrico il grande libri $X$ (apresso Giorgio Valentini, Venezia, 1617) dans sa dédicace à Louis XIII écrit à propos de l'assassinat d'Henri IV : « Quando in Italia, sei anni sono, venne la novella, che sua Maestà in luogo d'essere partita da Parigi coll'esercito, per conservare a tutta l'Europa la libertà, era stata uccisa da quella Tigre inhumana di quel Barbaro Assassino, l'Italia Madre de' belli Ingegni, e Altrice d'huomini grandi lagrimò dirottamente » (f. $2 r-v)$. Sur la portée européenne des événements français du XVI siècle est centrée la récente synthèse de C. Vivanti, Le guerre di religione nel Cinquecento, RomaBari, 2007.

9. Le phénomène de l'immigration et de l'intégration des italiens dans la France du XVI siècle a largement fait l'objet de recherches minutieuses, je me limite à rappeler les travaux de J.F. Dubost, La France italienne, XV et XVII ${ }^{\mathrm{e}}$ siècle, Paris, 1997 ; H. Heller, AntiItalianis in Sixteenth-Century France, Toronto, 2003; A.M. Battista, Politica e morale nella Francia dell'età moderna, Genova, 1998 ; G. Procacci, Machiavelli nella cultura europea dell'età moderna, Roma-Bari, 1995 ; pour une reconnaissance générale du phénomène je prends la liberté de renvoyer à E. Valeri, La diffusione europea dell'Umanesimo italiano, dans S. Luzzatto et G. Pedullà (dir.), Atlante della lettretura italiana, I, Dalle origini al Rinascimento, procuré par A. de Vincentiis, Torino, 2010, p. 616-620.

10. Ces expressions se retrouvent in « Dispacci da Roma » des ambassadeurs de Venise (à la date du 24 octobre 1592) rapportant un discours de Clément VIII et sont citées dans R. De Maio, La Curia romana nella riconciliazione di Enrico IV, dans Id., Riforme e miti nella Chiesa del Cinquecento, Napoli, 1973, p.160. Cf. A.E. Baldini, Botero e la Francia, dans Id. (procuré par), Botero e la 'ragion di Stato', Atti del convegno in memoria di Luigi Firpo 
(Torino 8-10 marzo 1990), Firenze, 1992, p. 335-359; D. Quaglioni, La prima recezione della 'Ragion di Stato' in Francia. Il 'De Repubblica' di Pierre Grégoire (1591), ibid., p. 395-403.

11. Filippo Sega (1537-1596) se trouvait en France depuis 1589 en tant que vice-légat du cardinal Enrico Caetani. Après le départ de ce dernier, il fut confirmé dans ses fonctions par le pape Grégoire XIV, puis il fut nommé par Innocent IX nonce en France le 6 dicembre 1591 et ensuite, le 15 avril 1592, par Clément VIII légat a latere. Sur les données biographiques de Sega, évêque de Plaisance (1578) et plus tard cardinal (1591), nonce en Espagne (1577-1581) et auprès de l'empire (1586-1587), voir Die Hauptinstruktionen Clemen's VIII. für die Nuntien und Legaten an den europäischen Fürstenhöfen, 1592-1602, dans Auftrag des Deutschen Historischen Instituts in Rom, bearbeitet von K. Jaitner, 2, Tübingen, 1984, I, p. CCXLVI-CCXLVIII, 52, et B. Barbiche, Les légats 'a latere' en France et leurs facultés aux XVI et XVII siècles, dans Archivum Historiae Pontificiae, 23, 1985, p. 162-163. Pour une bibliographie détaillée sur les nonces en France nous renvoyons à Kurie und Politik. Stand und Perspektiven der Nuntiaturberichtsforschung, herausgegeben von A. Koller, Tübingen, 1998, p. 424-425 ; 460-464. De la légation de Filippo Sega s'est occupée A.-c. Tizon-Germe, La représentation pontificale en France au début du règne d'Henri IV (1589-1594). Cadre politique, moyens humains et financiers, dans Bibliothèque de l'École des Chartes, 151, 1993, p. 37-85; Ead., Juridiction spirituelle et action pastorale des légats et nonces en France pendant la Ligue (1589-1594), dans Archivum Historiae Pontificiae, 30, 1992, p. 159-230.

12. I. Fernández Terricabras, Philippe II et la Contre-Réforme. L'Église espagnole à l'heure du Concile de Trente, Paris, 2001, p. 496-498 et ad indicem.

13. M.A. Visceglia, Il contesto internazionale della incorporazione di Ferrara allo Stato ecclesiastico (1597-1598), dans Schifanoia, 38-39, 2010, p. 113-130.

14. G. Picot, Histoire des États Généraux, Paris, 1888, t. IV, p. 69-108; Procès-verbaux des Etats Généraux de 1593, recueillis et publiés par A. Bernard, Paris, 1842 ; Ch. Labitte, Une assemblée parlamentaire en 1593. Procès-verbaux des États Généraux de 1593, publiés par M. Auguste Bernard, dans Revue des deux mondes, s. IV, 1842, 32, p. 260-285 ; R.J. Knecht, The rise and fall of Renaissance France 1483-1610, Oxford, 1996, p. 439-470.

15. R. De Maio, La Curia romana nella riconciliazione di Enrico IV... cit., p. 143-187.

16. ASV, Segreteria di Stato, Francia 36, f. $145 v$. La correspondance de Filipo Sega avec Pietro Aldobrandini est conservée en grande partie in BA, ms. 1103 et ms.1104; ASV, Segreteria di Stato, Francia 36, 37, 287 ; Borghese I, 232-234, f. 1-283 (comme dans les f. 1-320v del Barb. lat. 5825), III, 78; BAV, Barb. lat. 5825, f. 1-320v, deuxième numérotation après f. 369, f. 1-117r; Barb. lat.5826; Ottobon. lat.3211, 3212, 3217. Cf. Die Hauptinstruktionen Clemen's VIII...cit., p.52; L. von Pastor, Storia dei papi dalla fine del Medio Evo, XI, Clemente VIII (1592-1605), Rome, 1958, note 5, p. 47-48. Sur Pietro Aldobrandini, devenu cardinal le 17 septembre 1593, voir E. Fasano Guarini, Aldobrandini, Pietro, dans DBI, vol. II, Roma, 1960, p. 107-112 ; et les articles dans Schifanoia, 38-39/2010, parte II, Dagli Estensi al governo pontificio. La legazione di Pietro Aldobrandini, p. 111-282.

17. J. Boucher, Pellevé, Nicolas, dans A. Jouanna, J. Boucher, D. Biloghi, G. Le Thiec (éd.), Histoire et Dictionnaire des guerres de religion, Paris, 1998, p. 1195-1197.

18. Pierre de L'Estoile rappelle cette cérémonie dans ses Mémoires-Journaux, dans Journal de Henri IV, t. I, 1589-1600, Paris, 1948, p. 209. Sur cette source très particulière voir en dernier F. Greffe-J. Lothe, La vie, les livres et les lectures de Pierre de L'Estoile. Nouvelles recherches, Paris, 2004, mais aussi C.-G. Dubois, La conception de l'histoire en France au XVI siècle (1560-1610), Paris, 1977, p. 195-219. Le neveu de Sega, Girolamo Agucchi, rédigea un 
compte rendu enthousiaste de cette journée dans une lettre à Pietro Aldobrandini, Paris 7 janvier 1593 (ASV, Borghese III, 78, f. 31r-v).

19. P. de L'Estoile, Mémoires-Journaux... cit., p. 211.

20. La Satyre Ménipée ou la vertu du Catholicon, selon lédition princeps de 1594, avec introduction et éclaircissements par Ch. Read, Paris, 1878; la citation se trouve à p. 46, l'italique est dans le texte. Sur ce célèbre pamphlet, qui a connu de multiples éditions et a fait l'objet de nombreuses études, je me limite à rappeler les apports réunis in Études sur la Satyre Ménipée, réunies par F. Lestringant et D. Ménager, Genève, 1987 ; A.M. Brenot, Le corps pour royaume. Un language politique de la fin du XVI siècle et début du XVII e, dans Histoire, économie et société, 10, 1991, p. 441-466; en particulier sur la représentation de Sega dans la Satyre Ménipée je renvoie à mon "Una congiura letteraria». La fine delle guerre di religione in Francia tra satira e politica, dans Roma moderna e contemporanea, 11, 2003, 1/2, p. 79-118 (Congiure e complotti, numero monografico a cura di M. Caffiero e M.A. Visceglia).

21. La Satyre Ménipée... cit., p. 42.

22. A. d'Aubigné, Histoire Universelle, à Maillé, par Jean Moussat, 1616, p. 274 s., mais voir l'édition critique de A. Thierry, Genève, 1981-1999; pour les notices biographiques on renvoie à M. Lazard, Agripa d'Aubigné, Paris, 1998, et à l'article de J. Boucher dans Histoire et Dictionnaire des guerres de religion... cit., p. 681-683.

23. J.A. de Thou, Histoire Universelle, à La Haye, chez Henri Scheurleer, 1740, t. VIII (1591-1596), p. 225 : «Presque toutes les personnes sensées, qui étoient alors à Paris désaprouvoient cette Assemblée, comme faite à contre-tems; on prévoyoit qu'elle n'autoit aucun effet; que les Espagnols et leurs partisans agissoient imprudemment, et perdoient leurs peines. Hors de Paris, on s'en moquoit hautement ; et l'on étoit indigné de voir, que le Duc de Mayenne, malgré son expérience, se laissât emporter jusqu'à ce point par l'esprit de faction, et servit honteusement la passion des Espagnols, qu'il sçavoit être ses ennemis secrets ». Sur l'activité historiographique de de Thou voir en dernier I. De Smet, Thuanus. The making of Jacques-Auguste de Thou (1553-1617), Genève, 2006 ; cf. aussi les toujours stimulantes considérations de C. Vivanti, Lotta politica e pace religiosa in Francia fra Cinque e Seicento, Torino, 1963, p. 292-324, reproposé à l'attention des chercheurs dans sa récente traduction française, Guerre civile et paix religieuse dans la France d'Henry IV, Paris, 2006.

24. Sur la physionomie complexe du parti catholique français pendant les guerres de religion voir R. Descimon, Qui étaient les Seize ?Étude sociale de deux cent ving-cinq cadres laïs de la ligue radicale parisienne (1585-1594), Paris, 1983 ; J.-M. Constant, La Ligue, Paris, 1996.

25. G. Benzoni, Davila, Enrico Caterino, dans DBI, vol. XXXIII, 1987, p. 163-171 ; Id., La fortuna , la vita, l'opera di Enrico Caterino Davila, dans Studi veneziani, 16, 1974, p. 279-442 ; G. Spini, Enrico Caterino Davila e la 'Storia delle guerre civili in Francia'... cit ; L. Gambino, Enrico Caterino Davila storico e politico, Milano, 1984.

26. Cf. D. Frigo, Pubblicistica e storiografia nella cultura veneta del primo Seicento, dans E. Fasano Guarini-M. Rosa (éd.), L'informazione politica in Italia (secoli XVI-XVIII), Atti del seminario organizzato presso la Scuola Normale Superiore (Pisa, 23-24 juin 1997), Pisa, 2001, p. 83-136. 
27. E.C. Davila, Historia delle Guerre Civili di Francia...nella quale si contengono le operationi di quattro re Francesco II, Carlo IX, Henrico III et Henrico IIII, Venetia, appresso Tomaso Baglioni, 1630, p. 821.

28. Ibid.

29. La version reproduite par Davila correspond à une traduction effectuée par l'auteur lui-même (cf. L. Gambino, Enrico Caterino Davila storico e politico... cit., p. 88).

30. E.C. Davila, Historia delle Guerre Civili di Francia... cit., p. 829.

31. Pour une analyse juridique, politique et historique de la loi salique en France on renvoie à F. Cosandey, La Reine de France. Symbole et pouvoir, XVe-XVIII siècle, Paris, 2000 ;É. Viennot, La France, les femmes et le pouvoir. L'invention de la loi salique ( $V^{\mathrm{e}}-X V I^{\mathrm{e}}$ siècle), Paris, 2006.

32. E.C. Davila, Historia delle Guerre Civili di Francia... cit., p. 829.

33. Ibid., p. 831.

34. Ibid., p. 831-832.

35. Ibid., p. 839.

36. Ibid.

37. Ibid., p. 840.

38. A.E. Baldini, Frachetta, Girolamo, dans DBI, vol. IL, 1997, p.567-573 ; Id., Girolamo Frachetta: vicissitudini e percorsi culturali di un pensatore politico nell'Italia della Controriforma, dans Annali di storia moderna e contemporanea, 2/1996, p. 241-244 ; Id., Le guerre di religione francesi nella trattatistica italiana della ragion di Stato: Botero e Frachetta, dans Il Pensiero politico, 22, 1989, 2, p. 301-324.

39. S. Moretti, Da una "allegrezza» all'altra, dalla pace di Cateau Cambrésis alla notte di San Bartolomeo... cit., p. 249, note 58. Les Commentari delle cose successe nel Regno di Francia de Girolamo Frachetta ne furent jamais publiés et sont conservés manuscrits en plusieurs exemplaires. Les citations sont tirées de BAV, Urb. lat. 816, parte I, f. 166r-260v.

40. A.E. Baldini, Frachetta, Girolamo... cit., p. 569.

41. J. Boucher, Mayenne, Charles de Lorraine, duc de, dans Histoire et Dictionnaire des guerres de religion... cit., p. 1088-1092 ; J.-M. Constant, La Ligue... cit., ad indicem.

42. Lettre de Paolo Sarpi à Francesco Castrino du 25 novembre 1608, dans P. Sarpi, Lettere ai Protestanti... cit., II, p. 12. Sur la réalité composite et bigarrée du gallicanisme voir A. Tallon, Conscience nationale et sentiment religieux en France au $\mathrm{XVI}^{\mathrm{e}}$ siècle. Essai sur la vision gallicane du monde, Paris, 2002.

43. Sur le terme totatus utilisé par Paolo Sarpi pour la première fois dans sa lettre à Jacques Gillot du 15 septembre 1609, cf. V. Buffon, Chiesa di Cristo e Chiesa romana nelle opere e nelle lettere di fra Paolo Sarpi, Louvain, 1941, p. 61-63 et 97-148 ; P. Sarpi, Lettere ai Gallicani, édition critique procurée par B. Ulianich, Wiesbaden, 1961, p. XCI et CXLIII.

44. E.C. Davila, Historia delle Guerre Civili di Francia... cit., p. 841.

45. Sur la biographie et l'oeuvre de Campiglia voir G. Benzoni, Campiglia, Alessandro, dans DBI, vol. XVII, 1974, p. 537-539; S. Moretti, La trattatistica italiana e la guerra : il conflitto tra la Spagna e le Fiandre (1566-1609)... cit., en particulier p. 242-249; G. Spini, Enrico Caterino Davila e la 'Storia delle guerre civili in Francia'... cit., p. 91-97.

46. A. Campiglia, Delle turbolenze della Francia in vita del re Henrico il grande libri X... cit., p. 552. 
47. Ibid., p. 550-551.

48. BA, ms. 1103, f. 17-28 (incomplet) et f. 29-38 (autre exemplaire complet). Le titre n'apparaît dans aucune des deux versions du texte, mais dans le Catalogus codicum manuscriptorum praeter graecos et orientales in Bibliotheca Angelica..., Romae, 1893, p. 460.

49. Ibid., f. $17 r-v$.

50. Ibid., f. $37 r$.

51. Pour la politique française de Clément VIII avant l'absolution d'Henri IV voir L. von Pastor, Storia dei papi... cit., XI, p. 45 s. ; A. Borromeo, Il cardinale Cesare Baronio e la Corona spagnola, in Baronio storico e la Controriforma, Atti del convegno internazionale di studi, (Sora, 6-10 ottobre 1979), procuré par R. De Maio, A. Mazzacane, L. Gulia, Sora, 1982, p. 59-166; Id., Istruzioni generali e corrispondenza ordinaria dei nunzi : obiettivi prioritari e risultati concreti della politica spagnola di Clemente VIII, dans Das Papsttum, die Christenheit und die Staaten Europas 1592-1605. Forschungen $z u$ den Hauptinstruktionen Clemens'VIII, herausgegeben von G. Lutz, Tübingen, 1994, p. 119-204, avec annexe p. 205-233; H. de l'Epinois, La Ligue et les papes, Paris, 1886, p. 524 s.; P. Richard, La papauté et la Ligue française: Pierre d'Epinac, archevêque de Lion (1573-1599), Paris, 1901, p. 434 s.; plus en général sur le rapport entre la France e le pape cf. O. Poncet, La France et le pouvoir pontifical (1591-1661) : l'esprit des institutions, Rome, 2011.

52. A. Borromeo, Clemente VIII, dans Enciclopedia dei papi, Roma, 2000, p. 249-269 : p. 249 ; P. Simoncelli, Fuoriuscitismo repubblicano fiorentino 1530-54, Milano, 2006, ad vocem Aldobrandini, Silvestro.

53. Sur les orientations des ordres religieux romains en ce qui concerne la reconciliation $\mathrm{du}$ souverain pontife et d'Henri IV voir M. Gotor, I beati del papa. Santità, Inquisizione e obbedienza in età moderna, Florence, 2002, p. 4-9 et p. 141-144.

54. A. Borromeo, Clemente VIII... cit., p. 251.

55. BAV, Barb. lat. 5825, f. 86r-89v (II partie). Voir aussi l'Istruttione over discorso sopra le cose di Francia, dans A. Borromeo, Istruzioni generali e corrispondenza dei nunzi : obiettivi prioritari e risultati concreti della politica spagnola di Clemente VIII, dans Das Papsttum, die Christenheit und die Staaten Europas 1592-1605. Forschungen zu den Hauptinstruktionen Clemens' VIII... cit., p. 119-204, avec annexe p. 205-233 et p. 220-226.

56. BAV, Barb. lat. 5825, f. 89v-90r (II partie) : Pietro Aldobrandini à Filippo Sega, Rome, le 16 février 1593 : « Nel resto, come si è scritto sempre a V.S. Ill.ma, il Papa desidera ch'ella stia unita con il Duca di Feria et altri Ministri Cattolici presuponendosi però, che per quella parte si camini con buon fine, et a por veramente fine alli travagli di quel Regno, che quando fosse altrimente, non intende Sua Santità di vestirsi delle passioni di alcuno. E se V.S. Ill.ma usarà, come spera, buona diligenza quando parlarà con il duca di Feria, caverà facilmente qual sia l'ultima risolutione del Re, la quale saputa, potrà ella facilmente conoscere il fine qual sia, et essendo buono, se è riuscibile, o no, e secondo quello governarsi avvertendo ancora che sempre, indebolirà grandemente la forza degl'officij, ch'ella potesse fare a beneficio della stessa parte, e quanto più in aparenza massimamente mostrarà la neutralità della Sede Apostolica nelle passioni delli pretendenti, e che solo il fine di questa santa sede è la conservatione della Religione, la quale non può stare con il permettere un Re heretico, e la conservatione di quel Regno, tanto più saranno di autorità gli officij, che procederanno da lei ».

57. BAV, Barb. lat. 5825, f. 92r (II partie), lettre de Pietro Aldobrandini à Filipo Sega, Rome 29 avril 1593. 
58. Procès-verbaux des Estats Généraux de 1593... cit., p. 288-90.

59. Le 28 juin 1593 fut convoquée une assemblée générale du Parlement de Paris, au cours de laquelle Guillaume Du Vair prononça sa Suasion de l'Arrest pour la manutention de la Loy salique.

60. BAV, Barb. lat. 5825, f. $137 v$ (I partie).

61. BAV, Barb. lat.5825, f. 90v (II partie), lettre de Pietro Aldobrandini à Filippo Sega, Rome, le 27 mars 1593.

62. Ibid.

63. Procès-verbaux des Estats Généraux de 1593... cit., p. 344-349. Le 30 mars 1594 le Parlement de Paris jugea nuls tous les actes et les décrets de la Ligue y compris ceux ratifiés par les États Généraux de 1593.

64. ASV, Segreteria di Stato, Francia 36, f. $267 v$ (passage souligné dans le manuscrit).

65. BAV, Barb. lat.5825, f. 53v (II partie), lettre de Pietro Aldobrandini à Filippo Sega, Rome, le 26 septembre 1593 : « Circa quel che è stato riferito a V.S. Ill.ma delle voci sparse qui contro di lei, ella ha da sapere, che non sono pervenute a notitia di Sua Santità non essendo ella solita di dar orecchie facilmente a detrattori, ma di poner mente alla verità del fatto, e di quello contentarsi ».

66. Recueil des lettres missives de Henri IV, publié par M. Berger de Xivrey, III, (1589-1593), Paris, 1846, p. 791. Voir aussi le passage tiré de cette même lettre du 9 juin 1593 : « La proposition des points susdicts [la décision de se convertir] a esté plausiblement receve à Paris, quasy generallement, tan en l'assemblée que parmy les habitans, à quoy a grandement aydé la poursuicte que les Espagnols ont faicte en mesme temps de leurs pretentions pour avoir la couronne, faisans voir à un chacun leur insatiable ambition, qui les a rendus communement autant odieux, comme ils pensoient estre bien voulus. Mais c'est à ce coup qu'ils ont deployé leurs plus grands artifices, n'espargnans les grandes promesses et esperances de toutes façons à leurs partisans, ny argent pour aiguiser les langues venales des maulvais prescheurs, à faire detester et rejetter toute sorte d'accord, comme contraire à leur dessein ; en quoy l'on recongnoist les plus mauvais offices estre procedez du cardinal de Plaisance, qui du tout joinct aux praticques et intentions du roy d'Espagne, en est venu sy avant que de faire mesme protestation que eux de s'en aller, s'ils entroient seulement en traicté de la trefve avec moy; et finalement ne pouvans directement destourner le desir commun, que les principales villes et la noblesse du dict party ont du repos, chacun jugeant la perte inevitable de l'Estat, s'ils prennent autre resolution que de se reconcilier avec moy, en me faisant catholique » (p. 789).

67. ASV, Segreteria di Stato, Francia, 36, f. 31-42: «Relatione succinta fatta a Papa Clemente VIII dal Card.le di Piacenza legato in Francia di quanto passò nella sua legatione ", f. 40r (voir aussi la copie in Barb. lat. 5826, f. 31r-56v).

68. Sur la politique di Clément VIII concernant les événements de France voir B. Barbiche, Clément VIII et la France (1592-1605). Principes et réalités dans les instructions générales et les correspondances diplomatiques du Saint-Siège, in Das Papsttum, die Christenheit und die Staaten Europas 1592-1605. Forschungen zu den Hauptinstruktionen Clemens' VIII... cit., p. 99-118; sur les rapports entre Henri IV et la papauté après la reconciliation je renvoie à A. Tallon, Henry IV and the Papacy after the League, dans A. Forrestal, E. Nelson (éd.), Politics and Religion in Early Bourbon France, Basingstoke, 2009, p. 21-41; plus en général sur le nouveau cadre européen au lendemain de 1598 voir A. Tallon, L'Europe au XVI siècle. États et relations internationales, Paris, 2010. 
69. S. Moretti, Da una "allegrezza» all'altra, dalla pace di Cateau Cambrésis alla notte di San Bartolomeo... cit., p. 264.

\section{AUTEUR}

\section{ELENA VALERI}

« Sapienza » Università di Roma - elenavaleri@gmail.com - elena.valeri@uniroma1.it 


\title{
Érudition gallicane et censure romaine au tournant des $\mathrm{XVI}^{e}$ et $\mathrm{XVII}{ }^{e}$ siècles : Papire Masson devant l'Index
}

\author{
Jean-Louis Quantin
}

\section{NOTE DE L'AUTEUR}

Abréviations : ACDF : Archives de la Congrégation pour la Doctrine de la Foi ; BAV : Bibliotheca Apostolica Vaticana ; BL : British Library ; BNF : Bibliothèque Nationale de France ; BVR : Biblioteca Vallicelliana, Rome ; CPG : Clauis Patrum Graecorum ; CSEL : Corpus Scriptorum Ecclesiasticorum Latinorum ; CUF : Collection des Universités de France ; ILI : J. M. de Bujanda (éd.), Index des livres interdits, 11 vol., Sherbrooke-Genève, 1984-2002 ; PG : Patrologiae Cursus Completus, Series Graeca ; SC : Sources chrétiennes. Sauf précision contraire, tous les documents cités sont aux ACDF, fonds de l'Index. On a écrit Index, en romain, pour désigner la congrégation, Index pour le livre. L'orthographe des citations a été respectée, mais la ponctuation occasionnellement rectifiée ; les abréviations ont été élucidées.

1 L'érudition était, aux temps modernes, au cœur des relations entre Rome et la France, le style romain et le style gallican de catholicisme ${ }^{1}$. Sans doute fut-ce particulièrement vrai dans la seconde moitié du XVII ${ }^{e}$ siècle, alors que, d'un côté, l'érudition gallicane connaissait son apogée et que, de l'autre, s'affirmait un mouvement de retour aux sources, souvent teinté de rigorisme voire de jansénisme, qui tendait à réformer le catholicisme post-tridentin sur le modèle de "l'âge d'or de l'Église », aux IV et $\mathrm{V}^{\mathrm{e}}$ siècles. L'orientation fortement historique de la culture religieuse gallicane suscita alors à Rome, et parfois chez les mêmes hommes, aussi bien l'admiration que l'inquiétude. Assez largement déclassés sur le terrain érudit, agrippés au grand récit romanocentrique autrefois développé par Baronius dans ses Annales, les théologiens curialistes donnèrent 
souvent l'impression de ne savoir plus que condamner, au Saint-Office et à l'Index, des travaux auxquels ils étaient incapables de répondre ${ }^{2}$.

2 Si elles s'aggravèrent avec la crise janséniste, à partir de 1640, les inquiétudes de la papauté face à l'érudition gallicane n'étaient pourtant pas nouvelles. Elles sont déjà très apparentes, au tournant du XVI et du XVII ${ }^{\mathrm{e}}$ siècle, dans le cas de Papire Masson, condamné successivement pour un livre d'histoire (le De Episcopis urbis) et une édition de texte (les Opera d'Agobard). Le dossier - un des tout premiers concernant un gallican que l'on trouve aux archives de l'Index -, est d'autant plus intéressant qu'il est contemporain des grandes ambitions savantes romaines, alors que la papauté avait entrepris de faire de l'Urbs la capitale catholique de la philologie sacrée et que les Annales de Baronius étaient en cours de publication, sur la base de matériaux en partie fournis par l'érudition française ${ }^{3}$. On ne saurait donc incriminer, à ce stade, une éventuelle incompétence romaine : c'était bien une autre conception de l'histoire ecclésiastique qui était en cause.

\section{Les gallicanismes du De Episcopis urbis}

3 Les ennuis de Masson avec l'Index commencèrent avec la publication, en 1586, de son De Episcopis urbis. L'intérêt de cet épisode, pour voir « aux prises la Contre-Réforme romaine et le catholicisme gallican du XVI ${ }^{e}$ siècle sur le terrain de la critique historique ", avait été relevé en 1923 par Pierre Ronzy, qui avait eu le mérite de retrouver et de publier une censura détaillée, transmise à Masson par Baronius en $1602^{4}$. Malheureusement, outre des fautes de lecture assez nombreuses, et dont telle ou telle n'étaient pas sans conséquence pour l'interprétation - le censeur était ainsi supposé identifier Érasme à "Satan », alors qu'il l'avait en réalité qualifié de «Batave $»^{5}-$, P. Ronzy voulut attribuer le texte à Baronius lui-même, quoique la lettre du cardinal dît clairement le contraire ${ }^{6}$. Il était de toute manière impossible, tant que les archives de l'Index restaient inaccessibles, d'avoir une vue complète de l'affaire.

4 P. Ronzy, dans sa thèse non remplacée sur Masson, a consacré au De Episcopis urbis, un chapitre fouillé. On rappellera juste ici que l'ouvrage, par sa composition comme par son écriture, relève du genre de l'antiquariat, que Masson avait déjà pratiqué, dans le domaine profane, avec ses Annales Francorum de $1577^{8}$. Il se présente comme une suite chronologique des vies des papes, depuis Pierre jusqu'à Grégoire XIII, qui ne forme pas un récit continu et qui fait une grande place à la reproduction textuelle des sources, en bonne partie inédites. Le titre pourrait indiquer une tendance à minimiser la primauté du pape : il fut certainement interprété en ce sens par les censeurs romains, très susceptibles sur ce point, et à leur suite par P. Ronzy, quoiqu'il ne faille sans doute pas y sous-estimer la part de la coquetterie littéraire ${ }^{9}$. Le gallicanisme ecclésiologique n'est pourtant guère apparent dans le corps de l'ouvrage ${ }^{10}$. La vie d'Honorius $\mathrm{I}^{\mathrm{er}}$ passe ainsi absolument sous silence le monothélisme ${ }^{11}$. Masson évoque rapidement cette hérésie dans le pontificat d'Agathon, avec une curieuse bévue, qui doit être un lapsus : le concile occidental tenu à Rome pour préparer le troisième concile de Constantinople aurait " attesté qu'il n'y avait dans le Seigneur qu'une seule volonté et une seule opération $»^{12}$. L'anathème posthume lancé contre Honorius par le troisième concile de Constantinople est passé sous silence, alors qu'il s'agissait d'une objection déjà classique contre l'infaillibilité du pape ${ }^{13}$. Il est vrai que Masson ne s'appesantit nulle part sur les questions théologiques. Mais l'histoire qu'il fait du concile de Constance n'a rien sur la supériorité du concile sur le pape (le décret Haec sancta n'est pas cité) ${ }^{14}$, et les mentions du concile de Bâle, en reproduisant 
intégralement la bulle In minoribus agentes - où Enea Silvio Piccolomini, devenu le pape Pie II, avait rétracté le conciliarisme de sa jeunesse -, sont hostiles ${ }^{15}$.

5 L'orientation et le ton sont en revanche nettement gallicans dans l'ordre politique. Masson condamne avec insistance les interventions des papes au temporel, particulièrement lorsqu'il s'agit de la France, et souligne que le Pontife romain doit être pacifique et favoriser la concorde entre les princes. Dans sa vie de Grégoire VII, du reste favorable à ce pape ${ }^{16}$, l'excommunication de l'empereur Henri IV en 1076 suscite ce commentaire: "C'était alors une peine grave, car les papes avaient coutume de lancer rarement ces foudres et les excommunications étaient leurs seules armes, mais le plus souvent si fortes que le genre humain ne redoutait rien davantage $»^{17}$. Mentionnant ensuite la défaite de Rodolphe de Souabe, Masson en tire cette leçon : "Cette victoire [de l'empereur] doit avertir les évêques de la ville de Rome qu'ils ne doivent pas, dans l'intérêt de leur vengeance, même très juste, ordonner aux princes de prendre les armes pour leur destruction mutuelle»: il arrive souvent, en effet, que les méchants l'emportent sur les bons ${ }^{18}$. Les malheurs de Boniface VIII donnent lieu à un avertissement du même genre ${ }^{19}$. Grégoire XIII est au contraire loué pour avoir travaillé à établir la paix en Europe, mais l'éloge se double d'une mise en garde: les papes doivent agir ainsi car, s'ils sont privés de l'appui des rois, « ils sont nécessairement en butte au mépris, nus et abandonnés ", à la manière d'un rivage dont la mer s'est retirée ${ }^{20}$. P. Ronzy a fait l'hypothèse très vraisemblable que ces avertissements insistants s'inscrivaient dans la réaction gallicane à la bulle Ab immensa aeterni de Sixte-Quint, du 9 septembre 1585, privant Henri de Navarre de ses États et le déclarant inapte, ainsi que le prince de Condé, à succéder à la couronne de France ${ }^{21}$. Sur tous ces points, le De Episcopis urbis reflète très précisément l'attitude de la monarchie française vis-à-vis de la papauté - il n'est pas indifférent que l'ouvrage soit dédié à Henri III, comme l'avaient été, neuf ans plus tôt, les Annales Francorum ${ }^{22}$.

6 À ce gallicanisme royal se mêlent des traits qui relèvent plus spécifiquement du gallicanisme parlementaire. Son idéal de concorde entre le pape et le roi n'empêcha pas Masson de déplorer le concordat de 1516 par lequel Léon X avait accordé à François $I^{\text {er }}$ et à ses successeurs de nommer aux bénéfices majeurs : « en quoi Léon a certes paru avoir égard à l'intérêt des rois, mais faire un tort immense à la piété chrétienne. Quoique, en effet, les volontés des rois soient souvent excellentes, l'événement a montré que la discipline ecclésiastique s'est effondrée du fait de cette action ${ }^{23}$. Masson relève de même soigneusement, quoique sans commentaire, l'opposition du parlement de Paris, en 1576, à la permission donnée par Grégoire XIII à Henri III d'aliéner des biens ecclésiastiques pour 50000 écus de revenus «même sans l'accord des propriétaires et malgré leur opposition ", en contravention aux canons - la question était d'une brûlante actualité quand Masson écrivait ${ }^{24}$.

7 Le De Episcopis urbis est en outre imprégné d'un gallicanisme culturel, qui s'exprime occasionnellement par des remarques qu'on pourrait aussi bien qualifier d'anti-italiennes que d'anti-romaines. De l'usage de baiser la croix brodée sur la mule du pape, Masson écrit qu'il est «moins approuvé par les peuples d'en deçà des Alpes que par la nation italienne, qui est faite pour ces complaisances et ces abaissements ${ }^{25}$, et il lui oppose, puisqu'« il est équivalent de porter la croix sur son soulier et de la peindre par terre », la constitution du Code Justinien contre cette dernière pratique: recourir ainsi aux empereurs pour donner aux papes une leçon de respect pour la religion n'est sans doute pas innocent ${ }^{26}$. La bizarrerie de la monarchie pontificale, cette gérontocratie élective, 
inspire à Masson les plaisanteries dont les Français, érudits gallicans comme diplomates royaux, étaient alors coutumiers ${ }^{27}$. Les mœurs ou les comportements peu édifiants de plusieurs papes sont évoqués sans détour, et Masson paraît prendre plaisir à citer les plaisanteries, histoires drôles ou pasquinades auxquelles ils ont donné lieu.

8 Les ordres religieux, surtout mendiants, sont égratignés à plusieurs reprises: Honorius III, en approuvant les règles de saint Dominique et de saint François, pensait remédier à la corruption des mœurs, mais il causa involontairement un grand dommage à l'Église, puisque le clergé séculier se déchargea sur les mendiants de la prédication et devint oisif ${ }^{28}$. Masson prend occasion de la fondation des Théatins pour lancer une vive attaque contre les Jésuites: "Les Théatins sont différents des Jésuins, car ceux-ci s'imaginent être les seuls à avoir fait alliance (societatem) avec Jésus, mais le peuple en Italie et en Espagne a l'habitude de les appeler également Théatins »; les Jésuites " pèchent certainement par excès de sagesse, en ce qu'ils pensent qu'ils commanderont un jour au Ciel lui-même $»^{29}$. L'attaque est d'autant plus significative que Masson, ancien élève des Jésuites, était entré dans la Compagnie à l'issue de ses études : novice au Collège Romain en 1563, il enseigna dans plusieurs collèges jésuites, en Italie et en France - en dernier lieu à Paris, au collège de Clermont -, avant de quitter la Compagnie en 1569, et apparemment «avec éclat», même si la digression du De Episcopis urbis constitue sa première attaque publiée contre ses anciens confrères. La tradition jésuite le considéra en tout cas comme un apostat ${ }^{30}$.

9 Il faut cependant isoler ces passages pour pouvoir trouver "parfois à l'œuvre une apparence de satire et de pamphlet $»^{31}$. Le De Episcopis urbis était loin de s'y réduire. Parmi les papes récents, si le faste "plus royal que pontifical » de Paul IV et surtout son népotisme étaient discrètement blâmés, ses mesures contre les Juifs étaient hautement

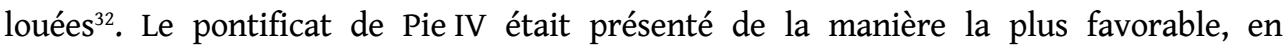
particulier pour l'exécution du cardinal Carlo Carafa : «le peuple romain, frappé par ce spectacle, fut ainsi rappelé à son devoir et n'osa plus ensuite entreprendre de révolutions $»^{33}$. En vantant ainsi l'absolutisme pontifical, Masson faisait de nouveau écho à la position de la monarchie française ${ }^{34}$. Pie $\mathrm{V}$, « excellent et très saint pontife, très remarquable exemple de toutes les vertus », et plus encore Grégoire XIII étaient célébrés pour avoir protégé les lettres et fondé des collèges ${ }^{35}$.

10 Surtout, écrivant d'après les sources originales, Masson balaya certaines légendes médiévales devenues intolérables pour la papauté post-tridentine, ainsi la papesse Jeanne ou le pacte de Sylvestre II avec le diable ${ }^{36}$. Dans ce second cas, il est vrai, la défense de la papauté se teintait de gallicanisme : outre que Sylvestre II (Gerbert d'Aurillac) était un pape français, il avait, avant son pontificat, soutenu un vif conflit avec Rome à propos de l'archevêché de Reims. Masson en avait longuement traité dans ses Annales Francorum, notamment d'après les lettres de Gerbert, encore inédites mais dont il avait pu consulter un manuscrit; Baronius, tout en utilisant son travail, lui reprocha plus tard sa faveur pour Gerbert ${ }^{37}$. Cette dimension n'était pourtant pas explicite dans le De Episcopis urbis, et Baronius put citer avec approbation ce qui y était dit du pontificat de Sylvestre II : Masson, "qui a tout lu », avait démontré que le prétendu pacte avec le diable était une invention du schismatique Beno, animé par sa haine contre les papes ${ }^{38}$. Quant à la papesse, Baronius fit un vif éloge de Masson, « un homme remarquable par l'intelligence et la piété », qui avait « fait s'évaporer toute cette fable ${ }^{39}$.

11 Masson, enfin, ne nourrissait aucune sympathie pour la Réforme, qu'il condamna sévèrement, quoique moins pour sa doctrine que pour les guerres civiles qu'elle avait 
déchaînées en France. De nombreuses digressions dénoncent les massacres et profanations perpétrés par les calvinistes ${ }^{40}$. Tout en reconnaissant les qualités intellectuelles de Calvin - et en s'abstenant de reprendre aucune des légendes répandues par les controversistes les plus violents -, Masson ne l'en qualifie pas moins de " vipère »: «nous devons donc beaucoup à l'année 1564 , où du moins ce montre a péri » ${ }^{41}$. Il est significatif que le jugement porté sur Luther, quoique d'une hostilité sans ambiguïté, soit moins violent dans le ton ${ }^{42}$.

\section{La première censure romaine du De Episcopis urbis}

Masson prévoyait-il que son travail serait mal reçu à Rome ? Il n'en laissa rien paraître. Sa principale préoccupation était que le De Episcopis urbis parvînt au pape le plus tôt possible. La dédicace à Henri III le prie de faire transmettre l'ouvrage à Sixte-Quint par son ambassadeur à Rome, et Masson, confiant que le pontife en "tirera un grand contentement et une grande joie ", ne craint pas de solliciter une récompense aussi bien du pape que du $\mathrm{roi}^{43}$. La conclusion de l'ouvrage s'adresse directement à Sixte-Quint: " nous déposons cette histoire à tes pieds et nous souhaitons qu'elle soit corrigée par toi, qui conserves et la foi et le siège de Pierre $»^{44}$. Après avoir redit crûment qu'une récompense serait bienvenue, Masson termine sur une triomphante profession de foi en la perpétuité du "siège apostolique ", que "tous les vents de l'iniquité » ne sauraient renverser: "et le pontificat sera comme une eau intarissable qui ne cesse jamais de couler » - image complètement renversée par rapport à celle, rencontrée plus haut, de la papauté condamnée au desséchement, si les eaux royales se retirent d'elle ${ }^{45}$. Pierre Ronzy a vu dans ces déclarations de l'ironie, et même de l'ironie " poussée un peu loin $»^{46}$. Mais, outre que Masson, on va le voir, désirait vraiment obtenir le patronage du pape et qu'on voit mal l'intérêt qu'il aurait eu à se moquer de lui ${ }^{47}$, c'est là une lecture anachronique. Au $\mathrm{XVI}^{\mathrm{e}}$ siècle, la critique morale de Rome, l'hostilité à l'italianisation de la Curie, la dénonciation de la volonté de puissance des papes n'excluaient nullement une fidélité sincère au Saint-Siège: les gallicans ne critiquaient tant la papauté que parce qu'ils espéraient sa réforme selon l'idéal gallican ${ }^{48}$. Les leçons prodiguées par Masson aux évêques de Rome n'étaient pas de simples effets rhétoriques à l'intention des lecteurs français : elles visaient bien leurs destinataires ostensibles. En août 1586, à peine le $D e$ Episcopis urbis sorti des presses, Masson écrivit en outre au cardinal Luigi d'Este, protecteur de France à Rome, pour le prier d'en transmettre un exemplaire au pape ${ }^{49}$.

La France et Rome sortaient alors à peine de la crise diplomatique qui s'était ouverte en juillet 1585 quand Sixte-Quint, en représailles au refus de Henri III de recevoir le nouveau nonce, avait expulsé l'ambassadeur de France, Jean de Vivonne. En août 1586, au terme de laborieuses négociations, ce dernier rentrait enfin à Rome ${ }^{50}$. Un de ses premiers gestes pouvait difficilement être d'aller porter au pape un ouvrage susceptible de prêter à polémique. En septembre, le duc de Luxembourg, envoyé en ambassade extraordinaire pour prêter obédience à Sixte-Quint, offrit à celui-ci, de la part de Henri III, des livres d'heures et des psautiers : présent sans risque, que Sa Sainteté trouva «très agréable " ${ }^{51}$. Le cardinal d'Este, qui avait joué un rôle décisif dans le règlement de la crise, avait les mêmes motifs d'éviter toute démarche inconsidérée; il était de surcroît malade - il mourut à la fin de l'année -, et avait dès lors cessé d'assister aux audiences et aux consistoires $^{52}$. 
14 Faute de réponse, Masson, en octobre, s'adressa, ou envisagea de s'adresser, directement à Sixte-Quint. Les actes de la conférence de Carthage entre catholiques et donatistes, en 411, dont l'érudit possédait un manuscrit, devaient, si l'on ose dire, servir d'appât: l'édition de ce texte, qu'il souhaitait dédier au pape, pourrait «dissiper la rage des calvinistes, qui ne sont pas différents des donatistes et les surpassent peut-être en fureur ». Dans une première version de sa lettre - Masson en prépara successivement au moins trois -, il allait jusqu'à déclarer au pape, avec une surprenante naïveté, qu'il accepterait volontiers un poste comme celui de secrétaire apostolique, qu'Innocent VI avait offert en vain à Pétrarque: "l'Italie me verra de nouveau, pour que je serve continuellement le Siège apostolique $»^{53}$. Il n'est pas sûr que la lettre ait été envoyée : il semble clair, en tout cas, qu'elle ne parvint pas à son destinataire. Masson trouva enfin un intermédiaire l'année suivante, en la personne de Giovanni della Torre, camérier d'honneur du pape, venu en France au début de 1587 pour apporter la barette cardinalice à Philippe de Lenoncourt, évêque d'Auxerre. Della Torre se chargea de rapporter avec lui à Rome une nouvelle mouture de la lettre à Sixte-Quint, - où l'appel au secours du pape, « contre le dénuement qui me menace en ces temps difficiles, à cause de la cherté du blé ", était encore plus insistant, - en même temps qu'un exemplaire du De Episcopis urbis ${ }^{54}$

Les offres de service de Masson ne séduisirent pas Sixte-Quint. L'édition princeps des Gesta collationis Carthaginensis parut en 1588 avec une dédicace à Élisabeth d'Autriche, veuve du roi Charles IX, retournée à Vienne depuis douze ans mais qui conservait de vastes revenus en France au titre de son douaire, et de laquelle Masson devait espérer quelque gratification : le passage de la lettre à Sixte-Quint sur « la rage des calvinistes, qui ne sont pas différents des donatistes et les surpassent peut-être en fureur ", y était remployé tel quel ${ }^{55}$. Quant au De Episcopis urbis, l'unique résultat des efforts déployés par l'érudit français paraît bien avoir été d'attirer sur lui l'attention de l'Index: rédigé en latin, et compte tenu de son sujet, l'ouvrage aurait sans doute fini par être examiné à Rome, mais il aurait pu y falloir des années. On imaginerait même volontiers que SixteQuint envoya lui-même à la congrégation, qu'il venait précisément de recréer, le volume qu'on lui avait offert ${ }^{56}$. Le cas de Masson évoque à cet égard celui de Montaigne qui avait porté lui-même à Rome, six ans plus tôt, l'exemplaire fraîchement imprimé des Essais qui fut soumis aux « docteurs moines ${ }^{57}$. L'examen du De Episcopis urbis fut confié à Silvio Antoniano, consulteur de l'Index et secrétaire du Sacré Collège, une des autorités en matière d'histoire à la Curie - il avait été associé à Baronius pour la révision officielle du Martyrologe Romain sous Grégoire XIII, et continuait de travailler avec lui à la nouvelle édition, avec notes ${ }^{58}$. Il fit son rapport à la séance du 8 octobre $1587^{59}$.

Cette censura ne se trouve pas dans les archives mais on peut probablement l'identifier à celle que, quinze ans plus tard, Baronius transmit à Masson: elle dut en tout cas lui ressembler beaucoup ${ }^{60}$. Il s'agit d'une critique minutieuse, tatillonne même, où l'on retrouve "la rigueur" et "l'extrême sévérité » qu'Antoniano, - ancien poète et humaniste converti à la cléricature et aux études sacrées en même temps que toute la culture romaine, - avait montrées, dix ans plus tôt, comme réviseur de la Jérusalem délivrée du Tasse, d'où il aurait voulu retrancher à la fois le merveilleux et l'amour, pour que le poème pût être lu «moins par des gentilshommes que par des religieux et des nonnes " ${ }^{61}$. Toutes les "élégances" païennes que Masson avait cru pouvoir employer ( "les destins », « les dieux ", " la fortune », ou encore "mettre au rang des dieux » pour canoniser) étaient épinglées ${ }^{62}$. Un passage où Jérôme racontait le mariage d'un homme 
qui avait enterré vingt femmes avec une femme déjà vingt-deux fois veuve, « pouvait être omis, et plus encore l'épigramme de Martial» sur Fabius et Christilla; «il fallait omettre » la mention qu'Augustin avait eu un fils naturel ${ }^{63}$. L'éloge rendu à l'intelligence de Calvin et à ses talents littéraires était relevé, même si le censeur notait que Masson n'en approuvait pas pour autant « la secte $»^{64}$. Un passage qui dénonçait comme contraire au christianisme l'usage d'abandonner aux bêtes les corps des suppliciés était écrit « avec trop d'âpreté, et d'ailleurs cela ne se fait pas partout $»^{65}$.

17 De telles critiques relevaient dès lors de la routine de la censure romaine. La traque de « la fortune » et, en général, de tout ce qui revenait à « mélanger les choses profanes avec les sacrées " était devenue systématique à partir des années 1570 - Masson, qui avait connu Rome sous Pie IV, n'avait pas conscience du changement culturel qui s'était produit ${ }^{66}$. Le Tasse fit vainement valoir que ces formules étaient « tellement adoucies par l'usage » que plus personne ne les prenait littéralement ${ }^{67}$. Cette nouvelle intransigeance, qui fut appliquée à Montaigne ${ }^{68}$, valait aussi pour les ouvrages historiques, au mépris des conventions de l'historiographie humaniste ${ }^{69}$. Il en allait de même de l'interdiction d'adresser aucun éloge, même purement littéraire, à des hérétiques ${ }^{70}$. Quant au caractère dangereusement subversif de toute critique des pratiques judiciaires, on se rappellera que les censeurs romains avaient reproché à Montaigne « d'estimer cruauté ce qui est au delà de mort simple $»^{71}$.

Dans l'ordre plus spécifiquement historique, les reproches adressés au De Episcopis urbis peuvent être rapprochées des propositions présentées à l'Index par William Allen, quelques mois plus tôt, pour la correction des Vies de Platina ${ }^{72}$. Dans le détail, il est vrai, les censures se recoupent très rarement, à l'image des ouvrages eux-mêmes. Pratiquement la seule exception concerne la légende médiévale d'Anastase II, frappé de mort par la volonté divine pour avoir communiqué avec les hérétiques, pour laquelle Masson citait le Décret de Gratien : son censeur ordonna de "corriger tout le passage ", comme l'avait fait Allen pour Platina ${ }^{73}$. On a vu, en revanche, comment Masson avait rejeté la papesse Jeanne et le pacte de Sylvestre II avec le diable : l'une et l'autre histoire figuraient dans Platina, et Allen n'avait pas manqué d'en prescrire l'expurgation ${ }^{74}$. Le censeur du De Episcopis urbis ne trouva rien à redire à la Vie de Sylvestre II. Il reprit juste, dans la réfutation de la fable de la papesse, des expressions trop libres ("Laïs ", " Thaïs », "vile prostituée »), une citation de l'historien byzantin Laonicus Chalcondyle, sur la chaise percée où l'on faisait asseoir le nouveau pape pour vérifier sa virilité, - « il vaudra mieux le réfuter » sans le citer ${ }^{75}$-, et surtout un mouvement indigné : «Et les papes voient cette prostituée mise au nombre des évêques et rangée parmi leurs prédécesseurs : et ils supportent pourtant ce très ancien déshonneur de leur siège ${ }^{76}$ ? "L'orientation générale du censeur de Masson, en revanche, était semblable à celle d'Allen : pour l'un comme l'autre de ces futurs cardinaux - si c'est bien à Antoniano que nous avons affaire -, toutes les critiques morales adressées à la Curie romaine, toutes les mentions des vices des papes devaient être absolument supprimées ${ }^{77}$. Le revers de cette expurgation était l'accusation d'avoir écrit " trop sèchement », c'est-à-dire trop brièvement peut-être, mais surtout d'une manière pas assez édifiante, de Jésus-Christ dans le cas de Masson, du concile de Nicée dans celui de Platina ${ }^{78}$. La bévue de Masson faisant professer le monothélisme au concile de Rome sous Agathon était relevée ${ }^{79}$. Quant au gallicanisme de Masson, le censeur en condamna indifféremment toutes les manifestations, des avertissements aux papes à faire régner la concorde entre les princes ${ }^{80}$ jusqu'à la critique du concordat ${ }^{81}$ et au rappel de l'opposition du parlement de Paris aux aliénations inuitis 
possessoribus $^{82}$. Même l'envoi à Sixte-Quint était blâmable : non que le censeur trouvât quelque ironie dans ces protestations de soumission au Siège apostolique, mais Masson y sollicitait du pape - en réalité du pape et du roi - une récompense «d'une façon peu respectueuse $»^{83}$. Ce rappel aux bonnes manières, en conclusion d'une censure qui mêlait le théologique au moral, traduisait sans doute le grand projet post-tridentin de disciplinement des paroles et des gestes, pour fonder une société de déférence ${ }^{84}$. Il pourrait aussi refléter la différence sociale entre Antoniano, fils comme Masson d'un marchand aisé mais formé tout jeune à la politesse de Cour, grâce aux mécènes princiers qui s'étaient penchés d'eux-mêmes sur l'enfant prodige, et un ancien pédant de collège en quête de patrons, qui, en dernière analyse, publiait pour vivre ${ }^{85}$.

Il semble clair que, dans le cas du De Episcopis urbis comme dans celui des Vies de Platina, la congrégation envisageait une expurgation plutôt qu'une prohibition: outre que c'était là la tendance générale dans cette période vis-à-vis des ouvrages " de la seconde classe » (condamnés individuellement, par opposition aux ouvrages d'auteurs hérétiques, dont toute la production était condamnée en bloc) et en particulier pour les ouvrages humanistes, la minutie même de la censure ne se comprendrait guère autrement ${ }^{86}$. Il fut encore question de Masson à la séance du 15 octobre, sans que le procès-verbal donne plus de précisions ${ }^{87}$. Averti - ce qui confirme le lien entre l'hommage du De Episcopis urbis à Sixte-Quint et son examen par l'Index -, Della Torre prévint à son tour Masson. Le 15 novembre 1587, celui-ci répondit à son protecteur pour le supplier de représenter à la congrégation «qu'il n'y eut jamais d'homme plus disposé ni plus désireux que moi de corriger les passages où j'aurai fait erreur ", pourvu qu'on lui transmît des instructions pour la correction ${ }^{88}$. Le lendemain, il écrivit à Sixte-Quint pour protester solennellement de sa soumission : «s'il est plus utile à l'Église sainte et apostolique que les livres sur les souverains Pontifes que j'ai publiés [on notera la correction apportée au titre] soient anéantis au lieu de vivre plus longtemps, je souhaite qu'ils soient biffés d'un seul trait et qu'ils périssent au berceau ». Et Masson de promettre de faire toutes les corrections qui lui seraient demandées ${ }^{89}$.

Transmises à l'Index, les deux lettres furent lues à la séance du 7 janvier 1588: «on décida à l'unanimité qu'il fallait corriger le livre et avertir l'auteur, et le soin de répondre à Masson fut confié au cardinal Ascanio Colonna $»^{90}$. Tout porte à penser que celui-ci ne s'acquitta jamais de cette tâche. Juste deux semaines plus tard, la congrégation était complètement réorganisée, et reprise en main, par Sixte-Quint. Pour près d'une décennie, le sort du De Episcopis urbis allait se trouver étroitement lié aux péripéties, désormais bien connues, de la publication du nouvel Index librorum prohibitorum romain (le troisième, après ceux de 1559 et 1564), en fonction des rapports de force entre la congrégation de l'Index, le Saint-Office et le pape.

\section{Le long cheminement d'une mise à l'Index}

De 1588 à 1590, ce fut la préparation de l'Index de Sixte-Quint. L'attitude romaine à l'égard de Masson dans cette période est sans doute bien exprimée par l'Espagnol José Esteve, qualificateur de l'Index, que Sixte-Quint avait nommé évêque de Viesti, dans le royaume de Naples. Dans un traité Sur le baisement des pieds du pontife romain, dédié à Sixte-Quint et publié à Rome dans les premiers mois de 1588, Esteve apostropha vivement Masson pour ce qu'il avait dit de cette cérémonie dans le De Episcopis urbis, mais en lui marquant des égards et en l'invitant à se corriger lui-même. Masson était un «homme savant et, à ce 
que je crois, honnête $»^{91}$, qui avait lui-même déposé son livre aux pieds du pape ${ }^{92}$. Esteve l'avertissait donc "pour que, dans les autres éditions, tu corriges cela ainsi que d'autres choses, ce que j'espère vraiment que tu feras, pour ne pas paraître t'abandonner toimême et outrager un si grand travail, fruit de tant de veilles $"^{93}$. Le De Episcopis urbis fut finalement inscrit dans l'Index de Sixte-Quint, "à moins qu'il ne soit d'abord corrigé d'après les règles" générales voulues par le pape: la vingt et unième de celles-ci prescrivait un gigantesque programme d'expurgation, pour supprimer non seulement toutes les propositions susceptibles de recevoir une note théologique, mais encore toutes «les épithètes élogieuses » attribuées aux hérétiques, toutes les mentions des destins ou de la fortune, «tous les exemples qui blessent les rites, les personnes ou la dignité ecclésiastiques", "les facéties qui dénigrent la réputation d'autrui ». L'Index était imprimé à la mort de Sixte-Quint, en août 1590. On sait qu'il fut alors immédiatement suspendu par le Saint-Office, qui en fit saisir tous les exemplaires imprimés, et qu'il n'eut aucune diffusion ${ }^{94}$.

La préparation du nouvel Index fut ensuite mise en sommeil, tandis que, en un an et demi, ne se succédaient pas moins de quatre conclaves. Par ordre du pape Grégoire XIV, dont le règne de dix mois fut le plus long de ces pontificats éphémères, l'Index en 1591 se consacra exclusivement à la révision de la Vulgate ${ }^{95}$. Masson, laissé sans nouvelles, prit alors le parti de s'adresser à Baronius, en qui il pouvait espérer trouver un nouvel intermédiaire à Rome : l'Oratorien avait en effet, dans son édition du Martyrologe Romain, cité avec éloge les Annales Francorum ${ }^{96}$. Masson s'en autorisa pour lui envoyer, au début de juillet 1591, une lettre de prise de contact, où, après les politesses d'usage ( «il est beau d'être loué par un homme renommé comme toi »), il lui glissait : "Si par hasard sont venus entre tes mains six livres De Episcopis urbis, de saint Pierre à Sixte-Quint, répondsmoi, je t'en prie, ce que tu penses de cet ouvrage. Je fais en effet le plus grand cas de ton jugement, et il vaudra tout pour moi $»^{97}$.

Baronius répondit le 4 août, après quelques amabilités sur les Annales Francorum et la gratitude que vouaient à leur auteur tous les savants de Rome, qu'il avait cherché en vain à se procurer le De Episcopis urbis mais qu'il avait « entendu dire par des hommes doctes qu'il y avait certaines choses qui offensaient les oreilles des catholiques ${ }^{98}$. On n'hésitera pas à reconnaître dans ces hommes doctes Antoniano, très lié à l'Oratoire romain. La formule de Baronius faisait en outre écho, avec une imprécision sans doute délibérée, à la notion d'offense aux oreilles pieuses, qui inspirait tout le travail d'expurgation des censeurs de l'Index dans cette période ${ }^{99}$. Il s'agit d'une note théologique, dont le sens est précis: est piarum aurium offensiva « une proposition qui, quoiqu'elle dise le vrai, soit dit ce qu'il convient de taire à cause du respect que l'on doit aux choses saintes, soit le dit d'une manière qui fait tomber celles-ci dans le mépris ${ }^{100}$. La majorité des passages relevés par le censeur du De Episcopis urbis rentraient de fait dans cette catégorie. C'était donc bien une censure technique et officielle qu'évoquait Baronius, quoique avec les formes et les codes d'une correspondance entre deux savants. Masson s'y méprit ou feignit de s'y méprendre. Il récrivit en retour qu'il allait envoyer à Baronius par courrier "son ouvrage sur les pontifes romains ${ }^{101}$. Il était peiné que certains passages « déplaisent à quelques personnes modérées et savantes, particulièrement si ce sont des Italiens, nation dont j'ai toujours considéré qu'elle l'emportait en jugement sur toutes les autres ». Il ferait les corrections que ces personnes et Baronius estimeraient nécessaires, à l'exemple d'Hippocrate reconnaissant ces erreurs. Cette référence toute profane, assez 
commune dans la rhétorique humaniste, montre bien qu'il s'agit ici d'un jugement de science, non d'autorité : du pape et de la congrégation de l'Index, il n'était pas question ${ }^{102}$.

L'Index ne reprit ses travaux interrompus qu'en avril 1592, après l'élection de Clément VIII ${ }^{103}$. Tandis que l'entreprise d'expurgation des livres était relancée, en vue d'un futur Index librorum expurgandorum, la congrégation s'employa à publier sans plus attendre un nouvel Index librorum prohibitorum ${ }^{104}$. En septembre 1592, les consulteurs chargés de rendre des avis sur « les auteurs ou les livres à ajouter ou à ôter dans l'Index » ${ }^{105}$, se divisèrent sur le cas de Masson. Pierre Morin le rangeait parmi les auteurs catholiques dont il fallait «épargner la réputation » et qui devaient être réservés pour l' Index expurgatorius, où leurs erreurs seraient énumérées précisément ${ }^{106}$. Gonzalo Ponce de León et Marcantonio Maffa étaient pour qu'on l'inclût dès à présent, le premier précisant cependant que ce devrait être dans une liste à part d'auteurs catholiques, bien distingués des hérétiques ${ }^{107}$. La censura faite cinq ans plus tôt par Antoniano avait apparemment été égarée ou perdue ${ }^{108}$ : elle n'aurait du reste guère permis de trancher le débat puisque, s'il s'agissait bien, encore une fois, de celle qu'envoya plus tard Baronius à Masson, - elle ne consistait qu'en une longue liste de passages à expurger. Le 10 octobre 1592, un nouvel avis sur le De Episcopis urbis fut donc demandé à Robert Bellarmin, figure-clef de la congrégation dans cette période ${ }^{109}$. Celui-ci rédigea deux textes, d'une part une censura, dans l'ordre du livre, où étaient relevés trente-trois passages condamnables, d'autre part une synthèse, en sept points ${ }^{110}$. La censura n'apportait presque rien de nouveau par rapport à celle d'" Antoniano", mais elle était beaucoup plus sélective : les formules païennes, l'épigramme de Martial, la bévue sur le concile de Rome et le monothélisme, la critique du concordat même, tout cela était laissé de côté. C'est qu'il ne s'agissait pas cette fois de préparer l'expurgation du De Episcopis urbis, mais bien d'en motiver la prohibition. La synthèse articulait des reproches généraux non seulement contre l'ouvrage ( $~$ il est incomplet », " il contient beaucoup d'inepties ») mais contre son auteur, et ce tant dans l'ordre des mœurs («il a travaillé avec négligence », « il est assez malveillant ») que dans celui de la foi ( il est suspect de l'erreur de ceux qui nient au Souverain Pontife une puissance coactive sur tous les chrétiens ", «il est suspect de même de l'erreur de ceux qui condamnent les ordres de religieux mendiants $)^{111}$. L'historiographie récente sur l'Index a fait généralement apparaître Bellarmin comme un modéré. Dans les débats sur la censure de Platina en 1587, où il intervint juste après Allen, il s'écarta sur plusieurs points de celui-ci. À propos des papes de la fin du IX $\mathrm{IX}^{\mathrm{e}}$ siècle et du $\mathrm{X}^{\mathrm{e}}$ siècle, au temps de la "pornocratie pontificale», Allen avait protesté : «Platina n'a pas écrit les vies mais les vices de ces papes, il faut donc l'expurger ${ }^{112}$. Bellarmin avait été beaucoup plus nuancé : "Je ne sais s'il convient d'expurger les vices de ces papes comme s'ils étaient faux, comme le juge le censeur [Allen]. Même si tous ne sont pas vrais, la plupart le sont. Les crimes de Sergius III » et des papes suivants sont racontés par Luitprand. "Or Luitprand a vécu à cette époque, comme il l'indique lui-même dans son œuvre ${ }^{113}$. Ce respect de la vérité historique était une stratégie apologétique: pour Bellarmin, les vices individuels de certains papes prouvaient que l'indéfectibilité du Saint-Siège était fondée sur les promesses divines, non sur des vertus humaines ${ }^{114}$. Dans sa censure de Masson, en revanche, il nota que « dans la Vie de Sergius III, il rapporte et répète trop souvent d'après Luitprand certains vices énormes des Pontifes romains $»^{115}$. Et Bellarmin balaya l'argument qu'il avait lui-même fait valoir dans le cas de Platina : "son excuse, à savoir qu'il appartient à un historien de raconter fidèlement les événements, ne paraît pas recevable. En effet, comme je l'ai dit plus haut, il ne mérite pas le nom d'historien, puisqu'il n'expose les vies des papes ni complètement ni dans l'ordre ${ }^{116}$. De même, sur 
l'histoire de Benoît IX vendant le siège apostolique à Grégoire VI, qu'Allen aurait voulu supprimer dans Platina, Bellarmin avait objecté qu'elle était attestée par Hermannus Contractus, auteur contemporain et digne de foi: «il ne semble pas que l'on doive supprimer dans Platina des affirmations qui sont vraies et qui se lisent dans des auteurs approuvés $»^{117}$. Bellarmin n'en reprocha pas moins à Masson ce qu'il avait écrit de la simonie de Nicolas III, « en citant de nombreux vers de Dante », où ce pape est placé dans la troisième bouge du huitième cercle de l'Enfer ${ }^{118}$.

La contradiction apparente vient de ce que Bellarmin soumettait le De Episcopis urbis à une lecture inquisitoriale, tournée vers l'hérétique caché, suspect, hypocrite ${ }^{119}$. Selon la logique caractéristique de cette démarche, l'auteur et le livre s'incriminaient mutuellement. Le soupçon d'hérésie se fondait sur le livre ${ }^{120}$ mais il était justifié aussi par le contexte («le titre De Episcopis Urbis choque avec raison à notre époque, alors que fleurissent les hérésies des luthériens, qui soutiennent que les pontifes romains ne sont pas les pontifes de toute l'Église ${ }^{121}$ ) et par la personne même de Masson, chez qui Bellarmin dénonçait une attitude de désobéissance: "Il cite souvent Érasme, Mélanchthon, Calvin, Palingenio, et il indique assez qu'il a lu ces auteurs, quoiqu'ils soient interdits et qu'il ne soit pas vraisemblable qu'il ait la permission de lire des livres de ce genre, puisqu'il n'est pas théologien mais avocat $»^{122}$ - le reproche supposait évidemment que l'Index romain, quoique non reçu en France, y obligeait au moins au for interne. Bellarmin ne manquait pas non plus de relever que Masson « louait Calvin», sans dire un mot des violentes attaques dont cet éloge était immédiatement suivi ${ }^{123}$ : procédé qu'on ne pourrait qualifier autrement que de malhonnête, s'il ne traduisait la conviction que Masson, suspect d'hérésie, ne méritait aucun crédit dans ses protestations d'orthodoxie. Il est difficile de ne pas soupçonner ici une animosité, sinon personnelle, du moins de famille religieuse, contre un ancien confrère devenu un ennemi de la Compagnie Bellarmin et Masson auraient même passé presque une année ensemble au Collège Romain, en $1563^{124}$. Quoique le jésuite ne formulât pas de recommandation (de votum proprement dit), sa conclusion implicite était bien que le De Episcopis urbis méritait d'être mis à l'Index.

Masson trouva alors un défenseur en la personne de l'helléniste français Pierre Morin, établi définitivement depuis 1575 à Rome, où il collaborait aux grandes entreprises textuelles, bibliques, patristiques et conciliaires, qu'avait lancées la papauté1 ${ }^{125}$. Morin était depuis 1587 consulteur de l'Index, où il fut loin de plaider systématiquement pour l'indulgence : en avril 1587, il s'était prononcé pour l'inclusion d'Érasme parmi les auteurs hérétiques ${ }^{126}$; en 1592-1593, il fut un adversaire acharné de la République de Bodin ${ }^{127}$. En l'absence du secrétaire de la congrégation, le dominicain Paolo Pico, ce fut lui qui le suppléa à la réunion du 10 octobre 1592, celle même où l'examen du De Episcopis urbis fut confié à Bellarmin ${ }^{128}$. À la réunion suivante, le 24 octobre, il présenta lui-même un mémoire "pour Papire Masson et François Juret ${ }^{129}$. Ce dernier, chanoine de Langres, très lié au milieu des juristes gallicans, avait été mis en cause pour avoir glissé, dans une note à son édition des Lettres de Symmaque, que Rome ne portait plus son nom que «par une usurpation frauduleuse » et n'était "que le cadavre immonde de son ancienne splendeur $»^{130}$ : thème humaniste classique mais qui pouvait aussi nourrir la plus violente polémique anti-romaine et anti-papale ${ }^{131}$. Il semble du reste que Juret n'ait fait que citer une invective contre Rome attribuée à Joseph Scaliger, qui fut abondamment diffusée en manuscrit au tournant du XVI ${ }^{\mathrm{e}}$ et du XVII ${ }^{\mathrm{e}}$ siècle ${ }^{132}$. Les Index espagnols, à partir de celui 
de 1583-1584, ordonnèrent en tout cas la suppression des deux lignes en question ${ }^{133}$ et Juret fut inscrit dans l'Index de Sixte-Quint ${ }^{134}$.

L'intervention de Morin en faveur des deux érudits gallicans tenait vraisemblablement en partie à un sentiment national, mais elle exprimait surtout une solidarité sociale - le sentiment national ne l'avait pas rendu favorable à Bodin. Masson et Juret, souligne-t-il, sont «de ceux qui recherchent les monuments ecclésiastiques dans les meilleures bibliothèques et qui les mettent au jour pour l'utilité publique » - « Masson, dans les Vies des souverains pontifes, a écrit énormément de choses très rares et qui ne sont pas généralement connues "; Juret a récemment publié les lettres d'Yves de Chartres ${ }^{135}$. Des hommes de ce genre doivent être encouragés, "sinon par des louanges et des récompenses, du moins en les traitant avec indulgence et bienveillance ». Morin, dont les lettres de ces années à ses patrons romains quémandent, avec une insistance dont il souffrait lui-même, "les récompenses de [s]es travaux", devait penser à sa propre situation ${ }^{136}$. Les découvertes des érudits, aussi bien, «montrent que nous sommes les vrais fils et héritiers de l'Église primitive, ce qui constitue le plus solide rempart contre les novateurs et les ennemis de l'Église ». Tel était effectivement l'esprit dans lequel Morin travaillait lui-même sur les Pères grecs ${ }^{137}$. Son plaidoyer pour Masson et Juret était en même temps une autocélébration de l'érudition. Soulignant qu'une mise à l'Index était infamante pour des auteurs catholiques, Morin en trouvait la preuve dans « ce qu'ont dit ceux qui ont récemment plaidé pour Speroni et pour Juste-Lipse». L'allusion était transparente à Bellarmin, implicitement accusé de pratiquer le deux poids, deux mesures. À la réunion du 10 octobre 1592, il était intervenu pour que la Politique de Juste Lipse fût retirée de l'Index, afin de laisser l'auteur en donner une nouvelle édition, corrigée selon les indications des censeurs romains ${ }^{138}$. Lipse, ancien élève des Jésuites, avait été deux ans novice dans la Compagnie mais, à la différence de Masson, en était sorti avec l'accord de ses supérieurs ; il y comptait de nombreux amis, et les jésuites avaient joué un rôle décisif dans son retour au catholicisme, au printemps 1591, puis dans sa toute récente réinstallation à Louvain ${ }^{139}$.

Morin joignait à son mémoire, pour contre-balancer la censura de Bellarmin, une série d'extraits du De Episcopis urbis : les attaques de Masson contre Luther et le «poison » de sa secte, l'éloge qu'il faisait du cardinal Hosius pour avoir réfuté Luther et Calvin, les louanges qu'il adressait à Grégoire XIII, la conclusion où il déposait son livre aux pieds de Sixte-Quint ${ }^{140}$. Pour donner plus de poids à son intervention, Morin avait en outre immédiatement sollicité Baronius, dont il était proche : il lui rendit de précieux services pour ses Annales en lui traduisant des textes grecs tirés des bibliothèques romaines ${ }^{141}$, et il semble avoir joué un rôle, justement dans cette période, pour le mettre en rapport avec le milieu érudit gallican ${ }^{142}$. Dès le 10 octobre 1592, Baronius écrivit à Pico pour attester, en enjolivant ou, plus exactement, en théologisant quelque peu les choses, qu'il avait été en correspondance avec Masson et que celui-ci s'était déclaré « prêt à corriger les erreurs qu'il avait commises, en s'en remettant entièrement à la censure de la sainte Église romaine $»^{143}$. À la séance de l'Index du 24 octobre, après que Bellarmin et Morin eurent pris la parole devant les cardinaux, il fut décidé « qu'il n'y ait aucun tri entre les auteurs mais qu'ils soient tous placés indifféremment dans l'Index avec une clause d'expurgation, et qu'on ajoute parmi eux Masson et Juste Lipse $»^{144}$.

29 Le De Episcopis urbis resta donc inclus dans l'Index imprimé en 1593, «à moins qu'il ne soit d'abord corrigé et rectifié $»^{145}$. Il en fut de même pour la Politique de Lipse et pour les notes de Juret sur Symmaque ${ }^{146}$. Les règles de Sixte-Quint avaient été abrogées mais la 
vingt et unième était reprise pratiquement sans changement dans la nouvelle instruction pour la correction des livres placée en tête du volume ${ }^{147}$. Ayant reçu un exemplaire de cet Index le 8 juillet 1593, Clément VIII décidait le lendemain de le suspendre ${ }^{148}$. Dans une liste d'objections, transmises à la congrégation en février 1594, le pape lui reprochait une excessive sévérité, notamment à l'égard de livres dus à des catholiques vivants ${ }^{149}$. «Outre la flétrissure qui est manifestement imprimée aux auteurs, il y a aussi un risque évident que, sous le coup de l'indignation, ils ne deviennent hérétiques »; il valait mieux ne pas faire figurer ces auteurs dans les Index (ni prohibitorius ni même expurgatorius) et les avertir de donner une rétractation, "ce qu'ils feront plus facilement et qui sera le meilleur parti pour la foi catholique", ou du moins attendre la publication de l'Index expurgatorius pour y marquer précisément les passages à corriger. Clément VIII donnait comme exemples Juste Lipse, Jean Bodin et Masson ${ }^{150}$.

Il a été suggéré avec vraisemblance que, s'agissant de Bodin, l'attitude du pape répondait en partie à des considérations diplomatiques, dans le cadre d'une politique française qui allait aboutir à l'absolution de Henri IV en septembre 1595, malgré le parti espagnol et le Saint-Office ${ }^{151}$. Il est possible que cette ligne pro-française ait aussi joué dans le cas de Masson, quoique Morin, on l'a vu, eût été extrêmement hostile à Bodin et que, à l'époque où il défendait le De Episcopis urbis, il tînt expressément la Ligue pour « le bon parti » ${ }^{152}$. En sens inverse, le fait que Ponce de León, partisan de la condamnation alors même qu'il était lui aussi un érudit, traducteur des Pères grecs et associé à l'édition des conciles, eût publié en 1593 un livre sur la "perpétuelle inhabilité » de Henri IV à la couronne de France, pour empêcher une réconciliation entre le Béarnais et la papauté, pourrait être significatif ${ }^{153}$. Mais il faut surtout relever que Clément VIII s'appuyait étroitement sur le milieu de l'Oratoire romain et que ses plus proches conseillers n'étaient autres que Baronius et Antoniano. Ce fut celui-ci, désormais maître de la chambre pontificale, qui transmit à la congrégation de l'Index le texte des objections pontificales, dont il était le dépositaire ${ }^{154}$. Baronius était intervenu personnellement en faveur de Masson; Antoniano avait composé une censura en vue d'une expurgation du De Episcopis urbis et il était lui aussi lié à Morin ${ }^{155}$. Les objections pontificales étaient en parfaite cohérence avec la position que, depuis 1587 et l'intervention de Della Torre, toute une partie des milieux romains avait adoptée à l'égard de Masson : obtenir de l'érudit français qu'il donnât luimême une réédition corrigée de son livre.

Dans la réponse officielle qu'elle présenta au pape, en mars $1594^{156}$, la congrégation de l'Index fit valoir qu'il y avait eu débat sur la question des livres dus à des auteurs catholiques vivants, mais qu'il avait été finalement décidé de les inclure : si les auteurs étaient vraiment catholiques, «ils souffriraient patiemment cette mise à l'épreuve »; si, par orgueil, ils ne l'acceptaient pas, ils ne supporteraient pas davantage que leurs erreurs fussent corrigées dans l'Index expurgatorius ${ }^{157}$. Un premier projet de réponse, au ton nettement plus vif, relevait que l'objection supposait bien peu de confiance en la solidité de la foi des auteurs. «Et pourquoi ont-ils négligé de corriger leurs livres eux-mêmes, alors que leurs amis les ont tant de fois avertis de le faire, et bien avant leur mise à l'Index ? Il y a assurément un grand danger pour les fidèles si la lecture de ces livres n'est pas interdite avant la publication de l'Index expurgatoire $»^{158}$.

Après plusieurs mois passés à réorganiser une nouvelle fois l'entreprise d'expurgation, la congrégation retourna en décembre 1594 à l'impression du nouvel Index prohibitorius, « selon les oppositions autrefois transmises par Sa Sainteté à la congrégation, et dont certaines avaient été acceptées et certaines rejetées par la congrégation ${ }^{159}$. Le cardinal 
Fédéric Borromée fut chargé de réexaminer tous les cas litigieux : Pico et lui passèrent "de nombreuses journées à consulter les livres et les censures ${ }^{160}$. Le cardinal fit son rapport dans trois séances successives, les 4 mars, 11 mars et 22 avril $1595^{161}$. Du De Episcopis urbis, il observa : «Il y a dans cet ouvrage beaucoup de choses fausses, téméraires et avancées avec impudence sur les Pontifes romains. Bellarmin a fait une expurgation. L'auteur promet pourtant de travailler avec ardeur à la correction de ses livres De uitis Episcoporum etc. Il écrivit une lettre à Sixte-Quint en $1587 »^{162}$. Le 11 mars - Morin, qui suppléait à nouveau Pico, n'y fut sans doute pas étranger ${ }^{163}$-, la congrégation envisagea de retirer Masson de l'Index en même temps que Lipse et que Juret. Le cardinal Ascanio Colonna se chargea d'écrire à tous trois et ordonna qu'on lui apportât les censures de leurs ouvrages ${ }^{164}$. La décision fut cependant renvoyée à une " congrégation plénière »-il n'y avait que quatre cardinaux présents ${ }^{165}$. À la réunion suivante, le 22 avril 1595, où tous étaient là, Lipse et Juret furent effectivement supprimés mais Masson fut conservé ${ }^{166}$. Lipse fit paraître au début de 1596 l'édition expurgée de sa Politique ${ }^{167}$; Juret ne donna jamais d'édition corrigée de son Symmaque mais les enjeux en étaient limités - il fit son retour dans l'Index en 1611 pour sa seconde édition d'Yves de Chartres, augmentée de notes nettement gallicanes, où Baronius était critiqué ${ }^{168}$.

Le De Episcopis urbis figura donc, comme en 1590 et 1593, dans l'Index de compromis qui vit enfin le jour en 1596, avec une formule modifiée: "sauf dans l'édition corrigée par l'auteur, avec approbation du Maître du Sacré Palais $»^{169}$. En pratique, comme la congrégation de l'Index le fit valoir à sa sœur aînée et rivale du Saint-Office dans le cas de Bodin - pour lequel la même formule avait été employée -, cette double restriction équivalait à une condamnation pure et simple ${ }^{170}$. L'effet symbolique, pourtant, n'était pas du tout le même. Preuve en est que le Saint-Office ne se satisfit pas de cette explication et imposa, dans la fameuse Observatio finalement placée en tête de l'Index de 1596, une condamnation pure et simple de la République ${ }^{171}$.

\section{Après la condamnation}

On ne sait quelles furent les réactions de Masson ni même - dans des années où les communications entre Rome et la France étaient très difficiles -, s'il fut exactement informé des événements. Après leur échange de 1591, la correspondance conservée de Baronius et de Masson s'interrompt pour une décennie ${ }^{172}$. Dans l'été 1593, Baronius écrivit à Juste Lipse pour l'informer que, "devant mes protestations et celles de très nombreuses autres personnes ", Clément VIII avait suspendu l'Index et qu'il faudrait plusieurs mois avant de trouver un accord : « toi donc, cher Juste, mets bien à profit cette occasion favorable " ${ }^{173}$. On n'a aucune trace d'une telle démarche à l'égard de Masson. Le De Episcopis urbis réapparut pour la dernière fois, et dans les lettres de Baronius et à l'Index, en 1601-1602. Peut-on imaginer qu'il y ait un lien avec le conflit de juridiction qui opposait alors la congrégation et le Maître du Sacré Palais - officiellement chargé d'approuver une édition corrigée qui n'avait toujours pas paru ${ }^{174}$ ? On notera que, au même moment, l'Index s'occupa à nouveau de la Politique de Lipse ${ }^{175}$. En 1601, dans des circonstances malheureusement très obscures, il semble que Nicolas Le Fèvre, le principal correspondant et collaborateur français de Baronius, lui ait fourni une attestation « de la piété et de la religion » de Masson, ce qui laisserait penser que celles-ci avaient été mises en cause à Rome ${ }^{176}$. Baronius avait été créé cardinal en 1596 et était membre de l'Index. Le 12 février 1602, en tout cas, il écrivit à Masson pour lui transmettre, « enfin », la critique 
du De Episcopis urbis. Affectant d'en prendre ses distances, il convenait que le censeur avait "enfoncé son poinçon" assez profondément et repris bien des affirmations sans gravité ou qui n'étaient que des citations. Mais «dans un ouvrage sur un tel sujet, particulièrement à notre époque, il est presque impossible d'être trop prudent ». Il revenait à Masson de faire un choix parmi toutes ces remarques et de " corriger ce que tu jugeras pouvoir à bon droit offenser les oreilles des gens de bien »- on retrouve cette manière habile d'envelopper rhétoriquement une censure théologique ${ }^{177}$. Le cardinal assurait finalement l'auteur que, "quoique cette censure ait été rédigée par autorité privée et non publique ", une édition corrigée d'après elle serait immédiatement permise par le Saint-Siège ${ }^{178}$. Il est patent que, là encore, Baronius dissimulait le véritable caractère de son échange avec Masson. En juillet 1594, après la rebuffade reçue de Clément VIII, la congrégation de l'Index avait envisagé un moment de s'adresser directement aux auteurs catholiques vivants - et Masson aurait été du nombre : un projet de lettre rédigé par le cardinal Valier les exhortait à « chanter la palinodie ", à l'exemple d'Augustin rédigeant ses Révisions; ils devaient s'adresser au nonce pour avoir communication des erreurs à corriger dans leurs livres et publier ensuite sous son autorité une édition expurgée ${ }^{179}$. L'idée avait été abandonnée presque aussitôt et il avait été décidé «que la congrégation n'écrive en aucune manière aux auteurs vivants, mais qu'ils soient seulement avertis par quelqu'un en privé de corriger les erreurs dans leurs livres $»^{180}$. C'était ce rôle que jouait Baronius et la censure qu'il transmettait était, selon toute vraisemblance, celle que l'Index avait autrefois fait composer pour l'expurgation du De Episcopis urbis et qui, sans les soubresauts de la congrégation, aurait dû être envoyée à l'auteur dès 1588 : celle d'Antoniano. Sept mois plus tard, le 16 septembre 1602, à une réunion de la "classe d'humanités, histoires et médecine » de l'Index - la congrégation venait de mettre en place une division en classes pour poursuivre à nouveau le serpent de mer de l'Index expurgatorius -, plusieurs consulteurs furent chargés d'examiner Masson, "quoique celui-ci ait été autrefois censuré par la congrégation et que la censure ait été transmise à l'auteur. C'est pourquoi il faut écrire au nonce en France pour qu'il voie et qu'il rapporte si l'auteur a effectivement fait imprimer son livre censuré » (expurgé). Il vaut de relever que, en l'absence de Baronius empêché, la réunion était présidée par son collègue, le cardinal Silvio Antoniano ${ }^{181}$. Le 22 novembre 1602, le cardinal de Terranova, qui assurait alors la correspondance de la congrégation, demanda effectivement au nonce Innocenzo del Bufalo de se renseigner ${ }^{182}$. La réponse fut décourageante : «Papire Masson confesse qu'il avait autrefois pensé à corriger et faire réimprimer son livre ». Mais il a abandonné ce projet, ayant constaté que, dans la censure reçue de Rome, on lui reproche d'avoir reproduit des lettres qu'il n'a fait que tirer des Variae de Cassiodore, « et que, à son avis, ce qu'on lui reproche n'est pas important ». Le De Episcopis urbis continuait donc à être lu et vendu en France dans l'édition originale ${ }^{183}$.

35 La classe d'humanités, histoires et médecine continua à se réunir jusqu'en 1604, presque toujours sans Baronius qui, "très occupé à ses Annales ecclésiastiques", rejeta tout le travail, d'abord sur Antoniano, puis, après la mort de celui-ci, en août 1603, sur le cardinal Arnaud d'Ossat, son nouveau " collègue pour la censure des livres d'humanités » : le nom de Masson n'apparaît jamais dans les procès-verbaux ${ }^{184}$. Le De Episcopis urbis ne figure pas dans le volume d'expurgations qui fut finalement compilé par le Maître du Sacré Palais et publié en 1607, unique et ultime résultat de tant d'efforts ${ }^{185}$. L'incapacité romaine, à la différence de l'Inquisition espagnole, à organiser l'expurgation des livres est bien sûr un phénomène général, mais tout se passa, dans ce cas particulier, comme si l'on avait décidé d'enterrer l'affaire. Au moins chez d'Ossat, un des principaux agents de la diplomatie 
française à Rome, ancien négociateur de l'absolution de Henri IV, des considérations politiques durent tenir leur part ${ }^{186}$.

De Thou, à qui Masson avait communiqué la lettre de Baronius de février 1602 et la censure qui y était jointe, expliqua plus tard que Masson avait « compris ce jugement comme le conseil d'un ami bienveillant", l'avait soumis à ses autres amis, et s'en était finalement remis à la postérité « qui, avec un jugement incorruptible, paierait un jour à ce qui avait été bien dit ou mal dit l'honneur ou l'infamie qui leur étaient dus $»^{187}$. Cette fière formule, où tout lecteur du temps reconnaissait le discours prêté par Tacite à Cremutius Cordus, accusé de lèse-majesté pour ses Annales sous Tibère - la plus grande figure antique de l'historien défiant la tyrannie -, exprime à l'évidence les propres sentiments de de Thou devant la mise à l'Index de son Histoire ${ }^{188}$. Au XX $X^{e}$ siècle, P. Ronzy a tranché qu'il était tout simplement « impossible » pour Masson d'accepter les corrections demandées par Rome, puisqu'elles eussent impliqué de trahir «sa conscience d'historien ${ }^{189}$. Il faudrait dès lors considérer que les solennelles promesses de soumission faites d'avance par Masson avaient une valeur, comme disent les linguistes, perlocutoire: elles valaient profession de catholicité, visaient à convaincre Rome qu'il était enfant de l'Église romaine, mais n'étaient pas destinées à être prises littéralement. Il semble pourtant bien que Masson ait dit vrai au nonce et qu'il ait, un moment, envisagé de s'exécuter. Un exemplaire du De Episcopis urbis, aujourd'hui conservé à la British Library, porte sur la page de titre cette mention: «Papire Masson a corrigé son présent ouvrage conformément à la censure du cardinal Baronius et à l'esprit de la cour de Rome ${ }^{190}$. Tous les passages incriminés dans la censura d'Antoniano y sont corrigés en marge. Le titre De Episcopis urbis devient De summis pontificibus, superi et fata sont remplacés par Deus, secta, pour parler des ordres religieux, par ordo ${ }^{191}$ : pour faire bonne mesure, Masson fit même quelques corrections supplémentaires du même genre, qui avaient été oubliées par la censure ${ }^{192}$. L'attaque contre les « Jésuins » (corrigés en Jésuites) ${ }^{193}$, les avertissements aux papes ${ }^{194}$, les nombreuses citations blâmées par Antoniano, tout cela est marqué d'un signe de suppression ${ }^{195}$. La mention élogieuse des talents de Calvin disparaît au profit d'une attaque redoublée contre sa secte « qui sera à jamais odieuse à la France, souillée de tant de meurtres et de tant de sang par l'hérésie de cette secte impie qui s'est répandue chez elle $»^{196}$. Le seul point sur lequel Masson tint bon était, de manière remarquable, le Concordat: "Je n'ai pas osé condamner l'action de Léon dans ce concordat avec le roi très chrétien, quoique j'aie proposé, peut-être trop fortement, mon avis. L'événement fait juger des actions ${ }^{197}$. La lettre de Baronius de février 1602 est en outre copiée parmi les préliminaires, à la suite de la dédicace à Henri III : faut-il penser que Masson pensait l'inclure dans la nouvelle édition, à titre de caution d'orthodoxie ${ }^{198}$ ? Ou simplement que cet exemplaire corrigé était destiné à être soumis à ses amis, conformément au témoignage de de Thou, et qu'il voulut leur donner tout le dossier? Que l'édition ainsi préparée n'ait jamais paru, pourrait ainsi être, dans une certaine mesure, une décision collective du milieu érudit gallican.

37 Trois ans après que Baronius lui eut promis l'approbation romaine pour son De Episcopis urbis expurgé, Masson fut à nouveau condamné, pour son édition d'Agobard de Lyon. L'affaire demande une étude à part, mais il faut au moins relever qu'elle illustre à nouveau et une certaine inconscience de Masson et l'ambiguité de la position de Baronius. Sitôt son livre sorti des presses, Masson se hâta d'en envoyer un exemplaire au cardinal, qui l'en remercia chaleureusement le 8 août 1605. Le 26 août, au cours d'une réunion de l'Index à laquelle participaient Baronius mais aussi Bellarmin, un des traités d'Agobard 
dont Masson donnait l'édition princeps, Sur les images, fut prohibé comme « rempli de diverses hérésies ${ }^{199}$. Cette promptitude reflète-t-elle seulement la nervosité romaine face à ce qu'on pourrait appeler une iconophobie érudite gallicane, ou la congrégation ne saisit-elle pas l'occasion de faire payer à l'éditeur l'inexécution de ses promesses quant au De Episcopis urbis ${ }^{200}$ ? L'indignation que causa à Masson cette nouvelle condamnation dut en tout cas dissiper définitivement ses velléités de soumission ${ }^{201}$.

De l'envoi à Sixte-Quint du De Episcopis urbis jusqu'à la condamnation d'Agobard, il s'écoula près de vingt ans. Il serait aisé, mais d'un intérêt limité, de faire rentrer les difficultés de Masson avec les autorités romaines dans un grand récit, soit pour y reconnaître, dans la ligne de la vieille historiographie libérale, «la manifestation d'un ordre dogmatique qui, par sa nature même, ne peut pas faire place à une recherche historique libre et indépendante $»^{202}$, soit pour rattacher Masson au «catholicisme antiromain » voire, tant qu'à faire, à « l'antiromanisme catholique ». Le premier schéma serait, à tout prendre, le plus défendable. Non seulement « la liberté de l'histoire » est un principe invoqué en propres termes par Masson ${ }^{203}$, mais il apparaît plausible, pour qui considère les choses dans une longue durée et de haut, que le conflit entre l'érudition gallicane et l'autorité romaine ait été une des sources de la distinction moderne entre l'ordre du dogme et celui de l'histoire. On peut considérer, en ce sens, par un légitime anachronisme, qu'il se jouait bien, dans les échanges entre Masson et ses censeurs, quelque chose comme ce que nous appelons aujourd'hui l'indépendance de la recherche. Et il est vrai que, même à s'en tenir à un strict point de vue historique, la position de Masson, qui publiait des textes, et celle des censeurs, qui les supprimaient, n'étaient pas équivalentes. Une interprétation aussi générale ne rend pourtant guère compte de ce qui se passa effectivement. Si les condamnations de Masson peuvent rétrospectivement apparaitre fatales, on ne saurait oublier que ce fut dans l'un et l'autre cas, pour le $D e$ Episcopis urbis comme pour l'Agobard, l'érudit français qui se jeta, si l'on ose dire, dans la gueule de la censure en envoyant ses livres à Rome. En outre, dans le cas du De Episcopis urbis au moins, l'inscription de l'ouvrage à l'Index fut loin d'aller de soi et suscita, dans les milieux romains eux-mêmes, beaucoup d'hésitations et même d'oppositions.

On ne saurait donc mobiliser ici la catégorie de «catholicisme antiromain »- désormais en vogue, grâce à une promotion acharnée, même chez les historiens modernistes, quoique son enracinement patent dans la polémique confessionnelle et l'apologétique des $\mathrm{XIX}^{\mathrm{e}}$ et $\mathrm{XX}^{\mathrm{e}}$ siècles eût dû la leur rendre suspecte. Le De Episcopis urbis comporte des traits anticurialistes et, si l'on y tient, antiromains : seule une lecture unilatérale peut accoler cette étiquette à l'ouvrage tout entier. Masson était si loin d'être antiromain qu'il ambitionnait d'entrer au service de la papauté, et précisément à la faveur de son livre : pareil projet suppose une grande ignorance de ce qu'était alors la papauté, mais il prouve que l'intention de Masson n'était en aucune façon d'écrire un livre contre Rome. On le comprit du reste bien à Rome où, si l'on excepte peut-être Bellarmin, les censeurs ne considérèrent et ne traitèrent jamais l'auteur du De Episcopis urbis comme un ennemi. Clément VIII, dont l'opinion en fait d'antiromanisme doit quand même compter pour quelque chose, le rangea expressément parmi les auteurs catholiques auxquels il convenait d'épargner la honte d'une mise à l'Index. Sauf à faire de Masson un hypocrite complet, ce qui est bien peu vraisemblable, et en supposant même qu'il n'ait jamais 
sérieusement envisagé d'expurger son livre, ses engagements répétés à le faire valent au minimum profession de fidélité au Siège romain. Si la censure du De Episcopis urbis se laisse malaisément réduire au schématisme whig du dogme contre la liberté, elle rentre plus mal encore dans l'opposition mécanique de deux blocs, de quelque vocabulaire qu'on l'habille - P. Ronzy opposait pour sa part «les gallicans» et «les catholiques non gallicans $»^{204}$.

Aux XVI ${ }^{e}$ et XVII ${ }^{e}$ siècles, l'affrontement bien réel, sur le terrain érudit, entre tenants des thèses romaines et champions des libertés gallicanes se déploya dans une série de microconflits, où il était mêlé à d'autres enjeux et inséré dans des combinaisons complexes de solidarités, d'affinités et d'oppositions. L'Index et le Saint-Office, aussi bien, ne fonctionnèrent jamais en vase clos, ni par rapport au champ théologique catholique ni par rapport à la République des Lettres. Il n'était pas rare que les censeurs fussent engagés dans des correspondances savantes, des échanges de services ou des controverses avec les auteurs mêmes dont ils examinaient les livres ${ }^{205}$. Le sort de Masson à l'Index fut fortement influencé par la protection initiale de Della Torre, l'animosité de Bellarmin contre un jésuite " apostat », la sympathie de Morin pour un compatriote engagé dans des études voisines. Sur le De Episcopis urbis en lui-même, le milieu curialiste semble avoir été unanime. La censure d'Antoniano transmise par Baronius, la critique publique d'Esteve, la censure de Bellarmin se recoupent. La divergence portait sur la personne de Masson. Il a été justement souligné, à propos des censures théologiques aux temps modernes, que «le pragmatisme romain est en général moins sensible aux idées et systèmes qu'aux dispositions et attitudes qui trahissent l'indépendance ou l'insubordination ${ }^{206}$. Bellarmin, lisant le De Episcopis urbis avec un a priori hostile, y voit se trahir l'hétérodoxie profonde de l'auteur : à ses yeux, les affirmations de Masson sur la puissance du pape ou sur le clergé régulier font système et le rendent suspect d'hérésie. D'autres y relèvent un catalogue, long mais discontinu, d'erreurs et surtout d' "offenses aux oreilles pieuses", comme autant de scories qu'il suffirait de corriger une à une et qui ne mettent pas en cause la catholicité de l'auteur. Ils entendent donc « épargner » ce dernier : nullement le disculper mais l'amener à censurer lui-même son propre travail, en faisant sienne la norme romaine. Cette indulgence ambiguë commande une manière bien particulière de s'adresser à l'auteur, sur le mode de la correspondance lettrée, en dissimulant le plus possible la violence symbolique de l'échange : les blâmes sont recouverts d'éloges, les commandements sont présentés comme des conseils, le censeur affecte de s'excuser de la censure qu'il transmet ${ }^{207}$. Le danger était évidemment que l'auteur refusât de comprendre et traitât la censure comme un conseil d'ami : en faisant effectivement ainsi et en ne donnant jamais d'édition expurgée de son livre, Masson adoptait la position qu'allaient suivre, tout au long du XVII e siècle, à peu près tous les érudits gallicans. Contrainte dès lors, si l'on ose dire, d'abattre son jeu, Rome n'avait plus d'autre option que de frapper à découvert, au risque d'exaspérer les auteurs et d'amoindrir l'impact des mises à l'Index au rythme de leur multiplication. La condamnation du De Episcopis urbis présente des spécificités qui interdisent d'y voir seulement un élément d'une série. Elle n'en doit pas moins, avec celle d'Agobard qui la redoubla, être placée aux origines du discrédit de l' Index parmi les érudits gallicans, en une progressive perte d'autorité qui finit par faire, selon le mot de Jean de Launoy, de « l'Index des livres à interdire à la Curie, l'Index des livres à lire dans l'[ancienne] Église romaine et dans l'Église gallicane $»^{208}$. 


\section{ANNEXES}

\section{Document 1}

Lettre de Papire Masson à Giovanni della Torre, 15 novembre 1587

Protocolli I, fol. 610r (copie)

Illustrissimo et Eccellentissimo Signore mio osservandissimo,

Per le lettere che Vestra Eccellentia Illustrissima è piacciuto scrivermi hò imparato duo cose, L'una che secondo la richiesta ch'io glie n'havevo fatta, La s'è degnata di presentar' a Nostro Signore in mio nome i miei sei libri de Episcopis Urbis. Delqual favore non posso ne potrò mai ringratiarla secondo che la cosa merita : L'altra che i miei libri sudetti sendo stati veduti et assaminati da persone dotte, come dalli Illustrissimi Signori Cardinali della Congregazione dell'Indice, ci hanno trovato molte cose che meritano esser corrette, et erano intorno a esse per corrigerle senza il rispetto di Vestra Eccellentia Illustrissima la quale supplico humilissamente (poiché in favore delle buone lettere li piace accettar questa fatica) di farli intendere che mai huomo non fu più pronto ne desideroso di emendare quei luoghi, dove haverò errato quanto che son'io (si come hò già promesso sommettendoli a i piedi di Nostro Signore) pure che diano a Vestra Eccellentia Illustrissima la regola et forma secondo che gli pare che detti libri habbino d'essere corretti. Alla quale ci ubidirò molti volontieri quando sopra di ciò haverò ricevuto i suoi commandamenti, restando in questo mentre affettionatissimo servitore di Vestra Eccellentia Illustrissima alla quale prego dal Signor Iddio ogni suo maggior contento. Di Parigi li XV di Novembre 1587.

Di Vestra Eccellentia Illustrissima

Humilissimo e devotissimo servitore

Papirio Massone

\section{Document 2}

Lettre de Papire Masson à Sixte-Quint, 16 novembre 1587 (signature autographe)

Protocolli I, fol. $613 \mathrm{r}$

Beatissime Pater, si utilius est sanctae et Apostolicae Ecclesiae, libros de summis Pontificibus a me editos extingui, potius quam diutius uiuere, opto ut litura una deleantur, et in cunis pereant. Id factum equidem non improbabo, qui tanti habeo libris illis carere, ne propter eos saepius reprehendar, Hoc [sic] enim uerecunda cogitatio eius 
qui notas praesertim Apostolicas pertimescit, non est uituperanda. Pacianus Barcinonensis ecclesiae episcopus, olim dicebat, nullus artifex opera sua contemnit, nec uilia esse putat quae fecit ${ }^{209}$, ego contra sentio, et ita adducor ut credam, a praestantissimo quoque minus aestimari sua, quam quae alius fecerit. Itaque libros meos, ut reprobos nummos, malo ipse damnare, quam illos turpi pertinacia, aduersus aequissimos censores pertinacissime tueri. Magnorum enim uirorum magni sunt lapsus, et is demum foeliciter cecidisse existimatur, qui statim ab aliquo erigi potuit. Itaque per salubrem Christi memoriam, sanctitatem tuam supplex oro, ut si quid aduersus pietatem minus pie a me scriptum est, notam apponi iubeas ad malum uersum, et cupientem emendare humaniter doceas, tempestiue enim corrigetur id opus, quod natalem diem bis celebrare nondum potest. Bene vale sanctissime Pater. Lutetiae Parisiorum XVI Calen. Decemb. 1587.

Sanctitati tuae addictissimus

Papirius Massonus.

\section{Document 3}

Pierre Morin, Pro Papyrio Massono et Francisco Iureto. Die 24 Octobris

Protocolli I, fol. 612r-v (autographe)

Papyrius Massonus in uitis Summorum Pontificum quamplurima scripsit recondita admodum, nec peruagata. Is enim in eorum est numero, qui monumenta Ecclesiastica inuestigant in optimis bibliothecis, eaque, communi utilitati seruientes, in lucem edunt : qui sane, pro eo ut eis gratia habeatur, dolore afficiendi non sunt : in eorumque scripta, satius est, leniori censura animaduerti.

In his quoque est Franciscus Iuretus, qui proxime Iuonis Carnotensis Episcopi diuulgauit epistolas, easque annotationibus illustrauit. Is si in Notationibus ad Symmachi epistolas ea posuit, quibus ueteris Romae monumenta auersa ac situ horrida esse intelligitur, siue ea desiderat siue, quod est uerisimilius, de iis non laborat, quid causae est, cur in eius scripta seuerius inquiratur, hominis sentientis cum Ecclesia Catholica, et ab omnibus haeresibus abhorrentis? Nec huiusmodi hominum debilitanda industria est : sed potius si non laude et praemiis, at certe indulgentia et humanitate incitanda est: uel ob eam caussam, quod, quae diuulgant, contra haereticos aperte faciunt, ostenduntque, primitiuae Ecclesiae ueros nos filios ac haeredes esse : quod aduersus nouatores et hostes ecclesiae firmissimum est propugnaculum.

De Papyrio Massono dixerat mihi Reuerendus Caesar Baronius, uideri sibi, literarum ab eo ad se missarum, habendam esse rationem. Quas literas, cum peterem ab eo, ut ederet, non habere se respondit, sed, quae in iis essent, libenter chirographo suo testificari.

Atque hanc prohibitorii Indicis notam bonos Catholicosque uiros deprecari, perspicuum est ex eorum oratione, qui proxime pro Sperone proque Lipsio dixerunt.

\section{Document 4}

Baronius au secrétaire de l'Index, Paolo Pico 
Protocolli I, fol. 605r (autographe)

Adi 10 di Ottobre 1592.

Io Cesare Baronio fo fede come scrivendomi da Leone Papirio Massone congratulandosi meco delle miei Annali, con l'instessa mi domandò, che mi pareva della sua fatiga fatta in scriver la vita de Romani Pontefici. Io gli risposi, che il libro mai l'havevo possuto havere, ancorche cercato l'havesse; ma che havevo udito dire da huomini dotti, che vi erano alcune cose che offendevano le orecchie de cattolici. Alla qual lettera mi respose, che mi regratiava del'avertimento datogli, et che era apparacchiato ad emendare in quanto errato havesse [remettendosi tutto alla censura della S. Rom. Chiesa ${ }^{210}$. Doppo questo non è passato altro fra noi. del che tutto su fo certa fede con la presente scritta e sottoscrivo di propria mano.

Io Cesare Baronio affermo quanto di sopra et sottoscrivo.

\section{NOTES}

1. Sur la notion de style, voir l'excellente définition de P. Lake et M. Questier, Introduction dans eid. (éd), Conformity and Orthodoxy in the English Church, c. 1560-1660, Woodbridge, 2000, p. xviii : «By this [a style of divinity or piety] we mean a synthesis of positions, opinions and modes of affect, constructed by a variety of contemporary groups always in polemical struggle the one with the other ». Sur le gallicanisme comme style de catholicisme, on se permet de renvoyer à J.-L. Quantin, Le catholicisme classique et les Pères de l'Église. Un retour aux sources (1669-1713), Paris, 1999, p. 16-17.

2. Outre les études pionnières de Bruno Neveu réunies dans Érudition et religion aux XVII et XVIII siècles, Paris, 1994, voir J.-L. Quantin, Protecteur et censeur : Giovanni Bona et la culture religieuse gallicane, dans Rivista di Storia e Letteratura religiosa, 46, 2010, p. 533-577; La menace des faits: érudition moderne et condamnations romaines, dans Ph. Levillain (éd.), "Rome, l'unique objet de mon ressentiment ». Regards critiques sur la papauté, Rome, 2011 ( Collection de l'École française de Rome, 453), p. 137-163. La question de l'influence française sur le milieu réformateur romain vient d'être reprise à fond dans l'importante thèse de Fr. Bustaffa, Michelangelo Ricci (1619-1682). Biografia di un cardinale innocenziano, Università degli Studi della Repubblica di San Marino, 2011.

3. Voir P. Petitmengin, À propos des éditions patristiques de la Contre-Réforme : le "Saint Augustin » de la Typographie Vaticane, dans Recherches Augustiniennes, 4, 1966, p. 199-251; id ., Les éditions patristiques de la Contre-Réforme romaine, dans Mariarosa Cortesi (éd.), I Padri sotto il torchio. Le edizioni dell'antichità christiana nei secoli XV-XVI. Atti del Convegno di Studi Certosa del Galluzzo Firenze, $25-26$ giugno 1999, Florence, 2002, p. 3-31 ; J.-L. Quantin, Baronius et les sources d'au-delà des monts: la contribution française aux Annales, dans L. Gulia (éd.), Baronio e le sue fonti. Atti del Convegno internazionale di studi, Sora 10-13 ottobre 2007, Sora, 2009 (Fonti e Studi Baroniani, 4), p. 51-101.

4. P. Ronzy, Les relations de Baronius et de Papire Masson d'après leur correspondance et des documents inédits (1591-1607), dans Annales de l'Université de Grenoble, 34, 1923, p. 265-306 : la censura est publiée p. 277-299, d'après BNF, Ms. Latin 11416, fol. 75r-89v. P. Ronzy, p. 275, 
n. 3, a relevé que le manuscrit était une copie; M. Borrelli, Ricerche sul Baronio II, dans Studi secenteschi, 8, 1967, p.120, a précisé qu'elle lui semblait de la main de Masson. L'écriture est effectivement identique à celle de la seconde moitié (livres IV, $\mathrm{V}$ et VI) du supplément inédit de Masson au De Episcopis urbis, BNF, Ms. Latin 5148, qui donne l'impression d'un autographe (P. Ronzy, Bibliographie critique des œeuvres imprimées et manuscrites de Papire Masson (1544-1611), Paris, 1924, p. 137, donne le manuscrit tout entier pour autographe mais il me semble indiscutable que les deux parties sont de deux mains différentes : voir infra, n. 6). Masson pourrait avoir fait cette copie pour la soumettre à ses amis (voir infra, n. 186).

5. BNF, Ms. Latin 11416, fol.89r : Erasmum quem aiunt magnum Germaniae decus esse. Quis nescit Batauum fuisse? P. Ronzy, Les relations, cit., p. 297, lit: Quis nescit Satanam fuisse? et commente en note : «L'identification que Baronius établit d'Érasme à Satan ne laisse pas de surprendre sous la plume de Baronius ». Certains écarts viennent de ce que Ronzy a corrigé ou complété les citations du censeur d'après l'original du De Episcopis urbis, mais d'autres sont clairement des fautes de lecture.

6. La lettre de Baronius à Masson, du 12 février 1602, a été copiée dans BNF, Ms. Latin 11416, fol. 76v-77r, d'une autre main, à la suite de la censure, sur des feuillets restés blancs (le bifolium correspondant a ensuite été relié en tête mais il contient bien la fin de la censure, fol. 76r-v). L'écriture est celle du copiste de la première moitié (livres I, II et III) du supplément au De Episcopis urbis, BNF, Ms. Latin 5148: pourrait-il s'agir de Jean Masson, frère de Papire, qui lui servait d'amanuensis (P. Masson, Libri sex, de Episcopis urbis, qui Romanam Ecclesiam rexerunt, rebusque gestis eorum, Paris, 1586, fol. 220r; P. Ronzy, Un humaniste italianisant, cit., p. 328-329, 344, 581-582, 587-588)? Une autre copie, sur un feuillet rajouté, figure dans BVR, Ms. Q 44, fol. 25bis r-v : c'est la source de l'édition dans C. Baronius, Epistolae et opuscula, éd. R. Alberici, 3 vol., Rome, 1759-1770, II, p. 69-70. La lettre est également copiée dans l'exemplaire de Londres du De Episcopis urbis, sur lequel voir infra, n. 190. Baronius prend ses distances du texte qu'il transmet (infra, n. 177) mais P. Ronzy, Les relations, cit., p. 277, n. 1, voit là des « précautions oratoires ». Alberici, dans son édition de Baronius, Epistolae et opuscula, cit., II, p. 69 notes a et b, avait déjà supposé que l'animaduersio était de Baronius lui-même, mais sur la base d'une chronologie erronée (infra, n. 97). La censura est attribuée à Baronius dans BNF, Ms. Latin 11416, sur la page de titre, fol. 75r (Censura Caesaris Baronii Cardinalis in Libros de Episcopis Urbis Papirii Massoni), et en tête du texte fol. 78r (Correctiones Baronii in librum de Episcopis Urbis), mais il s'agit d'ajouts par des mains plus récentes et cela peut s'entendre de la transmission qu'il en avait faite (voir aussi la note dans l'exemplaire de Londres, infra, n. 190). P. Ronzy, Les relations, cit., p. $300 \mathrm{n}$. 1, et plus longuement dans sa thèse, Un humaniste italianisant. Papire Masson (1544-1611), Paris, 1924, p. 645-648, attribuait en outre à Baronius des annotations sur le supplément au De Episcopis urbis, BNF, Ms. Latin 5148. Comme l'a noté M. Borrelli, Ricerche sul Baronio II, cit., p. 121, cette attribution est sans fondement.

7. P. Ronzy, Un humaniste italianisant, cit., p.343-431 et Notes additionnelles, p. 641-645. Voir aussi, p. 57-64 sur les sources, en particulier épigraphiques, recueillies par Masson à Rome, et pour une analyse du contenu de l'ouvrage, la thèse complémentaire de P. Ronzy, Bibliographie, cit., p. 81-94. Le travail de P. Ronzy, interrompu par la Première Guerre mondiale et mené à bien après celle-ci, reste très utile.

8. P. Masson, Annalium libri quatuor : quibus res gestae Francorum explicantur, Paris, 1577. 
9. Voir les explications de P. Masson, De Episcopis urbis, cit., fol. 270v-272r. Pour les censeurs romains, voir infra, n. 121, et comparer les reproches faits à Sigonius (P. Prodi, Storia sacra e controriforma. Nota sulle censure al commento di Carlo Sigonio a Sulpicio Severo, dans Annali dell'Istituto storico-germanico in Trento, 3, 1977, p. $94-95$ et 101). P. Ronzy, Un humaniste italianisant, cit., p. 377, a vu là « une intention marquée de diminuer le prestige de la papauté ». Mais il soupçonne aussi, p. 392, "quelque mystérieuse signification religieuse et quelque relent d'hétérodoxie dans le terme de Seruator qu'il [Masson] affecte d'employer de préférence à Saluator quand il s'agit de l'appliquer au Christ » (voir déjà p. 174). C'était pourtant là un trait de purisme des plus répandus, qu'Érasme avait fait entrer dans sa parodie de Credo cicéronien (Dialogus Ciceronianus [1528], éd. P. Mesnard, dans Opera omnia Desiderii Erasmi Roterodami, t. I/2, Amsterdam, 1971, p. 641). Il est bien connu que Dominus seruator faillit même être employé dans le décret du concile de Trente sur le sacrement de l'Ordre, en 1562, sans plusieurs évêques, dont le cardinal de Lorraine, qui intervinrent pour qu'on y rétablît Dominus saluator (Concilium Tridentinum. Diariorum, actorum, epistularum, tractatuum noua collectio. Edidit Societas Goerresiana, VI, Fribourg en Br., 1965, p. 39, 105, 124, 149, 173, 207). Voir encore les plaintes de Baronius dans Martyrologium Romanum ad nouam Kalendarii rationem, et Ecclesiasticae historiae ueritatem restitutum. Gregorii XIII Pont. Max. iussu editum. Accesserunt notationes atque Tractatio de Martyrologio Romano. Auctore Caesare Baronio, Secunda editio ab ipso auctore emendata et compluribus aucta, Anvers, 1589, 9 novembre, p. 495-496.

10. P. Ronzy, Un humaniste italianisant, cit., p. 377-378, me semble exagérer le gallicanisme ecclésiologique du De Episcopis urbis. Ayant cru (Les relations, cit., p. 283 n. 6) que le censeur romain avait relevé une affirmation de «la fameuse doctrine gallicane de la supériorité du concile sur le pape ", il a attribué catégoriquement cette doctrine à Masson (Un humaniste italianisant, cit., p. 377) : mais il s'agit d'un contresens (voir infra, n. 79). Quant à l'affaire de Hincmar de Laon (Les relations, cit., p. 285 n. 3; Un humaniste italianisant, cit., p. 378), elle concernait la légitimité des appellations au pape du jugement d'un concile national, qui est une autre question.

11. Masson, De Episcopis urbis, cit., fol. 113r-114r.

12. Ibid., fol. 121r : coacti sunt Romae occidentales Episcopi centum uiginti quinque, et unam in domino uoluntatem atque operationem esse testati sunt: quarum rerum acta extant. Hoc sapienti Bedae etiam debemus. Bède dit évidemment tout le contraire: Quo in tempore idem Papa Agatho cum synodum congregaret Romae centum uigintiquinque episcoporum, aduersus eos qui unam in Domino Saluatore uoluntatem atque operationem dogmatizabant, [...] placuit hoc inter cetera eiusdem synodi gestis inseri (Tertius tomus operum Venerabilis Bedae, historica, uitas aliquot Sanctorum, ac collectanea quaedam complectens, Bâle, [1563], col.186-187 [= Ecclesiastical History of the English people, V, 19, éd. B. Colgrave and R. A. B. Mynors, Oxford, 1991, p. 522-524]). On notera que Masson ne paraît pas avoir consulté les lettres mêmes du concile de Rome, insérées dans les actes de Constantinople III et dès lors aisément accessibles dans les collections conciliaires. Voir par exemple l'édition de Laurentius Surius, Tomus Secundus Conciliorum omnium, tum generalium tum prouincialium atque particularium, quae iam inde ab Apostolorum Temporibus usque in praesens habita sunt, Cologne, 1567, p. 908-926 [CPG 9417-9418].

13. Masson, De Episcopis urbis, cit., fol.121r, se borne à résumer ainsi les décrets de Constantinople III : Ea synodo decretum duas uoluntates et duas actiones in Christo credendas, qui aliter sentirent anathemate notatis. Le monothélisme d'Honorius est longuement traité, en revanche, dans le supplément, BNF, Ms. Latin 5148, fol. 47v-48r (passage partiellement 
publié par P. Ronzy, Un humaniste italianisant, cit., Notes additionnelles, p. 646). Sur ce supplément resté inédit, voir ibid., p. 407-425; une première version était prête pour l'impression en 1591, d'après la lettre de Masson à Baronius du 5 septembre 1591, dans Baronius, Epistolae et opuscula, cit., I, p. 241.

14. Masson, De Episcopis urbis, cit., fol. 339r-340v.

15. Ibid., fol. 344r-345r et fol. 354r-362v.

16. Masson, ibid., fol. $184 \mathrm{v}$ et $186 \mathrm{r}$, rejette catégoriquement le témoignage du cardinal Beno (Benno), très utilisé par les protestants, comme inspiré par la haine et ne méritant aucun crédit. Sur l'image de Grégoire VII au XVI ${ }^{\mathrm{e}}$ siècle, voir P. Golinelli, L'incontro di Canossa (1077) negli Annales Baroniani e nella storiografia confessionale, dans L. Gulia (éd.), Baronio e le sue fonti, cit., p. 243-264.

17. Masson, De Episcopis urbis, cit., fol. $185 \mathrm{r}$ : Ea poena tum grauis erat, quia id fulmen iaculari Pontifices raro consueuerant, solaque eorum arma excommunicationes erant, sed ita ualida plerumque ut genus mortalium nihil formidabilius putaret (Masson date l'excommunication de 1079).

18. Ibid., fol.185v : Quae uictoria Episcopos urbis Romae monere debet ne uindiciae suae, etsi iustissimae causa principes in mutuam perniciem arma sumere iubeant.

19. Ibid., fol. 266v : Episcopos urbis moneo, ne unquam Reges amicos sponte inimicos faciant. non enim putent pontifices frenos se a Deo datos Regibus ut eos pro arbitrio cohibeant uelut equos intractatos et nouos: admoneant et precentur, precesque eorum syncerae instar imperii erunt; minari, terrefacere, arma ciere Episcopos non decet, summaque concordia inter principes suprema Pontificum potestas existimanda est.

20. Ibid., fol.419r: id enim a pontificibus fieri debet. nam quemadmodum refluente Oceano repente omnem aquam recedere uidemus ac alueum littusque suum nudum ac fere cinericium relinquere, ita a pontifice, si Reges ac Caesares aliquo impetu se aut sua retrahant, necesse sit ipsos nudos atque desertos in litore contemni.

21. P. Ronzy, Un humaniste italianisant, cit., p. 344 n. 3, et 399 n. 2. Pour l'opposition à la bulle, voir par exemple S. Daubresse, Le Parlement de Paris ou la voix de la raison (1559-1589), Genève, 2005, p. 231-233. L'achevé d'imprimer du De Episcopis urbis est du 21 juillet 1586.

22. Voir A. Tallon, Diplomatie, Réforme catholique et conscience nationale : la Papauté au miroir de la monarchie française pendant les guerres de religion, dans Annuaire-Bulletin de la Société de l'Histoire de France, 1999, p. 21-51.

23. Masson, De Episcopis urbis, cit., fol. 385r : Qua in re Leo consulere quidem regibus uisus est, sed christianae pietati ingens detrimentum inferre. etsi enim regum uoluntates optimae sane saepe sunt, euentus tamen docuit disciplinam ecclesiasticam hoc facto concidisse. Voir A. Tallon, Conscience nationale et sentiment religieux en France au XVI siècle, Paris, 2002, p. 110-122, « Le concordat, péché originel de la monarchie absolue ».

24. Masson, De Episcopis urbis, cit., fol. 418v : Senatu Parisiensi clausulam tantum illam [inuitis et contradicentibus possessoribus] non probante. Voir S. Daubresse, Le Parlement de Paris, cit., p. 235-237, et, pour les nouvelles exigences de Henri III en 1585-1586, Girolamo Ragazzoni évêque de Bergame, nonce en France. Correspondance de sa Nonciature, 1583-1586, éd. P. Blet, p. 94-115.

25. Masson, De Episcopis urbis, cit., fol. 287r : hoc scio consuetudinem illam Cisalpinis populis minus probari quam Italicae genti ad huius generis obsequia et demissiones natae. On notera que 
Masson emploie une formule très proche à propos des Juifs : nationem natam seruituti (fol. 408v).

26. Ibid., fol. 287r. Voir Codicis DN. Iustiniani sacratiss. Principis PP. Aug. Repetitae praelectionis Libri XII. Commentariis Dionys. Gothofredi I.C. illustrati, Lyon, 1583, col. 78 [= Codex Iustinianus I, 8, 1, éd. P. Krüger, Berlin, 1877, p. 89].

27. Voir Masson, De Episcopis urbis, cit., fol. 406r (sur l'éphémère Marcel II) : moritur deinde Paulus [III], moritur Iulius [III]. ô Cardinales quam uehementer uos Episcoporum urbis uarietas, mutatioque delectat, et quam magno odio est uobis longaeui uita pontificis. Comparer A. Tallon, Diplomatie, cit., p. 33-35 ; id., Les Conclaves dans l'historiographie de la Contre-Réforme, dans M. Firpo (éd.), Nunc alia tempora, alii mores. Storici e storia in età postridentina. Atti del Convegno internazionale Torino, 24-27 settembre 2003, Florence, 2005, p. 25-46.

28. Masson, De Episcopis urbis, cit., fol. 216v-217r. Nombreuses autres références dans P. Ronzy, Un humaniste italianisant, cit., p. 88 n. 3. Voir aussi p. 254-255.

29. Masson, De Episcopis urbis, cit., fol. 408r : Hi sunt alii a Iesuinis, [sic] nam hi sibi uidentur soli societatem contraxisse cum Iesu, uulgus tamen eos quoque Theatinos in Italia Hispaniaque uocare solet, [...] in eo sane nimium sapientes [cf. Ecclésiaste 7, 17] quod se putant caelo uel ipsi quandoque imperaturos. Sur ce nom de Théatins donnés aux Jésuites, voir A. D. Wright, Catholicism and Spanish Society under the reign of Philip II, 1555-1598, and Philip III, 1598-1621, Lewiston-Queenston-Lampeter, 1991, p. 54, 56, 164.

30. P. Ronzy, Un humaniste italianisant, cit., p.96-100, 116, 388, 427-428, 607-608. Cf. G. Dupont-Ferrier, Du Collège de Clermont au lycée Louis-le-Grand (1563-1920), 3 vol., Paris 1921-1925, III, p. 54, n 413bis. Pour la rancune gardée à Masson par ses anciens confrères, voir aussi A. Lynn Martin, The Jesuit Mind. The mentality of an elite in early modern France, Ithaca, NY, 1988, p. 120.

31. Comme le fait P. Ronzy, Un humaniste italianisant, cit., p. 385, dont la lecture du De Episcopis urbis a été visiblement influencée par la censure romaine qu'il avait découverte.

32. Masson, De Episcopis urbis, cit., fol. 408r-v.

33. Ibid., fol. 410r: quo spectaculo attonitus populus Romanus admonitus est officii, nec rebus nouis studere postmodum est ausus.

34. A. Tallon, Diplomatie, cit., p. 36-39.

35. Masson, De Episcopis urbis, cit., fol. 415v, 416r (optimus ac sanctissimus pontifex, omnisque uirtutis praestantissimum exemplar), 417v, 420v (sur la correction du droit canon et la réforme du calendrier).

36. Masson, De Episcopis urbis, cit., respectivement fol. 137r-141r et 168v-171r. Voir P. Ronzy, Un humaniste italianisant, cit., p. 354-358. Masson n'est pas mentionné par A. Boureau, La papesse Jeanne, Paris, 1988 ; quelques remarques sur ce point dans St. Zen, Baronio storico. Controriforma e crisi del metodo umanistico, Naples, 1994, p. 215-216, qui insiste sur la dimension « misogyne » des arguments de Masson.

37. P. Masson, Annales, cit., p. 212-218. Voir C. Baronius, Annales ecclesiastici, X, Rome, 1602, ad ann. 995 [n. I], p. 893 : qui eam ex ipsis [scriptis Gerberti] historiam texuit Papirius Masso, ipsique immerito fauet. Baronius, p. 881-882, ad ann.992 [n. XXXIX-XL], avait auparavant reproduit d'après Masson la lettre de Gerbert à l'empereur Otton. Sur Masson, Baronius et les lettres de Gerbert, voir J.-L. Quantin, Baronius et les sources d'au-delà des monts, cit., p. 91-95. - Je cite toujours Baronius d'après les éditions originales de chaque 
volume mais j'ajoute entre crochets la numérotation des paragraphes (des «nombres ») dans l'édition de référence (Lucques, 1738-1759).

38. Baronius, Annales, X, ad ann. 999 [n. III-VIII], p. 926-927. Baronius voyait là la différence entre cette fable et celle de la papesse, qu'il mettait par ailleurs sur le même plan, nisi quod illam [de Ioanne Papissa] leuitas excogitauit; istam autem (ut audisti) nequitia (p. 927).

39. Ibid., p. 111, ad ann. 853 [n. LXII] : Papyrius Maso in Galliis uir quidem praestans ingenio, et pietate, in uolumine suo, quod scripsit de Urbis Episcopis, ut uentus fumum, euanescere totam in auras fabulam fecit.

40. Voir par exemple Masson, De Episcopis urbis, cit., fol. 265v et 344r-345r. Autres références dans P. Ronzy, Un humaniste italianisant, cit., p. 394.

41. Masson, De Episcopis urbis, cit., fol. 410v: Ioannes Caluinus anno aetatis quinquagesimo tertio Geneuae extinctus est, uiperae similis, ad quam securos somnos capere Gallia non poterat, Hieronymi [ep. 117, 3 ; CSEL 55, 426] enim uerbis uti liceat. [...] Cuius uiri non quidem sectam, sed excellentis ingenii uires scribendique grauitatem mirari necesse est; quamquam pudet fateri hoc monstrum in Gallia natum [...]. Multum ergo debemus anno millesimo quingentesimo sexagesimo quarto, quo quidem portentum illud extinctum est. Pour l'attitude de Masson vis-àvis de Calvin, voir P. Ronzy, Un humaniste italianisant, cit., p. 51, 115-118, 132-134, 313-317, 635-639; I. Backus, Life Writing in Reformation Europe. Lives of Reformers by Friends, Disciples and Foes, Aldershot, 2008, p.169-186; ead., Un chapitre oublié de la réception de Calvin en France. La Vita Caluini de Jean-Papire Masson (1583) : Introduction, édition critique et traduction, dans Bulletin de la Société de l'Histoire du Protestantisme Français, 155/1, janvier-mars 2009 [ Jean Calvin et la France], p. 181-207.

42. Masson, De Episcopis urbis, cit., fol. 384v (voir infra, n. 140). Ce point a été bien vu par P. Ronzy, Un humaniste italianisant, cit., p. 393.

43. Masson, De Episcopis urbis, cit., fol. *2r-3r : plurimum gaudii et laetitiae hauriet ex hoc opere. La dédicace est traduite intégralement par P. Ronzy, Un humaniste italianisant, cit., p. 398-399.

44. Masson, De Episcopis urbis, cit., fol. 421r : hanc historiam pedibus tuis subiicimus, eamque emendari cupimus ab te qui Petri et fidem et sedem tenes. Traduction partielle de cette conclusion dans P. Ronzy, Un humaniste italianisant, cit., p. 400.

45. Masson, De Episcopis urbis, cit., fol. 421v : nam sic est apostolica sedes quasi proposita atque aedita in altum, ut ab omnibus uentis nequitiae circumflari, a nullo tamen aut opprimi aut euerti possit eritque pontificatus ueluti aqua perennis quae perpetuo fluit.

46. P. Ronzy, Un humaniste italianisant, cit., p. 399-400.

47. P. Ronzy, ibid., p. 399, n. 2, propose même de reconnaître dans De Episcopis urbis, cit., fol. 160v (ab electoribus Pontificum siue casu, siue industria neminem unquam ad summum sacerdotium uocatum esse, qui uel luscus, uel claudus, uel gibberosus esset, uel qui minimam deformitatis notam haberet), « une allusion malicieuse à ce que l'on racontait de l'élection de Sixte-Quint ", rejetant son bâton une fois élu: mais, outre que cette légende semble une invention postérieure, dont on ne trouve pas trace dans les correspondances du temps (voir J. A.von Hübner, Sixte-Quint, 3 vol., Paris, 1870, I, p. 249-250 n. 1; G. de Bremond d'Ars, Le Père de Madame de Rambouillet. Jean de Vivonne, sa vie et ses ambassades près de Philippe II et à la Cour de Rome d'après des documents inédits, Paris, 1884, p. 167 n. 1 ; L. von Pastor, Geschichte der Päpste seit dem Ausgang des Mittelalters, X, Fribourg en Br., 1926, p. 39), l'interprétation est bien forcée. Il est vrai que le passage est relevé par le censeur 
romain (P. Ronzy, Les relations, cit., p. 287) mais ne serait-ce pas parce qu'il le jugeait peu respectueux pour les papes en général, ou peut-être pour les conclaves? Signalons qu'il s'agit d'un très rares passages non corrigés dans l'exemplaire de Londres (voir infra). Pour un autre passage supposément insultant pour Sixte-Quint, voir infra, n. 76.

48. Voir A. Tallon, Conscience nationale, cit., p. 237-280.

49. Masson mentionne le fait dans ses projets de lettre à Sixte-Quint (voir note suivante). Sur Luigi d'Este, voir P. Portone, DBI, XLIII, 1993, p. 383-390, s.v.

50. G. de Bremond d'Ars, Jean de Vivonne, cit., p. 180-192, 197, 199-200 ; Girolamo Ragazzoni. Correspondance de sa Nonciature, éd. citée, « Introduction », p. 73-90, 102-103, 126.

51. G. de Bremond d'Ars, Jean de Vivonne, cit., p. 201.

52. Ibid., p. 245 et 247-248.

53. Brouillons d'une lettre de Masson à Sixte-Quint, octobre 1586, publiés par P. Ronzy, Un humaniste italianisant, cit., Pièce IV, p. 654 et 655: ut spero liber ille excutiet rabiem Caluinianorum qui non sunt dissimiles Donatistis ac furore superiores fortasse. [...] et si uis quod Petrarcha offerente Innocentio sexto recusauit id mihi cisalpino homini munus tribuere, iterum me uidebit Italia, ut Apostolicae sedi perpetuo inseruiam. Sur ces différents brouillons et leurs variantes, voir ibid., p. 133 n. 1, et p. 401-402; sur le désir de longue date de Masson de retourner en Italie et d'y trouver un patron, ibid., p. 146-147. Sur Innocent VI et Pétrarque, voir Masson, De Episcopis urbis, cit., fol. 293v-294r, d'après la lettre de Pétrarque au cardinal de Talleyrand (Seniles, I, 4; Pétrarque, Lettres de la vieillesse, éd. E. Nota, I, Paris, 2002, p. 40-47) : Masson n'omet pas de relever qu'Innocent VI avait d'abord cru faussement que Pétrarque pratiquait la magie.

54. Brouillon d'une lettre de Masson à Sixte-Quint, 6 février 1587, publié par P. Ronzy, Un humaniste italianisant, cit., Pièce V, p. 655: per Ioannem Turrianum cubicularium tuum; aduersus inopiam quae his difficillimis temporibus propter annonae caritatem me uexatura breui uidetur. P. Ronzy, ibid., p.402-403, n'avait pu identifier le personnage mais il s'agit certainement de Giovanni della Torre, nommé en 1589 évêque de Veglia, puis nonce en Suisse de 1595 à 1606, sur lequel on verra Die Hauptinstruktionen Clemens' VIII. für die Nuntien und Legaten an den europäischen Fürstenhöfen, 1592-1605, éd. Kl.Jaitner, 2 vol., Tübingen, 1984, I, p.CCLIX-CCLXI ; S. Andretta, DBI, XXXVII, 1989, p. 567-570, s.v. Sa mission en France est attestée par une lettre du cardinal Girolamo Rusticucci au nonce Frangipani, Rome, 30 décembre 1586 : «N.S. ha destinato il Conte Giovanni dalla Torre, suo Camerier secretario [sic], che fu Nipote del Cardinale della Torre buona memoria a portare la baretta al Sig. Cardinale de Lenoncourt, et domani dovrà partire, havendo già basciato i piedi a N.S. presa licenza" (Correspondance du nonce en France Fabio Mirto Frangipani (1568-1572 et 1586-1587), nonce extraordinaire en 1574, 1575-1576 et 1578, éd. A. Lynn Martin, Rome, 1984, p. 353, sans aucune note sur ce point).

55. Gesta collationis Chartagini [sic] habitae Honorii Caesaris iussu inter Catholicos et Donatistas [...]. Opus non solum Theologis, sed etiam Iurisconsultis ualde utile, éd. P. Masson, Paris, 1588, fol. $\uparrow+\uparrow 1 \mathrm{r}$ : rabiem eorum [Caluinistarum], qui non sunt dissimiles Donatistis et Circuncellionibus, ac furore fortasse superiores. Sur l'ouvrage, les indications de P. Ronzy, Bibliographie critique, cit., p. 110-111, sont à corriger par J.-L. Quantin, Baronius et les sources d'au-delà des monts, cit., p. 85-86 n. 103. Masson, fol. $\uparrow \dagger \uparrow 1 v$, justifie sa dédicace par ses origines foréziennes, le Forez faisant partie du douaire d'Élisabeth. L'hypothèse de P. Ronzy, Un humaniste italianisant, cit., p. 509, selon laquelle il s'agissait de se concilier les ligueurs, n'est guère convaincante ; sur les rapports anciens de Masson avec la reine, voir ibid., p. 119-122. Pour 
compléter la notice moins que minimale de Roman d'Amat, Dictionnaire de biographie française, XII, 1970, col.1203, il y a malheureusement peu à tirer de L. de Beauriez, Élisabeth d'Autriche (femme de Charles IX) et son temps. Une reine catholique au siècle de la Réforme, Paris, 1884. Sur le douaire d'Élisabeth et ses largesses, par l'intermédiaire d'Ogier de Busbecq, voir J. A. de Thou, Historiae sui temporis, Londres, 1733, III, l. LX, § XV, p. 409 ; V, l. CIV, § VII, p. 179 ; voir aussi Brantôme, Second volume des Dames, dans Recueil des Dames, poésies et tombeaux, éd. É. Vaucheret, Paris, 1991 (Bibliothèque de la Pléiade), p. 503.

56. Voir V. Frajese, Nascita dell'Indice. La censura ecclesiastica dal Rinascimento alla Controriforma, Brescia, 2006, p. 107-120 : «La piccola primavera del $1587 »$ (qui reprend, avec quelques additions, la partie homonyme de id., La politica dell'Indice dal Tridentino al Clementino (1571-1596), dans Archivio italiano per la storia della pietà, 11, 1998, p. 282-296). Sur la difficile circulation des livres entre Rome et Paris dans cette période, voir J.-L. Quantin, Baronius et les sources d'au-delà des monts, cit., p. 85-86 et 100-101; infra, n. 97.

57. Journal de voyage de Michel de Montaigne, éd. Fr. Rigolot, Paris, 1992, p. 92, 119, 131 ; texte des censures publié par P. Godman, The saint as censor. Robert Bellarmine between Inquisition and Index, Leyde, 2000, p. 339-342. Voir J.-R. Armogathe et V. Carraud, Les Essais de Montaigne dans les archives du Saint-Office, dans J.-L. Quantin et J.-Cl. Waquet (éd.), Papes, princes et savants dans l'Europe moderne. Mélanges à la mémoire de Bruno Neveu, Genève, 2007, p. 79-96; Ph. Desan, Apologie de Sebond ou justification de Montaigne?, dans id. (éd.), Dieu à nostre commerce et société. Montaigne et la théologie, Genève, 2008, p. 192-196. Ce rapprochement m'a été suggéré par Peter Mack, lors du séminaire que j'ai donné à l'Institut Warburg de Londres, le 13 janvier 2012, «French scholars and Roman censorship, 16th-18th cent. ».

58. Pour une vue d'ensemble, voir les notices de P. Prodi, DBI, III, 1961, p. 511-515, et M.T. Fattori, dans A. Prosperi, avec V.Lavenia et J. Tedeschi, dir., Dizionario dell'Inquisizione, 4 vol., Pise, 2010, I, p.70-71, et le petit livre de V.Frajese, Il popolo fanciullo. Silvio Antoniano e il sistema disciplinare della controriforma, Milan, 1987. Antoniano apparaît comme consulteur, dans la congrégation renouvelée par Sixte-Quint, le 14 juillet 1587 (G. Fragnito, La Bibbia al rogo. La censura ecclesiastica e i volgarizzamenti della Scrittura (1471-1605), Bologne, 1997, p.145-146 n.12), mais avait déjà été consulteur de la congrégation en 1581 (E. Patrizi, Silvio Antoniano. Un umanista ed educatore nell'età del Rinnovamento cattolico (1540-1603), nouvelle édition, 3 vol., Macerata, 2010, I, p. 127). En 1584, il avait été un des éditeurs envisagés pour l'Histoire ecclésiastique d'Onofrio Panvinio (St. Bauer, The Censorship and Fortuna of Platina's Lives of the Popes in the sixteenth century, Turnhout, 2006, p. 111-112). Il est traditionnellement considéré comme un des membres de la commission établie par Grégoire XIII en 1580 pour réviser le Martyrologe Romain (voir par exemple Benoît XIV, De Seruorum Dei beatificatione et Beatorum canonizatione liber quartus, editio 3a [Opera, IV], Rome, 1749, Pars 2a, c. XVII, p. 709, suivi sur ce point par H. Laemmer, De Martyrologio Romano. Parergon historico-criticum, Ratisbonne, 1878, p. 15). Le rôle exact qu'il joua à ce stade demeure obscur (Martyrologium Romanum. Editio princeps (1584), éd. M. Sodi et R. Fusco, Cité du Vatican, 2005, p.XXXIII) mais il fut certainement un des collaborateurs de Baronius pour l'édition plantinienne de 1589 (infra, n. 96) : voir Baronius à Antonio Talpa, 9 juillet 1588, dans Baronius, Epistolae et opuscula, cit., III, p. 31.

59. Protocolli B, fol.53r (transcrit dans Diari, I, fol. 27r) : Censuras retulerunt [...] Siluius Antonianus in Papirium Massonium. La date à laquelle cette censura avait été confiée à Antoniano n'apparaît nulle part. Sur le rapport entre les Protocolli originaux et le Diario, 
compilé ultérieurement et très sommaire pour ces années, voir G. Fragnito, Bibbia al rogo, cit., p. 112 n. 2, 119 n. 19, 157 n. 51 ; St. Bauer, Censorship of Platina's Lives, cit., p. 114, n. 30.

60. Supra, n. 4. La censure envoyée par Baronius à Masson était sans doute possible une censure officielle de l'Index (voir infra, n. 181) ; or les archives de la congrégation ne font état que de deux censures du De Episcopis urbis, celle d'Antoniano et celle de Bellarmin, laquelle est tout à fait différente de celle que transmit Baronius. La difficulté est que la censure d'Antoniano semble avoir déjà manqué dans les archives en 1592 (infra, n. 108): mais Baronius, très proche d'Antoniano, pouvait aisément en obtenir un exemplaire de l'auteur. Si elle avait été définitivement perdue, on comprendrait mal que la congrégation se fût adressée à un troisième censeur au lieu d'envoyer la censura de Bellarmin. On observera que celle d'Allen sur Platina a elle aussi disparu des archives (St. Bauer, Censorship of Platina's Lives, cit., p. 113 n. 28, et 250).

61. Sur cette affaire célèbre, voir T. Tasso, Lettere poetiche, éd. C. Molinari, Parme, 1995, en particulier les lettres du Tasse à Scipione Gonzaga, 11 février 1576, p. 309-311 ( i il rigore »), et 5 mars 1576, p. 322-323 («la soverchia severità »); du Tasse à Antoniano, 30 mars 1576, p. 342-362; du Tasse à Scipione Gonzaga, 24 avril 1576, p. 426-427 (« non tanto da cavalieri quanto da religiosi e de monache »); A. Quondam, "Sta notte mi sono svegliato con questo verso in bocca ». Tasso, Controriforma e classicismo, dans G. Venturi (éd.), Torquato Tasso e la cultura estense, 3 vol., Florence, 1999, II, p. 561-590.

62. Voir BNF, Ms. Latin 11416, fol. 83r-v, 85r, 87r-v, 88r-v, 89r-v, 76r (P. Ronzy, Les relations , cit., p. 287, 288, 290, 292, 293, 294, 295, 297, 298, 299) : superi et fata christianis delictis irata, caelites, fortuna, in fatis erat, permittentibus superis, relatio inter diuos...

63. BNF, Ms. Latin 11416, fol. 78v et 88v (P. Ronzy, Les relations, cit., p. 279 et 295). Voir Masson, De Episcopis urbis, cit., respectivement fol.43r-v (citant Jérôme, ep.123, 9 [CSEL 56/1, 82-83] et Martial, Epigrammes, 8, 43 [éd. D. R. Shackleton Bailey, Stuttgart, 1990, p. 259]) et 352r.

64. BNF, Ms. Latin 11416, fol. 76r : Caluini ingenium et scribendi grauitatem miratur tametsi sectam non probat (P. Ronzy, Les relations, cit., p. 299 lit facta au lieu de sectam). Voir supra, n. 41.

65. BNF, Ms. Latin 11416, fol. 78v : Impii ergo sumus Christiani, qui affecta ultimo supplicio fratrum corpora feris dilaniandis exponimus [= Masson, De Episcopis urbis, cit., fol. 29r]. Nimis acerbe et tamen id ubique non fit (P. Ronzy, Les relations, cit., p. 279, lit sit).

66. Masson quitta Rome définitivement peu après l'intronisation de Pie $\mathrm{V}$, cui spectaculo egomet adolescens interfui (De Episcopis urbis, cit., fol. 413r). Voir P. Ronzy, Un humaniste italianisant, cit., p. 76.

67. Le Tasse à Scipione Gonzaga, 4 oct. 1575, Lettere poetiche, éd. citée, p. 243 («tanto ammollite dall'uso »). « Mescolare le cose profane con le sacre » est un reproche fait plus tard au Tasse par Fédéric Borromée (R. Ferro, L'esercizio della scrittura nel pensiero di Federico Borromeo, dans Studia Borromaica, 16, 2002, p. 221): le parallèle avec Silvio Antoniano a été noté par E. Patrizi, Silvio Antoniano, cit., I, p. 209, n. 14. Voir G. Fragnito, Torquato Tasso, Paolo Costabili e la revisione della "Gerusalemme Liberata", dans Schifanoia, 22/23, 2002, p. 57-63.

68. Montaigne, Journal de voyage, éd. citée, p. 119 et 131 ; P. Godman, The saint as censor, cit., p. 341.

69. Voir G. Fragnito, Torquato Tasso, cit., p. 60 ; P. Prodi, Storia sacra e controriforma, cit., p. 101. 
70. Un des censeurs de Montaigne l'accusa ainsi d'avoir loué « Beza et Buccanano per boni poeti » (P. Godman, The saint as censor, cit., p. 339).

71. Montaigne, Journal de voyage, éd. citée, p.119; P. Godman, The saint as censor, cit., p. 342.

72. Au printemps 1587 : voir St. Bauer, Censorship of Platina's Lives, cit., p. 113-114.

73. BNF, Ms. Latin 11416, fol.80r (P. Ronzy, Les relations, cit., p. 281): totus hic locus castigandus; Masson, De Episcopis urbis, cit., fol. 81v, citant Decretum Gratiani, D. 19, c. 9 ( Corpus Iuris Canonici, éd. E. Friedberg, 2 vol., Leipzig, 1879-1881, I, col. 64). Comparer St. Bauer, Censorship of Platina's Lives, cit., p. 294, avec les notes.

74. Voir St. Bauer, Censorship of Platina's Lives, cit., p. 95-96, 308, 315-316. Antoniano, en 1584, avait spécialement relevé les erreurs de Platina sur ces deux questions (ibid., p. 111)

75. P. Ronzy, Les relations, cit., p. 285 (Omittenda uidentur Chalcondylae uerba de sede perforata. Satius fuerit refellere) ; Masson, De Episcopis urbis, cit., fol. 140v-141r, citant (dans la traduction latine alors seule disponible) Laonicus Chalcondyle, Historiae de Origine ac rebus Gestis Turcorum, 1. VI, dans Nicephori Gregorae, Romanae, hoc est Byzantinae historiae Libri XI, éd. H. Wolf, Bâle, 1562, col. 410-411 [= PG 159, 299-302]. Masson ne cite du reste le passage que comme fabulam e fabula. L'Histoire de Chalcondyle faisait partie des ouvrages que les jésuites du Collège Romain, en décembre 1592, désignèrent comme à expurger en priorité. Voir le votum de Bellarmin, Protocolli K, fol.134r, en réponse à l'ordre de la congrégation du 12 décembre 1592 (Diari, I, fol. 62v) : il est cosigné par Juan Azor et Pedro Parra, collègues de Bellarmin au Collège Romain et membres depuis septembre de la «troisième classe » d'expurgateurs qu'il présidait (Diari, I, fol.53v; P. Godman, The saint as censor, cit., p. 274-275, a publié le texte correctement mais en supprimant les signatures d'Azor et Parra). En 1602, l'Index entreprit finalement une expurgation de Chalcondyle ( infra, n. 181).

76. P. Ronzy, Les relations, cit., p. 285. Masson, De Episcopis urbis, cit., fol. $139 \mathrm{v}$ : Et Pontifices quidem meretricem illam in Episcoporum numero collocatam, et inter antecessores suos positam uident : et tamen ferunt antiquissimum illud sedis suae opprobrium? Masson, il est vrai, ajoute immédiatement : Atque utinam Gregorius decimustertius hanc historiam legere potuisset. credo enim illum uirum, qui summa pietate in Deum fuit, tantum dedecus passurum non fuisse .P. Ronzy, Un humaniste italianisant, cit., p. 399 n. 2, a voulu voir là une flèche de plus contre le pape régnant («Masson regrette que Grégoire XIII n'ait pu lire son histoire, ce qui n'est pas très flatteur pour Sixte-Quint»). Mais il s'agit clairement pour Masson d'excuser les papes, tout en relevant sa propre contribution : Grégoire XIII aurait déjà mis fin au scandale (comme, sous-entend Masson, Sixte-Quint va à présent le faire) s'il avait pu connaître la démonstration décisive du De Episcopis urbis.

77. Voir P. Ronzy, Les relations, cit., passim, et comparer St. Bauer, Censorship of Platina's Lives, cit., p. 143-149. On retrouve la même attitude dans le cas de Sigonius (P. Prodi, Storia sacra e controriforma, cit., p. 87).

78. BNF, Ms. Latin 11416, fol. 78r : de Christo nimis ieiune loquitur ; P. Ronzy, Les relations, cit., p. 278, lit strenue. Comparer St. Bauer, Censorship of Platina's Lives, cit., p. 284 (De Concilio Nicaeno ieiune nimis scribit) et aussi le reproche fait à Sigonius par Sirleto (P. Prodi, Storia sacra e controriforma, cit., p. 88-89 n. 38).

79. BNF, Ms. Latin 11416, fol. 81r (P. Ronzy, Les relations, cit., p. 283). P. Ronzy, ibid., n. 6, explique que le censeur visait « la fameuse doctrine gallicane de la supériorité du concile sur le pape » : il s'agit évidemment d'un contresens (voir supra, n. 12). 
80. BNF, Ms. Latin 11416, fol. 86v (P. Ronzy, Les relations, cit., p. 291): Omitti potest illa monitio ad Episcopos Urbis [dans la Vie de Boniface VIII : voir supra, n. 19]. Le passage parallèle dans la Vie de Grégoire XIII n'est en revanche pas relevé.

81. BNF, Ms. Latin 11416, fol. 89r : damnat Leonis factum in Concordatis cum Rege Francisco, et Christianae pietati damnum ingens intulisse ait; P. Ronzy, Les relations, cit., p. 296, lit Augustissimo au lieu de cum Rege.

82. BNF, Ms. Latin 11416, fol. 76r : De clausula Inuitis et contradicentibus possessoribus, quam a Pio et Gregorio usurpatam ait, a Senatu Parisiensi non probatam. Hoc debuit omitti (P. Ronzy, Les relations, cit., p. 299, lit uoluit). Voir supra, n. 24.

83. BNF, Ms. Latin 11416, fol. 76v (P. Ronzy, Les relations, cit., p. 291) : Sixtum alloquens: Si quod munus accepero agam gratias, sin minus non desinam solem aspicere. Parum reuerenter. Voir Masson, De Episcopis urbis, cit., fol. 421r: Si quod munus aut a sanctitate tua, aut a Christianissimo Rege Francorum accepero, agam utrisque uestrum gratias quantas potero: sin minus non desinam solem aspicere, et quantum in me erit prodesse Reipubl. et pietati Christianae.

84. Voir le chapitre éponyme de V. Frajese, Il popolo fanciullo, cit., p.44-56; D. Knox, Disciplina: le origini monastiche e clericale del buon comportamento nell'Europa cattolica del Cinquecento e del primo Seicento, dans P. Prodi, avec C. Penuti (éd.), Disciplina dell'anima, disciplina del corpo e disciplina della società tra medioevo ed età moderna, Bologne, 1994, p. 63-99 (sur Antoniano, p. 86-87); O. Niccoli, Creanza e disciplina: buone materie per $i$ fanciulli nell'Italia della controriforma, ibid., p. 929-963 (p. 960-962).

85. J.A. de Thou, Papirii Massoni Vita, en tête de P. Masson, Elogiorum pars prima, éd. J. Balesdens, Paris, 1638, fol. e6v, ennoblit sans doute les choses quand il assure que Masson opera sua principibus ac summae dignitatis uiris ad decus potius quam spe praemii nuncupare consueuisset, tout en notant significativement qu'il était ainsi supra conditionem liberalis. P. Ronzy, Un humaniste italianisant, cit., reste assez vague sur ces questions. Voir surtout p. 157-158 sur la pension de six cents livres que, selon François Hotman, Henri III aurait accordée à Masson pour écrire les Annales Francorum. Une bonne partie des publications de Masson (éloges et écrits de circonstance) sont clairement d'ordre alimentaire (voir par exemple ibid., p. 121-122) et il servit d'écrivain à gages, vers 1585 , à Don António, prieur de Crato, prétendant malheureux au trône de Portugal (ibid., p. 325-326). Suppliant Antoniano de l'aider à obtenir du pape la rétribution de ses services (voir infra, n. 136), l'érudit Pierre Morin soulignait la différence de leurs parcours : Haec expedi ueteri amiculo, dedito a prima aetate studiis ignobilis otî: cum tu nobile et cum dignitate coniunctum otium sequereris: quem adolescentem memini Ferrariae olim splendidam domum habuisse, ac celebre auditorium apud forum, [...] cum audirem dici, multas te Liuii historias Cardinali Ferrariensi memoriter recitauisse, ipsumque Cardinalem, ac eos qui adessent in summam admirationem adduxisse (Morin à Silvio Antoniano, 1595, dans P. Morin, Opuscula et epistolae , éd. J. Quétif, Paris, 1675, p. 369). On se rappelle les mises en garde de B. Castiglione, Il Libro del Cortegiano, éd. A. Quondam et N. Longo, [Milan], 1999, 1. 2, c. 18, p. 146, contre les demandes aux princes.

86. Voir V. Frajese, Nascita dell'Indice, cit., p.115-119, même si la thèse générale de l'auteur, selon laquelle livre « de la seconde classe » était synonyme de livre expurgeable, n'est pas recevable (voir par exemple id., Permessi di lettura, dans A. Prosperi, dir., Dizionario dell'Inquisizione, cit., III, p.1194, et contra, G. Fragnito, Gli studi sulla censura ecclesiastica nella prima età moderna : bilanci e prospettive, dans L. Gulia, I. Herklotz et St. Zen (éd.), Società, cultura e vita religiosa in età moderna. Studi in onore di Romeo De Maio, Sora, 2009, p. 174 n. 55). L'activité d'Antoniano à l'Index porta en outre essentiellement sur 
l'expurgation des livres (G. Fragnito, La Bibbia al rogo, cit., p. 176, n. 18). Il n'était pas membre de l'Index quand il examina la Gerusalemme liberata, et sa révision relevait de la censure préventive, mais il s'agissait bien de mettre l'ouvrage en état de paraître (cf. A. Quondam, Tasso, cit., p. 567-568). Voir en outre la lettre de Masson à Della Torre, Appendice, Document 1, qui dit expressément que l'Index se préparait à corriger son livre.

87. Protocolli B, fol. 55r (transcrit dans Diari, I, fol. 27v) : De Papirio Massonio [tractatum].

88. Lettre en italien du 15 novembre 1587, Protocolli I, fol.610r, publiée en Appendice, Document 1. L'adresse n'est pas conservée mais le destinataire ne saurait être que Della Torre.

89. Lettre latine à Sixte-Quint datée du 16 novembre 1587, ibid., fol. 613r, publiée en Appendice, Document 2.

90. Diari, I, fol. 30r : Lectae litterae Massonii et decretum communi uoto corrigendum librum et animaduertendum authorem et Cardinali Ascanio commissa responsio ad Massonium. L'original dans Protocolli B, fol.70r, a seulement: De Papirio Massonio. quod corrigatur liber, et animaduertatur author, avec cette note en haut de la page : Lettere di Massonio.

91. J. Esteve, De Osculatione pedum Romani Pontificis ad S.D.N. Sixtum V. P.O.M. Adiecta eiusdem Auctoris disputatione de Coronatione, et Leuatione, seu Portatione Papae. Omnia nunc ex repetita praelectione, multis ex partibus locupletata et aucta, et ab Haereticorum calumniis, pluribus argumentis, Patrum testimoniis, et traditione defensa, Rome, 1588 : uirum doctum, ac ut arbitror probum. La dédicace à Sixte-Quint est datée de Rome, 15 mars 1588. La première édition, dédiée à Grégoire XIII, avait paru à Venise en 1578. Tout le chapitre XVIII de cette édition augmentée, p. 144-158, est une réponse à Masson. Sur Esteve, voir la notice de Catholic Church and modern science. Documents from the Archives of the Roman Congregations of the Holy office and the Index. Volume I. Sixteenth-century documents, éd. U. Baldini et L. Spruit, Rome, 2009, IV, p. 2847, et surtout V. Peri, Il numero dei concili ecumenici nella tradizione cattolica moderna, dans Aevum, 37, 1963, p. 461-463.

92. J. Esteve, De Osculatione pedum, cit., p. 155 : quod profecto de probo uiro non crederem, qui historiam hanc Romani Pontificis pedibus subiicit, postulans illam ab eo qui Petri fidem et sedem tenet, emendari. Voir supra, n. 44.

93. Ibid., p. 157: Haec habui O Papiri uir optime, quem pie et ut uirum probum decet animaduerterem, ut in aliis editionibus haec et alia emendares, quod te profecto spero facturum, ne tibi deesse, tantumque opus tot uigiliis elaboratum, uiolare uidearis.

94. Voir la reproduction de l'Index de 1590, dans ILI, IX, p. 799-800 et 838 (Papyrii Massonii libri sex, De uitis Episcoporum urbis Romae, nisi prius ex superioribus regulis corrigantur). Pour l'histoire de la congrégation, V. Frajese, Nascita dell'Indice, cit., p. 120-137 (reprenant id., La politica dell'Indice, cit., p. 297-312).

95. Voir Diari, I, fol. 43r-46r. P. Godman, The saint as censor, cit., p. 141 et encore p. 148, place toutes ces réunions de 1591 en 1592.

96. Martyrologium Romanum (Anvers, 1589), cit., $1^{\text {er }}$ mai, p. 193, note f (sur saint Sigismond de Bourgogne) : Papirius Maso [sic], qui etsi breuius, diligentius tamen caeteris (mea sententia) res Francor. conscripsit ; 25 août, p. 377, note c (sur saint Louis) : Papirius Masson. qui ea quae a caeteris erant praetermissa, summa industria collegit. Voir P. Masson, Annales, cit., respectivement p. 26 et 315-347. Baronius recommande les Annales de Masson dans son Ordo qui seruandus proponitur in historia Ecclesiastica peruestiganda, dont la forme définitive est postérieure à 1586 (St. Zen, Baronio storico, cit., Appendice I, p. 352). Pour l'usage qu'il 
en fit de fait dans les Annales ecclesiastici, voir J.-L. Quantin, Baronius et les sources d'au-delà des monts, cit., p. 65.

97. Masson à Baronius, Biblioteca Vallicelliana, Rome, Ms. Q 45, f. 6r, publiée dans Baronius, Epistolae et opuscula, cit., II, p. 68-69 : Ac si forte in manus tuas inciderunt libri sex de Episcopis urbis a Diuo Petro ad Sixtum Quintum, rescribe obsecro quid de illo opere sentias. Nam iudicium tuum plurimi faciam, eritque mihi instar omnium. La lettre est simplement datée ineunte Iulio. Alberici, ibid., p. 69, note b, l'a placée en 1601 parce qu'il croyait que la lettre de Baronius du 12 février 1602 (voir infra, n. 177), qu'il publiait à la suite, était une réponse à celle-ci. Mais P. Ronzy, Les relations, cit., p. 266 n. 4, et 267 n. 2 (suivi par M. Borrelli, Ricerche sul Baronio II, cit., p. 121), a justement relevé que la véritable réponse de Baronius était une lettre perdue du 4 août 1591, à laquelle Masson répondit à son tour le 5 septembre (voir infra, n. 98 et 101). St. Zen, Baronio storico, cit., p. 65 n. 73, et 108 n. 61, qui renvoie pourtant à Ronzy, conserve la datation d'Alberici. La lettre de Baronius à Pico (appendice, document 4), confirme définitivement la chronologie de Ronzy.

98. Est seul conservé de cette lettre le passage sur les Annales Francorum, transcrit par Martin Billet de Fanières, un érudit du début du XVIII ${ }^{e}$ siècle, Ex epistola Caesaris Baronii nondum cardinalis data Romae pridie Non. Aug.1591, parmi une série de testimonia sur Masson, BNF, Ms. Français 24519, fol. 310r (autre copie, faite sur la précédente, parmi les papiers de l'abbé Drouyn, Ms. Français 22861, fol. 53r), et publié par P. Ronzy, Les relations, cit., p. 269. Ce qui concerne le De Episcopis urbis est connu par la réponse de Masson et par la lettre de Baronius à Pico, qui concordent entièrement sur ce point.

99. G. Fragnito, Gli studi sulla censura ecclesiastica, cit., p. 174.

100. Br. Neveu, L'erreur et son juge. Remarques sur les censures doctrinales à l'époque moderne, Naples, 1993, p. 303-304, citant la définition des Salmanticenses.

101. Masson à Baronius, 5 septembre 1591, dans Baronius, Epistolae et opuscula, cit., I, p. 241 : opus meum de Romanis Pontificibus. St. Zen, Baronio storico, cit., p. 37 et p. 65, n. 73, s'est imaginé qu'il s'agissait d'un livre différent du De Episcopis urbis.

102. Masson à Baronius, 5 septembre 1591, dans Baronius, Epistolae et opuscula, cit., I, p. 241-242: Nam quaedam in eo [opere] esse, quae modestis, et eruditis aliquot uiris displiceant, moleste fero; praesertim si sunt Itali, quam gentem iudicio ualere prae caeteris semper existimaui : correcturus quicquid, et iis, et tibi uidebitur, more scilicet magnorum uirorum, qui, et si sua emendant, nihil tamen laudis et gloriae sibi detrahunt; quod Hippocrati claro admodum auctori accidisse, Celsus [De medicina, VIII, 4, 3-4 ; éd. I. Mazzini, Pise-Rome, 1999, p. 248] ait, quem simplex ueri erroris confessio nobiliorem apud omnes reddidit. Ce supposé aveu d'Hippocrate est également rapporté par Plutarque et par Quintilien (voir J. Jouanna, Hippocrate, Paris, 1992, p. 495). Pierre Morin s'y réfère à propos de son travail sur les conciles grecs : voir Morin à Fédéric Borromée, 1594, dans P. Morin, Opuscula et epistolae, cit., p. 326 (futuris est évidemment une coquille pour suturis). L'équivalent religieux était évidemment Augustin rédigeant ses Retractationes et ce fut celles-ci que l'Index donna en modèle aux auteurs dans son projet de lettre de 1594 (infra, n. 179).

103. Pour une vue générale, voir V. Frajese, Nascita dell'Indice, cit., p. 138-147 (reprenant id., La politica dell'Indice, cit., p. 312-320).

104. Après avoir hésité, la congrégation décida le 18 juillet 1592 de commencer par publier l'Index prohibitorius (Diari, I, fol. 46v et 47r).

105. Voir Diari, I, fol. 50r-v, 51r, 53r (29 août, 5 septembre, 12 septembre, 26 septembre 1592). Addendi uel demendi s'entend par rapport à l'Index de 1564. 
106. Protocolli $\mathrm{K}$, fol.100r (votum signé Petrus Morinus): Parcendum puto Catholicorum authorum existimationi, ut [...] Papyrii Massoni. [...] Laeditur enim horum existimatio, si ante diuulgetur eos errasse, quam errata in publicum edantur. Nam interea nonnulli peius de iis existimabunt, quam meriti sint. Ac nihil omnino damni fit, si horum errata in expurgatorium indicem conferantur. quod faciendum arbitror. Il s'agissait donc de faire profiter Masson du principe posé par la congrégation le 5 septembre 1592: Decretum quod piis ac doctis scriptoribus de Christiana Republica bene meritis inter scribendum in aliquo offendentibus honor deferatur ut in Indice non reponantur (Diari, I, fol. 50r). Sur Morin, voir infra.

107. Protocolli $\mathrm{K}$, fol. 96r (Gonsalvus Pontius: liste d'auteurs à inclure in altero distincto prorsus Indice) et 106r (votum Domini Abbatis Maffe). L'idée de diviser omnes indices Prohibitorium et Expurgatorium, ne ullo modo Catholici misceantur cum haereticis, avait été avancée par Alfonso Chacón, et Ponce de León s'y était rallié, ibid., fol.97r. Sur Marcantonio Maffa, notice dans Catholic Church and modern science, éd. U. Baldini et L. Spruit, cit., IV, p. 2882 ; sur Ponce de León, voir infra, n. 153.

108. Le De Episcopis urbis ne figure pas dans l'Index librorum qui olim de mandato Illustrissimae Congregationis Indicis expurgati, seu correcti sunt, et quorum censurae apud Secretarium Congregationis asseruantur, quas tamen fere omnes recognoscere, et reuidere oportet, Protocolli $\mathrm{K}$, fol. 188r-190r. Le texte est très probablement celui qui avait été demandé à Pico à la réunion de l'Index du 27 avril 1592, quand la congrégation reprit ses travaux ( Diari, I, fol. 46v : Commissum fuit Secretario ut in sequenti Congregatione singulis Cardinalibus traderet [...] notam authorum et librorum quorum expurgatio est, et quorum potissimum expurgatio desideratur). Il est suivi, de la même écriture, fol. 190v-191r, de Nota Librorum expurgandorum, seu corrigendorum quam Illustrissimae Congregationi tradidit R. Dominus Petrus Gallesinius Prothonotarius, où figure le De Episcopis urbis, fol.191r: Gallesini, d'après les ouvrages de référence, étant mort en 1590 ou autour de cette date, il pourrait s'agir d'une ancienne liste retrouvée dans les archives. Autres copies, où les deux textes sont associés de la même manière, fol. 196r-199r et 202r-205r. Le De Episcopis urbis est également inclus dans une liste d'Alfonso Chacón, Libri praeter contentos in indice Pii IV, qui utiliter expurgari possent, ibid., fol. 151v, qui pourrait dater de 1592. Masson est marqué en revanche comme déjà expurgé (avec la mention «R. » pour désigner une expurgation faite à Rome) dans une liste ultérieure, fol. 243r-246r : Papirius Massonius R. (245v) - autres copies, de la même main, dans Protocolli R, fol. 7r-10r, et Protocolli Z, fol. 540r-544r : il s'agit de la liste lue par Pico à la séance de l'Index du 6 mars 1593 (voir Diari, I, fol. 64r ; G. Fragnito, Aspetti e problemi della censura espurgatoria, dans L'Inquisizione e gli storici: un cantiere aperto. Tavola rotonda nell'ambito della conferenza annuale della ricerca (Roma, 24-25 giugno 1999), Rome, 2000, p. 176 n. 58). Le Commentariolum uniuersorum quae in Archiuio sacrae Congregationis Indicis asseruantur apud secretarium, BAV, Ms. Vat. lat. 6861 (sur lequel on verra G. Fragnito, Un archivio conteso: le "carte» dell'Indice tra Congregazione e maestro del Sacro Palazzo, dans Rivista Storica Italiana, 119, 2007, p. 1309 n. 119), fol. 56v, donne en plus la référence dans les Protocolli tels qu'ils étaient alors classés: Papirius Massonius Romana [censura]. I. 581. Cette censura romaine doit être celle de Bellarmin. Voir encore infra, n. 162, le témoignage de Fédéric Borromée.

109. Protocolli $\mathrm{K}$, fol. 211r-v, transcrit dans Diari, I, fol.56v-57r : Die 10 octobris [1592] Congregatio habita apud Illustrissimum Cardinalem Veronensem ubi interfuerunt omnes una cum Magistro Sacri Palatii et Belarminio, et ex legitima causa cum licentia absente Secretario, Petrus Morinus ex eiusdem Secretarii Commissione uices gessit. [...] commissum eidem Bellarminio ut censuram in Massonium sequenti Congregationi referat. 
110. Protocolli I, fol. 606r-v (De Papirii Massoni libris, quos inscripsit de uitis Episcoporum Urbis ) et 607r-609v (De Papirii Massoni libris, quos de uitis Pontificum Maximorum scripsit). Les deux textes, non signés, sont autographes. Ils ont été publiés, avec sa négligence ordinaire, par P. Godman, The saint as censor, cit., p. 279-283. Celui-ci affirme étrangement, p. 163, que Bellarmin examina " an incomplete version », apparemment parce que Bellarmin écrit au début de son rapport: Opus hoc imperfectum est. Mais il s'agit évidemment d'un reproche fait à l'ouvrage: Non enim continet integras historias de uita, et rebus gestis Pontificum, sed solum fragmenta quaedam hinc inde decerpta (Protocolli I, fol. 606r). La censura de Bellarmin couvre du reste l'ensemble du De Episcopis urbis.

111. Protocolli I, fol. 606r-v : 1. Opus hoc imperfectum est [...]. 2. Non pauca continet inepta [...]. 3. Auctor operis negligenter in hoc opere uersatus est [...]. 5. Auctor est satis maledicus [...]. 6. Suspectus est erroris illorum, qui negant summo Pontifici potestatem coactiuam in omnes christianos [...].7. Suspectus est item erroris illorum, qui damnant ordines religiosorum mendicantium [...]. Le quatrième reproche général concerne la citation d'auteurs interdits ( infra, n. 122).

112. St. Bauer, Censorship of Platina's Lives, cit., p. 309 : non uitas, sed uitia eorum Platina scripsit, ideo purgandus.

113. Ibid., p. 309-310: Sed nescio an expediat omnia pontificum istorum uitia, ac si falsa essent, expungere, ut censor iudicat. Pleraque enim uera sunt, etsi non omnia. Narrantur enim scelera Sergii III qui Formosum exhumauit etc. a Liuthprando [...]. Vixit autem Liuthprandus illo ipso tempore, ut ipse in suo opere indicat.

114. Voir l'excellent commentaire de St. Bauer, ibid., p. 141-142, qui cite les passages correspondants des Controverses.

115. Protocolli I, fol. 607r: In uita Sergii III. fol. 154 pag. 1. et fol. 157. pag. 1. et 2. refert, et repetit saepius ex Luitprando enormia quaedam uitia Romanorum Pontificum. Comparer la censure d'« Antoniano », BNF, Ms. Latin 11416, fol. 82v-83r ; P. Ronzy, Les relations, cit., p. 286.

116. Protocolli I, fol. 606r-v : nec recipienda uidetur excusatio eius, quod uidelicet ad historicum pertineat fideliter res narrare. nam, ut supra dixi, non meretur ipse nomen historici, cum nec integre, nec ordine uitas Pontificum describat. Voir Masson, De Episcopis urbis, cit., fol.158v : Hactenus Luitprandus, cuius testimonio non utor, nisi quia ueram narrationem rerum praeteritarum omittere turpe esset historiam scribenti.

117. St. Bauer, Censorship of Platina's Lives, cit., p. 316-317 : Non uidentur autem esse delenda in Platina, quae uera sunt et in probatis auctoribus leguntur.

118. Protocolli I, fol. 608r : In uita Nicolai III. Non puduit, inquit, eum agnatorum causa simoniam exercere, etc. et probat adductis multis uersibus Dantis. Le passage avait été relevé par «Antoniano » (BNF, Ms. Latin 11416, fol. 86r ; P. Ronzy, Les relations, cit., p. 290). Voir Masson, De Episcopis urbis, cit., fol. 252r-253r, citant Dante, Inferno, chant XIX, v. 69-105 [ Opere, edizione nazionale, a cura della Società Dantesca Italiana, VII/2, Vérone, 1966, p. 321-325] : on notera que Masson a eu soin de découper sa citation juste avant le passage le plus fortement anti-romain (et, dans le contexte du XVI ${ }^{e}$ siècle, celui qui évoquait le plus la polémique protestante), où la Rome papale est identifiée à la prostituée de l'Apocalypse (v. 106-111). Masson, fol. 253r, ajoute que plerique historiarum scriptores aiunt res sacras eum uendidisse, mais ne donne pas de références.

119. Voir Br. Neveu, L'erreur et son juge, cit., p. 394-396 et 472-473.

120. Protocolli $\mathrm{I}$, fol. $607 \mathrm{v}$ : proinde auctorem suspectum reddi eius haeresis, quae negat summis Pontificibus coactiuam potestatem, et iurisdictionem in omnes christianos, et praesertim in Reges. 
121. Ibid.: Titulus, de Episcopis Urbis, hoc tempore non sine causa offendit, cum haereses Lutheranorum uigeant, quae Romanos Pontifices totius Ecclesiae Pontifices non esse contendunt. «Antoniano » avait lui aussi noté : Titulus ipse offendit, mais sans faire le lien avec les protestants (BNF, Ms. Latin 11416, fol. 78r ; P. Ronzy, Les relations, cit., p. 277).

122. Protocolli I, fol. 606r : 4. Citat saepe Erasmum, Melanthonem [sic], Caluinum, Palingenium. et satis indicat, se hos autores legere, cum tamen prohibiti sint, et non sit verisimile eum habere facultatem libros eiusmodi legendi, cum non sit Theologus, sed causidicus. Masson avait été reçu avocat au Parlement en 1576 mais n'exerça pratiquement jamais (P. Ronzy, Un humaniste italianisant, cit., p. 222-224 et 514). Sur les licences de lecture des livres interdits, alors effectivement limitées aux théologiens et aux canonistes, voir G. Fragnito, Gli studi sulla censura ecclesiastica, cit., p. 171.

123. Protocolli I, fol. $608 \mathrm{v}$ : In uita Pii IIII. fol. 410. pag. 2. laudat Caluinum, cuius uiri, inquit, non quidem sectam, sed excellentis ingenii uires scribendique grauitatem mirari necesse est. La citation est exacte mais, coupée de ce qui précède et de ce qui suit (voir supra, n. 41), donne une tout autre impression que dans son contexte.

124. L'attaque de Masson contre les jésuites est relevée, ibid. D'après la reconstitution chronologique de P. Ronzy, Un humaniste italianisant, cit., p. 44-46, Masson serait arrivé au Collège Romain au plus tard dans les premiers jours de 1563 et y serait resté jusqu'en octobre, où il aurait été envoyé à Naples, tandis que Bellarmin (au Collège Romain d'octobre 1560 à octobre 1563) partait de son côté pour Florence. Voir X.-M. Le Bachelet, Bellarmin avant son cardinalat, 1542-1598. Correspondance et documents, Paris, 1911, p. 44-45. On peut imaginer que Bellarmin recueillit des informations sur Masson (par exemple qu'il était avocat) lors de son séjour en France pour accompagner la légation du cardinal Caetani, en 1590. Masson prononça une harangue lors de l'entrée de Caetani à Paris (P. Ronzy, Un humaniste italianisant, cit., p. 514-516). Sur les rapports entre la suite du légat et le milieu érudit gallican, voir A. Loisel, Vie de M. Pierre Pithou, Sieur de Savoye, Advocat en Parlement, dans Divers opuscules tirez des Memoires de M. Antoine Loisel, Advocat en Parlement, éd. Cl. Joly, Paris 1652, p. 270.

125. Voir V. Peri, Due protagonisti dell'editio Romana dei concili ecumenici: Pietro Morin ed Antonio d'Aquino, dans Mélanges Eugène Tisserant, VII, Cité du Vatican, 1964, p. 131-232, surtout 131-170; P. Petitmengin, À propos des éditions patristiques de la Contre-Réforme: le "Saint Augustin" de la Typographie Vaticane, dans Recherches Augustiniennes, IV, 1966, p. 213-214 et 216-217.

126. G. Fragnito, Bibbia al rogo, cit., p. 145 n. 12 ; V. Frajese, Nascita dell'Indice, cit., p. 107-108 n. 44, et 113 (sur Érasme: Morin avait été cette fois d'accord avec Maffa). Le procès-verbal de la séance du 15 février 1587 (Protocolli B, fol. 4r, transcrit dans Diari, I, fol. 16v), où Morin prêta serment comme consulteur, est désormais publié dans Catholic Church and modern science, éd. U. Baldini et L. Spruit, cit., I, p. 342-344. Lorsque l'Index recommença à fonctionner normalement, en avril 1592, il était le seul consulteur présent, Diari, I, fol. 46r.

127. Voir D. Petri Morini de Bodino votum, Protocolli K, fol. 242r-v (copie) : le texte n'est pas daté mais il doit dater de la fin de 1592 ou du début de 1593 puisque Morin, avant de revenir à la charge, rappelle ses efforts infructueux pour faire condamner la République absolument (et non seulement donec corrigatur), cum apud Illustrissimum et Reuerendissimum Dominum Cardinalem Alanum de conficiendo Romano Indice prauorum librorum conuentus haberetur. Allen avait été chargé le 14 novembre 1592 de veiller à l'impression de l'Index et 
son travail fut approuvé, quibusdam immutatis, lors des réunions du 5 décembre 1592 et du 6 février 1593 (Diari, I, fol. 59r, 62r, 63r).

128. Voir supra, n. 109. L'écriture du procès-verbal original, Protocolli K, fol. 211r-v, qui n'est effectivement pas celle du secrétaire de l'Index, Paolo Pico, est celle du votum signé Petrus Morinus dans le même volume (supra, n. 106). Les deux dernières mentions, rajoutées à la fin, sur Lipse et Masson, sont cependant de la main de Pico. Signalons que l'exemplaire du De Episcopis urbis à la BVR, coté P.V.55, porte sur la page de titre l'inscription Petrus Morinus.

129. Protocolli I, fol.612r-v, publié en Appendice, Document 3. Le titre, de la même écriture, se lit au verso du bifolium, fol.617v (selon une procédure usuelle, plusieurs documents ont été mis les uns dans les autres pour former un cahier et ont ensuite été reliés tels quels) : Pro Papyrio Massono et Francisco Iureto. Die 24 Octobris. Le texte n'est pas signé mais l'écriture est celle de Morin, et la position défendue est identique à celle de son votum signé (voir note précédente).

130. Q. Aurelii Symmachi, VC. P.V. et Cos. Ord. Epistolarum ad diuersos libri decem, éd. Fr. Juret, Paris, 1580, Notae, paginées à part, p. 15 : Nunc uero nominis sui decoctrix iacet, et est nihil aliud quam suae uenustatis pristinae spurcum cadauer. Je prends decoctor au sens juridique, comme dans Codex Iustinianus X, 31, 40 (decoctor pecuniae publicae). Sur Juret, voir Ph. Papillon, Bibliothèque des auteurs de Bourgogne, 2 vol., Dijon, 1742, I, p. 355-361; La bibliothèque de François Juret (1553-1626), Inventaire établi par F. Regnèr, avec la collab. de J.-P. Oddos, Troyes, 1986 (Aux origines de la bibliothèque Bouhier, 2) ; R. Zuber, Tombeaux pour des Pithou : frontières confessionnelles et unité religieuse (1590-1600), dans M.-M. Fragonard et P.-E. Leroy (éd.), Les Pithou, les lettres et la paix du royaume. Actes du Colloque de Troyes (13-15 avril 1998), Paris, 2003, p. 164-165. Son édition de Symmaque avait été revue par Pierre Pithou : voir J.-P. Callu, En marge de vieux livres: les manuscrits perdus de Symmaque, dans Revue d'Histoire des Textes, 6, 1976, p. 205-206; id., Deux interpolations au Livre I ${ }^{\text {er }}$ des Lettres de Symmaque, dans Antiquité tardive et humanisme. De Tertullien à Beatus Rhenanus, Turnhout, 2005, p. 181-182.

131. Voir L. Sozzi, La polémique anti-italienne en France au seizième siècle (1971-1972), repris dans Rome n'est plus Rome. La polémique anti-italienne et autres essais sur la Renaissance, Paris, 2002, p. 69-70 et 74; G. Labrot, L'image de Rome. Une arme pour la Contre-Réforme, 1534-1677, Seyssel, 1987, p. 41-47.

132. Elle fut publiée en 1643 (avec d'autres pièces anti-romaines) à la suite de La Rome ridicule de Saint-Amant. Voir In Romam, Iosephi Scaligeri scazon, dans Saint-Amant, Euvres, éd. J. Bailbé et J. Lagny, 5 vol., Paris, 1967-1979, III, p. 78-79: Spurcum Cadauer pristinae Venustatis, [...] Tui Pudoris, Nominisque decoctrix. Sur la diffusion du texte, on trouvera de riches références dans E. H. Barker, Parriana: or Notices of the Rev. Samuel Parr, LL.D., II, Londres, 1827, p. 201-204 (consultable sur Google Books).

133. ILI, IX, p. 866 et 1032, $\mathrm{n}^{\circ} 73$; Index Librorum prohibitorum et expurgatorum Ill. ${ }^{\mathrm{mi}}$ ac $R^{\mathrm{mi}}$ D. D. Bernardi de Sandoval et Roxas [...] auctoritate et iussu editus, Madrid, 1612, Index Librorum expurgatorum, paginé à part, p. 341 (seule correction demandée dans l'ouvrage). Voir aussi Fr. Moya del Baño, Un nuevo y desconocido libro de la biblioteca de Quevedo: Q. Aurelii Symmachi Epistolarum ad diuersos libri decem, dans Amica verba in honorem prof. Antonio Roldán Pérez, Murcie, 2005, p. 699-701.

134. ILI, IX, p. 814. Dans leurs vota (supra, n. 106-107), Morin avait cité Juret parmi les auteurs à épargner tandis que Maffa l'avait inclus dans la seconde classe de l'Index; 
Gonsalvus Pontius paraît avoir hésité : Franciscus Iuretus est rayé dans sa liste d'auteurs à ajouter, et sa liste d'auteurs à ôter porte: qui nullo modo. Franciscus Iuretus. Franciscus Victoria. Robertus Bellarminus (Protocolli K, respectivement fol. 100r, 105r, 96r-v).

135. Iuonis episcopi Carnotensis epistolae. Eiusdem Chronicon de Regibus Francorum, éd. Fr. Juret, Paris, 1585.

136. Voir V.Peri, Due protagonisti, cit., p. 143-144, d'après la série des lettres de Morin à Fédéric Borromée en 1593-1594, publiées dans P. Morin, Opuscula et epistolae, cit., et ce qu'en dit Morin lui-même, Ad Nicolaum Proust Descarneaux, nepotem suum. De uita et scriptis suis, ibid., p. 7-8: Ad Borromaeum, praetermittendae [Epistolae] quibus laborum peto premia [... ]. Sed cum facultatem mihi deesse uiderem uoluntati nauandi parem, coactus sum petere, quae satius erat non petenti ultro dari. Mais le thème revient dans d'autres correspondances : voir par exemple Morin au cardinal Giovanni Evangelista Pallotta, 20 octobre 1593, ibid., p. 357 : laborum meorum praemia in haec usque tempora dilata esse; Morin à Silvio Antoniano,

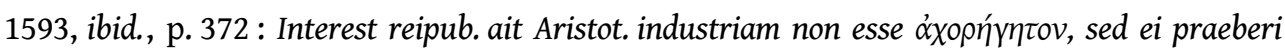
idoneos sumptus.

137. Voir Morin à Fédéric Borromée, juillet 1595, dans Opuscula et epistolae, cit., p. 330 (en corrigeant le texte d'après la conjecture de V. Peri, Due protagonisti, cit., p. 139, n. 39); Morin à Silvio Antoniano, 1593, dans Opuscula et epistolae, cit., p. 372.

138. Protocolli B, fol. $211 \mathrm{v}$, transcrit dans Diari, I, fol. 57r : et instante Lelio Peregrino et attestante Patre Belarminio decretum quod Iustus Lipsius deleatur ab Indice. Sur la préparation de l'édition expurgée des Politica et le rôle de Bellarmin, voir Juste Lipse, Politica. Six books of politics or political instruction, éd. J. Waszink, Assen, 2004, introduction, p. 120-124 et 173-190 (qui aurait néanmoins gagné à connaître la bibliographie italienne sur l'histoire de l'Index) ; la censura de Laelius Peregrinus (Lelio Pellegrini) est publiée en appendice, p. 712-714. Le cas de Speroni avait été discuté à la même réunion. Voir Protocolli B, fol. 211v, transcrit dans Diari, I, fol. 57r : Lectum memoriale pro Dialogis Speronis et decretum quod censura tradatur Magistro Sacri Palatii. Il s'agit de la supplique présentée par son petitfils Ingolfo Conti, Protocolli I, fol.503r. Les Dialogues de Sperone Speroni avaient été interdits pour la première fois par un décret du Maître du Sacré Palais de 1574 (U. Rozzo, La letteratura italiana negli 'Indici' del Cinquecento, Udine, 2005, p. 52-53). Pour la suite de l'affaire, voir Diari, I, fol. 67v (11 avril 1593); Agostino Valier à l'Inquisiteur de Venise, 11 avril 1593, Epistolae Archiepiscoporum, Episcoporum, Inquisitorum etc., 6 [Index, III/6], fol. 230r; Protocolli M, fol. 45r et 46r.

139. J. Kluyskens, Justus Lipsius (1547-1606) and the Jesuits with four unpublished letters, dans Humanistica Lovaniensia, 23, 1974, p. 244-270; J. De Landtsheer, Le retour de Juste Lipse de Leyden à Louvain selon la correspondance (1591-1594), dans Chr. Mouchel (éd.), Juste Lipse (1547-1606) en son temps. Actes du colloque de Strasbourg, 1994, Paris, 1996, p. 347-368; J. Waszink, introduction à J. Lipse, Politica, cit., p. 15-17 et 23.

140. Protocolli I, fol. 615r-616v (de l'écriture de Morin), citant Masson, De Episcopis urbis, cit., fol. 384v (Secta enim illa dici non potest quam noxia fuerit segeti Christianae, et quam late per Europam uirus suum semenque diffuderit), 418r, 419r-v, 420r-v, 421r-v.

141. Ainsi la lettre de Constantin à Arius et ses associés [CPG 2042], que Baronius publia dans Annales ecclesiastici, III, Rome, 1592, ad ann. 319 [n. VI-XXI], p.192-196 (quam Latinitate donauit R.P. Petrus Morinus, uir cum aliarum disciplinarum, tum Graecarum facultatum peritia clarus, mihi uero (quod magni facio) amicitia et usu rerum Ecclesiasticarum coniunctissimus). J.-L. Quantin, Baronius et les sources d'au-delà des monts, cit., p. 59-60 n. 21. 
142. Voir Baronius, Annales, III, cit., p. 99, ad ann. 313 [n. XXXIV].

143. Lettre autographe signée, adressée à Pico, Protocolli I, fol. 605r, publiée en Appendice, Document 4.

144. Diari, I, fol.57v:Die 24 octobris [1592] Congregatio habita apud Illustrissimum Card. Veronensem ubi interfuerunt omnes cum Magistro Sacri Palatii et Belarminio et Morino. [...] Decretum quod nullus authorum habeatur delectus sed omnes indifferenter reponantur in Indice cum nota repurgationis inter quos adnumerentur Massonius et Iustus Lipsius.

145. ILI, IX, p. 897 (Papyrii Massonii libri sex, De Vitis Episcoporum Urbis Romae, nisi prius corrigantur, et emendentur).

146. Ibid., p. 876 et 887.

147. ILI, IX, p. 860 (De Correctione Librorum, § 2).

148. Sur cette suspension et une vue générale des événements jusqu'en 1596, je renvoie une fois pour toutes à V. Frajese, Nascita dell'Indice, cit., p. 147-175 (reprenant pour l'essentiel id., La politica dell'Indice, cit., p. 320-345) et G. Fragnito, Proibito capire. La Chiesa e il volgare nella prima età moderna, Bologne, 2005, p. 45-72.

149. Objections de Clément VIII contre l'Index de 1593, Protocolli $\mathrm{M}$, fol. 281r-284v (publiées d'après ce manuscrit, avec un grand nombre d'erreurs, par V. Frajese, La politica dell'Indice, cit., p.346-349). On en trouve plusieurs autres copies, Protocolli M, fol. 263r-264v, et encore 265r-267v ; Protocolli P, fol. 49r-51r ; Protocolli R, fol. 11r-13v. Le texte n'a pas de titre: dans les procès-verbaux de l'Index, il est indifféremment désigné comme obiectiones aduersus Indicem et oppositiones contra Indicem (Index, Diari, I, fol. 71r-72v).

150. Protocolli $\mathrm{M}$, fol. $282 \mathrm{v}: 9^{\circ}$ : uiuentium Catholicorum libri multi recensentur. Cui rei attentius prospiciendum est: nam praeter notam quae auctoribus plane inuritur, subest etiam euidens periculum ne indignati haeretici efficiantur. Hoc loco sunt Iustus Lipsius, Papirius Massonius, Ioannes Bodinus, Iulius Scaliger, et alii, unde uel erunt hic et etiam in expurgatorio Indice expungendi, et admonendi Auctores ad edendas retractiones [sic] quod facilius ipsi praestabunt, et erit catholicae fidei consultius, uel hic expungantur et in expurgatorio annotentur loca emendatione digna (les deux autres copies dans Protocolli $\mathrm{M}$, qui sont manifestement inférieures, ont indignitati au lieu de indignati ; dans Protocolli $\mathrm{P}$, indignitati a été corrigé en indignati ; Protocolli $\mathrm{R}$ a bien indignati : cette dernière leçon est clairement la bonne). Jules César Scaliger était effectivement catholique, même si sa position religieuse exacte a été discutée (voir A. Ch. Fiorato, Jules-César Scaliger, bien ou mal sentant, dans J. Cubelier de Beynac et M. Magnien (éd.), Acta Scaligeriana. Actes du colloque international organisé pour le cinquième centenaire de la naissance de Jules-César Scaliger, Agen, 1986, p. 13-33) mais il était mort en 1558: il s'agit très probablement d'une confusion avec son fils Joseph (bien vivant mais protestant).

151. G. Fragnito, Diplomazia pontificia e censura ecclesiastica durante il regno di Enrico IV, dans Rinascimento, $2^{\mathrm{e}}$ s., 42, 2002, p. 160-165 ; ead., Proibito capire, cit., p. 66-72.

152. Voir dans son votum sur Bodin, Protocolli $\mathrm{K}$, fol. 242r, la manière dont il répond à l'objection que Bodin réside à Laon, ciuitate Catholicarum partium : audiui eum in illam urbem casu incidisse, non sponte, et consulto uenisse. Nec de homine nunc queritur : cuius existimationem subleuare debet eius urbis laus, quae bonarum est partium. At ipsemet ne Ciuitatis in qua uiuit laudem imminuat utque, quod ibi fortasse audit, uere Catholicus habeatur damnare librum suum debet. 
153. G. Ponce de León, Scholastica assertio pro disciplina ecclesiastica. Qua demonstratur Henrici Borbonii Biarnensis ad Galliae Regnum perpetua inhabilitas, Rome, 1593. Voir J. A. de Thou, Historiae sui temporis, cit., V, l. CVII, § XII, p. 298-303. Sur Ponce de León, brève notice dans Catholic Church and modern science, éd. U. Baldini et L. Spruit, cit., IV, p. 2914. Sur ses travaux érudits, voir É. Legrand, Bibliographie hispano-grecque, 3 vol., New York, 1915-1917, II, n 341, 347, 354 ; l'introduction de M. Jugie à Théophane de Nicée, Sermo in sanctissimam Deiparam, Rome, 1935, p. VII-VIII ; V. Peri, Il numero dei concili ecumenici, cit., p. 463-464 ; J. López Rueda, Helenistas españoles del siglo XVI, Madrid, 1973, p. 366-367.

154. Diari, I, fol. 71r (15 janvier et 12 février 1594).

155. Voir quatre lettres de Morin à Antoniano en 1593-1595, publiées dans P. Morin, Opuscula et epistolae, cit., p. 365-376. Sur le milieu de la Vallicella et la place que, sans être oratorien, y tenait Antoniano, voir V. Frajese, Nascita dell'Indice, cit., p.147-150 ; id., Tendenze dell'ambiente oratoriano durante il pontificato di Clemente VIII. Prime considerazioni e linee di ricerca, dans Roma moderna e contemporanea, 3, 1995, p. 57-80.

156. Réponse de la congrégation de l'Index aux objections contre l'Index de 1593, Protocolli $\mathrm{M}$, fol. 242r-251r (publiée d'après ce manuscrit, de manière très fautive, par V. Frajese, $L a$ politica dell'Indice, cit., p. 349-356). Autres copies, Protocolli K, fol. 253r-261r ; Protocolli P, fol. 53r-56v ; Protocolli U, fol. 33r-39v (cette copie est la seule à avoir un titre: Responsio S. Congregationis DD. Cardinalium ad quaedam capita in Indice librorum prohibitorum notata. 26 Febr. 1594). Ce document, rédigé par le cardinal Allen, faisait la synthèse des réponses apportées par les cardinaux à la réunion du 26 février 1594 ; approuvé à la réunion du 12 mars (un samedi, jour des réunions de l'Index), il fut présenté au pape par le Maître du Sacré Palais, au nom de la congrégation de l'Index, à la réunion du Saint-Office du 17 mars (Index, Diari, I, fol. 72r-v) : il s'agissait d'un jeudi, feria quinta, jour normal de réunion du Saint-Office coram Sanctissimo (voir le procès-verbal, S.O., Decreta, 1594, fol. 218v-219v, où la question de l'Index n'est pas mentionnée). V. Frajese, La politica dell'Indice, cit., p. 349, et encore Nascita dell'Indice, cit., p. 158, donne à tort la date bizarre du 27 mars.

157. Protocolli $\mathrm{M}$, fol. 246v-247r: De uiuentium catholicorum libris in utramque partem aliquoties disceptatum est, tandem iustis ut nobis uidebatur rationibus, itum est in eam sententiam ut adscriberentur, cum speremus fore ut, si uere catholici ac conuersi sint, ac frumentum et non palea existant, hanc cribrationem libenter patiantur, [...] aut si id ex superbia non ferant, nec errata in Indice Censorio castigari aequo animo laturos existimauimus.

158. Protocolli R, fol. 16r : Ad nonum. Certe parum in fide firmi esse creduntur, qui in Indice ob eorum contra fidem aut bonos mores perperam scripta notabunt [sic], ad haereticorum partes transfugere posse suspicantur. Et quare neglexerunt ipsi libros suos corrigere totiens ab amicis, et multo antequam in Indice ponerentur admoniti? Profecto periculosum ualde est Christifidelibus si horum librorum lectio non prohibeatur antequam Index expurgatorius emitatur. Il s'agit de la mise au net de réponses portées en marge d'un exemplaire des objections pontificales, fol. 12 .

159. Diari, I, fol. 83v (3 décembre 1594): cum reliquis pro noua Indicis impressione necessariis iuxta oppositiones olim a Sanctissimo Congregationi transmissas, et per Congregationem quaedam probata, et quaedam reiecta fuere. Ce fut dans l'intervalle que la congrégation envisagea d'écrire directement aux auteurs pour leur faire expurger leurs livres (infra, n. 179). 
160. Ibid., fol. 84r : [Secretarius] cum Cardinali Borromeo pro Indicis reuisione per multos dies libros, et Censuras reuoluendo fuit.

161. Ibid., fol. 84v, 85r, 85v. Voir une copie de cette relatio dans Protocolli $\mathrm{M}$, fol. 236r-241v : elle n'est ni datée ni signée mais le contenu de la première partie (lettres A à C), fol. 236r-237v, correspond très exactement aux livres discutés à la réunion de l'Index du 4 mars 1595, Diari, I, fol. 84v (pour la réunion du 11 mars, voir infra, n. 163). Les décisions prises sont notées en marge, de la même écriture. Une autre copie, où sont portées de même les décisions, Protocolli P, fol. 22r-25v, est la source de l'édition partielle (limitée aux auteurs "scientifiques») dans Catholic Church and modern science, éd. U. Baldini et L. Spruit, cit., I, p. 267-270. Cette seconde copie étant immédiatement suivie dans le registre P, fol.26r-27r, d'une copie d'un avis De correctione librorum, signé du Maître du Sacré Palais, Bartolomé de Miranda, les éditeurs (ou leurs collaborateurs...) ont cru avoir affaire à un document unique : ils ont attribué l'ensemble à Miranda et même découpé sa signature pour la coller à la fin de leur édition du texte de Borromée (p. 270), avec une datation imprécise «post 1593, ante 1596 ». Mais le votum de Miranda (dont on trouve l'original, Protocolli $\mathrm{M}$, fol. 233r-v, suivi du billet autographe d'envoi de Miranda à Pico, fol.234r) n'a rien à voir: il fut composé entre le 19 juin, quand, conformément à la décision du 16 mai, le manuscrit de l'Index lui fut transmis pour un ultime examen, sous le contrôle du cardinal Francisco Toledo (Diari, I, fol. 85v-86r), et le $1^{\text {er }}$ juillet 1595 , quand l' Index fut définitivement approuvé pour être présenté officiellement au Pape au consistoire du 3 juillet (ibid., fol. 86r: Magister S. Palatii uerbo et scripto retulit quae sibi animaduersione digna uidebantur pro noui Indicis correcti impressione, quorum quaedam approbata fuerunt ab Illustrissimo Card. Toleto atque, ex unanimi omnium sententia quibusdam rursus immutatis, decretum quod in proximo consistorio Sanctissimo Domino Nostro ab omnibus Cardinalibus Congregationis Index per tantum temporis et toties a multis examinatus et correctus offerretur approbandus ut eodem Sanctissimo annuente imprimi posset).

162. Protocolli M, fol. 239r-v : Papirii Massoni de uitis Episcoporum Urbis Romae. In hoc libro multa de Romanis Pontificibus falsa, temeraria atque impudenter prolata etc. Belarminus confecit expurgationem, uerum auctor pollicetur operam suam summa animi alacritate in emendatione librorum de uitis Episcoporum etc. Scripsit Epistolam ad Sixtum V. anno 1587. Ces précisions laissent penser que le dossier Masson dans les archives de l'Index était dès lors constitué tel qu'il se présente aujourd'hui.

163. Le procès-verbal de cette réunion est conservé dans Protocolli $M$, fol. 181r-v. Le texte n'est pas daté mais il est de l'écriture de Morin (il est désigné dans la table du volume comme Petrus Morinus de uariis libris, mais il s'agit clairement d'un compte rendu). Outre que le contenu correspond parfaitement à la relatio de Borromée, Protocolli $\mathrm{M}$, fol. 238r-239v, la seule réunion depuis octobre 1592 où Morin fit à nouveau fonction de secrétaire fut celle du 11 mars 1595 (Diari, I, fol. 85r-v : D. Petrus Morinus Congregationis Typographiae Secretarius uices suppleuit F. Pauli Picci Secretarii tunc infirmi). Morin était intervenu une seconde fois en faveur de Juret à la réunion de l'Index du 4 décembre 1593 ( Diari, I, fol. 70r).

164. Protocolli $\mathrm{M}$, fol. 181r : Iuretus tollendus ex indice. Itidem Lipsius. Massonus tollatur ex indice [ces trois mots sont écrits au-dessus de la ligne, pour remplacer un texte plus long rayé et illisible, le papier étant rongé]. Ad [hos] tres se scripturum esse Illustrissimus D. Cardinalis Ascanius Columna dixit : et afferantur ad eum censurae.

165. Le compte rendu officiel finalement inscrit dans Diari, I, fol. 85r, porte simplement Illustrissimus D.Cardinalis Borromeus prosequutus est suam relationem sed nihil est 
determinatum totumque negotium ad plenam Congregationem est remissum ut absoluta relatione Cardinalis Borromei determinari possit quid tum circa Instructionem tum circa Librorum et Auctorum prohibitionem uel permissionem agendum sit, sans nommer aucun auteur en particulier. Étaient présents les cardinaux Agostino Valier, Fédéric Borromée, Ascanio Colonna, et Terranova (Simon Tagliavia d'Aragon), lequel venait juste d'être nommé, propter decessum ab Urbe Cardinalis Asculani (Girolamo Bernieri). Marcantonio Colonna était malade et Toledo porté comme absent. Allen était mort le 16 octobre 1594.

166. Le procès-verbal ne donne pas de précisions (Diari, I, fol. 85v : Cardinalis Borromeus prosequutus est suam relationem, quam etiam in scripto tradidit, et quibusdam deletis, mutatis, et additis per Congregationem approbata fuit correctio Indicis), mais voir les annotations en marge de la relatio de Borromée, Protocolli $\mathrm{M}$, fol. 238v-239r : pour Juret, auferatur ab Indice ; pour Lipse, deleatur ab Indice ; pour Masson, retineatur in Indice. Cette réunion du 22 avril 1595 était la première depuis le 11 mars.

167. J. Waszink, introduction à J. Lipse, Politica, cit., p. 189-190.

168. Inonis episcopi Carnotensis epistolae collatione multorum manuscriptorum codicum restitutae, auctae et emendatae. In illas obseruationum liber non antea editus. Eiusdem Iuonis Chronicon de Regibus Francorum, Editio secunda, Paris, 1610. Sur la condamnation de l'ouvrage, après trois censurae successives, voir Diari, II, fol. 26r (8 janvier 1611), 26v (12 février 1611), 28v (23 juillet 1611); Protocolli S, fol. 268r-273v.

169. ILI, IX, p. 968, n 949 : Papyrii Massonii, libri sex, De uitis Episcoporum Urbis Romae, nisi fuerit [sic] ex correctis, ab auctore, cum approbatione Magistri Sacri Palatii. La clause avait été introduite pour Juste Lipse dans un ultime repentir de l'Index de 1593 (ibid., p. 420-421). Le manuscrit de l'Index de 1596 approuvé pour l'impression par le cardinal Toledo (Index, $\mathrm{XVI}$ ), qui témoigne d'hésitations de dernière minute, en particulier sur Bodin (voir fol. 52v et G. Fragnito, Proibito capire, cit., p. 70 n. 111), n'a aucune correction en ce qui concerne Masson, fol.70r: Papyrii Massonii Libri sex de uitis Episcoporum Urbis Romae nisi fuerint ex correctis ab auctore, cum approbatione Magistri Sacri Palatii (le tilde de fuerint a été oublié dans l'imprimé).

170. Relation présentée par la congrégation de l'Index à Clément VIII, $1^{\mathrm{er}}$ mai 1596 , publiée par A. E. Baldini, Jean Bodin e l'Indice dei libri proibiti, dans Cr. Stango (éd.), Censura ecclesiastica e cultura politica in Italia tra Cinquecento e Seicento. VI giornata Luigi Firpo, Atti del Convegno 5 marzo 1999, Florence, 2001, Appendice, nº 2, p. 96-97: duplici clausula limitatur [Index], quod liber sit correctus ab auctore et a Magistro Sacri Palatii approbatus, quod perinde est, ac si sub aliis uerbis omnino prohibeatur. A. E. Baldini attribue le texte au secrétaire Pico, mais G. Fragnito, Proibito capire, cit., p. 50 n. 53, y voit plutôt l'œuvre du cardinal Agostino Valier.

171. ILI, IX, p. 931.

172. Voir la liste des lettres conservées dans Borrelli, Ricerche sul Baronio II cit., p. 120-121. Même entre Baronius et Nicolas Le Fèvre, le plus important de ses correspondants français, la correspondance conservée s'interrompt entre 1592 et 1596 (ibid., p. 158-159) et cette lacune tient au moins en partie à une interruption effective. Voir Le Fèvre à Baronius, 29 septembre 1596 (après que Baronius eut pris l'initiative de renouer le contact), dans Baronius, Epistolae et opuscula, cit., III, p. 187 : mihi, qui Lutetiae permansi quandiu in armis stetit, urbem Rege Christianissimo potito, nec dum cum Summo Pontifice bene conuenienti, Romam scribere tutum non fuisse. Cette raison valait a fortiori dans le cas de Masson, qui s'était davantage compromis avec la Ligue. 
173. Baronius à Lipse, 31 juillet 1593, Iusti Lipsi epistolae. Pars VI : 1593, éd. J. De Landtsheer, Bruxelles, 1994, p. 250 : Bene accidit his diebus ut, reclamante me et aliis quamplurimis a Sanctissimo Domino Nostro Index uetitorum librorum iam cusus ipse ne uendatur uetitus sit, quod multa in eo reperta sint emendatione digna; complures credo uoluentur menses, antequam discrepantium sententiae in unum conueniant. Tu uero, mi luste, opportuna hac bene utere occasione. Il s'agit d'une réponse à la lettre du 30 mai 1593 (ibid., p. 190-191), par laquelle Lipse avait pris l'initiative d'engager une correspondance.

174. G. Fragnito, Un archivio conteso, cit., p. 1276-1318.

175. Voir P. Godman, The saint as censor, cit., p. 209-210; J. Waszink, introduction à J. Lipse, Politica, cit., p. 123.

176. La seule source sur cette affaire est un extrait d'une lettre de Baronius transcrit, de manière malheureusement inintelligible, par Billet de Fanières, dans son recueil de testimonia sur Masson, BNF, Ms. Français 24519, fol. 311v (copie par Drouyn, Ms. Français 22861, fol. 53v), et publié par P. Ronzy, Les relations, cit., p. 273 : Testimonium pietatis et relligionis quod Papirio Massonio habuit occasionem dedisti periucundum sane fuit. 1601. Romae pridie idus Novembris. P. Ronzy propose de corriger en Testimonium pietatis et religionis quod $<a>$ Papirio Massonio habui <et cui occasionem dedisti periucundum sane fuit, et de comprendre que ce témoignage de piété était le fait de solliciter une censure du De Episcopis urbis, que Baronius lui aurait finalement envoyée le 12 février 1602 (interprétation reprise dans P. Ronzy, Un humaniste italianisant, cit., p. 405 et 645). Mais, outre que la phrase ainsi reconstituée n'est guère latine, on est très loin de la transcription de Billet de Fanières. Si l'on suppose que celui-ci a simplement eu du mal à déchiffrer l'écriture, effectivement très difficile, de Baronius, le plus économique paraît être de corriger en Testimonium pietatis et relligionis quod Papirio Massonio habita occasione dedisti periucundum sane fuit. Il s'agit certainement, en tout cas, d'un témoignage rendu par Le Fèvre à Masson: voir Baronius à Masson, 12 février 1602, dans Baronius, Epistolae et opuscula, cit., II, p. 70, lui promettant sa protection tum ingenii et doctrinae tuae merito, tum Fabri nostri [...] commendatione. Sur les rapports de Baronius et de Le Fèvre, voir J.-L. Quantin, Baronius et les sources d'au-delà des monts, cit., p. 84-100.

177. Baronius à Masson, 12 février 1602, dans Baronius, Epistolae et opuscula, cit., II, p. 69 (pour les différentes copies manuscrites de cette lettre, dont l'original a disparu, voir supra, n. 6) : in qua [animaduersione] uides stylum a censore altius impressum, multaque confixa uel leuia et parum reprehendenda, uel non tam tua quam aliorum quos laudas. Sed hoc ille nimirum spectauit, in huius argumenti opere, hoc praesertim seculo, cautionem nimis esse uix posse [...]. Tibi uero difficile non erit ex his multis ea seligere et castigare, quibus bonorum aures offendi iure posse senties.

178. Ibid., p. 69-70 : Quod ubi feceris, spondere audeo, tametsi censura haec priuata, non publica auctoritate perscripta sit, nihil morae futurum quominus libri tui a Sede Apostolica permittantur.

179. Minuta literarum transmittendarum per Congregationem ad Authores superstites, ut propria opera expurgent ipsi, ut Papirius Massonius, Iustus Lipsius, Franciscus Iuretus, Ioannes Bodinus, Ioannes Baptista Porta, Protocolli M, fol. 222r-v: Ideo exemplo Diui Thomae, qui opusculum Concordantiarum, et D. Augustini qui libros retractationum fecerunt, sic etiam Tu carissime Frater quam primum ex te ipso palidoniam [sic] cane, et quae expurganda erunt a Nuntio Apostolicae Sedis, cui modum expurgationis transmisimus, cognosces, ex cuius approbatione et auctoritate publicare poteris, et impressioni mandare opus tuum cum censura ab omnibus approbandum et laudandum. Une autre version, qui me parait la première, est conservée, ibid., 221r-v ( palinodiam aequo animo cane); suivent des minutes de lettres aux universités (fol. 225r-v et 
226r-v) et aux nonces (227r-v). Le texte a été publié, avec des fautes de transcription véritablement étonnantes qui le rendent entièrement inintelligible, dans Catholic Church and modern science, éd. U. Baldini et L. Spruit, cit., I, p. 276-278. Les éditeurs, qui attribuent ce texte au secrétaire Pico, le datent avant 1596 et après le décret du 23 juillet 1594 par lequel la congrégation décida de ne pas écrire directement aux auteurs (voir note suivante). Il est évident qu'il doit au contraire être antérieur à cette décision et qu'il faut le placer entre le 27 mars (réponse de l'Index à Clément VIII) et le 23 juillet 1594. Mais sa date exacte est clairement fournie par le procès-verbal de la réunion du 2 juillet 1594 : Commissum Illustrissimo D.Card. Veronensi ut minutam litterarum per Congregationem mittendarum ab Authores, Inquisitores, Uniuersitates, ordinarios et Nuntios conficiat quae in sequenti Congregatione approbabitur (Diari, I, fol. 76v ... publié dans Catholic Church and modern science, éd. U. Baldini et L. Spruit, cit., I, p. 368).

180. Diari, I, fol. 77r (23 juillet 1594): Decretum quod Authoribus uiuentibus nullatenus per Congregationem scribatur, sed priuatim solum ab aliquo admoneantur, ut errores corrigant in suis libris. La congrégation ne s'étant réunie ni le 9 ni le 16 juillet, il s'agit donc bien de la séance où les minutes de Valier furent examinées. On notera que le projet d'écrire aux auteurs apparaît pour la première et dernière fois le 2 juillet: dans les réunions précédentes, il n'avait été question, selon le procès-verbal, que de lettres aux nonces, aux évêques, aux inquisiteurs et aux universités (Diari, I, fol. 74v et 75r, 11 et 18 juin 1594).

181. Diari, I, fol. 159r: D. Sacristae [Angelo Rocca] iniunctum ut recognoscat opera Suidae, et Massonii [...]. Item Ugonio [Pompeo Ugonio] Massonius et Chrispinus. Item D. Sponde Calcondila et Suidas. [...] Item Candido [Giacomo Candido] Massonius quamuis olim fuerit censuratus per Congregationem et Autori transmissa Censura. Ideo scribendum Nuntio Galliarum, ut uideat et referat, an effetualiter librum Auctor censuratum impresserit. Pour l'organisation en classes, voir ibid., fol. 154v-155r (2 août 1602). Sur les avatars et l'échec final du projet d'Index expurgatorius romain, voir G. Fragnito, Aspetti e problemi della censura espurgatoria, cit., p. 161-178; ead., "In questo vasto mare de libri prohibiti et sospesi tra tanti scogli di varietà et controversie ": la censura ecclesiastica tra la fine del Cinquecento e i primi del Seicento, dans Cr. Stango (éd.), Censura ecclesiastica, cit., p.1-35; E. Rebellato, Il miraggio dell'espurgazione. L'Indice di Guanzelli del 1607, dans Società e Storia, 31, 2008, p. 715-742.

182. Terranova au nonce en France, 22 novembre 1602, Registrum Litterarum uulgarium et latinarum S. Congregationis Indicis. Ab anno 1582 usque 1602 [Index, V/1], fol.176r: «Et perche alcuni anni sono fù prohibito il libro di Papirio Massonio de Episcopis Urbis, et à sua instanza li fù mandata da Roma la censura per ristamparlo correto, V.S. potrà informarsi se ha esseguito, et darne aviso del tutto». Cette correspondance ne concernant que l'Index et non la Secrétairerie d'État, on ne trouve aucune mention de Masson dans Correspondance du nonce en France Innocenzo del Bufalo évêque de Camerino (1601-1604), éd. B. Barbiche, Rome-Paris, 1964.

183. Del Bufalo à Terranova, 13 janvier 1603, Epistolae Archiepiscoporum, Episcoporum, Inquisitorum etc., 7 [Index, III/7], fol. 427r : « Papirio Massonio confessa che hebbe pensiero già di corregere, et far' ristampare il suo libro de Episcopis Urbis, mà havendo visto, che cosi dice egli medesimo, che nella Censura, vien tassato in alcune epistole, di cosa, ch'egli ha cavato da Cassiodoro, et che non è cosa di rilievo, secondo il suo giuditio, quello di che vien censurato, che non pensa più ne a correggerlo, ne a ristamparlo, et quà si legge, et si vende nella sua prima impressione ». Les lettres sont celles d'Athalaric, sur la simonie dans les élections pontificales: voir Masson, De Episcopis urbis, cit., fol. 87v-89v, et la censure, BNF, Ms. Latin 11416, fol. 80r (P. Ronzy, Les relations, cit., p. 282). 
184. Voir les procès-verbaux de cette congregatio minor, Diari, I, fol. 161r (20 novembre 1602), 163r (14 janvier 1603: D. Cardinalis Baronius propter multas occupationes legittime impeditus totum hoc negotium remisit ad D. Cardinalem Antonianum), 163r-v (13 mars 1603), $165 \mathrm{v}$ (12 juin 1603), 166r (17 juillet 1603), 169v (4 février 1604 : cui [Baronio] pro Censura librorum humanarum disciplinarum datus fuerat Collega Cardinalis Dossat in locum demortui Cardinalis Antoniani suffectus [...]. Cardinalis Baronius excusauit se ueluti occupatissimum in Annalibus ecclesiasticis et totum negotium suae classis ex ordine Sanctissimi reiecit in Cardinalem Dossat), 169v (13 février 1604). En réponse à la lettre de Del Bufalo, Terranova avait par ailleurs suggéré de confier l'expurgation de Masson à une commission de docteurs de Sorbonne, que le nonce, sur instructions de l'Index, cherchait alors à mettre en place en France même, mais le projet n'eut aucune exécution : voir Terranova à del Bufalo, 19 mars 1603, Registrum Litterarum omnium S. Congregationis Indicis. Ab anno 1603 usque 1616 [Index, VI/1], fol. 2v, et sur le projet, G. Fragnito, Diplomazia, cit., p. 151-159.

185. G. M. Guanzelli da Brisighella, Indicis librorum expurgandorum in studiosorum gratiam confecti tomus primus, Rome, 1607.

186. Voir A. Degert, Le cardinal d'Ossat, évêque de Rennes et de Bayeux (1537-1604). Sa vie, ses négociations à Rome, Paris, 1894 ; B. Barbiche, L'influence française à la cour pontificale sous le règne de Henri IV, dans Mélanges d'archéologie et d'histoire [de l'École française de Rome], 77, 1965, p. 277-299.

187. De Thou, Papirii Massoni Vita, cit., fol. e7v-e8r : quod iudicium Papirius tanquam beneuoli amici consilium interpretabatur, et aliis amicis discutiendum proponebat, de cetero posteritati, quae recte secusque dictis decus aut infamiam incorrupto iudicio olim repensura esset, integrum negotium relinquebat. La Vie de Masson par de Thou dut être rédigée vers 1612 (P. Ronzy, Un humaniste italianisant, cit., p. 612 et 621).

188. Voir Tacite, Annales, 4, 35 (éd. P. Wuilleumier, Paris, 1975, p. 35) : suum cuique decus posteritas rependit.

189. P. Ronzy, Un humaniste italianisant, cit., p. 406-407, 554-555, 557.

190. Masson, De Episcopis urbis, cit. (BL, cote 4855.d.27). Note sur la page de titre : Papirius Masso hoc suum opus emendauit secundum censuram Cardinalis Baronii et mentem curiae Romanae. Cet exemplaire avait été signalé par M. Borrelli, Ricerche sul Baronio II, cit., p. 120. L'écriture ne me paraît pas celle de Masson mais il faudrait vérifier si elle peut être celle de son amanuensis.

191. Voir par exemple Masson, De Episcopis urbis, cit., fol. 159v, 217r, 258r, 390r, 397r,

192. Voir par exemple ibid., fol. 220r: Iusti ecclesia devient diui Iusti ecclesia; in oppido Germani devient in oppido diui Germani.

193. Ibid., fol. 408r (Jésuites).

194. Ibid., par exemple fol. 266v (voir supra, n. 19).

195. Ibid., par exemple fol.43r-v (Jérôme et Martial) et 81v (le Décret de Gratien sur Anastase II). Voir respectivement supra, n. 63 et 73.

196. Ibid., fol. 410v : Cuius uiri sectam nunquam non exosam habebit Gallia tot caedibus, tanto sanguine foedata ex grassata in ea impiae illius sectae haeresi (au lieu de Cuius uiri non quidem sectam, sed excellentis ingenii uires scribendique grauitatem mirari necesse est).

197. Ibid., fol. 385v (rogné à la reliure) : factum autem Leonis <in> huius modi concordatis cum Christianissimo rege damnare non aus<i> licet liberius forte quid sentiam pr<op>onam exitus acta probat. Voir supra, n. 23. 
198. Comme il fit dans son édition de Dungal, en tête de laquelle il publia deux lettres de Baronius, du 8 août 1605 et du 5 novembre 1606, qui l'encouragaient à cette publication : Dugali liber responsionum aduersus Claudii Taurinensis Episcopi sententias, ad Hludouivum Imper. eiusque filium Lotharium Augustum, éd. P. Masson, Paris, 1608, p. 6-7.

199. Diari, I, fol. 175r : Agobardi episcopi Lugdunensis de Imaginibus liber, nuper a Massonio illustratus et impressus; ;et [...] cum sint diuersis Haeresibus respersi omnino prohibeantur. Voir J.-L. Quantin, Baronius et les sources d'au-delà des monts, cit., p. 65-66.

200. Pour un possible parallèle, voir le cas de Thomas Dempster, étudié par I. Herklotz, Antiquarische Werke auf dem Index der verbotenen Bücher. Leone Battista Alberti, Lilio Gregorio Giraldi, Thomas Dempster, dans Studi in onore di Romeo De Maio, cit., p. 330-338.

201. Voir de Thou à Christophe Dupuy, 12 février 1606, dans J. A. de Thou, Historiae sui temporis, cit., VII, section I, p. 13. Dupuy avait annoncé la condamnation d'Agobard dans sa lettre du 20 septembre 1605, De Thou and the Index. Letters from Christophe Dupuy (1603-1607), éd. A. Soman, Genève, 1972, p. 50.

202. Pour citer la conclusion de l'étude très superficielle de J. M. de Bujanda, La censure ecclésiastique sur les cuvres historiques, dans M. Firpo (éd.), Nunc alia tempora, cit., p. 265-277, où Masson, et les gallicans en général, ne sont du reste pas mentionnés.

203. De Thou à Christophe Dupuy, 12 février 1606, dans J. A. de Thou, Historiae sui temporis, cit., VII, p. 13 ; De Thou, Papirii Massoni Vita, cit., fol. e7r-v.

204. P. Ronzy, Un humaniste italianisant, cit., p. 564.

205. Un cas particulièrement net est celui de Bona (J.-L. Quantin, Protecteur et censeur, cit.).

206. Br. Neveu, L'erreur et son juge, cit., p. 166. Voir encore p. 452 sur « la "notion large" de l'hérésie qui fait entrer en ligne de compte des éléments concrets, des considérations de personnes et de circonstances, dispositions intimes d'un auteur, habitus moral et conduite ecclésiastique, présomption d'une résistance de la volonté chez les assertores", et les références données supra, n. 119. Les défauts formels de L'erreur et son juge doivent porter une part de responsabilité dans les contresens, mais on demeure étonné par la thèse que V. Frajese, Nascita dell'Indice, cit., p. 326-327 n. 23, a prétendu attribuer à Bruno Neveu, en se gardant de donner aucune référence précise à l'intérieur d'un livre de 750 pages (« si sostiene l'esistenza di un metodo di censura dottrinale che si applicherebbe al significato del testo escludendo rigorosamente la valutazione della volontà dell'autore e dunque ogni giudizio sulla persona »). L'article qu'attaque en même temps V. Frajese (Br. Neveu, Juge suprême et docteur infaillible: le pontificat romain de la bulle In Eminenti (1643) à la bulle Auctorem Fidei (1794), dans Mélanges de l'École française de Rome. Moyen Âge-Temps modernes, 93, 1981, p. 215-275, repris dans Érudition et religion, cit., p. 385-450) ne dit rien de tel non plus. Il est faux, enfin, que cette supposée thèse de Br. Neveu ait été critiquée par Fr. Beretta, la polémique en question (à laquelle on peut par ailleurs regretter que $B r$. Neveu se soit laissé associer) ne portant absolument pas sur cette question: voir $\mathrm{Br}$. Neveu et P.-N. Mayaud, L'affaire Galilée et la tentation inflationniste. À propos des notions d'hérésie et de magistère impliquées dans l'affaire, dans Gregorianum, 83, 2002, p. 287-311; Fr. Beretta, L'affaire Galilée et l'impasse apologétique. Réponse à une censure, dans Gregorianum, 84, 2003, p. 169-192.

207. Les mêmes procédés avaient été employés vis-à-vis de Montaigne, cette fois dans le cadre d'une conversation (J.-R. Armogathe et V.Carraud, Les Essais de Montaigne, cit., p. 82-83). 
208. J. de Launoy, Censura responsionis qua Fr. Norbertus Caillocius sese mendaciis atque erroribus nouis irretiuit, Paris, 1663, p. 50 : Haec omnia in Curia spectant ad Indicem librorum prohibendorum, sed in Romana et Gallicana Ecclesia ad Indicem librorum legendorum.

209. Citation de mémoire de Pacien de Barcelone, Contre le traité des Novatiens (Lettre III), 26, 3 (SC 410, 266-268).

210. Le passage entre crochets, qui ne correspond à rien dans la lettre de Masson (supra, n. 102), est une addition faite en marge par Baronius.

\section{AUTEUR}

\section{JEAN-LOUIS QUANTIN}

École pratique des Hautes Études - jean-louis.quantin@ephe.sorbonne.fr 


\title{
"Onde non apparisca che anco tra $i$
} cattolici siano diversità d'opinioni in quello che riguarda la fede »: i sermoni di Ignazio di Loyola e le censure della Facoltà di Teologia del 1611 tra Parigie Roma

\author{
Miguel Gotor
}

1 L'11 ottobre 1611 il nunzio in Francia Roberto Ubaldini scriveva al cardinale Scipione Borghese una lettera preoccupata in cui lo avvisava che il $1^{\circ}$ ottobre la Sorbona aveva censurato tre sermoni in onore del beato Ignazio di Loyola, scritti rispettivamente da un agostiniano e da due domenicani. Un gesuita aveva tradotto in francese le prediche e la censura era stata « con troppa passione procurata da un padre spagnolo pur domenicano che si chiama fra Juan Gallardo che pochi mesi sono venne a Parigi [...] il quale pretendeva che i detti sermoni fossero pieni di errori, impertinenze e anche eresie e che s'era giudicato tenuto di vendicare i Padri della sua natione e religione, della ingiuria » presente nel libro ${ }^{1}$.

2 A tutta prima si ha l'impressione di trovarsi davanti a una tipica bega fratesca, alimentata dalla consueta rivalità tra ordini vecchi e nuovi e destinata a incattivirsi ulteriormente a causa degli orgogli e dei pregiudizi nazionali dei diversi protagonisti. La questione, però, si sarebbe rivelata ben presto più significativa di così dal momento che avrebbe coinvolto l'università di Parigi, i gesuiti francesi e i difficili rapporti ed equilibri tra Parlamento, sovrano, mondo gallicano, nelle sue differenti varianti interne, e la Sede apostolica, nel corso di una fase storica mossa e incerta, quella della reggenza di Maria de' Medici all'indomani dell'assassinio di Enrico IV ${ }^{2}$. 
3 Il libro Trois tres-excellentes Predications, oggetto dell'attenzione del nunzio, fu pubblicato in Francia nel 1611 a cura del gesuita François Solier ${ }^{3}$. L'edizione originale, in lingua spagnola, uscita a Sevilla nel $1610^{4}$, era stata prontamente tradotta nello stesso anno in italiano da due diversi editori milanesi ${ }^{5}$; nel 1611, insieme con la traduzione francese ne circolava anche una in lingua latina ${ }^{6}$. Si tratta dunque di un'opera di successo, il prodotto di un investimento editoriale a livello europeo che aveva visto la collaborazione di alcuni tra i principali ordini religiosi della cattolicità.

4 Il domenicano catalano Jaime Rebullosa aveva scritto il primo sermone, da lui pronunciato a Barcellona, nella chiesa di Belén della Compagnia di Gesù, nella quarta domenica dell'Avvento del 1609 , nel giorno in cui era stata celebrata la festa di beatificazione di Ignazio, in presenza del governatore del principato di Catalogna. Il frate predicatore aveva già avuto contatti con il mondo gesuita perché aveva tradotto in spagnolo nel 1605 la seconda delle Relazioni Universali di Giovanni Botero ${ }^{7}$. L'autore della seconda predica era il domenicano aragonese Pedro Deza, maestro di teologia, il quale aveva celebrato l'evento nella casa professa dei gesuiti di Valencia il 26 gennaio del $1610^{8}$. L'agostiniano andaluso Pedro de Valderrama, noto predicatore e priore del convento di Sant'Agostino a Sevilla, aveva composto il terzo sermone, anch'esso celebrato nel 1610, ossia nel primo anniversario della beatificazione di Ignazio di Loyola9 .

5 Presso la Biblioteca Nazionale di Francia sono conservati due esemplari dell'opera che qui interessa: uno pressoché intonso ${ }^{10}$, l'altro recante i segni dell'inchiostro censorio del suo primo lettore, verosimilmente il frate domenicano Juan Gallardo che lo consegnò ai teologi della Sorbona affinché lo esaminassero. Ciò consente anzitutto di ricostruire $\mathrm{i}$ meccanismi di funzionamento della fabbrica censoria che dunque ebbe due livelli di intervento : quello del lettore denunciante e poi quello dei teologi della Sorbona; inoltre, permette di collocare quest'azione dentro la temperie politica, culturale e religiosa di quei mesi difficili, ancora dominati dall'ombra lunga e sinistra dell'omicidio di Enrico IV, le «Grand Henry d'heureuse memoire, notre souverain Prince, tres-aymé Pere et tressingulier protecteur" dei gesuiti, come ricordava il traduttore francese nella sua introduzione ${ }^{11}$. Un periodo reso ancora più travagliato dalla perdurante minaccia dinastica che gravava sul regno di Francia, nel corso della complessa transizione dai Valois ai Borbone: Enrico IV, infatti, si era sposato una prima volta nel 1572 con Margherita di Valois senza avere eredi e il matrimonio era stato annullato dalla Santa Sede nel 1599, l'anno prima delle seconde nozze con Maria de' Medici, da cui era nato il futuro Luigi XIII. Tuttavia, nel caso in cui il papa avesse voluto rivedere la decisione di nullità del primo matrimonio, automaticamente il figlio di Enrico IV sarebbe stato escluso dalla successione al trono, un'eventualità che, ancora nel gennaio 1612, il nunzio Ubaldini ventilava in una lettera indirizzata al cardinale nipote ${ }^{12}$.

6 I problemi rilevati dall'anonimo censore domenicano prima di sottoporre l'opera all'attenzione dei teologi della Sorbona possono essere ridotti a quattro nuclei tematici principali. Il primo riguarda la teologia dei miracoli. Il frate predicatore sottolineava e postillava una serie di espressioni in cui si esaltavano le doti taumaturgiche di Ignazio nel campo dei calcoli renali e sul fronte anti-demoniaco e i suoi miracoli venivano giudicati «mieux qualifiés » e « plus excellents » di quelli di altri santi canonizzati. Per non parlare di quelle riprovevoli digressioni in cui si diceva che una donna aveva visto l'anima di Ignazio ascendere al cielo, « enveloppée d'un globe de feu ardent $»^{13}$.

7 Questo attacco al miracolismo ignaziano riprendeva delle critiche già circolanti a Roma sempre in ambiente domenicano, come si deduce da una denuncia anonima che aveva 
raggiunto il Sant'Uffizio in quegli stessi mesi. L'ignoto autore della delazione sosteneva di non avere mai « veduta cosa di momento maneggiata con maggior arte et conclusa con maggior fretta et riuscita con minor applauso o con maggior mormorazione », che la beatificazione di Ignazio ${ }^{14}$. Ricordava, inoltre, all'assessore del Sant'Uffizio che i gesuiti avevano fatto scomparire tutti gli esemplari della vita del loro fondatore scritta da Pedro de Ribadeneyra, in quanto in essa si negava a Ignazio qualsiasi potere taumaturgico e si affermava che l'unico suo vero miracolo era stato di avere fondato la Compagnia ${ }^{15}$. L'estensore della denuncia, infine, auspicava che Paolo V si rendesse conto « che il modo con che i Padri Gesuiti empiono i libri di miracoli fatti dopo la morte è questo : che van persuadendo a tutti gli infermi che possono o vero alle loro mogli o parenti che facciano il tal et tal voto o si raccomandino al B. Ignatio. Quelli che guariscano (già che in tanto numero bisogna che ne guariscan molti) si scrivono per miracoli del B. Padre con molta solennità di testimoni, fede, etc. Quelli che non guariscano si tacciano. Et chi è che si pigli pensiero d'andarli sapendo?». E che lo stesso stava accadendo con un altro gesuita, il «santo vivo " Bernardino Realino: «Se colui guarisce scribe et fac processum. Quei che stan poi peggio, o si muion, di questi silentium magnum $»^{16}$. L'obiettivo polemico di questa svolta miracolistica era il cardinale Roberto Bellarmino, il quale aveva dichiarato pubblicamente « che da 200 anni in qua non è stato canonizato santo alcuno che habbia fatto maggior miracoli del B. Ignatio », esattamente come era ripreso anche nelle Trois tres-excellentes predications esaminate ${ }^{17}$.

8 Il secondo gruppo di censure di Juan Gallardo era più scontato : i predicatori attribuivano a Ignazio il titolo di santo in diversi luoghi del testo e ciò era considerato illegittimo ${ }^{18}$.Così anche erano cassate tutte quelle espressioni che tendevano a equiparare Ignazio a Gesù Cristo facendolo " Lieutenant general de Iesus-Christ sur terre $»^{19}$.

9 Il terzo nucleo censorio riguardava le parti in cui era esaltata l'eccezionalità dei gesuiti, giudicato un ordine speciale e misterioso. Per Deza essi avevano una "pureté angelique » e vivevano "comme Anges du ciel », studiavano la notte e confessavano di giorno ${ }^{20}$, ed erano i nuovi e degni eredi dei francescani e dei domenicani ${ }^{21}$. La Compagnia, inoltre, era l'ordine più prudente che fosse mai esistito, con uno stile di vita misterioso e affascinante perché «Personne ne sçait ce qu'on mange en leurs refectoirs, personne ne veoid ce qu'on appreste en leurs cuisines [...] $»^{22}$.

10 L'ultimo insieme di interventi concerneva l'orazione mentale e, più in generale, la pratica di comportamenti estremi come l'eremitaggio, la preghiera, la disciplina e i digiuni frequenti. Ad esempio, nel testo si ricordava che Ignazio prendeva tre volte al giorno la disciplina come san Domenico, faceva tutti i giorni sette ore di preghiera vocale in ginocchio, e che i gesuiti compivano «l'exercice des oraisons mentales $»^{23}$. Naturalmente, il lettore-censore domenicano concludeva la sua fatica sottolineando che l'opera aveva ricevuto l'approvazione di Matthieu le Heurt, dottore in Teologia dell'università di Parigi, il quale non aveva trovato nulla di contrario alle « determinations de l'Eglise Catholique Apostolique \& Romaine $»^{24}$. I fatti, però, avrebbero mostrato che la situazione era ben più ingarbugliata di così perché, come denunciato dal nunzio Ubaldini, la Facoltà di Teologia dell'università di Parigi aveva esaminato l'opera e deciso di proibirla.

11 La censura ufficiale della Facoltà di Teologia fu pubblicata in un esemplare bilingue franco-latino nel novembre 1611, un testo interessante giacché offre la possibilità di seguire l'evolversi delle differenti posizioni in seno all'istituzione accademica ${ }^{25}$. Il teologo Jean Filesac presiedette la seduta del $1^{\circ}$ ottobre e dichiarò di avere ricevuto il libro da una persona di cui si taceva il nome. Il collegio deliberò quasi all'unanimità perché André 
Duval risultò essere l'unico oppositore. Tra le innumerevoli correzioni proposte dall'anonimo lettore, i teologi individuarono quattro proposizioni principali. La prima ricorreva in un passo del sermone dell'agostiniano Valderrama, il quale aveva sostenuto che i miracoli di Ignazio erano più numerosi di quelli degli apostoli e anche più efficaci di quelli di Mosè giacché era sufficiente scrivere il nome di Ignazio su una carta per operare grandi meraviglie, senza ulteriori intercessioni ${ }^{26}$. I Sorbonisti avevano sentenziato che preferire dei miracoli incerti a quelli che devono essere tenuti per articoli di fede era "scandaloso, erroneo, blasfemo ed empio ${ }^{27}$. Anche la seconda censura interessava Valderrama, laddove aveva affermato che i costumi di Ignazio in vita erano stati così gravi e santi che nell'opinione celeste soltanto san Pietro, la madre di Dio e suo figlio Gesù avevano avuto « le bien de la veoir $»^{28}$. La sola idea che Dio avesse potuto ricevere qualche «bien» dalla visione di un'altra creatura era giudicata da quel consesso di teologi un'eresia scandalosa e manifesta ${ }^{29}$. La terza censura dei Sorbonisti ricorreva, invece, nella predica del domenicano Deza, il quale, nel ricordare l'ufficio dei fondatori di ordini religiosi, aveva citato un brano della lettera agli Ebrei di San Paolo, sostituendo però al nome di Gesù quello di Ignazio ${ }^{30}$. Anche ciò era valutato "blasfemo ed empio " $^{31}$. La quarta e ultima censura si trovava infine nel sermone del domenicano Rebullosa ${ }^{32}$ : la sua affermazione era in parte cattolica ove dichiarava correttamente che il papa era il vicario di Gesù Cristo in terra, ma conteneva « una forma di parlare eretica » quando sosteneva che il pontefice era il legittimo successore di Gesù̀ ${ }^{33}$.

Come si è detto, la censura della Facoltà di Teologia vide l'affermazione di Jean Filesac e la messa in minoranza di André Duval, un contrasto su un caso specifico che conferma l'esistenza di una visione composita di quel grande fenomeno politico, culturale e religioso che fu il gallicanesimo francese, capace di contenere l'espansione del protestantesimo e di impedirne l'affermazione. Una visione del mondo, è stato giustamente detto ${ }^{34}$, in cui anche il cosiddetto gallicanesimo universitario si presenta pieno di sfumature e di tensioni interne, non meno sfaccettate e plurali di quelle presenti nel gallicanesimo ecclesiastico-episcopale e in quello parlamentare ${ }^{35}$.

Filesac, infatti, promosso dottore della Sorbona nel 1590, ove insegnò teologia fino alla morte nel 1638, era l'esponente di un gallicanesimo universitario moderato, da sempre contrario ai gesuiti e alle tesi del teologo Bellarmino in materia di rapporti tra potestà pontificia e potestà regia ${ }^{36}$. Nel 1605 aveva pubblicato il suo più importante trattato, significativamente intitolato De sacra episcoporum auctoritate, ove spiegava che ogni vescovo nella sua diocesi era il legittimo e ordinario inquisitore della fede e aveva perciò la facoltà di esaminare e condannare i sudditi nell'ambito della propria giurisdizione. Certo, il papa era l'ultimo giudice della fede e dei costumi, ma la sua autorità non era smisurata e non poteva prescindere dalla funzione episcopale sicché Filesac si rifiutava di riconoscere al sovrano pontefice il titolo di episcopus universalis ${ }^{37}$. In ogni caso, pur criticando le prerogative assolutistiche della Santa Sede, egli non era favorevole alle tendenze scismatiche presenti, per quanto in forma minoritaria, nel movimento gallicano universitario e parlamentare.

Ad esempio, le sue posizioni erano ben diverse da quelle del collega Edmond Richer, syndic della Sorbona fino al 1612, che proprio nel 1611 - l'anno della censura dei sermoni su Ignazio - aveva pubblicato il Libellus de ecclesiastica et politica potestate, in cui considerava i re di Francia sovrani di diritto divino, indipendenti sul piano spirituale e temporale dal papa $^{38}$. Richer assumeva una visione aristocratica della struttura ecclesiastica, per la quale al pontefice spettava un primato di onore, ma non teologico, dal momento che 
l'esercizio del potere apparteneva al corpo dei pastori partecipanti al consiglio generale della Chiesa. Tali idee erano radicalmente conciliariste e trovavano il sostegno politico di un ampio milieu parlamentare che si serviva di esse per rafforzare il potere e le prerogative dell'istituzione rispetto al re di Francia, impegnato in una difficile mediazione con Roma, il clero diocesano e i corpi intermedi del regno.

Filesac sostituì nel 1612 Richer nella carica di syndic della Sorbona di cui divenne decano nel 1627. Egli era uno storico avversario dei gesuiti che vedeva come acerrimi nemici sia in campo universitario-accademico, sia sul piano dottrinario, così da impegnarsi a censurare le loro opere, trovando sempre la coerente opposizione di Duval. A partire da quella di Bellarmino circa il diritto del papa di deporre il sovrano eretico, il Tractatus de potestate Summi Pontificis in rebus temporalibus condannato nel novembre 1610, e l'opera De rege et regis institutione di Juan de Mariana, proibita nel giugno dello stesso anno sino all'interdizione del libro di Francisco Suárez Defensio fidei del $1614^{39}$. Ancora nel 1626 Filesac avrebbe svolto un ruolo decisivo nelle campagne contro il Tractatus de haeresi, schismate [...] et de potestate Romani pontificis in his delictis puniendis del gesuita Antonio Santarelli, in cui per la prima volta la Facoltà di Teologia dell'Università di Parigi adottò ufficialmente la tesi della indipendenza assoluta del re in rapporto al papa in materia temporale, anche in questo caso avendo come avversario Duval ${ }^{40}$.

16 L'opposizione di Duval alla censura dell'agiografia ignaziana del 1609 non deve sorprendere perché si tratta di un'interessante personalità in grado di incarnare con il proprio percorso biografico (si pensi solo all'intensità delle sue relazioni prima con Enrico IV e poi con il cardinale Richelieu) non soltanto la ricchezza ideale del gallicanesimo transalpino, bensì anche la cifra degli equilibri tra questo e la corona di Francia e il ruolo di mediazione svolto da Roma ${ }^{41}$. Duval era un prete secolare, considerato uno dei migliori direttori di coscienza di Parigi e su questo terreno incontrò $i$ gesuiti, di cui fu strenuo difensore prima, durante e dopo il periodo del loro allontanamento dalla Francia dal 1594 al $1604^{42}$, una battaglia che condusse di pari passo con la difesa dell'autorità papale contro le tendenze regaliste più intransigenti del fronte gallicano.

Duval ebbe relazioni con François de Sales, Vincent de Paul e con la fondatrice delle Visitandine Jeanne de Chantal e fu consigliere teologico della cosiddetta école abstraicte, riunitasi intorno al cappuccino Benedetto da Canfield, e animata da una spiritualità profondamente influenzata dalla mistica renano-fiamminga ${ }^{43}$. Inoltre, promosse l'introduzione della riforma carmelitana in Francia consigliando e aiutando suor Marie de l'Incarnation (Barbe Acarie), della quale scrisse l'agiografia nel $1621^{44}$. Su consiglio del cardinale Jacques du Perron, Enrico IV nominò Duval nel 1597 a una delle due cattedre di teologia dell'Università di Parigi da lui istituite. Duval ebbe stretti rapporti con il nunzio Maffeo Barberini, il futuro Urbano VIII, e si oppose, a partire dal 1606, alle tesi del gallicanesimo intransigente di Richer, in questo condividendo la battaglia con l'episcopalista Filesac. All'opera di Richer del 1611 anche Duval come Filesac fece seguire l'anno successivo un Elenchus pro suprema romani pontificis in Ecclesiam potestate e il De suprema romani pontificis in Ecclesiam potestate dissertatio quadripartita nel 1614. Ciò nonostante, nel 1609, i due si trovarono divisi in occasione della condanna dell'agiografia di Ignazio di Loyola qui esaminata, a dimostrazione che la posizione centrista dentro il gallicanesimo universitario fosse, in questa circostanza, quella di Filesac (antigesuitica, ma antiscismatica, filoepiscopale, critica delle prerogative romane), mentre le due ali estreme e opposte venissero occupate dal regalista Richer e dal filo-romano e filo- 
gesuitico Duval. Costui, negli anni successivi e grazie al cosiddetto « duvalisme », riuscì a stemperare le posizioni più estreme del fronte ultramontano e di quello gallicano, così da diventare l'autentico interprete della politica regia grazie alla speciale collaborazione con il cardinale Richelieu ${ }^{45}$.

L'altro protagonista di questa vicenda editoriale, finora rimasto sullo sfondo, fu il gesuita François Solier, il traduttore dell'opera incriminata. Egli era maestro di novizi, insegnante di retorica e dal 1608 al 1611 visse a Poitiers, ove vennero pubblicati i tre sermoni. Si impegnò attivamente nella fondazione del collegio gesuitico di Saintes di cui divenne anche padre spirituale e rettore. Solier, nel corso della sua vita, svolse una funzione oscura, ma non secondaria di mediatore culturale tra Francia, Spagna e Italia traducendo opere importanti della spiritualità gesuitica come il De Oracion mental di Francisco Arias, le agiografie di Francisco Borja e di Diego Laínez di Pedro de Ribadeneyra e il Trattato dell'angelo custode di Francesco Albertini ${ }^{46}$. Solier reagì immediatamente alla censura del libro da parte della Facoltà di Teologia dell'Università di Parigi e già il 9 ottobre 1611 si produsse in una polemica Lettre iustificative à sien $a m y^{47}$. Un'apologia che qualche bibliografia, come già sottolineava Carlos Sommervogel, ha attribuito senza motivo al più noto gesuita Gaspar de Seguiran, confessore di Luigi XIII ${ }^{48}$.

19 Nella lettera il gesuita ripercorreva le quattro "pierres d'achoppement » sollevate dai Sorbonisti dimostrando come, a suo giudizio, in ognuna di esse gli autori delle prediche avessero voluto usare un linguaggio popolare, tipico del genere declamatorio dei sermoni (dimostrativo ed encomiastico), ove facilmente potevano esserci delle amplificazioni che invece non ricorrevano nel genere deliberativo o giudiziario. Inoltre, faceva notare che se si fossero condannati quei passi si sarebbero dovute proibire tutte " les Anthopopathies » presenti sovente nelle Sacre scritture, ossia quei procedimenti retorici che attribuivano a Dio passioni, sensazioni e affetti umani. Anche nel caso della sostituzione del nome di Gesù con quello di Ignazio nella epistola paolina vi erano precedenti illustri come quello di Luis de Granada che aveva inserito il nome di san Domenico.

20 Solier fingeva con il suo anonimo interlocutore di non avere ancora letto il decreto della Facoltà di Teologia che pure gli era stata inviato, un espediente probabilmente necessario per evitare di rispondere in maniera diretta alla quarta censura, quella che aveva il profilo dottrinario più imbarazzante. Secondo il gesuita, Deza aveva scritto che l'ordine di San Francesco aveva compiuto dei miracoli nell'ambito della povertà volontaria, ma il passo incriminato per i censori era un altro, più precisamente quello dell'altro domenicano Rebullosa, laddove si dichiarava che il papa fosse il diretto successore di Gesù. Quella di Solier era stata dunque una svista interessata, già denunciata come tale nel 1615 dal Mercure François ${ }^{49}$.

21 La parte più interessante della risposta del gesuita era la seconda : censurare il testo di tre dottori e predicatori fra i più noti nella penisola iberica avrebbe voluto dire introdurre in Francia un'inquisizione più rigorosa di quella spagnola, ma anche del Sant'Uffizio romano dal momento che i tre sermoni circolavano liberamente nei due paesi cattolici senza che il maestro del Sacro Palazzo o l'Inquisizione romana avessero trovato qualcosa da ridire ${ }^{50}$. Inoltre, i Sorbonisti con la loro azione avrebbero fatto il gioco degli ugonotti che già gongolavano per quell'umiliante censura e avrebbero criticato indirettamente il papa che aveva beatificato una personalità come Ignazio, evidentemente poco stimata dalla Facoltà di Teologia di Parigi ${ }^{51}$. In realtà, secondo Solier, la vera questione in gioco era un'altra : con quell'azione la Facoltà di Teologia stava provando ad ampliare la sua giurisdizione per impedire che i gesuiti rientrassero in possesso del collegio di Clermont, l'attuale Louis 
le Grand, una vicenda in cui " on a procedé avec plus de passion que de raison». Al termine della sua lettera il gesuita diventava sferzante, sottolineando come quella vicenda avrebbe confermato il detto delle altre nazioni: Decreta Sorbonae non traseunt Sequanam, ossia i «Decreti della Sorbona non oltrepassano la Senna "; l'effetto, però, sarebbe stato doppiamente controproducente in quanto la censura avrebbe dato un'incredibile pubblicità a quei sermoni, che sarebbero stati riconosciuti oltre i loro meriti52.

L'insolenza della risposta di Solier ebbe il prevedibile effetto di eccitare vieppiù gli animi dei Sorbonisti e di coinvolgere nella querelle anche Roma attraverso i normali canali diplomatici affidati al nunzio Ubaldini. Per questa ragione l'affaire può essere seguita anche grazie al suo epistolario, una fonte preziosa poiché è in grado di conciliare la storia delle idee con quella delle pratiche politiche concrete. L'11 ottobre 1611 il nunzio scriveva al cardinale Borghese informandolo che la vicenda aveva l'obiettivo di «far perdere la devotione del Beato e discreditare i gesuiti contro i quali si vede che cresce ogni giorno l'animosità di questa Sorbona ${ }^{53}$. Il presidente della Sorbona aveva fatto ogni sforzo per prevenire lo scandalo ordinando al sindyc Richer « che in ciò non innovasse cosa alcuna ", ma i gesuiti avevano sottovalutato il negozio « in modo che non avvisarono i loro amici, $\mathrm{i}$ quali se si fossero trovati alla Congregatione forse non sarebbe successa la censura ", che perciò si sarebbe potuta evitare. Richer, come si ricorderà membro del fronte gallicano più intransigente, aveva deciso di non esporsi direttamente e aveva fatto proporre la censura al più moderato Filesac, ma il primo presidente comunque se ne era « mostr[ato] molto offeso ».

Il domenicano Juan Gallardo si era recato dall'auditore del nunzio orgoglioso del successo ottenuto sostenendo di volere «far bruciare il libro per arresto del Parlamento » ed era convinto di riuscirvi grazie all'intervento dell'avvocato regio Louis Servin. Quel Servin, capofila dei «politiques » in Parlamento, che pur professandosi buon cattolico - secondo quanto scriveva Ubaldini in una lettera del 27 dicembre 1610 - era fra quanti avevano l'obiettivo di separare il reame di Francia dalla Santa Sede ${ }^{54}$. L'auditore del nunzio, perciò, rimproverò Gallardo per non avere sottoposto i sermoni alla censura preventiva del Sant'Uffizio di Roma e "gli proibì di ricorrere al suddetto Parlamento, si come egli promise di astenersene da Parigi $»^{55}$.

L'8 novembre 1611, Ubaldini affermò che, nonostante gli «offiti interposti» con i principali ministri e teologi della Sorbona, non aveva potuto impedire « la confirmatione della censura dei tre sermoni $»^{56}$. Il danno era grave poiché si proibiva in Francia ciò che era stato concesso in Spagna e in Italia « quasi che nei suddetti luoghi, si proceda troppo trascuratamente in questa materia, e s'approvi per buono e pio quello che questa Facoltà asserisce empio et heretico, onde apparisca che anco tra i cattolici siano diversità d'opinioni in quello che riguarda la fede ». Il nunzio temeva anche che le università di Spagna potessero reagire alla censura con una loro apologia contro la Sorbona « la quale non tacendo aprirà le porte a uno scisma tra quelle università e queste ». Per queste ragioni il nunzio avrebbe provato ad affidare il negozio direttamente a Paolo V in modo che tutto fosse riferito " all'infallibilità della decisione di cotesta Santa Sede ».

Tuttavia, la mediazione del nunzio fallì a causa della lettera giustificativa di Solier che ebbe l'effetto di rafforzare i fronti contrapposti, risultando a tutti che i gesuiti « siano stati troppo arditi nella suddetta lettera et habbino troppo sensibilmente piccata questa facoltà $~^{57}$. Il nunzio prometteva di recuperare per l'avvenire alla causa dei gesuiti alcuni 
esponenti della Facoltà di Teologia, ma certo quei padri in futuro avrebbero dovuto "governarsi come conviene $»^{58}$.

Ubaldini così facendo anticipava il consiglio che sarebbe giunto da Roma il 7 dicembre che infatti approvava la sua prudente condotta : « tutti i mali che V.S. prevede poter nascere dalla censura dei 3 sermoni in Spagna de Beato Ignatio et dalle riposte sono da temer grandemente onde si deve procurare d'impedirli per tutte le vie et mezzi ». Nel frattempo a Roma si erano avvertiti i padri gesuiti «ad essere meno vehementi, et più communicativi dei loro pensieri prima che porli in essecutione $»^{59}$.

Ancora il 23 novembre 1611 la censura non era stata stampata né iscritta presso i registri della facoltà e, per evitare che in Spagna sorgessero querele, il nunzio sensibilizzò alla causa anche l'ambasciatore iberico. Gli sembrava ormai chiaro che il collegio dei teologi aveva "proceduto troppo precipitosamente contro il solito della facoltà che in simile materie suole voler udire gli interessati il che si havessero fatto non ho dubbio che i padri Gesuiti gli haveriano data compita soddisfatione $»^{60}$. La censura non poteva " essere più grave perché qualifica i 4 punti contenuti in essa come empii, scandalosi, heretici e blasphemi in che credo che la facoltà abbi ecceduto i termini de loro pretesi privilegi papali in materia di censurar libri ». Poi a esacerbare gli animi c'era stata la reazione dei gesuiti che «si sono risentiti troppo [...] mordacemente con la loro lettera giustificatoria ». Senza la missiva di Solier - chiosava il nunzio - «sarebbe stato più facile impedire la confirmatione della censura con l'autorità di detti ministri che offesi anch'essi da detta lettera, non la volsero interporre ${ }^{61}$. Anche il nunzio, come Solier, rivelava quale fosse il vero oggetto del contendere : il generale della Compagnia di Gesù avrebbe dovuto comandare ai suoi padri francesi di impedire che qualcuno scrivesse e offendesse come aveva fatto il gesuita, «e massime questo corpo della facoltà, la quale s'attacca sopra ogni minimo soggetto, per impedirgli la giusta pretensione che essi hanno di rimettere qui il collegio », ossia rientrare a Clermont ${ }^{62}$.

Il 7 dicembre 1611 il nunzio comunicava al cardinale Borghese la brutta notizia: nonostante gli avessero garantito che la censura non sarebbe stata pubblicata né registrata, purtroppo da due giorni ne circolavano per Parigi molti esemplari, fra cui quello qui analizzato ${ }^{63}$. Un'altra edizione di questo testo venne stampata nel 1612 in almeno tre occasioni ${ }^{64}$. Secondo Ubaldini sia il primo ministro sia il cancelliere della Sorbona avevano finto di credere che la copia pubblicata fosse uscita di straforo contro la volontà degli stessi dottori, ma con questo pretesto si erano astenuti «dal farne rimuovere con i capi d'essa che senza dubbio, ne sono gli autori, come potrebbero o doverebbero risolutissimi di non disgustare la detta Facoltà per i fini molto ben noti a V.S.Ill.ma », ossia quelli relativi al collegio di Clermont ${ }^{65}$. In effetti, il 2 dicembre 1611, tutto il corpo dell'università aveva presentato un ricorso al Parlamento contro i gesuiti che « contro la forma della loro remissione in Parigi» del 1603 avevano continuato ad avere in quel collegio classi di grammatica e di umanità a convittori e pensionari, che, facendo concorrenza all'università, andavano scacciati ${ }^{66}$. Il nunzio aveva parlato anche con la reggente Maria de' Medici affinché si impedissero « le declamazioni contro i padri nel Parlamento » ricordandogli quanto per la « quiete del Regno » fosse decisivo il ruolo della Compagnia di Gesù, la quale essendo «in grandissima stima e credito non passerebbe senza pericolo di seditione qualsivoglia risolutione che si pigliasse contro di loro », soprattutto perché il regime adottato era in vigore dai tempi di Enrico IV « con saputa e tolleranza sua ». 

icembre 1611 si svolsero nel Parlamento le discussioni tra gli avvocati delle part sulla questione se incorporare la Compagnia di Gesù nella Facoltà di teologia. L'avvocato dell'università parlò a lungo facendo "un riassunto di tutte le calunnie, ingiurie e impronture proferite dai Gesuiti $~^{67}$, fra cui quella di avere causato la morte dei due ultimi re di Francia, un argomento ripreso pure dall'avvocato regio Servin nella seduta del 3 gennaio 1612. Anche il rettore dell'università " punse quanto più si può la compagnia [...]» e concluse: «che se piaceva al Parlamento d'incorporare la Compagnia nell'università, gli pareva che si potesse fare, a condizione però che i Padri dichiarassero qual si sia la loro dottrina sopra queste questioni : se il papa stia sotto o sopra il concilio, se habbia alcun potere diretto o indiretto nel temporale dei principi; se la confessione sacramentale si deve o possi rilevare dove si tratta della vita d'un Principe, e se i chierici sono esenti o sottoposti a i principi e ai suoi ministri secolari ». Ovviamente, i gesuiti dovevano, fra le altre cose, rigettare la dottrina del regicidio, iniziare a scrivere contro di essa, denunciare le future cospirazioni contro il sovrano e insegnare che il re di Francia nelle cose temporali non riconosceva altro superiore che Dio onnipotente, tanto che nessuna potenza né autorità avrebbe mai potuto sospendere o privare il re del suo reame né sciogliere i sudditi del sovrano dal giuramento di fedeltà e obbedienza che gli era dovuto « par toute sorte de droits divins, naturels, et humains». Alcuni gesuiti avrebbero voluto pronunciare una dichiarazione che accoglieva questi aspetti, fissati nel decreto del 22 dicembre 1611, ma il nunzio Ubaldini li sconsigliò « perché non era conveniente in modo alcuno che una Religione andasse avanti Tribunale de giudici secolari » e quindi propose loro di differire la questione dichiarando "che credono nei suddetti articoli quello che ne crede il comun consenso della Chiesa cattolica ».

Nella seduta del 3 gennaio 1612 i gesuiti si acconciarono al consiglio del nunzio promettendo solennemente che «in quello che non è fede e contra bonos mores, la Compagnia non insegnerebbe altrimenti di quello che insegna la Sorbona, conforme alla loro Costitutione che è sotto la regola terza dei professi di Theologia $»^{68}$. La Compagnia con queste parole accettava la sottomissione al Parlamento, ma riusciva a evitare che la Facoltà di Teologia deliberasse in merito dando così veste dottrinaria definitiva a quel pronunciamento politico. Un risultato interlocutorio che segnò la momentanea sconfitta delle tesi di Duval - favorevole anche in questo dibattito alle posizioni dei gesuiti - ma anche del rigorista Richer, da lì a poco costretto da Luigi XIII ad abbandonare la carica di sindyc della Sorbona in favore proprio del mediatore Filesac, l'accorto protagonista anche della censura dell'agiografia di Ignazio da cui abbiamo preso le mosse.

31 L'occhio del nunzio consente di capire che in quel torno di mesi, dall'ottobre 1611 al gennaio 1612 , la questione agiografica dei miracoli di Ignazio e le dispute teologiche intorno a essi nascondevano ben altri conflitti e campi di interessi contrapposti nel concreto mondo dell'insegnamento universitario, della formazione della classe dirigente francese e dei rapporti tra Parlamento, reame e gesuiti, in un contesto storico necessariamente inasprito all'indomani dell'assassinio di Enrico IV. Quando ormai i giochi erano fatti sarebbe arrivato anche il parere del Sant'Uffizio di Roma che il 4 gennaio 1612 si limitò a prendere atto della censura della Facoltà di Teologia ai sermoni di Ignazio, in una riunione a cui parteciparono, tra gli altri, i cardinali Bellarmino e François de la Rochefoucauld, antico protettore di Duval ${ }^{69}$.

32 L'imbarazzante vicenda sarebbe stata sepolta per secoli dentro i dissimulanti armadi dell'erudizione ecclesiastica della Controriforma, se Pierre Bayle non fosse stato l'unico a riprenderla nel suo Dictionnaire historique et critique del $1695^{70}$ : solo l'inquieta anima 
scettica di un ugonotto, convertitosi al cattolicesimo, poi ritornato al calvinismo ed educato dai gesuiti avrebbe avuto la sufficiente sensibilità per interessarsi a tali censure sommerse in grado di corrodere i margini dei processi di confessionalizzazione in atto senza però riuscire a mutare il corso del grande alveo della storia religiosa europea che avrebbe portato nel 1622 Ignazio di Loyola all'onore degli altari. Non a caso nelle pagine di Bayle ricorreva il nome di uno dei più puntuti esponenti dei politiques francesi, quello dell'umanista Étienne Pasquier, autore nel 1602 di Le Catéchisme des Iesuites. In quest'opera egli aveva predetto che gli artifici adottati dai gesuiti per fare canonizzare il loro fondatore non sarebbero riusciti tanto facilmente. Pasquier aveva colto l'occasione del processo di santità in onore del fondatore dei gesuiti per raccontare come «les Papelards », con la loro setta della «Papelardie », si fossero insinuati in Francia grazie al «Machiavelisme d'Ignace pour donner vogue à la Secte» e per ribadire come la Chiesa gallicana e i gesuiti fossero incompatibili in quanto quei padri erano comparabili ai luterani ${ }^{71}$.

Aveva quindi buon gioco Bayle a ironizzare su queste infiammate parole di Pasquier del 1602 spiegando che la beatificazione di Ignazio del 1609 aveva certamente raddoppiato il suo "chagrin", ossia dispiacere. Bayle infatti non concepiva "più rude mortificazione che quella di vedere beatificato un uomo di cui si è detto tanto male» in vita ${ }^{72}$. "Ciò avrebbe dovuto rendere più circospetti gli autori critici. Io attacco un uomo, dovrebbero loro pensare, che un giorno potrebbe essere messo fra le litanie prima della mia morte [...] Ma rispetto alla censura e alla critica uno non è al riparo neppure se attende la morte di qualcuno; verrà forse un papa che metterà nel numero dei santi colui che aveva maltrattato e vi dirà di raccomandarvi all'intercessione della persona che avete offeso ». Un'eventualità che il pungente sarcasmo di Bayle giudicava terribile giacché rassomigliava a quei decreti del Parlamento che ti costringevano « à épouser la meme fille qu'on avoit deshonorée ».

Sullo sfondo di queste tensioni si intravedeva la sottile trama che negli anni successivi avrebbe portato a una nuova pacificazione tra i gesuiti e la corte di Francia, manifestatasi, ad esempio, in occasione della riapertura nel 1619 del collegio di Clermont e soprattutto con la canonizzazione di Ignazio di Loyola nel 1622. In quella circostanza Luigi XIII svolse un ruolo di pressione determinante grazie a un canale preferenziale di comunicazione instauratosi in funzione anti-spagnola tra il ramo italiano dell'ordine, guidato dal cardinale Bellarmino, quello francese e i porporati del partito transalpino presenti in curia $^{73}$. A prevalere sarebbero stati i processi di costruzione delle Chiese nazionali (non necessariamente di Stato) in Francia come in Italia e, dunque, gli accordi pattuiti sul filo della ragion di Stato fra sovrani. Un processo in cui il gallicanesimo francese, in tutta la sua multiforme complessità e varietà di posizioni, avrebbe costituito un elemento importante nella storia della formazione della coscienza nazionale transalpina. A un critico acuto di quei processi come Bayle sarebbe rimasto il gusto dell'erudizione e la pratica spassionata della ricerca storica, a noi oggi la certezza che in quel giorno di ottobre del 1611, nelle stanze della Facoltà di teologia dell'Università di Parigi, non si discusse soltanto dei miracoli di Ignazio, ma di molto altro ancora perché, anche fra quelle austere mura, pulsava il cuore della storia d'Europa al ritmo dei suoi « cattolicesimi al plurale ». 


\section{NOTE}

1. Ubaldini a Borghese, Parigi 11 ottobre 1611, in Biblioteca Nazionale di Francia di Parigi, da ora in poi BNF, fondo italiano ms. 1200, Lettres tirées des Registres de la Nonciature d'Ubaldini depuis 1608 jusques à 1616 touchant la doctrine et les sentiments du Royaume, fol. 96v-97r. Alla lettera rispose il segretario di Scipione Borghese, Porfirio Feliciani, l'8 novembre 1611, in Biblioteca Angelica di Roma, da ora in poi BA, mss 1215, Registro di Lettere scritte del secretaro Porfirio Feliciani a mons. Vescovo di Montepulciano Nunzio del papa in Francia negli anni 1609,1610 e 1611, fol. 292v.

2. Su questa fase, con particolare attenzione ai rapporti tra gesuiti e autorità monarchica, si veda E. Nelson, Jesuits and the Monarchy. Catholic Reform and Political Authority in France (1590-1615), Hampshire-Burlington-Roma, 2005, p. 11-56 e 147-209, J.-C. Dhôtel, Histoire des jésuites en France, Paris, 1991, p. 23-28 e C. Sutto, Henry IV et les Jésuites, in Renaissance and Reformation/Renaissance et Réforme, 17, n. 4, 1993, p. 17-24, ma anche P. Blet, Jésuites et libertés gallicanes en 1611, in Archivum historicum societatis Jesu, 24, 1955, p. 165-188.

3. Trois tres-excellentes predications prononcees au iour et feste de la Beatification du glorieux patriarche le Bien-heureux Ignace fondateur de la Compagnie de Jésus. par Le Reverend Pere et Docteur Pierre de Valderame, Prieur du Couvent de Sainct Augustin de Seville. Le Reverend P. et Docteur F. Pierre Deza de l'ordre S. Dominique, au Couvent de Valence. Le R. P. Presenté F. Iacques Rebullosa du mesme Ordre S. Dominique, et la cité de Barcellonne. Le tout nouvellement traduict par le P. François Solier Religieux de la Compagnie de Iesus, Poictiers, par Antoine Mesnier Imprimeur \& Libraire ordinaire du Roy en l'Université, 1611 (BNF, D-53936).

4. Biblioteca Nazionale di Spagna di Madrid, da ora in poi BNS, Sermon que predicó el F. Pedro de Valderrama [...] en la fiesta de la Beatificacion del Glorioso Patriarcha San Ignacio Fundador de la Compañia de Iesvs, Sevilla, Luis Estupiñan, 1610. Ma anche con postille di lettura ai margini, BNS, Sermon que predico el muy reuerendo padre M.F. Pedro Deça, de la Sagrada Religion de Predicadores, en las fiestas que se celebraron en la yglesia de la [...] Cōpañia de Iesus, de [...] Valencia a 24, 25 y 26 de Enero del Año 1610, por la Beatificacion del [...] Padre Ignacio de Loyola [...], impresso a deuocion del Doctor Iuan Baptista Guardiola.

5. Predica del M. R. P. maestro F. Pietro di Valderrama Prior del Convento di Sant'Agostino di Seviglia, predicata nella festa della beatificazione del glorioso patriarca Ignatio fondatore dell'inclito ordine della Compagnia di Giesu dedicata dall'autore ai Padri di quella. Et tradotta di Spagnuolo in italiano, Milano, appresso Girolamo Bordoni, 1610 (conservato nella Biblioteca Bertoliana di Vicenza). L'altro esemplare conosciuto si trova presso la Biblioteca Trivulziana di Milano, Jayme Rebullosa, Predica del molto r. Padre presentato f. Giayme Rebullosa dell'Ordine di san Domenico predicata nella chiesa di Betleem della Compagnia di Giesu nella citta di Barcellona la domenica quarta dello Advento 1609 [...] tradotta di spagnolo in italiano con una relatione delle allegrezze fatte in Lisbona in simile occasione, Milano, per l'her. di Pacifico Pontio \& Gio. Battista Piccaglia, stampatori della Corte archiepiscopale, 1610.

6. Tres eximie conciones in solemni festo Canonisationis, sive beatificationis, gloriosi Patriarchae Beati Ignatii [...] Petrum de Valderama [...] Petrum Dezam [...] Jacobum Rebulosam [...], excusae Pictavii per Antonium Mesnierum impressorem et Bibliopolam ordinarium Regium, Academiae Pict., 1611. 
7. L'edizione si intitola Teatro de los mayores principes del mundo y causa de las grandezas de sus Estados, Barcelona 1605. Su Rebullosa si veda Enciclopedia universal ilustrada europeoamericana, XLIX, Madrid, 1958, p. 1124.

8. J. Quétif, J. Echard, Scriptores ordinis praedicatorum recensiti, notisque historicis et critici illustrati, II, Lutetiae Parisiorum, J.B.Christophorum Ballard Christianissimi Regis Monotypographum \& c. via Sancti Joannis-Bellovacensis sub signo Montis Parnassi et Nicolaum Simart Serenissimi Delphini Typographum via Iacobea sub signo Delphini Coronati, 1721, p. 375a.

9. Per un profilo biografico del frate agostiniano si rinvia all'Enciclopedia universal ilustrada europeo-americana, LXVI, Madrid, 1929, p. 492.

10. L'esemplare senza segni censori si trova in BNF, 8-00-416.

11. Sull'assassinio del re, con un'attenzione specifica al ruolo svolto dai gesuiti nella diffusione del pensiero politico sul tirannicidio, è ancora valido R. Mousnier, L'assassinat d'Henri IV. 14 mai 1610, Paris, 2008 (I ed. 1964), p. 63-110 e 229-250.

12. Lettera di Ubaldini a Borghese, Parigi, 3 gennaio 1612 : « e quel che è peggio che hoggi sia libero agl'ugonotti o a' cattivi cattolici et a chi desidera romori o turbolenze in questo Regno, di appellare ad futurum concilium dalla dichiaratione di nullità et dissolutione del putativo matrimonio del re defunto con la regina Margarita et così da mettere in controversia la legitimità del Re d'hoggi e la reggenza della Regina » (riportato da P. Blet, Jésuites et libertés gallicanes en 1611, cit., p. 180).

13. Trois tres-excellentes predications... cit., p. 50, 57 e 88-89.

14. Archivio segreto Vaticano, da ora in poi ASV, Fondo Borghese, serie II, n. 28, fol. $112 \mathrm{r}-115 \mathrm{v}$, da cui sono tratte anche le successive citazioni.

15. Ho approfondito la questione nel mio Hagiografía y censura libraria: la vida de Ignacio de Loyola de Pedro de Ribadeneyra entre corte de reyes y obediencia romana, in J. Martínez MillánH. Pizarro Llorente, E. Jiménez Pablo (a cura di), Los jesuitas: Religión, política y educación (siglos XVI-XVIII), Congreso Internacional de la Red «The Court Studies», Madrid, 20-22 de junio de 2011, Madrid, 2012, p. 1007-1028. Sull'elaborazione dell'immagine agiografica di Ignazio nei primi decenni di vita della Compagnia di Gesù si veda anche G. Mongini, Censura e identità nella prima storiografia gesuitica (1547-1572), in M. Firpo (dir.), Nunc alia tempora, alii mores. Storici e storia in età postridentina. Atti del Convegno internazionale, Torino, 24-27 settembre 2003, Firenze, 2005, p. 169-188.

16. Sul riconoscimento dei poteri taumaturgici di Bernardino Realino e l'avvio della sua procedura di canonizzazione quando il sacerdote era ancora in vita si rinvia a J.M. Sallmann, Santi barocchi. Modelli di santità, pratiche devozionali e comportamenti religiosi nel Regno di Napoli dal 1540 al 1750, Lecce, 1996, p. 203-209, M. Spedicato, La lupa sotto il pallio: religione e politica a Lecce in antico regime (secc. XVI-XIX), Roma-Bari, 1996, p. 84 e G. Sodano, Promozione dei culti e processi di canonizzazione nel Regno di Napoli nell'età moderna, in B. Pellegrino (dir.), Ordini religiosi, santi e culti tra Europa, Mediterraneo e Nuovo Mondo (secoli XV-XVII), I, Galatina, 2009, p. 278-279.

17. La frase attribuita a Bellarmino è ricordata in ASV, Fondo Borghese, serie II, n. 28, ff. 113v, e viene riportata anche in Trois tres-excellentes predications... cit., p. 50, senza però fare il nome del cardinale gesuita.

18. Ivi, p. $48,108,129$, 134. Sul tema, affrontato negli stessi anni anche a Roma, si rinvia al mio libro I beati del papa. Santità, inquisizione e obbedienza in età moderna, Firenze, 2002, p. 57-64 e 156-170. 
19. Trois tres-excellentes predications... cit., p. 4, 23.

20. Ivi, p. 122, 129.

21. Ivi, p. 135.

22. Ivi, p. 145, 148.

23. Ivi, p. $125,141,143,165,167-168,171,189-191$.

24. Si veda ivi, l'Approbation finale dell'opera anch'essa sottolineata dal censore.

25. Censura Sacrae Facultatis Theologiae Parisiensis adversus quatuor propositiones exceptas ex libro ita inscripto, BNF, fond français ms 22087, Librairie libelles diffamatoires et livres prohibés 1413-1680, fol. 98r-100v. Il testo mi è stato segnalato da Gigliola Fragnito che ringrazio.

26. La prima proposizione si trova in Trois tres-excellentes predications... cit., p. 54-55 e 151.

27. Censura Sacrae Facultatis Theologiae Parisiensis... cit., fol. 100v.

28. La seconda frase censurata è in Trois tres-excellentes predications... cit., p. 91.

29. Censura Sacrae Facultatis Theologiae Parisiensis... cit., fol. 100v.

30. Il terzo passo incriminato è in Trois tres-excellentes predications... cit., p. 112.

31. Censura Sacrae Facultatis Theologiae Parisiensis... cit., fol. 100v.

32. L'ultimo brano da censurare è in Trois tres-excellentes predications... cit., p. 207.

33. Censura Sacrae Facultatis Theologiae Parisiensis... cit., fol. 100v.

34. A. Tallon, Conscience nationale et sentiment religieux en France aux $\mathrm{XVI}^{\mathrm{e}}$ siècle. Essai sur la vision gallicane du monde, Paris, 2002, p. 1-24.

35. Sulle tensioni presenti all'università di Parigi in questi anni si veda il terzo capitolo dell'opera di C. Jourdain, Histoire de l'Université de Paris au XVII et au XVIII ${ }^{\mathrm{e}}$ siècle, I, Paris, 1888, p. 96-136. Per le resistenze al potere regio presenti nella Facoltà di teologia in questa fase cfr. A. Tuilier, Histoire de l'Université de Paris et de la Sorbonne. I. Des origines à Richelieu, Paris, 1994, p. 405-432. Sul gallicanesimo universitario, per il periodo successivo, si rimanda a J.M.Gres-Gayer, Le Gallicanisme de Sorbonne. Chroniques de la Faculté de Théologie de Paris (1657-1688), Paris, 2002.

36. Si consulti il profilo bio-bibliografico tracciato da J. Lecler, Dictionnaire d'histoire et de géographie ecclésiastiques, IV, Paris, 1956, col. 1278-1279.

37. Sul punto cfr. A.-G. Martimort, Le gallicanisme de Bossuet, Paris, 1954, p. 19.

38. Si veda su quest'opera e il suo autore C. Sutto, Tradition et innovation, réalisme et utopie: l'idée Gallicane à la fin du XVI et au début du XVII ${ }^{\mathrm{e}}$ siècle, in Renaissance and Reformation/ Renaissance et Réforme, 8, 1984, p. 278-297. Ancora utile E. Puyol, Edmond Richer. Étude historique et critique sur la rénovation du gallicanisme au commencement du XVII siècle, I e II, Paris, 1876.

39. Su tali condanne e il pensiero politico gesuita in materia di tirannicidio cfr. ora H. Höpfl, Jesuit Political Thought. The Society of Jesus and the State, c. 1540-1630, Cambridge, 2004, p. 321 e s.

40. Sull'affaire Santarelli si veda V. Martin. Le gallicanisme politique et le clergé de France, Paris, 1929, p. 163-244 e ora S. De Franceschi, La genèse française du catholicisme d'État et son aboutissement au début du ministériat de Richelieu: les catholiques zélés à l'épreuve de l'affaire Santarelli et la clotûre de la controverse autour du pouvoir pontifical au temporel (1626-1627), in Annuaire-bulletin de la Société de l'histoire de France, 2001, p. 19-63. 
41. Per questa personalità si rimanda al profilo delineato da L. Cognet, Dictionnaire d'histoire et de géographie ecclésiastiques, XIV, Paris, 1960, col. 1213-1216. Si veda ora S. De Franceschi, Gallicanisme, antirichérisme et reconnaissance de la romanité ecclésiale : la dispute entre le cardinal Bellarmin et le théologien André Duval (1614), in Papes, princes et savants dans l'Europe moderne. Mélanges à la mémoire de Bruno Neveu, réunis par J.-L. Quantin et J.C. Waquet, Genève, 2007, p. 97-121.

42. Sul processo ai gesuiti del 12 luglio 1594 intentato dall'Università di Parigi si rinvia a M. De Waele, Pour la sauvegarde du roi et du royaume. L'expulsion des Jésuites de France à la fin des guerres de religion, in Canadian Journal of History/Annales Canadiennes d'histoire, 29, n. 2, 1994, p. 267-280. Si veda anche V. Martin, La reprise des relations diplomatiques entre la France et le Saint-Siège en 1595, in Revue des sciences religieuses, I, 1921, p. 338-384 e 2, 1922, p. 233-270 e B. Barbiche, Le bannissement et le rappel des Jésuites (1594-1603), in Henry IV et les Jésuites. Actes de la journée d'études universitaires organisée le samedi 18 octobre 2003 à la Flèche, La Flèche, 2004, p. 27-37. Sulle relazioni tra Enrico IV e il papato dopo la riconciliazione cfr. A. Tallon, Henry IV and the Papacy after the League, in A. Forrestal-E. Nelson (dir.), Politics and Religion in Early Bourbon France, U.K.-U.S.A, 2009, p. 21-39.

43. Sul mistico cappuccino si rinvia a O. de Veghel, Benoit de Canfield (1562-1610). Sa vie, sa doctrine, son influence, Roma 1949. Per la «mistica riformata » si veda M. de Certeau, Crise sociale et réformisme spirituel au début du XVII siècle. Une «Novelle spiritualité» chez les Jésuites français, in Revue d'Ascétique et de mystique, 41, 1965, p. 339-386. Sul «modello renanofiammingo ", contrapposto a quello "aristotelico-tomista " e sulla sua ricezione in Francia ai tempi di François de Sales si veda M. Bergamo, L'anatomia dell'anima. Da François de Sales a Fénelon, Bologna, 1991, p. 52-141. Per i rapporti con la coeva spiritualità italiana, in particolare gesuitica e francescana, cfr. A. Malena, L'eresia dei perfetti. Inquisizione romana ed esperienze mistiche nel Seicento italiano, Roma, 2003, p. 227-237 e S. Stroppa, Riletture secentesche di Canfield e Gagliardi tra "Extase des Oeuvres» e mistica della volontà, introduzione a Pietro Battista da Perugia, Scala dell'anima per arrivare in breve alla contemplazione, perfezione et unione con Dio, in Archivio italiano per la storia della pietà, 9, 1996, p. 177-279.

44. Sull'introduzione della riforma carmelitana in Francia, Madame Acarie e il ruolo svolto da Duval cfr. Ch. Renoux, Madame Acarie « lit » Thérèse d'Avila au lendemain de l'Édit de Nantes, in B. Hours (dir.), Carmes et Carmélites en France du XVII e siècle à nos jours. Actes du Colloque de Lyon (25-26 septembre 1997), Paris, 2001, p. 117-154; B.B. Diefendorf, Barbe Acarie and her Spiritual Daughters: Womens's Spiritual Authority in Seventeenth-Century France, in C. Van Wyhe (dir.), Female Monasticism in Early Modern Europe. An Interdisciplinary View, Hampshire-Burlington, 2008, p. 155-172 e S.-M. Morgain, Pierre de Bérulle et les Carmélites de France : la querelle du gouvernement, 1583-1629, Paris, 1995, p. 160-178.

45. Sui rapporti con Richelieu e sul "duvalisme » come "spirito del giusto mezzo » si rinvia a J. Calvet, Un confesseur de Saint Vincent de Paul. André Duval. Docteur de Sorbonne, in Petites Annales de Saint Vincent de Paul, 4, 1903, p. 135-146 e 166-176.

46. Si veda E. O'Neill-J.M. Domínguez, Diccionario Histórico de la Compañía de Jesús. Biográfico-Temático, IV, Roma-Madrid, 2001, p. 3603.

47. Lettre iustificative du pere François Solier respondant à un sien amy touchant la censure de quelques Sermons faits en Espagne à l'honneur du Bienheureux Pere Ignace de Loyola, fondateur de la Compagnie de Iesus, A Poictiers, par Antoine Mesnier imprimeur du Roy \& de l'Université, 1611. 
48. C. Sommervogel, Bibliothèque de la Compagnie de Jésus, VII, Bruxelles-Paris, 1896, col. 1357-1366: 1363-1364.

49. Cfr. La continuation du Mercure Francois, ou suite de l'Histoire de l'Auguste Regence de la Royne Marie de Medicis sous son fils le Tres-chrestien Roy de France et de Navarre Loys XIII, II (1610-1612), Paris, chez Estienne Richer au Palais, sur le Perron Royal, 1615, p. 144b-151b: $146 b$.

50. Lettre iustificative du pere François Solier... cit., p. 30.

51. Ivi, p. 30-31.

52. Ivi, p. 32 e 35.

53. BNF, fondo italiano ms. 1200 , fol. $96 \mathrm{v}-96 \mathrm{r}$ da dove sono tratte anche le successive citazioni (Ubaldini a Borghese, Parigi 11 ottobre 1611).

54. Lettera citata da P. Blet, Jésuites et libertés gallicanes en 1611... cit., p. 166 nota 2.

55. Ivi, fol. 97r.

56. Ivi, fol. 97v (Ubaldini a Borghese, Parigi, 8 novembre 1611).

57. Ivi, fol. 98 r.

58. Ivi, fol. $98 \mathrm{v}$.

59. BA, mss 1215, fol. 304v-305r (lettera di Feliciani a Ubaldini, Roma 7 dicembre 1611).

60. BNF, fondo italiano ms. 1200, fol. 99v (Ubaldini a Borghese, Parigi 23 novembre 1611).

61. Ivi, fol.100r da dove sono tratti anche i successivi rimandi (Ubaldini a Borghese, Parigi 23 novembre 1611).

62. Sulla questione del collegio di Clermont si veda P. Blet, Jésuites et libertés gallicanes en 1611... cit., p. 167-169.

63. BNF, fondo italiano ms. 1200, fol. 100v (Ubaldini a Borghese, Parigi 7 dicembre 1611).

64. Ian Petit, Sensure [sic!] de la sacree faculte de theologie de Paris, contre quatre propositions, tirees d'vn liure ainsi intitule. Trois tres-excellentes predications, prononcees au iour \& feste de la beatification du glorieux patriarche, le bien heureux Ignace, fondateur de la compagnie de Iesus, Tertia editio, a Paris, 1612, conservato presso la Biblioteca comunale Planettiana di Jesi.

65. BNF, fondo italiano ms. 1200, fol.100v, anche per le successive citazioni (Ubaldini a Borghese, Parigi 7 dicembre 1611).

66. I difficili rapporti tra i gesuiti e il Parlamento di Parigi sono analizzati da C. Sutto, Le Roi et le Parlement dans la pensée et l'action des Jésuites français (1590-1625) in A. Stegmann (dir.), Pouvoir et institutions en Europe au XVI ${ }^{\mathrm{e}}$ siècle, Paris, 1987, p. 263-274.

67. BNF, fondo italiano ms. 1200, fol.103r-103v anche per gli ulteriori rinvii (Ubaldini a Borghese, Parigi 21 dicembre 1611).

68. Ivi, fol. 104r-104v (Ubaldini a Borghese, Parigi 3 gennaio 1612).

69. Archivio della Congregazione per la Dottrina della Fede, So, Decreta 1612, fol. 16-17, seduta del 4 gennaio alla presenza dei cardinali Paolo Sfondrati, Lorenzo Bianchetti, Roberto Bellarmino, Ferdinando Taverna, François de la Rochefoucauld, Fabrizio Verallo, Agostino Galamini e Felice Centini.

70. Pierre Bayle, Dictionnaire historique et critique, II, Rotterdam, chez Michel Bohm, 1720, p. 1736-1747: 1744-1745, note X e Y.

71. [Étienne Pasquier], Le Catéchisme des Iesuites ou Examen de leur doctrine, A Villafranche, chez Guillaume Grenier 1602, p. 47a-52a e 88, 91a-100a, 315a. 
72. Bayle, Dictionnaire historique et critique... cit., p. 1745, nota Y.

73. Una memoria anonima e senza titolo in francese che riporta la lettera di Luigi XIII a Gregorio XV, «fra tutti i principi cristiani, quella più calorosa » è in BNS, mss 9716, fol. $371 r-375 r$ : fol. 372r-373r.

\section{AUTORE}

\section{MIGUEL GOTOR}

Università degli Studi di Torino - gotor.miguel@gmail.com 


\title{
Histoire de censures inversées : Nicolas Chichon, Suárez et Saint-Office (1624-1637)
}

\author{
Jean-Pascal Gay
}

\begin{abstract}
«[...] dico vobis et si non dabit illi surgens eo quod amicus eius sit propter inprobitatem tamen eius surget et dabit illi quotquot habet necessarios et ego vobis dico petite et dabitur vobis quaerite et invenietis pulsate et aperietur vobis ", Luc, 11, 8-9.
\end{abstract}

1 Le cas dont on traite ici est marqué par une profonde disproportion entre le matériau archivistique $^{1}$ qui permet de l'étudier et la trace qu'il a laissée ${ }^{2}$. Peut-être d'ailleurs cette disproportion est-elle le résultat de la force des pratiques et des institutions de censure auxquelles a été confronté le théologien minime dont il s'agit ici. Le père Nicolas Chichon, minime provençal, qui consacre une bonne part de sa vie et de son activité théologique à essayer de prouver l'hétérodoxie de Suárez et d'en convaincre les institutions ecclésiastiques françaises et romaines, est en effet véritablement un oublié. Pourtant, il semble avoir été un théologien longtemps assez bien reçu dans sa province, de l'aveu même de ses supérieurs. II conduit par ailleurs, depuis son refuge de la Trinité-des-Monts, un combat de douze ans contre la doctrine du père de la seconde scolastique devant le tribunal du Saint-Office et s'engage dans une querelle autour de l'authenticité et de la valeur théologique d'homélies de Valérien de Cimiez. Jean-Louis Quantin a récemment étudié magistralement ce conflit dans une étude qui fait donc ressortir cet étrange personnage de l'oubli ${ }^{3}$. Ce conflit d'érudition n'est pas sans lien avec ses attaques contre Suárez puisque Nicolas Chichon repère dans ces homélies une doctrine semi-pélagienne. Dans un cas comme dans l'autre, Chichon s'affronte aux jésuites et est pris dans les dynamiques plus vastes des controverses religieuses au lendemain de la conclusion des congrégations de auxiliis4.

Du point de vue de l'histoire institutionnelle du regard romain sur la France, c'est un cas relativement exceptionnel de documentation importante pour une affaire doctrinale française gérée par la Congrégation de l'Inquisition, plutôt que par l'Index, avant que la crise janséniste ne conduisent la curie romaine à repenser les outils de son rapport 
doctrinal avec la France. Il s'agit donc de comprendre ici cet épisode comme un épisode de l'histoire de la modification du rapport institutionnel et doctrinal à la France mais encore comme un moment de l'histoire de l'évolution des contextes doctrinaux et du statut socio-politique de l'objet-doctrine dans les deux espaces concernés.

\section{Chichon et le Saint-Office : rencontres antijésuites}

3 Le fr. Nicolas Chichon apparait dans les sources du Saint Office autour de 1625. La documentation s'étale ensuite avec quelques interruptions et quelques pics jusqu'en 1638 . Sa cause se déroule donc toute entière pendant le long pontificat d'Urbain VIII commencé en 1623, pape souvent proche de la France et des Jésuites. Chichon est signalé en 1625 au Cardinal Desiderio Scaglia par le dominicain Costantino Testi ${ }^{5}$ lequel relate au cardinal un entretien avec le général des minimes qui non seulement lui fait part des doutes d'un théologien français de son ordre sur Suárez, mais encore de sa volonté d'obtenir pour ce dernier licence de le réfuter. Testi indique encore avoir répondu que la bonne manière de procéder serait d'informer la Sacré Congrégation. Le dominicain prend par ailleurs sur lui de transmettre au cardinal une liste des propositions notées par le théologien français, et dont il faut donc supposer que le général en possède un exemplaire ${ }^{6}$. Le schéma, on le voit, est classique dans la prise en compte des problèmes français à ce moment : c'est à partir d'informations italiennes que le cas de Chichon attire l'attention de l'Inquisition romaine.

4 Une seconde lettre de Testi, d'octobre 1624, cette fois à destination de la congrégation ${ }^{7}$, précise que le mémoire vise à obtenir une licence pour écrire contre un volume paru "sous le nom» de Suárez, licence devenue nécessaire depuis la conclusion des controverses de auxiliis et la confirmation des constitutions sur ce sujet par Urbain VIII. À cette date la parution du De Gratia de Suárez est encore toute récente, puisque l'édition lyonnaise par Cardon et Cavellat, qui suit d'un an l'édition de Coimbra, date de $1620^{8}$. Selon le témoignage de Testi, le requérant proteste bien «ne pas croire que de la plume du P. Suárez aient pu sortir des erreurs si manifestes » et donc considérer à ce moment, ou faire semblant de considérer, que s'il y avait des erreurs chez Suárez elles auraient déjà été repérées 9 . De fait, dans la lettre que Chichon avait écrit au général des minimes pour présenter sa cause, laquelle est ensuite transmise au Saint-Office, accompagné du catalogue des erreurs repérées dans l'édition de Suárez, il entendait prouver « par plus de cinquante motifs, que ledit livre n'est pas venu d'un si grand homme ${ }^{10}$.

5 La congrégation se saisit de l'affaire, non point tant en raison de la nationalité française de l'auteur que de la mise en cause de Suàrez. En novembre $1624^{11}$, les cardinaux inquisiteurs ordonnent au vicaire général des minimes d'écrire à Chichon pour qu'il envoie le livre et les erreurs repérées. À ce moment, Chichon ne semble par ailleurs pas avoir recherché lui-même l'intervention de l'Inquisition dans sa cause. S'il est probable qu'il ait eu recours au général pour contourner les autorités provinciales de l'ordre pour obtenir une autorisation de publication, il ne semble pas avoir pensé en aucune façon à s'adresser à l'Inquisition romaine.

6 À l'été 1625 , il est présent à Rome. La première mention de son audition par la congrégation date du 23 juillet ${ }^{12}$. De même, le premier mémoire remis par ce dernier à l'Inquisition, et qui est une nouvelle liste des quarante-trois erreurs repérées dans Suárez est daté de la fête de Saint-Apollinaire ${ }^{13}$. Début août, son cas est transmis à deux consulteurs, Marco Antonio Cappelli, mineur conventuel et le régent du couvent carme de 
Santa Maria in Traspontina, Domenico Campanella ${ }^{14}$. La cause semble alors progresser normalement.

7 C'est peut-être encouragé par l'accueil fait à ses critiques du théologien jésuite, que Chichon commence à ce moment à avancer devant l'Inquisition la question de l'authenticité et de l'orthodoxie des homélies de Valérien de Cimiez. Au plus tard minovembre 1625, il remet au Saint-Office un mémoire contre Gennade et surtout contre Valérien ${ }^{15}$, dont il met en cause le semi-pélagianisme. Cette mise en cause ayant été étudiée précisément par Jean-Louis Quantin ${ }^{16}$, on ne mentionnera ici que ce qui est utile à la compréhension de la manière dont le Saint-Office a traité plus généralement le cas Nicolas Chichon. Chichon, quelques années après l'édition de Gennade par le luthérien Geverhard Elbershorts, renouvellait contre-lui des accusations de semi-pélagianisme. Il l'accusait en sus d'avoir non seulement attribué un faux apollinariste à Jules Ier, mais encore de l'avoir fait volontairement, accusation «exemplaire de la démarche inquisitoriale de Chichon ». S'agissant de Valérien, la question posée par Chichon porte à la fois sur la doctrine de dix-neuf homélies attribuées à un Valérien évêque, éditées par le P. Sirmond en 1612 et sur leur attribution par ce dernier à Valérien de Cimiez. Le 12 décembre, la Congrégation ordonne l'examen par les qualificateurs de la doctrine des homélies éditées par Sirmond, qui a lieu le 31 décembre. Parmi les examinateurs de l'ouvrage, outre cinq dominicains dont celui qui avait signalé le cas de Chichon, Costantino Testi, et Tomas de Lemos, on trouve Luke Wadding qui intervient ensuite dans l'examen des erreurs trouvées par le minime chez Suárez, et le cistercien Ilarione Rancati, qualificateur depuis 1624, anti-moliniste déterminé et proche du franciscain irlandais. Dans la congrégation qui examine les homélies seuls Agostino Oreggi, théologien d'Urbain VIII et lui aussi nommé récemment par ce dernier comme consulteur, et le jésuite Terenzio Alciatici, un correspondant de Sirmond, prennent un peu leur défense, en recommandant un examen plus approfondi.

8 Cette congrégation n'est cependant pas conclusive et le 7 janvier 1626, la congrégation demande un nouvel examen à Oreggi et au Maître du Sacré Palais, Ridolfi. Malgré cette demande, c'est finalement une nouvelle congrégation des qualificateurs qui est réunie le 16 février 1626 et qui, nonobstant l'adjonction de deux nouveaux qualificateurs, aboutit à une confirmation des recommandations précédentes: suppression du titre de saint, interdiction du livre ou au mieux autorisation assortie de notes et d'un avertissement. Le Pape cependant ne se rend pas aux recommandations des théologiens du Saint-Office, et le 5 mars 1626, ordonne de faire écrire par Muzio Vitelleschi à Sirmond pour obtenir des éclaircissements notamment sur le titre de saint attribué à Valérien

9 Peut-être est ce en raison de cet échec et d'éventuels encouragements que Chichon revient de nouveau sur les erreurs de Suárez ${ }^{17}$. Le 11 mars, dans une séance du mardi, tout en renouvelant ses ordres aux supérieurs pour que Chichon soit bien traité, la congrégation lui ordonne de s'entretenir à nouveau avec le régent de Santa Maria in Traspontina, Domenico Campanella, auquel est joint cette fois le franciscain irlandais Luke Wadding, déjà partie prenante dans l'examen des homélies ${ }^{18}$. Wadding était arrivé à Rome comme théologien d'Antoine de Trejo, évêque de Carthage, vicaire général de l'ordre franciscain et surtout, ambassadeur extraordinaire de Philippe III dans le cadre de la campagne espagnole pour obtenir une définition de l'Immaculée conception ${ }^{19}$. Après l'échec de la mission de ce dernier, il était demeuré à Rome. Au moment de son implication dans l'examen du cas de Nicolas Chichon, il a très récemment fondé le Collège Irlandais de Saint Isidore. Promoteur du scotisme et d'un certain rigorisme pastoral, 
Wadding est en conflit récurrent avec les jésuites à Rome, et sera dans les années 1640 un des théologiens romains les plus bienveillant à l'égard des arguments jansénistes ${ }^{20}$. Campanella, de son côté, est un ancien jésuite, et sa position sur la scène des controverses théologiques du second quart du siècle demeure mal connue, même si, comme Jean-Louis Quantin le note ${ }^{21}$, il est un adversaire résolu de la théologie janséniste de la grâce au moment de l'examen des propositions tirées de l'Augustinus. Sur le fond, c'est bien de Suárez, et non d'un éventuel Pseudo-Suárez qu'il est désormais question dans les entretiens avec les consulteurs.

Les deux causes, de Valérien et Gennade d'une part, et des erreurs de Suárez d'autre part, s'entremêlent jusqu'au renvoi de Chichon à la fin du mois de septembre 1626. Un même mémoire ${ }^{22}$ demande une conclusion de la cause de Valérien et de Gennade et la réunion d'une congrégation des consulteurs sur les erreurs de Suárez, en réponse duquel, le 28 avril 1626, Chichon obtient d'être entendu par les théologiens en congrégation et qu'on cherche dans les archives du Saint-Office s'il y a un exemplaire de l'Institution Chrétienne de Calvin pour permettre d'étayer ses accusations ${ }^{23}$. En mai, après qu'il a demandé que les propositions, tant relevant du nestorianisme, du pélagianisme que du luthéranisme et du protestantisme soient examinées dans l'ordre dans lequel il les a dénoncées, les cardinaux ordonnent de l'entendre dans la congrégation des théologiens sur chacune des propositions qu'il a avancées ${ }^{24}$. Le 4 juin, la réponse de Sirmond est lue dans la Congrégation et le pape décide de demander au jésuite une édition assortie d'avertissements qui devront être préalablement approuvés par le Saint-Office.

11 À partir de ce moment, la congrégation semble plus hésitante dans son appréhension de Nicolas Chichon et de ses accusations. Ses instances contre Suárez semblent un moment être moins bien accueillies. Chichon demande à être de nouveau entendu pour pouvoir répondre aux objections faites en défense du théologien espagnol (sur le fait et sur le droit) ${ }^{25}$. Le 17 juin, la Congrégation se contente d'ordonner à Chichon de transmettre au Saint-Office une note écrite avec les erreurs remarquées chez Suárez et qu'on le renvoie avec bienveillance ${ }^{26}$. Le 3 juillet 1626 surtout, après une nouvelle, et apparemment longue audition de Chichon, les consulteurs décident unanimement que les oppositions faites ne subsistent pas.

12 Pourtant le 27 juillet 1626 - et c'est bien le signe du caractère certainement instrumental de son cas - les cardinaux continuent à pousser l'examen de la cause de Chichon et ordonnent la qualification des propositions extraites de Suárez sur la base d'un recueil de dix erreurs composé par le minime ${ }^{27}$. En réalité d'ailleurs, la demande précédente qui lui est faite en juin d'établir un catalogue d'erreur est peut-être même pour une partie des cardinaux un moyen d'anticiper sur ce consensus des théologiens, en déplaçant la question à celle d'un catalogue de propositions à considérer dans l'absolu. Au même moment encore, Chichon essaie toujours de pousser une censure de Valérien tout en se plaignant du retard du décret ${ }^{28}$. En août, les cardinaux font transmettre aux qualificateurs la copie d'une note de Chichon sur les deux premières propositions dénoncées dans son plus récent indicule ${ }^{29}$ et convoquent une congrégation de ces derniers pour le $18^{30}$. Les consulteurs qui interviennent en l'occurrence sont Nicolò Ridolfi, le maître du Sacré Palais, le commissaire du Saint-Office, Ippolito Maria Lanci, Lorenzo Orsacchi da Empoli, procureur général des Augustins, le carme Domenico Campanella, Niccolò Riccardi, le jésuite Terenzio Alciati, Alessandro Boccabella, Ilarione Rancati, Luke Wadding, et le socius du commissaire Costantino Testi, le même qui avait signalé la cause au cardinal Scaglia. Tous avaient fait partie de la congrégation des qualificateurs du 31 décembre 
1625 qui avait en un sens donné raison à Chichon à propos de la doctrine des homélies de Valérien. Des participants à cette congrégation ne manquaient d'ailleurs que Tomàs de Lemos et Agostino Oreggi. Tous donc connaissaient parfaitement l'ensemble de la cause.

C'est l'intervention du Souverain Pontife qui met fin au processus. Oreggi, intervient dans la congrégation pour signifier aux cardinaux les ordres du pontife sur le cas Chichon. Par décret du 2 septembre $1626^{31}$, la Congrégation ordonne à Chichon de laisser son dossier au Saint-Office et de retourner dans son pays. Il est renvoyé en France avec ordre de l'Inquisition aux supérieurs de pourvoir aux nécessités de son retour ${ }^{32}$. C'est donc avant l'arrivée de la réponse d'une enquête faite dans les manuscrits de Saint-Gall sur l'origine du titre de saint pour Valérien, que la décision de renvoyer Chichon intervient, et intervient en lien explicite avec l'examen de sa dénonciation des propositions tirées de Suárez. La lettre en effet n'arrive avec le courrier du Nonce que le 5 septembre et le rapport au Pape, établissant la bonne foi de Sirmond, n'en est fait que le 17. Peut-être l'arrivée de cette lettre explique-t-elle que les consignes données le 9 septembre, demandant que le Commissaire négocie avec le procureur général des Minimes un départ honorable pour la France ne sont pas immédiatement appliquées. En tous cas, après le rapport finalement fait au Pape, la congrégation, après avoir entendu Chichon, ordonne le 23 septembre au procureur général des minimes et au correcteur de la Trinité-desMonts de lui donner 80 écus pour son voyage en France et surtout une attestation que le renvoi se fait «honorifice ». Le Pape cependant s'oppose le jour même à ce décret et demande que le minime quitte Rome sans témoignage de renvoi avec les honneurs. Clairement le cas Chichon est pris à ce moment dans des tensions entre le Souverain Pontife et les cardinaux de l'Inquisition ${ }^{33}$, et Urbain VIII semble vouloir manifester sa désapprobation de la manière dont le cas Chichon a été traité par les Inquisiteurs et même peut-être utilisé par eux.

\section{Nicolas Chichon : pèlerin du Saint-Office et de l'antijésuitisme}

14 De retour en France, Chichon semble mal accueilli par les autorités locales et est envoyé à Rennes $^{34}$. Selon lui, en réalité, les difficultés durent depuis le début des années 1620 , ce qui explique probablement la lettre écrite directement au général pour obtenir licence d'écrire contre le de gratia de Suárez. Son retour se fait donc dans ce contexte préexistant de tensions. Or, malgré les circonstances de son départ, Chichon semble s'être considéré comme mandaté pour poursuivre la controverse autour du semi-pélagianisme des homélies de Valérien et se prévaloir de ses relations avec l'Inquisition romaine dans ses relations avec les supérieurs de l'ordre. Le provincial, le P. Chavyneau se plaint ainsi dans une lettre au général que Chichon affirmait que les supérieurs qui l'empêchaient de publier encourrait l'excommunication, certainement pour désobéissance aux ordres du Saint-Office ${ }^{35}$.

Chichon est d'autant plus pressé d'écrire que Théophile Raynaud compose, à la demande de Sirmond comme le signale J.-L. Quantin, une Disquisitio theologica en défense de Valérien de Cimiez qui le met en cause nommément et l'affuble du sobriquet de Parcus Charitatis tout en le qualifiant de criminator de Valérien. Le texte dont J.-L. Quantin note qu'il a été achevé en 1628 n'est publié qu'en 1632 et sans mention dans le titre de l'ordre des minimes ${ }^{36}$. Chichon semble avoir eu connaissance de l'ouvrage dès 1630, alors que celui-ci était encore intitulé, Contra Criminatorem Minimum. Il veut s'engager dans une 
réponse et semble avoir argué du décret qu'il pense avoir obtenu contre l'édition des homélies de Valérien par Sirmond. Il se voit interdire de le faire par son provincial, lequel lui signifie par ailleurs une interdiction de se rendre à Rome avant d'avoir parlé avec les supérieurs, indication en creux que le premier voyage de Chichon à Rome était donc déjà perçu en France comme une tentative pour échapper à la censure locale.

Par ailleurs, Chichon s'implique aussi dans les débats théologico-politiques français du temps. Il compose à Rennes un de iustitia, aujourd'hui perdu, qui est un parallèle de l'ensemble des lois ${ }^{37}$. L'ouvrage semble avoir posé problème à deux égards. D'une part, il s'y serait à nouveau aventuré sur le terrain de la question de auxiliis; selon ce qu'en dit Chichon lui-même, il s'agirait en fait d'un commentaire sur la Prima Secundæe, qui contenait certainement une mise en cause de la science moyenne. D'autre part, il a contenu un de occidendo tyrannum dans lequel Chichon prenait position contre toutes formes de justification du tyrannicide. Le traité devait être placé sous la protection des parlementaires de Bretagne et en particulier du premier président. À ce moment, on le sait, la question du tyrannicide et avec elle celle de la place de la Compagnie de Jésus dans le royaume est prise dans un conflit de long terme entre les Parlements et la monarchie sur le régime et la nature de la pacification du royaume depuis la fin des guerres de Religion $^{38}$. Un de occidendo tyrannum paru sous la protection du Parlement de Bretagne, était donc loin d'être neutre à ce moment de l'histoire des controverses théologicopolitiques en France. Comme E. Nelson, l'a montré, la protection accordée à la Compagnie et sa transformation en France en ordre dynastique, a aussi pour fonction d'affirmer face aux Parlements que la pacification se fait sous le contrôle du pouvoir royal dans un régime de grâce. Le paradoxe est ici bien sûr qu'il y avait une manière de défendre la personne des rois de France qui pouvait apparaître comme une mise en cause de leur autorité. Les supérieurs minimes pouvaient y être d'autant plus sensible, qu'après des relations tendues avec Henri IV jusqu'à la fin du siècle, l'ordre tend au début du XVII siècle à se présenter comme un ordre de fondation royale, et que plusieurs auteurs minimes s'engagent dans une apologétique religieuse de l'obéissance au souverain ${ }^{39}$. Parmi les plus actifs promoteurs de cette nouvelle ligne spirituelle et politique on trouve le P. André Chavyneau, qui est justement à ce moment le provincial qui s'oppose à Nicolas Chichon ${ }^{40}$.

17 La censure française de Chichon est donc un exemple peu original de la censure préventive qui se développe en France à ce moment ${ }^{41}$. Alors que le Parlement de Bretagne, en réalité partie prenante dans le conflit que l'ouvrage envisage de traiter, ne joue pas son rôle de censeur, les autorités internes de l'ordre, apparemment en dialogue avec le pouvoir royal se chargent d'empêcher la parution de l'ouvrage. En août 1630, en raison de ses tentatives pour obtenir publication des écrits composés pensant son séjour rennais, Chichon est convoqué devant le chapitre provincial de la province de Tours et emprisonné. Il parle d'une incarcération commencée avant le chapitre et d'une durée d'au moins sept mois. Ses écrits sont mis dans un coffre scellé, probablement à la même date. Peut-être du fond de sa prison, Chichon fait appel au Général et au Saint-Office. 
L'acte d'appel présenté devant le chapitre invoque une fois de plus le patronage du SaintOffice, Chichon jugeant son provincial incapable en raison de sa désobéissance aux ordre de la congrégation ${ }^{42}$. Il demande au général d'être transféré à Venise ou à Rome afin de pouvoir publier ses ouvrages qu'il dit approuvés par le Maître du Sacré Palais. Surtout dans sa lettre présentant sa supplique au général et indiquant son appel au Saint-Office parce qu'on l'empêche de répondre à Raynaud, Chichon insiste sur le rôle joué par les jésuites dans son emprisonnement et dans la censure de ses livres, censure qu'il juge d'autant plus injuste qu'il affirme qu'il ne nomme aucun théologien dans son de iustitia ${ }^{43}$, preuve en creux qu'il évoquait certainement par l'implicite la doctrine de Suárez dont il n'avait pas réussi à obtenir la censure à Rome.

Le général des minimes écrit fin octobre 1630 en France pour demander des explications. La correspondance qu'il échange avec le provincial Chavyneau signale l'agacement de ce dernier ${ }^{44}$. Dans une réponse particulièrement cinglante, le supérieur français s'étonne que le général prenne au sérieux un homme aussi inquiet et qui a été la cause de tant de scandales. Chichon, écrit-il, passe son temps à faire appel auprès de toutes les autorités possibles: le roi, le Parlement, la «Sainte Congrégation» (probablement celle des réguliers) et l'Inquisition, "quamvis nesciat de quo, ne in quem debeat appelare ». Il transmet cependant des lettres de Chichon pour le cardinal Scaglia, le maître du Sacré Palais et la Congrégation, signalant ainsi d'ailleurs clairement quels sont ceux sur lesquels Chichon pense pouvoir se reposer. Le général de son côté remet l'intégralité de la cause au Saint-Office, demandant des instructions sur la manière dont il doit se comporter à l'égard de Chichon ${ }^{45}$. Cette intervention du général se fait aussi dans contexte de tension entre les provinces françaises et la curie généralice, après la cassation de l'élection du P. Bachelier en 1628, religieux dont Chichon semble avoir été proche, et ensuite son transfert à la charge de procureur général ${ }^{46}$.

La Congrégation reçoit en réalité l'appel puisque le 16 janvier 1631, elle décide le même jour de demander au général des Jésuites de lui faire transmettre le livre de Théophile Raynaud et d'en empêcher la diffusion, de solliciter le nonce pour qu'il retrouve les textes de Chichon et de faire ordre au général des Minimes d'imposer le silence à ce dernier. Le provincial de Tours de son côté cherche à éloigner le religieux de sa province et demande son transit dans sa province de naissance (la province de Provence), transit que la Congrégation concède au mois d'août $1631^{47}$, et qui permet d'ailleurs en réalité de libérer Chichon pour qu'il puisse se rendre à Rome. Peut-être est-ce d'ailleurs un expédient pour contourner des oppositions ou des difficultés légales autour de l'appel de ce dernier.

\section{Asile et exil romain d'un plaideur importun}

Chichon est à Rome au plus tard en mars 1632. À ce moment, il semble par ailleurs qu'il se présente devant plusieurs congrégations, y compris devant celle des réguliers. Néanmoins, c'est devant le Saint-Office qu'il obtient quelques succès. Sur sollicitation de Chichon et sur l'avis de l'Inquisition, c'est le Pape lui-même qui fait ordonner aux supérieurs de faire parvenir ses écrits à Rome ${ }^{48}$ et le commissaire du Saint-Office relaie l'ordre auprès du général des minimes ${ }^{49}$. La congrégation ordonne même aux supérieurs locaux de restituer l'argent que Chichon avait amené à Tours pour faire imprimer ses livres $^{50}$. Faisant référence à des informations qu'il aurait obtenues de la province de Tours, Chichon explique le délai dans l'envoi de ses écrits depuis la France, par le fait que le provincial de Tours aurait recherché et obtenu une lettre de faveur «tanto facile ad 
ottenir ", ordonnant d'empêcher cet envoi ${ }^{51}$. L'accusation a évidemment pour fonction de montrer que le supérieur encourt les censures canoniques pour recours au pouvoir séculier quand l'obéissance à un ordre royal non-sollicité n'aurait évidemment pas pu être attaquée. Alors que Chichon se plaint des difficultés que lui fait encore le même provincial par l'intermédiaire du correcteur de la Trinité qui est un de ses proches, les cardinaux renouvellent leurs instances aux supérieurs de traiter Chichon correctement, et envisagent un temps la possibilité de l'autoriser à imprimer un traité De natura humana destituta et restituta ${ }^{52}$. En octobre 1632, après une nouvelle audition du minime, un membre de la congrégation lit aux cardinaux une lettre du roi de France indiquant que plusieurs œuvres de Chichon ont été brûlées par son ordre, signe d'une montée en importance de l'affaire et de la volonté du souverain de préserver les supérieurs tourangeau ${ }^{53}$. La date de destruction des écrits de Chichon est en réalité incertaine ${ }^{54}$. Il n'est pas du tout impossible qu'ils aient été détruits en réaction aux demandes du Saintoffice.

21 Chichon se concentre alors non plus sur les ouvrages brûlés, pourtant cause de son appel à Rome et au Saint-Office mais sur l'accusation de pélagianisme portée contre Valérien de Cimiez et sur son conflit avec Raynaud à ce sujet. Il indique par ailleurs avoir subi des pressions de l'ambassadeur pour se désister. À partir de ce moment, le thème des recours au pouvoir séculier devient régulier dans les lettres et mémoires de Chichon, qui va jusqu'à demander fin 1632 - début 1633 la convocation du P. Chavyneau à Rome devant le Saint-Office ${ }^{55}$.

L'année 1633 voit la cause progresser régulièrement. En janvier la congrégation ordonne qu'il soit entendu par Desiderio Scaglia, assisté du procureur général des conventuels, du commissaire du Saint Office et d'Ilarione Rancati ${ }^{56}$. En février, c'est au même cardinal de Crémone qu'on l'envoie présenter ses instances pour la suppression du texte de Raynaud contre lui ${ }^{57}$. En avril, la congrégation lit la lettre écrite par le nonce en mars 1633, en réponse aux sollicitations que lui a faites l'Inquisition en juin de l'année précédente. Le nonce, qui a tardé à répondre en raison d'autres impératifs mais aussi parce qu'il a essayé de clarifier l'affaire avec le provincial des minimes, indique que la réponse qu'on lui faite en France est que les livres ont déplu au roi et ont été supprimés ${ }^{58}$.

Bien qu'ayant reçu par deux fois cette information concernant l'attention portée par le roi au cas Nicolas Chichon, la congrégation lui accorde en partie ce qu'il demande dans la cause des écrits de Valérien de Cimiez. En mars 1633, les cardinaux avaient déjà demandé l'exécution des décrets de juin 1626 et de janvier 1631 et envoyé Rancati signifier au général des jésuites leur volonté d'être obéis. Le 31 août 1633, la congrégation sur la relation de Scaglia, ordonne l'exécution des décrets du 4 juin 1626 imposant à Sirmond de publier une édition corrigée et annotée des homélies de Valérien et du 16 janvier 1631 intimant à Muzio Vitelleschi d'empêcher la diffusion de la Disquisitio de Raynaud ${ }^{59}$. Rancati est d'ailleurs envoyé au général pour lui signifier le désir du Saint-Office d'être obéi. Vitelleschi écrit alors à Sirmond ${ }^{60}$ dont il reçoit une première réponse datée du 31 janvier 1634, laquelle est examinée par les cardinaux en juin qui ordonnent alors à l'Assistant de France de s'adresser au cardinal Barberini ${ }^{61}$, peut-être d'ailleurs parce que l'Inquisition a du mal à se procurer les sources nécessaires au jugement, en particulier la Disquisitio Theologica.

Plus surprenant, les informations venues de France semblent sans effet durable sur l'accueil fait au Saint-Office aux accusations de Chichon contre Suárez. Quand Chichon présente un nouveau mémoire pour demander la publication du décret contre Raynaud et 
pour demander d'être entendu sur trois chapitre d'erreurs de Suárez - pourtant déjà précédemment évoqués (la virginité de Marie, l'affirmation selon laquelle le Christ serait «Fils de la Sainte Trinité », et la parenté de sa doctrine avec le nestorianisme) - il est à nouveau reçu par le cardinal Scaglia en octobre $1634^{62}$. Lorsqu'il remet un nouveau résumé en douze chefs des erreurs de Suárez, c'est encore à Rancati qu'il est envoyé pour en discuter ${ }^{63}$. Durant l'année 1635, Chichon continue de soumettre des mémoires au Saint Office et est encore entendu par la congrégation le 27 juin $^{64}$. La cause ne semble plus progresser de manière significative, mais la congrégation continue d'accorder sa protection au turbulent minime. Chichon obtient même que le Saint-Office intime au provincial de Tours de remettre ses ouvrages au Nonce, malgré le fait que la congrégation ait été mise au courant de leur destruction ${ }^{65}$.

Le traitement du cas semble cependant atteindre un point de rupture à la fin de l'année 1636. Les supérieurs et les frères du couvent royal essayent de relayer devant le SaintOffice l'accusation portée contre Chichon d'être un perturbateur de la communauté. Une supplique (à laquelle les cardinaux répondent début décembre 1636) demande que la congrégation accepte de "réformer et modérer sa manière de vivre » et se propose de l'informer plus avant sur la violence et les prétentions exorbitantes de Chichon ${ }^{66}$. Une lettre légèrement antérieure détaille les motifs de plaintes en renvoyant aussi à leur ancienneté puisque Chichon perturbe la communauté depuis plus de cinq ans : il ne ferait aucun cas des supérieurs, arguant en permanence de l'autorité de la congrégation et prétendant pour ses affaires se dispenser des exigences de la vie régulière ${ }^{67}$. La manière dont Chichon se prévaut de l'autorité du Saint-Office contre les supérieurs et notamment la manière dont il dit considérer que ces derniers tomberaient sous des peines et censures pour ne pas le laisser agir à sa guise, accusation qui se trouvait déjà dans les lettres de Chavyneau transmises au Saint-Office, revient dans plusieurs des plaintes relayées par la communauté en 1636. Chichon réduirait toutes ses actions à ce seul motif et prétendrait ne pas faire un pas "sans ordre exprès de Sa Sainteté et de la Congrégation " ${ }^{68}$. Il semble d'ailleurs que, conscient de ce ces plaintes, Chichon, reproduisant finalement le geste qu'il avait posé au chapitre de Tours, ait fait appel au Saint-Office devant le chapitre de la communauté. D'ailleurs, les suppliques qu'il adresse au Saint-Office contre les PP. Jean Vatrouville et Georges Carrel, ancien correcteur et actuel correcteur, ont été conservées ${ }^{69}$ . Il faut noter à ce sujet, qu'indépendamment des accusations de Chichon, les supérieurs de la Trinité-des-Monts font aussi le lien avec le volant français du cas Chichon. Une de ses suppliques présente Georges Carrel comme son ancien supérieur et persécuteur en France. Une fois encore les cardinaux protègent Chichon, puisque tout en lui ordonnant d'obéir à ses supérieurs ${ }^{70}$, ils reçoivent encore ses plaintes et insistent sur la nécessité de le traiter avec douceur.

Début janvier 1637, juste après donc la discussion de ses plaintes, parvient au Saint-Office la réponse du Nonce aux sollicitations précédentes du mois d'avril ${ }^{71}$. Ce dernier transmet avec sa propre lettre, trois lettres de 1636 du provincial, mais aussi des copies de correspondance de 1632 transmises par ce même provincial. Dans cet ensemble, la plus importante est la lettre, datée du 12 août 1632, adressée par le roi à Jean de Galard, comte de Brassac, ambassadeur à Rome. La lettre indique qu'ordre a été donné au P. Chavyneau de brûler les écrits de Chichon, ce dont Brassac doit rendre compte auprès du Pape pour éteindre la cause introduite par Chichon contre ses supérieurs devant la congrégation des réguliers $^{72}$. La copie transmise à ce moment à l'Inquisition est la copie certifiée de l'exemplaire conservé alors par les minimes de la province de Touraine. Elle est transmise 
avec deux lettres d'octobre 1632 du P. Lambert écrites à Chavyneau, une pour lui indiquer la réception des documents envoyés de France et notamment de la la lettre pour l'ambassadeur, et une autre racontant la visite du même Brassac au couvent, lequel avait alors convoqué Chichon pour lui signifier que c'était par ordre du roi que ses écrits avaient été brûlés ${ }^{73}$. Les minimes y ont par ailleurs fait joindre une lettre de Jean de Bourgneuf, sieur de Cussé, le premier président du Parlement de Bretagne, à Chichon du 10 mars 1632, par lequel le magistrat non seulement désavoue le livre De Iustitia que le minime prévoyait de lui dédier, mais loue la prudence du provincial Chavyneau et encourage Chichon à se "désambarraser de l'examen de tous ces livres d'autruy " qui l'inquiètent et sont peu conformes à sa profession régulière ${ }^{74}$. On le voit donc, les minimes français en transmettant ces lettres par l'intermédiaire du Nonce n'essaient donc pas seulement de couvrir leurs actes de l'autorité royale, mais encore de désarmer la confiance que la congrégation semble faire à Chichon en lui signifiant que ce dernier sait parfaitement ce qui est advenu de ses papiers et pourquoi, et que par conséquent ses recours sont sans fondements.

Pour autant, la cause ne s'éteint pas immédiatement. Peut-être averti du coup porté à Chichon par l'arrivée des lettres venues de France, Muzio Vitteleschi présente une supplique au Saint-Office demandant une copie des propositions mises en cause dans le De Gratia de Suárez, et insistant sur la qualité du théologien espagnol, lequel a bien mérité " de la Religion Catholique et de ce Saint Siège " $^{75}$. Il se peut aussi que cette supplique soit la réaction à une nouvelle instance de Chichon du 22 avril 1637 contre la doctrine de Suárez. À cette date, en tous cas, Chichon est encore envoyé à Ilarione Rancati ${ }^{76}$. Ce n'est finalement qu'en août 1637 que son ultime mémoire, résumant cette fois les principales erreurs de Suárez en sept propositions, se voit simplement apposer la mention lectum ${ }^{77}$. Chichon disparait alors de la documentation inquisitoriale, le silence achevant une cause de douze années.

\section{Chichon et l'engagement de la monarchie française dans les conflits internes de son ordre}

À ce moment, et ce n'est peut-être pas sans lien avec l'extinction de la cause, Chichon qui a réussi à se maintenir au couvent de la Trinité-des-Monts, semble de plus en plus concerné par les conflits internes à l'ordre. Il est impliqué dans la contestation de l'élection du génois Pizzurno après la mort du général en janvier 1637, contestation portée largement par certains minimes français et occasion d'une demande de multiplication des provinces françaises. Au moment de l'affaire Flache-Bachelier, un mémoire contre la visite général de la Province de France par Bachelier indique ainsi que ce dernier «a instigué les Pères Chichon et Burso de faire la poursuitte à Rome contre l'élection [du général] et les y a favorisés ", notant d'ailleurs dans une allusion tout à fait claire à Chichon que Bachelier «a intelligence avec les esprits discoles de l'ordre $»^{78}$. Le dossier sur Bachelier conservé dans les papiers du chancelier Séguier contient d'ailleurs une courte mais intéressante note sur Chichon et sur son rôle dans les conflits internes de l'ordre. La note, destinée aux autorités politiques, fait partie d'un ensemble de pièces en soutient de la cause de l'élection de Pizzurno et du Collègue Français élu lors du chapitre génois de $1637^{79}$. Bachelier, provincial de Champagne a essayé de faire exclure de la nation de France plusieurs provinces pourtant réunies à elle au chapitre de 1623 lorsque lui même était Collègue pour la France. Cette exclusion, en modifiant l'ordre des 
provinces, lui permettait d'être délégué au chapitre au titre de son provincialat. Dans cette affaire on retrouve les principaux protagonistes français et minimes du cas Chichon: c'est en effet le P. Chavyneau qui agit au nom de plusieurs des provinces françaises pour défendre le général italien élu à Gênes et pour refuser la réorganisation des provinces présentée par Bachelier comme un moyen d'augmenter le nombre de voix françaises au chapitre, réorganisation qui a valu à ce dernier le soutien de la monarchie laquelle semble avoir interdit aux minimes de communiquer avec le général et promu la nomination de Bachelier comme vicaire général pour la France ${ }^{80}$. Dans cette affaire Chichon semble avoir été un opposant clé à Pizzurno. Selon un mémoire qui défend par ailleurs Chavyneau, Chichon qui à cette date aurait réussi à se rapprocher de l'ambassadeur de France, le maréchal d'Estrées, aurait obtenu de ce dernier qu'il fasse expulser Pizzurno du couvent royal de la Trinité-des-Monts où il demeurait comme procureur général de l'ordre. Une fois celui-ci élu au généralat Chichon aurait « pris de son authorité particulière, qualité de procureur des provinces de France ». Mais après avoir été "désadvoüeé des principales et délaissé des autres", il aurait "obtenu procuration de monsieur l'ambassadeur prétendant en cela la protection des Religieux françois prétendus oppressez par les estrangers ${ }^{81}$. C'est la raison de la note écrite spécifiquement contre Chichon, laquelle outre qu'elle met en cause les initiatives prises par l'ambassadeur sans consultation des supérieurs, demande que si l'on poursuit la cassation de l'élection de Pizzurno, la conduite de la cause soit confiée «à un homme de meilleure condition et plus modérée ». La note essaie d'ailleurs de raviver la mémoire du cas Chichon auprès de l'autorité royale. Dès le titre son auteur rappelle que Chichon «a composé un livre de occidendo tyranno ", brûlé par ordre du roi et du cardinal, qu'à Rome il a essayé d'écrire sur les mêmes matières et que le comte de Brassac avait obtenu du Pape qu'on lui impose silence. Le rédacteur de l'advis fait de Chichon l'auteur des troubles dans l'ordre, placés ainsi dans la continuité de sa résistance à l'autorité royale dans le cas de ses écrits :

Cet esprit inquiet n'ayant plus de quoy s'exercer s'est pris au tiers et au quart; et a suscité diverses brouilleries dans le couvent qui en rendent la demeure odieuse et insupportable aux bons religieux et en spécial depuis peu s'estant prévalu de l'esprit de Monsieur le mareschal d'Estré y a par son authorité introduit des religieux tels qu'il a voulu; a dans les élections déclarés inhabiles aux charges et offices ceux qu'il a jugé à propos, menassé les uns fait traicter indignement les autres par ledict sieur Ambassadeur soubs prétextes d'intérest d'estat et de nation. Et affin que le général de l'ordre souffrit de ses violences aussy bien que les particuliers. Il a soubs l'authorité duditct sieur Ambassadeur disputé l'élection du Collègue général françoys et puis celle du général, et a tant obtenu sur luy que par divers artifices on aict deffendu par lettre de cachet aux provinciaux de France, de recognoistre ledit général, jusques à ce que nostre Sainct Père ait jugé sur ce différend. C'est ce qui mect l'ordre des minimes en grand hasard, attandu l'impunité des discoles faute de supérieur auquel on puisse avoir recours.

L'avis se conclut sur l'avertissement du danger que représente Chichon pour le maintien de la France en possession du couvent de la Trinité, attendu que les jugements concédant le couvent «ne sont fondés que sur leur probité de vie », et demande donc logiquement que Chichon en soit retiré, ce qui invite alors à une lecture différentes des tentatives antérieures de 1636 pour obtenir du Saint-Office son expulsion, tentatives elles-mêmes peut-être prises dans des luttes de faction. Selon Benoist Pierre, les années 1630 et 1640 seraient marquées dans l'ordre par l'opposition entre deux tendances, dont l'émergence résulterait de la manière dont plusieurs religieux s'engagent dans «l'exaltation de la 
gloire royale $»^{82}$. L'une serait favorable à la tutelle d'un correcteur général étranger, quand l'autre serait plus sensible à l'autonomie de la branche française et resterait " globalement dans l'esprit de la double fidélité au roi et au pape, en accordant désormais la priorité au premier ». En l'occurrence, dans cette affaire où Chichon joue clairement un rôle important, c'est pourtant Chavyneau, fidèle thuriféraire de l'autorité royale qui serait du côté des défenseurs du général italien, quand c'est au contraire Chichon, qui, quoique vraisemblablement sensible à une forme de sentiment religieux gallican, est dans les années 1620 et 1630 clairement perçu comme désobéissant à l'autorité royale, qui est l'agent de Bachelier soutenu par le pouvoir français. En même temps, il demeure certainement vrai que des tensions de ce type existent et que Chichon et Bachelier arrivent à ce moment à faire passer auprès des autorités politiques - et notamment de l'ambassadeur - leur positionnement comme procédant justement d'une telle configuration des tensions internes.

\section{Le cas Chichon, I'Inquisition et la politisation des controverses doctrinales}

Ce qui frappe alors est aussi comment les tensions politiques ouvrent à un certain nombre d'acteurs des possibilités d'exploitation de la reconfiguration des grammaires de la vie régulière qu'elles imposent. Ceci vaut d'ailleurs pour l'autre contexte important du cas Chichon, la politisation des controverses doctrinales. De ce point de vue, les relations de Chichon avec les ambassadeurs du roi à Rome sont particulièrement intéressantes. Au début des années 1630, Brassac, informé par le pouvoir royal, le considère clairement comme désobéissant et dangereux. À la fin des années 1637, François Annibal d'Estrées fait de lui l'agent de ce qu'il voit comme la défense des intérêts du roi dans les conflits internes à l'ordre. Dans l'intervalle, les papiers du comte de Noailles pour l'année 1634 contiennent deux pièces concernant Nicolas Chichon: une lettre du roi à son ambassadeur et une lettre de Chichon adressée au même ${ }^{83}$. La lettre du roi a pour objet non seulement d'informer Noailles sur le cas Chichon mais aussi de l'envoyer au couvent pour faire brûler les papiers du minime sur une information de Chavyneau selon lequel Chichon "estoit sur le même subjet» que celui qui lui avait valu la prison et la destruction de ses manuscrits en France. La lettre de Chichon est une auto-justification de ses actions particulièrement intéressante :

Supplie très humblement frère Nicolas Chichon Minime, v[ot]re Excellence, et expose, qu'ayant traité des affaires de la foy avec honneur et augmentation d'icelle, contre un auteur Hespagnol, fust tousjours contrecarré par la faveur des Hespagnols, qui obtinrent le délaiement de l'examen des aultres propositions erronées pour arrester l'affaire. Ce pourquoy le suppliant demanda congé et obédience à la $S[$ ain]te Congrégation du S[ain]t Office pour s'en retourner en France. Mais par l'artifice de la même faction, fust envoyé à Renes, ou estant composa plusieurs oeuvres. Et entre aultres les paralelles du droit civil tant ancien des douze table, que nouveau, avec le droit divin des Juifz, avec de belles et sélectes questions, et entre aultres traicta qu'il n'est jamais permis de tuer les Roys, monstrant cela être défendu par le droict divin, naturel, des gens, civil et ecclésiastique, et par raisons démonstratives, lequel oeuvre fust veu par Mons[ieu]r le premier présidant de Cussé et du procureur général de sa Majesté au Parlement de Bretagne, lesquelz désirans estre imprimé et dédié à Mons[ieu]r le premier présidant et conjointement audit parlement, ayant le suppliant la permission d'imprimer de ses supérieurs majeurs vint à Tours, où il fust détenu avec toutes ses 
compositions, et cinquante pistolles, et empesché d'imprimer ne pouvant le suppliant recourir à qui de droict convenoit, cependant fust fait un livre contre son ordre et sa personne. De laquelle détention s'estant après appelé à Rome, et heu recours à la $\mathrm{S}$ [ain]te Congrégation a obtenu plusieurs décrets, mais tous invalidés par l'Eminent Cardinal Scaille, le maistre du Sacré Palais et son général calabrois et espagnol; telement que par leur artifice est empesché d'avoir ses escritz et cinquante pistolles (receues pour l'impression); et que pis est, devant le suppliant estre entendu sur deux autheurs, qu'il soustient hérétiques, par décret de la $\mathrm{S}$ [ain]te Congrégation, le susdit Cardinal a rapporté la cause donnant faulx entendre à la S[ain]te Congrégation, disant que le suppliant avoit esté entendu au détriment de la religion et notamment de sa personne.

Ce pourquoy supplie très humblement votre excellence le protéger, et favoriser à ce que ses escrits soyent transportés à Rome pour estre veus et appreuvés pour estre très utiles à l'estat et à la conservation de la personne de noz Roys de France luy faire la faveur de baiser les piedz à Sa Sainteté pour luy représenter mieulx ses affaires et le recommander au Cardinal Barbarin, qui despuis peu a les sceaux de laditte Congrégation.

31 La lettre est évidemment remplie de contre-vérités. Chichon présente son renvoi en 1626 comme un congé volontaire, affirme avoir eu de ses supérieurs une autorisation large de ses supérieurs pour imprimer alors qu'il affirme en France écrire de par l'autorité du Saint-Office, et surtout que les décrets qu'il aurait « obtenu » ont été invalidés par l'action conjointe du cardinal Scaglia, du maître du Sacré Palais Niccolò Ricardi et du général des minimes. On sait qu'au contraire les dominicains, à commencer justement par le maître du Sacré Palais et leur ancien confrère qu'est le cardinal de Crémone, ont introduit et soutenu la cause de Chichon au Saint-Office ${ }^{84}$. Riccardi en particulier était clairement considéré par Raynaud comme un ennemi de la Compagnie. Surtout, dans le «second procès de Valérien » c'est sur le rapport de Scaglia qu'est pris le décret du 31 août 1633 qui demande l'exécution du décret du 4 juin 1626 et par lequel l'Inquisition décide de presser Vitelleschi pour obtenir que Sirmond se justifie. Certes à ce moment Scaglia fait clairement partie de la faction espagnole de la curie romaine, faction dominante au SaintOffice. Par ailleurs à ce moment précis, même si Chichon considère ne pas obtenir suffisamment de l'Inquisition, et essaie surtout d'obtenir la publication du décret de 1631 qu'il lit comme un décret de suppression de la Disquisitio de Raynaud de celle du décret de 1626 qu'il voit comme un décret de censure de Valérien ${ }^{85}$. Quand justement Chichon renouvelle fin 1634 ses accusations contre le "théologien Hespagnol ", c'est à nouveau par Scaglia qu'il est reçu ${ }^{86}$. Ce qui est alors remarquable n'est pas tant la versatilité de Chichon mais bien plus le fait qu'elle soit possible.

32 C'est qu'en réalité la capacité de Chichon a instrumentaliser le processus de censure s'inscrit dans une généralisation des pratiques d'instrumentalisation des pratiques de régulation doctrinale. Bien entendu, le cas Chichon est pris dans la politisation des controverses doctrinales à un moment où les vives tensions des congrégations de auxilis continuent de structurer le champ doctrinal.

Ce sont alors les modes par lesquels les acteurs se manipulent et manipulent le processus de décision inquisitorial qui deviennent pertinents pour comprendre l'état et les formes de la politisation du champ doctrinal. 

des adversaires ne sont pas originaux, ils n'en sont pas moins intéressants dans leur réversibilité. Chichon ne cesse par exemple de revenir dans ses mémoires et suppliques sur les motions spirituelles derrière ses actions. Il présente d'ailleurs son passage à la controverse contre les erreurs des autres catholiques, dans la continuité de sa lutte contre l'hérésie, insistant par ailleurs sur le fait que c'est Dieu qui lui a inspiré le mouvement de combattre l'erreur et notamment son minutieux examen de Suárez. Dans la lettre qu'il écrit à son général en 1624, laquelle commence la cause, Chichon indique ainsi que c'est la guérison d'une hydropisie qui l'a convaincu que Dieu voulait qu'il fasse imprimer son travail ${ }^{87}$. En même temps, il semble bien que le langage qu'il utilise devant ses interlocuteurs de la congrégation ne soit pas le même que celui qu'il utilise devant les autres religieux des différentes communautés auxquelles il appartient. Ce point est d'ailleurs repris et retourné systématiquement par ses adversaires et notamment ses supérieurs, qui font fréquemment références au fait que Chichon aurait allégué des révélations surnaturelles sur les matières théologiques contestées et de s'en être autorisé auprès des communautés locales. Dans la lettre envoyée par le général à la congrégation au moment de la reprise de la cause de Chichon, il indique avoir reçu des informations du provincial de Tours indiquant que Chichon affirme avoir eu des révélations sur l'hérésie du P. Suárez et d'autres jésuites et sur sa mission d'en purger l'Eglise. Dans ses rapports avec le Saint-Office, cependant, Chichon ne va guère au delà de mentions d'inspirations et d'instigations divines dont il ne précise jamais le statut, par exemple lorsqu'il évoque la composition de son traité De iustitia humana lors de son retour en France. Pourtant la forme même des différentes versions de l'Isagoge errorum établissant la liste des erreurs repérées par Chichon chez Suárez atteste que, même devant le tribunal inquisitorial, Chichon semble ne pas avoir voulu renoncer, au moins à la forme de ce qu'il a probablement vécu comme une révélation puisque tout en modifiant le contenu théologique des propositions qu'il repère chez le jésuite espagnol, il maintient un temps le nombre précis de quarante-trois erreurs. Quand des résumés des erreurs lui sont demandés, il continue de les fournir en nombres symboliques de douze, dix ou sept. La congrégation ne pouvait pas ne pas voir les fondements des accusations implicites de dérive mystique portées par ses supérieurs contre Chichon.

C'est en effet aussi la manière dont la congrégation utilise Chichon qui semble tout à fait signifiante. Tout d'abord dans ses relations avec le minime français, l'Inquisition a plusieurs reprise fait le choix d'ignorer des informations dont elle dispose. L'exemple le plus flagrant est celui de la manière dont la congrégation fait semblant d'ignorer à plusieurs reprise que le Roi a ordonné, ou dit avoir ordonné (ce qui revient pratiquement au même), la destruction des papiers du bouillant théologien. La survie de la cause repose à plusieurs occasions sur cette ignorance feinte. De la même manière, l'accusation de motifs cachés de Chichon est portée dans plusieurs des correspondances qui parviennent à la congrégation. Le Père Le Page correcteur du couvent de la Trinité des Monts dénonce ainsi dès 1626 une stratégie de Chichon pour se maintenir à Rome ${ }^{88}$. De la même manière encore, la Congrégation semble ne rien faire face aux plaintes fréquentes, répétées et relativement attestées selon lesquelles Chichon ne cesse d'utiliser abusivement l'autorité du Saint-Office dans ses rapports avec plusieurs autorités et en particulier avec ses propres supérieurs. Sur le caractère même de ce dernier, les témoignages extérieurs semblent avoir été de peu d'effet pendant longtemps. Dès 1631, la congrégation dispose de lettres transmises par la province de Tours non seulement mettant Chichon vigoureusement en cause et le décrivant comme «tout à fait étranger au génie de la 
Religion ${ }^{89}$. Il est même décrit comme obstiné et dément. Même la relative véhémence de Chichon à l'endroit des retards de la procédure inquisitoriale et du délai pour obtenir une condamnation des auteurs qu'il accuse, ne semble pas lui valoir de réprimande.

Enfin, comme le suggère Jean-Louis Quantin, la question du cas Chichon est prise dans les rapports entre Urbain VIII et sa propre Inquisition. On a vu le Pape jouer un rôle décisif dans la conclusion de la première cause de Chichon au Saint-Office et dans son renvoi. Il faut peut-être ajouter qu'il n'est pas impossible que les théologiens et cardinaux qui utilisaient Chichon pour continuer à faire vivre la cause du suarézisme ${ }^{90}$ et plus généralement de la doctrine jésuite de la grâce, peut-être en l'attente d'un changement de conjoncture politico-théologique. Ainsi il est relativement frappant de voir que la longue durée de la cause de Chichon n'empêche pas que son cas ne parvienne que très rarement devant le Pape. En 1631-1632, au moment de la réouverture de la cause, deux décrets seulement sont pris en feria quinta, et c'est bien Urbain VIII qui ordonne à ce moment que les écrits de Chichon soient envoyés par les supérieurs locaux à Rome. À ce moment, comme le rappelle Jean-Louis Quantin, la politique du Pape à l'égard des Habsbourgs lui vaut un conflit majeur avec la faction espagnole et une menace de déposition ce qui conduit peut être Urbain VIII à laisser plus de champ libre au SaintOffice ${ }^{91}$. L'ordre du Pape d'écrire en France à propos de Chichon est pris le 4 mars 1632 soit quatre jours seulement avant la protestation de Gaspare Borgia en consistoire. Au minimum tout ceci constitue le contexte politique immédiat du renouveau de la cause. Il n'est pas impossible donc que sa durée s'explique par la capacité et la volonté de certains acteurs au Saint-Office de la maintenir vivante.

Par ailleurs, dans ce contexte particulier, il est aussi frappant de voir comment l'Inquisition joue sur la valeur et la signification de ses propres décrets. Ainsi, c'est à ce moment, au plus fort du second temps de la présence de Chichon à Rome, lorsque le Saint-Office reprend la cause de Valérien, que le décret d'août 1633 reprend deux décrets antérieurs ceux du 4 juin 1626 et du 16 janvier $1631^{92}$ dont les cardinaux demandent l'exécution, à la suite de quoi Rancati rencontre le général des jésuites qui écrit à son tour à Sirmond. De manière tout à fait significative, Chichon demandait déjà (en décembre 1632) à ce qu'on lui communiquât " les deux décrets » de censure contre Raynaud d'une part et Valérien de l'autre, afin de constater si la condamnation des deux auteurs y était expresse $^{93}$. Au commencement de 1633, c'est encore Chichon, à qui on a transmis le décret du 16 janvier en réponse à la requête précédente, qui en demande l'exécution, initiant ainsi la procédure qui aboutit au décret de renouvellement d'août $1633^{94}$. On voit donc tout d'abord ici que Chichon sert finalement de facilitateur et de catalyseur de la procédure qui en réalité vise la Compagnie et sa théologie. Mais ce qui frappe surtout est alors la capacité du Saint-Office à mobiliser l'histoire immédiate de sa propre procédure. Ainsi peut-on parler de véritable invention du décret de juin 1626, décret certes défavorable à la Compagnie, mais suivi justement en 1626 de la prise de position du Pape contre le minime. De la même manière, le décret de janvier 1631, un des rares pris coram sanctissimo, ordonnait au P. Vitteleschi de transmettre le pamphlet de Raynaud «si librum habet $\aleph^{95}$, et au Nonce d'en chercher copie. Le décret d'août 1633 présente implicitement le défaut d'exécution de ces deux décrets comme des désobéissances. En réalité, le Nonce avait répondu en mai 1631 ne parvenir à trouver d'exemplaire de la Disquisitio ni à Lyon, ni à Paris ${ }^{96}$. Quant au général, si on ne trouve pas trace de réponse de sa part, il n'y a pas non plus de trace d'une insistance de la part de l'Inquisition pour qu'il prenne sur lui d'obtenir un exemplaire du texte de Raynaud. La procédure ancienne jointe à la 
marginalisation des autres actes qui l'entourent sert à la relance de la cause à ce moment particulier.

\section{Conclusions}

38 Au final ce qui caractérise cette affaire est qu'à ce moment particulier de l'histoire des relations franco-romaines et de l'histoire des controverses et des pratiques de censures doctrinales, l'opportunité offerte par le cas Chichon ne se traduit pas du côté du SaintOffice romain par une quelconque revendication d'autorité doctrinale sur la France. Même les velléités de contrôle de l'activité éditoriale jésuite en France sont de peu d'importance. Quant à la correspondance avec la Nonce, elle est d'autant plus limitée que ce dernier ne semble guère tenté de se mettre en peine dans une cause où la position de la monarchie française est claire et explicite et peut-être aussi parce que la secrétairerie d'État n'est pas non plus dupe de l'utilisation de la cause par les théologiens du SaintOffice. Par ailleurs, l'état des rapports de force doctrinaux à Rome conduit même à favoriser un théologien français par ailleurs fermement gallican, même si la forme de son gallicanisme est à ce moment incompatible avec les attentes doctrinales de la monarchie française. Au final le cas Chichon se joue donc entre deux scènes remarquablement hétérogènes et qui par ailleurs construisent d'autant mieux leur hétérogénéité que les autorités réciproques qui les régissent se concèdent mutuellement le contrôle sur leur propre espace de publicité. Les espace ouverts à Chichon et que ce dernier parvient très efficacement à exploiter sont à la fois celui de cette hétérogénéité des contextes locaux mais aussi celui de la politisation des controverses doctrinales sur la scène romaine au lendemain des congrégations de auxiliis, laquelle lui permet justement d'échapper aux formes de politisation propres des controverses doctrinales en France.

En même temps, cette capacité d'une série d'acteurs (individuels, collectifs, institutionnels) à exploiter les procédures de censure dans le cadre de cette politisation demeure tout de même fortement limitée par la force de la forme-doctrine et le respect de l'institution inquisitoriale pour la formalité théologique de ses propres procédures. Dans le cas de Chichon, la faiblesse théologique de ses accusations contre Suárez avec des propositions trop simples et improbables et une accusation très crue de pélagianisme et de nestorianisme, fait que si les cardinaux ou théologiens qui le protègent peuvent lui demander de renouveler et reformuler régulièrement ses accusations, ils ne peuvent guère en faire la base d'un examen détaillé de la doctrine du théologien espagnol, de sorte que sa cause ne peut pas ne pas avoir une durée de vie limitée, quelque soit son utilité politique. Il faudrait pouvoir comparer ce dossier de ce point de vue avec d'autres plus tardifs. Mon sentiment est que cette la formalité des pratiques d'examen doctrinal ${ }^{97} \mathrm{a}$ sensiblement évolué à la fin du XVII siècle et que justement la cause de Chichon fait apparaître le contraste avec des pratiques de manipulations de la procédure et du vocabulaire de la censure qui semblent plus évidentes à la fin du $\mathrm{XVII}^{\mathrm{e}}$ siècle $^{98}$. Paradoxalement d'ailleurs, l'intensification de l'attention de l'Inquisition aux questions doctrinales françaises n'est certainement pas sans lien avec ce glissement de la formalité des pratiques de censures à Rome. 


\section{NOTES}

1. ACDF, un gros dossier dans les Censurae Librorum 1607-1625, dossier 18, Acta in Scripta Pris Nicolai Chicon [sic] Galli, in quibus pretendit probare reperiri plures errores in operibus Pris Suarez, 691-800, dossier 19, Acta in doctrinam homiliarum quas Pater Syrmundus Societ.Iesu sub titulo Valeriani episcopi Canobiensis typis mandari curavit, 802-825 et plusieurs décrets entre 1625 et 1637, une mention dans la correspondance diplomatique française depuis Rome, quelques mentions dans les papiers du chancelier Séguier, volume 49 dans le dossier sur les différends entre les minimes dans l'affaire dite Flache-Bachelier, BNF, Ms. fr. 17588, 238-530 et plusieurs sources imprimées concernant l'activité de controversiste antiprotestant de Chichon et la querelle autour des homélies de Valérien de Cimiez. Notons enfin une mention anonyme, neutre et rapide dans la correspondance de Mersenne, lettre 225 à André Rivet, 17 septembre 1632 indiquant que Théophile Raynaud a écrit « contre un des nostres qui essaye à Rome de faire condamner $\mathrm{S}$. Valère ancien évesque (que le P. Sirmond avoit fait imprimer des manuscrits) de Pelagianisme et de luy faire oster le nom de Saint que porte le manuscrit », Correspondance du P. Marin Mersenne Religieux Minime, t. III, Cornelis de Waard (éd.), Paris, 1969, p. 330.

2. Il est mentionné dans l'Histoire du Couvent royal de la Trinité du Mont Pincio à Rome, de F. Bonnard, Paris, 1933, p. 172 et dans P.J.S. Whitmore, The Order of Minims in seventeenth-century France, La Haye, 1967, p. 104. Une notice et quelques mentions dans les travaux d'Odile Krakovich, Le couvent des Mimines de la Place Royale, dans Paris et île de France, 30, 1979, p. 87-258 (117) et La vie intellectuelle dans les trois couvents minimes de la place Royale, de Nigeon et de Vincennes, dans Bulletin de la Société de l'Histoire de Paris et de l'îlede-France, 109, 1982, p. 23-175 (p. 125).

3. J.-L. Quantin, Philologie et querelle de la grâce au XVII siècle: Sirmond, Valérien de Cimiez et le Saint-Office, dans J. Elfassi, C. Lanéry et A.-M. Turcan-Verkerk (dirs.), Amicorum Societas. Mélanges offerts à François Dolbeau, Florence, 2013, 699-739. Je remercie vivement et chaleureusement l'auteur de m'avoir communiqué ce texte avant sa parution.

4. Sur lesquels on renverra à P. Broggio, La teologia e la politica. Controversie dottrinali,Curia romana e Monarchia spagnola ta Cinque e Seicento, Florence, 2009.

5. J.-L. Quantin indique que Costantino Testi (1584/5-1637) était d'une famille originaire de Ferrare au service de la maison d'Este, art. cit., n. 82. En 1625 au plus tard, Testi est socius du commissaire du Saint-Office.

6. Lettre de frà Costantino Testi au cardinal Scaglia, 27 août 1624, ACDF, Censurae Librorum 1607-1625, 692. La première liste des erreurs repérées chez Suárez se trouve en 693-694.

7. Lettre du 9 octobre 1624, ACDF, Censurae Librorum 1607-1625, 696.

8. F. Suárez, Operis de divina gratia tripartiti Pars Prima. Continens Prolegomena sex, duosque priores de necessitate divinae gratiae ad honesta opera libros, Lyon, 1620.

9. Dans la lettre de Testi à la congrégation du 9 octobre 1624, «E perche nella lra di VS Illma il fatto appare diversamente spiegato da quello ch'io scrissi al Sr Cardinale di Cremona, io glie ne aggiungerò qui brevemente il racconto, affinche non si equivochi. Un teologo de PP. Minimi scrive al suo Generale, e li domanda licenza di poter scrivere contro 
un tal libro publicato sotto nome del P. Franc. Suarez dopo la morte di lui, e manda al detto Generale copia delle propositioni pessime ch'in detto volume ha ritrovate. Non aggiunge però il titolo del libro, ne dice qual ne sia la materia. Si protesta bene di non credere che dalla penna del P. Suarez siano usciti errori tanto manifesti, e conoscuti da ogni christiano per eretici, e dannati dalla Chiesa ", ACDF, Censurae Librorum 1607-1625, 696.

10. «Et perche io desidero in tutto et per tutto far tutto qualche comentari havendo cognosciuto dintr'un libro posthume atribuito al Padre Suares quaranta tre errori non ho osato impugnarli supra il nome del P. Suares : ma al contrario io provo per piu di cinq.ta motivi che detto libro non e uscito d'un tanto grando personaggio, et disputo contra quel Suares falso ", lettre de Chichon au général des Minimes, datée de l'octave du SaintSacrement (1624, du couvent de Nigeon [sur la colline de Chaillot]), ACDF, Censurae Librorum 1607-1625, 698.

11. Décret du 24 novembre 1624, ACDF, Censurae Librorum 1607-1625, 697.

12. ACDF, Decreta 1625, 125v : 23 juillet, Chichon est envoyé au cardinal Asculanum [= d'Ascoli : Felice Centini (1562-1641)]

13. ACDF, Censurae Librorum 1607-1625, 700.

14. ACDF, Decreta 1625, 132v, décret du 5 août 1625.

15. ACDF, Censurae Librorum 1607-1625, 704-705, appendice 1 dans l'article de J.L. Quantin.

16. J. L. Quantin, art. cit.

17. Aucune pièce dans le dossier ne concerne Suàrez avant mars 1626, du moins si l'on peut dater de ce moment la lettre de Chichon à la congrégation dans laquelle il demande des examinateurs pour les quarante-trois erreurs repérées chez Suárez, [ACDF, Censurae Librorum 1607-1625, 706] et auquel le décret du 11 mars 1626 répond.

18. ACDF, Decreta 1626, 43v, décret du 11 mars.

19. Sur ce personnage important dans l'histoire des controverses doctrinales de la seconde moitié du siècle, voir B. Jennings, Father Luke Wadding, Dublin, 1957 et en particulier dans ce volume L. Ceyssens, Florence Conry, Hugh de Burgo, Luke Wadding and Jansenism, p. 295-404 ; J. O'Shea, The Life of Father Luke Wadding, Dublin, 1885 ; A. McKenna, Luke Wadding, dans Dictionnaire de Port-Royal, Paris, 2004, 1013 ; J. Mercier, Wadding, Luc, dans Dictionnaire de théologie catholique, 15, II, Paris, 1950, col.3495-349. Pour son rôle à Rome, voir P. Broggio, Un teologo irlandese nella Roma del seicento: il francescano Luke Wadding, dans P. Broggio, F. Cantù (dir.), Teologia e teologi nella Roma dei Papi (XVI-XVII secolo), dans Roma moderna e contemporanea, 2010, p. 151-178; eod., La teologia e la politica, p. 183-192.

20. Th. O'Connor, Irish Jansenists 1600-70. Religion and Politics in Flanders, France, Ireland and Rome, Dublin, 2008, p. 71-72.

21. J. L. Quantin, art. cit.

22. ACDF, Censurae Librorum 1607-1625, 708.

23. ACDF Decreta, 1626, 69v, décret du 28 avril.

24. Lettre à la congrégation, ACDF, Censurae Librorum 1607-1625, 710 et décret en répons, $711 \mathrm{v}$ et Decreta 1626, 78v, décret du 13 mai.

25. ACDF, Censurae Librorum 1607-1625, 712. 
26. ACDF, Decreta 1626, 99, décret du 17 juin.

27. ACDF, Decreta 1626, 129v, ACDF, Censurae Librorum 1607-1625, 720v.

28. ACDF, Censurae Librorum 1607-1625, f ${ }^{\circ} 715$ mémoire de Chichon avec une annotation du 29 juillet 1626, cité par J.-L. Quantin.

29. ACDF, Censurae Librorum 1607-1625, 722.

30. ACDF, Censurae Librorum 1607-1625, 723v décret du 8 août 1626.

31. ACDF, Decreta 1626, 156.

32. ACDF Decreta 1626, 162, décret du 9 septembre.

33. ACDF Decreta 1626, 174v-175, décret du 23 septembre.

34. Dans une lettre du 17 avril 1634 à l'ambassadeur de France à Rome, Chichon présente cet envoi à Rennes comme le résultat de l'action de la faction qui s'est opposée à lui à Rome, c'est-à-dire les Espagnols, Aff. Etr., Corres. Dipl., Rome 48, f 75 , dans une lettre de 1630 au Général des Minimes il présente aussi son envoi à Rennes « in extremitas Provinciae » comme un exil, ACDF, Censurae Librorum 1607-1625, 727.

35. Lettre d'André Chavyneau au Général, ACDF, Censurae Librorum 1607-1625, 733.

36. Valerianus Cemeliensis Episcopus integer Doctrinae labisque purus. Disquitio Theologica, qua Massiliensium, sive Semipelagianorum error circa saluts initium, accurate excutitur: et Parcus Charitatis, Valeriani criminator, repellitur. A Theophylo Raynaudo, Societatis Iesu, Theologo, Lyon, Claude Landry, 1632. Les approbations accordées par Robert Berthelot (Episcopus Damasci), Jean Claude De Ville, promoteur général de l'archidiocèse de Lyon et Étienne Binet, provincial des jésuites de Lyon, datent de juillet à septembre 1628.

37. Voir la lettre d'appel au Général, ACDF, Censurae Librorum 1607-1625, 727.

38. E. Nelson, The Jesuits and the Monarchy. Catholic Reform and Political Authority in France (1590-1615), Aldershot, 2005.

39. B. Pierre, Servir Dieu et le Roi : les Minimes et le pouvoir royal des guerres de Religion à la Guerre de Trente Ans, dans B. Pierre, A. Vauchez (dir.), Saint François de Paule et les Minimes en France de la fin du XVe au XVII siècle, Tours, 2010, p. 68-86.

40. Il est l'auteur en 1623, d'un Discours du devoir du magistrat à la prière d'un seigneur de ses amys et en 1628 des Lettres d'un solitaire au Roy, Princes et Seigneurs faisans la guerre aux rebelles. Avec un remerciement à la noblesse de l'affection qu'elle a tesmoignée ua service du Roy à l'abord des Anglois devant La Rochelle [textes signalés par B. Pierre, art. cit.]

41. Les censeurs d'office sont crées en 1623 et en 1629 c'est au Chancelier que revient la prérogative du choix des théologiens de la Faculté chargés d'approuver les livres religieux, H.-J. Martin, Livre, pouvoirs et société à Paris au XVII siècle (1598-1701), Genève, 1969, t. 1, p. 440-471. Il est difficile de ne pas lier en partie ces évolutions de la censure religieuse aux conflits théologiques de la fin du premier quart de siècle.

42. Acte d'appel dans ACDF, Censurae Librorum 1607-1625, 725.

43. ACDF, Censurae Librorum 1607-1625, 727.

44. La correspondance est transmise au Saint-Office par le général lorsqu'il remet la cause aux cardinaux, les trois lettres de Chavyneau se trouvent en ACDF, Censurae Librorum $1607-1625,732,733$ et 736 .

45. ACDF, Censurae Librorum 1607-1625, 724.

46. Odile Krakovich, Le couvent des Mimines de la Place Royale, dans Paris et Île de France, 30 (1979), p. 87-258 (117). L'auteur se trompe cependant dans la chronologie en faisant jouer 
un rôle important à Chichon à Rome en 1628. L'affaire dont il est question dans les pièces qu'elle utilise est la contestation de l'élection de Pizzurno en l'absence des française au chapitre de Gênes à l'automne 1637 et l'interdiction faite aux provinces françaises de communiquer avec ce dernier, P. J. S. Whitmore, op. cit., p. 103.

47. ACDF, Decreta 1631, 151, décret du 27 août.ACDF.

48. ACDF, Decreta 1632, 42, décret du 4 mars.

49. ACDF Censurae Librorum 1607-1625, 745.

50. ACDF, Decreta 1632, 51v, dércret du 23 mars.

51. ACDF, Censurae Librorum 1607-1625, 749

52. ACDF, Decreta 1632, 152, décret du 5 octobre.

53. ACDF, Decreta 1632, 155v, décret du 12 octobre.

54. Il est par contre certain que contrairement à ce qu'écrit Odile Krakovich [qui se base en fait sur une mention de l'ouvrage dans les manuscrits de la BNF] dans sa courte notice sur Chichon le de Occidendo tyrannum n'a jamais été publié [O. Krakovich, La vie intellectuelle dans les trois couvents minimes de la Place Royale, de Nigeon et de Vincennes, op. cit., p. 125.

55. ACDF, Censurae Librorum 1607-1625, 755.

56. ACDF, Decreta 1633, 14, décret du 19 janvier

57. ACDF, Decreta 1633, 39, décret du 2 mars.

58. ACDF, Censurae Librorum 1607-1625, 757 [date au dos, 758v]

59. ACDF, Censurae Librorum 1607-1625, 762v ; Decreta 1633, 150v.

60. On trouvera la lettre à l'Archivum Romanum Societatis Iesu, Franc 5 I 418v

61. ACDF, Censurae Librorum 1607-1625, 764 [lettre de Jacques Sirmond à Vitteleschi], 765v décret du 21 juin 1634 ; Decreta 1634, 109.

62. ACDF, Censurae Librorum 1607-1625, 764 [supplique de Chichon], et 767v, décret du 11 octobre 1634.

63. ACDF, Censurae Librorum 1607-1625, 770 [mémoire de Chichon], 771v et Decreta 1634, 199v, décret du 29 novembre.

64. ACDF, Decreta 1635,70 [25 avril], et 107v [ 27 juin]. Ces décrets ne se retrouvent pas dans le dossiers des Censurae Librorum.

65. ACDF, Decreta 1636, 67v, décret du 16 avril.

66. ACDF, Censurae Librorum 1607-1625, 774 [décret en réponse du 2 décembre 1636, 786v]

67. ACDF, Censurae Librorum 1607-1625, 775 [décret en réponse du 26 novembre 1636, $784 \mathrm{v}]$.

68. «Il sud Pre pretende come ha fatto sempre d'essere essente della iurisditione de superiori, quando tratta et e occupato [...] per negotii et servitio del Sto officio, et per solidare q.a pretensione pnta certi libelli d'appellationi, quasi l'impedissero di attenderci, dove li chiama suoi, adversarii, et parti, et l'incolpa con li loro adherenti quali sono tutti i frati d'essere incorsi in tutte le censure ecclesiastiche. / Pretende di potere uscire, come ha fatto sin adesso ogni volta che gli ne viene il capriccio sforzando i superiori di assignarli subito un compagno senza c'habbia rispetto ne risguardo ne a gironi, tempi , hore incommode ne a radunanze c'habbiano da fare i Padri ne all'altri impedimenti et necessita del convento basta che dua, e per affari et negoti del Sto Officio riducendo a q.o 
scopo tutte le sue attioni, essentioni, et astite del Con.to protestando di non far un passo senza espresso ordine di Sua Santità e di cotesta S. Cong.ne / Non si può esplicare, ma ben si provare colla testimonianza universale de tutti i padri, l'insulti, le violenze, et indegnità che usa contro i superiori e frati quando non adheriscono a i suoi capriccii, et quando essi superiori cosi per li bisogni et neccessità del con.to come per il tempo staordinario che il P.re vuol uscire non gli ponno subito assignar compagno. Non solamente li strapazza et minaccia con parole inguriose et gesti indecenti, et li chiama scommunicati, ribelli, et inobendienti al Papa et al Sto officio, ma anco presume contro ogni osservanza regolare d'uscire solo senza compagno come ha fatto, q.i giorni adietro, et minaccia far il simile per l'avvenire m.re non li sara subito assignato un compagno ogni volta che vorra uscire conforme alla facoltà, dice, che li danno i sacri canoni, et l'ordine espresso che n'ha de cotesta S. Cong.ne. / Pocchi giorni sono che in mezzo capitolo in presentia di tutti li Padri, invece di riconoscere l'errore ch'aveva fatto d'uscire solo, p.nto un libello d'appellatione al superiore, et con voce elata li chiama scommunicato, formalmente inobediente ribelle, privato et indegno della superiorità, et non lo riconosceva per superiore, et altre iniurie del che restono attoniti i Padri tanto più che si faceva beffe de precetti del sup.re di moderar la voce e le parole »,ACDF, Censurae Librorum 1607-1625, 776.

69. ACDF, Censurae Librorum 1607-1625, 777, 778 et acte d'appel en 779.

70. Décret du 2 décembre 1636, ACDF, Censurae Librorum 1607-1625, 786v

71. Lettre du nonce du 16 décembre 1636, lue au Saint-Office le 21 janvier 1637, Censurae Librorum 1607-1625, 786 [date de réception en 791].

72. «Monsieur le Comte de Brassac, ayant esté averty qu'un Religieux minime vouloit faire imprimer un livre qui contenoit des choses qui méritoient plustost estre supprimées que publiés comme il désiroit, contre la volonté mesme de ses supérieurs, j'ay cy devant donné ordre au PChavyneau provincial de Touraine de brusler les escrits dudict religieux, ce que vous témoignerez à nostre St Père, affin que la congrégation des réguliers estant informée que cela s'est fait par mon commandement fasse cesser les plaintes que ledict religieux fait contre ses supérieurs pour ce regard comme je m'asseure que Sa Saincteté aura agréable qu'il soit faict, priant Dieu qu'il vous ait Monsr le comte de Brassa en sa sainte garde ", ACDF, Censurae Librorum 1607-1625, 788.

73. ACDF, Censurae Librorum 1607-1625, 789, 790.

74. «Monsieur, j'ay receu vostre lettre escripte de Rome, du 13 Mars laquelle m'oblige à vous assurer en vérité que ce qui m'a meu à escrire au RP Chavyneau la lettre de laquelle vous me parles a esté la desfiance que j'ay eu qu'au livre que vous aviez composé de la Justice et que vous vouliez faire imprimer il ne s'y trouvast quelque discours inutiles qui d'ailleurs eussent donné juste subiect d'offence au publiq à quoy j'ay convié le R.P. Chavyneau de prandre garde et prévenir par sa censure le desplaisir qui vous pouvois arriver de cela et à tous ceux de v[ot]re ordre. Il est à louer de la prudente conduite qu'il a porté en cette occurrence, et le devez remercier de la bonté que avez receu de luy, Monsr l'estime que je fais de v[ot]re piété et de vos vertus et de la bonne volonté que vous m'assurez que vous avez tousjours pour moy me forcent à vous dire que vous debver chercher v[ot]re repos avec Dieu et vous désambarrasser de l'examen de tous ces livres d'autruy qui vous inquiètent et peuvent distraire d'autres exercices de dévotion qui vous seront plus aggreables et plus convenables à la vie religieuse que vous professez ", ACDF, Censurae Librorum 1607-1625, 791. La lettre est signée "Cussé », Jean de Bourgneuf est sieur de Cucé. Il est premier président du Parlement de Bretagne depuis 1597, voir la notice « Parlement de Bretagne » dans l'Encyclopédie, t. 12, Neuchâtel, 1765, p. 51. 
75. Supplique du général des jésuites, ACDF, Censurae Librorum 1607-1625, 795. Elle est non datée mais placée dans le dossier avant une lettre du 22 avril 1637.

76. ACDF, Decreta 1637, 71, décret du 15 avril.

77. Mémoire dans ACDF, Censurae Librorum 1607-1625, 799, mention lectum 800v, et Decreta 1637, 131, décret du 26 août.

78. Raisons que les Pères Provincial, Collègues et deffiniteurs de la province de France, dicte de Paris, de l'ordres Minimes opposent contre le R. Père Simon Bachellier prétendant faire la Visitte Généralle de ladicte province en vertu d'une commission du Rme Père Général, BNF, Ms. fr. 17588, 249.

79. P. J. S. Whitmore, op. cit., p. 103.

80. Voir Mémoire à ce que Raphael Pizurno gennois demeure Général de l'ordre des Minimes et que la division que l'on procure faire des provinces de France soubs prétexte de multiplier les suffrages de France aux chapitre généraux est abusive, BNF, Ms. fr. 17588, 257.

81. Ibid.

82. B. Pierre, art. cit., p. 79.

83. Affaire étrangères, Rome 48,74 : lettre du Roi au comte de Noailles; 75 , lettre du P. Chichon au Comte de Noailles. Les deux documents portent la même date du 17 avril 1634.

84. Voir J.-L. Quantin, art. cit.

85. ACDF, Censurae Librorum 1607-1625, 766, supplique de Chichon au Saint-Office (examinée le 11 octobre 1634, 767v).

86. Ibid.

87. «Dio m'ha fatto la gratia d'uscire d'una hydropisia tutta manifesta che mi fa grandemente confidare nella gratia d'iddio che fa chio m'obligo a stamparlo, ", ACDF, Censurae Librorum 1607-1625, 698.

88. Voir la première lettre de Jean Le Page à la Congrégation : « Espone alle SS. VV. Illme Il Pre Correttore del Convento della Sma Trinità de Monti humilissime loro oratore qualmente il suo Convento si ritrova gravato d'alcuni frati forestieri che sotto pretesto di negotii particolari si trasengono qui in Roma et in particolare dal Pre fra Nicolo Chisson [...] », Censurae Librorum 1607-1625, 714.

89. Voir les quatre lettres transmises par le général au Saint Office ACDF, Censurae Librorum 1607-1625, 731, 732, 733 et 736.

90. Au delà des congrégations de auxiliis, Suárez avait fait l'objet de quelques attaques au Saint-Office, par exemple en 1621-1622 autour de la question de la confession à distance, voir R. de Scoraille, François Suarez, de la Compagnie de Jésus, d'après ses lettres, ses autres écrits inédits, et un grand nombre de documents nouveaux, Paris, 1912-1913, v. 2, ch. 2, p. 89. Voir aussi E. Elorduy, Suárez en las controversias sobre la Confesion Epistolar, dans Archivo teologico granadino, 15, 1952, 215-292.

91. Voir aussi, A. Leman, III et la rivalité de la France et de la Maison d'Autriche 1631-1635, Lille, Paris, 1920, (Mémoires et travaux des facultés catholiques de Lille) et M. A. Visceglia, "Congiurarono nella degradazione del Papa per via di un Concilio » : la protesta del cardinale Gaspare Borgia contro la politica papale nella guerra dei Trent'anni, dans Roma moderna e contemporanea, 11, 2003, p. 167-93.

92. ACDF, Decreta 1633, f॰150v. Transcription du décret dans Quantin, art. cit., n. 207. 
93. « Supplicat devotus orator, ut dignetur sacra congregatio sibi concedi utriusq decreti copiam, cum ad hoc sint edita, ut prosint manifestata", ACDF Censurae Librorum $1607-1625,752$

94. ACDF Censurae Librorum 1607-1625, 759.

95. ACDF Censurae Librorum 1607-1625, 759

96. ACDF Censurae Librorum 1607-1625, 760

97. Sur la notion de "formalité des pratiques» et son importance pour l'analyse historiques des transformations du catholicisme au XVII siècle voir M. de Certeau, La formalité des pratiques. Du système religieux à l'éthique des Lumières (XVII ${ }^{\mathrm{e}}$ XVIII ${ }^{\mathrm{e}}$ siècles), dans L'Écriture de l'histoire, Paris, 1975, p. 153-214.

98. À titre de comparaison, on se permet de renvoyer à J.-P. Gay, Stratégies polémiques et champ doctrinal. La querelle du péché philosophique et les lignes de fracture d'un catholicisme fin de siècle, dans S. H. de Franceschi (dir.), Ruine et Survie de Port Royal, Chroniques de PortRoyal, 62, 2012, 167-200.

\section{AUTEUR}

\section{JEAN-PASCAL GAY}

Université de Strasbourg - EA 3400 ARCHE - jpgay@unistra.fr 


\title{
Paolo Sarpi a colloquio con i gallicani
}

\author{
Corrado Pin
}

alla memoria di Corrado Vivanti

Nel post-scriptum di una lettera a Ludovico Camerario del 10 aprile 1636, Ugo Grozio riportava l'incipit con cui Paolo Sarpi (1552-1623) da Venezia, in data 12 maggio 1609, si rivolgeva al giurista parigino Jacques Gillot : Si quam libertatem - così, senza preamboli - in Italia aut retinemus aut usurpamus, totam Franciae debemus. Vos et dominationi resistere docuistis et illius arcana patefecistis ${ }^{1}$; e aggiungeva, riandando alla recente contesa dell'Interdetto, che solo grazie ai francesi (nisi vos subvenissetis) Venezia aveva potuto resistere al pontefice romano. Un riconoscimento sincero per quegli aiuti politici, ma soprattutto dottrinari, espresso da Sarpi a uno dei più vivaci e battaglieri esponenti del gallicanesimo del primo Seicento, l'interlocutore epistolare al quale il frate veneziano si rivolgerà con più aperta confidenza. Quell'incipit Grozio l'aveva copiato sostando nella parigina biblioteca dei de Thou, di cui erano responsabili i fratelli Pierre e Jacques Dupuy. Un centro sarpiano, quello parigino, non meno attivo nel perpetuare la memoria di Sarpi di quello veneziano facente capo al confratello e discepolo fra Fulgenzio Micanzio e a un esiguo, ma battagliero manipolo di patrizi veneti, devoti custodi del messaggio sarpiano. A loro François-Auguste de Thou e il ginevrino, ma avvocato al Parlamento di Parigi, Elie Diodati, strettamente in contatto con i Dupuy, si erano rivolti per ottenere originali o copie di manoscritti sarpiani. Era così finito nella biblioteca dei de Thou, dopo molte insistenze, per es., il Trattato dell'Inquisizione ${ }^{2}$; e forse avevano ricevuto da Micanzio una prima stesura della Vita del padre Paolo, anch'essa presente presso i Dupuy, dove l'aveva potuta leggere ancora il Grozio ${ }^{3}$; ma Giorgio Contarini, uno dei patrizi della cerchia sarpiana, non si era lasciato convincere a far uscire da Venezia copia della «prima abbozzatura » dei tre capitoli di un'opera di fra Paolo intitolata Della potestà de' prencipi, che a detta di Micanzio se portata a termine sarebbe stata « la più bella et importante composizione [...] mai comparsa al mondo ». Ai Dupuy erano tuttavia pervenute se non le «206 rubriche» del disegno dell'intera opera, almeno le prime 34, che Grozio aveva copiato e di cui aveva espresso viva ammirazione, scrivendo al fratello Willem : Optarem et ego ultimam adiectam manum operi isti fratris Pauli, cuius pulchritudo quae futura fuerit satis ex titulorum delineatione apparet ${ }^{4}$. Ma su quest'opera incompiuta, strettamente connessa con il 
carteggio di fra Paolo con Gillot, dirò più avanti. Merita invece tornare un momento a Parigi, quando nella primavera del 1617 Sarpi, finalmente ma ormai troppo tardi, faceva pervenire a Jacques-Auguste de Thou il manoscritto dell'Istoria dell'Interdetto. Era Jacques Gillot a chiedere al servita veneziano il permesso di trarne copia, come sappiamo dall'ultima lettera al parigino del 4 luglio 1617, in cui fra Paolo, oltre a dargli il suo assenso, si raccomandava vivamente (maxime cupio) di portare i suoi saluti a Petrum Puteanum, recens notum, al quale, ricordava il servita veneziano, de Thou aveva affidato bibliothecae et editionis historicae cura ${ }^{5}$. Si chiudeva così, con un saluto al Dupuy, il cerchio dell'epistolario sarpiano con il mondo gallicano, che si era aperto con una lettera del 23 marzo 1604 proprio allo storico parigino, che Sarpi ringraziava per il dono della Pars prima delle Historiae sui temporis, soprattutto per aver fatto pervenire «nelle tenebre di queste reggioni » italiane una particolareggiata « cognitione » di quel turbolento ma vivace mondo francese. E non era di circostanza il sentito apprezzamento allo storico per avere saputo narrare la verità con «la libertà d'esprimerla senza odio o timore » a utilità di « tutte le province christiane " $^{6}$. «Libertà » e "province christiane » al di là delle singole confessioni sono due temi che ricorreranno nei rapporti di Sarpi con il mondo gallicano, in particolare nei due carteggi che prenderò in considerazione, quello più corposo con Jacques Leschassier, avvocato del Parlamento di Parigi, che va dal settembre 1607 al luglio 1613, e quello con il già nominato Jacques Gillot, dal marzo 1608 al novembre 1612, per riprendere nel luglio 1616 e terminare un anno dopo. All'accuratissima edizione del 1961, dovuta a Boris Ulianich, delle Lettere ai gallicani e all'ampia introduzione rimando per tutti i problemi connessi, dalle note biografiche, alle modalità con cui i carteggi avvengono, alla non del tutto chiara interruzione, solo in parte da addebitare alla preoccupazione per la segretezza, garantita quasi unicamente dalla disponibilità degli ambasciatori veneziani a Parigi appartenenti alla 'setta' sarpiana. Ma prima di avanzare a volo d'uccello alcune considerazioni su quei carteggi, mi permetto di osservare che se quello di Sarpi, come è stato autorevolmente affermato, è « senza ombra di dubbio, il più bell'epistolario vivente del secolo XVII " italiano ${ }^{7}$, e a contribuire a questo risultato figurano anche i carteggi sopra menzionati, tuttavia bisogna anche riconoscere che di fatto questi ultimi sono stati da sempre, anche in questi ultimi decenni, i meno frequentati. Prova ne sia che nelle Opere sarpiane uscite nell'ormai lontano 1969 a cura di Gaetano e Luisa Cozzi, e a tutt'oggi «il vertice - come è stato ancora recentemente scritto ${ }^{8}$-, senza alcun dubbio, delle ricerche intorno a Sarpi di tutto il Novecento ", nel ricchissimo capitolo La svolta nella vita del Sarpi. Contatti con gallicani e protestanti. 1607-1610 viene dedicata ai due gallicani poco più di una pagina, pur acuta, di presentazione e solo sette lettere, delle 80, del loro carteggio. Una scelta d'altronde comune ai più attenti studiosi sarpiani e, se si vuole, con qualche ragione : gli anni 1607-1610 sono quelli che vedono Sarpi al centro dell'attenzione non solo dell'ostile mondo romano, intento a smascherare presso il governo veneziano l"eretico' fra Paolo, ma anche di quello riformato con frequenti colloqui del servita con agenti protestanti e calvinisti d'Europa presenti a Venezia ${ }^{9}$. Motivi politici, si diceva già allora, in vista del gran disegno di formare un fronte europeo antiasburgico ; ma il mondo riformato non nascondeva vive anche se poco fondate speranze di portare Venezia nell'ambito della Riforma, facendo leva sull'indispensabile collaborazione politica e religiosa di Sarpi. Insomma, c'è al centro, come d'altronde da sempre, il problema del Sarpi cattolico o riformato, che finisce, come nel caso del carteggio con i gallicani, con l'oscurare o almeno col mettere in secondo piano aspetti di pari rilievo anche se meno appariscenti. 
2 Tema ineludibile quello delle convinzioni religiose di Sarpi, che s'affaccia da subito e percorre, benché in sordina, anche i carteggi con Leschassier e Gillot, con un Sarpi che senza alcun preambolo, ben sapendo a chi si rivolge, denuncia la mondanizzazione del papato romano confrontato con quello della Chiesa antica. Il papato e il suo totatus, secondo la celebre definizione data a Gillot ${ }^{10}$, l'ingens monstrum, l'horribilem illam omnipotentiam, o l'hanc tremendam et exorbitantem potestatem, unitamente ai suoi maggiori sostenitori, i gesuiti ${ }^{11}$, nonché il concilio di Trento e suoi decreti, ritmano quei carteggi e in taluni momenti, soprattutto dopo il 1610, diventano quasi ossessionanti. Abbondante dunque la messe di spunti sul papato e la curia romana, responsabili del tradimento del messaggio evangelico, ma tutto ciò non rappresenta la peculiarità di quel colloquio con $\mathrm{i}$ gallicani, dove il tema teologico (eccettuato quello ecclesiologico, ma non invadente) viene di norma evitato.

3 Il Sarpi di quei carteggi è quello che, una volta conclusa la vicenda dell'Interdetto, fa i conti con la nuova situazione politico-religiosa europea e veneziana; è il consultore intento a chiarire il suo ruolo, ancora indefinito, nei rapporti con il governo veneziano in vista di un'azione che riporti Venezia (grazie alla presenza attiva del frate veneziano e del patriziato a lui più vicino) nell'alveo di quei paesi europei che hanno già avviato, sotto molteplici forme, un ridimensionamento del ruolo politico della Chiesa romana. Un Sarpi concreto, lungimirante, che segue strade più realisticamente percorribili di quella, parallela, del febbrile contatto con i riformati europei nel loro perseguimento di un disegno dai contorni tanto imprecisi quanto storicamente inconsistenti di una rivoluzione religiosa in Venezia.

Sono la rievocazione dell'Interdetto e la situazione del dopo-Interdetto i temi che aprono il carteggio di Sarpi con Jacques Leschassier, con un incipit della prima lettera sorprendente e di indimenticabile effetto :

Dormiebamus (vir clarissime) profundum ac diuturnum soporem, cum fulmine ac tronitru excitati, caput semisomnes ereximus, ac statim, fragore cedente, eodem lethargo demersi sumus $^{12}$.

L'anno dell'Interdetto si era rivelato per Venezia una provvidenziale occasione per liberarsi d'improvviso da un lungo torpore, ma appena conclusa la contesa, denuncia Sarpi, si era tornati a bere "qualche oppiata del vase che addormenta tutti ${ }^{13}$. Non importa ora soffermarci né su quella esaltante esperienza politico-religiosa, né sullo sconfortante successivo disarmo generale del patriziato veneziano, che l'amico di Sarpi, il futuro doge Nicolò Contarini, bollava come " appuntamento di servitù », ora che nelle principali magistrature governative stava prendendo il sopravvento il patriziato filocuriale, che aveva con forza voluto la conclusione di quella lotta, e che ora cercava di ristabilire con Roma relazioni amichevoli, mettendo in sordina i motivi del passato contendere. Importa invece qui sottolineare quanto, poche righe dopo, Sarpi confidava al Leschassier, cioè che, grazie a quel risveglio, de vera libertate ecclesiae cogitare coepi. Dunque, un Sarpi inizialmente impreparato ad affrontare quelle discipline poi coltivate durante l'Interdetto (se intese come « cose serie, e non come a passatempi ${ }^{14}$, chiariva), dal momento che fino ad allora, confessava, « io aveva tutti i miei gusti nelle naturali e matematiche $»^{15}$. 
Nessuna intenzione di sminuire il fascino eccezionale dei pamphlets sarpiani usciti al tempo dell'Interdetto, che avevano suscitato l'entusiasmo, tra i tanti, di un Isaac Casaubon e di un Philippe Canaye de Fresnes. Un fascino, scrive Gaetano Cozzi, « di quelle pagine che sembrano riscoprire, nell'ambito della Chiesa di Roma, il respiro franco e coraggioso dell'antichità cristiana, e sciogliere le istituzioni dal peso dell'autorità temporale per riproporle nei limiti e nella grandezza di un'autorità spirituale $»^{16}$. Il lucido dettato sarpiano e i severi messaggi religiosi - inusitati allora nel clima controriformistico italiano - avevano fatto passare in secondo piano la debolezza iniziale del Sarpi giuridico, che si muoveva a disagio su un terreno non suo, così come traballante appariva la sua preparazione sul piano storico-ecclesiologico ${ }^{17}$. D'altronde durante la 'guerra delle scritture', esplosa nell'estate del 1606, che aveva visto fronteggiarsi gli intellettuali ecclesiastici e laici italiani ed europei, non solo Sarpi, tra quanti si erano schierati a fianco di Venezia, aveva guardato con particolare interesse alla Chiesa francese, al ruolo che vi aveva il sovrano, alle tradizioni delle libertà gallicane, alla dottrina conciliaristica, all'elaborazione del diritto ecclesiastico dei suoi giuristi. Quasi un percorso obbligato per i controversisti filoveneziani, non trovando pressoché nulla che potesse venir loro utile in quel frangente della cultura storica o religiosa della Serenissima.

7 A maggior ragione, in quel riflusso del dopo-Interdetto bisognava restare ancorati al mondo d'oltralpe, se non si voleva ripiombare nel tradizionale torpore. Già negli ultimi consulti del periodo dell'Interdetto, intesi a scongiurare un accordo con il pontefice, Sarpi aveva messo in guardia il governo veneziano dal rischio di un ricominciare daccapo. Nella sua dura condanna del papato controriformistico, il consultore aveva allora accomunato tanto le " nuove congregazioni de' religiosi ", che " così nelle confessioni, come in tutti li colloqui spirituali » inculcano «a qualche semplici » che il papa ha «dominio temporale [...] sopra tutti li prìncipi ", quanto i prelati veneti che "hanno tutti fatto giuramento al papa in forma di vassallaggio ", e dai quali quindi lo Stato non può ricevere sostegno, poiché « hanno li benefizi da Roma e di là ancora aspettano maggior grandezza ${ }^{18}$. Temi ricorrenti nel colloquio di Sarpi con Leschassier il nefasto influsso delle «nuove congregazioni » e i rapporti più difficili di un tempo con la gerarchia ecclesiastica veneta; ma era tutta la materia mista, prospettava fra Paolo a quel patriziato sempre più disposto ad accomodarsi col pontefice, che si prestava a futuri cedimenti alle pretensioni de' ecclesiastici, come recita l'omonima scrittura ${ }^{19}$, dove sono elencate ben 61 'pretensioni' della Chiesa romana, tra cui l'Inquisizione, la materia testamentaria e quella beneficiaria, il diritto d'asilo, gli ospedali, i monti di pietà, la giurisdizione su greci, su ebrei, sul Fondaco dei Tedeschi, il controllo dello Studio di Padova, la potestà coattiva pretesa dal papa e dai vescovi, i giuramenti, i beni immobili ecclesiastici ecc.

8 A quanti a Venezia avevano lottato in nome dell'autonomia politica e religiosa da Roma senza giungere a una irrealistica rottura con il papato, rimaneva quale sprone per continuare nell'azione intrapresa l'esempio del mondo francese, con una Chiesa che serbava la sua autonomia riconoscendosi unita intorno al suo sovrano, che garantiva la pace politica e religiosa anche in presenza di una confessione riformata dentro lo Stato. Un modello che trovava uniti nell'ammirazione il doge dell'Interdetto, Leonardo Donà, $\mathrm{e}$ Paolo Sarpi, come mostra un significativo episodio, che aveva al centro un libello gallicano, fatto conoscere al doge dall'ambasciatore francese a Venezia, Canaye de Fresnes, presentandolo come «la più bella, la più dotta scrittura che si possa vedere in lingua francese, nella quale è essortato il Re [...] a pigliar [l']utilissima impresa di un 
concilio generale $»^{20}$. Per il Donà Sarpi aveva tradotto sia quel libello, anonimo ma di Guillaume Ribier, intitolato Discours au Roy, sia la successiva risposta del gallicano a un contradditore, col titolo Apologie pour le discours au Roy sur la reunion de ses subjects en une mesme et seule religion, in cui Sarpi riconosceva con compiacimento molte proposizioni sparse nei suoi consulti e nei pamphlets a stampa del tempo dell'Interdetto, quelli che il papa Paolo V bollava come "pieni di dottrine eretiche", non ultima la proposta calorosamente sostenuta dal servita veneziano già nell'aprile 1606 di un appello della Serenissima al futuro concilio generale, proposta presto scartata dal Senato come troppo eversiva. Il caso Ribier si chiudeva a Venezia con un curioso corollario : con tempestività il testo francese del Discours au Roy usciva a stampa a Venezia con la traduzione sarpiana a fronte per volontà del doge Donà ${ }^{21}$. Una riconferma, se ce ne fosse stato bisogno, dello stretto legame culturale e religioso della Venezia dell'Interdetto e del dopo-Interdetto con la Francia cattolica di Enrico IV, su cui non è il caso ora di insistere.

9 Ma nel carteggio con Leschassier, e solo grazie a quel carteggio, veniamo informati di qualcosa di più : del progetto, quanto mai grandioso, di fra Paolo di trasporre sia pur con $\mathrm{i}$ debiti adeguamenti quel modello gallicano o più generalmente francese nel contesto politico-religioso veneziano. Non c'è lettera al giurista parigino, in cui il consultore veneziano, con l'intento di chiedere lumi giuridici su analoghi casi francesi, non riferisca su quanto sta affrontando in Collegio : materie di rilievo alcune, si vedrà, ma altre anche di poco conto (motivo questo, non ultimo, della scarsa valorizzazione del carteggio), che vedono fra Paolo in un faticoso tirocinio alle prese con la complessa materia giurisdizionale; ecco allora il tema delle censure ecclesiastiche per un rettore veneziano in Istria scomunicato dal vescovo di Trieste, o quello dell'exequatur regio inesistente nella prassi veneziana, eppure maximum caput libertatis ${ }^{22}$, o ancora i criticatissimi seminari tridentini, la commenda di una ricca abbazia, il giuspatronato della Repubblica anche sul clero regolare, l'accettazione, costantemente deplorata da Sarpi, dei decreti tridentini da parte della Repubblica veneta, la degradazione dei chierici, la professio fidei dei dottorandi allo Studio patavino, e potrei continuare. Il colloquio con Leschassier è tutto un susseguirsi di quesiti su istituti giuridici veneziani da rivedere, modellandoli sulla prassi giuridica francese, un avanzare perplessità su allegazioni di discutibili auctoritates, su canoni antichi, decretales pontificie, giurisprudenze di varie nazioni, in impaziente attesa dei responsi di quel maestro d'oltralpe, uomo " di tanta dottrina ", « nella cognizione de' canoni ecclesiastici il più dotto uomo ch'abbia conosciuto", così Sarpi ad altri corrispondenti, fino a confessare di «non essere in età più fresca, ché certamente non potrei contenermi di passar li monti » per conoscerlo, e rimpiangendo più volte di non avere in Venezia per collega " un tal consultore $»^{23}$.

10 E con il costante sostegno dell'amico gallicano fra Paolo prepara la più ambiziosa riforma che intende introdurre in Venezia, quella della materia beneficiaria. Impresa ardua, da promuovere con cautela, utilizzando quel poco di autonomia rimasta alla Serenissima, modificando formule, ripristinando leggi trascurate, discutendo di giuristi, di consuetudini e leggi, della prassi francese e di quella veneziana, controllando sistematicamente l'operato dei rettori di Terraferma e, non ultimo, affrontando l'aperta ostilità delle grandi casate del patriziato $e$ quibus episcopi et abbates assumuntur e del patriziato minore qui plures sunt, et eo pervicaciores nel procacciare a Roma qualche prebenda per i figli ${ }^{24}$. In ea cardo nostrae libertatis vertitur ${ }^{25}$, ripete spesso al Leschassier, riferendo della sua battaglia per la riforma beneficiaria ; ma già nell'aprile del 1610, dopo un anno e mezzo di tentativi, doveva tristemente ammettere che, nonostante tutti gli 
sforzi, neque dum quicquam obtinere potui ${ }^{26}$; poi per tre anni, quanto durerà ancora il carteggio con l'illustre giurista gallicano, di quell'esaltante progetto fra Paolo non farà più parola; e andrà disperso tra i suoi scartafacci, incompiuto e presto dimenticato, l'ampio consulto che stava preparando per una lettura in Senato ; consulto ricchissimo, in cui ci si imbatte in interi brani tolti di peso dal vivace carteggio in materia del servita con Leschassier; un consulto, verrebbe da dire, scritto a quattro mani, a cominciare dall'incipit, che dopo un avvio dal piglio biblico («quando Dio vuole conservare o augumentare uno Stato, assiste quelli che soprastanno al governo e li aggiuta ad impedire que' disordini che la potrebbono alterare »), passa, tra il sentenzioso e il provocatorio, alla ferma ammonizione :

È grandissima maraviglia, da non attribuirsi ad altro che alla divina custodia speciale, che questo Dominio si conservi, donando il pontefice più beni e più onori alli sudditi di Vostra Serenità che essa medesima non può donare, et essendo quello che il pontefice dona non cosa aparente e fumosa, ma vere e reali facoltà e richezze ample e grandi e molte, dove quelli onori che da Vostra Serenità sono donati per lo più non prestano se non sola materia di esercitarsi nella virtù e sono senza utile; $\mathrm{e}$ quelli che sono con qualche utilità sono pochi e di tenue profitto rispetto alli benefici ecclesiastici.

11 Un sincero omaggio al maestro parigino, il quale gli aveva manifestato tutta la sua sorpresa (la « grandissima maraviglia » di Sarpi), considerando

quo modo fieri potuit ut respublica duraret respublica suprema, cum multo plures et maiores honores det pontifex quam respublica, et satius sit ad cardinalatum et caeteras dignitates ecclesiasticas aspirare, quam ad ducatum venetum et caeteros honores reipublicae, quae sumptibus nobiliorum suorum, magis quam propriis, res suas ubique agere videtur.

Considerazioni che il servita veneziano faceva immediatamente sue, mentre informava Leschassier della sua faticosa e inconcludente opera di convincimento presso il patriziato: in hoc laboro, commostrans, quantum damni pariat habere in suis civitatibus et locis tot homines, eosque divites, qui omnem fortunam suam alteri principi acceptam referant ${ }^{27}$.

È questo solo uno dei tanti esempi che si potrebbero portare della convinta ammirazione per Jacques Leschassier e della pronta messa in atto della lezione del maestro parigino da parte del consultore veneziano ; che però mostra di muoversi in piena indipendenza nel contemporaneo Trattato delle materie beneficiarie, lavoro che, travalicando il caso specifico di Venezia e le eventuali riforme da introdurre nel Dominio, presenta un Sarpi - pur compiutamente indottrinato nella aggiornata cultura giuridica e filologica del Leschassier -, che sa guardare con straordinaria autonomia, attraverso l'istituto giuridico della materia beneficiaria, alla storia della Chiesa nella sua progressiva mondanizzazione e nel crescente perseguimento di interessi politici ed economici, che soffocano la sua originaria vocazione spirituale. Piace peraltro osservare con Gaetano Cozzi come l'Histoire de l'origine et $d u$ progrès des revenus ecclésiastiques di Richard Simon rappresenti «il massimo riconoscimento che la cultura storica del Seicento rendesse a quest'operetta del frate veneziano »; un dono, questa volta, aggiungiamo, della cultura veneziana a quella francese.

14 Nel dovermi congedare dal ricchissimo carteggio con Leschassier, che spalanca orizzonti come nessun altro carteggio sarpiano sul difficile ma stimolante rapporto del consultore con la classe dirigente veneziana, pur sempre tra le più vivaci e intelligenti d'Italia e $\mathrm{d}^{\prime}$ Europa $^{28}$, mi preme almeno sottolineare quello che considero il merito maggiore del giurista gallicano nei riguardi di Sarpi : l'avere favorito e accompagnato, più di ogni altro, una vera o propria conversione del frate veneziano al mondo del diritto, come è possibile 
seguire attraverso quell'eccezionale epistolario di formazione giuridica, forse unico nel mondo del diritto italiano del tempo; una conversione che inizia con la lettura di fra Paolo, al tempo dell'Interdetto, dell'ammiratissima Consultatio Parisii cuiusdam de controversia inter sanctitatem Pauli $V$ et Serenissimam Rempublicam Venetam, ad virum clarissimum Venetum e subito dopo del De la liberté ancienne et canonique de l'Eglise gallicane, aux Cours souveraines de France di Leschassier ${ }^{29}$. Quel vuoto culturale veneziano, che Sarpi aveva percepito durante il dibattito della 'guerra delle scritture', ora gli appariva in tutta la sua gravità e marcava vistosamente l'enorme distanza di cultura politica e giuridica tra Francia e Venezia ; distanza difficile da colmare, poiché, riconosceva Sarpi, vos iam ad summam arcem pervenistis; nos adhuc in initiis haeremus. Di qui l'aperta ammissione della sua impreparazione e la decisione di mettersi alla scuola dell'avvocato parigino, prendendo definitivamente le distanze dalla cultura giuridica dello Studio patavino, dove, riferiva ironicamente Sarpi, si deprecava che «lo studio delle leggi fosse andato rovinando ", postquam moderni aliqui voluerunt per historias et latinitatem leges interpretari ${ }^{30}$, cioè proprio quanto caratterizzava la migliore tradizione giuridica francese della scuola culta, di cui era esponente ammirato lo stesso Leschassier. Il diritto veneto, poi, che constava di paucissimae leggi ed esimeva i giudici da una preparazione giuridica, finiva per rivelarsi, secondo il frate veneziano, un pericolo costante per la sovranità della Repubblica. Senza una riforma della dottrina giuridica, riconosceva Sarpi, non ci si liberava dalla papalis monarchia, che era cresciuta proprio sub barbarie; dove invece latinitas revixit, lì era stata abbassata; e mentre in Francia abbondavano gli antiquitatis assertores, in Italia era già un miracolo ad Accursium redire ${ }^{31}$. Sorprendente questo Sarpi che mostra, lui di tutt'altra formazione, una coscienza così alta per la scienza giuridica, tanto da dichiararla indispensabile per la lotta contro Roma.

In questa temperie di studio e di azione, condotti in costante contatto con Parigi, non stupisce di leggere in una lettera inviata da Sarpi al residente veneziano a Napoli, Agostino Dolce, per avere informazioni sull'exequatur regio, una enunciazione tanto impegnativa quanto inattesa: «Ho gran desiderio - scriveva nell'estate del 1609 - non solo di metter insieme tutti li buoni instituti per quali un dominio vien governato con quiete in questi nostri tempi assai turbolenti, ma ancora li fondamenti e raggioni con quali essi instituti si sostentano $»^{32}$. Sentiamo in questa dichiarazione tutto il lungo apprendistato alla scuola di Leschassier in vista del grandioso disegno di una riforma politica e religiosa veneziana. Un disegno che prevedeva un ripensamento in profondità sullo Stato moderno, come si intuisce dal carteggio, da tempo iniziato, con Jacques Gillot, il fervente gallicano che già conosciamo, inviso ai gesuiti «per il bene che hai fatto al mondo - gli scriveva Sarpi il 15 settembre 1609 - con la pubblicazione degli atti del concilio di Trento e con i trattati in difesa della libertà gallicana $»^{33}$.

In quella stessa lettera, Sarpi ringraziava l'amico parigino per l'invio del libro di William Barclay De potestate papae an et quatenus in reges et principes seculares ius et imperium habeat (1609), libro che susciterà, come ben noto, un ampio dibattito non solo in Francia in seguito alla replica di Bellarmino con il suo Tractatus de potestate Summi Pontificis in rebus temporalibus (1610). Dal settembre 1609 all'ottobre 1610, in un carteggio non fitto ma densissimo di riflessione politica sui rapporti fra potestà civile ed ecclesiastica, tra regno celeste e regno mondano, Sarpi, dopo avere pienamente lodato la dottrina (mihi maxime 
probantur ${ }^{34}$ ), sottoponeva tuttavia a rigorosa critica, giudicandole inconsistentes, le soluzioni fornite da quell'autorevole esponente della dottrina gallicana (e nella critica sarpiana rientrerà ben presto anche il pensiero di Edmond Richer, fino al più tardo $D e$ ecclesiastica et politica potestate del 1611), in sostanza auspicanti una equilibrata convivenza dei due supremi poteri. Per Sarpi, invece, la sovranità - semplifico al massimo - che è solo secolare, non contempla compromessi : nessuna pacifica coesistenza paritaria è possibile tra i due poteri (non possunt colligari nullo modo, nullis vinculis, nullis nexibus, nisi alter sub altero, prorsus et in omnibus, ponatur), poiché la maiestas non vult mutuas operas, illas vult omnes subiectas, nihil oportet rege maius, nihil regi par. E allora «nella vita civile» non c'è posto per due poteri uguali e indipendenti, cum ambae potestates, ecclesiastica et saecularis [...] necesse est vel alteram alteri, vel ambas alicui summae potestati humane subesse, pena fare della christianam rempublicam un monstrum biceps ${ }^{35}$. Qui la millenaria diatriba di Stato e Chiesa risulta superata: nessuno scontro (né incontro), perché non c'è terreno su cui incontrarsi o scontrarsi ; nell'ambito temporale non c'è spazio per un potere della Chiesa in quanto Chiesa, che vive in un'altra dimensione, quella spirituale. Si tratta di una soluzione che prescinde da presupposti religiosi, perché tutta giustificata in nome del principio puramente laico della sovranità del Principe, che è tale perché Principe, non perché cristiano, come invece Sarpi ancora ribadiva al tempo dell'Interdetto, dietro le suggestioni gallicane. Un percorso nuovo, dunque, che fra Paolo aveva compiuto in stretta condivisione di idee e di analisi (ed è un vero peccato che ci manchino le lettere di Gillot) con il giurista parigino : Quod ad te scripseram - gli confermava fra Paolo il 2 marzo 1610 de potestatibus, quibus hic mundus et regnum coelorum administratur, antea mea fuerat opinio tantum, modo cum tibi probari videam, ac etiam ratione firmari, mea erit sententia ${ }^{36}$. A Gillot, che lo incitava ad affrontare in una sistematica opera la complessa dottrina, considerandolo dotato delle indispensabili competenze di un giurista, di un teologo e di un politico, Sarpi rispondeva dichiarando la sua inadeguatezza, ma intanto sottoponeva all'amico parigino la soluzione sopra ricordata, pregandolo tuttavia di tenere per sé (in sinum tuum liberius commisi, quae tamen omnibus communicari nolim) quelle provvisorie deduzioni (mea imperfecta), che avevano un così stimato interlocutore (satis magnum theatrum tu mihi $e^{37}$ ).

Ritroveremo quelle considerazioni, esposte in forme più radicali, nel già menzionato Della potestà de' prencipi, lavoro abbozzato tra il 1610-1611, presto interrotto e non più ripreso, che alterna a passi di eccezionale efficacia comunicativa e di cristallina espressività, degni del miglior Sarpi, momenti poco perspicui, che finiscono con il trascinare l'assunto iniziale di grande respiro in una diatriba di carattere controversistico. Qui basti un solo passo, notevole per il piglio vigoroso e il rigore espositivo :

Il re e Prencipe, di che parlo, debbe aver esso la maestà, sia mo esso un uomo particolare, overo un'adunanza de pochi o de molti, come nell'aristocrazia e democrazia, non vi è differenza. Chi ha la maestà commanda a tutti e nessuno può commandar a lui ; egli non ha obligazione ad alcuno, tutti sono obligati a lui, non è soggetta a nessuna legge umana, sia qual si voglia, ma egli commanda eziandio a tutte le leggi, né in modo alcuno può obligarsi ad alcuno delli suoi sudditi ; se in una regione sarà legge che oblighi il re, quello non sarà re di che parliamo, ma soggetto a chi l'obliga a quella legge. Il re che è sovrano non commanda secondo le leggi ma alle leggi stesse, resta ubligato solo a Dio e alla sua conscienzia. [...] è tenuto il Prencipe governar bene, ma non ha obligazione di ciò al popolo, ma a Dio; è obligato se giura, se promette, ma non al popolo, se ben a Dio e alla conscienzia propria; eli giuramenti che li re sovrani fanno nelle loro coronazioni non sono ubligazioni al popolo, ma a $\mathrm{Dio}^{38}$. 
18 un testo che colpisce, commenta Corrado Vivanti, per la decisa affermazione di teorie assolutistiche con cui si attribuisce al principe un potere totalmente legibus solutus; un'affermazione che va al di là della stessa concezione monarchica francese, anticipando « alcuni approdi del pensiero politico secentesco », tra cui « il germogliare di principî laici nella società politica $\|^{39}$. E una radicalità ancora più scoperta si coglie nelle relative 'rubriche', come quelle che recitano : «Che la principal cura data da Dio al Prencipe è della religione »; «Che la cura del Prencipe è di far che li sudditi tengano la verità », $\mathrm{e}$ persino : «Al Prencipe appartiene congregar li ministri [ecclesiastici] per avvisar sopra la verità e sopra la disciplina della Chiesa $»^{40}$. Formulazioni perentorie, geometriche, che al di là delle dottrine gallicane e del pensiero politico-giuridico di Bodin anticipano non solo il groziano De imperio summarum potestatum circa sacra,ma fanno anche intravedere le soluzioni radicali hobbesiane sul rapporto Stato-Chiesa.

Concezioni lontane dal tono colloquiale dei consulti, che in quel torno di tempo Sarpi andava componendo, dove in realtà compito ben più circoscritto e realistico del consultore veneziano era quello di suggerire le modalità giuridiche per limitare l'invadenza di una Chiesa romana che, forte del suo diritto canonico e di una prassi consolidata da secoli, pretendeva e di fatto esercitava una sua sovranità sul territorio e sui sudditi della Serenissima; un'invadenza a cui il sovrano patriziato veneziano non sempre aveva saputo reagire con la fermezza mostrata in occasione della contesa dell'Interdetto.

Nonostante il conclamato mito della Serenissima, allora ampiamente diffuso anche oltralpe, della sua «libertà intellettuale e religiosa $»^{41}$, l'epistolario sarpiano è tutto percorso dalla coscienza del perdurante giogo politico e religioso delle " due monarchie ", spagnola e romana, che grava "sopra il collo d'Italia », « una sopra i corpi e l'altra sopra le anime $\aleph^{42}$, a cui il servita con inconsueta caparbietà contrappone l'irriducibile ideale del vivere libero e "della libertà del parlare $»^{43}$. Sarpi confida (in sinu amici), a Leschassier : iugo premimur, quod quidam amant, alii levius exoptant, quidam excutere prorsus vellent; in postremis ego ${ }^{44}$. Nei carteggi con i due giuristi gallicani la voce libertas non manca naturalmente di rimandare alle libertates ecclesiae gallicanae, come si è visto, tuttavia la libertas, a cui più di frequente Sarpi allude, è quella dell'affrancazione dal " giogo ».

21 È una siffatta libertas, in quei carteggi, a farsi metro di confronto tra la Francia e l'ItaliaVenezia. Vos iam ad summam arcem pervenistis; nos adhuc in initiis haeremus, aveva scritto Sarpi, con il ribadito auspicio: utinam particula libertatis vestrae uteremur ${ }^{45}$ Che poi quel giogo per fra Paolo sia anzitutto da identificare nell'Inquisizione romana è troppo noto. Un giogo talmente pesante che per liberarsene sarebbe stata necessaria una guerra in Italia : "Se sarà guerra in Italia [...] l'Inquisizione cesserà e l'Evangelio averà corso ", scriveva nella primavera del 1610 all'ugonotto Jérôme Groslot de L'Isle, e lo ripeteva qualche mese dopo a Leschassier, osservando che il papa aveva le sue buone ragioni per voler la guerra lontano dall'Italia, nam inter arma Inquisitio cessaret ${ }^{46}$. E all'Inquisizione s'accompagnava, ancor più gravoso, il giogo sulla parola (loquendi libertatem) e sul pensiero, tant'è vero che durante la controversia dell'Interdetto, i romani non solo, denunciava Sarpi, nobis ademisse agendi et loquendi libertatem, ma pretendevano di controllare etiam nostris cogitationibus et animis ${ }^{47}$. Sconfortante l'ammissione espressa a Leschassier: Libens eos libros lego, qui ab hominibus liberis compositi sunt. Italis ingenium non 
deest, neque tamen illo uti possunt ${ }^{48}$; e pur non giustificando il comportamento pusillanime di molti intellettuali italiani, ribadiva l'incresciosa situazione: nisi bello aliquis aditus ad conscientiae libertatem aperiatur, loqui libere non audemus. Sic sumus Itali! Pauci bene agere volunt, et qui id cupiunt, non nisi tuto aggrediuntur ${ }^{49}$. Non è questa la sede per soffermarci sugli occhiuti controlli dell'Inquisizione sul commercio di libri provenienti soprattutto da oltre confine, e su cui Sarpi amaramente ironizza :

Ella non potrebbe immaginarsi - così a Groslot de L'Isle - quanto siamo custoditi dagli innamorati della nostra libertà, così in casa, con spie, come nelli circonstanti paesi, con guardie aperte. In Inspruch ed in Trento si fanno ricerche e diligenze esquisite, che non siano portati libri qua. Hanno in Bergamo, Verona, ed in Vinezia stessa, diligentissime spie, per esplorare a chi siino inviati pacchetti. A me questi andamenti non dispiacciono, sapendo che moroso geloso acquista sempre maggior odio, e constringe in fine a scuotere il giog $0^{50}$.

Situazione insopportabile e opprimente (domini librorum esse volunt!: denuncia amaramente a Leschassier ${ }^{51}$ ) quella che Sarpi mette davanti agli amici francesi (poco importa qui se gallicani o riformati), ma si ha l'impressione che gli amici d'oltralpe stentino a cogliere tutta la gravità delle conseguenze religiose e civili lamentata dal consultore, forse ancora impressionati dalla libertas mostrata dai veneziani durante la contesa dell'Interdetto ${ }^{52}$.

E mi piace allora concludere con l'allarmato auspicio di Sarpi rivolto agli amici gallicani e in particolare al 'maestro' Jacques Leschassier sul gravissimo caso di censura libraria, questa volta interessante il libero e vivace mondo parigino, con la nota vicenda di Edmond Richer e del suo De ecclesiastica et politica potestate (1611) :

Ut dixi - scriveva preoccupato il servita veneziano -, arbitror libertatem vestram, et (addam) nostram, in eo stare, ut libellus ille vivat, et orbi appareat esse catholicos qui illum probent, quamvis sint qui damnent, et esse publicam auctoritatem qui illum defenda ${ }^{53}$.

Ora erano in gioco, avvertiva Sarpi, anche la Chiesa gallicana e lo Stato sovrano francese, ma ancor più la varietà e ricchezza del mondo dei cattolici, che non intendevano riconoscersi in un unico cattolicesimo, nonostante che il nunzio pontificio a Parigi, Roberto Ubaldini, tacciasse l'opera del Richer nient'altro che «un riepilogo dell'abominevole dottrina di Marsilio da Padova, dell'Illirico, di fra Paolo da Venezia e di tutti gli eresiarchi che abbiano mai scritto contro la supremazia di san Pietro ${ }^{54}$.

\section{NOTES}

1. P. Sarpi, Lettere ai gallicani, a cura di B. Ulianich, Wiesbaden, 1961, p. CLXXXIV.

2. Si vedano in merito le interessanti informazioni di St. Garcia, Elie Diodati et Galilée. Naissance d'un réseau scientifique dans l'Europe $d u \quad X V I I^{\mathrm{e}}$ siècle, préface d'I.Pantin (Bibliothèque d'Histoire des Sciences), Firenze, 2004, p. 64-80.

3. Cfr. A. Barzazi, Fulgenzio Micanzio, Vita del padre Paolo, in P.Guaragnella, R. Abbaticchio, G. De Marinis Gallo (dir.), L'incipit e la tradizione letteraria italiana. Seicento e Settecento, Lecce, 2010, II, p. 32. 
4. Cfr. P. Sarpi, Della potestà de' prencipi, a cura di N. Cannizzaro, con un saggio di C. Pin, Venezia, 2006 ; Sarpi aveva abbandonato l'opera sul finire del 1610 dopo averne abbozzato i tre primi capitoli e steso un piano di lavoro con 206 'capi' o 'rubriche' (il testo si legge alle p. 31-74, i 206 Capi d'un trattato imperfetto di padre Paolo alle p. 75-88). Sulla pagina autografa di Grozio, che copia le prime 34 'rubriche', scrive H.J.van Dam, Italian friends. Grotius, De Dominis, Sarpi and Church, in Nederlands archief voor Kerkgeschiedenis, 75, 1995, p. 189-215, segnatamente le p. 212-213: "Shortly afterwards, Grotius sent the outline of an unfinished book by Sarpi to his aged friend, the Remonstrant leader Wtenbogaert. It consists only of the titles of the projected chapters, but they are enough to show how fine a book this would have been, according to Grotius. Grotius' own manuscript of De imperio has one leaf, superscribed 'fra Paolo', containing what is undoubtedly the outline in question, written in Italian, in his own hand. The titles of 34 chapters are given, and it is immediately clear that they must have pleased Grotius »; e sull'opera rimasta incompiuta Grozio scrive al fratello Willem, in data 10 settembre 1639.

5. Sarpi, Lettere ai gallicani... cit., p. 163.

6. Ivi, p. 167.

7. Cfr. A. Asor Rosa, Genus italicum. Saggi sulla identità letteraria italiana nel corso del tempo, Torino, 1997, p. 354 (già in Id., "Istoria del concilio tridentino » di Paolo Sarpi, in Letteratura italiana. Le Opere, II. Dal Cinquecento al Settecento, Torino1993).

8. Cfr. M. Ciliberto, Alcune ipotesi su Sarpi, in Id., Pensare per contrari : disincanto e utopia nel Rinascimento, Roma 2005, p. 447 ; ma si veda anche l'importante recensione di C. Vivanti, L'opera che mancava su Paolo Sarpi, in Rivista storica italiana, 82, 1971, p.917-925; naturalmente, il riferimento è a P. Sarpi, Opere, a cura di G. e L. Cozzi, Milano-Napoli, 1969 (rist. nei « Classici Ricciardi-Mondadori », Milano-Napoli, 1997).

9. Su questo periodo con la missione veneziana del calvinista Jean Diodati, i rappresentanti dell'Unione Protestante di Halle, l'inviato dell'influente principe riformato Christian von Anhalt, Christoph von Dohna, le quotidiane relazioni con l'intraprendente ambasciatore inglese Sir Henry Wotton attraverso il cappellano dell'ambasciata William Bedell di tendenze puritane basti il rimando, con bibliografia essenziale, a cap. III.1. Sarpi consultore in iure : un incerto e difficile avvio (anni 1607-1609) dell' Introduzione, in P. Sarpi, Consulti, a cura di C. Pin, I (1606-1609), Pisa-Roma, 2001, t. I, p. 65-83, segnatamente p. 71.

10. Il termine totatus è usato da Sarpi la prima volta nella lettera a Gillot del 15 settembre 1609, quando scrive che ciò a cui aspirano a Roma non est primatus, sed totatus, si liceat vocabulum effingere ex eo quod abrogato omni ordine totum omnino uni tribuunt, cfr. Sarpi, Lettere ai gallicani... cit., p. 134.

11. Basti almeno l'accusa bruciante: Non satis habent, nobis ademisse agendi et loquendi libertatem, nisi etiam nostris cogitationibus et animis impotenter dominentur, in Sarpi, Lettere ai gallicani... cit., p. 128.

12. Ivi, p. 3.

13. Cfr. P. Sarpi, Lettere ai protestanti, a cura di M.D. Busnelli, Bari, 1931, I, p. 4, 4 settembre 1607. La bibliografia sull'Interdetto veneziano del 1606-1607 è molto ampia, qui basti il rimando a G. Benzoni (a cura di), Lo Stato marciano durante l'interdetto 1606-1607, Atti del XXIX Convegno di Studi Storici, Rovigo, 3-4 novembre 2006, Rovigo, 2008.

14. Sarpi, Lettere ai protestanti... cit., I, p. 22, 22 luglio 1608. 
15. Lettera del 22 luglio 1608 all'ugonotto Jerôme Groslot de L'Isle, ivi.

16. Cfr. Sarpi, Opere... cit., p. 121.

17. Sull'argomento si veda l'Introduzione $\mathrm{Da}$ avvocato della Serenissima a consultore del Senato, in Sarpi, Consulti, I, tomo I, p. 30-37.

18. Cfr. consulto 19, in Sarpi, Consulti cit., I, p. 463-479; per il consulto Come metter fine al monitorio si legga ivi, p. 450-457.

19. Cfr. Sarpi, Consulti cit., I, p. 480-488, segnatamente p. 488.

20. Archivio di Stato di Venezia, Collegio, Esposizioni, Roma, reg. 15, c. 156v-157r, 14 maggio 1607.

21. Su tutto il caso, di cui Sarpi informa gli amici francesi, sulla sua traduzione consegnata al doge Donà e sul recente rinvenimento dell'edizione veneziana a stampa, finora sconosciuta, si veda $\mathrm{M}$. Venard, Le projet d'un nouveau concile dans la France d'Henri IV , in Autour du concile de Trente (XVI ${ }^{e}-X V I I^{e}$ ), éd. M. Viallon, Saint-Étienne, 2005, p. 47-60.

22. Cfr. Sarpi, Lettere ai gallicani cit., p. 23, 2 settembre 1608.

23. Per i passi citati dal carteggio a Groslot de L'Isle e ad Antonio Foscarini, si veda Sarpi, Lettere ai gallicani... cit., p. LXXXI.

24. Ivi, p. 64, 22 dicembre 1609 ; sulle pingui entrate ecclesiastiche, appannaggio di grandi case patrizie, si veda la Premessa al consulto 84 con relativa bibliografia in Sarpi, Consulti cit., II, p. 915-925.

25. Sarpi, Lettere ai gallicani... cit., p. 81, 27 aprile 1610.

26. Ivi, 17 agosto, p. 90.

27. Per il testo del consulto e per una meno sbrigativa documentazione sul contesto di detto consulto 84 (fine 1609 - primi mesi 1610), si rimanda alla relativa Premessa e alle note in Sarpi, Consulti cit., II, p. 915-925, in particolare per le citate lettere di Leschassier del 25 gennaio e di Sarpi del 30 marzo 1610.

28. Cfr. G. cozzi, Paolo Sarpi tra Venezia e l'Europa, Torino, 1979, Introduzione, p. XIII ; C. Vivanti, Introduzione in Sarpi, Istoria del concilio tridentino, a cura di C.Vivanti, Torino,1974, p. XXXV ; sui giudizi non benevoli sul patriziato veneziano cfr. c. Pin, «Qui si vive con esempi, non con ragione ": Paolo Sarpi e la committenza di Stato nel dopo-Interdetto, in Ripensando Paolo Sarpi. Atti del Convegno Internazionale di Studi, 17-19 ottobre 2002, in occasione del $450^{\circ}$ della nascita di Paolo Sarpi, Ateneo Veneto, a cura di C. Pin, Venezia 2006, p. 367-368.

29. Sulle due opere cfr. Ulianich in Sarpi, Lettere ai gallicani cit., p. LXXIII-LXXIV ; merita riportare quanto Sarpi nella sua prima lettera a Leschassier del 4 settembre 1607 scriveva : Apparuit eo tempore consultatio tua ex qua, iuxta proverbium, velut ex ungue leonem, te cognovimus, quam et maxime aestimantes illico hic imprimi curavimus. Ego illam avide perlegi, sed et libellum de la liberté, qui post apparuit, in quibus valde placuit, quod aperte ostenderis, nedum antiquum codicem canonum extitisse, sed quibus canonibus constaret edocueris, in Sarpi, Lettere ai gallicani... cit., p. 4.

30. Ivi, p. 12, 13 maggio 1608.

31. Ivi, p. 34, lettera del 23 dicembre 1608.

32. Cit. in sarpi, Consulti... cit., I, Introduzione, p. 13.

33. Sarpi, Lettere ai gallicani... cit., p. 136, lettera del 15 settembre 1609 ; il testo latino recita : pro beneficiis quae orbi praestitisti publicatis actis concilii Tridentini, ac tractatibus pro 
gallica libertate. Affrontare il tema della raccolta di documentazione sul Tridentino esigerebbe una lunga digressione; ma è doveroso almeno osservare come proprio in una lettera a Gillot del 18 marzo 1608 s'affacci per la prima volta lo specifico argomento dell'allestimento del cantiere sarpiano in preparazione di quella che sarà l'Istoria del concilio tridentino; momento ancora preliminare alla composizione dell'storia, ma prima esplicita testimonianza di un rinnovato interesse di Sarpi all'argomento, che porterà in breve alla decisione, a cui non sembra pertanto estraneo proprio il giurista parigino, di metter mano all'Istoria, cfr. ivi, p.127-129. Sul probabile inizio della composizione del capolavoro sarpiano intorno al 1610-1611 mi permetto di rimandare a C. Pin, Les Consulti de Paolo Sarpi et son Histoire du concile de Trente, in Autour du concile de Trente... cit., p. 95-100 ; naturalmente, va accantonata la datazione troppo precoce del 23 agosto del 1608 quale prima esplicita testimonianza del progetto sarpiano di mettere mano a una storia del Concilio, progetto confidato da Sarpi a Christoph von Dohna, l'inviato del principe Christian von Anhalt : grazie alle ricerche di Boris Ulianich (Christoph von Dohna, Christian von Anhalt e la 'Istoria del Concilio Tridentino' di Paolo Sarpi, in Annuarium historiae conciliorum, 31, $\mathrm{n}^{\circ} .2$, 1999, p. 367-426, segnatamente p. 387-388 e nota) sappiamo con certezza che tale colloquio non avviene, come stabilito da M.D.Busnelli, nel 1608 (cfr. Sarpi, Lettere ai protestanti cit., II, p. 128), ma almeno cinque anni dopo.

34. Scrive Sarpi di Barclay: Cuncta quae hic auctor magno iudicio collegit et digessit in hoc opusculo, mihi maxime probantur. Si invicem sermones miscuissemus, vel alter alterius scripta vidisset, non poterat ille ad meum sensum aptius ordine digerere, quae ego sparsim in meis disputationibus cum Romanis nostris exposui, in Sarpi, Lettere ai gallicani... cit., p. 136, 29 settembre 1609.

35. Ivi, p. 137, 29 settembre 1609.

36. Ivi, p. 144.

37. Ivi, p. 143-144, 8 dicembre 1609.

38. Cfr. Sarpi, Della potestà de' prencipi... cit., p. 52.

39. C. Vivanti, Sarpi e la Chiesa nell'età della Controriforma, in Studi Veneziani, N.S., 54, 2007, p. 132.

40. Cfr. Sarpi, Della potestà de' prencipi... cit., p. 52 e 76.

41. Cfr. W.J. Bouwsma, L'autunno del Rinascimento 1550-1540, Bologna, 2003, p. 160.

42. Cfr. Sarpi, Lettere ai protestanti... cit., I, p. 282-283.

43. L'espressione si legge all'inizio del Libro V dell'Istoria dell'Interdetto, cfr. P. Sarpi, Istoria dell'Interdetto, a cura di C. Pin, Conselve (Padova), p. 181.

44. Sarpi, Lettere ai gallicani... cit., p. 79, 27 aprile 1610.

45. Ivi, p. 98

46. Ivi, p.92, 14 settembre 1610; per la citazione precedente cfr.Sarpi, Lettere ai protestanti... cit., I, p. 120, 27 aprile 1610. Sul tema della guerra in Italia si veda di A. Denis, Venise 1608-1610: paix ou guerre, dans la correspondance de Paolo Sarpi, in Bibliothèque d'Humanisme et Renaissance, 67, 2005, p. 625-640.

47. Cfr. Sarpi, Lettere ai gallicani... cit., p. 128, lettera a Jacques Gillot del 18 marzo 1608.

48. Ivi, p. 84, 8 giugno 1610.

49. Cfr. Sarpi, Lettere ai protestanti ... cit., II, p. 209, lettera a Philippe Duplessis-Mornay del 6 luglio 1610. 
50. Ivi, I, p. 153, 8 luglio 1608.

51. Cfr. Sarpi, Lettere ai gallicani... cit., p. 78, 27 aprile 1610.

52. Merita ricordare come una lettera anonima (ma subito e con ragione attribuita al gesuita Antonio Possevino) indirizzata a Sarpi nell'agosto del 1606 denunciasse, sia pur con buona dose di esagerazione, che nella Venezia dell'Interdetto « gli eretici, gli apostati, i scismatici godono una diabolica libertà » e che «il tremendo tribunal del Santo Offizio s'incomincia aver in deriso e in ludibrio", cfr. C. Pin, "Capo, maestro e consultore d'un infamissimo scisma »: Paolo Sarpi e l'interdetto di Venezia del 1606-1607, in G. Benzoni (a cura di), Lo Stato marciano... cit., p. 216-217.

53. sarpi, Lettere ai gallicani... cit., p. 115, 14 agosto 1612.

54. Dispaccio del 31 gennaio 1612, cit. in G. Piaia, Marsilio da Padova nella Riforma e nella Controriforma. Fortuna ed interpretazione, Padova, 1997, p. 374.

\section{AUTEUR}

\section{CORRADO PIN}

Istituto Italiano per gli Studi Filosofici, Napoli - cp41@libero.it 


\section{Venise et la France}




\title{
Le mythe politique de la Sérénissime contre les hantises de théocratie. L'hétérodoxie vénitienne face à l'orthodoxie romaine au début de la crise de l'Interdit (1606-1607)
}

\author{
Sylvio Hermann De Franceschi
}

1 Les temps posttridentins ont soudainement assisté à l'impétueuse réassurance politique d'une papauté dont l'autorité avait pu sembler un temps ébranlée sous l'effet dévastateur de la diffusion des thèses adoptées par les réformateurs protestants. Au tournant des XVI ${ }^{\mathrm{e}}$ et $\mathrm{XVII}^{\mathrm{e}}$ siècles, les théologiens défenseurs du pontificat romain se rangent derrière la doctrine - pour la première fois formulée dans les célèbres Disputationes de controuersiis christiance fidei (1586-1593) du jésuite Robert Bellarmin (1542-1621) - de la potestas indirecta du pape in rebus temporalibus, qui revendique pour le souverain pontife le droit d'intervenir au temporel pour autant que les intérêts du spirituel le requièrent ${ }^{1}$. D'un inquiétant projet de réaffirmation de la puissance du Saint-Siège a témoigné avec éclat la crise de l'Interdit vénitien (1606-1607)², qui a été l'occasion d'une impressionnante polémique où s'est exprimé un antiromanisme catholique très virulent.

2 Les causes ponctuelles du différend qui éclate un an après que le pape Paul $\mathrm{V}$ a accédé au trône de saint Pierre sont connues. Le 17 avril 1606, le nouveau pontife fulmine la Bulle Superioribus mensibus par quoi il excommunie le doge et le Sénat de la Sérénissime et impose au territoire de la république lagunaire le plus drastique des interdits ecclésiastiques. À l'origine de la sentence pontificale, l'adoption par la Seigneurie de trois lois qui allaient, d'après Paul $\mathrm{V}$, à l'encontre de la liberté de l'Église : la première, du 23 mai 1602, réglait la question de la dévolution des biens immeubles autrefois ecclésiastiques et depuis détenus en emphytéose par des laïcs en tranchant l'épineux dilemme au détriment des gens d'Église dans le cas d'une extinction de la lignée directe de l'emphytéote; la deuxième, du 10 janvier 1603, interdisait la construction d'édifices 
religieux, églises, monastères, hospices, sans l'expresse autorisation préalable du pouvoir séculier; la troisième, du 26 mars 1605, limitait sévèrement la capacité des sujets vénitiens de faire des legs pieux et faisait prohibition d'aliéner perpétuellement des biens immeubles laïcs en faveur de personnes ecclésiastiques sans accord de la puissance lagunaire. Autre grief retenu par le souverain pontife à l'encontre des autorités vénitiennes, la bruyante incarcération, durant l'été 1605, de Scipione Saraceni, chanoine de Vicenza, accusé d'avoir rompu les sceaux publics apposés aux portes de la chancellerie de l'évêché vicentin, alors vacant, et surtout d'avoir poursuivi de ses indécentes assiduités une veuve de la noblesse du lieu, allant jusqu'à souiller sa porte d'excréments après que ses avances véhémentes ont été, et fort vaillamment, repoussées. Presque au même moment, le redouté Conseil des Dix se saisissait de la personne de Marcantonio Brandolin Valdemarin, abbé de Nervesa, à qui l'on reproche, entre autres, empoisonnement, homicide, inceste, parricide, escroqueries, stupre, viols et violences diverses. Assurément peu fréquentable, l'abbé entretient chez lui un prêtre sinistrement renommé pour ses pratiques de sorcellerie et ses vénéneuses compétences; il fait régulièrement bastonner ses concitoyens quand ils ont le malheur de lui déplaire; il entretient des relations charnelles avec sa propre sœur. Si la dignité ecclésiastique du chanoine et de l'abbé leur valait sans doute le droit de n'être déférés que devant un tribunal d'Église, la gravité des chefs d'inculpation, criminels ou relatifs à l'ordre public, pouvait sans contredit les qualifier pour une justice civile.

3 Aux réclamations du pontife romain, qui exigeait du pouvoir lagunaire qu'il révoquât les trois lois de discorde et qu'il remît les deux prisonniers au magistrat ecclésiastique, la Sérénissime a opposé les obligations qui lui incombaient pour rester fidèle à un modèle politique devenu mythique ${ }^{3}$ - discours qui mêlait adroitement les principes d'un républicanisme d'origine florentine et la référence aux impératifs absolutistes de la moderne raison d'État ${ }^{4}$. D'origine désormais pluriséculaire, le mythe politique vénitien avait gagné en force au lendemain du désastre d'Agnadel, le 14 mai 1509 : les troupes de la Sérénissime avaient été sévèrement défaites par l'armée du roi de France Louis XII. Venise avait affronté ensuite une crise politique et institutionnelle dont le traumatisme allait perdurer pendant plusieurs décennies. Or, au grand étonnement des contemporains, les institutions vénitiennes avaient été capables de solidement résister aux vives turbulences engendrées par le conflit de la Ligue de Cambrai - stupéfiante résistance qui avait permis de présenter la Sérénissime comme un modèle exemplaire de buon governo et la seule incarnation historique encore du meilleur régime politique selon les théoriciens depuis Aristote, soit un État mixte, composant harmonieusement les avantages respectifs de la monarchie, de l'aristocratie et de la démocratie. Dès lors, immédiate la reprise du mythe d'un modèle républicain indestructible et dont l'impavide solidité est soigneusement mise en relief dans deux textes capitaux qui participent pleinement à l'aménagement historique de ce que John Pocock a appelé «le moment machiavélien ${ }^{5}$. Rédigé entre 1525 et 1527, le traité Della Repubblica dei Venetiani (1540) de Donato Giannotti (1492-1573) est œuvre d'un exilé florentin antimédicéen, ami de Machiavel, et qui a autrefois fréquenté les Orti Oricellari avant d'enseigner à l'Université de Pise ${ }^{6}$. Patriote, Giannotti n'est pas un admirateur inconditionnel de la rivale lagunaire ; en elle, il a seulement cru trouver l'enviable incarnation du régime mixte vanté par Aristote et Polybe, soit une solution terrestre dont pût s'inspirer Florence pour répondre aux défis posés par la crise qu'elle traversait. Écrit dans les années 1520 ou 1530, et assurément moins technique que le traité de Giannotti, le De magistratibus et Republica Venetorum de Gasparo Contarini (1483-1542) ne tente pas de brosser un tableau complet 
des institutions vénitiennes ${ }^{7}$; adoptant d'emblée le ton d'un panégyrique, Contarini insiste quant à lui sur l'exceptionnelle virtù développée par les citoyens de la Sérénissime dans le cadre d'une existence civile qui est active - suivant une exigence pour la première fois formulée par les humanistes civiques de Florence. Si différents soient-ils, Giannotti et Contarini ont chacun été poussés à leurs méditations par les événements qui ont suivi le conflit de la Ligue de Cambrai, secousse politique inaugurale sans quoi ne pouvait naître un mythe vénitien. En survivant à un désarroi militaire et institutionnel qui avait dû emporter sous le poids de ses décombres les conditions de son autonomie temporelle, Venise a administré la preuve de l'irréfragable perfection de sa constitution. Avec Contarini s'affirme pour la première fois le thème, fondamental chez les penseurs politiques $\mathrm{du} \mathrm{XVI}^{\mathrm{e}}$ siècle, d'une libertas Veneta tenue pour immarcescible ${ }^{8}$. Mythe dont la prégnance continue à s'affirmer au tournant des $\mathrm{XVI}^{\mathrm{e}}$ et $\mathrm{XVII}{ }^{\mathrm{e}}$ siècles, alors même que la Sérénissime assiste au début de son déclin diplomatique. Dans ses Antiveneti rédigés pour défendre les positions de la papauté à l'occasion de la crise de l'Interdit, Tommaso Campanella (1568-1639) évoque une Venise "unica fenice, vergine sempre, libera sempre $"^{9}$ - il décelait involontairement la vigueur renouvelée de deux éléments cruciaux dans la définition du mythe vénitien, soit la millénaire longévité d'institutions pérennes et la liberté originelle.

Dès le début des contestations entre la papauté et les autorités lagunaires, le heurt entre deux libertés, l'ecclésiastique et la républicaine, et qui s'affirment également imprescriptibles, est frontal ${ }^{10}$. Le 17 avril 1606, la Bulle Superioribus mensibus conclut le processus de rupture initié six mois auparavant ${ }^{11}$. S'adressant aux gens d'Église, réguliers et séculiers, qui résident sur le territoire de la Sérénissime, Paul V rappelle d'abord que les récents décrets vénitiens comportent des dispositions qui répugnent à l'autorité du Saint-Siège et portent gravement atteinte à la liberté et à l'immunité ecclésiastiques, libertas ac immunitas ecclesiastica ${ }^{12}$. La suite du texte énumère les trois lois incriminées et s'indigne de l'arrestation du chanoine Saraceni et de l'abbé Brandolin. Pour le pontife romain, le doute n'est pas permis : les méfaits des gouvernants de la Sérénissime portent un grave préjudice à l'autorité pontificale, Sedis Apostolicee ac nostrce auctoritati, aux privilèges des personnes ecclésiastiques, personarum ecclesiasticarum priuilegiis, et aux droits de l'Église, ecclesiarum iuribus; ils détruisent même liberté et immunité ecclésiastiques, ipsam libertatem ac immunitatem ecclesiasticam ${ }^{13}$. Au doge et au Sénat vénitien, vingt-quatre jours sont accordés pour annuler leurs lois, libérer les deux ecclésiastiques incarcérés et promettre de s'abstenir de promulguer à l'avenir semblables décrets contre la liberté, l'immunité et la juridiction de l'Église et du Saint-Siège, contra libertatem, immunitatem et iurisdictionem ecclesiasticam ac nostram et Sedis Apostolice auctoritatem ${ }^{14}$. La Bulle Superioribus mensibus soulevait inlassablement la question de la libertas ecclesiastica, de quoi le pape restait le suprême garant ecclésial contre les empiétements du pouvoir civil.

5 Face à l'orthodoxie ecclésiologique maintenue par le souverain pontificat, le pouvoir vénitien a aussitôt défendu les principes d'un républicanisme considéré comme non moins orthodoxe et que venaient justifier les composantes désormais caractéristiques du mythe politique de la Sérénissime. Adressée à l'ambassadeur vénitien à Rome, Agostino Nani, le 5 novembre 1605, une délibération du Sénat prise l'avant-veille, 3 novembre, est particulièrement éloquente. Alors que la rupture avec le Saint-Siège n'est pas encore à l'ordre du jour, le Sénat a appris avec stupéfaction que Paul V s'était plaint à Nani de l'arrestation du chanoine Saraceni et de la législation vénitienne relative à l'aliénation de 
biens laïcs en faveur de personnes ecclésiastiques. Étonnement d'autant plus grand que les dirigeants de la Sérénissime, est-il affirmé, n'ont jamais eu pour intention d'offenser le pape. Au contraire le souverain pontife ne craint-il pas, lui, de porter atteinte à la libre intégrité de la République: "Contra l'uso ordinario et in pregiuditio della libertà del nostro governo, si pretende che noi habbiamo a render conto delle deliberationi che fa la Republica per servitio del suo Stato et in beneficio de' suoi sudditi ${ }^{15}$. » Les autorités républicaines n'ont jamais entendu empiéter sur la juridiction d'autrui, encore moins sur celle du Saint-Siège. Elles acceptent d'offrir au pape quelques explications, mais elles ne le font que par chrétienne considération puisqu'elles affirment en même temps « che né per termine di conscientia, né per alcuna sorte di obligo non dovemo render conto ad alcuno delle deliberationi che la Republica, nata et conservata sempre libera per gratia del Signor Dio, fa per solo benefitio del Stato suo et de' suoi sudditi $»^{16}$. Discours qui conjoint étroitement souveraineté républicaine, liberté originelle, bien public et droit divin - pour les Vénitiens comme pour les théologiens romains, il n'est manifestement de puissance que de Dieu. Le Sénat n'oublie naturellement pas d'invoquer les valeurs essentielles d'un pouvoir républicain qui se fonde sur une prudence proverbiale, une insigne piété, une vénérable maturité et le consciencieux respect des impératifs du buon governo - gouverner est d'abord conserver: "Le deliberationi che nascono dal Senato, ch'è Principe di inveterata prudentia et di altretanta pietà et religione, sono fatte sempre con gran maturità, et questa [legge] particolarmente [intorno alla alienatione delli beni laici] è stata fatta per termine di buon governo, et ha in sé somma honestà, poiché attende alla conservatione non meno de' sudditi che della Republica istessa ${ }^{17}$. » Le Sénat le redit : par sa récente législation, il n'ordonne rien aux ecclésiastiques; ses dispositions ne s'appliquent qu'à ses sujets laïcs et à leurs biens, sur lesquels il prétend détenir puissance et domination absolues, assoluta potestà et dominio. Quant à l'incarcération du chanoine Saraceni et de l'abbé Brandolin Valdemarin, les autorités lagunaires justifient leur geste par les nécessités de la raison d'État: "Quando non vi fusse un conseglio tale che reprimesse la insolenza di ecclesiastici nelli delitti enormi, si sovertirebbono li popoli, et se inquietarebbe il Stato quando fussero lasciati in libertà di fare tutto quello che li venisse voglia ${ }^{18}$.» Affirmation d'une autorité d'autant plus imprescriptible qu'elle est un don de Dieu : aux revendications romaines, le pouvoir vénitien opposait une souveraineté républicaine intangible.

6 En d'autres termes, la cité lagunaire mêlait à son républicanisme traditionnel, et pour la défense duquel elle entendait lutter, des éléments d'absolutisme qui devaient - du moins l'espérait-on - lui valoir la bienveillance de monarques chrétiens peu soucieux de voir l'emprise de l'Espagne se consolider en péninsule italienne après un éventuel triomphe du Saint-Siège. Au lendemain de la fulmination de la Bulle Superioribus mensibus, le discours tenu par l'ambassadeur vénitien en France, Piero Priuli, lors d'une audience que lui a accordée le roi Henri IV est parfaitement clair. Le diplomate en rend compte le 9 mai 1606 dans une dépêche adressée à la Seigneurie ${ }^{19}$. Au roi de France, Priuli a remontré qu'il n'était pas possible de satisfaire aux demandes du pape «senza particolar danno della libertá et ragioni della Serenissima Republica ». Venise entend préserver ses libertés républicaines et sa souveraineté sans avoir, par ailleurs, l'ambition condamnable d'étendre le champ de sa domination : « [La Republica] ha per fine di venerare Sua Santitá come padre, sostentare li suoi popoli come buon principe, et esser stata ardente in conservare le sue giuridittioni, come non è punto ambitiosa di amplificarle, né avida ad usurpare quelle degli altri. » Se décrit, au contraire, et comme en négatif, le portrait du pape en mauvais prince désireux d'accroître indûment ses prérogatives au détriment de 
la santé du corps ecclésial. À l'égard de quoi les dirigeants vénitiens ne peuvent que répéter une doctrine visiblement vectrice d'absolutisme : «Oltre all'esser signori liberi et assoluti ne' loro Stati, non conosc[o]no nel loro dominio altra superioritá che quella di Dio solo. » À son interlocuteur, Henri IV a manifesté bienveillance et compréhension, avouant qu'il considérait lui-même que les réclamations pontificales allaient trop loin.

7 Les témoins directs du conflit ont naturellement suivi avec intérêt grandissant l'affrontement qui se déroulait sous leurs yeux entre deux conceptions chacune également absolutiste, l'une qui mettait en avant l'orthodoxie ecclésiologique d'une liberté ecclésiastique imprescriptible, et l'autre qui se prévalait du mythe politique vénitien pour sauvegarder les libertés républicaines. Observateur attentif des événements, Philippe Canaye de Fresnes (1551-1610) ${ }^{20}$, ambassadeur de France à Venise, a témoigné d'un choc par où Rome a acquis confirmation douloureuse de l'hétérodoxie d'une modernité politique qui s'abritait désormais derrière la récente raison d'État. Le 15 avril 1606, le diplomate rendait compte de la situation vénitienne à François d'Alincourt, son homologue en cour de Rome. Canaye de Fresnes relève que les dirigeants de la Sérénissime ont été extrêmement surpris par l'opiniâtreté du pontife romain et qu'ils estiment unanimement "ne pouvoir donner [à Sa Saincteté] le contentement qu'elle désire sans préjudicier grandement à leur souveraineté $»^{21}$. L'ambassadeur a examiné les textes produits par les défenseurs du Saint-Siège, et son verdict est sans appel - la cause de la Sérénissime est celle de n'importe quel prince : «J'ai mis quelque peu le nez és écrits des docteurs canonistes, et advouë que si Sa Saincteté les croit, non seulement la condemnation de cette République est toute certaine, mais il faudra mesme abolir une bonne partie des ordonnances de nos Roys et apprendre une nouvelle jurisprudence à nos Parlemens; mais qui joindra la prudence politique à l'estude des loix et des canons reconnoistra avec moy que ce seroit une entreprise bien haute de vouloir faire un monde nouveau et heurter toutes les couronnes de la Chrestienté2 2 . » En vertu de quoi Canaye de Fresnes considérait que le plus prudent était d'attendre et de laisser la longueur de temps et la patience l'emporter sur l'impatience et l'emportement d'un pontife irréfléchi.

8 Au fil des dépêches qu'il adresse à ses correspondants, et en particulier au souverain français, Canaye de Fresnes témoigne de l'expression conquérante d'un républicanisme de plus en plus intransigeant. Le 15 avril 1606, il informe Henri IV des justifications apportées par les Vénitiens aux lois incriminées par Paul V. Concernant l'interdiction d'édifier hospices, couvents et monastères sans autorisation préalable du Sénat, les autorités lagunaires invoquent fermement la sécurité de leur État : « Depuis peu, quelques malins esprits, voulans couvrir leurs mauvaises intentions du prétexte de dévotion, ont voulu introduire des religieux de pays estranges dans aucunes de leurs forteresses et leur $\mathrm{y}$ construire des monastères en lieux manifestement suspects et préjudiciables à la seureté desdites places ${ }^{23}$. Au surplus, les dirigeants vénitiens n'entendent évidemment pas brider la dévotion de leurs populations ni manifester une quelconque hostilité à l'égard du pape - la mesure n'a été prise que par souci du bien public : « [Le Sénat] a voulu seulement pourveoir aux inconvéniens dont tout prince se doit garder, jugeant plus à propos de le faire par une loy générale que par deffences particulières, qu'il faudroit réitérer autant de fois qu'on voudroit attenter pareilles constructions ${ }^{24}$. » Quant à la prohibition d'aliéner des biens immeubles laïcs en faveur de personnes ecclésiastiques, il a été précisé que le Sénat ne souhaitait pas interdire à l'Église de plus rien acquérir à Venise, mais qu'il voulait seulement être averti en temps utile des acquisitions projetées pour pouvoir éventuellement s'y opposer « selon que le bien de l'Estat le comportera » ${ }^{25}$. 
Les autorités vénitiennes ont, semble-t-il, été prévenues par plusieurs villes de leur territoire que les terres commençaient à manquer pour supporter les charges fiscales que leur imposait la Dominante. La défense de la République impliquait que des décisions fussent prises: "Vérone et Bresce ont remonstré que l'Église continuant à tousjours acquérir sans jamais rien aliéner, elle ne tardera plus guère à dépouiller entièrement les autres Estats et demeurer seule dame de toute la terre, ce qui a meu le Sénat à faire le susdit règlement afin de conserver l'harmonie et proportion entre les membres du corps politique sans laquelle nul Estat ne peut subsister ${ }^{26}$. Canaye de Fresnes suivait ici à la lettre les arguments proposés au Sénat par le servite Paolo Sarpi (1552-1623) ${ }^{27}$, nommé consulteur in iure de la Sérénissime en janvier 1606 et qui allait se faire le zélé pourfendeur des prétentions théocratiques du Saint-Siège au nom de l'intérêt républicain. La métaphore classique du corps politique surgissait opportunément pour rappeler que l'Église ne devait pas anéantir les ressources du bras séculier. Conception que confirmait un légalisme rigoureusement républicain : «Si tout père de famille peut deffendre l'aliénation de sa terre à son héritier, la République ne peut avoir moins d'authorité en cela qu'un particulier ${ }^{28}$. » Le Sénat a demandé à Canaye de Fresnes de se faire l'écho de ses raisons auprès d'Henri IV dans la mesure où, selon les Vénitiens, les revendications du pape «n'offencent pas seulement la souveraineté de la République, mais heurtent également tous les Estats et couronnes chrestiennes ${ }^{29}-$ il s'agissait de s'attirer l'appui du roi de France en soulignant la communauté de cause qui devait l'unir à la Sérénissime contre le pontife romain. Inévitable, la précieuse mention d'une liberté originelle de la République, dépôt sacré pour la transmission duquel il faut lutter : « [Le Sénat] ne peut de moins faire que de se conserver en ses anciennes authoritéz et laisser sa liberté aussi entière à sa postérité comme il l'a receuë de ses prédécesseurs ${ }^{30}$. » La raison d'État se dressait contre les prétentions anachroniquement théocratiques du Saint-Siège - moderne Grégoire VII, Paul V voulait apparemment ressusciter le rêve médiéval d'une universelle domination de la papauté: «Le commun des sénateurs en parle si librement qu'ils disent en pleine place que le pape bute à se faire seul monarque souverain tant du temporel que du spirituel, et tous autres roys et princes, subalternes et relevans de luy ${ }^{31}$ . » Dans la crise qui commençait, le combat mené au nom de la défense du républicanisme vénitien intéressait manifestement l'ensemble des souverains chrétiens.

Que les partisans de la cause vénitienne aient aussitôt insisté sur la nécessité de préserver la mythique libertas Veneta, rien d'étonnant. L'argument répondait très exactement aux injonctions d'un pape qui prétendait s'en tenir à sauvegarder la libertas Ecclesice. Le 13 mai 1606, Canaye de Fresnes informe d'Alincourt, et en termes très significatifs, de la vanité de ses efforts pour apaiser les tensions entre la Sérénissime et le Saint-Siège: "Ces Seigneurs m'ont tousjours fait response que si le pape ne touchoit le fondement de leur Estat et liberté, il n'y a rien qu'ils fissent si volontiers que de luy complaire, mais tant qu'ils le voyent résolu à leur ruine, ils sont contraints, à leur grand regret, d'en venir où ils en sont venus, protestant néantmoins de n'avoir aucune prétention de troubler le repos public s'ils ne sont forcéz ${ }^{32}$.» Raison d'État et mythe politique de Venise sont ici conjoints pour justifier la pertinacité des autorités lagunaires. La Sérénissime n'oublie évidemment pas de régulièrement rappeler son immémoriale et superlative catholicité, désormais composante cruciale du mythe et qui permet de rejeter les soupçons d'hétérodoxie. Le 18 mai, Canaye de Fresnes fait savoir à Henri IV que lors de sa dernière audience, le doge lui a déclaré que « si le Pape ne touchoit les fondemens de leur Estat et ne leur demandoit chose qu'ils [les Vénitiens] ne luy peuvent accorder sans faire un Estat tout nouveau, ils se fussent efforcéz de luy donner satisfaction, mais 
qu'appercevant tant de mauvaise volonté en luy, ils ne peuvent de moins faire que de conserver la liberté et authorité qu'ils ont receuë de leurs ancestres par une si longue suite de siècles, sans toutesfois se départir aucunement de la vraye religion catholique, laquelle a tousjours flory en cette République, et sans troubler la paix de l'Italie ${ }^{33}$.» Position de quoi ne s'est pas écarté Piero Priuli. Le 23 mai, l'ambassadeur rend compte à la Seigneurie d'un entretien qu'il vient d'avoir avec Henri IV ${ }^{34}$. Priuli a expliqué au souverain que les dirigeants vénitiens avaient un but «pieno di zelo christiano » et que leur gouvernement «non poteva far di meno di persistere in difesa della libertá nella quale il Signore Dio l'haveva fatto nascere». Certes, reconnaissait le diplomate, l'inflexibilité de la Seigneurie face à l'intransigeance du pape pouvait engendrer des effets extrêmement nuisibles à la Chrétienté, mais la faute en revenait au seul pontife romain, "poiché la natura et la ragione insegna la conservatione delle cose proprie». Conservation par droit naturel - l'analyse dit l'indéniable légitimité, et l'orthodoxie indirectement, de la position adoptée par la Sérénissime dans son différend avec la papauté. Hétérodoxe, au contraire, et dangereuse à l'État l'ambition d'un pontife qui ne voulait manifestement pas se contenter «della auttoritá semplice pontificale, poiché, intromettendosi nelli governi delli príncipi, pretendeva quella superioritá temporale, la quale, sí come è impropria del suo ufficio, cosí non gli doveva essere permessa dal mondo, né con altri Stati ». Pour les Vénitiens, il y a, dans le geste de Paul V, une démesure déséquilibrante de Chrétienté, l'aveu à peine dissimulé d'une antichrétienne volonté de puissance. L'ambassadeur répétait encore que la cause de la Sérénissime était celle de tous les princes: si, en effet, le souverain pontife l'emportait sur les Vénitiens, « resterá diminuita l'auttoritá d'ogni principe et sará norma, per l'avvenire, la providenza nelli Stati, perché, essendo privati della auttoritá delli sudditi et della sopraintendenza nelli beni de' particolari, resterá senza anima la forza del governo, essempio di tanto pregiuditio et danno che conviene quella prudentia de' savi príncipi pensare ad impedire il progresso a cosí grande abbuso ». L'appétence absolutiste de l'État moderne ne pouvait que contrevenir aux nostalgies théocratiques d'une papauté qui, insensible au passage du temps, regardait obstinément vers un passé d'âge d'or.

10 Alors que la rupture est consommée, le pouvoir lagunaire doit plus que jamais insister sur sa volonté de demeurer en catholicité. Sensible - peut-être excessivement- aux arguments des Vénitiens, Canaye de Fresnes s'indigne, dans une lettre à d'Alincourt du 27 mai, d'une excommunication "donnée si précipitamment contre une République si catholique, si dévote au Sainct-Siège, et qui ne peut estre accusée d'avoir usurpé chose quelconque sur les droicts de l'Église $»^{35}$. Le diplomate français estime que, faute d'abandonner sa rigueur, le pape prend le risque, assurément exorbitant, de perdre « l'un des plus beaux et utiles membres de l'Église catholique ${ }^{36}$. De fait, Canaye de Fresnes ne cachait pas à Henri IV, dans une missive du 29 mai, que les Vénitiens étaient décidés à ne pas céder aux injonctions du souverain pontife: "S'il ne révoque luy-mesme son excommunication, cette République ne se departira jamais de la résolution qu'elle a prinse de couler plustost en l'estat présent tout le temps de ce pape, quelque long qu'il puisse estre, que de faire bresche à sa liberté et conservation ${ }^{37}$. » L'attitude bienveillante du roi de France, qui a prié Paul V d'accepter de suspendre temporairement ses censures pour que pussent commencer des négociations, n'a pourtant pas entamé l'obstination de la Sérénissime. Le 2 juin, Canaye de Fresnes ne laisse que peu d'espoir à Henri IV : « Quant à ce que j'avois proposé, que la République lève aussi et révoque ses ordonnances, [il m'a été répondu] que ce seroit luy oster entièrement sa souveraineté, la conservation de laquelle elle s'asseure estre trop chère à Vostre Majesté pour la presser ou requérir de 
chose qui la puisse préjudicier ${ }^{38}$. » Invocation significative, derechef, du principe moderne de souveraineté. Au diplomate français, le Sénat n'a pas manqué de remontrer qu'il était illusoire de vouloir de lui qu'il mît à mal l'héritage qui lui avait été transmis - les gouvernants vénitiens estiment ne pouvoir toucher à aucune de leurs décisions, à moins de vouloir "entièrement altérer l'estat auquel la République s'est conservée depuis douze siècles $»^{39}$. Si le pape se veut le garant du dépôt de la foi et l'intègre caution d'une tradition religieuse ininterrompue, Venise ne s'en pose pas moins comme gardien d'une transmission inaltérée de son mythe politique originel - à charge, donc, pour le Sénat d'en assurer la conservation: "Le Sénat supplie Vostre Majesté d'avoir tousjours en recommandation le droict d'un prince inquiété et troublé sans cause légitime et considérer que le pape, quoy qu'il die et proteste de paroles du contraire, si est-ce qu'en effect il entreprend manifestement sur la souveraineté temporelle des princes, voulant astraindre la République à recevoir de sa grâce et de son bénéfice ce qui luy appartient de son plein droict comme à tous autres princes souverains ${ }^{40}$. La cité lagunaire entendait mettre le roi de France de son côté en se présentant comme un rempart contre le projet pontifical d'un asservissement concerté des potentats chrétiens.

11 La stratégie ne pouvait être efficace sans que fût constatée une orthodoxie catholique patente des Vénitiens. Dès la rupture des relations diplomatiques entre le Saint-Siège et la Sérénissime ${ }^{41}$, le Sénat s'est employé à couper court aux accusations d'hérésie - précieux, encore une fois, le témoignage de Canaye de Fresnes : «Cette République veut que tout le monde cognoisse [...] qu'elle est si ferme et constante en la religion catholique que les injures qu'elle reçoit de Sa Saincteté ne la pousseront jamais à se départir du respect et obéissance deuë au Sainct-Siege, ainsi que ce Prince me l'a par plusieurs fois protesté en termes si exprèz qu'il seroit à désirer qu'ils peussent estre ouys de tous ceux qui prennent occasion de ce différend de dire que l'authorité pontificale soit aujourd'huy en dispute entre les catholiques ${ }^{42}$." Protestations d'autant plus nécessaires que commence à se développer en juin 1606 une controverse imprimée particulièrement imposante entre les défenseurs des deux parties. Les autorités vénitiennes prennent soin de séparer dans le conflit les dimensions religieuse et politique : «Les derniers mots que j'ay eus du Sénat sont qu'en ce qui concerne la spiritualité et la religion, il se prosternera tousjours devant le pape et luy rendra toute obéissance, mais qu'il ne peut moins faire que de maintenir aussi l'authorité qu'il a receue de Dieu és choses temporelles ${ }^{43}$. " Le Sénat a d'ailleurs appris avec colère que le pape menaçait de faire citer le doge devant le Saint-Office pour hérésie - de quoi Canaye de Fresnes ne prévoit rien de bon tant est grande la susceptibilité des dirigeants lagunaires : «Il n'y a nul doute que si Sa Saincteté en vient là, elle ne voye le lendemain les armes de cette République dans son Estat et soit par cette porte-là ou par quelqu'autre, il est impossible que ce schisme ne soit suivy d'un très grand désordre, auquel nul n'a tant à perdre que celuy qui est responsable du salut des âmes ${ }^{44}$. » En d'autres termes, au lieu de protéger la foi, le pape même la mettait en péril par des décisions précipitées et irréfléchies. Terrible de lucidité, le constat tiré par Canaye de Fresnes dans une missive du 2 juin à Louis Le Fèvre de Caumartin, son homologue auprès des cantons suisses : « Et combien la docte Compagnie des Jésuites soit d'autre advis et deffende cette Bulle comme ouvrage du Sainct Esprit, si ne me puis-je persuader que le Sainct Esprit mette la main à chose où il y a tant à redire et qui importe si peu au bien de la foy catholique ${ }^{45}$. " Oublieux de sa mission première, le souverain pontife semait le trouble en catholicité et utilisait les armes spirituelles pour servir ses intérêts temporels. 
eu très rapidement concurrence d'orthodoxies entre l'autorité romaine et le pouvoir lagunaire. Le pape pouvait certes se prévaloir de son magistère suréminent dans l'Église, mais la Sérénissime persistait à justifier sa résistance aux revendications pontificales par le recours à un mythe politique désormais instrumentalisé pour valider le caractère orthodoxe de ses choix diplomatiques. Dans une lettre à d'Alincourt du 3 juin, Canaye de Fresnes rappelait que l'attitude inflexible des dirigeants vénitiens procédait du seul souci du bien de l'État: "Cette République dit qu'elle ne peut révocquer ny suspendre ses ordonnances qu'elle ne fasse préjudice à sa souveraineté temporelle, sur laquelle le pape n'a que voir, estant certain que le prince qui n'a pouvoir de faire les loix et ordonnances nécessaires pour le bien et la conservation de son Estat ou qui est contrainct d'en passer par l'advis d'autruy ne peut estre appelé souverain ${ }^{46}$.» Soucieux de ne donner au pape aucun prétexte pour légitimer son animosité, le gouvernement lagunaire a suspendu la publication de plusieurs ouvrages rédigés pour sa défense. Les prévisions de Canaye de Fresnes restent quand même largement pessimistes : «Il court icy un bruit lourd que Sa Saincteté fait informer de la vie et mœurs du prince de cette République, prétendant qu'il soit suspect d'hérésie ; si cela se vérifie, il n'en faut pas d'avantage pour remplir l'Italie de feu et de sang ${ }^{47}$. " À suivre le diplomate, il ne faut pas espérer que la Sérénissime révoque jamais les lois incriminées. Les Vénitiens sont si persuadés de la nullité de la sentence d'excommunication rendue par Paul V à leur encontre qu'ils n'envisagent même pas d'en demander absolution - ils sont toutefois disposés à un accommodement, " pourveu que ce soit sans toucher au fondement de leur Estat et liberté, car de cela ils n'en peuvent gratifier personne $\aleph^{48}$. Même fermeté était démontrée en France par Piero Priuli, qui cherchait à éviter les pièges que lui tendait le nonce Maffeo Barberini ${ }^{49}$. Dans une dépêche à la Seigneurie du 6 juin, le diplomate rendait compte de sa dernière audience auprès de Villeroy, secrétaire d'État des affaires étrangères du roi Henri IV ${ }^{50}$. Priuli a encore insisté sur la nécessité dans laquelle se trouvait Venise de défendre les libertés républicaines - la cause était d'intérêt commun aux princes de la Chrétienté : «Gli dissi che ero stato a render gratie a Sua Maestá delli favori che la Serenitá vostra riceveva da Essa, movendosi [...] per conoscere le giuste ragioni [della Serenissima Republica], le quali gli fanno conservare costantemente la libertá del suo Stato. Il che, se non havesse fatto, et non facesse, sarebbe, oltre il proprio danno, di cattivo essempio agl'altri príncipi, poiché la causa si può dir commune, pretendendo al presente il Pontefice, con la Serenitá vostra sola, quello che, col tempo, vorrá pretendere con tutti gl'altri. » L'ambassadeur vénitien a soigneusement fait porter la responsabilité du différend sur le seul souverain pontife - quant à l'obstination de la Sérénissime, nul ne pouvait lui en tenir rigueur : « [Gli risposi che] la Serenitá vostra haveva dati quegli ordini che si convenivano, come principe prudentissimo, per la sicurezza del suo Stato, et quanto al non passar piú innanti, questo dipendeva dalle attioni del Pontefice, non essendo conveniente che, trattandosi di materie temporali, la Serenitá vostra si lascii opprimere dalla auttoritá del Papa, essendo le Signorie vostre Eccellentissime nate libere et col comando assoluto ne' loro Stati. » L'antique libertas veneta exigeait que la puissance du gouvernement lagunaire fût absolue sur son territoire, et la papauté n'était pas fondée à prétendre le contraire.

Le pouvoir républicain avait pris ses décisions en suivant les maximes qui participaient au corps de doctrine de la moderne raison d'État et qui devaient être les mêmes pour chaque prince, y compris le pape. D'où la stupéfaction ressentie par les contemporains devant l'intransigeance du Saint-Siège. Le 10 juin, Canaye de Fresnes confiait à d'Alincourt son profond étonnement : «Le préjudice que cette excommunication apporte à l'authorité 
pontificale est si manifeste qu'il n'y a personne si aveugle qui ne le voye. Le bien qu'on en peut promettre à Sa Saincteté est fort doubteux [...]. Je ne sçay donc quelle prudence il y a d'affectionner tant une procédure qui apporte une perte si présente et évidente pour l'espérance d'un advantage fort douteux et incertain ${ }^{51}$. " La suite du propos montrait à quel point Canaye de Fresnes était désormais imbu d'un mythe politique vénitien qui semblait correspondre à ses intimes convictions gallicanes - elle signifiait aussi la prise de conscience d'une modernité politique à quoi se heurtait une papauté dont les conceptions paraissaient se périmer inexorablement: "Vouloir contraindre une République si ancienne et si puissante que cette-cy de révoquer ses loix faites avec meure déliberation et à la requeste de ses principales villes pour le bien de son Estat, croyez-moy, Monsieur, que c'est une haute entreprinse et qui est plus aisée à soustenir aux escoles de droict canon qu'à y faire condescendre les princes souverains ${ }^{52}$.» Les princes souverains: l'expression dit, dans la fébrile cursivité de la dépêche, l'émergence d'une nouvelle réalité dont le Saint-Siège peine apparemment à prendre la mesure. Le souvenir angoissant d'Agnadel resurgit soudainement le 28 juin au détour d'une dépêche de Canaye de Fresnes à Henri IV, mais il est clair que les Vénitiens sont enfin parvenus à l'exorciser: "[Ce Sénat] veut bien qu'on croye que quand le Pape viendroit à bout de faire une autre ligue de Cambray, ils deffendront leur liberté jusques à l'extrémité et y employeront le verd et le $\sec ^{53}$.» À force d'exigences, et démesurées, le pape est devenu péril de Chrétienté. L'obstination vénitienne se nourrit de la hantise du spectre d'Agnadel, mais aussi de rumeurs insistantes qui présentent Paul $V$ en pontife furieux et si forcené qu'il dédaigne désormais le bien de l'Église : «Il se dit icy que [Sa Sainteté] a permis qu'il se soit tenu des discours en sa présence si extravagants et si préjudiciables à toutes les couronnes chrestiennes que quand elle les auroit toutes subjuguées à force d'armes, elle ne pourroit plus insolemment triompher de leur submission ${ }^{54}$. À l'orthodoxie de la raison d'État vénitienne est prévisiblement opposée l'hétérodoxie chrétienne d'un pape qui, pour assurer la réalisation de ses desseins temporels impies, finit par méconnaître les Saintes Écritures - terrible, la conclusion tirée par le doge, dont Canaye de Fresnes rapporte les récents et expressifs propos à Henri IV dans une missive du 30 juin 1606: «[Si le pape] prétend de pouvoir augmenter la majesté que les princes souverains recognoissent tenir immédiatement de la grâce de Dieu, il faut par nécessité qu'il prétende aussi avoir en ses thrésors la source de ladite authorité temporelle, chose néantmoins manifestement répugnante à la parole de Dieu, à la doctrine des Saincts Pères et aux escrits mesmes de ceux qui ont de nostre temps catholiquement escrit de la puissance papale, et du cardinal Bellarmin entr'autres ${ }^{55}$.» Paul $\mathrm{V}$ était renvoyé à un jugement unanime de la catholicité dont la Sérénissime tenait qu'elle ne devait rien craindre puisqu'elle avait respecté ses devoirs de fidèle chrétien.

14 L'argumentaire était solidement en place dont les gouvernants vénitiens ne devaient plus démordre durant l'année au cours de laquelle s'est déroulé le conflit de l'Interdit. Alors qu'à ses débuts balbutiants, le mythe politique de Venise avait été dominé par l'idée que la Sérénissime était l'incarnation parfaite du governo misto et d'une république aristocratique, il semble qu'au début $\mathrm{du} \mathrm{xvII}^{\mathrm{e}}$ siècle, le discours mythique vénitien franchit une nouvelle étape : Venise proclame désormais à la face du monde la perpétuité de sa domination, l'inaltérabilité de son institut originel à travers les pires épreuves, d'Agnadel jusqu'à l'Interdit, et finalement sa catholicité indéfectible, au même titre que le Très-Chrétien. Contre le magistère romain, la Sérénissime affirme que la raison d'État est validation assurée de l'orthodoxie des décisions prises par l'autorité politique souveraine - à Paolo Sarpi, le soin, au beau milieu de la crise de 1606-1607, de revendiquer 
explicitement une infaillibilité du prince en matières temporelles, de la même manière que le pape prétend être infaillible ratione fidei et morum. À bien des égards, l'Interdit a renforcé la prégnance d'un mythe politique vénitien désormais assimilé aussi à son opposition à Rome. De quoi allait rapidement témoigner le célèbre, mais anonyme, Squittinio della libertá veneziana (1612), qui n'a pas hésité à s'en prendre à l'un des aspects les plus aigus du mythe vénitien, soit la prétendue liberté civile d'immémoriale origine. Cinq ans après la conclusion de l'Interdit, le livre dénonçait à Venise l'application sans vergogne d'une raison d'État dénaturée, simulacra imperii seu libertatis, et camouflée sous le visage séduisant d'un règne d'avenant mensonge : défaite sur le plan diplomatique, la papauté tentait laborieusement, et d'ailleurs vainement, de prendre une revanche doctrinale.

\section{NOTES}

1. Sur l'ecclésiologie de Bellarmin, voir J. de La Servière, La théologie de Bellarmin, Paris, 1909, Fr. X. ARNOLD, Die Staatslehre des Kardinals Bellarmin. Ein Beitrag zur Rechts- und Staatsphilosophie des konfessionellen Zeitalters, Munich, 1934, et, plus récemment, Fr. Motta, Bellarmino. Una teologia politica della Controriforma, Brescia, 2005, et S. Tutino, Empire of Souls. Robert Bellarmine and the Christian Commonwealth, Oxford, 2010. On se permet également de renvoyer à S. De Franceschi, L'autorité pontificale face au legs de l'antiromanisme catholique et régaliste des Lumières : réminiscences doctrinales de Bellarmin et de Suárez dans la théologie politique et l'ecclésiologie catholiques de la mi-XVIII siècle à la mi-XIX ${ }^{\mathrm{e}}$ siècle, dans Archivum Historice Pontificice, 38, 2000, p. 119-163, id., Le pouvoir indirect du pape au temporel et l'antiromanisme catholique des âges pré-infaillibiliste et infaillibiliste : références doctrinales à Bellarmin et à Suárez dans la théologie politique et l'ecclésiologie catholiques du début du XIX siècle à la mi-XX ${ }^{\mathrm{e}}$ siècle, dans Revue d'Histoire de l'Église de France, t. 88, 2002, p. 103-149, et id., Le modèle jésuite du prince chrétien. À propos du De officio principis Christiani de Bellarmin, XVII ${ }^{\mathrm{e}}$ siècle, LIX/4, 2007, p. 713-728.

2. Sur l'Interdit vénitien et ses échos en Europe, on se permet de renvoyer à S. De Franceschi, Raison d'État et raison d'Église. La France et l'Interdit vénitien (1606-1607) : aspects diplomatiques et doctrinaux, Paris, 2009, et id., La crise théologico-politique du premier âge baroque. Antiromanisme doctrinal, pouvoir pastoral et raison du prince: le Saint-Siège face au prisme français (1607-1627), Rome, 2009.

3. Sur le mythe politique de Venise, outre l'étude de J. Beneyto, Fortuna de Venecia. Historia de una fama política, Madrid, 1947, voir les travaux fondamentaux de G. Fasoli, Nascita di un mito, dans Studi storici in onore di Gioacchino Volpe per il suo 80 compleanno, 2 vol., Florence, 1958, t. $\mathrm{I}^{\text {er }}$, p. 445-479, repris dans ead., Scritti di storia medievale, éd. F. Bocchi, A. Carile, et A. I. Pini, Bologne, 1974, p. 445-472, et de Fr. Gaeta, Alcune considerazioni sul mito di Venezia, dans Bibliothèque d'Humanisme et Renaissance, 23, 1961, p. 58-75. Consulter aussi R. Pecchioli, Il mito di Venezia e la crisi fiorentina del '500, dans Studi storici, 3, 1962, p. 451-492, repris dans id., Dal mito di Venezia all'ideologia americana. Itinerari e modelli della storiografia sul repubblicanesimo dell'età moderna, Venise, 1983, p. 17-73. Pour une 
présentation iconographique, voir D. Rosand, Venezia figurata : the Iconography of a Myth, dans Interpretazioni veneziane. Studi di storia dell'arte in onore di Michelangelo Muraro, Venise, 1984, p. 177-196, et id., Myths of Venice. The Figuration of a State, Chapel Hill (N. C.), 2001. Sur l'évolution du mythe au $\mathrm{xvI}^{\mathrm{e}}$ siècle, consulter B. Marx, Venedig altera Roma - Transformationen eines Mythos, dans Quellen und Forschungen aus Italienischen Archiven und Bibliotheken, 60, 1980, p. 325-373, id., Il mito di Venezia nel primo Cinquecento, dans A. Buck et B. Guthmüller (dir.), La città italiana del Rinascimento fra utopia e realtà, Venise, 1984, p. 137-163, et M. Zanetto, Mito di Venezia ed antimito negli scritti del Seicento veneziano, Venise, 1991.

4. Sur le républicanisme vénitien, voir W. J. Bouwsma, Venice and the Defense of Republican Liberty. Renaissance Values in the Age of the Counter Reformation, Berkeley-Los Angeles, 1984 ( $\left.{ }^{1} 1968\right)$. Pour une première approche - encore discutée - du républicanisme florentin, voir H. Baron, The Crisis of the Early Italian Renaissance. Civic Humanism and Republican Liberty in an Age of Classicism and Tyranny, Princeton, 1966 ( $\left.{ }^{1} 1955\right)$. Pour un bilan historiographique, consulter J.Hankins (dir.), Renaissance Civic Humanism. Reappraisals and Reflexions, Cambridge, 2000. Sur l'histoire des doctrines de la raison d'État, voir un récent état des lieux dans L. Catteeuw (dir.), Réalisme et mythologie de la raison d'État, Revue de synthèse, 1. Une question de mémoire historique, $\mathrm{cxxx} / 2,2009$, et 2. Des combats pour l'histoire, $\mathrm{cxxx} / 3$, 2009.

5. J.G. A. Pocock, The Machiavelian Moment. Florentine Political Thought and the Atlantic Republican Tradition, Princeton, 1975, Le moment machiavélien. La pensée politique florentine et la tradition républicaine atlantique, trad. française, Paris, 1997, "Giannotti et Contarini. Venise comme concept et comme Mythe », p. 271-324.

6. D. Giannotti, Della Republica de' Viniziani, Rome, 1540, repris dans ID., Opere, éd. F. Diaz, 2 vol., Milan, 1974, t. I $^{\text {er }}$, Opere politiche, p. 27-151. Pour une mise en contexte florentine de l'œuvre de Giannotti, consulter G. Cadoni, Crisi della mediazione politica e conflitti sociali. Niccolò Machiavelli, Francesco Guicciardini e Donato Giannotti di fronte al tramonto della Florentina Libertas, Rome, 1994.

7. Sur Gasparo Contarini, voir G. Fragnito, Cultura umanistica e riforma religiosa : il De officio boni uiri ac probi episcopi di Gasparo Contarini, dans Studi Veneziani, 2, 1969, p. 75-189, J. B. Ross, Gasparo Contarini and his friends, dans Studies in the Renaissance, 17, 1970, p. 192-232 et id., The emergence of Gasparo Contarini : a bibliographical essay, dans Church History, 31, 1972, p. 1-24. Sur la pensée politique de Contarini, voir F. Gilbert, The date of the composition of Contarini's and Giannotti's books on Venice, dans Studies in the Renaissance, Renaissance Quarterly, 14, 1967, p. 172-184, id., Religion and politics in the thought of Gasparo Contarini, dans Action and conviction in early modern Europe. Essays in memory of E. H. Harbison, éd. T. K. Raab et J. E. Seigel, Princeton, 1969, p. 90-116, G. Fragnito, Aspetti della censura ecclesiastica nell'Europa della Controriforma : l'edizione parigina delle opere di Gasparo Contarini, dans Rivista di storia e letteratura religiosa, 21, 1985, p. 3-48, ead., Gasparo Contarini. Un magistrato veneziano al servizio della cristianità, Florence, 1988, et E. G. Gleason, Gasparo Contarini: Venice, Rome and Reform, Los Angeles-Berkeley, 1993. Voir aussi Fr. Cavazzana Romanelli (dir.), Gasparo Contarini e il suo tempo. Atti del convegno, Venezia 1-3 marzo 1985, Venise, 1988.

8. Voir J.-L. Fournel, Le modèle politique vénitien. Notes sur la constitution d'un mythe, dans Théories de la libre république du Quattrocento aux Lumières, Revue de synthèse, CxviII/2-3, 1997, p. 207-219. 
9. T. Campanella, Antiveneti, éd. L. Firpo, Florence, 1945, p. 13.

10. On se permet de renvoyer à S. De Franceschi, Antiromanisme catholique et liberté ecclésiastique. La question de la libertas ecclesiastica au temps de l'Interdit vénitien (1606-1607), dans S.-M. Morgain (dir.), Libertas Ecclesiæ. Esquisse d’une généalogie (1650-1800), Paris, 2010, p. 113-133.

11. Bulle Superioribus mensibus, Rome, 17 avril 1606, ASv [Archivio Segreto Vaticano], ss [ Segreteria di Stato] Venezia 36, fo $219 \mathrm{r}^{\circ}-223 \mathrm{r}^{\circ}$.

12. Ibid., $\mathrm{f}^{\circ} 219 \mathrm{r}^{\circ}$ : "Ducem et Senatum Reipublice Venetorum in eorum consiliis, plura et diuersa decreta, tum Sedis Apostolice auctoritati et Ecclesiasticee libertati ac immunitati contraria, tum generalibus Conciliis et sacris Canonibus, necnon Romanorum Pontificum constitutionibus repugnantia statuisse."

13. Ibid., fo $219 \mathrm{v}^{\circ}$.

14. Ibid., f $\mathrm{f}^{\circ} 220 \mathrm{v}^{\circ}$.

15. Cité dans G. Capasso, Fra Paolo Sarpi e l'Interdetto di Venezia, Florence, 1880, p. III-IV.

16. Cité ibid., p. IV.

17. Cité ibid., p. IV.

18. Cité ibid., p. vi.

19. Priuli à la Seigneurie, Paris, 9 mai 1606, BNF (Bibliothèque nationale de France), Italien $1755, \mathrm{f}^{\circ} 23 \mathrm{r}^{\circ}-26 \mathrm{r}^{\circ}$.

20. Sur Canaye de Fresnes, voir Th. Wanegffelen, Ni Rome ni Genève. Des fidèles entre deux chaires en France au XVI e siècle, Paris, 1997, «Le choix de Philippe Canaye, sieur de Fresnes : confessionnel ou religieux?», p. 446-450, et surtout G. Cozzi, Paolo Sarpi tra il cattolico Philippe Canaye de Fresnes e il calvinista Isaac Casaubon, dans Bollettino dell'Istituto di Storia della Società e dello Stato veneziano, 1, 1959, p. 27-154, repris dans id., Paolo Sarpi tra Venezia e l'Europa, Turin, 1979, p. 3-133. On se permet de renvoyer également à S. De Franceschi, La diplomatie henricienne et les ambitions françaises de suprématie temporelle sur la république chrétienne. L'idée de Chrétienté dans la correspondance diplomatique de Philippe Canaye de Fresnes, ambassadeur de France à Venise pendant l'Interdit (1606-1607), dans Histoire, Économie et Société. Époques moderne et contemporaine, xxIII/4, 2004, p. 551-585, et id., Les valeurs de l'honnête négociation. Prudence et imprudences diplomatiques au temps de l'Interdit vénitien (1606-1607), dans Revue d'histoire diplomatique, 2008/3, p. 193-221.

21. Canaye de Fresnes à d'Alincourt, Venise, 15 avril 1606, dans Ph. Canaye de Fresnes, Lettres et ambassade, 3 vol., Paris, 1635-1636, t. III, Où il est traité particulièrement du différend du Pape Paul $V$ avec la République de Venise, de l'ordre que l'on a tenu au procédé de cet affaire, et de tout le traité jusques à l'accommodement, Paris, 1636, p. 1.

22. Ibid., p. 2-3.

23. Canaye de Fresnes à Henri IV, Venise, 15 avril 1606, ibid., p. 6.

24. Ibid., p. 6.

25. Ibid., p. 6.

26. Ibid., p. 7.

27. Sur Sarpi, voir F. Chabod, La politica di Paolo Sarpi, Rome, 1952, D. Wootton, Paolo Sarpi.Between Renaissance and Enlightenment, Cambridge, 1983, V. Frajese, Sarpi scettico. Stato e Chiesa a Venezia tra cinque e seicento, Bologne, 1994, et Paolo Sarpi. Politique et religion en Europe, éd. M. Viallon, Paris, 2010. On se permet également de renvoyer à S. De 
Franceschi, Paolo Sarpi et Fulgenzio Micanzio. L'extrémisme catholique antiromain du début du $\mathrm{XVII}^{\mathrm{e}}$ siècle, dans S. De Franceschi (dir.), Antiromanisme doctrinal et romanité ecclésiale dans le catholicisme posttridentin ( $\mathrm{XVI}^{\mathrm{e}}-\mathrm{XX}$ siècles). Actes de la journée d'études de Lyon (30 novembre 2007), Chrétiens et Sociétés, Documents et mémoires, 7, Lyon, 2009, p. 45-71, et id., Romanité et universalité de la communauté ecclésiale. Le débat catholique sur les caractères de la véritable Église au temps de Paolo Sarpi, dans Paolo Sarpi. Politique et religion en Europe, cit., p. 105-138.

28. Canaye de Fresnes à Henri IV, Venise, 15 avril 1606, dans Ph. Canaye de Fresnes, op. cit. ,t. III, p. 7.

29. Ibid., p. 8.

30. Ibid., p. 8.

31. Ibid., p. 8.

32. Canaye de Fresnes à d'Alincourt, Venise, 13 mai 1606, ibid., p. 32.

33. Canaye de Fresnes à Henri IV, Venise, 18 mai 1606, ibid., p. 36.

34. Priuli à la Seigneurie, Paris, 23 mai 1606, BNF, Italien 1755, fo $27 \mathrm{r}^{\circ}-29 \mathrm{r}^{\circ}$.

35. Canaye de Fresnes à d'Alincourt, Venise, 27 mai 1606, dans Ph. Canaye de Fresnes, op. cit., t. III, p. 49.

36. Ibid., p. 49.

37. Canaye de Fresnes à Henri IV, Venise, 29 mai 1606, ibid., p. 54.

38. Canaye de Fresnes à Henri IV, Venise, 2 juin 1606, ibid., p. 60.

39. Ibid., p. 60.

40. Ibid., p. 61.

41. Sur la rupture entre Venise et la papauté, on se permet de renvoyer à S. De Franceschi, De l'incident à la crise : les débuts du conflit de l'Interdit vénitien (1605-1606), dans L. Bély et G. Poumarède (dir.), L'incident diplomatique, XVI $\mathrm{e}^{\mathrm{e}} \mathrm{XVIII} \mathrm{e}^{\mathrm{e}}$ siècle, Paris, 2010, p. 151-167.

42. Canaye de Fresnes à Henri IV, Venise, 2 juin 1606, dans Ph. Canaye de Fresnes, op. cit., t. III, p. 61.

43. Ibid., p. 61.

44. Ibid., p. 62.

45. Canaye de Fresnes à Caumartin, Venise, 2 juin 1606, ibid., p. 66.

46. Canaye de Fresnes à d'Alincourt, Venise, 3 juin 1606, ibid., p. 67.

47. Ibid., p. 68.

48. Ibid., p. 69.

49. Sur l'affrontement qui oppose Priuli à la nonciature de France, voir S. De Franceschi, La difficile négociation de la neutralité. Les entretiens d'Henri IV avec Piero Priuli, ambassadeur de Venise, et Maffeo Barberini, nonce en France, au début de l'Interdit vénitien (1606), dans S. Andretta, S. Péquignot, M.-K. Schaub, J.-Cl. Waquet et Ch. Windler (dir.), Paroles de négociateurs. L'entretien dans la pratique diplomatique de la fin du Moyen Âge à la fin du XIX siècle, Rome, 2010, p. 173-191.

50. Priuli à la Seigneurie, Paris, 6 juin 1606, BNF, Italien $1755, \mathrm{f}^{\circ} 36 \mathrm{r}^{\circ}-38 \mathrm{v}^{\circ}$.

51. Canaye de Fresnes à d'Alincourt, Venise, 10 juin 1606, dans Ph. Canaye de Fresnes, op. cit., t. III, p. 70. 
52. Ibid., p. 71.

53. Canaye de Fresnes à Henri IV, Venise, 28 juin 1606, ibid., p. 87.

54. Ibid., p. 88-89.

55. Canaye de Fresnes à Henri IV, Venise, 30 juin 1606, ibid., p. 99-100.

\section{AUTEUR}

\section{SYLVIO HERMANN DE FRANCESCHI}

École pratique des hautes études, Paris - sylvio.de-franceschi@laposte.net 


\title{
«Si quid e Gallia afferatur, avide lego ». Reti intellettuali, libri e politica tra Venezia e la Francia nella prima metà del Seicento
}

\author{
Antonella Barzazi
}

1 Il ruolo di rilievo rivestito dal mondo veneto nelle relazioni culturali tra l'Italia e la Francia lungo l'arco cronologico che va dal tardo Cinquecento ai primi anni del Seicento è un dato ben noto. Dal libro di Cecilia Rizza su Peiresc e l'Italia, del 1965, fino ai saggi presentati sotto lo stesso titolo da Marc Fumaroli nel 2009, numerosi lavori hanno delineato momenti e figure di un confronto ripercorso da punti di vista volta a volta letterari, artistici, scientifici e dalla particolare angolatura del viaggio, pratica di formazione particolarmente diffusa presso le élite nobiliari e di toga transalpine ${ }^{1}$. Su un altro, distinto versante - quello della storia politico-religiosa - si sono invece svolti gli studi sui rapporti instaurati tra Venezia e la Francia intorno alla vicenda dell'interdetto del 1606 e alla personalità di Paolo Sarpi. A partire dalle ricerche di Cozzi e Ulianich fino al volume recente di De Franceschi, uno scavo documentario imponente ha fatto luce sugli echi francesi della controversia veneto-pontificia, ricostruendo i molteplici aspetti di un dialogo che, divenuto particolarmente intenso durante l'età di Enrico IV, sarebbe poi andato incontro a un rapido esaurimento dopo il trauma dell'assassinio del Borbone ${ }^{2}$.

Di fronte a un quadro di studi ricco, ma disomogeneo, in cui i diversi contributi stentano spesso a intrecciarsi, è parso utile - nella prospettiva degli sguardi incrociati - ricomporre in una visione d'insieme i risultati acquisiti, integrandoli con gli apporti di un ricco materiale epistolare, manoscritto, ma in parte non trascurabile già edito a partire dal Settecento. Questo consente di mettere a fuoco e di disporre lungo cronologie più distese una trama di rapporti che dallo scorcio del XVI secolo si protese ben oltre la straordinaria congiuntura del primo decennio del XVII, dentro la fase dell'emarginazione di Venezia dal novero delle potenze europee scandita dai falliti tentativi antiasburgici ai confini orientali, dalla crisi valtellinese e dalla guerra di Mantova. Anche in questo periodo 
difficile il richiamo alla Francia continuò ad agire sull'ambiente intellettuale veneto, assumendo diverse inflessioni e assecondando dislocazioni politiche. E la vecchia Repubblica riuscì ancora - per parte sua - $\mathrm{a}$ parlare $\mathrm{a}$ una Francia impegnata nella faticosa costruzione delle proprie istituzioni politiche ed ecclesiastiche.

3 A distanza di alcuni decenni dalla pubblicazione dei suoi scritti, Gaetano Cozzi rimane lo storico che ha saputo rendere al meglio il senso di profonda vicinanza alla Francia diffuso a Venezia tra il finire del Cinquecento e l'inizio del Seicento. Si trattava di un correlato dell'orientamento antispagnolo e antipontificio prevalso nella linea politica della Serenissima dopo la svolta antioligarchica e legalitaria degli anni ottanta del XVI secolo : per il settore del patriziato che si era affermato allora alla guida della Repubblica, la fiducia nel ruolo equilibratore della Francia in Europa faceva tutt'uno con l'attrattiva di un mondo culturale e religioso complesso, in grado di superare contrasti laceranti e di ritrovare l'unità politica, aprendo così nuovi orizzonti nell'universo cattolico ${ }^{3}$. Ad alimentare questi atteggiamenti aveva contribuito tra l'altro la presenza in città, in veste di ambasciatori francesi, di uomini dall'acuta sensibilità politico-religiosa come André Hurault de Maisse e Philippe Canaye de Fresnes i quali, muovendo da itinerari personali del tutto diversi, avevano maturato una comune contrarietà all'accoglimento in Francia dei decreti del concilio di Trento e apprezzavano a loro volta, nella Venezia dell'epoca, l'esempio di un cattolicesimo alieno dall'ossequio al papa, sostanziato di esigenze spirituali profonde. Con il tempestivo riconoscimento della successione di Enrico IV, la Serenissima si era confermata ai loro occhi come il naturale interlocutore di un disegno politico mirato a rilanciare il ruolo della Francia in Europa e a sottrarre la Chiesa di Roma all'esclusiva tutela della Spagna ${ }^{4}$.

4 Ben presente, il riferimento francese, anche a Padova, tra l'Università - dove dal 1592 insegnava Galilei - e altri circoli culturali, primo fra tutti quello che si riuniva nella casa di Gian Vincenzo Pinelli, intorno a una biblioteca ricca e largamente disponibile ${ }^{5}$. Pinelli aveva tenuto a lungo rapporti epistolari con Claude Dupuy, padre dei più noti Pierre e Jacques, futuri animatori del cabinet Dupuy, ma la corrispondenza si era spenta lentamente dopo l'ingresso a Parigi, nel 1588, delle forze della Lega, che aveva provocato la disgrazia politica e personale di Claude ${ }^{6}$. Pinelli morirà nel 1601, ma due anni prima era stata fondata, nella dimora padovana del cardinale Federico Corner, l'accademia dei Ricovrati, che per un decennio avrebbe funzionato da punto d'aggregazione per una società intellettuale fatta di patrizi veneziani, di docenti dell'Università, di ecclesiastici colti uniti dall'interesse per la filologia e l'antiquaria, dal culto del latino classico e insieme da larghe aperture alle nuove frontiere della ricerca scientifica ${ }^{7}$.

$5 \mathrm{Su}$ questo sfondo vediamo muoversi protagonisti di lungo corso delle relazioni intellettuali franco-venete: il canonico del duomo Antonio Querenghi, a Padova tra il 1597 e il 1605 in una pausa della sua carriera romana e a sua volta proprietario di una biblioteca fornita e aperta, monsignor Paolo Gualdo, amico di Galilei e futuro biografo di Pinelli, Alvise Lollino, patrizio e dal 1596 vescovo di Belluno, grande appassionato di libri e codici. Quindi il gruppo dei più giovani : Lorenzo Pignoria, che nel 1602, trentenne, diventerà segretario del vescovo di Padova Marco Corner, il coetaneo e amico di Pignoria Martino Sandelli, parroco e latinista, Girolamo Aleandro il giovane e il ferrarese nonché futuro cardinale Guido Bentivoglio, entrambi passati a Roma all'aprirsi del Seicento. 
Organicamente inserite nella gerarchia ecclesiastica, legate da rapporti cordiali ai gesuiti, queste figure condividono «una coscienza intellettuale e politica di stampo filofrancese», come ha sottolineato Uberto Motta nel suo lavoro su Antonio Querenghi, vicino a Clemente VIII e legato agli oratoriani della Vallicella ${ }^{8}$. Le cerchie padovane gravitanti tra casa Querenghi e i Ricovrati intersecano del resto l'orbita culturale del celebre ridotto veneziano dei fratelli Andrea e Nicolò Morosini, frequentato da patrizi di diverso orientamento politico e da dotti di passaggio per la capitale e nel quale le scottanti vicende francesi - ancora vive nella diretta esperienza di alcuni dei partecipanti costituiscono argomento importante di discussione ${ }^{9}$. Con questi ambienti entra in contatto nel 1599 il ventitreenne Enrico Caterino Davila: di ritorno dagli assedi finali delle guerre di religione in Francia, vi inizia un legame d'amicizia duraturo con Lollino e con Flavio Querenghi, il giovane nipote di Antonio, e conosce Bentivoglio ${ }^{10}$. Lo stesso anno si affaccia al variegato mondo intellettuale veneto-padovano il diciannovenne Nicolas Fabri de Peiresc, giunto in Italia insieme al fratello minore per seguire i corsi di giurisprudenza dello Studio di Padova e compiere quel viaggio nella penisola che imprimerà su di lui il marchio duraturo di uno spiccato gusto collezionistico e di una raffinata bibliofilia ${ }^{11}$. Venivano poste così le premesse di uno scambio epistolare dapprima occasionale e intermittente, ma destinato a diventare negli anni uno degli assi principali dell'esteso carteggio italiano di Peiresc ${ }^{12}$.

6 Tra gli interlocutori veneti del giovane francese incontriamo, oltre a Gualdo e Pignoria, anche Paolo Sarpi. Nel 1602 Peiresc, sulla via del ritorno a Aix, si offre di « servirlo » « di libri o d'altro ", mentre gli comunica da Montpellier le proprie entusiastiche impressioni sulle lezioni del giurista riformato vicentino Giulio Pace da Beriga ${ }^{13}$. All'anno successivo risale la prima traccia di un contatto - mediato probabilmente dall'ambasciatore Canaye des Fresnes - tra Sarpi e la personalità egemone del mondo politico-culturale parigino, Jacques-Auguste de Thou, alla ricerca di materiali per la continuazione dell'Historia sui temporis ${ }^{14}$. Di questa il frate servita riceverà in seguito i primi due volumi, che portavano la narrazione fino al 1572. Nel 1604 Sarpi si adopererà per procurare a un altro corrispondente francese, il filologo calvinista Isaac Casaubon, che a Lione studiava l'ebraico, una copia del Corano, concessa in prestito da un patrizio veneziano legato a Galilei, Agostino Da Mula ${ }^{15}$.

7 Sulle prime prove di una rete di comunicazione tra uomini di cultura con interessi essenzialmente eruditi si sarebbe presto abbattuta la tempesta dell'interdetto. Il precipitare, nel 1606, di contrasti da tempo latenti tra la Serenissima e il papa, la prospettiva, annunciatasi fin dal profilarsi dello scontro, di un intervento mediatore di Enrico IV, mettevano in gioco questioni - il rapporto tra cattolicesimo e autorità romana, il ruolo dei gesuiti - profondamente sentite nella Francia di quegli anni, questioni che investivano direttamente gli elementi fondanti della chiesa nazionale. Sylvio De Franceschi ha recentemente riconsiderato con grande ampiezza di dettagli la "perception française de l'interdit», evidenziando i risvolti diplomatici e dottrinali di una mediazione che prefigurava - a cinque anni dalla pace di Lione - la ripresa di una politica italiana della Francia e metteva a rischio l'impegno della monarchia per instaurare un'intesa durevole con Roma ${ }^{16}$. La controversia tra la Repubblica e Paolo V doveva confermare le ragioni della solidarietà tra le due " églises soeurs " ${ }^{17}$, introducendo note nuove e diverse nelle corrispondenze tra mondo veneto e francese.

Durante l'intero arco della contesa - tra l'aprile 1606 e l'aprile 1607 - il flusso delle informazioni erudite e bibliografiche appare come soverchiato dagli echi dello scontro in 
atto e dalla trasmissione degli scritti polemici diffusi dalle due parti. Quelli di Sarpi, in particolare, subito ricercati in Francia, varcano le Alpi per il tramite dei rispettivi ambasciatori e vengono fatti tradurre in francese ${ }^{18}$. Tra lo scorcio del $1606 \mathrm{e}$ i primi giorni del 1607 Peiresc li procura a Guillaume Du Vair, presidente del parlamento di Aix, al seguito del quale si è recato qualche mese prima a Parigi ${ }^{19}$. A Venezia giungono invece $\mathrm{i}$ numerosi testi francesi originati dall'interdetto: da quelli, più noti, di Louis Servin, Jacques Leschassier, Edmond Richer fino al Discours au roi di Guillaume Ribier, un appassionato appello alla convocazione di un concilio nazionale francese per ristabilire l'unità della fede cattolica, che sarà volto successivamente in italiano da Sarpi su richiesta del doge Leonardo Donà ${ }^{20}$. Il presidente De Thou è al centro dello scambio di libelli e notizie. A lui Sarpi promette d'inviare, all'indomani della conclusione della vertenza, un puntuale resoconto della vicenda, rispondendo alla sollecitazione trasmessagli attraverso l'ugonotto Jérôme Groslot de l'Isle, in visita a Venezia nella primavera del $1607^{21}$. Nell'arco di un anno il ruolo del frate servita è così radicalmente cambiato : non più il religioso dotto e deferente di fronte a più noti e autorevoli studiosi, è ora il capofila di una grande battaglia contro le pretese temporalistiche del papato romano, in grado di dialogare con rappresentanti di spicco dell'ambiente politico-culturale e religioso francese.

9 Il mondo intellettuale veneto interessato al dialogo con la Francia si presenta ora diviso. Lo scoppio della contesa ha sorpreso Gualdo e Pignoria a Roma, al seguito del vescovo di Padova Marco Corner. Se il primo affida a un manoscritto autobiografico il sollievo per aver potuto così evitare " quella travagliosa confusione " ${ }^{22}$, il secondo, già poco entusiasta del soggiorno romano, sfoga proprio con Peiresc il disagio per la « rissolutione sì poco christiana » del governo veneziano e l'ossessione di non poter più tornare in patria ${ }^{23}$. All'indomani della composizione diplomatica della vertenza, in un clima avvelenato da opposte interpretazioni sulla natura del compromesso raggiunto sotto l'egida della Francia ${ }^{24}$, Antonio Querenghi sarà coinvolto nell'organizzazione di un'abboccamento del polemista tedesco Kaspar Schoppe con Sarpi, teso a ottenere dal consultore veneziano una formale abiura delle sue posizioni per evitare ulteriori ritorsioni pontificie. Patrocinata verosimilmente dal cardinale francese Jacques Davy Du Perron, d'intesa con l'ambasciatore veneziano a Roma, la missione dello Schoppe, rimasta senza esito, potrà contare sulla collaborazione del senatore Donato Morosini, un patrizio legato all'ambiente intellettuale padovano e vicino, per le sue posizioni caute nei confronti del papa, ad un altro Morosini, il già menzionato Andrea ${ }^{25}$. Sempre nel 1607, per impulso di Paolo V, Querenghi avviò la stesura di una Historia veneti interdicti. L'abbozzo rimasto tra le sue carte restituisce una trattazione "misuratamente apologetica» dei problemi filosofici sottesi a una vicenda i cui sviluppi concreti venivano lasciati da parte ${ }^{26}$. Le pressioni pontificie si eserciteranno, tramite il nunzio a Venezia, anche sul vescovo Lollino il quale tuttavia eviterà di prendere posizione contro Sarpi, suo vecchio amico ${ }^{27}$. Stretti tra patriottismo veneziano e imperativi dello status ecclesiastico, questi uomini marcavano la propria distanza dalle scelte del patriziato più ostile alla Chiesa e dal frate che se ne era fatto interprete, evitando tuttavia di entrare nel vivo della polemica.

10 L'interdetto doveva così orientare lo sviluppo successivo delle relazioni epistolari tra l'area veneta e la Francia. Qualche reticenza si avverte nelle comunicazioni tra Peiresc, di nuovo a Aix dopo un viaggio in Inghilterra e in Olanda, e le sue conoscenze padovane. A Gualdo, rimasto a Roma, dove aveva ultimato la stesura della vita di Gian Vincenzo Pinelli, Peiresc manda nel novembre 1607 i propri rallegramenti, ma esprime al contempo un 
rammarico : nella sua biografia non si sarebbe potuto includere un elogio di Pinelli scritto da De Thou. Peiresc avrebbe avuto infatti difficoltà a chiederla al presidente, che non aveva mai ricevuto da Pignoria le informazioni a suo tempo richieste sul filologo cremonese del Cinquecento Gabriele Faerno ${ }^{28}$. La discreta sortita, caratteristica dello stile epistolare di Peiresc, suggerisce una sorta di sospensione dei corrispondenti padovani di fronte a De Thou che, schierato apertamente dalla parte di Venezia, vedeva allora la propria opera principale sottoposta al vaglio della censura romana ${ }^{29}$. È in ogni caso negli anni del post-interdetto che s'instaura una triangolazione epistolare tra Aix, Roma e Padova. Si tratta ancora di uno scambio a maglie larghe, che subisce gli incerti del recapito attraverso le reti mercantili e una certa distrazione da parte di Peiresc, accettata con indulgenza da Gualdo, ma puntualmente rimarcata da Pignoria ${ }^{30}$. I tre corrispondenti s'informano vicendevolmente sui rispettivi studi, chiedono riscontri biografici e filologici, si procurano ritratti di letterati, copie di manoscritti e iscrizioni, piccoli reperti archeologici, edizioni a stampa rare e novità bibliografiche, cogliendo le opportunità offerte dai circuiti librari in cui si trovano inseriti ${ }^{31}$. E celebrano i grandi protagonisti della repubblica delle lettere europea che in quel periodo vanno scomparendo: da Giuseppe Giusto Scaligero al celebre antiquario fiammingo Gorleus, al naturalista francoolandese Clusius $^{32}$. L'invio a Peiresc della vita del Pinelli completata da Gualdo è occasione per rievocare un modello culturale avvertito come non più riproponibile ${ }^{33}$. La trama delle notizie lascia trasparire i fili che si annodano nel più esteso orizzonte filofrancese in cui i padovani si muovono, all'ombra di patrizi come il già ricordato Donato Morosini, spesso presente in queste lettere: nel maggio 1609 Gualdo dà conto dell'imminente arrivo al vicino castello del Catajo, appartenente agli Obizzi, del cardinale Alessandro d'Este, accompagnato da Antonio Querenghi ${ }^{34}$.

11 Molto lontani i registri e i contenuti della corrispondenza che parallelamente Sarpi intrattiene dal suo convento veneziano, intensificando le relazioni con gallicani e ugonotti stabilite durante l'interdetto. Non che manchino, anche qui, richiami a temi di personale interesse, storico-filologici o scientifici. Ma al frate che entra stabilmente al servizio della Repubblica in qualità di consultore per le materie teologiche $\mathrm{e}$ giurisdizionali, i carteggi con l'avvocato del parlamento parigino Jacques Leschassier, con il consigliere Jacques Gillot offrono anzitutto la possibilità d'affinare la conoscenza degli istituti giuridici francesi e della disciplina ecclesiastica in vigore al di là delle Alpi ${ }^{35}$. Quando Sarpi si confronta con i corrispondenti sui deliberati di un antico concilio o analizza minutamente prerogative e diritti regolanti la collazione di vescovati e prebende, la sua attenzione non va al restauro o all'edizione di un testo, ma ai processi di lungo periodo che - dall'antichità cristiana fino al concilio di Trento - hanno modellato le strutture ecclesiastiche, va alla prassi beneficiaria della chiesa di Francia che, con le proprie «libertà», offre agli Stati italiani un modello di autonomia rispetto all'imporsi del centralismo romano. "Si quam libertatem in Italia aut retinemus aut usurpamus, totam Franciae debemus ", dichiara Sarpi in una famosa lettera del 1609 a Gillot ${ }^{36}$. Di qui la ricerca continua dei libelli, dei trattati, delle raccolte di documenti che in quegli anni centrali per l'elaborazione delle dottrine gallicane vengono illustrando la storia delle istituzioni ecclesiastiche del Regno ${ }^{37}$. "Si quid e Gallia afferatur, avide lego", scrive ancora Sarpi a Gillot $^{38}$ : da quegli scritti, richiesti spesso in più esemplari, si augura di poter trarre rimedi adeguati al pericoloso disimpegno e alle cautele che vede ormai diffondersi nel gruppo dirigente veneziano, man mano che la stagione dell'interdetto si allontana nel tempo. 

epistolario 'militante', finalizzato a un preciso progetto politico : l'inserimento di Venezia in un fronte antiasburgico compatto, in grado di spezzare le pretese d'egemonia della Spagna e del papato sull'Europa e la morsa stretta sulla penisola italiana ${ }^{39}$. Così, mentre si pone alla scuola dei giuristi gallicani, Sarpi non esita a dichiarare, nel più libero colloquio epistolare con Groslot de l'Isle, la propria delusione di fronte alla linea conciliante adottata da Enrico IV. «Con li continui offici che si stasse bene col papa » - rileva il 27 aprile 1610 - il re «ha dato fomento a' papisti ed impedimento a' buoni ${ }^{40}$. Il trauma dell'assassinio del Borbone detterà di qui a poco a Sarpi lettere cariche di devozione $\mathrm{e}$ gratitudine per la lezione offerta dalla Francia e tuttavia intrise di una profonda convinzione : le possibilità concrete di un ruolo propulsivo della monarchia francese sul continente europeo erano tramontate, con gravissimo rischio per l'Italia. "Doleo non vestra tantum sed et nostra etiam causa ", comunicherà Sarpi a Gillot nell'ottobre $1610^{41}$. " Calamitas fit nobis communis, quibus vestris successibus animi adduntur, vel minuuntur", ripeterà nel gennaio 1611, davanti alla ripresa dell'azione dei gesuiti e al profilarsi di una nuova offensiva di Roma per l'accoglimento della decretazione tridentina ${ }^{42}$. In seguito manifesterà a più riprese la propria apprensione per le divisioni provocate nel composito universo gallicano dalla destituzione di Edmond Richer dalla carica di sindaco della Sorbona e per il moltiplicarsi dei sintomi di un'irreversibile rimonta dell'influenza del cattolicesimo romano nel paese ${ }^{43}$.

13

carattere di fondo del carteggio sarpiano discende anche la sua peculiare cifra comunicativa, che all'analisi puntuale di leggi e istituti intreccia la denuncia dei misfatti del totato asburgico-papale e brani di tenore prettamente informativo redatti alla maniera degli avvisi dalle corti e dai fronti europei. Si tratta del resto della corrispondenza di un uomo pubblico, ben consapevole dei meccanismi del potere, inserito a fondo nei circuiti delle notizie ${ }^{44}$. Sulle lettere che vanno e vengono dalla cella del suo convento si esercitano così, insieme, le insidie della Curia romana e dei suoi emissari e il controllo delle cerchie politiche di riferimento. Oltre al confratello e collaboratore Fulgenzio Micanzio, è in particolare il patrizio Domenico Molin, esponente di punta dello schieramento più apertamente avverso al papa e alla Spagna, a condividerne le relazioni, tanto da sostituirlo occasionalmente nello scambio con Leschassier ${ }^{45}$. Tra la fine del 1611 e l'inizio del 1612 è proprio Molin a inviare al giurista parigino la scrittura sarpiana Delle contribuzioni de' chierici, con un'iniziativa non gradita dall'autore, che terrà a giustificare con il destinatario le semplificazioni operate in quella scrittura d'ufficio ${ }^{46}$. Un'occhiuta sorveglianza aveva circondato per contro la richiesta di una relazione sull'interdetto rivolta a Sarpi fin dal 1607 da De Thou. Lo scritto che il consultore veneziano era andato redigendo - quel caposaldo della storiografia sarpiana noto con il titolo di Istoria dell'Interdetto - era cresciuto su se stesso tra ripensamenti dello stesso Sarpi e remore del suo entourage rispetto alla divulgazione di una versione ufficiale della controversia con il papa $^{47}$. Nel 1610 sembrava giunto il momento opportuno al recapito, quando un patrizio vicino a Sarpi, Agostino Nani, veniva nominato ambasciatore straordinario a Parigi per l'incoronazione di Luigi XIII e si rendeva disponibile a portare con sé il testo, per rinunciarvi tuttavia poco dopo ${ }^{48}$. L'inoltro rimaneva ancora congelato, mentre Sarpi faceva balenare a Groslot la possibilità di ottenere le «memorie» dell'interdetto dall'Inghilterra, da una trasposizione in inglese che aveva consentito di eseguire a William Bedell, cappellano dell'ambasciatore d'Inghilterra a Venezia ${ }^{49}$. Solo l'approdo a Parigi, nel 1616, di un ambasciatore veneziano considerato particolarmente affidabile come Vincenzo Gussoni, appartenente alla cerchia sarpiana, avrebbe offerto l'occasione 
per onorare - tardivamente - l'impegno con De Thou. Lo storico gallicano, morto nel maggio 1617, non avrà comunque il tempo di utilizzare il testo, rimasto nelle mani del Gussoni. Lo stesso Sarpi autorizzerà Gillot a servirsene per trarne ogni notizia utile, « caractere tantum mutato $»^{50}$.

14 La vicenda del passaggio oltralpe della storia dell'interdetto - che prefigurava aspetti peculiari della complessa tradizione dei testi sarpiani - finiva così per dilatarsi lungo l'intera parabola delle corrispondenze del frate veneziano con il mondo francese. La fase più intensa dello scambio, segnata dalla dura prova dell'assassinio di Enrico IV, si era progressivamente esaurita nell'arco del 1613, di pari passo con lo spegnersi delle aspettative del servita nei confronti di una Francia che sembrava scivolare nuovamente verso lo scontro tra fazioni, scossa nel prestigio internazionale conquistato con Enrico IV, incapace di svolgere un ruolo efficace di contrasto alla supremazia spagnola. Sarpi e Micanzio avevano frattanto dirottato il loro impegno verso nuove relazioni con ambienti politico-religiosi inglesi e olandesi e si adoperavano per favorire un'alleanza della Serenissima con le potenze protestanti del nord ${ }^{51}$.

L'effimera ripresa, nel 1616, delle comunicazioni con De Thou, Gillot e Groslot de l'Isle avrà luogo sotto l'impressione dell'accoglimento dei decreti tridentini da parte dell'assemblea del clero francese, avvenuto l'anno prima. Di fronte al concretarsi di un esito paventato da tempo, Sarpi lasciava trasparire - scrivendo a Gillot - il proprio sconforto: e Gallia unde olim adiumenta libertatis abunde hauriebamus, modo exeunt instrumenta servitutis ${ }^{52}$. Ma continuava ad appellarsi alla comunità intellettuale parigina, che incoraggiava a resistere alle pressioni crescenti della Chiesa di Roma. Quanto a Venezia, attraversava a sua volta un momento particolarmente critico. Il settore del gruppo dirigente più legato alla memoria dell'interdetto aveva a lungo auspicato lo scoppio di un conflitto in grado di rimettere in discussione gli equilibri di potere in Italia. E nel 1615 il conflitto era infine scoppiato ai confini orientali della Repubblica, dove la tensione con gli Asburgo veniva tenuta alta dalle incursioni della pirateria uscocca foraggiata dagli arciducali d'Austria. Le dispendiose operazioni militari - con l'arruolamento di truppe olandesi e il versamento di sussidi al duca di Savoia in vista di un attacco alla Lombardia spagnola - avevano però presto ristagnato senza esiti significativi, tra il crescente disagio dell'ampia parte del patriziato che considerava la guerra una scelta finanziariamente troppo gravosa e azzardata dal punto di vista politico e religios $0^{53}$. «Troppo desiderio di quiete», diffusa acquiescenza ai « partiti di pace » degli spagnoli : così Sarpi dipingeva a Groslot de l'Isle la situazione veneziana nel marzo 1617, evocando con accenti profetici un accordo imminente che, "in apparenza tollerabile", avrebbe condotto a "una servitù totale d'Italia " ${ }^{54}$. Rispetto a uno sbocco del genere rimaneva l'auspicio che «l'Inghilterra o la Germania fossero più vigilanti » ${ }^{55}$. La Francia una Francia costretta dalle divisioni interne a mantenere buoni rapporti con la Spagna era ormai assente dai suoi orizzonti.

16

Se si considera nel suo insieme il flusso delle corrispondenze tra l'area veneta e la Francia, non può sfuggire la netta sfasatura cronologica tra gli epistolari sarpiani e quelli che fanno capo a Paolo Gualdo e Lorenzo Pignoria. Gli anni tra il 1610 e il 1613, quelli del maggiore impegno per Sarpi, si collocano all'interno di una lunga sospensione delle 
comunicazioni tra i padovani e Peiresc. Nell'aprile 1614 era Gualdo a scrivere all'erudito provenzale : lo ragguagliava sugli « occhiali » di Galilei e gli faceva notare che da quasi un quinquennio gli amici veneti attendevano sue notizie ${ }^{56}$. Sono state ipotizzate, per questo silenzio, ragioni contingenti: il maggiore coinvolgimento di Peiresc nella carica di consigliere al parlamento di Aix, la passione per l'astronomia suscitata in lui dalla pubblicazione del galileiano Sidereus nuncius, che lo distraeva dai radicati interessi antiquari ${ }^{57}$. Non è da escludere che l'impegno del carteggio fosse diventato meno appetibile dopo la partenza di Gualdo da Roma, per un lungo intervallo a Vicenza, proprio mentre a Padova l'attività dei Ricovrati languiva ${ }^{58}$. La lettera di Peiresc a Gualdo del 5 ottobre 1614, cui ne veniva allegata un'altra per Pignoria, costituisce una sorta di ricapitolazione dei disguidi e delle inadempienze reciproche, con relativa richiesta di perdono, suggellata dall'invio a entrambi di un ritratto di madonna Laura, omaggio ai comuni interessi petrarcheschi ${ }^{59}$.

17 Nel corso del 1615, con Gualdo nuovamente in Curia, lo scambio triangolare d'informazioni e libri torna assiduo : da Roma prendono la via di Aix opere di antiquaria e storia ecclesiastica, scritti di Galilei e dei suoi critici, a cominciare dagli attacchi del gesuita Christoph Scheiner, celato sotto lo pseudonimo di Apelle; da Padova Pignoria spedisce - oltre ai suoi lavori storico-antiquari, che ne vanno definendo la figura di studioso $^{60}$ - volumi procurati presso i librai veneziani, copie d'iscrizioni lapidarie e di documenti, rispondendo ai puntuali interrogativi di Peiresc ${ }^{61}$. La trama delle notizie e dei saluti lascia intravedere, dietro i due corrispondenti, la presenza costante delle personalità da sempre interessate al dialogo culturale con il mondo francese : Andrea $\mathrm{e}$ Donato Morosini, il vescovo di Belluno Lollino, gli amici passati alla corte di Roma, Querenghi e Aleandro ${ }^{62}$.

18 Di qui a poco le relazioni con Peiresc sarebbero andate incontro a un ulteriore rilancio. Nella tarda primavera del 1616 l'erudito di Aix si trasferiva infatti nuovamente a Parigi insieme a Guillaume Du Vair, nominato garde de sceaux nell'ambito di un profondo ricambio ai vertici ministeriali. Diversamente da quanto previsto in origine, il soggiorno era destinato a prolungarsi fino all'ottobre 1623, oltre la morte dello stesso Du Vair ${ }^{63}$. Ai corrispondenti veneti la nuova posizione di Peiresc, definitivamente cooptato nei circoli intellettuali della capitale, offriva una possibilità inusitata d'accesso alla piazza libraria parigina e di contatto con un più vasto orizzonte europeo. Attraverso Peiresc riprendevano anche le relazioni con De Thou, figura egemone nella cultura della capitale : nei mesi che intercorreranno tra l'autunno 1616 e la morte del presidente, nel maggio 1617, Gualdo e Pignoria torneranno a inviargli le informazioni e i materiali sugli uomini di lettere del Cinquecento che sarebbero dovuti entrare nella progettata prosecuzione dell'Historia sui temporis, ma rimarranno alla fine inutilizzati ${ }^{64}$. Sul nuovo sfondo, infine, un carteggio ancorato pressoché esclusivamente al recinto dell'erudizione e dell'antiquaria si apriva alle vicende politiche. Giunto a Parigi in un momento particolarmente difficile per la monarchia - fra la tregua con i principi ottenuta dalla reggente a Loudon e l'arresto del Condé - Peiresc registrava puntualmente nelle sue lettere l'alternarsi di presagi «di guerra civile» e di momentanee schiarite, riferiva sulla «mutazione [...] de' più vecchi e principali ministri », segnalava le mosse di Maria de' Medici e le offensive contro le fortezze tenute dagli aristocratici ribelli che stavano accompagnando la contrastata presa del potere da parte di Luigi XIII ${ }^{65}$.

19 Gli amici padovani dovevano seguire con particolare apprensione questi ragguagli. Se la frazione più battagliera del gruppo dirigente veneziano si era ormai allontanata dalla 
Francia, i patrizi moderati cui Gualdo e Pignoria erano legati rimanevano convinti della necessità, per la Serenissima, di uno stretto legame con la monarchia francese, che aveva rinsaldato i rapporti con la Sede apostolica e perseguiva una politica estera distensiva e pacifista. Tutt'altro che indifferenti ai timori di un accerchiamento asburgico, rimanevano risolutamente contrari ad alleanze avventurose con i paesi protestanti, foriere di preoccupanti scenari religiosi, e giudicavano la guerra contro gli arciducali d'Austria come un pericoloso ritorno degli spiriti del 1606, che rischiava di distogliere la Repubblica da una tradizione costantemente rivolta al mantenimento della quiete ${ }^{66}$. Premevano perciò per una rapida composizione del conflitto sotto l'egida di una Francia libera da fazioni, saldamente unita nel cattolicesimo, unica possibile garante di un accordo tra Venezia e gli Asburgo e di un duraturo equilibrio in Europa. Di tale prospettiva, che orientava allora entrambe le diplomazie, veneziana e francese, si faceva interprete lo stesso Peiresc. "Se abbiamo la pace - scriveva a Gualdo nel settembre 1616 se ne sentiranno gli effetti costì ne' motivi di Austria; se abbiamo la guerra, se ne vorranno valere i nemici di cotesta Serenissima Repubblica ${ }^{67}$.

Qualche tempo prima Gualdo aveva inviato a Peiresc, sollecitandone la presentazione al re, il manoscritto delle Turbulenze della Francia in vita del re Henrico il Grande del vicentino Alessandro Campiglia, già segretario a Padova dei Ricovrati e vicino all'ambasciatore Brûlart de Léon ${ }^{68}$. Si trattava di una ricostruzione minuziosa, dall' « andamento faticoso e trasandato ${ }^{69}$, del periodo compreso tra il 1553, anno della nascita del futuro Enrico IV, e il 1595. Campiglia vi proponeva con passione il mito del sovrano trionfante su fazioni politiche pretestuosamente ammantate di motivazioni religiose, guidato dalla provvidenza nella pacificazione d'una Francia rimasta cattolica a dispetto delle lusinghe di calvinisti e fautori della tolleranza, «Hercole novello», fermato da " tigre inhumana " nella missione intrapresa di conservare con i suoi eserciti " a tutta l'Europa la libertà ", come lo stesso autore scriverà nella dedica a Luigi XIII dell'edizione a stampa.

Le Turbulenze della Francia - che, come Peiresc aveva previsto, non fruttarono all'autore alcuna ricompensa, a parte la "benignissima risposta » regia e il dono differito d'una catena d'oro ${ }^{70}$ - davano corso a una riflessione dipanatasi lungo l'arco di quasi un ventennio tra l'ambiente politico-culturale filofrancese veneto, la corte estense e le relative diramazioni curiali, collocandosi in un nascente filone di pubblicazioni riguardanti la recente storia del Regno. Nel 1615 era uscita a Modena l'Historia della morte d'Enrico Quarto re, versione italiana del vibrante resoconto dello storiografo di corte Pierre Matthieu, eseguita - dietro la formale attribuzione al precettore di lingua francese di casa d'Este Jean-Bernard de la Baffarderie - dal cardinale Alessandro sotto la guida del padovano Antonio Querenghi, che da Roma continuava a svolgere la funzione di segretario estense ${ }^{71}$. Nel 1618 sarà la volta di un altro scritto di Matthieu, le Osservationi di stato e di historia sopra la vita e i servigii del signor di Villeroy, volto in italiano dal medesimo illustre traduttore ${ }^{72}$. L'operetta, che rendeva omaggio alla memoria dell'antico ministro di Enrico IV, uscito definitivamente di scena, era pervenuta al cardinale ferrarese Bonifacio Bevilacqua, probabilmente grazie all'intervento del nunzio pontificio a Parigi Guido Bentivoglio $^{73}$. Lo stesso Bevilacqua aveva in mano, poco dopo, due nuovi testi di Matthieu, l'Histoire romaine d'Aelius Sejanus e le Prospérités malheureuse d'une femme cathénoise. Trasparenti metafore dei drammatici casi di Concino Concini e della moglie Leonora Dori, questi trovarono a loro volta un traduttore in un "Gelato Accademico Umorista ", indicazione di paternità che riconduce all'accademia romana, e furono pubblicati nel 1619 a Ferrara $^{74}$. Incorniciata da queste prime prove della fortuna italiana di Matthieu, l'opera 
del Campiglia veniva impressa a Venezia dal tipografo Giorgio Valentini nel febbraio 1617, per giungere a Parigi solo nell'agosto. Prima ancora della stampa aveva suscitato indignate proteste da parte degli spagnoli ed era finita nel mirino della censura romana ${ }^{75}$. Certamente, come ha rilevato Benzoni, troppo marcate dovettero apparire, nelle pagine dello storico vicentino, "la simpatia per tutta l'attività del Borbone », estesa anche alla madre Giovanna d'Albret, accesa calvinista, e « l'angolatura, del tutto politica » adottata nell'analisi delle vicende ${ }^{76}$. Ma non passarono certamente inosservate ai censori romani allora molto attenti a contenere ogni attacco al ruolo e all'azione della Spagna l'entusiastica esaltazione del primato del trono di Francia, orchestrata attingendo ai temi classici della contrapposizione ideologica tra le due grandi monarchie, e l'insistenza sul radicato vincolo tra la penisola italiana e il re Cristianissimo ${ }^{77}$. Malgrado la mobilitazione di amici e sostenitori, l'opera non potrà evitare l'iscrizione all'Indice donec corrigatur ${ }^{78}$.

Il nostalgico monumento eretto dal Campiglia alla Francia di Enrico IV, pilastro della « libertà » dell'Europa e dell'« Italia particolarmente »"79 era un sasso nello stagno della politica estera filospagnola perseguita dalla Reggenza. La sua comparsa nella capitale francese mirava presumibilmente a propiziare un fattivo intervento di Luigi XIII nel complesso gioco diplomatico in corso, volto alla stipulazione della pace tra la Repubblica e gli arciducali d'Austria. Dopo che il governo veneziano aveva accettato, alla fine del 1616, una proposta di mediazione avanzata da Filippo III, il primo negoziato condotto a Madrid era rimasto senza esito, ma le sollecitazioni della corte di Francia avevano favorito una riapertura della trattativa a Parigi. Per Venezia ne erano stati incaricati due patrizi schierati su fronti opposti : l'ambasciatore ordinario Vincenzo Gussoni, poco più che quarantenne, vicino a Sarpi e strenuo fautore della guerra, e il più anziano $e$ autorevole Ottaviano Bon, pacifista a oltranza, legato da antica consuetudine alla cerchia padovana e in particolare a Lollino ${ }^{80}$. Diplomatico esperto, Bon era giunto in Francia oltre un anno prima, in qualità di ambasciatore straordinario, per affiancare Gussoni in uno scabroso confronto sulla richiesta veneziana di libero passo lungo la via dei Grigioni per le truppe assoldate oltralpe, destinato ad arenarsi tra le resistenze della Spagna, i veti del nunzio pontificio in Francia Ubaldini e l'acquiescenza del governo di Maria de' Medici, sovrastato dalla ribellione dei principi. Nell'estate 1617 tuttavia la svolta politica seguita all'assunzione del potere da parte di Luigi XIII, pareva autorizzare aspettative diverse. In realtà le pressioni convergenti degli spagnoli, dei francesi e del nuovo nunzio Guido Bentivoglio, antico sodale padovano e amico personale di Bon ${ }^{81}$, convinceranno quest'ultimo ad accelerare i tempi e a concludere - forzando la volontà del collega più giovane e le stesse commissioni ricevute - un accordo che si limitava a confermare $\mathrm{i}$ capitoli stipulati a Vienna fin dal 1612 riguardo all'allontanamento degli uscocchi dalla costa dalmata, ma risultava blando e dilatorio rispetto al complesso contenzioso tra Venezia e le autorità del Regno di Napoli per la giurisdizione sull'Adriatico, sotteso alla questione uscocca. Un accordo che separava inoltre - contro gli auspici per una compiuta sistemazione dei problemi italiani - la posizione del duca di Savoia, alleato della Serenissima. Siglata il 6 settembre 1617 a Parigi e ratificata venti giorni dopo a Madrid, la " pace d'Italia » avrebbe fatto esplodere a Venezia le tensioni politiche latenti, accentuate dall'aperta dissociazione di Gussoni dalle decisioni dell'ambasciatore straordinario ${ }^{82}$. Si apriva una polemica dai lunghi strascichi, che farà rasentare la crisi diplomatica : gli ambasciatori veneziani, richiamati e convocati davanti al Senato per esser venuti meno al mandato loro conferito, saranno trattenuti a Parigi in attesa di garanzie a tutela delle loro persone e dello stesso operato dei ministri francesi. Difesi a Venezia dal Brûlart de Léon, potranno rimpatriare solo all'inizio del 1618. 

Ma il divampare di proteste e recriminazioni, tra l'aggressività perdurante delle autorità spagnole in Adriatico e in Valtellina, insinuavano in loro una crescente inquietudine. $\mathrm{Ne}$ cogliamo le tracce lungo i margini della discussione erudita, nell'andirivieni delle segnalazioni e delle commissioni librarie. Sullo scorcio del 1617 l'appello a una Francia che stava deludendo ogni speranza si caricava d'angoscia e di cattivi presagi. Le sorti d'Italia erano ormai segnate - scriveva Paolo Gualdo a Peiresc - se i francesi non davano corso al più presto a qualche "generosa risolutione $"^{83}$. Anche Pignoria si staccava da lapidi e reperti documentari per commentare con Peiresc il rapido evolvere della situazione in Boemia, per evocare casi politico-religiosi scottanti come quello di Marcantonio De Dominis, la cui opera veniva allora censurata tanto dalla Sorbona che dal collegio dei teologi dell'università patavina ${ }^{84}$. Nei plichi che inviava a Parigi trovavano ora posto gli scritti originati dalla battaglia pubblicistica e storiografica che accompagnava la laboriosa esecuzione della « pace d'Italia ». Nell'arco del 1618 Pignoria spediva a Peiresc, insieme a più copie delle Turbulenze della Francia del Campiglia, la «terza parte dell'Istoria degli Uscocchi», con ogni probabilità il Supplimento dell'Historia degli Vscochi di Minuccio Minucci arciuescouo di Zara, pubblicato anonimo da Sarpi nel $1617^{85}$; il « racconto della guerra del Friuli ", da identificare quasi certamente con l'opera Guerre d'Italia tra la Serenissima Republica di Venetia e gli arciducali di casa d'Austria, comparsa a firma di tal Pomponio Emigliani milanese ${ }^{86}$; il « manifesto della congiura », indicazione che potrebbe far pensare a una scrittura sul preteso intrigo diplomatico tessuto dall'ambasciatore spagnolo a Venezia marchese di Bedmar, nella denuncia del quale era esplosa, nella primavera di quell'anno, la diffusa tensione antispagnola ${ }^{87}$.

Nello stesso periodo Gualdo e Pignoria accoglievano a Padova l'ex ambasciatore Ottaviano Bon, che prima ancora di lasciare la Francia aveva deciso di ritirarsi a vita privata proprio nella città universitaria ${ }^{88}$. I vecchi amici gli si stringevano intorno, malgrado lo sconcerto per gli esiti della trattativa parigina e il crescente pessimismo nei confronti della monarchia di Luigi XIII ${ }^{89}$. Da Parigi Bentivoglio cercava di tener vivi gli spiriti filofrancesi dell'ambiente politico-culturale moderato. Scriveva a Gualdo approvando la scelta del Bon di abbandonare le affannose cure della politica e assicurando del «degno concetto " in cui il negoziatore del trattato con gli arciducali era tenuto alla corte del Cristianissimo ${ }^{90}$. E richiamava alle ragioni profonde del rapporto con la Francia, « uno Stato - scriveva nel 1619 a Gualdo - sì grande, sì diviso in materia di religione, sì spesso agitato dalle discordie civili, c'ha una delle maggiori Corti d'Europa \& uno de' più riguardevoli governi del mondo", provvisto d'una qualità «unica e singolare»: «quella delle continove mutationi che vi si veggono», autentica palestra, dunque, di " governo de' Regni » ${ }^{91}$. La rappresentazione della Francia che il nunzio delineava, rivelatrice delle inflessioni della politica pontificia sullo scorcio del pontificato di Paolo V, doveva suonare di rimprovero a Giambattista Gualdo, giovane nipote di Paolo. Giunto a Parigi sul finire del 1618 per prender parte alle ultime battute di un annoso affaire politico-religioso - il ritorno al cattolicesimo del giurista vicentino Giulio Pace, aspirante a una cattedra nello Studio di Padova -, Giambattista se n'era ripartito già nel marzo 1619, rinunciando alla straordinaria opportunità di osservare « le cose di questo Regno e di questa Corte », in grado di « servir di scuola a tutti gli altri paesi $»^{92}$. Alle immagini proposte da Bentivoglio facevano da polemico contrappunto gli attacchi che contemporaneamente, da Parigi, sferrava contro la Francia l'ambasciatore della Repubblica Angelo Contarini, esponente della cerchia patrizia sarpiana. Già all'indomani del suo insediamento, all'inizio del 1619, Contarini aveva invitato il Senato a metter da parte ogni aspettativa di aiuto da parte di 
una monarchia francese priva di guida sicura, lacerata dai contrasti e dai concorrenti appetiti dei ministri, ridotta all'impotenza dall'attivismo asburgico. Nessuna illusione, in lui, rispetto a un re come Luigi XIII, diviso dalla madre da un conflitto insanabile, succube della Spagna e dell'insinuante operare del nunzio pontificio, intento a combattere gli ugonotti più che a farsi valere «negli affari della Valtellina » e nella penisola italiana ${ }^{93}$.

All'aprirsi della guerra dei trent'anni opposti atteggiamenti nei confronti della Francia continuavano dunque a marcare il discrimine tra differenti settori del gruppo dirigente, riproponendo le divaricazioni ideologiche radicate nella stagione dell'interdetto. Quanto a Bentivoglio, continuerà a reiterare i suoi buoni uffici anche dopo il nuovo scacco all'iniziativa francese rappresentato dal brutale intervento spagnolo in Valtellina nel luglio 1620. L'11 novembre, a tre giorni dalla battaglia della Montagna bianca, annunciava a Paolo Gualdo la recente presa di Pau da parte delle forze regie, un colpo decisivo inferto agli ugonotti del Béarn, con il quale la Francia riacquistava - a suo dire - un sovrano degno «d'un San Luigi $»^{94}$. Gualdo era pregato di mettere a giorno degli ultimi avvenimenti gli «amici nostri», primo tra tutti «il nostro signor Bono». Alla fine del 1619, mentre tornavano ad affacciarsi progetti d'alleanza tra la Serenissima, il duca di Savoia e le Province Unite d'Olanda che facevano ben sperare Sarpi e Micanzio, Ottaviano Bon era stato posto nuovamente sotto accusa, da un Senato profondamente diviso, per aver fatto circolare in forma anonima la sua relazione sulla pace del 1617 , divenuta una sorta di manifesto della politica estera cauta e pragmatica patrocinata dalla fazione moderata del patriziato ${ }^{95}$. Una politica che guardava ostinatamente alla Francia.

Nell'aprile 1622 Pignoria riferiva a Giambattista Gualdo che Peiresc avrebbe desiderato riavere una mezza pietra donata vent'anni prima, a Venezia, allo zio Paolo Gualdo, morto nell'ottobre precedente. "Io ho comodità ogni settimana di scrivere al detto Signore ", precisava l'erudito padovano, offrendo di occuparsi della spedizione ${ }^{96}$. Dopo la scomparsa dell'amico più anziano, Pignoria si era assunto in prima persona la prosecuzione di un dialogo divenuto ormai consuetudine. Un dialogo che, al passaggio tra il secondo e il terzo decennio del secolo, assicurava l'inserimento in una rete di corrispondenze europee in via d'espansione : quando, nel 1623, Peiresc rientrava in Provenza, il suo circuito epistolare proteso dalla Francia verso l'area mediterranea - s'intersecava ormai con quello dei fratelli Pierre e Jacques Dupuy, più giovani cugini nonché eredi spirituali e materiali di Jacques-Auguste De Thou. Sull'onda del cordoglio di amici e conoscenti per la morte del presidente, il carteggio dei Dupuy, in precedenza intermittente e occasionale, si era rapidamente infittito e andava diramandosi dalla Francia verso i maggiori centri culturali olandesi - Leida in primo luogo -, verso l'area germanica, verso Roma, destinata a confermarsi, con il pontificato di Urbano VIII, come il principale crocevia nella penisola dell'informazione scientifico-erudita e delle notizie politiche provenienti dalle corti europee e dai fronti di guerra ${ }^{97}$.

In un orizzonte comunicativo più esteso e complesso Pignoria si sforzava di tener vivo il ruolo del polo padovano. A incoraggiarlo, a sostenerne le iniziative era ora il senatore Domenico Molin. L'amico di Sarpi, partecipe dei rapporti del consultore veneziano con gallicani e protestanti francesi, aveva visto crescere la propria autorevolezza politica di pari passo con il moltiplicarsi delle sue relazioni con i maggiori rappresentanti della ricerca filologica d'oltralpe : dai francesi Casaubon e Claude Saumaise, agli olandesi Daniel 
Heinsius, Jan van Meurs, Gerhard Voss ${ }^{98}$. Con le sue ampie frequentazioni, con la sua biblioteca generosamente aperta agli interessati, era diventato il principale interlocutore dell'ambiente tradizionalmente più coinvolto, sotto l'egida del milieu aristocratico moderato e filocuriale, nei rapporti con la Francia. L'ascendente del «signor Domenico ", il senso di una deferente familiarità nei suoi confronti, aleggiavano sul colloquio epistolare tra Gualdo e Pignoria fin dallo scorcio degli anni dieci ${ }^{99}$. Nel decennio successivo Molin avrebbe steso sul mondo intellettuale veneto una rete mecenatesca e clientelare della quale il padovano Pignoria costituirà uno dei più accreditati referenti. Per conto proprio, degli amici, di docenti dell'Università Pignoria chiedeva al senatore libri in prestito, entrature presso studiosi italiani e stranieri, contatti con tipografi e librai, ma anche sostegno presso le magistrature della capitale per la soluzione di controversie giudiziarie della più varia natura ${ }^{100}$. Molin, per parte sua, accordava benigno interessamento, formulava pareri su punti d'erudizione controversi, faceva circolare, oltre ai suoi libri, le missive giuntegli dai corrispondenti transalpini ${ }^{101}$. E seguiva da vicino le discussioni tra Pignoria e Peiresc, intervenendo su singole questioni - come quella delle misure e dei pesi antichi e moderni, che da tempo appassionava l'erudito di Aix ${ }^{102}$-, suggerendo ulteriori spunti. Nel 1624 Peiresc e, per suo tramite, lo storico e geografo André Duchesne saranno ad esempio coinvolti in una ricostruzione della « discendenza di quelli della casa Molin dopo le guerre oltramarine $»^{103}$.

Il passaggio di testimone nel controllo della principale corrente di scambi con la Francia sottolineava i profondi mutamenti in corso nella politica veneziana. Mentre procedeva il ricambio generazionale nel gruppo dirigente ${ }^{104}$, tendevano a esaurirsi le dinamiche politiche che avevano dominato il primo ventennio del secolo. Sul fronte interno la contrapposizione tra famiglie filocuriali e avverse a Roma incrociava ormai altre profonde fratture nel corpo aristocratico : quella, in primo luogo, tra le case più ricche e influenti e il patriziato di scarsi mezzi escluso dal cerchio del potere, destinata a esplodere dopo il 1625 nel movimento di Renier Zeno ${ }^{105}$. Quanto alla politica estera, il rilievo assunto dopo il 1620 dalla questione della Valtellina doveva favorire il tramonto della linea bellicista volta all'alleanza con l'olanda, rivelatasi velleitaria, e richiamare il governo veneziano a un proficuo rapporto con la Francia, dalla quale sembrava ragionevole attendersi - con l'ormai prevedibile ascesa di Richelieu - un'azione contro l'egemonia degli Asburgo finalmente determinata, almeno in parte sottratta ai condizionamenti della diplomazia pontificia. Un'alleanza con la monarchia di Luigi XIII s'imponeva come obiettivo prioritario per la Repubblica anche agli occhi di chi, come Domenico Molin, era stato tra i fautori dell'asse antiasburgico con le potenze protestanti e rimarrà sempre diffidente rispetto al laborioso ridisegno della presenza internazionale francese ${ }^{106}$. Di fronte all'inevitabile ralliement tuttavia la Serenissima doveva porsi - nella visione del senatore - con l'orgoglio e la consapevolezza di un'esemplare tradizione politica e culturale. Con la sua dedizione agli studi, con le ramificate corrispondenze, con l'incoraggiamento offerto a eruditi di differente estrazione, Molin mirava certamente a celebrare se stesso e la propria ambizione, ma riproponeva insieme l'idea di una grande Venezia, capace di svolgere ancora un ruolo di prim'ordine in Europa. Tra gli echi della guerra che si espandeva sul continente, un ceto di governo lacerato da contrasti profondi finiva così per convergere sulla necessità di stringersi alla Francia. saranno il primo risultato di un faticoso confronto politico-diplomatico, destinato ad 
accompagnarsi a un rilancio del filone di pubblicazioni francesi avviato nel decennio precedente, il cui aspetto più vistoso sarà l'exploit delle traduzioni di Pierre Matthieu.

Le versioni comparse dal 1615 al 1619, accolte con unanime favore dai letterati veneti più legati alla Francia, avevano riguardato alcuni scritti minori dello storiografo di corte francese ${ }^{108}$. Ma tra il 1623 e il 1625 i torchi degli stampatori veneziani Bartolomeo Fontana e Barezzo Barezzi ne sfornarono ripetutamente gran parte delle opere maggiori. In questo breve arco di tempo l'Histoire de France et des choses memorables advenues aux provinces estrangeres durant sept années de paix du regne de Henry IV, l'Histoire des derniers troubles de France sous le regne des rois très-chrestiens Henri III [...] et Henry IV, l'Histoire véritable des guerres entre les deux maisons de France et d'Espagne [...] jusqu'à la paix de Veruins furono presentate, in una sorta di rincorsa tra le due tipografie, in versioni italiane eseguite da traduttori diversi e in edizioni dai titoli differenti, singolarmente o in volumi che contenevano anche altri testi di minor mole dell'autore, già editi in Italia - come le Osservazioni di Stato [...] del Signor di Villeroy - ovvero proposti per la prima volta ${ }^{109}$. La fortuna di Matthieu si dislocava dagli elitari circoli filofrancesi veneto-modenesi verso un'industria editoriale in grado di far fronte alla crescente richiesta del mercato e di adeguarsi alle direttive impartite dalla censura romana rispetto alla circolazione di opere che toccavano nodi particolarmente delicati e discussi della storia di Francia. Nel 1620 la condanna all'Indice donec corrigatur aveva colpito l'Histoire des derniers troubles de France, « un requisitoire argumenté » contro la Lega cattolica e una simpatetica apologia di Enrico IV, sfociante a tratti nell'aperta difesa della libertà di coscienza ${ }^{110}$. Morto l'autore nel 1621, la condanna venne confermata due anni dopo, ma l'opera sospesa fu ugualmente offerta al pubblico italiano nel quadro dell'ondata di versioni che si stava allora avviando, grazie al lavoro di un cospicuo gruppo di traduttori-manipolatori di testi ${ }^{111}$.

La competizione tra case tipografiche, lo stesso impegno nell'adattamento di testi già censurati o potenzialmente condannabili scandivano le tappe del successo di un autore che scortava il lettore lungo i meandri della grandiosa officina politica del secondo Cinquecento francese, suscitando l'interesse degli appassionati alle questioni di Stato e di governo e dei letterati impegnati in discussioni stilistiche e storiografiche ${ }^{112}$. Il ciclo editoriale che decretava la fortuna italiana di Matthieu tendeva peraltro a riflettere l'andamento delle relazioni tra Venezia e la Francia. Inaugurato nel clima d'insicurezza e sospensione creato dall'inerzia della politica estera della Reggenza, decollava nel biennio 1623-24, nel pieno di una ripresa del dialogo tra le diplomazie; rallentava quindi, fin quasi a fermarsi, tra il 1625 e il 1626, quando le speranze suscitate dall'invasione della Valtellina decisa da Richelieu venivano travolte dalla sconfitta francese per mano degli spagnoli e definitivamente seppellite dalla pace di Monçon ${ }^{113}$. Sarebbe ripartito negli anni difficili della guerra di successione di Mantova, mentre la ricerca di un'intesa con la Francia tornava a Venezia in primo piano, in uno scenario reso più drammatico dal dilagare in Italia del conflitto europeo.

Nel 1628, con l'offensiva spagnola nel Monferrato ormai in corso, Barezzi riprendeva la pubblicazione di ristampe e nuove versioni delle opere principali di Matthieu, alle quali accostava, secondo una strategia ormai collaudata, altri testi dello storico francese non ancora disponibili in italiano. Comparivano così l'Historia memorabile di Luigi XI, il Giuditio politico sopra la vita di Luigi XI, nonché uno Specchio della scienza politica, una raccolta delle «massime più sententiose del detto Mattei », allestita - a tenore del frontespizio - dallo stesso Barezzi, non nuovo del resto a operazioni di questo genere ${ }^{114}$. Sempre nel 1628 usciva con il marchio di Giacomo Scaglia e Francesco Baba anche l'Historia di San Luigi IX, 
tradotta dal bolognese Giovanni Battista Parchi e riproposta dalla stessa stamperia l'anno successivo $^{115}$. pubblicazioni appare connotata dalla presenza di una scaltrita figura di traduttore e consulente editoriale : Girolamo Canini, frate gesuato originario di Anghiari, ma vissuto tra Venezia e Padova, dove fu anche priore del convento del suo ordine ${ }^{116}$. Noto per una versione degli Essais di Montaigne, che lasciò manoscritta, e per i commenti aggiunti all'edizione veneziana di Tacito del 1618, Canini si era affacciato al cantiere editoriale di Barezzi ormai esperto delle possibilità e dei limiti consentiti alle figure impegnate nell'ambito dell'attività tipografica. Intorno al 1620 aveva negoziato con i revisori dell'Indice le correzioni da apportare, in vista della stampa, alla sua versione del Traité de la cour di Eustache du Réfuge ${ }^{117}$. $\mathrm{E}$ da Roma aveva dedicato nel 1625 al cardinale Barberini gli Aforismi politici cavati dall'Historia d'Italia di M. Francesco Guicciardini, dove condensava in precetti e sentenze brani guicciardiniani isolati dal contesto, disinnescandone la vena polemica. Da quell'anno, rientrato a Padova, Canini si era messo al lavoro per fornire a Barezzi ulteriori traduzioni degli scritti di Matthieu, cimentandosi tra l'altro con la censurata Histoire des derniers troubles de France ${ }^{118}$. filone veneziano di pubblicazioni francesi : l'edizione, uscita nel 1629 presso il tipografo Giacomo Sarzina, di tre volumi di Lettere del cardinale Arnauld d'Ossat, dal Canini «tradotte dal francese, messe insieme, \& arricchite di alcuni Discorsi » ${ }^{119}$. I primi due tomi erano introdotti da un'ampia dedica al patriarca di Aquileia Agostino Gradenigo, lungo la quale il traduttore e curatore intrecciava le lodi del dedicatario con quelle del prelato francese, protagonista, insieme al Davy Du Perron, del negoziato che avrebbe condotto alla riconciliazione di Enrico IV con Clemente VIII. Del Gradenigo - già membro dell'accademia dei Ricovrati, amico del fondatore Federico Corner e di Guido Bentivoglio Canini ricordava l'illustre discendenza e il legame con i cardinali Bernardo Navagero e Agostino Valier, «suoi zii nella linea materna ${ }^{120}$. Ne rimarcava inoltre la conoscenza profonda a suo tempo acquisita del cardinale francese, degli "alti e generosi concetti » che avevano guidato il d'Ossat, in stretta unione d'intenti con Enrico IV e il segretario Villeroy e di concerto con papa Clemente VIII, verso l'obiettivo della pacificazione del Regno e del « già tanti anni mal menato et alla ruina inclinante Mondo Christiano ». In un «argomento » che precedeva il testo delle lettere Canini stagliava invece il procedere accorto e lungimirante di papa Aldobrandini nel travagliato passaggio della successione del Borbone. Quanto al terzo volume dell'epistolario, risultava dedicato a Flavio Querenghi, nel ricordo dello zio Antonio il quale, a sua volta grande estimatore delle doti del d'Ossat, aveva giudicato quest'ultimo «degno dell'aureo treppiede della civil prudenza».

Le due dediche delle Lettere erano entrambe datate $1^{\circ}$ settembre 1629. La congiuntura era allora per Venezia particolarmente critica. Nel marzo di quell'anno, nel quadro dell'intensa azione diplomatica intrapresa da Urbano VIII, una lega a sostegno del duca di Mantova era stata conclusa tra la Serenissima, la Francia, il duca di Savoia e il papa stesso. I leader storici del fronte antiasburgico veneziano, Domenico Molin e il futuro doge Nicolò Contarini, erano riusciti a superare le tendenze neutralistiche ormai diffuse nel loro stesso schieramento e a far approvare dal Senato l'invio nel Mantovano di contingenti militari, mentre la Francia avrebbe messo in campo le sue truppe a Casale. Ma in ottobre la rapida resa del presidio di Canneto d'oglio agli imperiali avrebbe confermato 
l'inadeguatezza militare della Repubblica già emersa in precedenti occasioni, dalla guerra di Gradisca del 1615-16 alle manovre in Valtellina ${ }^{121}$. Alla vigilia di una prova umiliante per l'esercito veneziano la celebrazione orchestrata dal Canini del «nobilissimo triumvirato » - Enrico IV, Villeroy, d'Ossat - che, d'intesa col pontefice, aveva riportato la Francia al centro del gioco politico europeo, lo stesso riferimento al patrizio-cardinale Valier, comprimario di quella svolta, miravano a riattualizzare il collaudato schema d'azione del gruppo aristocratico moderato. Legato ai Barberini e alla cerchia dei letterati padovani filofrancesi, Canini forzava ideologicamente la lettura della riconciliazione del Borbone con Roma, richiamando il ceto di governo veneziano a una politica volta alla pace e alla neutralità, affidata alla guida delle più autorevoli famiglie 'papaliste', garantita da uno stabile accordo tra la Francia e il papato. Un accordo che nella convergenza tra Enrico IV e Clemente VIII trovava il proprio antecedente ideale.

Nel 1630, mentre le repliche delle opere di Matthieu si susseguivano a ritmo rallentato ${ }^{122}$, usciva dalla stamperia di Tommaso Baglioni la Storia delle guerre civili di Francia di Enrico Caterino Davila. Sorta di punto d'arrivo d'un ciclo editoriale inscritto in una stagione cruciale della politica estera veneziana, l'opera suggellava l'annoso confronto degli ambienti veneti con un tormentato periodo della storia francese, costituendone il frutto forse più significativo, certamente il più duraturo. L'esperienza personale dei conflitti di religione in Francia che l'autore aveva compiuto negli anni giovanili si era decantata nel tempo, lungo i percorsi di una carriera militare al servizio della Repubblica accompagnata dallo scambio costante con un amico più anziano e autorevole come Alvise Lollino e intervallata da ripetuti soggiorni a Padova. Qui Davila, uomo d'armi sensibile al richiamo della pace, aveva conversato con i Querenghi, zio e nipote, con i patrizi Ottaviano Bon e Donato Morosini; vi era tornato poi più volte tra il 1623 e il 1628, di ritorno dalla Dalmazia, dove - nei momenti liberi dagli impegni di governatore di Zara - aveva dato forma alla memoria ricomponendola alla luce delle discussioni e degli studi successivi ${ }^{123}$. Dalla tessitura, più volte interrotta e ripresa, di una trama composita doveva scaturire una narrazione ancorata a un saldo filo conduttore. Messe da parte le motivazioni religiose, cui veniva negata ogni autonomia, le «guerre civili» si dipanavano nella loro logica dominante di scontro politico, di aspra competizione per il potere tra fazioni e grandi corpi della società francese. Da questo gigantesco urto d'ambizioni e d'interessi concreti Davila vedeva dipartirsi l'« itinerario salvifico del degradato e vilipeso istituto monarchico ", un percorso guidato dalla provvidenza, destinato a culminare con l'ascesa al trono di Enrico IV ${ }^{124}$.

Maturata nel dialogo con gli esponenti di lungo corso di quel patriziato filofrancese moderato che nell'esito degli sconvolgimenti francesi continuava a trovare stimoli per la riflessione e l'azione politica, la Storia delle guerre civili veniva alla luce all'ombra di una dedica a Domenico Molin. La « felice protezione » del senatore - dichiarava Davila - aveva garantito all'autore la "quiete» necessaria per condurre a termine il lavoro, dopo « lunghi travagli ». Avrebbe ora permesso all'opera di comparire «nella pubblica via » con il sostegno dell'«incorrotta censura» di un uomo politico dotato di «nobili ornamenti » in « tutte le scienze e [...] le discipline $»^{125}$.

Alla data in cui licenziava, da Brescia, la sua Storia - il $1^{\circ}$ febbraio 1630 - Davila ricopriva da oltre un anno l'ufficio di sergente maggiore delle ordinanze e curava l'allestimento delle difese della Repubblica ai confini occidentali. Dopo gli insuccessi dei mesi precedenti, l'intesa franco-veneta si stava avvitando ancora una volta nella spirale di sollecitazioni, attese, reciproche accuse di scarso impegno che da tempo caratterizzava le 
relazioni diplomatiche tra la Serenissima e la monarchia di Luigi XIII. Le cautele e l'attendismo del Senato lasciavano presagire l'esito negativo dell'alleanza: la presa imperiale di Mantova del luglio 1630, preceduta dalla disastrosa ritirata dell'esercito veneziano a Valeggio, ne sancirà il tramonto, sotto l'impressione del propagarsi della peste. Dall'accordo di Ratisbona dell'ottobre 1630 alla pace di Cherasco della primavera 1631, le trattative diplomatiche tra la Francia e l'Impero, minacciato dall'avanzata svedese, dovevano registrare il successo della mediazione di Urbano VIII. Venezia rimaneva invece ai margini del negoziato. Il progetto di restituirle « un ruolo attivo, da protagonista, in Italia e in Europa ${ }^{126}$, inseguito - tra dissidi e contraddizioni - dal suo gruppo dirigente, era sfumato.

Domenico Molin, l'uomo politico che più si era speso per questo disegno, non si rassegnava. Nel 1631 farà pubblicare a Leida, da Elzevier, le Notae in Donatum Ianotium et Casparem Contarenum cardinalem de Republica Veneta del giurista e letterato veneziano Nicolò Crasso: a questa riproposizione dei capisaldi della mitografia costituzionale cinquecentesca, a lui stesso dedicata, aveva contribuito con materiali e suggerimenti ${ }^{127}$. La Venezia del mito, con il suo volto più propriamente culturale, splendente del glorioso passato rinascimentale, s'era affacciata qualche tempo prima nella lunga e studiata dedica «Serenissimae Venetorum Reipublicae» premessa alle Plinianae Exercitationes da Claude Saumaise, uno dei tanti illustri corrispondenti stranieri del senatore ${ }^{128}$.

Divenuto promotore di studi filologici e antiquari, Molin non aveva dimenticato Sarpi. E rimaneva ben presente nell'altro capitolo delle relazioni intellettuali tra Venezia e la Francia che, iniziato con l'interdetto, ruotava intorno ai testi del consultore veneziano.

All'inizio degli anni trenta l'immagine di Sarpi tendeva a connotarsi, al di qua e al di là delle Alpi, in modo opposto, secondo un modulo speculare di presenza-assenza. Grande nemico della curia romana, autore di un'opera esecrata come l'Istoria del concilio tridentino, risultava ormai - nella penisola italiana - condannato a una sopravvivenza clandestina, formalmente assente. Anche a Venezia la figura del servita era andata incontro a una difficile assimilazione e a una graduale eclissi : gli ultimi anni della sua vita, pur trascorsi nell'intensa attività al servizio del governo veneziano, erano stati segnati dal deludente tramonto della linea politica di contrapposizione a Roma con cui si era identificato e che veniva ora indicata come fallimentare, foriera del progressivo isolamento internazionale della Repubblica. La stessa sedimentazione di una versione di Stato sull'interdetto aveva contribuito a sminuirne il ruolo. L'Historia veneta ah anno 1521 ad anno 1615 del senatore e pubblico storiografo veneziano Andrea Morosini, allestita postuma per la stampa e pubblicata nel 1623 dopo faticose discussioni all'interno del patriziato, presentava un racconto della vertenza con Paolo $\mathrm{V}$ in cui al frate servita era riconosciuta una funzione, essenzialmente tecnica, di consulente teologico-giuridico, privo di ogni influenza politica ${ }^{129}$. Un Sarpi abile e fedele servitore dello Stato, dunque, del quale si apprezzava l'attività pubblica testimoniata dal corpus dei consulti, ma si doveva necessariamente ignorare l'opera di storico e in particolare la corrosiva Istoria del concilio tridentino, della quale la Repubblica continuò a negare ufficialmente l'attribuzione al suo consultore fino a Settecento inoltrato ${ }^{130}$.

43 Nell'orizzonte francese, per contro, Sarpi era diventato una presenza sempre più profilata. L'irruzione sulla scena, nel 1619, dell'Istoria del Concilio tridentino, fatta 
pubblicare a Londra da Marcantonio De Dominis dietro il labile velo dello pseudonimo Pietro Soave Polano, aveva rilanciato l'attenzione nei suoi confronti, riportando nuovamente in Francia l'asse di un confronto che i rapporti instaurati da Sarpi e Micanzio con il mondo inglese avevano spostato oltremanica.

Fin dal luglio 1619 l'Istoria era a Parigi, in mano a Peiresc che, dopo averla ricevuta dall'erudito e geografo inglese William Camden, aveva deciso di sondare l'ambiente romano tramite il fedele corrispondente veneto Girolamo Aleandro ${ }^{131}$. Con lo stile insinuante dell'abile tessitore di dialoghi trasversali, Peiresc scriveva all'erudito di curia segnalando la straordinaria importanza dell'argomento affrontato nell'opera contenente "particolari minutissimi » dell'assise tridentina -, amplificando le voci subito circolate a proposito di interventi arbitrari compiuti sul testo dal De Dominis e auspicando una confutazione di parte romana. Alla cauta sortita di Peiresc faceva riscontro a stretto giro una risposta interlocutoria dell'Aleandro, che dichiarava di non aver ancora visto capitare a Roma l'Istoria, destinata peraltro ad essere proibita il 18 novembre. A due mesi di distanza Aleandro darà avviso del ricevimento delle copie inviate dallo stesso Peiresc al cardinale di Santa Susanna, comunicando che difficilmente avrebbe potuto ottenere una licenza di lettura ${ }^{132}$.

L'apertura di un confronto, discretamente auspicata da Peiresc, da francese coinvolto nelle polemiche sul recente accoglimento dei decreti tridentini, non poteva che rimanere un miraggio ${ }^{133}$. All'esigenza espressa da Sarpi e Micanzio, all'indomani della stampa londinese, di un'edizione dell'Istoria del concilio tridentino che rimediasse agli arbitri di De Dominis verrà invece incontro la traduzione francese dell'opera eseguita dal calvinista Jean Diodati, vecchia conoscenza dei due serviti veneziani, e pubblicata a Ginevra nel 1621 ${ }^{134}$. Alla fine del 1623, le varianti verranno inviate da Ginevra a Pierre Dupuy dal cugino di Jean Diodati, Élie, con raccomandazioni di stretto riserbo ${ }^{135}$. Il percorso attraverso il quale le correzioni dell'autore pervennero al traduttore non è precisamente documentato, ma ci riporta in ogni caso alle diramazioni ginevrine della rete di relazioni europee gravitante intorno ai fratelli Dupuy ${ }^{136}$.

Dopo l'affaire dell' Istoria del concilio tridentino, la morte di Sarpi nel gennaio 1623 - che sgombrava il campo dalle preoccupazioni per la sua incolumità - doveva incoraggiare aspettative di una prossima diffusione di copie di testi sarpiani rimasti nella disponibilità di Micanzio e dei patrizi che erano stati più vicini al consultore ${ }^{137}$. Sarà l'uscita dall'ombra di quelle "memorie » dell'interdetto a suo tempo inviate a de Thou a segnare l'avvio di una fase nuova. Tra il 1624 e il 1626 furono impresse almeno sette tra edizioni ed emissioni dell'opera : tra queste una stampa ginevrina dal titolo Historia particolare delle cose passate tra 'l sommo pontefice Paolo V e la Serenissima Republica di Venetia gl'anni 1605, 1606, 1607 (Ginevra, Jean de Tournes, 1624) e la traduzione francese di Jean Decordes, canonico di Limoges, gallicano e amico dei Dupuy, che dichiarava d'aver trattenuto nel cassetto la sua versione per circa sei anni, in attesa di una prima edizione italiana del testo ${ }^{138}$. All'interno del " groviglio » tipografico ${ }^{139}$ si coglie dunque ancora la traccia della collaborazione tra i Dupuy e i cugini Jean e Élie Diodati. Da qui in avanti troviamo anche Peiresc coinvolto attivamente nella diffusione dei lavori di Sarpi. Ricevuto lo scritto sull'interdetto dai Dupuy, lo procura ai corrispondenti, esprimendo apprezzamento per $\mathrm{i}$ libri « de Paolo Soave, qui meritent bien d'estre veus et conservez » ${ }^{140}$. Di concerto con $\mathrm{i}$ Dupuy cerca notizie sulla circolazione di altri scritti sarpiani e ne commissiona in Italia ulteriori esemplari a stampa. Questi saranno destinati a viaggiare - lungo $i$ consolidati assi dello scambio librario - insieme alle amate opere d'erudizione ${ }^{141}$. 

De Thou, figlio ventenne del defunto presidente, impegnato in un viaggio che l'avrebbe Dupuy, il giovane rappresentante della prestigiosa dinastia parlamentare si addentrerà accortamente nell'ambiente veneziano, tra gli strascichi dell'ostilità alla Francia suscitata dalla recente pace di Monçon ${ }^{144}$. E otterrà benevola accoglienza dai due più accreditati custodi della memoria di Sarpi. Se da Molin, preso da mille impegni, riceverà nel corso di un breve incontro «caresses » e un non meglio identificato « petit mémoire ", Micanzio, succeduto a Sarpi nella carica di consultore, gli impartirà la lettura di brani della biografia del maestro, che stava allora scrivendo, e qualche informale lezione sulle opere sarpiane ${ }^{145}$. Gli farà inoltre dono di un ritratto di fra Paolo, di un esemplare dell'Istoria dell'Interdetto « où il y a quelque chose plus qu'aux nôtres »"146, di alcune trascrizioni di consulti $^{147}$. L'ospite francese mancherà invece l'obiettivo di riportare in patria una copia del «traité de l'origine de l'Inquisition et comme elle se doit maneggiare ", ovvero la scrittura Sopra l'officio dell'inquisizione, in cui Sarpi aveva raccolto nel 1613 - ad uso del governo - le norme che regolavano l'attività del Sant'Ufficio in territorio veneziano, «la plus belle qu'il ait faite ", a detta sempre di fra Fulgenzio ${ }^{148}$. Incalzato da Pierre Dupuy, che si faceva probabilmente carico della curiosità dell'intera cerchia franco-ginevrina, De Thou aveva cercato d'ingraziarsi Micanzio con la promessa di alcune primizie librarie, ma si era scontrato con la tenace contrarietà di Molin alla divulgazione di uno scritto pubblico su una materia particolarmente delicata ${ }^{149}$. Un anno dopo, al ritorno da Roma, fra Fulgenzio lo allettava con la promessa di «retirer le traité de l'Inquisition des mains d'un de ses amis qui l'a et le tient fort cher», ma il senatore continuava a resistere « sur ce que c'est une escriture publique de laquelle il n'est pas permis de tirer copie $»^{150}$.

All'interno di quello che assume i contorni di un gioco di sponda tra Micanzio e Molin, un canale per il passaggio oltralpe doveva alla fine essersi aperto, se nel 1632 il «trattato dell'Inquisizione» compariva lungo la rete dei corrispondenti dei Dupuy. Era Grozio, rientrato da Parigi in Olanda, a scrivere in quell'anno a Jean Decordes che lo stava copiando, forse da un esemplare fornito dallo stesso canonico limosino : un esito che non dovette riuscire del tutto gradito a Micanzio, strenuo avversario degli arminiani ${ }^{151}$. Con l'invio di quel testo tanto ricercato i devoti di Sarpi rilanciavano in Europa - sullo sfondo dei decisivi avvenimenti del 1628-31 - un'immagine battagliera di Venezia, distante da quella messa in campo dal neutralismo dei moderati. La pubblicazione a stampa della scrittura sull'Inquisizione avrebbe comunque avuto luogo solo nel 1638. Analogamente a quanto accaduto per l'Istoria dell'interdetto, con l'indicazione di quell'anno e del successivo 1639, sarebbero comparse un buon numero di edizioni, una delle quali - tirata dalla stessa stamperia Chouët che aveva impresso la traduzione dell'storia del concilio tridentino eseguita dal Diodati - ci riporta ragionevolmente agli ambienti che da quasi un ventennio erano impegnati nella divulgazione in Francia delle opere sarpiane ${ }^{152}$. Morto, alla fine del 1635, anche Domenico Molin, gli impegni di riservatezza erano caduti, e la ripresa dell'offensiva di Richelieu contro la Chiesa di Roma accresceva la suggestione della disciplina giuridica veneziana esposta in quel « trattato », che assumerà, nei manoscritti $\mathrm{e}$ nelle stampe, titoli ampiamente variabili. L'Historia della Sacra Inquisitione apparsa a Ginevra, con falsa data topica di Serravalle, $1638^{153}$, finiva così per uscire in coincidenza 
con le grandi collezioni curate da Pierre Dupuy, le Libertez de l'église gallicane e le Preuves des libertés de l'Église gallicane (1638-39), che riaprivano il conflitto con il papa.

Tra il viaggio veneziano del giovane De Thou e l'approdo alla stampa dell'opera sull'Inquisizione gli ormai numerosi scritti di Sarpi in circolazione diventavano in Francia oggetto di progetti editoriali più articolati. Ambizioso quello annunciato nel 1635 da Grozio, tornato a Parigi come ambasciatore di Svezia : una raccolta che avrebbe dovuto comprendere gli opuscoli "apologetici Reipublicae venetae contra Pontificem», la storia " accuratissima » dell'interdetto, il «de ecclesiarum immunitate », il « librum de Inquisitione " e la stessa Vita del padre Paolo di Micanzio. Stampata a Leida solo nel 1646, la Vita seguiva itinerari di diffusione manoscritta in tutto analoghi a quelli della produzione del servita veneziano ${ }^{154}$.

51 Il disegno di Grozio sarebbe rimasto senza esito. Il lavoro intrapreso in Francia sui testi del consultore veneziano si avviava lungo altre strade. Pierre Dupuy stava allora costituendo quelle raccolte sarpiane destinate a connotare in maniera originale la sua biblioteca, specchio di un impegno culturale militante, sollecitato dalle vicende politiche e religiose contemporanee. Nelle esigenze e negli interessi del ceto parlamentare gallicano si radicava così una proliferazione di copie a penna di cui è facile oggi ritrovare le tracce nei fondi manoscritti della Bibliothèque Nationale de France, dove lettere $\mathrm{e}$ opere del servita si trovano accostate a vari materiali di attinenza sarpiana : sommari ed estratti, cronologie del concilio di Trento, racconti di singoli particolari biografici, esemplari della Vita del padre Paolo. Questi manoscritti, trattati con sufficienza dai cataloghi ottocenteschi in quanto testimoni - di scarso pregio estetico e testuale - di scritti usciti a stampa, attendono di essere studiati e riportati ai loro specifici contesti. Seguirne le tracce potrà contribuire a spiegare gli enigmi bibliografici, i falsi e le contraffazioni che costellano la storia editoriale di Sarpi, illuminando al contempo i percorsi di assimilazione di una peculiare eredità veneziana dipanatisi tra le età di Enrico IV e di Mazzarino.

Mentre un rapido declino colpiva i flussi tradizionali del commercio internazionale del libro erudito, l'affermazione di Sarpi in Francia si accompagnava al graduale diradarsi dei fili delle corrispondenze veneto-francesi attive ormai da decenni ${ }^{155}$. Durante gli anni trenta i protagonisti uscivano di scena uno dopo l'altro. Nel 1631 moriva di peste Lorenzo Pignoria, sepolto tra grandi onori tributatigli da Domenico Molin ${ }^{156}$. Quattro anni dopo, con la scomparsa dello stesso Molin, il dialogo tra Venezia e l'Europa perdeva il suo principale animatore. «Après Vincentio Pinelli et il Molino decedés - scriverà a Peiresc Gabriel Naudé, di ritorno da un soggiorno a Padova, nel 1636 - vous restés seul leur successeur en ce digne emploi de favoriser les lettres et lettrés ${ }^{157}$. Ma anche l'erudito provenzale sarebbe morto l'anno dopo.

53 Come lo stesso Naudé registrava nelle sue lettere, non mancavano del tutto i continuatori della precedente stagione. Il canonico di S. Giorgio in Alga Giacomo Filippo Tomasini, ad esempio, già legato al Molin e formatosi agli studi eruditi all'ombra di Pignoria, aveva prima affiancato e poi sostituito l'amico nel carteggio con Peiresc. Aveva inoltre mantenuto contatti occasionali con i Dupuy, ai quali s'era premurato d'inviare l'appassionato medaglione redatto in morte del Pignoria e farà quindi avere altre sue opere ${ }^{158}$. Il suo attaccamento alla cultura erudita e bibliografica francese respirata tra Venezia e Padova doveva essere stato rinsaldato proprio dalla familiarità con Naudé, nata durante le visite padovane del celebre bibliotecario, entrato al servizio del cardinale Guidi di Bagno ${ }^{159}$. Nel 1639 Tomasini presenterà le sue Bibliothecae patavinae manuscriptae - una 
raccolta di cataloghi delle principali collezioni cittadine di codici - come frutto degli incoraggiamenti ricevuti da Naudé e da Jacques Gaffarel ${ }^{160}$. I riferimenti al mondo francese si moltiplicavano, lungo le pagine e sui frontespizi della sua folta produzione a stampa. Se nel 1636 aveva dedicato a Claude d'Expilly, presidente del parlamento di Grenoble, la Vita del giurista e docente dello Studio di Padova Marcantonio Pellegrini, la seconda edizione degli Elogia virorum literis et sapientia illustrium veniva offerta nel 1644 ad Anna d'Austria e Mazzarino ${ }^{161}$. Nel 1650 infine le Bibliothecae venetae manuscriptae publicae et privata $e^{162}$, risultato di una laboriosa ricognizione sui fondi manoscritti veneziani, uscivano fregiandosi del nome dei fratelli Jacques e Pierre Dupuy.

Mentre il legame con il mondo gallicano e parlamentare parigino veniva reiterato da un epigono della società letteraria filofrancese primoseicentesca, una fase dei rapporti culturali tra Venezia e la Francia poteva dirsi definitivamente conclusa. Nei primi decenni del secolo lo scambio intellettuale tra i due mondi si era alimentato di consonanze profonde, tenute vive da una radicale opzione politico-religiosa antispagnola. Pur tra alti e bassi e con variabili inflessioni, l'ancoraggio alla sfera francese era rimasto, per il ceto di governo della Serenissima, un costante punto fermo, che aveva ispirato discussioni e progetti e incoraggiato l'interesse reciproco. Ma a metà Seicento gli orizzonti erano mutati : il duello tra le due monarchie si stava risolvendo definitivamente a vantaggio della Francia e la potenza spagnola appariva avviata al declino. Quanto a Venezia, emarginata dalla grande politica europea, era impegnata nel logorante conflitto per la difesa di Candia. Uscita sconfitta da una guerra venticinquennale, sostenuta comunque tutta con le proprie forze, doveva fare i conti con una Francia intenta a imporre il proprio primato sull'Europa. L'auspicato declino spagnolo, diventato realtà, non spingerà questa volta il gruppo dirigente veneziano a sollecitare un più energico impegno francese in Italia. La suggestione del modello statale e della cultura del grand siècle si andava imponendo anche al patriziato lagunare, ma cresceva insieme il timore di un assorbimento della Repubblica nell'orbita politica di Luigi XIV. Sullo scorcio degli anni settanta le interessate profferte della diplomazia francese, che caldeggiava un'alleanza facendo strumentalmente appello a comuni principi di politica ecclesiastica, saranno così rifiutate da Venezia. Abbandonata l'antica fiducia nella Francia, la Repubblica preferiva ormai volgersi ai nemici di sempre, gli Asburgo d'Austria ${ }^{163}$.

\section{NOTE}

1. C. Rizza, Peiresc e l'Italia, Torino, 1965 ; M. Fumaroli e F. Solinas (a cura di), Peiresc et l'Italie, Actes du colloque international, Naples, le 23 et le 24 juin 2006, Istituto Italiano per gli Studi Filosofici, Palazzo Serra di Cassano, Parigi, 2009.

2. Mi limito qui a rinviare a G. Cozzi, Paolo Sarpi tra il cattolico Philippe Canaye de Fresnes e il calvinista Isaac Casaubon (1959), in Id., Paolo Sarpi tra Venezia e l'Europa, Torino, 1979; P. Sarpi, Lettere ai gallicani, éd. B. Ulianich, Wiesbaden, 1961 ; S.H. De Franceschi, Raison d'État et raison d'Église. La France et l'Interdit vénitien (1606-1607): aspects diplomatiques et doctrinaux, Parigi, 2009. 
3. G. Cozzi, Il doge Nicolò Contarini, in Id., Venezia barocca. Conflitti di uomini e idee nella crisi del Seicento veneziano, Venezia, 1995, p. 35-41.

4. Sul de Maisse e sull'ex calvinista Canaye, convertitosi al cattolicesimo nel 1601, nell'imminenza della nomina all'ambasciata veneziana, cfr. ivi, p. 38-39, e Cozzi, Paolo Sarpi tra il cattolico Ph. Canaye de Fresnes... cit., p. 23-30.

5. Cfr. A. Nuovo, Ritratto di collezionista da giovane : Peiresc a casa Pinelli, e A.M. Raugei, Amor libri. Peiresc e la biblioteca di Gian Vincenzo Pinelli, entrambi in Fumaroli e Solinas (a cura di), Peiresc et l'Italie... cit., p. 1-17 ; 19-29.

6. A.M. Raugei (a cura di), Une correspondance entre deux humanistes: Gian Vincenzo Pinelli et Claude Dupuy, Firenze, 2001.

7. Cfr. A. Maggiolo, I soci dell'Accademia patavina dalla sua fondazione (1500), Padova, 1983, p. 9 ; E. Riondato (a cura di), Dall'Accademia dei Ricovrati all'Accademia Galileiana, Atti del convegno storico per il quarto centenario della fondazione (1599-1999), Padova, 11-12 aprile 2000, Padova, 2001; sul quadro culturale padovano di fine Cinquecento rinvio inoltre a G. Cozzi, Galilei, Sarpi e la società veneziana, in Id., Paolo Sarpi tra Venezia e l'Europa... cit., p. 135-160.

8. Cfr. U. Motta, Antonio Querenghi (1546-1633). Un letterato padovano nella Roma del tardo Rinascimento, Milano, 1997, p.151-229, che presenta un convincente ritratto di questo gruppo, destinato a mantenere stretti legami malgrado le differenti traiettorie personali. Sul vicentino Paolo Gualdo (1553-1621), i suoi rapporti con l'Oratorio romano e con i gesuiti, il suo attaccamento al semplice status di monsignore che gli consentiva di coltivare le sue passioni letterarie e il suo raffinato collezionismo: G. Cozzi, Intorno al cardinale Ottavio Paravicino, a monsignor Paolo Gualdo e a Michelangelo da Caravaggio, in Rivista storica italiana, 73, 1961, p. 36-68. Su Aleandro (1574-1629), Bentivoglio (1577-1644) e Lollino (1552-1625), cfr. in Dizionario biografico degli italiani (= DBI) le voci loro dedicate, rispettivamente nei volumi 2, 1960 (di A. Asor Rosa) ; 8, 1966 (di A. Merola) ; 65, 2005 (di S. Benedetti). Lollino $\mathrm{fu}$ in rapporto con i negoziatori dell'assoluzione di Enrico IV, nonché futuri cardinali, Jacques Davy Du Perron e Arnauld d'Ossat. Nel 1596, insieme a Sarpi, accolse a Venezia Du Perron, reduce dalla missione a Roma, al quale esibì i propri libri (L. Alpago Novello, La vita e le opere di Luigi Lollino vescovo di Belluno [1596-1625], Venezia, 1933, p. 36). Cfr. inoltre : F. Zen Benetti, Per la biografia di Lorenzo Pignoria, erudito padovano (+1631), in M.C. Billanovich, G. Cracco e A. Rigon (a cura di), Viridarium floridum . Studi di storia veneta offerti dagli allievi a Paolo Sambin, Padova, 1984, p. 317-336.

9. G. Trebbi, Venezia tra '500 e '600 nell'opera storica di Andrea Morosini, in Studi veneziani, 25, 1993, p. 79, 87-88.

10. G. Benzoni, La fortuna, la vita, l'opera di Enrico Caterino Davila, in Studi veneziani, 16, 1974, p.320-324; E. Veronese, La biblioteca di Flavio Querenghi, professore di filosofia morale (1624-1647) nello Studio di Padova, in Quaderni per la storia dell'Università di Padova, 9-10, 1976-77, p. 185-213.

11. Rizza, Peiresc... cit., p.12-13; Nuovo, Ritratto di collezionista. I due giovani francesi giunsero a Padova negli ultimi giorni del 1599.

12. Rizza, Peiresc... cit., p. 45-105; P.N. Miller, Nicolas-Claude Fabri de Peiresc and the Mediterranean World: Mechanics, in C. Berkvens-Stevelinck, H. Bots, J. Häseler (a cura di), Les grands intermédiaires culturels de la République des Lettres. Études de réseaux de correspondances du XVI e au XVIII siècles, Parigi, 2005, p. 103-125. 
13. Rizza, Peiresc... cit., p. 168 ; Ulianich, Saggio introduttivo in Sarpi, Lettere ai gallicani... cit., p. XIV.

14. Ivi, p. XIV.

15. Ivi, p. XVII-XVIII ; Cozzi, Paolo Sarpi tra il cattolico Ph. Canaye des Fresnes... cit., p. 45, 97.

16. Ivi, p. 48-50 ; De Franceschi, Raison d'État... cit.; B. Barbiche, L'influence française à la cour pontificale sous le règne de Henry IV, in Mélanges de l'École française de Rome, 77, 1965, p. 277-299.

17. A. Tallon, Conscience nationale et sentiment religieux en France au XVI siècle, Parigi, 2002, p. 165-183.

18. Ulianich, Saggio introduttivo, in Sarpi, Lettere ai gallicani... cit., p. XIX. Sull'impegno dell'ambasciatore veneziano in Francia Pietro Priuli per la diffusione di scritti favorevoli alla Repubblica, anche da lui espressamente commissionati, cfr. F. De Vivo, Francia e Inghilterra di fronte all'interdetto di Venezia, in M. Viallon (a cura di), Paolo Sarpi. Politique et religion en Europe, Parigi, 2010, in part. p. 174-178.

19. Rizza, Peiresc... cit., p. 169-170. Sulla collocazione di Du Vair nell'«engrenage polémique » del periodo dell'interdetto e sui suoi rapporti con Peiresc cfr. R. Descimon, Guillaume Du Vair (7 mars 1556-3 août 1621). Les enseignements d'une biographie sociale, in Guillaume Du Vair. Parlementaire et écrivain (1556-1621), Ginevra, 2005, p. 41-57.

20. Ulianich, Saggio introduttivo, in Sarpi, Lettere ai gallicani... cit., p.XXIV-XXXI; A. Buffardi, Contributo allo studio della fortuna di Paolo Sarpi in Francia durante il Seicento, in Studi secenteschi, 6, 1965, p. 268-271. Sullo scritto del Ribier, che sarà deputato del terzo stato agli Stati generali del 1614, cfr. M. Venard, Le projet d'un nouveau concile dans la France d'Henri IV, in M. Viallon (a cura di), Autour du concile de Trente, Actes de la table ronde de Lyon (28 février 2003), Saint-Étienne, 2006, p. 47-60 ; informazioni relative alla traduzione sarpiana sono in C. Pin, Les Consulti de Paolo Sarpi et son Histoire du concile de Trente, ivi, p. 83.

21. Sarpi, Lettere ai gallicani... cit., p. 168-169 (lettera a De Thou del 6 giugno 1607).

22. Cozzi, Intorno al cardinale Ottavio Paravicino... cit., p. 43.

23. « Io sono in Roma - scrive Pignoria il 23 maggio 1606 - con timore di trattenermici gli anni se Dio Nostro Signore non mira con occhio di pietà la Republica nostra, la quale nella persona del sommo pontefice ha preso a cozzare co'l giusto e con l'honesto. Io sento tanto travaglio di rissolutione sì poco christiana, che non lo so esprimere ». Bibliothèque Nationale de France, Parigi (= BNF), Fond Français 9540, fol. 20. Profondamente infastidito dalle consuetudini di vita nella capitale pontificia, Pignoria era consolato solo dal contatto con $\mathrm{i}$ « luoghi memorabili per la santità e antichità »; ritornerà definitivamente, dopo due anni, nella sua Padova. Cfr. Zen Benetti, Per la biografia di L. Pignoria... cit., p. 320 ; inoltre, per il carteggio Pignoria-Peiresc, C. Volpi, Lorenzo Pignoria e i suoi corrispondenti, in Nouvelles de la République des lettres, 1992-II, p. 71-127.

24. Rinvio in proposito alle puntuali ricostruzioni di Corrado Pin in P. Sarpi, Consulti, vol. I/1 : I Consulti dell'Interdetto (1606-1607), ed. C. Pin, Pisa-Roma, 2001, p. 506-511; 518-519.

25. Motta, Antonio Querenghi... cit., p. 258-260 ; i due Morosini, che non erano parenti, condividevano il timore per le conseguenze di un allontanamento di Venezia dalla sfera del cattolicesimo romano. Per le posizioni del più noto tra loro cfr. Trebbi, Venezia tra ' 500 e '600... cit., p. 117-129. Sulle forti pressioni esercitate da Roma su Sarpi, sul confratello Fulgenzio Micanzio e sugli altri 'teologi' filoveneziani, appartenenti a ordini religiosi e al 
clero secolare, cfr. A. Barzazi, Immagini, memoria, mito :l'ordine dei serviti e Sarpi nel Seicento, in C. Pin (a cura di), Ripensando Paolo Sarpi, Atti del convegno internazionale di studi nel $450^{\circ}$ anniversario della nascita di Paolo Sarpi, Venezia, 2006, p. 491-499.

26. Motta, Antonio Querenghi... cit., p. 261-268 (la citazione da p.263). Il frammento fu oggetto di una ripresa nel 1613.

27. Benzoni, La fortuna, la vita, l'opera... cit., p. 336.

28. Cfr. Lettere d'uomini illustri che fiorirono nel principio del secolo decimosettimo non più stampate, Venezia, Baglioni, 1744, p. 227 (Peiresc a Gualdo, 21 novembre 1607). La Vita Ioannis Vincentii Pinelli patricii genuensis di Gualdo uscì ad Augusta quello stesso anno.

29. A. Soman, De Thou and the Index. Letters from Christophe Dupuy (1603-1607), Ginevra, 1972, p. 15-20. La partenza del cardinale Davy Du Perron da Roma nel 1607 lasciò priva di protezioni efficaci l'Historia, che - stante il rifiuto dell'autore di concordare modifiche al testo - finì all'Indice nel novembre 1609. Cozzi, Paolo Sarpi tra il cattolico Ph. Canaye de Fresnes... cit., p. 97-98. Le notizie su Faerno perverranno infine a De Thou, alla vigilia della condanna dell'opera. Cfr. Lettere d'uomini illustri... cit., p. 233 (Peiresc a Gualdo, 25 settembre 1609).

30. Ivi, p. 113 (Pignoria a Gualdo, 9 novembre 1609).

31. Sull'apporto di studiosi e collezionisti privati allo slancio del commercio europeo del libro erudito tra Cinque e Seicento cfr. I. Maclean, Scholarship, Commerce, Religion. The learned book in the age of confessions, 1560-1630, Cambridge, Mass., and London, 2011, p. 171-210.

32. Cfr. in BNF, Fonds Français 9540, le lettere di Pignoria a Peiresc del 1608-1609; inoltre la lunga missiva di Peiresc a Gualdo del 25 settembre 1609 in Lettere d'uomini illustri... cit., p. 229-237.

33. Ivi, p. 236-237 (Peiresc a Gualdo, 25 sett 1609).

34. Ivi, p. 104 (Pignoria a Gualdo, 15 maggio 1609). Querenghi era divenuto segretario del cardinale nel febbraio di quell'anno (Motta, Antonio Querenghi... cit., p. 279). Nato nel 1568, Alessandro d'Este aveva conseguito a Padova la laurea in utroque iure, soggiornando quindi per anni al Catajo. S. Calonaci, Con gli occhi di Argo. La politica del cardinale Alessandro d'Este dopo la devoluzione (1599-1624), in E. Fumagalli e G. Signorotto (a cura di), La corte estense nel primo Seicento. Diplomazia e mecenatismo artistico, Roma, 2012, p. 166.

35. Sull'aprirsi di Sarpi alla cultura giuridica francese, lontana da quella, per lui deludente, espressa dai giuristi accademici italiani e in specie padovani, cfr. C. Pin, Paolo Sarpi consultore della Serenissima e i giuristi dell'Università di Padova, in Studi veneziani, 56, 2008, p. 207-226.

36. Sarpi, Lettere ai gallicani... cit., p. 131, 12 maggio 1609.

37. Cfr. ivi, Ulianich, Saggio introduttivo, p. XLII-XLIV ; LXXXVI-LXXXIX.

38. Il passo è sempre nella lettera a Gillot del 12 maggio 1609, ivi, p. 132.

39. Sull'impronta di quello che è stato definito un «carteggio d'azione» (Cozzi, Nota introduttiva a P. Sarpi, Opere, éds. G. e L. Cozzi, Milano-Napoli, 1969, p. 365), cfr. F. De Vivo, "Il vero termine di reggere il suddito»: Paolo Sarpi e l'informazione, in Pin (a cura di), Ripensando Paolo Sarpi... cit., p. 237-270. Con espressione calzante, seppure applicata a un uomo che aveva ormai passato i cinquant'anni, Corrado Pin ha definito la corrispondenza di Sarpi con i gallicani - in particolare con Leschassier - «epistolario di formazione " (Pin, Introduzione a Sarpi, Consulti... cit., I /1, p. 90). 
40. P. Sarpi, Lettere ai protestanti, ed. M.D. Busnelli, Bari, 1931, I, p. 119 (lettera a J. Groslot de l'Isle del 27 aprile 1610). Cfr. Ulianich, Saggio introduttivo, in Sarpi, Lettere ai gallicani... cit., p. L-LIII.

41. Ivi, p. 147, 12 ottobre 1610.

42. Ivi, p. 150, 4 gennaio 1611.

43. Pur dissentendo dalla tesi richeriana della coordinazione dei due poteri, ecclesiastico e civile, Sarpi richiese l'invio di più esemplari del De ecclesiastica et politica potestate e seguì con intensa partecipazione la vicenda del sindaco della Sorbona, della quale tenne a sottolineare le gravi implicazioni. Cfr. Ulianich, Saggio introduttivo, in Lettere ai gallicani... cit., p. XCIV-XCV ; inoltre le lettere inviate da Sarpi a Leschassier tra il marzo 1612 e la fine dell'anno, ivi, p. 107, 109, 112, 115-117, quelle a Gillot del 14 agosto e del novembre 1612 (ivi, p. 155-156); infine quelle a Groslot de l'Isle del 10 aprile e dell'8 maggio 1612 (Sarpi, Lettere ai protestanti... cit., p. 228-229). Sul significato e gli sviluppi del caso Richer : S.H. De Franceschi, Gallicanisme, antirichérisme et reconnaissance de la romanité ecclésiale. La dispute entre le cardinal Bellarmin et le théologien parisien André Duval (1614), in J.-L. Quantin e $\mathrm{J}$.-C. Waquet (a cura di), Papes, princes et savants dans l'Europe moderne. Mélanges à la mémoire de Bruno Neveu, Ginevra, 2007, p. 97-121; Id., La crise théologico-politique du premier âge baroque. Antiromanisme doctrinal, pouvoir pastoral et raison du prince: le Saint-Siège face au prisme français (1607-1627), Roma, 2009, in part.cap. IV : Le richerisme et l'âge d'or du catholicisme antiromain.

44. La dimensione informativa dell'epistolario sarpiano e la figura di un Sarpi «novellista " e "curioso", particolarmente attento agli usi della notizia, sono state efficacemente messe a fuoco in De Vivo, «Il vero termine di reggere il suddito »... cit.

45. Cinque lettere scritte da Molin nel 1611-12 a Leschassier sono in Sarpi, Lettere ai gallicani... cit., p. 249-251. Molin, non ancora quarantenne, era nato nel 1572.

46. C. Pin, "Qui si vive con esempi, non con ragione »: Paolo Sarpi e la committenza di Stato nel dopo-interdetto, in Pin (a cura di), Ripensando Paolo Sarpi... cit., p. 375-376. Il trattatello sarpiano, completato nell'ottobre 1611, si legge in P.Sarpi, Scritti giurisdizionalistici, ed. G. Gambarin, Bari, 1958, p. 233-247 ; cfr. Ulianich, Saggio introduttivo, in Sarpi, Lettere ai gallicani... cit., p. CXXXVIII-CXXXIX.

47. Sulla stesura dell'Istoria e gli itinerari della tradizione manoscritta, cfr. l'Introduzione di C. Pin a P. Sarpi, Istoria dell'Interdetto, éd. C. Pin, Padova, 2006, p. XIX-XXXIX ; Ulianich, Saggio introduttivo, in Lettere ai gallicani... cit., p. CIII-CVII.

48. «Per dubbio che li venisse in mente, o perché propose la cosa in Collegio ", spiegherà in seguito Sarpi a Groslot de l'Isle. Sarpi, Lettere ai protestanti... cit., p. 243 (25 settembre 1612). Il Nani era stato ambasciatore a Roma ai tempi dell'interdetto.

49. V. in Sarpi, Lettere ai protestanti cit, p. 174, 244, le missive a Groslot de l'Isle del 10 maggio 1610 e del 25 settembre 1612 ; Ulianich, Saggio introduttivo, in Lettere ai gallicani... cit., p. CIII-CVII. William Bedell, con il quale Sarpi e Micanzio avevano avviato rapporti fin dal 1608, era rientrato in patria nei primi mesi del 1610 (G. Cozzi, Nota introduttiva a Sarpi, Opere... cit., p. 228-231).

50. Sarpi, Lettere ai gallicani... cit., p. 163, lettera a Gillot del 4 luglio 1617.

51. Al 1612 risale l'avvio della corrispondenza parallela di Sarpi e Micanzio con Dudley Carleton, ambasciatore inglese a Venezia e quindi in Olanda; tre anni dopo Micanzio iniziò uno scambio epistolare con sir William Cavendish dei conti di Devonshire, destinato a esaurirsi nel 1628. Per riferimenti più puntuali su questi carteggi cfr. Cozzi, Nota 
introduttiva a Sarpi, Opere... cit, p. 635-642, e A. Barzazi, Micanzio, Fulgenzio, in DBI, 74, 2010, p. 115-116.

52. Sarpi, Lettere ai gallicani... cit. p. 159, 17 febbr 1617.

53. G. Cozzi, Venezia nello scenario europeo, in G.Cozzi, M. Knapton, G. Scarabello, La Repubblica di Venezia nell'età moderna. Dal 1517 alla fine della Repubblica, Torino, 1992, p. 97-100 ; Cozzi, Nota introduttiva a Sarpi, Opere... cit., p. 1017-1019.

54. Sarpi, Lettere ai protestanti... cit., p. 279-280 (28 marzo 1617).

55. Ivi, p. 280 ; cfr. inoltre la lettera del 29 marzo 1617 (ivi, p. 280-281).

56. BNF, Fond Français 9543, fol. 48, lettera da Padova del 14 aprile 1614. Come rilevato a suo tempo da Rizza, Peiresc... cit., p. 26-27, è in realtà l'intera corrispondenza italiana di Peiresc a diradarsi, in quell'arco di tempo.

57. Ivi, p. 190-203 ; M. Bucciantini, M. Camerota, F. Giudice, Il telescopio di Galileo. Una storia europea, Torino, 2012, p. 165-171.

58. A Vicenza fin dall'agosto 1609 , Gualdo tornò a Roma nel giugno 1614, per rientrare definitivamente in patria nell'estate 1615. Sul 'sonno' dei Ricovrati dopo il 1609 cfr. Maggiolo, I soci dell'Accademia... cit., p. 10.

59. Lettere d'uomini illustri... cit., p. 238. Riprendevano nello stesso periodo anche le comunicazioni di Peiresc con Aleandro, a Roma. Arcigna, inizialmente, la reazione di Pignoria : « del signor Nicolò io direi pazzie, ma praestat tacere », protestava con Gualdo il 10 ottobre 1614. Ivi, p. 158.

60. Come la Vetustissimae tabulae aeneae sacris Aegyptiorum simulacris celatae accurata explicatio, uscita a Venezia nel 1600 e nel 1605 e nuovamente a Francoforte nel 1608, o il De servis et eorum apud veteres ministeriis commentarium (Augusta, 1613). Zen Benetti, Per la biografia di Lorenzo Pignoria... cit., p. 318.

61.

Diverse spedizioni di libri da Roma, con le relative note di spesa, risultano dalle lettere di Gualdo a Peiresc del gennaio-febbraio 1615 in BNF, Fond Français 9543, fol. 54-62; il 20 novembre 1614 (BNF, Nouv. Acq. Franç. 5173, fol. 22), Gualdo avvisava Peiresc del mancato reperimento dello scritto galileiano Sulle cose che stanno sull'acqua. L'andamento degli scambi tra Pignoria e il corrispondente francese si ricava dalle missive di entrambi a Gualdo, edite in Lettere d'uomini illustri... cit.

62. Cfr. ad esempio le lettere di Pignoria a Gualdo del 27 giugno 1614 e del 20 settembre 1615 in Lettere d'uomini illustri... cit., p. 126-127 e 206.

63. Rizza, Peiresc... cit., p. 27-28. In una lettera a Gualdo del 30 aprile 1616 Peiresc dava disposizioni per il recapito dei plichi a lui diretti, ipotizzando di trattenersi nella capitale per non più di due mesi. Biblioteca Nazionale Marciana, Venezia (= BNM), Cod. it. X, 68 [6401], fol. 84).

64. « Egli è personaggio di gran nome - scriveva Peiresc a Gualdo a proposito di De Thou l'11 ottobre 1616 (Lettere d'uomini illustri... cit., p. 277) - e sebben non ha soddisfatto in tutto agli interessi di Roma, quel poco che può esser soggetto a censura o radiazione impedirà difficilmente che non viva lungamente la sua opera e perciò potrà durarci la memoria di que' letterati che vi saranno menzionati ». Con De Thou Peiresc condividerà in seguito il gusto delle «informazioni curiosissime» inviate da Padova su figure quali Giangiorgio Trissino, Cesare Campana, Antonio Pigafetta. Cfr. ivi, p. 278; inoltre : p. 280 (25 gennaio 1617), p. 284 (3 aprile 1617) ; inoltre Rizza, Peiresc... cit., p. 125-127. 
65. Cfr. ad esempio le lettere a Gualdo del 25 gennaio, del 3 aprile e dell' 8 agosto 1617 in Lettere d'uomini illustri... cit., p. 283, 285, 290-292.

66. Erano, queste, le posizioni del più autorevole portavoce dello schieramento moderato, Andrea Morosini (Trebbi, Venezia tra '500 e '600... cit., p. 96-100 ; 125-129). Il nesso tra opzioni politico-militari e 'novità' religiose trovava, nella visione di Morosini, un'eloquente esemplificazione proprio nell'esperienza francese : l'alleanza di Francesco I con la lega di Smalcalda veniva da lui indicata come la lontana, nefasta premessa delle guerre di religione (ivi, p. 99).

67. Lettere d'uomini illustri... cit., p. 275, Parigi, 20 settembre. Tra il 1611 e il 1619 rappresentò la Francia a Venezia Charles Brûlart de Léon, che incarnò la linea conciliante nei confronti della Spagna invalsa tra la reggenza di Maria de' Medici e la prima parte del regno di Luigi XIII. Molto apprezzato dal Brûlart fu l'ambasciatore veneziano in Francia Pietro Contarini il quale, tra il 1613 e il 1616, portò avanti un'azione improntata a forte senso istituzionale e a un'idea tradizionale di Venezia (G. Benzoni, Contarini, Pietro, in DBI, 28, 1983, p. 267-271). Poco amato da Sarpi, che evitò di avvalersene per il recapito delle proprie lettere ai corrispondenti parigini e gli riservò giudizi astiosi (Ulianich, Saggio introduttivo... cit, p. LXIV), Contarini fece invece da tramite degli scambi epistolari di Gualdo e Pignoria con Peiresc (Lettere d'uomini illustri... cit., p. 273, 276, 282).

68. G. Benzoni, Campiglia, Alessandro, in DBI, 17 (1974), p. 537-539; Peiresc aveva accolto l'opera, nella stessa lettera del 20 settembre 1616 (Lettere d'uomini illustri... cit., p. 275), come « cosa di gran travaglio e degna di persona meritevole e generosa ».

69. Benzoni, Campiglia, Alessandro... cit., p. 538.

70. « S'egli avesse dedicata la sua opera alla Regina madre sola, o congiontamente ad essa, e alla Maestà del Re suo figlio - aveva subito fatto presente l'erudito di Aix a Gualdo - se ne sarebbe potuto aspettare più di gratitudine, sendo quest'opera in linguaggio che gli è naturale, e in soggetto, che gli deve essere carissimo » (Lettere d'uomini illustri... cit., p. 275-276).

71. L. Zilli, Le succès italien de Pierre Mathieu, historiographe de Henri IV, in Avènement d'Henri IV. Quatrième centenaire, Agen-Nérac 18-20 mai 1990 : Les Lettres au temps de Henri IV, Pau, 1991, p. 238-239 ; la paternità della traduzione è stata accertata, sulla scorta del carteggio tra Querenghi e Alessandro d'Este, da U. Motta, Tradurre Pierre Matthieu al principio del Seicento : la parte degli umanisti italiani, in Testo a fronte, 19, 1998, p. 117-126; la problematica collocazione del cardinale Alessandro d'Este, tra inclinazione filofrancese e imperativi di fedeltà politica alla Spagna, è finemente delineata da Calonaci, Con gli occhi di Argo... cit., p. 181-188. Sulle opere e la figura di Matthieu (1563-1621), passato da una giovanile adesione alla Lega cattolica all'appassionato sostegno a Enrico IV, cfr. L. Lobbes, L'oeuvre historiographique de Pierre Matthieu ou la tentative d'embrigader Clio, in D. Bohler e C. Magnien-Simonin (a cura di), Écritures de l'histoire (XIV $-X V I^{\mathrm{e}}$ siècle), Ginevra, 2005, p. 495-519; inoltre J. Boucher, La difficulté d'être acteur et rédacteur de l'histoire à la fin du XVI ${ }^{\mathrm{e}}$ et au début du XVII siècle, ivi, p. 311-319.

72. Le Remarques d'estat et d'histoire sur la vie et les services de monsieur de Villeroy erano state pubblicate a Lione nello stesso 1618. La versione italiana, impressa per la prima volta a Modena, sarà ristampata a Venezia, Firenze e Bracciano tra il 1618 e il 1621.

73. In una lettera del 26 dicembre 1618 al cardinale Alessandro d'Este Bentivoglio riferiva la soddisfazione del Matthieu per la diffusione in Italia dei suoi scritti (Guido Bentivoglio, Raccolta di lettere scritte in tempo delle sue nuntiature di Fiandra e di Francia, Liegi, 1635, p. 88, 
90 ; cfr. inoltre Motta, Tradurre Pierre Matthieu... cit., p. 126). Sul Bevilacqua (1571-1627), promosso al cardinalato nel 1598 da Clemente VIII, nel quadro della politica di gratificazioni alle famiglie nobili ferraresi perseguita dopo la devoluzione della città allo Stato pontificio: G. De Caro, Bevilacqua, Bonifazio, in DBI, 9, 1967, p. 786-788. Nel 1621 Bevilacqua era indicato come l'unico pensionario francese nel Sacro Collegio. Calonaci, Con gli occhi di Argo... cit., p. 179-180.

74. L'Historia d'Elio Seiano e l'Historia delle prosperità infelici d'una femmina di Catanea comparvero nuovamente tra il 1619 e il 1621, separatamente o in unico volume, a Ferrara, Bracciano, Macerata, Venezia e Ronciglione. Non appena lo scritto era giunto al Bevilacqua, Querenghi aveva cercato di convincere il cardinale Alessandro d'Este a cimentarsi ancora una volta nella traduzione, corroborando le sue insistenze con un passo tratto dalla dedica dello scritto di Matthieu a Luigi XIII, una sorta di vibrante appello a conservare integra l'autorità regia, in grado - a suo parere - di richiamare l'attenzione di tutti gli «spiriti politici». BNM, Cod. it. X, 97 (6567), fol. 94r. (lettera senza data).

75. Come documenta E. Bonora ( $L a$ "censura inavvertita ». Censura romana e opere di storia tra l'Italia e la Francia nel primo Seicento, in Rivista storica italiana, 125, 2013, p. 64), le Turbulenze della Francia erano state segnalate dal Sant'Ufficio all'inquisitore di Bologna come opera pericolosa fin dal dicembre 1616.

76. Benzoni, Campiglia, Alessandro... cit., p. 539 ; cfr. anche Id., La fortuna, la vita, l'opera... cit., p. 389-393.

77. La dedica delle Turbulenze a Luigi XIII, «maggiore re dell'Europa» e «figliuolo primogenito della Chiesa » non si limitava a ricordare l'amore per Enrico IV dell'« Italia, madre de' belli ingegni \& altrice d'huomini grandi", ma evocava anche le imprese italiane di Carlo VIII e Luigi XI. Il 20 febbraio 1617, nell'annunciare a Peiresc l'avvenuta pubblicazione del libro «molto curioso » del Campiglia, «mio paesano», Paolo Gualdo riferiva che "li spagnuoli, parendo che in quello sia intaccata la loro reputatione", avevano «tentato di farlo prohibere et adhuc sub Indice lis est»; si stava comunque facendo "quanto si può per diffenderlo ». Correspondance de Peiresc et Aleandro, éd. J.F. Lhote e D. Joyal, Clermont-Ferrand, 1995, I, p. 154). L'8 agosto 1617 Peiresc sollecitava da Gualdo aggiornamenti sul "successo dell'opposizione degli Spagnuoli contra la edizione del libro del sig. Campiglia », chiedendo l'invio di « qualche esemplare » (Lettere d'uomini illustri cit., p. 286). Di concerto con Gualdo, il vicentino aveva cercato di guadagnarsi il sostegno dei cardinali Pietro Aldobrandini e Giambattista Leni, dopo quello dei veneziani Giovanni Dolfin e Matteo Priuli. BNM, Cod.it.X, 68 (6401), lettera di Campiglia a Gualdo, senza luogo, del 6 febbraio 1618. Interventi censori su passi critici nei confronti della Spagna contenuti in opere storiche francesi sono ricordati in Bonora, $L a$ "censura inavvertita »... cit., p. 56-59; per l'arsenale ideologico impiegato tra Cinque e Seicento nel confronto polemico tra Francia e Spagna : M.A.Visceglia, Gli «humori» delle nazioni. La rappresentazione della Spagna nella Francia del primo Seicento (1590-1635), in Dimensioni e problemi della ricerca storica, 2, 1995, p. 39-68.

78. Questa ebbe luogo il 30 giugno 1621, a quasi tre anni di distanza dalla scomparsa dell'autore, morto - riferirà Gualdo a Peiresc il 7 ottobre 1618 - mentre scriveva la seconda parte dell'opera, dedicata alle vicende di Enrico IV dopo la conversione al cattolicesimo (BNF, Fonds français, 9543, fol. 71).

79. Così, ancora, la dedica al giovane Borbone. 
80. Su Gussoni e Bon, nati rispettivamente nel 1575 e nel 1552, cfr. G. Gullino, Gussoni, Vincenzo, in DBI, 61, 2004, p. 581-584; M. Pasdera, Bon, Ottaviano, in DBI, 11, 1969, p. 421-424; per i rapporti tra Bon e Paolo Gualdo cfr. la lettera di Peiresc a Gualdo del 25 gennaio 1617 (Lettere d'uomini illustri... cit., p. 282); numerose le lettere a Bon nell'epistolario di Lollino (Epistolae miscellaneae, Belluno, Viezzeri, 1641), il quale - dopo aver redatto una Vita di Andrea Morosini - lasciò manoscritta anche una biografia del Bon, entrambe in latino (Alpago Novello, La vita e le opere di Luigi Lollino... cit., p. 276-277). La complessa vicenda politico-diplomatica è esposta in Cozzi, Nota introduttiva a Sarpi, Opere... cit., p. 1020-1023.

81. Molti i ricordi dell'esperienza padovana nelle confidenziali lettere scritte da Bentivoglio a Paolo Gualdo tra il 1616 e il 1620, edite in Lettere d'uomini illustri... cit., p. 401 e segg; cfr. anche la lettera da Bruxelles del 21 gennaio 1612 in Bentivoglio, Raccolta di lettere... cit., p. 24.

82. «Le conclusioni di pace - commenterà ironicamente Sarpi in un parere al governo veneziano - sogliono aver la trattazione piena di difficoltà e l'essecuzione facile, a questa è avvenuto il contrario, che [...] con facilità è stata conclusa, e nel bel principio dell'essecuzione ha scontrato in accidente inaudito nelli secoli passati ».Cozzi, Nota introduttiva a Sarpi, Opere... cit., p. 1025.

83. BNF, Fond français, 9543, fol.67, lettera del 17 dicembre 1617. Di pressioni dell'ambasciatore veneziano a Roma sull'arcivescovo di Lione, inviato di Luigi XIII a Roma, per l'attuazione delle « conventioni della pace stabilita dal re di Francia » scriveva Querenghi al cardinale d'Este. BNM, Cod. it. X, 97 (6567), fol. 106v. (lettera priva di data, ma della primavera 1618).

84. BNF, Fond français, 9540, fol. 46 e s., lettera di Pignoria a Peiresc, 12 agosto 1618 (dove si riferisce di una progettata stampa cumulativa delle censure padovane e parigine); ivi, 9543, fol. 68, lettera di Gualdo a Peiresc, 7 marzo 1618. Sulle reazioni in Francia al De republica ecclesiastica dell'ex arcivescovo di Spalato cfr. De Franceschi, La crise politicothéologique... cit., p. 562-571; per la presa di posizione dei teologi di Padova: A. Poppi, Presenza dei francescani conventuali nel Collegio dei teologi dell'Università di Padova. Appunti d'archivio (1510-1806), Padova, 2003, p. 65-68.

85. BNF, Fond Français, 9540, fol.44, Pignoria a Peiresc, 20 maggio 1618 ; lo scritto sarpiano è in P. Sarpi, La Repubblica di Venezia, la Casa d'Austria e gli Uscocchi. Aggionta e supplimento all'sstoria degli Uscocchi Trattato di pace et accomodamento, éds. G. e L. Cozzi, Bari, 1965 ; per la presenza dell'opera presso Peiresc : Rizza, Peiresc... cit., p. 178. Sul polemico e denso lavoro di Sarpi cfr. F. De Vivo, Historical justifications of Venetian Power in the Adriatic, in Journal of the History of Ideas, 64, 2003, p. 171-176; una comparazione con la pubblicistica di parte spagnola sugli uscocchi è in V. Nider, Sarpi, Quevedo e la pubblicistica sulla guerra degli Uscocchi, in M. G. Profeti (a cura di), Giudizi e pregiudizi. Percezione dell'altro e stereotipi tra Europa e Mediterraneo, Firenze, 2009, I, p. 211-237.

86. «Che non è stato - postillava Pignoria - poca ventura l'haverlo ». BNF, Fond Français, 9540, fol. 91, lettera del 16 settembre 1618. A metà Settecento Marco Foscarini (Della letteratura veneziana, I, Padova, Stamperia del Seminario, 1752, I, p. 289-290) ricondurrà lo scritto, uscito con l'indicazione fittizia «In Poistorf, per Peter Gat» e senza data, alla penna di un patrizio veneziano.

87. Il termine Manifesto è in realtà presente nel sottotitolo di uno scritto Ragioni della Republica Venetiana contro Uscochi, stampato nel 1617 e circolato insieme all'Historia del 
Minucci e ai due testi sarpiani sugli uscocchi, l'Aggionta e il Supplimento (Sarpi, La Republica di Venezia, la Casa d'Austria... cit., p. 431-432). Sulla congiura legata al nome dell'ambasciatore spagnolo, snodo importante per lo sviluppo degli opposti miti negativi seicenteschi di Venezia e della Spagna, cfr. P. Preto, La «congiura di Bedmar » a Venezia nel 1618 : colpo di stato o provocazione?, in Y.-M. Bercé, E. Fasano Guarini (a cura di), Complots et conjurations dans l'Europe moderne, Roma, 1996, p. 289-315; R. McKenney, "A Plot Discover'd?" Myth, Legend and the "Spanish" Conspiracy against Venice in 1618, in J. Martin, D. Romano (a cura di), Venice reconsidered. The history and civilization of an Italian City-State, 1297-1797, Baltimora-Londra, 2002, p. 185-216.

88. Sulla sua decisione si soffermano le lettere di Gualdo a Peiresc della primavera-estate 1618 (BNF, Fond Français, 9543).

89. Per le critiche alla conduzione del negoziato espresse al Lollino da Enrico Caterino Davila, pur favorevole alla conclusione dell'accordo, cfr. Benzoni, La fortuna, la vita, l'opera cit., p. 339-340. La delusione ingigantiva per contrasto il ricordo di Enrico IV. « Se non si trovava gl'anni passati quel pazzo che ammazzò nel maggior ascendente della buona fortuna di Francia il re Henrico quarto! », sospirava Querenghi in una lettera al cardinale d'Este dell'inizio del 1619. BNM, Cod. it. X, 97 (6567), fol. 113r. Il segretario estense stava allora lavorando alla stesura di una serie di « elogi » in versi dei re di Francia, da apporre ai ritratti che il cardinale intendeva collocare in una sala di Villa d'Este a Tivoli. Nonostante la scelta della forma poetica, Querenghi aveva voluto procedere a riscontri sulle opere di Robert Gauguin e soprattutto sugli Annales di Papire Masson, « che son creduti dai Francesi medesimi - scriveva - contener sicura e libera verità » (ivi, fol. 128r). Ma il cardinale Alessandro stroncherà un primo blocco di medaglioni, mentre ancora Querenghi stendeva quello, evidentemente assai impegnativo, di Enrico IV (ivi, fol. 128v-134v). C'è da chiedersi se il dissidio non segnalasse l'imminente rottura tra Alessandro e il suo segretario padovano, passato nel 1622 al servizio del cardinale Ludovico Ludovisi (Calonaci, Con gli occhi di Argo... cit., p. 166). Sui progetti estensi per la villa di Tivoli e il ruolo di Querenghi cfr., oltre a Motta, Antonio Querenghi... cit., p. 296-302, C. Occhipinti, Giardino delle Esperidi. Le tradizioni del mito e la storia di Villa d'Este a Tivoli, Roma, 2009, p. 59-65 ; 162-163 ; 189 ; 293-297 (che non ricordano comunque gli sfortunati profili querenghiani). Confermerebbe la familiarità di Querenghi con la storia della monarchia di Francia una testimonianza di Pignoria, non avvalorata da ulteriori riscontri documentari, circa un incarico attribuito a Querenghi, tramite il cardinale Jacques Davy Du Perron, per la stesura di una storia del regno di Enrico IV (Motta, Antonio Querenghi... cit., p. 139-140).

90. Lettere d'uomini illustri cit., p. 406, Parigi, 12 dicembre 1618. Espressioni di stima nei confronti del Bon e ricordi delle discussioni intrattenute con lui nella capitale francese al tempo del trasferimento di Maria de' Medici nel castello di Blois si leggono in Bentivoglio, Raccolta di lettere... cit., p. 96-97, Parigi 20 marzo 1619.

91. Ivi, p. 95.

92. Ivi, p. 96, Parigi, 20 marzo 1619. Dopo lunghe peregrinazioni tra le università tedesche e francesi, il calvinista Pace insegnava allora a Valence, in Provenza, dove peraltro sarebbe tornato, dopo un fugace intermezzo padovano, nel 1621. Cfr. A. Franceschini, Giulio Pace da Beriga e la giurisprudenza dei suoi tempi, Venezia, 1903, p. 38-53; Cozzi, Nota introduttiva a Sarpi, Opere... cit, p. 555-560.

93. Benzoni, Contarini, Angelo, in DBI, 28, 1983, p.111-119. Amico di Sarpi, vicino a Giambattista Marino, per conto del quale fece da tramite, da Parigi, con la tipografia 
veneziana di G.B. Ciotti, Contarini aveva ospitato presso l'ambasciata il nipote di Paolo Gualdo, dal quale era stato poi scavalcato nella trattativa per la conversione del Pace.

94. La missiva è in Lettere d'uomini illustri... cit., p. 412.

95. Anche in quest'occasione le accuse contro Bon finirono per essere ritirate dal Senato : nel marzo 1620 l'ex ambasciatore poté tornare nella sua amata Padova, della quale era eletto podestà. Cfr., per la vicenda, F. De Vivo, Patrizi, informatori, barbieri. Politica $e$ comunicazione a Venezia nella prima età moderna, Milano, 2012, p. 180-188; sull'avviluppata trattativa per un patto di mutua assistenza veneto-sabaudo-olandese : Cozzi, Venezia nello scenario europeo... cit., p. 104-106.

96. Lettere d'uomini illustri... cit., p. 219, Aix, 6 aprile 1622. La pietra « larga tre dita, lunga un dito, di colore verde scuro con macchie nere minute e certe righe bianche per dentro » era stata « fatta segare in Venezia » e divisa tra i due amici.

97. J. Delatour, Les frères Dupuy et leurs correspondances, in Berkvens-Stevelinck, Bots e Häseler (a cura di), Les grands intermédiaires culturels... cit., p. 61-101; su direttrici, stile e presupposti rispettivi della comunicazione epistolare di Peiresc e dei Dupuy cfr., oltre a Miller, Nicolas-Claude Fabri de Peiresc cit., J. Delatour, Les frères Dupuy et l'Italie, in Fumaroli e Solinas (a cura di), Peiresc et l'Italie... cit., p. 31-58; per i rapporti culturali tra la Francia e l'ambiente romano: J. Delatour, Abeilles thuaniennes et barberines: les relations des savants français avec les Barberini sous le pontificat d'Urbain VIII, in L. Mochi Onori, S. Schütze e F. Solinas (a cura di), I Barberini e la cultura europea del Seicento, Roma, 2007, p. 155-172.

98. Un convincente ritratto di Molin, uno dei più influenti uomini politici veneziani nell'arco di tempo tra il 1620 e il 1635, anno della morte, è in G. Cozzi, Una vicenda della Venezia barocca. Marco Trevisan e la sua "eroica amicizia", in Id., Venezia barocca... cit., p. 381-387 ; per le sue corrispondenze e le sue ambizioni culturali cfr. Id., Paolo Sarpi e Jan van Meurs, in Bollettino dell'Istituto di storia della società e dello stato veneziano, 1, 1959, p. 179-181, e A. Barzazi, La biblioteca di un mecenate: i libri di Domenico Molin, in Amicitiae pignus. Studi storici per Piero Del Negro, éds. U. Baldini, G.P. Brizzi, Milano 2013, p. 309-323.

99. Cfr. le lettere inviate nel corso del 1619 da Pignoria a Gualdo, allora a Venezia, in BNM, Cod. it. X, 66 (6400), e in Lettere d'uomini illustri... cit., p. 214 (10 gennaio 1619).

100. Un'ampia casistica si ricava da un fascio di lettere indirizzate da Pignoria al Molin tra il 1622 e il 1627, in BNM, Cod.it. XI, 20 (6789). Influente presso gli stampatori veneziani, Molin era in relazione con gli Elzevier di Leida, come attesta una sua lettera del 1622 a Jan van Meurs (Cozzi, Paolo Sarpi e J. van Meurs... cit., p. 180).

101. La pratica, diffusa all'interno delle reti di corrispondenze del tempo, suppliva alla mancanza di comunicazioni dirette e consentiva la condivisione delle informazioni. Cfr. Delatour, Les frères Dupuy... cit., p. 83.

102. Cfr. la lettera di Pignoria a Molin del 30 aprile 1624 in BNM, Cod. it. XI, 20 (6789), nella quale il senatore veniva pregato, a nome di Peiresc, di fornire campioni in oro e argento delle misure di peso veneziane; nella stessa lettera l'erudito padovano comunicava la richiesta, da parte di Peiresc, di una copia delle leggi nautiche e marittime della Repubblica.

103. Ivi, lettera del 27 febbraio 1624, dove Pignoria riferiva tra l'altro le espressioni di stima di Peiresc nei confronti di Molin. Nel 1636, nel manifestare a Élie Diodati il proprio dolore per la morte di quest'ultimo, Peiresc dichiarerà che Pignoria aveva sempre funto da tramite dei rapporti tra lui e il senatore veneziano (Rizza, Peiresc... cit., p. 181). Peiresc a sua volta faceva da ponte per le comunicazioni con i Dupuy, ma non mancavano 
rapporti diretti (un cenno a una mancata risposta del « signor Puteano » è nella lettera di Pignoria a Molin del 30 aprile 1624, citata alla nota precedente).

104. Nel 1618 era morto Andrea Morosini; lo seguiranno Ottaviano Bon, sullo scorcio del 1623, e nel 1625 il vescovo di Belluno Alvise Lollino. La fazione opposta perdeva a sua volta i suoi uomini di punta : dopo il doge Nicolò Donà (1618), scomparivano nel 1620 Giovan Francesco Sagredo, amico di Galilei e antigesuita accanito, nel 1621 Agostino da Mula, nel 1623 lo stesso Paolo Sarpi.

105. Sullo scontro che ebbe luogo allora nel ceto patrizio e che vide Domenico Molin schierato dalla parte dei 'papalisti' Corner contro lo Zeno, leader del patriziato povero, cfr. Cozzi, Il doge Nicolò Contarini... cit., p. 185-228.

106. Irriducibile critico della Francia rimaneva invece Fulgenzio Micanzio, che in una serie di lettere inviate tra il 1622 e il 1624 all'ambasciatore in Inghilterra Alvise Vallaresso stigmatizzava senza mezzi termini la doppiezza e l'inaffidabilità della politica di Luigi XIII e dei suoi ministri. Le missive, intercettate da emissari pontifici e inviate al nunzio pontificio a Vienna si conservano in Biblioteca Apostolica Vaticana, Barb. Lat. 9917 (ringrazio Filippo De Vivo, che ne ha in corso la pubblicazione e me ne ha fornito una trascrizione).

107. Id., Venezia nello scenario europeo... cit., p. 108-9.

108. Peiresc aveva peraltro cercato di raffreddare l'entusiasmo di Pignoria : di Matthieu scriveva il 16 aprile 1619 - non si faceva in Francia "gran conto, per essere persona assai poco giudiciosa e che si pagga d'ogni sorte di moneta». Rizza, Peiresc... cit., p. 161.

109. Tra questi ultimi c'erano le Continuationi delle opere principali fino ad anni più recenti e la Genealogia della real casa Borbona. Cfr. Zilli, Le succès italien de Pierre Mathieu... cit., p. 239-242.

110. Lobbes, L'œeuvre historiographique de Pierre Matthieu... cit., p. 497 ; per la vicenda censoria : Bonora, La « censura inavvertita »... cit., p. 61-69.

111. Un confronto tra l'originale francese e l'Historia delle rivolutioni di Francia (Venezia, Fontana, 1624), volta in italiano dal conte bolognese Alessandro Senesi tenendo conto dei rilievi dell'Indice, è condotto da Bonora, $L a$ «censura inavvertita »... cit., p. 64-66. Fra i traduttori di scritti minori di Matthieu figurano il già noto precettore estense J.-B. De la Baffarderie e Giovanni Tuilio, professore di umanità allo Studio di Padova e amico di Pignoria, che eseguì tra l'altro, nel 1624, la versione de Il principe glorioso, panegirico [...] del grande Enrico IV re di Francia.

112. Zilli, Le succès italien de Pierre Matthieu... cit., p. 244-245 ; J. Lafond, L'esthétique du «dir moderno» dans l'historiographie de P. Matthieu et de ses imitateurs, in Mélanges à la mémoire de Franco Simone. France et Italie dans la culture européenne, II : XVII et XVIII siècles, Ginevra, 1981, p.135-148; sulle polemiche suscitate dal successo della scrittura storica di Matthieu : E. Bellini, Agostino Mascardi tra 'ars poetica' e 'ars historica', Milano, 2002.

113. Cozzi, Venezia nello scenario europeo... cit., p. 115

114. Zilli, Le succès italien de Pierre Matthieu... cit., p. 242 ; il solo Giuditio politico, dedicato al gentiluomo e collezionista ferrarese Roberto Canonici, era stato anticipato da Barezzi nel 1627, anno in cui veniva anche riproposto l'Elio Sejano. Per un profilo del tipografo veneziano, che intervenne tra l'altro sui testi del Lazarillo de Tormes e di altri romanzi picareschi, da lui tradotti dallo spagnolo, cfr. A. Cioni, C. Mutini, Barezzi, Barezzo, in DBI, 6 (1964), p. 336-340. Tra il 1628 e il '29 Bartolomeo Fontana tentava una replica al Barezzi 
riproponendo l'Historia delle rivolutioni di Francia nella traduzione del Senesi e l'Historia di Francia [...] negli anni di pace del regno del chr. Henrico IV.

115. L'opera, secondo l'avviso del tipografo, era stata portata a Venezia da Parigi dallo stesso Parchi, transitato per la capitale francese al seguito del patrizio Angelo Contarini, di ritorno dall'ambasceria straordinaria in Inghilterra nell'estate del 1626. Zilli, Le succès italien de Pierre Matthieu... cit., p. 250.

116. Su Canini (1551-1631) cfr. G. Benzoni, Canini, Girolamo, in DBI, 18, 1975, p. 105-108; E. Balmas, Girolamo Canini traduttore di Montaigne, in Montaigne e l'Italia, Ginevra, 1991, p. 23-34.

117. Sulla vicenda del Trattato della corte del signor di Refuge, uscito a Venezia presso Giambattista Ciotti nel 1621, cfr. Bonora, La « censura inavvertita » cit., p. 71.

118. La versione di Canini sarà inclusa, postuma, nell'edizione delle Opere di Matthieu impressa a Venezia dal Barezzi nel 1638. Come segnalato da Benzoni (Canini, Girolamo cit., p. 107) nella sua prima prova dedicata allo storico francese, la Genealogia della [..] casa di Borbone dal re Faramondo fino ad HEnrico IV, Canini aggiunse un riferimento a Luigi XIII, magnificandone il recupero delle piazze ugonotte e la restituzione al clero dei beni sottratti agli « eretici».

119. Così il frontespizio delle Lettere a principi di negotii politici e di complimento divise in tre libri [...], Venezia, Giacomo Sarzina, 1629. L'aggiunta dei « discorsi » si era resa necessaria spiegava la dedica - per presentare $\mathrm{i}$ «maneggi» del d'Ossat «sotto l'ordine di un corso continuato ", tale da far " gustare assai meglio tutto l'intiero trattamento ».

120. Sul Gradenigo, nato nel 1570 e morto alla fine di settembre del 1629, cfr. M. Dal Borgo, Gradenigo, Agostino, in DBI, 58 (2002), p. 274-276.

121. Cozzi, Venezia nello scenario europeo... cit., p. 114.

122. Da segnalare, nel 1629-30, due ristampe, impresse rispettivamente da Fontana e Barezzi, delle fortunate Osservazioni di Stato [...] del Signor di Villeroy.

123. Benzoni, La fortuna, la vita, l'opera... cit., p. 369.

124. Ivi, p. 403-442 ; la citazione da Id., Davila, Enrico Caterino, in DBI, 33, 1987, p. 168.

125. Ciò - aggiungeva Davila - con «beneficio di grandissima conseguenza » : a fronte di viatico tanto autorevole, infatti, non vi sarebbe stato " più animo così severo, orecchia così difficile, giudicio così scrupoloso, né lingua così pungente » disposti a « opponersi a quello che da Lei sarà stato passato e ricevuto ». C'è da chiedersi se dietro questo auspicio non vi fosse una velata allusione alle sorti di altre narrazioni delle "guerre civili" francesi, finite nella rete dei controlli ecclesiastici (Storia delle guerre civili di Francia, Venezia, Tommaso Baglioni, 1630, p. non num.).

126. Cozzi, Venezia nello scenario europeo... cit., p. 116

127. C. Povolo, Crasso, Nicolò, in DBI, 30 (1984), p. 573-577.

128. Claudii Salmasii Plinianae exercitationes, Parigi, Drovart, 1629. In una lettera a François-Auguste De Thou del 12 giugno 1630 Molin segnalava che i due volumi della « dottisima intrapresa » del Salmasius erano da tempo in mano all'ambasciatore francese, in vista della presentazione al doge. BNF, Fonds Dupuy, 705, fol. 185.

129. D. Raines, Dopo Sarpi : il patriziato veneziano e l'eredità del servita, in Pin (a cura di), Ripensando Paolo Sarpi cit., p. 552-561. Lo sforzo compiuto dal Morosini e dai revisori della sua opera per presentare l'interdetto come un deragliamento episodico di relazioni 
sempre mirate all'accordo con il pontefice non impedì la tempestiva messa all'Indice dell'opera, avvenuta l'anno dopo la stampa.

130. A. Barzazi, Gli affanni dell'erudizione. Studi e organizzazione culturale degli ordini religiosi a Venezia tra Sei e Settecento, Venezia, 2004, p. 333-352.

131. Rizza, Peiresc... cit., p. 170-173.

132. La lettera di Aleandro del 19 gennaio 1620 è in Rizza, Peiresc cit., p. 173.

133. Come ha evidenziato De Franceschi (La crise théologico-politique... cit., p. 576-583) le stesse reazioni dell'ambiente parlamentare gallicano parigino di fronte all'Istoria furono molto circospette e contribuirono ad alimentare le pressioni del nunzio Bentivoglio sulla Sorbona per una censura, che non fu comunque mai pronunciata. Costituì forse una battuta tardiva di un dialogo riaperto dalla pubblicazione dell'opera sarpiana l'invio a Peiresc nel 1622, da parte di Aleandro, del frammento sull'interdetto di Venezia composto a suo tempo da Antonio Querenghi, in vista di una possibile pubblicazione congiunta con l'epitome querenghiana sulla guerra di Fiandra (BNF, N.A.F., 5173, 19 aprile 1622).

134. Sulle circostanze della stampa dell'Histoire du concile de Trente traduite de l'italien de Pierre Soave Polan par Jean Diodati (Genève, Gamonet, 1621) cfr. S. Garcia, Ginevra, fulcro della diffusione dell'opera di fra Paolo Sarpi nella prima metà del XVII secolo, in Rivista storica italiana, 114, 2002, p. 1007-1009. Il primo incontro tra Sarpi, Micanzio e Diodati risaliva alla visita a Venezia di quest'ultimo nel 1608.

135. Secondo le verifiche di Garcia (ivi), Dupuy riportò le correzioni sul proprio esemplare della stampa di Londra. Altrettanto farà Peiresc al momento della nuova edizione in lingua italiana, pure curata da Diodati e uscita a Ginevra nel 1629. Cfr. Lettres aux frères Dupuy, éd. P. Tamizey de Larroque, Parigi, 1888, I, p. 43, la lettera del 2 marzo 1629, in cui Peiresc ringrazia i Dupuy per l'invio delle correzioni.

136. S. Garcia, Élie Diodati et Galilée : naissance d'un réseau scientifique dans l'Europe du XVIIe siècle, Firenze, 2004, p. 59-65.

137. Indicativo il fatto che nel maggio 1624 il calvinista Daniel Heinsius s'interrogasse sugli scritti di Sarpi « in manu optimi Fulgentii » dopo il deposito della produzione « publica » del servita negli archivi della Repubblica. C. Pin, Progetti e abbozzi sarpiani sul governo dello Stato "in questi nostri tempi assai turbolenti", in Sarpi, Della potestà de' prencipi, éd. N. Cannizzaro, Venezia, 2006, p. 92-93.

138. Garcia, Ginevra... cit., p. 1011 ; J. Mesnard, La culture d'un chanoine de Limoges au début du XVII siècle: Jean Decordes (+1642), in Id., La culture du XVII siècle. Enquêtes et synthèses, Parigi, 1989, p. 122-141.

139. M. Infelise, Ricerche sulla fortuna editoriale di Paolo Sarpi (1619-1799), in Pin (a cura di), Ripensando Paolo Sarpi... cit., p. 522.

140. Lettres aux frères Dupuy... cit, I, p. 55, 29 gennaio 1625. Cfr. Rizza, Peiresc cit., p. 174, dove si segnala la copia manoscritta da lui fatta eseguire per P.P. Rubens. Peiresc tornerà anche a sondare gli umori della curia con una lettera all'Aleandro, la cui risposta sarà questa volta tranchante nei riguardi di Sarpi, «nero ministro del diavolo » (ivi). Gli strali di Aleandro erano puntualmente riferiti a P. Dupuy nella lettera cit. del 29 gennaio 1625.

141. «J'escrivis ces jours passez à Venise pour avoir l'Antiquità di Padova del Pignoria et Les papes de fra Paolo, dont je ne manqueray pas de vous faire part incontinent", comunicava Peiresc a P. Dupuy il 24 dicembre 1625, riferendosi probabilmente - con il 
compendioso titolo Les papes - all'Istoria dell'interdetto. Cfr. Lettres aux frères Dupuy... cit, I, p. 68.

142. Garcia (Ginevra... cit, p. 1012 ; Élie Diodati et Galilée... cit., p. 73-75) ipotizza un rapporto tra questo soggiorno e la stampa a Ginevra, nel 1626, presso Pierre Aubert, della Relation de l'estat de la Religion, versione curata da Jean Diodati della Relatione dello stato della religione, lo scritto di Edwin Sandys che nel 1608 Sarpi e Micanzio avevano fatto tradurre dal cappellano inglese William Bedell, per apporvi quindi una serie di commenti. Il testo del Diodati seguiva la stampa italiana tirata l'anno prima nella stessa Ginevra.

143. Delatour, Les frères Dupuy... cit., p. 79. Nato nel 1607, François-Auguste sarebbe stato decapitato nel 1642, nel quadro della repressione della congiura del marchese di CinqMars.

144. "En quoi ils ont double sujet de se plaindre de nous ", osserverà nella lettera ai Dupuy dell'8 dicembre 1626. Lettres de François-Auguste de Thou durant ses voyages en Italie et dans le Levant, 1626-1629, in Revue rétrospective ou bibliothèque historique, s. II, 3, 1835, p. 366. Cfr. Garcia, Elie Diodati et Galilée... cit., p. 76-77.

145. In particolare De Thou aveva potuto ascoltare il passo dell'opera di fra Fulgenzio riguardante l'attentato a Sarpi dell'ottobre 1607. Lettres de François-Auguste de Thou... cit., p. 369, 8 dicembre 1626. Sulla figura di Micanzio e la stesura della sua Vita del padre Paolo, cfr. Barzazi, Micanzio, Fulgenzio cit.; Ead., Fulgenzio Micanzio, Vita del padre Paolo, in P. Guaragnella, R. Abbaticchio, G. De Marinis Gallo (a cura di), L'incipit $e$ la tradizione letteraria italiana, II : Seicento e Settecento, Lecce, 2010, p. 27-36.

146. La missiva non specifica se si trattasse di copia a stampa o manoscritta. Lettres de François-Auguste de Thou... cit., p. 368.

147. Così pare si possa intendere il richiamo di De Thou a «plusieurs autres belle choses qu'il a faites sur les diverses occasions où il [Sarpi] a été consulté ». Ivi, p. 369.

148. Ivi, p. 368. Il testo della scrittura è in Sarpi, Scritti giurisdizionalistici... cit., p. 119-212. In un inciso sintatticamente poco chiaro, De Thou faceva anche riferimento al « livre des Asiles ", il consulto-trattato Sopra l'immunità delle chiese, redatto nel marzo $1620 \mathrm{e}$ custodito - come Micanzio gli aveva fatto presente - «dans le secret de Saint-Marc et ne voit jamais le jour» (Lettres de François-Auguste de Thou... cit., p. 368-369). In realtà di quello scritto (Sarpi, Scritti giurisdizionalistici... cit., p. 259-301) era uscita a Leida nel 1622, presso Elzevier, una versione latina con il titolo - echeggiato da De Thou - De iure asylorum, attribuita a tal Augerius Frikelburgius. L'edizione non è stata oggetto di studio e risulta solo menzionata in P. Van Heck, La fortuna di Paolo Sarpi in Olanda, in M. Viallon (a cura di), Paolo Sarpi. Politique et religion... cit., Parigi, 2010, p. 389.

149. Tra i libri di cui François-Auguste aveva promesso pronto recapito a Micanzio c'era l' Apologeticus pro rege Christianissimo Ludovico XIII adversus factiosas admonitionis calumnias in causa principum foederatorum (1626) di Nicolas Rigault. Lettres de François-Auguste de Thou... cit., III (1835), p. 369.

150. Il diniego di Molin è riferito nella lettera ai Dupuy del 19 dicembre 1627, edita, pure tra le Lettres de François-Auguste de Thou... cit., in Revue rétrospective ou bibliothèque historique , s. II, 4, 1835, p. 220 ; cfr. Garcia, Ginevra... cit., p. 1016. Il 6 gennaio 1628, De Thou - ormai in procinto di lasciare Venezia - raccomandava a P. Dupuy di tener calda la promessa di Micanzio scrivendogli presso un indirizzo sicuro, in modo da evitargli rischi analoghi a quelli che aveva corso in passato. Garcia, Élie Diodati et Galilée... cit., p. 77. L'unica missiva del servita conservata tra i carteggi della cerchia dei Dupuy, non autografa, è indirizzata, 
in data 19 luglio 1634, a Élie Diodati e contiene i ringraziamenti per l'invio dell'indice dell' Historia sui temporis di J.-A. De Thou, uscito in quell'anno, insieme a un caldo elogio di «quel grandhuomo da me singolarmente riverito in vita, la cui gloriosa memoria [...] honoro doppo la morte» (BNF, Fonds Dupuy, 632, fol. 176).

151. H. Grotius, Briefwiesseling, 'S-Gravenhage, 1966, V, p. 23, 12 febbraio 1632; a p. 29, la risposta di Decordes del 5 marzo 1632. Allo scritto Grozio si riferiva come "libro viri incomparabilis Pauli Servitae praesertim de argumento tam nobili causaque alibi magnorum motuum apud nos etiam belli tam pertinaciter exerciti ». Circa un anno dopo anche Peiresc chiedeva la scrittura sarpiana ai Dupuy (Rizza, Peiresc... cit., p. 177). La « mauvaise opinion de M. Grotius, comme de partisan d'Espagne » sostenuta da Micanzio è riferita anche in una lettera ai Dupuy di F.-A. De Thou, il quale, per parte sua, assicurava d'essersi adoperato "le mieux qu'il m'a été possible» per fargli cambiar idea. Cfr. Lettres de François-Auguste de Thou... cit., in Revue rétrospective ou bibliothèque historique, s. II, 3, 1835, p. 374, Venezia, 9 dicembre 1626.

152. Garcia, Ginevra... cit., p. 1014-1015 ; Infelise, Ricerche sulla fortuna editoriale... cit., p. 525-527, dove vengono segnalate altre edizioni ed emissioni del 1638-39, connesse ad altri contesti.

153. Un'altra stampa datata 1638 e ripresa nel 1639 , senza indicazione di luogo, recava il titolo Discorso dell'origine, forma, leggi ed uso dell'ufficio dell'Inquisitione nella città e dominio di Venetia, del P. Paolo dell'Ordine de' Servi [...].

154. All' Istoria del concilio tridentino si sarebbe invece dovuto riservare un volume a parte. Grotius, Briefwiesseling... cit., p. 343, lettera del 5 marzo 1635 a Oxenstierna ; H.J. Van Dam, Italian friends. Grotius, De Dominis, Sarpi and the church, in Nederlands Archief voor Kerkgeschiedenis/Dutch Review of Church History, 75, 1995, p. 211-214. Nelle mani di Grozio, da lui stesso trascritto, c'era inoltre un frammento dell'abbozzo, probabilmente sarpiano, di un trattato Della potestà de' prencipi, di recente pubblicato in una versione conservata alla Beinecke Library della Yale University (cfr. Sarpi, Della potestà de' prencipi... cit., tenendo presente la recensione di G. Trebbi in Studi veneziani, 56, 2008, p. 423-431). Per l'esemplare groziano, forse disceso dalla copia in BNF, Fonds Dupuy, 111, cfr. Van Heck, La fortuna... cit., p. 394-405; su quello esistente tra le carte di Peiresc a Carpentras : Rizza, Peiresc... cit., p. 178-181.

155. Sul riassetto del commercio librario avvenuto intorno al 1630 cfr. Maclean, Scholarship, commerce ... cit., p. 211-234.

156. G. Vedova, Biografia degli scrittori padovani, I, Padova, 1832, p. 91.

157. Les correspondants de Peiresc, éd. P. Tamizey de Larroque, II, Ginevra, 1972, p. 59, Rieti, 29 marzo 1636.

158. Su Tomasini (1595-1655) e la sua ricca produzione antiquaria e storico-bibliografica cfr. Vedova, Biografia... cit., II, p. 334-345 ; per i rapporti con Peiresc : Rizza, Peiresc... cit., p. 123 ; Delatour, Les frères Dupuy et l'Italie... cit, p. 36-37, che segnala l'unica lettera superstite di Tomasini ai Dupuy, del 21 novembre 1639. Il canonico fu membro dell'accademia veneziana degli Incogniti, che riunì, tra gli anni trenta e la metà del secolo, scapestrati libertini e composti studiosi in abito ecclesiastico (un suo profilo è incluso nelle Glorie degli Incogniti, Venezia, Valvasense, 1647, p. 189-191).

159. Numerosi i richiami a Tomasini nelle lettere di Naudé a Peiresc del 1633-36, da Padova e da Rieti, edite in Les correspondants de Peiresc... cit. ; cfr. inoltre G. Mirandola, Naudé a Padova, in Lettere italiane, 19, 1967, p. 239-247. 
160. Giacomo Filippo Tomasini, Bibliothecae patavinae manuscriptae publicae et privatae, Udine, Nicolò Schiratti, 1639, dedica al nunzio pontificio a Venezia Francesco Vitelli. Gaffarel, bibliotecario di Richelieu, era stato accolto a Venezia da Tomasini durante il viaggio compiuto nel 1633. Per questo versante dell'attività del canonico padovano: A. Barzazi, Ordini religiosi e biblioteche a Venezia tra Cinque e Seicento, in Annali dell'Istituto storico italo-germanico in Trento, 21, 1995, p. 218-228.

161. Giacomo Filippo Tomasini, Marci Antonii Peregrini I.C. [...] in celeberrimo Gymnasio Patavino iuris canonici professoris primarij Vita, Padova, Paolo Frambotto, 1636 ; gli Elogia (1644) furono stampati pure a Padova, da Sebastiano Sardi.

162. Come le Bibliothecae Patavinae, erano state impresse a Udine da Nicolò Schiratti.

163. G. Cozzi, La Repubblica di Venezia e il Regno di Francia tra Cinquecento e Seicento. Fiducia e sfiducia, in Venezia e Parigi, Milano, 1989, p. 136-144 ; Id., Venezia nello scenario europeo... cit., p.128-133.

\section{AUTORE}

\section{ANTONELLA BARZAZI}

Università degli studi di Padova - antonella.barzazi@unipd.it 


\section{Résumés}

dense dibertés de l'Église gallicane» face au pouvoir pontifical fut essentiellement affaire de juristes qui se posèrent en champions de l'indépendance du royaume. Les crises spectaculaires entre Rome et le parlement de Paris, toujours nées de situations conflictuelles particulières, sont bien connues, mais elles tendent à cacher les nombreux autres litiges résolus dans le secret du Palais de justice. Cette présente étude vise à présenter les différentes voies de recours juridique contre un acte romain devant le parlement de Paris au cours du XVI siècle : la complainte de novelleté qui, par exemple, fut invoquée dans un litige pour la possession d'une abbaye du Nord de la France pendant le règne de François $\mathrm{I}^{\mathrm{er}}$. Il $\mathrm{y}$ a aussi l'appel comme d'abus, voie de recours à la justice laïque contre une sentence de l'autorité ecclésiastique, qui fut utilisé lors de l'octroi d'indulgences en 1524 à Beauvais, ou à l'occasion de la réforme du couvent des Cordeliers à Paris pendant les années 1580. Les bulles pontificales, les textes portant sur le rapport entre temporel et spirituel furent également étroitement contrôlés par le Parlement car ils pouvaient affecter directement l'autorité royale. Ces exemples tirés de la pratique judiciaire montrent que si les tensions pouvaient être fortes, la confrontation n'était pas systématique. 


\section{della Controriforma}

7 Gigliola FRAGNITO, La censura ecclesiastica nell'Italia della Controriforma: organismi centrali e periferici di controllo

8 Il saggio intende delineare le varie fasi dell'organizzazione centrale e periferica del controllo librario e illustrare le ricadute che la complessa costruzione di apparati repressivi da parte della chiesa di Roma ebbe sull'applicazione delle norme censorie. A seguito della diffusione della Riforma protestante si assiste a un rafforzamento di vecchi organi (Maestro del Sacro Palazzo) e alla creazione delle Congregazioni dell'Inquisizione (1542) e dell'Indice (1572). Questa pluralità di organi deputati al controllo della stampa, dalle competenze mal definite, diede luogo a una costante e profonda conflittualità, che ebbe il suo immediato riflesso sulla redazione degli indici romani dei libri proibiti, ma anche sulla loro esecuzione sul territorio. Determinata a monopolizzare la materia censoria, la Congregazione dell'Inquisizione cercò di dirigere attraverso i suoi tribunali periferici le varie operazioni relative alla sorveglianza sulla circolazione del libro e di esautorare gli ordinari diocesani, cui gli indici tridentino (1564) e clementino (1596) affidavano un ruolo preminente.

Jean-Louis QUANTIN, Les institutions de censure religieuse en France (XVI ${ }^{e}-X V I I^{e}$ siècles)

Dans la France des $\mathrm{XVI}^{\mathrm{e}}$ et XVII ${ }^{\mathrm{e}}$ siècles, la censure - aussi bien au sens traditionnel, seul attesté alors, de jugement critique sur un texte, qu'au sens répressif et policier du terme -, était partagée entre plusieurs institutions concurrentes. Partant d'un système essentiellement ternaire, où les rôles étaient répartis entre facultés de théologie, magistrats et pouvoir royal, la tendance, tout au long du XVII ${ }^{\mathrm{e}}$ siècle, fut au renforcement de cette dernière instance aux dépens des deux autres, surtout en matière de censure préventive, que la monarchie, par le mécanisme du privilège, finit par se réserver complètement. La censure a posteriori, en revanche, resta partagée jusqu'à la Révolution. 
Un quatrième acteur, l'épiscopat, avait des prérogatives considérables en droit, tout en en étant largement dépossédé dans les faits : il tenta avec persévérance de reconquérir une place dans le contrôle des livres, notamment au travers de l'institution nouvelle qu'étaient les Assemblées du clergé. Ce conflit de juridiction jamais résolu fait de l'histoire de la censure un remarquable observatoire des rapports entre Église et État, pouvoir royal et parlements, gallicanisme des évêques et gallicanisme des magistrats.

Frédéric GABRIEL, La loi du magistère. Pouvoir ministériel et formes ecclésiales dans la controverse entre Cajétan et Almain (1511-1512)

12 À l'occasion du concile de Pise, deux ecclésiologies marquées s'affrontent et constituent pour la postérité un point de repère non négligeable pour se réclamer de telle ou telle orthodoxie. Les modalités d'attribution de la potestas séparent la théologie romaine de l'école parisienne. Cette dernière est défendue par Almain qui, dans plusieurs de ses œuvres, utilise les Octo quaestiones de potestate papae d'un auteur peu apprécié par la papauté: Guillaume d'Occam. Sous une forme scolastique éprouvée, la controverse remonte de l'instauration du pouvoir ecclésial plénier au critère de l'ultime recours, dans le cadre d'une orthodoxie conçue comme socle législatif. Ce critère est double et concerne non seulement le rapport du pape et du concile, mais aussi celui de deux théologiens, chacun se réclamant de la pure orthodoxie, liée à une autorité soit magistérielle, soit universitaire.

Benoît SCHMITz, Le pouvoir du pape sur les royaumes : la controverse entre catholiques romains et catholiques gallicans à propos des bulles de 1585, 1589 et 1591

Par trois fois durant la dernière décennie des guerres de religion, la papauté prétendit exercer son pouvoir de déposer les souverains. Les bulles pontificales provoquèrent une importante controverse imprimée opposant les catholiques romains et les catholiques gallicans. À travers la polémique qui mit aux prises le théologien jésuite Bellarmin et le juriste français Pierre de Belloy, puis, les ligueurs et les « politiques ", cet article met en lumière le fossé doctrinal qui les séparait quant au problème du pouvoir du pape sur les royaumes. La réconciliation d'Henri IV avec Rome n'aurait pas été possible si, dans chaque camp, certains n'avaient été disposés à s'affranchir de textes et de principes érigés en normes intangibles pour s'en remettre au pouvoir plénier du pape et du roi. La concorde entre ces deux puissances souveraines permit de dépasser, sans le résoudre, le conflit des doctrines.

Si les théologiens italiens et allemands répondirent à Luther par des traités qui défendaient le pouvoir du pape, les gallicans observèrent sur ce thème un silence inédit, après des décennies de lutte en faveur du conciliarisme. Cet article montre que les théologiens français n'ont toutefois pas déserté le terrain ecclésiologique et ont pris eux 
aussi toute la mesure de l'attaque lancée par Luther contre la conception traditionnelle qui donnait à l'autorité ecclésiastique un rôle essentiel quant au salut des âmes. Si l'influence des doctrines romaines augmenta, elle resta cependant limitée car les gallicans surent défendre le pouvoir de l'Église sans abdiquer leurs positions. Des années 1520 aux années 1560 , le pluralisme doctrinal catholique se manifesta donc moins par des hétérodoxies croisées que par des orthodoxies croisées, chacune défendant, dans la condamnation du protestantisme, à la fois la cause commune et le modèle qui lui était propre.

Michela CATTO, Les deux voies des catéchismes: les controverses et l'endoctrinement. France et Italie

Le mot catéchisme indique le livre du savoir religieux élémentaire, mais aussi la doctrine à mémoriser sans prétendre à aucune explication. Le double sens fut un produit des décisions tridentines qui progressivement ont mis fin à la tradition des catéchismes de controverse, c'est-à-dire des livres en dialogue avec les autres doctrines chrétiennes. Les catéchismes de Edmond Auger $(1563)$ ou de Pierre Canisius $(1556,1559,1566)$ furent jugés inadéquats. Dans les années qui suivirent la publication du Catéchisme romain (1566), en langue vulgaire et en latin, apparut un autre modèle : le catéchisme de Robert Bellarmin (1597) que la papauté essaya de promouvoir en imposant sa traduction dans toutes les langues et son usage dans les écoles de doctrine chrétienne, mais auquel en Italie et en France fut réservé un succès différent.

Giorgio CARAVALE, Censura romana e libri francesi nella seconda metà del ‘500. Qualche riflessione su normativa e casi specifici

Questo saggio affronta l'atteggiamento maturato nella seconda metà del '500 dalle istituzioni censorie romane nei confronti di alcune tra le principali opere francesi circolanti nella penisola italiana. Ricostruendo in particolare i casi degli Essais di Michel de Montaigne, della République di Jean Bodin e delle opere giuridiche di Charles Du Moulin l'autore mette in risalto la difficoltà di costruire una storia coerente e complessiva della censura di fronte alle molte variabili, politiche, diplomatiche, culturali, istituzionali, alla varietà degli attori in gioco e alla sovrapposizione di competenze giurisdizionali che intervengono in ciascuno dei casi presi in esame.

1 Elena VALERI, «Per la conservatione della religione e dello stato ». Les guerres de religion en France aux yeux des historiens italiens (XVI ${ }^{\mathrm{e}} \mathrm{XVII}$ siècle)

Davila, Campiglia, Frachetta, Tortora ne sont que quelques uns des historiens italiens qui entre le seizième et le dix-septième siècle se dédièrent aux guerres civiles françaises. Qu'ils s'inspirent à des intentions polémiques ou, par contre, apologétiques, leurs écrits, en examinant le destin du seul pays en mesure de s'opposer à la puissance espagnole en Europe, expriment des jugements à l'aune des dynamiques politiques et de la vie 
culturelle et religieuse de la fin du seizième siècle et avancent des hypothèses sur la " quiete d'Italia ", jugée comme garantie contre l'oppression de la péninsule de la part soit de l'Espagne que de l'Église de Rome. En croisant l'analyse des textes avec les biographies de ces auteurs et de certains des protagonistes des événements racontés il est évident que le débat qui eut lieu en Italie au sujet des guerres de religion en France ait contribué à renforcer les raisons de l'unité confessionnelle sur le plan religieux et celles de la pacification sur le plan politique.

Jean-Louis QUANTIN, Érudition gallicane et censure romaine au tournant des XVI et XVII siècles: Papire Masson devant l'Index

Sous le titre De Episcopis urbis, Papire Masson publia à Paris en 1586 les vies des papes, de Pierre à Grégoire XIII. L'ouvrage était marqué par un fort gallicanisme, politique et culturel plutôt que théologique, tout en condamnant fermement la Réforme protestante. Masson eut soin d'en faire présenter un exemplaire à Sixte-Quint. Transmis à la congrégation de l'Index, le De Episcopis urbis y fit l'objet, en octobre 1587, d'une censura du futur cardinal Silvio Antoniano, qui conclut qu'il devait être expurgé. Dans les dix ans qui suivirent, durant la difficile préparation du nouvel Index librorum prohibitorum, le De Episcopis urbis donna lieu à des débats répétés au sein de la congrégation. Face à Robert Bellarmin, partisan, dans une large mesure in odium auctoris, d'une condamnation absolue, l'helléniste français Pierre Morin prit la défense de Masson et, à travers lui, de l'érudition gallicane. Le De Episcopis urbis fut inclus dans l'Index de 1596, dans l'attente d'une édition expurgée, que Masson se refusa finalement à publier. L'affaire constitue ainsi un des tout premiers épisodes du conflit entre orthodoxie romaine et érudition gallicane.

Miguel GOTOR, "Onde non apparisca che anco tra $i$ cattolici siano diversità d'opinioni in quello che riguarda la fede» : $i$ sermoni di Ignazio di Loyola e le censure della Facoltà di Teologia del 1611 tra Parigi e Roma

Nel 1611 il gesuita François Solier pubblicò in Francia la traduzione del libro Trois tresexcellentes Predications che conteneva tre sermoni in onore del beato Ignazio di Loyola scritti rispettivamente da un agostiniano e da due domenicani. L'opera venne prontamente censurata dalla Facoltà di Teologia di Parigi che contestò alcuni tratti agiografici del miracolismo ignaziano. Il saggio ricostruisce i meccanismi di intervento della fabbrica censoria francese confrontando un opuscolo che raccolse gli interventi ufficiali dei teologi della Sorbona con l'esemplare dell'opera conservata presso la Biblioteca Nazionale di Francia che reca i segni del primo revisore domenicano. La ricerca consente di lumeggiare le tensioni esistenti tra l'università di Parigi, i gesuiti francesi e gli altri ordini religiosi e i difficili rapporti ed equilibri intercorrenti tra il Parlamento, il sovrano, il mondo gallicano (nelle sue differenti varianti interne) e la Sede apostolica, nel corso di una fase storica mossa e incerta, quella della reggenza di Maria de' Medici all'indomani dell'assassinio di Enrico IV. 

théocratie. L'hétérodoxie vénitienne face à l'orthodoxie romaine au début de la crise de l'Interdit (1606-1607) selon laquelle la Sérénissime était l'incarnation parfaite du governo misto et d'une république aristocratique, il semble qu'au début $\mathrm{du} \mathrm{xvII}^{\mathrm{e}}$ siècle, le discours mythique vénitien franchit une nouvelle étape : Venise proclame désormais à la face du monde la perpétuité de sa domination, l'inaltérabilité de son institut originel à travers les pires épreuves, d'Agnadel jusqu'à l'Interdit, et finalement sa catholicité indéfectible, au même titre que le Très-Chrétien. Contre le magistère romain, la Sérénissime affirme que la raison d'État est validation assurée de l'orthodoxie des décisions prises par l'autorité politique souveraine: au temporel, le prince est aussi infaillible que le pape l'est au spirituel. 
33 Antonella BARZAZI, «Si quid e Gallia afferatur, avide lego ». Reti intellettuali, libri e politica tra Venezia e la Francia nella prima metà del Seicento

34 Tra l'ultimo decennio del Cinquecento e il primo del Seicento le relazioni culturali tra Venezia e la Francia furono particolarmente intense. La partecipazione della Repubblica alle ultime battute della lunga crisi politico-religiosa francese e le successive vicende dell'interdetto del 1606 contribuirono a dar forma a una composita corrente di scambi epistolari e librari che avrebbe in seguito coinvolto eruditi e letterati ecclesiastici gravitanti intorno all'Università di Padova e ambienti politici della capitale di diverso orientamento ideologico. Su questo sfondo, dopo il 1615 , si avviò tra l'altro - di concerto tra settori moderati e pacifisti del ceto dirigente veneziano e la corte estense - un piano di pubblicazioni sulla recente storia francese che proseguì per l'intero corso degli anni venti, ritmato dagli alterni sviluppi del confronto diplomatico tra la Serenissima e la corte di Luigi XIII. Parallelamente la cerchia del patriziato marciano più legata alla memoria dell'interdetto utilizzò la collaudata rete dei contatti con il mondo intellettuale francese per promuovere la prima diffusione in Europa degli scritti di Paolo Sarpi. 